Uitrawideband Radar

Clutter Measurements of Forested Terrain, 1991-1992

D. M. Sheen

R. H. Severtsen

J. M. Prince

K. C. Davis

H. D. Collins

RECENT?

AUG $n$ ? 19:4

OST:

June 1993

Prepared for

Defense Advanced Research Projects Agency

with the U.S. Department of Energy

under Contract DE-AC06-76RLO 1830

Pacific Northwest Laboratory

Operated for the U.S. Department of Energy

by Battelle Memorial Institute

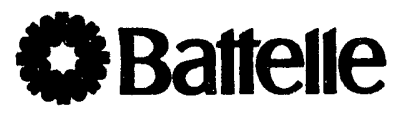




\title{
DISCLAIMER
}

This report was prepared as an account of work sponsored by an agency of the United States Government. Neither the United States Government nor any agency thereof, nor Battelle Memorial Institute, nor any of their employees, makes any warranty, expressed or implied, or assumes any legal liability or responsibility for the accuracy, completeness, or usefulness of any information, apparatus, product, or process disclosed, or represents that its use would not infringe privately owned rights. Reference herein to any specific commercial product, process, or service by trade name, trademark, manufacturer, or otherwise does not necessarily constitute or imply its endorsement, recommendation, or favoring by the United States Government or any agency thereof, or Battelle Memorial Institute. The views and opinions of authors expressed herein do not necessarily state or reflect those of the United States Government or any agency thereof.

\author{
PACIFIC NORTHWEST LABORATORY \\ operated by \\ BATTELLE MEMORIAL INSTITUTE \\ for the \\ UNITED STATES DEPARTMENT OF ENERGY \\ under Contract DE-ACO6-76RLO 1830
}

Printed in the United States of America

Available to DOE and DOE contractors from the

Office of Scientific and Technical Information, P.O. Box 62, Oak Ridge, IN 37831;

prices available from (615) 576-8401. FTS 626-8401.

Available to the public from the National Technical Information Sertice,

U.S. Department of Commerce, 5285 Port Royal Rd., Springfield, VA 22161. 
PNL-8645

UC-700

\section{ULTRAWIDEBAND RADAR CLUTTER MEASUREMENTS OF FORESTED TERRAIN, 1991-1992}
D. M. Sheen
R. H. Severtsen
J. M. Prince
K. C. Davis
H. D. Collins

June 1993

Prepared for Defense Advanced Research Projects Agency 1400 Wilson Boulevard Arlington, Virginia 22709 under U.S. Department of Energy Contract DE-AC06-76RLO 1830

Pacific Northwest Laboratory Richland, Washington 99352 


\section{Contents}

Acknowledgements $\ldots \ldots \ldots \ldots \ldots \ldots \ldots \ldots \ldots \ldots \ldots \ldots \ldots \ldots \ldots$ ix

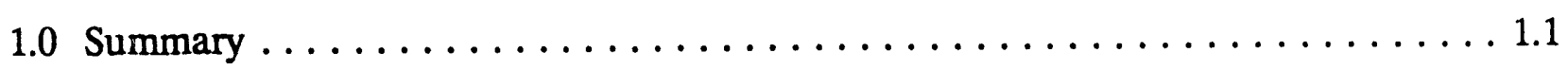

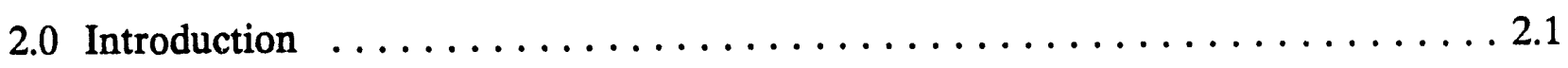

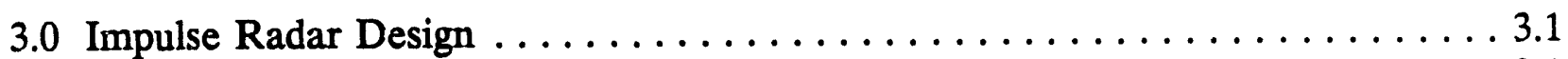

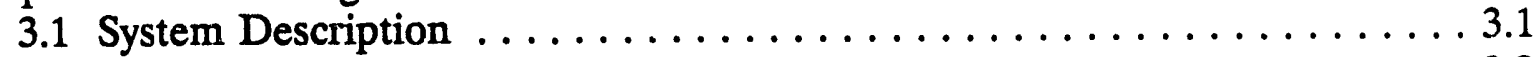

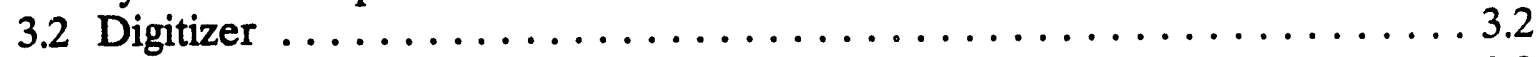

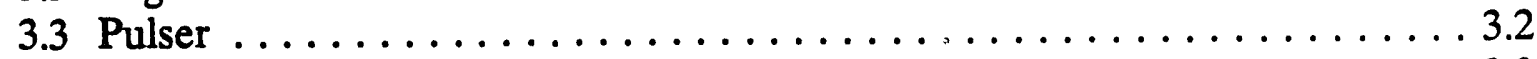

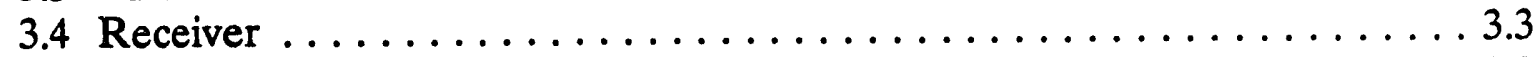

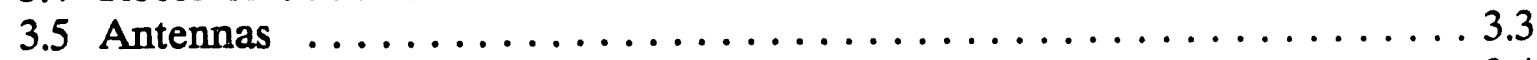

3.6 Impulse Radar System Point Measurements . . . . . . . . . . . . . . 3.4

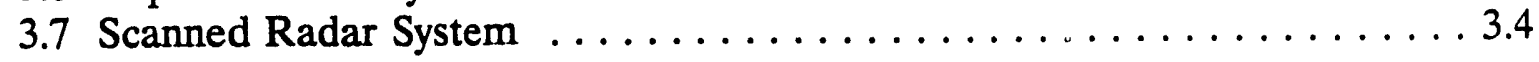

4.0 Radar Clutter Imaging and Calibration to Radar Cross Section . . . . . . . 4.1

4.1 Data Collection . . . . . . . . . . . . . . . . . . . . 4.1

4.2 Time Skew Correction and Coherent Integration . . . . . . . . . . 4.1

4.3 Frequency Dependent Apodization for Constant Beamwidth . . . . . . . 4.3

4.4 Synthetic Beam Steering/Focusing . . . . . . . . . . . . . . . 4.3

4.5 Calibration to Ultrawideband RCS and Clutter Coefficient . . . . . . . 4.4

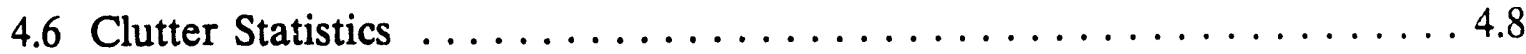

4.7 Long Record Lengths $\ldots \ldots \ldots \ldots \ldots \ldots \ldots \ldots \ldots \ldots \ldots$

4.8 Clutter Imaging Example . . . . . . . . . . . . . . . . 4.10

5.0 Site Selection and RFI Measurements $\ldots \ldots \ldots \ldots \ldots \ldots \ldots \ldots \ldots \ldots \ldots$

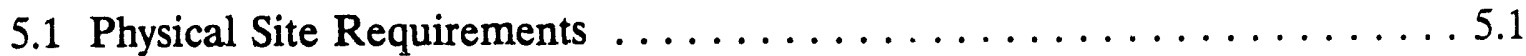

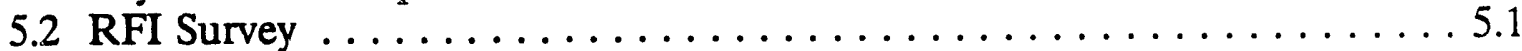

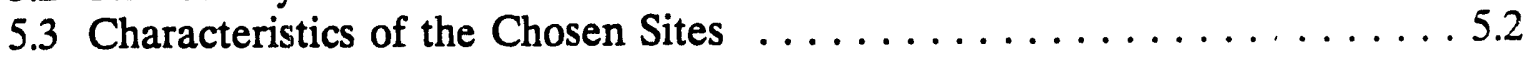

6.01991 Forest and Desert Measurements . . . . . . . . . . . . . . . 6.1

6.1 Impulse Forest Measurements (Sequim) $\ldots \ldots \ldots \ldots \ldots \ldots \ldots \ldots$

6.1 .1 Calibration . . . . . . . . . . . . . . . . . . 6.1

6.1 .2 Clutter Measurements . . . . . . . . . . . . . . 6.4

6.1 .3 Forest Clutter Analysis . . . . . . . . . . . . . . . 6.4

6.2 Step-chirp Forest Measurements (Sequim) . . . . . . . . . . . 6.6

6.3 Impulse Desert Measurements (Badger Canyon) $\ldots \ldots \ldots \ldots \ldots \ldots$

7.01992 Impulse Forest Measurements $\ldots \ldots \ldots \ldots \ldots \ldots \ldots \ldots \ldots \ldots$

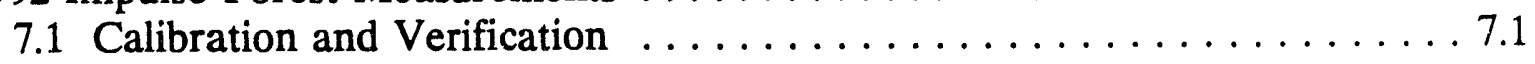


7.2 Clutter Measurements . . . . . . . . . . . . . . . . . . 7.4

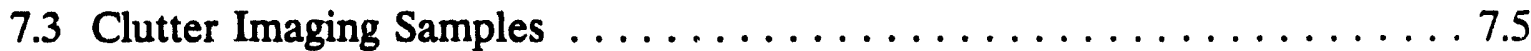

7.4 Noise (RFI) Measurements $\ldots \ldots \ldots \ldots \ldots \ldots \ldots \ldots \ldots \ldots \ldots .5 \ldots \ldots \ldots \ldots$

7.5 Forest Clutter Analysis $\ldots \ldots \ldots \ldots \ldots \ldots \ldots \ldots \ldots \ldots \ldots \ldots$

8.0 Comparison with Existing Data and Conclusions $\ldots \ldots \ldots \ldots . \ldots \ldots .1$

8.1 Overall Summary of Clutter Statistics $\ldots \ldots \ldots \ldots \ldots \ldots \ldots \ldots .1$

8.2 Range Resolution and Frequency Content Effects $\ldots \ldots \ldots \ldots \ldots . .2$

8.3 Comparison with Existing Narrow Band Data $\ldots \ldots \ldots \ldots \ldots \ldots .2$

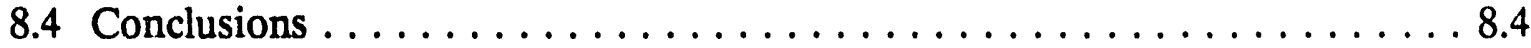

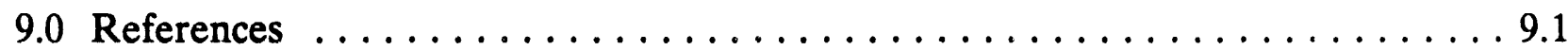

APPENDIX A: SPC Report on 1991 Sequim Measurements $\ldots \ldots \ldots \ldots \ldots$ A.1

APPENDIX B: Ground Truth for Original Site 1991 Sequim Measurements . . . B.1

APPENDIX C: Ground Truth for Maynard Site 1992 Sequim Measurements . . . . C.1 


\section{Figures}

2.1. Drawing of Scanned Clutter Data Collection System .............. 2.3

3.1. Impulse Radar System Block Diagram . . . . . . . . . . . . . . 3.5

3.2. $\quad 30 \mathrm{~kW}$ Pulser/Diode Module Pulse Response and Spectrurn . . . . . . . . . . 3.6

3.3. $\quad 100 \mathrm{~kW}$ Pulser/Diode Module Pulse Response and Spectrum . . . . . . . . . 3.7

3.4. Block Diagram of the Receiver $\ldots \ldots \ldots \ldots \ldots \ldots \ldots \ldots \ldots \ldots . . .6$

3.5. Measured Gain of the Receiver $(100-1000 \mathrm{MHz}) \ldots \ldots \ldots \ldots \ldots \ldots . . . \ldots \ldots$

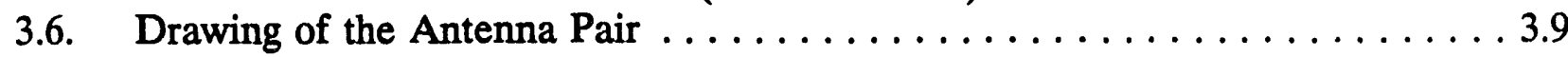

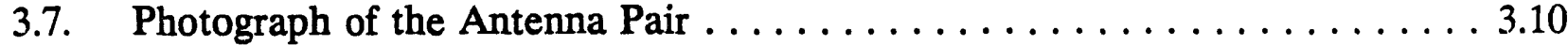

3.8. Transmission between Two Antennas $(100-1100 \mathrm{MHz}) \ldots \ldots \ldots \ldots . .11$

3.9. Isolation between Transmit and Receive Antennas $(100-1100 \mathrm{MHz}) \ldots \ldots .3 .12$

3.10. Vertical Antenna Pattern $\left( \pm 15^{\circ}\right)$ Averaged over $300-1000 \mathrm{MHz} \ldots \ldots \ldots . .13$

3.11. Horizontal Polarization Pattern $\left( \pm 15^{\circ}\right)$ Averaged over $300-1000 \mathrm{MHz} \ldots .3 .13$

3.12. Pulse Response/Spectrum from Flat Plate Calibration Target . . . . . . . . 3.14

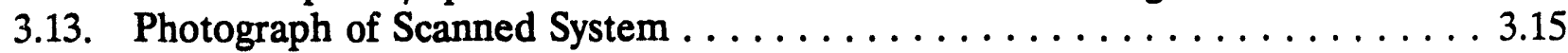

4.1. Unprocessed Calibration Target Response Image . . . . . . . . . . . 4.11

4.2. Calibration Target Image (Range-Angle) Calibrated to RCS . . . . . . . . . 4.12

5.1. Topographic Map Showing the Three Prospective Sites $\ldots \ldots \ldots \ldots \ldots .4 .4$

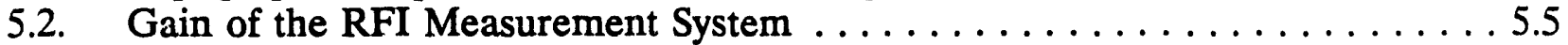

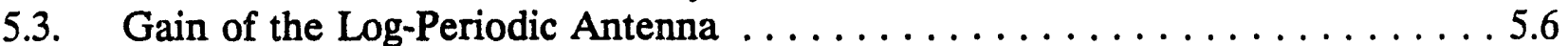

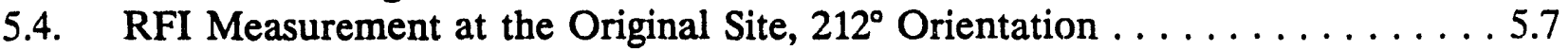

5.5. RFI Measurement at the Original Site, $304^{\circ}$ Orientation . . . . . . . . . 5.7

5.6. RFI Measurement at the Maynard Site, $72^{\circ}$ Orientation .......... 5.8

5.7. RFI Measurement at the Maynard Site, $334^{\circ}$ Orientation $\ldots \ldots \ldots \ldots \ldots 5.8$

5.8. RFI Measurement at the Road 150 Site, $58^{\circ}$ Orientation . . . . . . . . 5.9

5.9. RFI Measurement at the Road 150 Site, $224^{\circ}$ Orientation . . . . . . . . . 5.10

6.1. Panoramic Photograph Looking Outward from the 1991 Sequim Site . . . . . 6.9

6.2. Operations at the 1991 Sequim Site $\ldots \ldots \ldots \ldots \ldots \ldots \ldots \ldots \ldots \ldots .10 \ldots \ldots . \ldots \ldots$

6.3. Aerial Photograph of the 1991 Sequim Site $\ldots \ldots \ldots \ldots \ldots \ldots \ldots . \ldots .11$

6.4. Topographic Map of the 1991 Sequim Site . . . . . . . . . . . . . 6.12

6.5. Pseudo-Color Image of the A-scans Collected at the 256 Scanner Positions of the Calibration Target . . . . . . . . . . . . . . . . . . . . 6.13

6.6. Pseudo-Color SAR Image of Calibration Target Area Calibrated to Clutter Coefficient .................................6.14

6.7. Voltage Waveform/Spectrum for Calibration Target ............ 6.15

6.8. Windowed Voltage Waveform/Spectrum for Calibration Target . . . . . . 6.15

6.9. RCS Versus Range for the Calibration Target ............... 6.16

6.10. Reduced Resolution (100 MHz bandwidth) RCS Versus Range for the

Calibration Target . . . . . . . . . . . . . . . . . . . . . . 6.16

6.11. Pseudo-Color Calibrated SAR Image of a Relatively Low Clutter Region . . 6.17

6.12. Pseudo-Color Calibrated SAR Image of a Relatively Typical Clutter Region .................................6.17 
6.13. Pseudo-Color Calibrated SAR Image of a Relatively High Clutter Region . . 6.18

6.14. Distributions of VV Polarization Clutter Data Taken in Three Lines of

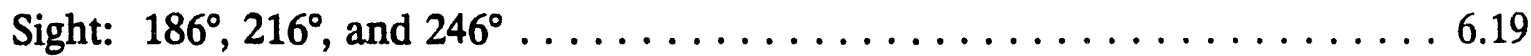

6.15. Distributions of HH Polarization Clutter Data Taken in Three Lines of

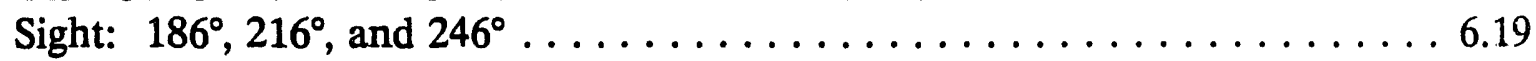

6.16. Distributions of Noise Equivalent Clutter Data . . . . . . . . . . . . . . . 6.20

6.17. Composite Clutter Map of the VV Data . . . . . . . . . . . . . . 6.20

6.18. Composite Clutter Map of the HH Data . . . . . . . . . . . . . . . . 6.21

6.19. Operations and Terrain at Badger Canyon Site . . . . . . . . . . . . . 6.21

6.20. Topographic Map of Badger Canyon Site . . . . . . . . . . . . . . . . 6.22

6.21. Received RFI Spectrum at Badger Canyon . . . . . . . . . . . . . . 6.23

6.22. Voltage Waveform/Spectrum for Badger Calibration Target . . . . . . . . . . 6.24

6.23. Windowed Voltage Waveform/Spectrum for Badger Calibration Target . . . 6.24

6.24. Pseudo-Color Calibrated SAR Image of Badger Calibration Target Area . . . 6.25

6.25. Pseudo-Color Calibrated SAR Image of Badger Clutter Region Showing

Essentially Noise (RFI) . . . . . . . . . . . . . . . . . . . 6.25

6.26. Pseudo-Color Calibrated SAR Image of Badger Clutter Region Showing

Discrete Scatterers over a Noise (RFI) Dominated Background . . . . . . . 6.26

6.27. Distributions of the RFI Dominated Clutter Coefficient Measured at

Badger Canyon ........................... 6.27

6.28. Distributions of the Noise Equivalent Clutter Coefficient Measured at

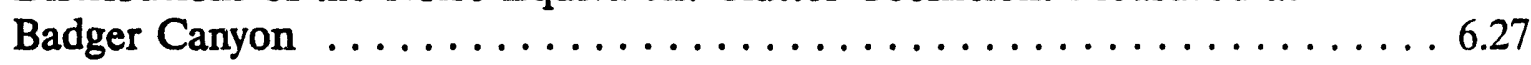

7.1. Panoramic Photograph Looking Outward from the Maynard Site . . . . . . 7.11

7.2. Photograph of the Scanner and Radar System at the Maynard Site . . . . . . 7.12

7.3. Topographic Map Showing the Maynard Site and Surrounding Terrain . . . . 7.13

7.4. Aerial Photograph of the Maynard Site and Surrounding Terrain . . . . . . . 7.14

7.5. Pulser Output Waveform and Spectrum Attenuated by $40 \mathrm{~dB} \ldots \ldots \ldots .7 .15$

7.6. Waveform Received from 3' by 4' Target at 35 Meters . . . . . . . . . . . . 7.15

7.7. Gated Waveform and Spectrum Received from 3' by 4' Target at 35

Meters . . . . . . . . . . . . . . . . . . . . . . . . 7.16

7.8. Pseudo-Color Image of the A-scans Collected at the 256 Scanner Positions

of the Calibration Target Area . . . . . . . . . . . . . . . . . 7.17

7.9. Focused Calibration Target Waveform and Spectrum . . . . . . . . . . 7.18

7.10. Focused Calibration Target Waveform Calibrated to RCS . . . . . . . . 7.18

7.11. Calibration Target Image (located in clutter) Calibrated to RCS . . . . . . . . 7.19

7.12. Photograph of 6' by $12^{\prime}$ and 3' by 4' Calibration Targets along the $28^{\circ}$ Line

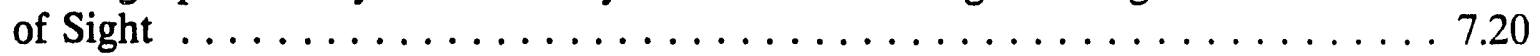

7.13. RCS Image of Clutter in Sector 2 (V pol.) . . . . . . . . . . . . 7.21

7.14. RCS Image of Clutter in Sector $2(\mathrm{H}$ pol. $) \ldots \ldots \ldots \ldots \ldots \ldots . \ldots \ldots$

7.15. RCS Image of Clutter in Sector $3(\mathrm{~V}$ pol.) $\ldots \ldots \ldots \ldots \ldots \ldots . \ldots \ldots$

7.16. RCS Image of Clutter in Sector 3 ( $\mathrm{H}$ pol.) . . . . . . . . . . . . . . . . . 7.24

7.17. Noise Equivalent Clutter Coefficient Distributions for $\mathrm{H}$ Pol at $70^{\circ}$

Orientation and at $1 \mathrm{~km}$ for 300-800 $\mathrm{MHz}$ Processing Bandwidth 7.25 
7.18. Noise Equivalent Clutter Coefficient Distributions for V Pol at $70^{\circ}$ Orientation and at $1 \mathrm{~km}$ for $300-800 \mathrm{MHz}$ Processing Bandwidth ...... 7.25

7.19. Composite Clutter Image of the VV Data $\ldots \ldots \ldots \ldots \ldots \ldots \ldots .26$

7.20. Composite Clutter Image of the HH Data ................ 7.26

7.21. Distributions of $\mathbf{3 0 0 - 8 0 0 ~} \mathrm{MHz}$ VV Polarization Clutter Data Taken in 6 Lines of Sight: $100^{\circ}, 70^{\circ}, 40^{\circ}, 10^{\circ}, 340^{\circ}$, and $310^{\circ} \ldots \ldots \ldots \ldots \ldots \ldots .27$

7.22. Distributions of $\mathbf{3 0 0 - 8 0 0 ~} \mathrm{MHz} \mathbf{~ H H}$ Polarization Clutter Data Taken in 6 Lines of Sight: $100^{\circ}, 70^{\circ}, 40^{\circ}, 10^{\circ}, 340^{\circ}$, and $310^{\circ} \ldots \ldots \ldots \ldots .27$

7.23. Distributions of $300-1000 \mathrm{MHz}$ VV Polarization Clutter Data Taken in 6 Lines of Sight: $100^{\circ}, 70^{\circ}, 40^{\circ}, 10^{\circ}, 340^{\circ}$, and $310^{\circ} \ldots \ldots \ldots \ldots \ldots .28$

7.24. Distributions of $300-1000 \mathrm{MHz}$ HH Polarization Clutter Data Taken in 6 Lines of Sight: $100^{\circ}, 70^{\circ}, 40^{\circ}, 10^{\circ}, 340^{\circ}$, and $310^{\circ} \ldots \ldots \ldots \ldots \ldots .28$ 


\section{Tables}

1.1. Summary of 1991 Impulse Clutter Measurements . . . . . . . . . . . . . . 1.3

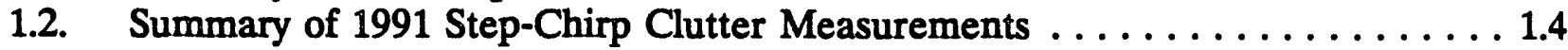

1.3. Summary of 1992 Impulse Clutter Measurements $\ldots \ldots \ldots \ldots \ldots \ldots \ldots 1.5$

3.1. Nominal Impulse Radar System Parameters .................. 3.1

3.2. Specifications of the Tektronix DSA 602A Digitizer ..............3.3

6.1. On-Axis RCS Measurements (UWB) of Known Targets Including the 6' by 12' Flat Plate and a 3' by 4' Flat Plate . .................... 6.3

6.2. Summary of VV and HH Polarization Clutter Data Taken in Three Lines

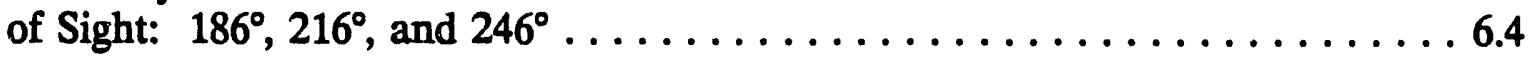

6.3. Summary of Noise Equivalent Clutter Data . . . . . . . . . . . . 6.5

6.4. Summary of Noise Equivalent Clutter Coefficient Measured at Badger . . . . 6.7

6.5. Summary of the RFI Dominated Clutter Data Taken at Badger Canyon . . . . 6.7

7.1. Radar Equation Closures (3' by 4' Target at 35 Meters) . . . . . . . . . . 7.1

7.2. RCS Measurements of Known Targets .................... 7.4

7.3. Sectors and Ranges Covered $\left(30^{\circ}\right.$ by $604.8 \mathrm{~m}$ per scan) . . . . . . . . 7.5

7.4. Noise Equivalent Clutter Coefficient Statistics at $1 \mathrm{~km}$ for $300-800 \mathrm{MHz}$ Processing Bandwidth and $70^{\circ}$ Orientation . . . . . . . . . . .

7.5. Noise Equivalent Clutter Coefficient Statistics at $1 \mathrm{~km}$ for $300-800 \mathrm{MHz}$

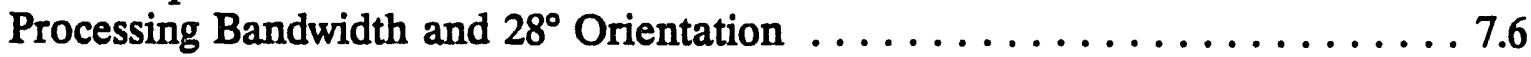

7.6. Noise Equivalent Clutter Coefficient at $1 \mathrm{~km}$ for Different Processing

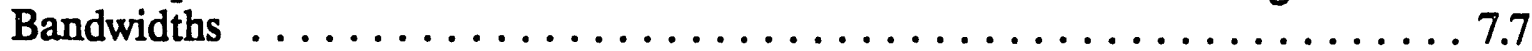

7.7. Summary of $300-800 \mathrm{MHz} \mathrm{VV}$ and $\mathrm{HH}$ Polarization Clutter Data Taken in 6 Lines of Sight: $100^{\circ}, 70^{\circ}, 40^{\circ}, 10^{\circ}, 340^{\circ}$, and $310^{\circ} \ldots \ldots \ldots \ldots \ldots . . \ldots 7$

7.8. Summary of 300-1000 MHz VV and $\mathrm{HH}$ Polarization Clutter Data Taken in 6 Lines of Sight: $100^{\circ}, 70^{\circ}, 40^{\circ}, 10^{\circ}, 340^{\circ}$, and $310^{\circ} \ldots \ldots \ldots \ldots \ldots . . \ldots$

8.1. Summary of UWB Clutter Values $\ldots \ldots \ldots \ldots \ldots \ldots \ldots \ldots \ldots \ldots \ldots \ldots .1$

8.3. MIT/LL Narrowband Radar Data $\ldots \ldots \ldots \ldots \ldots \ldots \ldots . \ldots \ldots . . \ldots \ldots$ 


\section{Acknowledgements}

This project was sponsored by the Balanced Technology Initiative/Defense Advanced Research Projects Agency (BTI/DARPA) under the direction of Dr. Dominic Giglio of DARPA. Technical guidance was given by Dr. James Ralson of the Institute for Defense Analyses (IDA), Mike Tuley of Georgia Tech Research Institute (GTRI), and Dr. George Ruck of Battelle Columbus. 


\subsection{Summary}

The ultrawideband (UWB) radar cilutter measurements project was conducted to provide radar clutter data for new ultrawideband radar systems which are currently under development. A particular goal of this project is to determine if conventional narrow band clutter data may be extrapolated to the UWB case. This report documents measurements conducted in 1991 and additional measurements conducted in 1992.

An experimental impulse radar system was designed and implemented specifically to perform these clutter measurements. The impulse system makes use of very short highpower pulses. A more conventional method of generating ultrawide bandwidths is to use a step-chirp system. This technique uses relatively long pulse widths and subsequent processing for pulse compression.

For both systems, a 19-meter linear scanner was used to provide a synthetic aperture of sufficient length to provide reasonable angular resolution. Since the aperture is synthesized in processing, an additional benefit is that a frequency-dependent aperture may be formed that has a constant beamwidth over the ultrawide bandwidth of the pulse or stepchirp system. The high range and angular resolution was used to maximize the number of clutter cells available at each measurement site.

The original project, conducted in 1991, consisted of clutter measurements of forested terrain in the Olympic National Forest near Sequim, WA. The impulse radar system used a $30 \mathrm{~kW}$ peak impulse source with a 2 Gigasample/second digitizer to form a UHF (300-1000 MHz) ultrawideband impulse radar system. Additional measurements were conducted in paraliel using a Systems Planning Corporation (SPC) step-chirp radar system. This system utilized pulse widths of 1330 nanoseconds over a bandwidth of 300$1000 \mathrm{MHz}$ to obtain similar resolution to the impulse system. Due to the slow digitizer data throughput in the impulse radar system and the higher average power available with the conventional step-chirp system, data collection rates were significantly higher using the step-chirp system. The step chirp system gathered data over a $120^{\circ}$ swath from 0.5 $\mathrm{km}$ to $2.5 \mathrm{~km}$ for $6.2 \mathrm{~km}^{2}$, for approximately 780,000 clutter cells $\left(1.5^{\circ}\right.$ by $0.214 \mathrm{~m}$ clutter cell size). The impulse system gathered data over a $90^{\circ}$ swath from $0.75 \mathrm{~km}$ to $1.2 \mathrm{~km}$ for $0.7 \mathrm{~km}^{2}$, for approximately 120,000 clutter cells $\left(1.5^{\circ}\right.$ by $0.214 \mathrm{~m}$ clutter cell size).

Additional forest clutter measurements were undertaken in 1992 to increase the amount of ultrawideband clutter data available, and especially, to increase the amount of data from the impulse radar system. The following improvements were made to increase the data collection rate of the impulse radar system. Peak power was increased from $30 \mathrm{~kW}$ to over $100 \mathrm{~kW}$ by the implementation of an improved solid-state pulser. The datathroughput burden on the digitizer was relieved by performing internal averaging in the instrument rather than outputting all waveforms to the computer. These improvements increased the clutter data collection rate by at least 10 times. The additional nower and 
data collection rate available are expected to increase the available range to approximately 3-4 kilometers.

The additional forested site was selected near to the site of the 1991 measurements. The site of the 1991 measurements is referred to as the "Original Site," and the site of the new measurements is referred to as the "Maynard Site." Total measurable terrain at this location covers an angular swath of up to $180^{\circ}$ and a range of $300 \mathrm{~m}$ out to $2-4 \mathrm{~km}$ for 800,000 up to 2,000,000 clutter cells. Scanned measurements were conducted in September and October 1992 at the Maynard Site. Over 60 scans were taken covering an angular swath of $180^{\circ}$ and ranges from $300 \mathrm{~m}$ to $3.3 \mathrm{~km}$. The area covered is approximately $17 \mathrm{im}^{2}$. Usable clutter data was obtained for approximately 1 million clutter cells.

Statistical results for the 1991 and 1992 clutter measurements are summarized in Tables 1.1 to 1.3 , including the approximate slope parameter for these results under the assumption that they fit the Weibull distribution. The 1991 impulse and step-chirp measurements were processed using a rectangular constant beamwidth window and a 300-1000 MHz frequency band. The 1992 impulse measurements were processed using a rectangular constant beamwidth window and a $300-800 \mathrm{MHz}$ frequency band. The frequency band was reduced for the 1992 measurements due to significant RFI in the $800-900 \mathrm{MHz}$ (cellular phone) band. These results are for coniferous forest with much of the illuminated area coming from facing slopes of the surrounding mountains. Thus, the clutter coefficient may be biased upward relative to other clutter measurements. 
Table 1.1. Summary of 1991 Impulse Clutter Measurements

\begin{tabular}{||l|c|c||}
\hline Polarization & $\mathrm{VV}$ & $\mathrm{HH}$ \\
\hline Frequency Band & $300-1000 \mathrm{MHz}$ & $300-1000 \mathrm{MHz}$ \\
\hline Aperture Window & Rectangular & Rectangular \\
\hline Angle Coverage & $171^{\circ}-261^{\circ}$ & $171^{\circ}-261^{\circ}$ \\
\hline Beamwidth (constant) & $1.5^{\circ}$ & $1.5^{\circ}$ \\
\hline Range Coverage & $750 \mathrm{~m}-1200 \mathrm{~m}$ & $750 \mathrm{~m}-1200 \mathrm{~m}$ \\
\hline Range Resolution & $0.214 \mathrm{~m}$ & $0.214 \mathrm{~m}$ \\
\hline Number of Cells & 117,800 & 120,900 \\
\hline Mean $\sigma^{\circ}$ & $-5.4 \mathrm{~dB}$ & $-9.0 \mathrm{~dB}$ \\
\hline Mediau $\sigma^{\circ}$ & $-12.4 \mathrm{~dB}$ & $-16.8 \mathrm{~dB}$ \\
\hline Std Dev $/$ Mean $\sigma^{\circ}$ &.-- & -- \\
\hline Max $\sigma^{\circ}$ & $14.1 \mathrm{~dB}$ & $12.4 \mathrm{~dB}$ \\
\hline Weibull Spread $\sigma^{\circ}$ & 2.17 & 2.44 \\
\hline
\end{tabular}


Table 1.2. Summary of 1991 Step-Chirp Clutter Measurements

\begin{tabular}{||l|c|c|}
\hline Polarization & VV & HH \\
\hline Frequency Band & $300-1000 \mathrm{MHz}$ & $300-1000 \mathrm{MHz}$ \\
\hline Aperture Window & Rectangular & Rectangular \\
\hline Angle Coverage & $171^{\circ}-291^{\circ}$ & $171^{\circ}-291^{\circ}$ \\
\hline Beamwidth (constant) & $1.5^{\circ}$ & $1.5^{\circ}$ \\
\hline Kange Coverage & $500 \mathrm{~m}-2500 \mathrm{~m}$ & $500 \mathrm{~m}-2500 \mathrm{~m}$ \\
\hline Range Resolution & $0.214 \mathrm{~m}$ & $0.214 \mathrm{~m}$ \\
\hline Number of Cells & 780,000 & 780,000 \\
\hline Mean $\sigma^{\circ}$ & $-7.4 \mathrm{~dB}$ & $-11.5 \mathrm{~dB}$ \\
\hline Median $\sigma^{\circ}$ & $-14 \mathrm{~dB}$ & $-18.8 \mathrm{~dB}$ \\
\hline Std Dev/Mean $\sigma^{\circ}$ & $4.2 \mathrm{~dB}$ & $4.7 \mathrm{~dB}$ \\
\hline Max $\sigma^{\circ}$ & $16 \mathrm{~dB}$ & $10 \mathrm{~dB}$ \\
\hline Weibull Spread $\sigma^{\circ}$ & 2.02 & 2.14 \\
\hline
\end{tabular}


Table 1.3. Summary of 1992 Impulse Clutter Measurements

\begin{tabular}{||l|c|c||}
\hline Polarization & VV & HH \\
\hline Freque ncy Band & $300-800 \mathrm{MHz}$ & $300-800 \mathrm{MHz}$ \\
\hline Aperture Window & Rectangular & Rectangular \\
\hline Angle Coverage & $115^{\circ}$ to $0^{\circ}$ to $295^{\circ}$ & $115^{\circ}$ to $0^{\circ}$ to $295^{\circ}$ \\
\hline Beamwidth (constant) & $1.35^{\circ}$ & $1.35^{\circ}$ \\
\hline Range Coverage & $300 \mathrm{~m}-3300 \mathrm{~m}$ & $300 \mathrm{~m}-3300 \mathrm{~m}$ \\
\hline Range Resolution & $0.3 \mathrm{~m}$ & $0.3 \mathrm{~m}$ \\
\hline Number of Cells & 974,000 & 974,000 \\
\hline Mean $\sigma^{\circ}$ & $-6.4 \mathrm{~dB}$ & $-9.3 \mathrm{~dB}$ \\
\hline Median $\sigma^{\circ}$ & $-18.4 \mathrm{~dB}$ & $-19.1 \mathrm{~dB}$ \\
\hline Std Dev/Mean $\sigma^{\circ}$ & $6.1 \mathrm{~dB}$ & $6.5 \mathrm{~dB}$ \\
\hline Max $\sigma^{\circ}$ & $22.8 \mathrm{~dB}$ & $23 \mathrm{~dB}$ \\
\hline Weibull Spread $\sigma^{\circ}$ & 2.97 & 2.83 \\
\hline
\end{tabular}




\subsection{Introduction}

Impulse and step-chirp radar systems were set up using a 19-meter linear scanner with the goal of providing as much forested terrain land clutter as possible. A conceptual drawing of the scanned radar systems is shown in Figure 2.1. The aperture of the scanner is used to form a small synthetic aperture over which data is gathered and stored in the computer for synthesis of a narrow scanned beam.

Ultrawideband radars are expected to be useful due to their simultaneous characteristics of high resolution and relatirely low frequency. For additional information see OSD/DARPA Ultra-Wideband Radar Review Panel (1990). High resolution is obtained from the ultra-wide bandwid'h, and the low frequency is useful for foliage and ground penetration. An additional application of this technology is for short range radar systems.

Ultrawideband radar systems may be realized using two different techniques. The first technique utilizes conventional radar methods in which a synthesized frequency is timegated to provide a relatively long pulse. Data recorded over a wide band of frequencies can then be pulse compressed using the Fourier Transform to provide the high resolution available in wideband systems. This technique is denoted "step-chirp." The second technique utilizes an instantaneously wideband signal, typically a very short pulse or impulse. This pulse may be generated using solid-state switches, spark gap generators, or optically activated switches, and other techniques. The transient signal is then received and digitized directly using a high sample rate digitizer. Advantages of this technique include simplicity of the system, high peak power rates available, and instantaneous (not pulse compressed) high range resolution. Disadvantages include: low average power, wide instantaneous noise bandwidth, and lack of control over the source characteristics.

Both of these measurement systems made use of a 19-meter linear scanner, which was used to allow synthesizing a narrow beamwidth. Nominal beamwidth for the antennas used allows data to be gathered over a nominal $30^{\circ}$ swath. Subsequent beam synthesis forms a beam on the order of $1^{\circ}$ beamwidth $(3 \mathrm{~dB})$. This beam is synthetically swept through a $\pm 15^{\circ}$ angular swath as shown in Figure 2.1. Several scanner positions were used to allow measurements over a $90-180^{\circ}$ total swath. An additional benefit of the scanned system is that a beam can be formed with an angular width that is independent of frequency. This is important for the clutter coefficient $\left(\sigma^{\circ}\right)$ to be rigorously defined. If the full scanned aperture were used to form the synthesized beam, then the beamwidth would decrease with increasing frequency. Using Fourier transforms of the transient data, the scanned data can be windowed with an aperture width proportional to the wavelength to realize a constant beamwidth as a function of frequency.

High range resolution is inherent in the impulse system and may be obtained by inverse Fourier Transformation in the step-chirp system. Thus 2 range-angle sectoral image of 
the data is obtained for each scan. Resolution of the data images is $1^{\circ}$ in angle and approximately 0.2 meters in range. Note that with the small 19-meter aperture, the range resolution will be much higher than the cross-range resolution (equal to range times beamwidth in radians).

The frequency range of interest is $300-1000 \mathrm{MHz}$, which is the UHF band. This band was chosen for a number of technological reasons. Many potential applications, such as foliage penetration and ground penetrating radar systems, are expected to use this frequency range. The lower frequency was chosen to keep antenna size reasonable and to eliminate the FM broadcast band. Radio frequency interference (RFI) is the dominant factor limiting the range of the ultrawideband radar systems. Note that this is not the case for conventional narrowband microwave radar systems which are typically thermal-noise limited. The upper frequency limit of $1000 \mathrm{MHz}$ was chosen since the impulse system requires a high-speed transient digitizer, and 2 Gigasamples/ second is the highest speed digitizer available (at the time of the measurements). Thus, to satisfy the Nyquist sampling criterion a limit of $1 \mathrm{GHz}$ was established.

Forested terrain was chosen ats the most important type of terrain to measure since it is expected to have high clutter levels and is therefore most important for the design of UWB short range radar systems that must operate in this environment. Forested terrain is also representative of the terrain type for foliage penetrating radar systems.

Statistical results from these measurements are important because it is unknown what the effect of high resolution (small clutter cell size) will have on the clutter statistics. Specifically, an increase in the occurrence of very high discrete clutter values due to the high range resolution, may cause an increase in the false alarm rate of UWB radar systems.

Ultrawideband radar forces a new interpretation of some conventional radar parameters. Ultrawideband systems typically have a high frequency to low frequency ratio is excess of 3 to 1 . Therefore, it may not be sufficient to simply use the center frequency for the computation of beamwidth, antenna gain, radar cross-section (RCS), clutter coefficient $\left(\sigma^{0}\right)$, etc. In this report, consistent formulas for high resolution RCS, and clutter coefficient are developed.

In particular, the synthesized beamwidth poses a problem for the definition of the clutter coefficient $\left(\sigma^{0}\right)$. If the full aperture of the linear scanner is used to synthetically form the narrow beam, then the beamwidth will be frequency dependent. That is, the beamwidth will decrease in proportion to the wavelength. The clutter coefficient is defined to be the RCS dirided by the area of a resolution cell. This leads to an inconvenient definition : the resolution cell size is frequency dependent. Therefore, a constant beamwidth is desirable, since the desired output is a set of clutter coefficient values that depend orily on the spatial coordinates, and not on the specific frequency within the band. This may be achieved in the synthetic beam steering of the data by 
dependent window to the linear aperture. The width of the window is set to be the full width of the aperture at the lowest frequency of interest and is then made to reduce in width proportional to the wavelength.

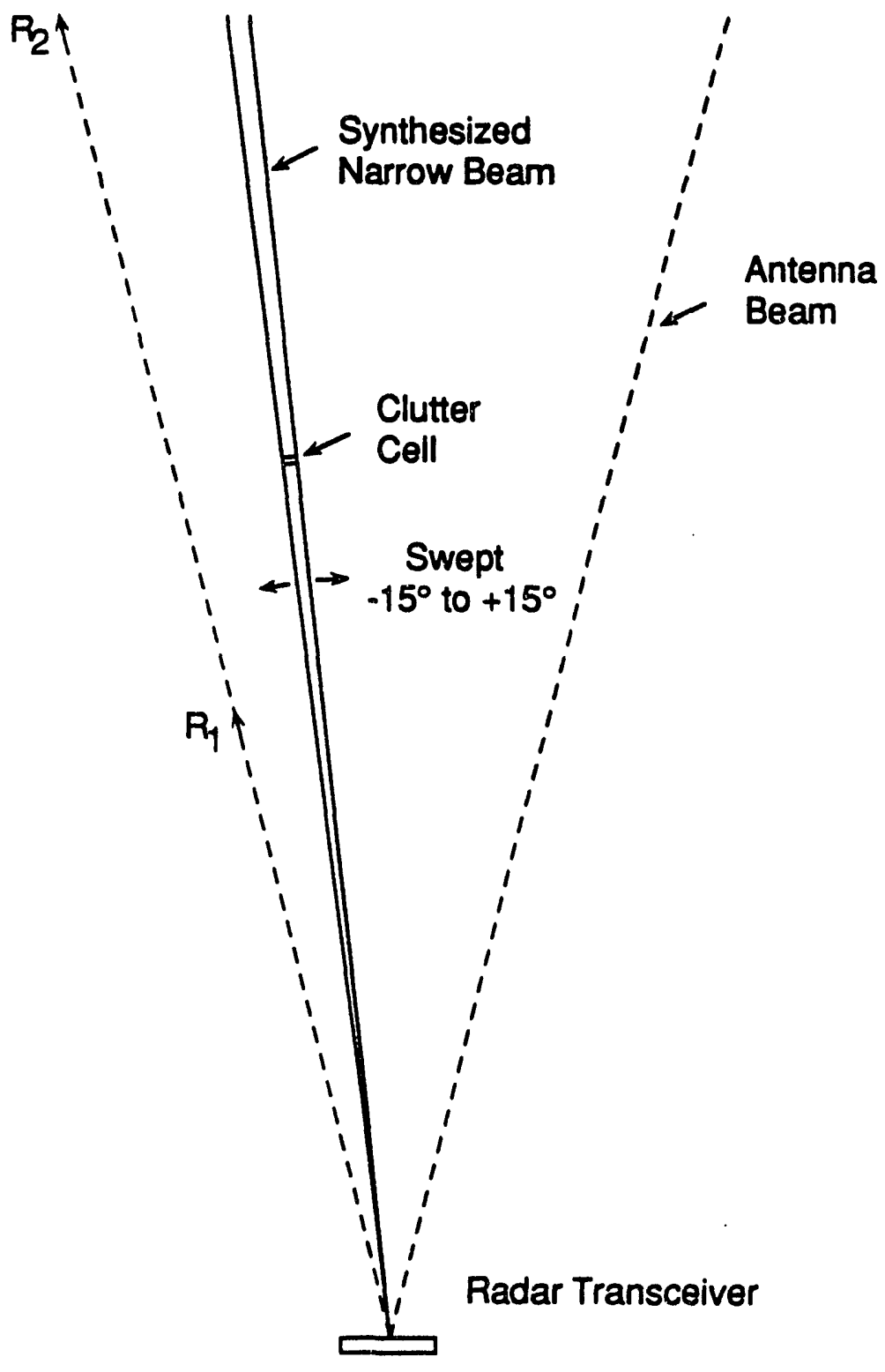

$19 \mathrm{~m}$ Scanner

Figure 2.1. Drawing of Scanned Clutter Data Collection System 


\subsection{Impulse Radar Design}

Due to the novelty of impulse radar systems, it was necessary to a develop a suitable experimental radar system for the ultrawideband radar clutter measurements. Commercially available components were used wherever possible in the impulse radar system.

The step-chirp system used was a Systems Planning Corporation Mark IV. This system was set up and operated by SPC during the 1991 measurements. Since this system has been commercially available for some time, it will not be discussed in great detail in this report. A brief description of the Mark IV as configured for these measurements is given in Appendix A.

\subsection{System Description}

A block diagram of the impulse radar system is shown in Figure 3.1. Components of this system include: the digitizer (Tektronix DSA 602A), high power pulser, receiver, antennas, and scanner. The nominal specifications are listed in Table 3.1.

Table 3.1. Nominal Impulse Radar System Parameters

\begin{tabular}{|l|l|}
\hline Transmitted Power & $100 \mathrm{~kW}$ (peak) \\
\hline Pulse Width & $<1 \mathrm{nsec}$ \\
\hline Antenna Bandwidth & $30^{\circ}$ (nominal) \\
\hline Linear Aperture & 19 meters \\
\hline Synthesized Beamwidth & $1-1.5^{\circ}$ \\
\hline Antenna Element Gain & $8-10 \mathrm{dBi}$ \\
\hline Digitizer Sample Rate & $2 \mathrm{GS} / \mathrm{s}$ \\
\hline Receiver Bandwidth & $300-1000 \mathrm{MHz}$ (nominal) \\
\hline Receiver Noise Figure & $2 \mathrm{~dB}$ (nominal) \\
\hline Range Resolution & $0.214 \mathrm{~m} \mathrm{(700} \mathrm{MHz} \mathrm{BW)}$ \\
\hline
\end{tabular}

Operation of the high power pulser is controlled by the PRF Generator which generates a short logic pulse approximately 300 times per second to trigger the main pulser (Current Research model HVTP). The output of the main pulser is passed through a 
diode pulse sharpening network to the transmitting antenna. A delay generator is used to trigger the digitizer after a prescribed delay has occurred. The received signal is boosted by an amplifier module near the antenna and then routed to the digitizer. The data received by the digitizer is then transferred to the computer or averaged internally and then transferred to the computer. The data is stored temporarily on a large disk drive and then permanently archived to $8-\mathrm{mm}$ tape.

Critical transmitter and receiver modules are located on the carriage of the 19-meter linear scanner to limit cabling losses. The scanner carriage is controlled by the computer, with data recorded uniformly across the full aperture.

\subsection{Digitizer}

The transient digitizer forms the heart of the impulse radar receiver. A Tektronix DSA $602 \mathrm{~A}$ digitizer with an analog bandwidth of $\mathrm{DC}$ to $1000 \mathrm{MHz}$ was used in the impulse radar system. This digitizer has 8 bits of resolution and a 2 Gigasamples per second (2 GS/s) sample rate. This allows sampling up to the Nyquist frequency of $1000 \mathrm{MHz}$. Data can be transferred to the computer using the IEEE-488 interface. This interface has a fairly slow data transfer rate of approximately 10,000 samples per second as configured in the impulse radar system. This allows approximately 20512 sample waveforms per second to be transferred to the compute:

An additional feature of this digitizer is that it can record the time delay (or skew) from the trigger to the first data sample. This time shift will in general be random from 0 to 500 picoseconds (at $2 \mathrm{GS} / \mathrm{s}$ ). Often it will be required that many waveforms be recorded and subsequently summed in order to increase the signal-to-noise ratio. The time-skew value can be used to re-align (de-skew) the waveforms prior to summing in the computer. This feature can thus be used to maintain coherence over many waveforms and improve the signal-to-noise ratio. Key specifications of the DSA 602A digitizer are summarized in Table 3.2.

\subsection{Pulser}

A Current Research model FTP and Current Research model IDM diode sharpening network were selected for the transmitter power impulse generator for the 1991 measurements. The output of the pulser is passed through the diode sharpening network which reduces the pulse width to approximately 400 psec. A Current Research model HVTP and Current Research model MIDM diode sharpening network were selected for the transmitter power impulse generator for the 1992 measurements. The output pulse width is approximately 400 psec. 
Table 3.2. Specifications of the Tektronix DSA 602A Digitizer

\begin{tabular}{||c|c||}
\hline \multicolumn{2}{|c|}{ Tektronix DSA 602A } \\
\hline Digitizer Sample Rate & $2 \mathrm{GS} / \mathrm{s}$ \\
\hline Bandwidth & DC-1000 MHz \\
\hline A/D Resolution & 8 bits \\
\hline Sensitivity & $10 \mathrm{mV} /$ div to $1 \mathrm{~V} /$ div \\
\hline Record Length & 512 to 32,768 \\
\hline Data Transfer & IEEE-488 \\
\hline Synchronization & $\begin{array}{c}\text { Records delay to first sample } \\
\text { (time skew) }\end{array}$ \\
\hline
\end{tabular}

The first version of this pulser was capable of generating a pulse with peak amplitude in excess of 1200 volts $(50 \mathrm{ohm}$ load) for a peak power of approximately $30 \mathrm{~kW}$. The second version of this system is capable of generating a peak amplitude of approximately 2500 volts $(50 \mathrm{ohm}$ load) for a peak power of approximately $125 \mathrm{~kW}$. Typical output pulses and spectra for these two pulser systems are shown in Figures 3.2 and 3.3.

\subsection{Receiver}

The receiver module was designed to limit the bandwidth and amplify the received signals. A block diagram of the receiver is shown in Figure 3.4. The limiter was used to protect the amplifiers from the large transmitter leakage signal that occurs during transmitter pulsing. The $300 \mathrm{MHz}$ low pass filter was used to eliminate unwanted RFI, predominantly from FM broadcast stations. The $850 \mathrm{MHz}$ high pass filter was used to prevent significant aliasing in the DSA 602 digitizer. The amplifiers simply increase the signal strength prior to transmission over approximately 30 meters of cable to the digitizer. The receiver has a measured gain of approximately $54 \mathrm{~dB}$ over the $300-850$ $\mathrm{MHz}$ band, as shown in Figure 3.5.

\subsection{Antennas}

The antennas for the impulse radar system must have moderate gain, beamwidth of at least $30^{\circ}$, and acceptable transient response. Commercially available wideband antennas in the UHF frequency band are often variations of log-periodic antennas. These 
antennas are not well suited to our application since the phase center shifts with frequency and therefore widens the transmitted pulse.

Transverse electromagnetic (TEM) horn antennas were chosen for the impulse system due to their wideband operation and excellent pulse response. A commercial antenna. could not be found so a pair of antennas were fabricated at PNL. Separate transmit. and receive antennas are necessary to prevent the transmitter pulses from damaging the receiver. A metallic screen was also positioned between the transmit and receive antennas to further increase the isolation between the transmitter and receiver.

A drawing of the antenne pair is shown in Figure 3.6, and a photograph is shown in Figure 3.7. The bandwidth of the TEM horn antennas is demonstrated in Figure 3.8 in which the antennas were placed approximately $10 \mathrm{~m}$ apart and the transmission coefficient was measured. The isolation between the transmit and receive sides of the TEM antenna pair is shown in Figure 3.9.

Antenna patterns were computed in the following way. The TEM antenna pair was placed on a tripod with another TEM horn used as a receive antenna approximately 10 $\mathrm{m}$ away. The antenna pair was then rotated $\pm 15^{\circ}$ to obtain the pattern. A calibrated scale for the gain measurements was obtained by comparison with a log-periodic antenna of known gain. The vertical polarization antenna pattern measured in this way is not symmetric due to the presence of the metallic screen in between the two antennas. When the antenna pair is used in the radar system the effective antenna gain will be symmetric since the transmit and receive antennas have the screen on opposite sides. The effective symmetrical antenna gain is therefore the geometric mean of the positive and negative angle patterns. In addition, the patterns at 300,650 , and $1000 \mathrm{MHz}$ were averaged as will be the case for the wideband impulse system. The effective vertical and horizontal polarization lateral antenna patterns are presented in Figures 3.10 and 3.11.

\subsection{Impulse Radar System Point Measurements}

To demonstrate acceptable pulse response and proper operation of the radar system, the impulse radar system was configured outside our facility and the following point measurement was made. The reflected transient response and spectrum from a 6' by $12^{\prime}$ flat plate calibration target at a range of approximately 100 meters was recorded and is shown in Figure 3.12.

\subsection{Scanned Radar System}

The transportable scanner is used to position the antennas along the 19-meter horizontal linear aperture. The scanner is a full two dimensional scanner capable of scanning an 
aperture in excess of 19 meter by 5 meters. The y-axis capability was used simply to lower and raise the antenna pair. During data collection the antennas are raised to the maximum height allowed by the scanner. A photograph of the scanner and radar system is shown in Figure 3.13. Accuracy of this scanner is significantly better than $1 \mathrm{~mm}$, which is extremely high accuracy for the frequency range of the impulse radar system. This scanner design has been effectively used for two-dimensional close range imaging at 10 $\mathrm{GHz}$ and $35 \mathrm{GHz}$.

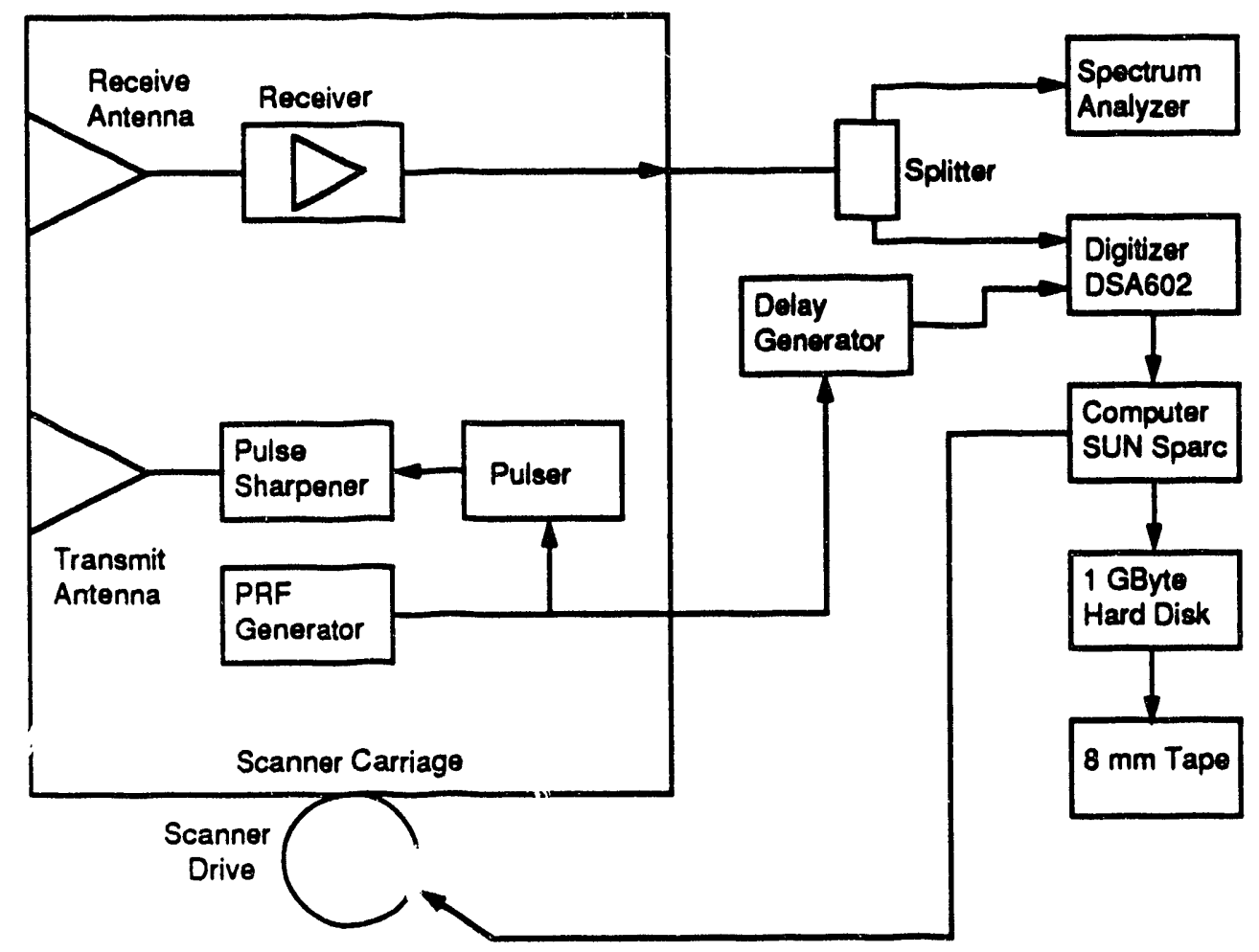

Scanner carriage moves over a

Computer and digitizer are connected to linear $19 \mathrm{~m}$ aperture scanner by approximately $100 \mathrm{ft}$ cables

Figure 3.1. Impulse Radar System Block Diagram 

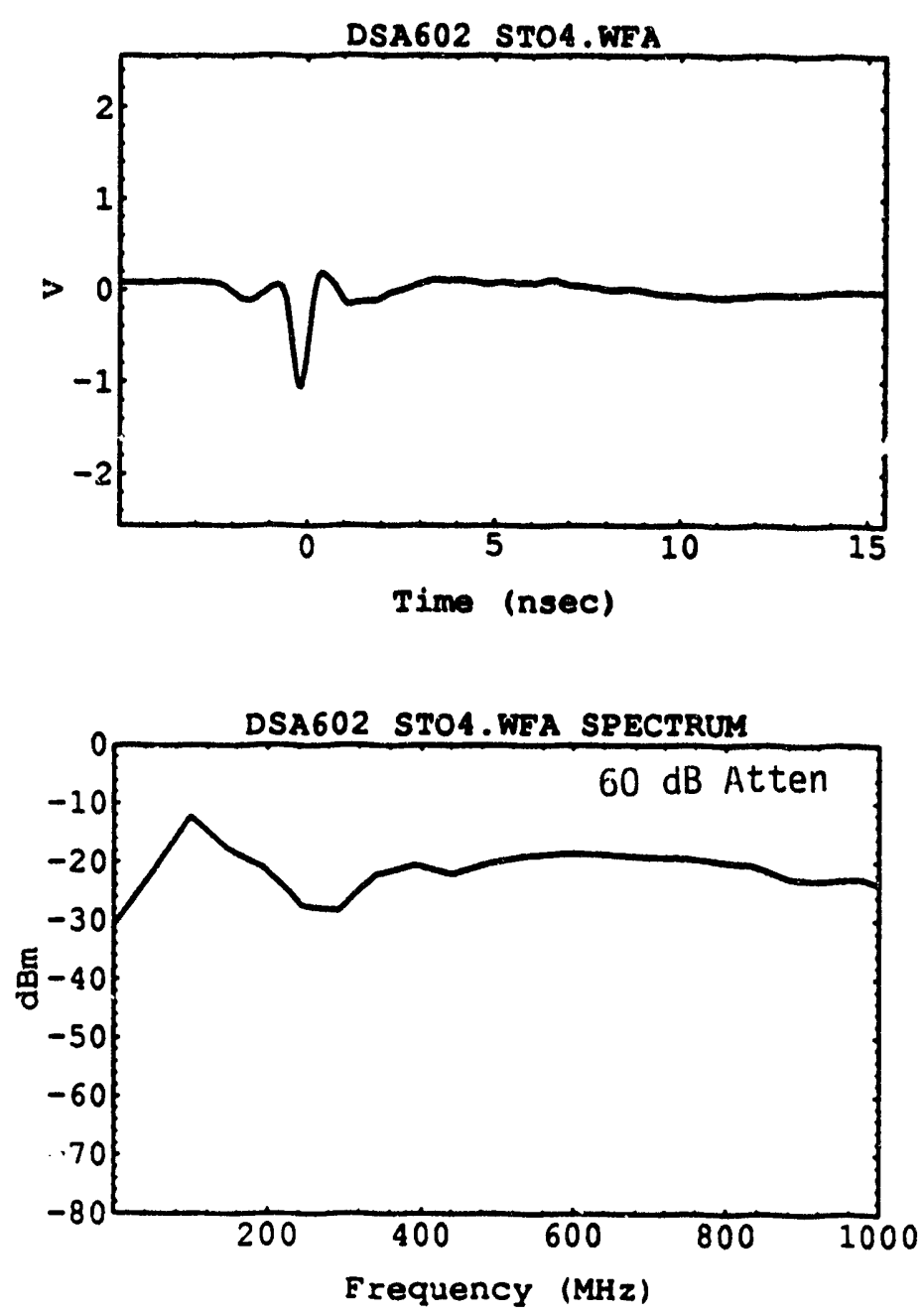

Figure 3.2. $30 \mathrm{~kW}$ Pulser/Diode Module Pulse Response and Spectrum 

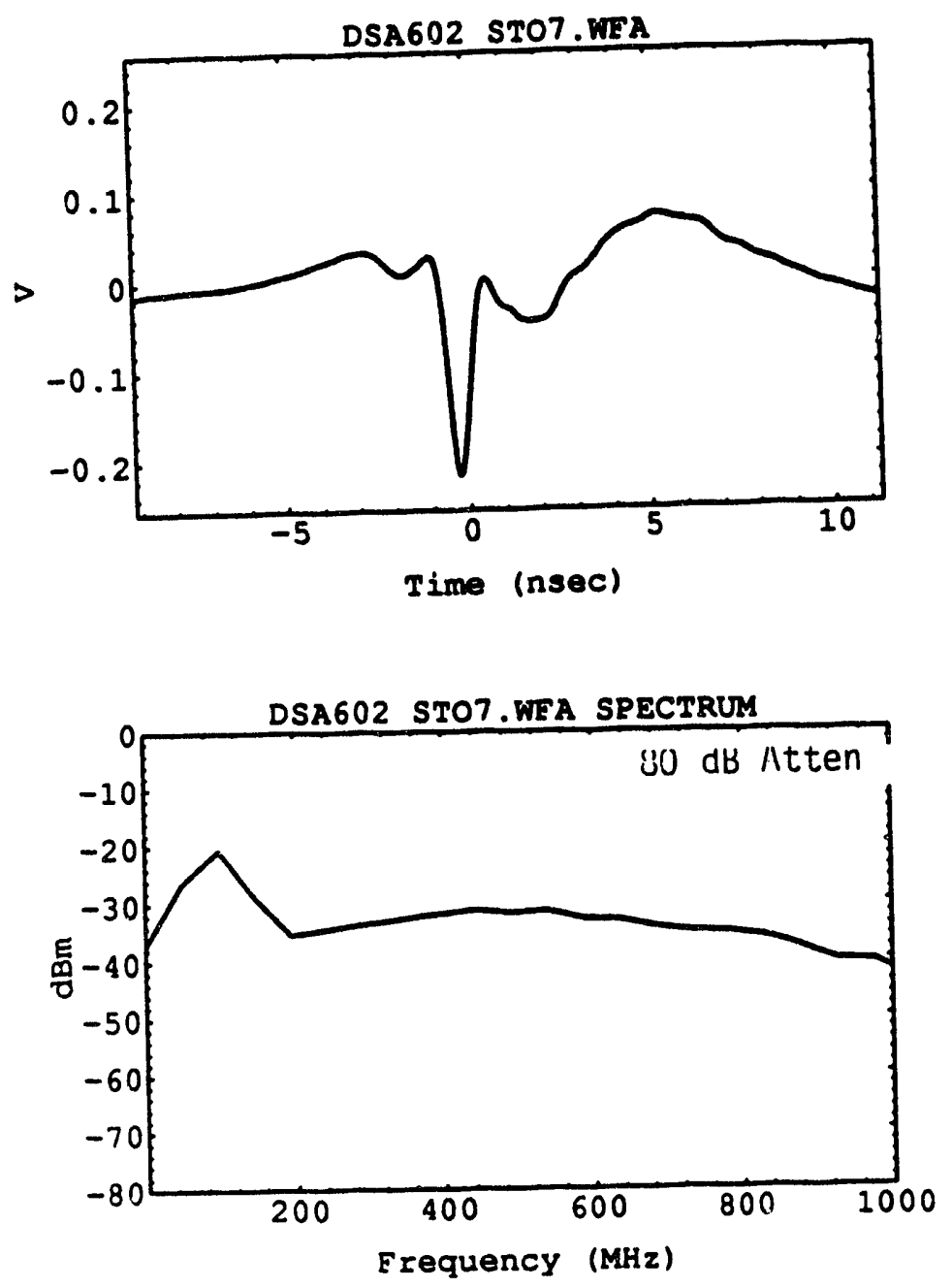

Figure 3.3. $100 \mathrm{~kW}$ Pulser/Diode Module Pulse Response and Spectrum 


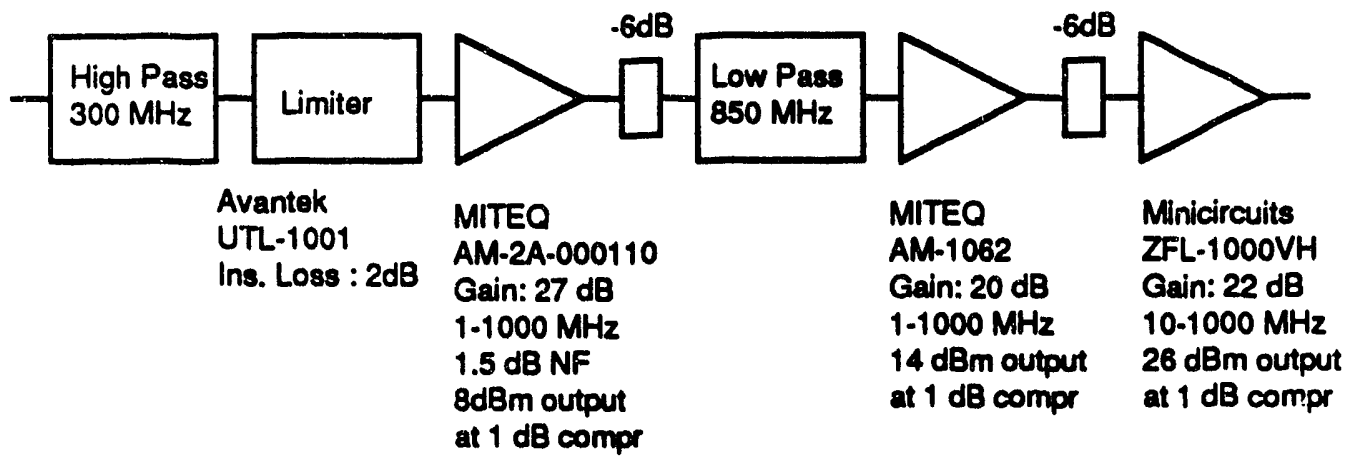

Recumar Elocin Diesiom

Figure 3.4. Block Diagram of the Receiver

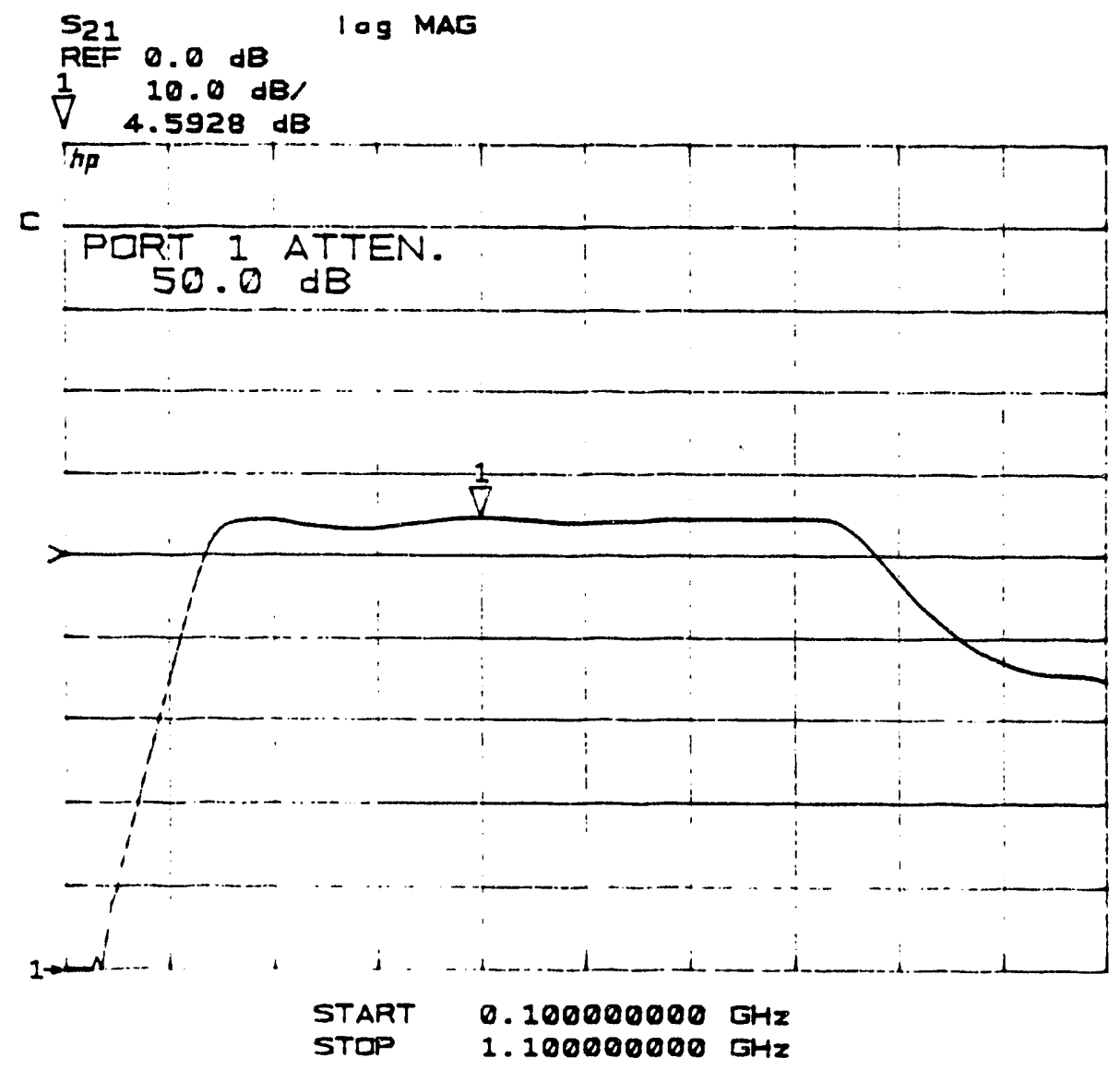

Figure 3.5. Measured Gain of the Receiver (100-1000 MHz) 

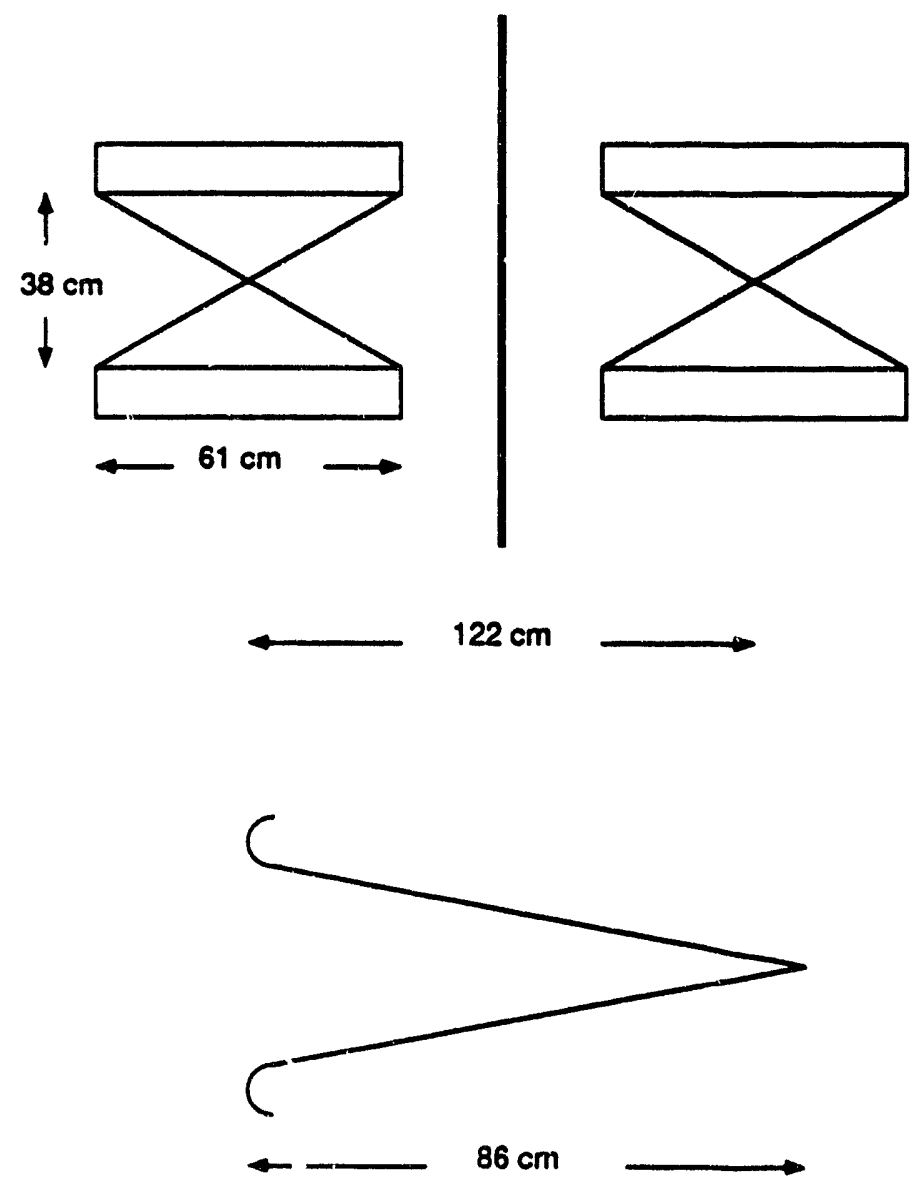

Figure 3.\%. Drawing of the Antenna Pair

Artennar Peir 


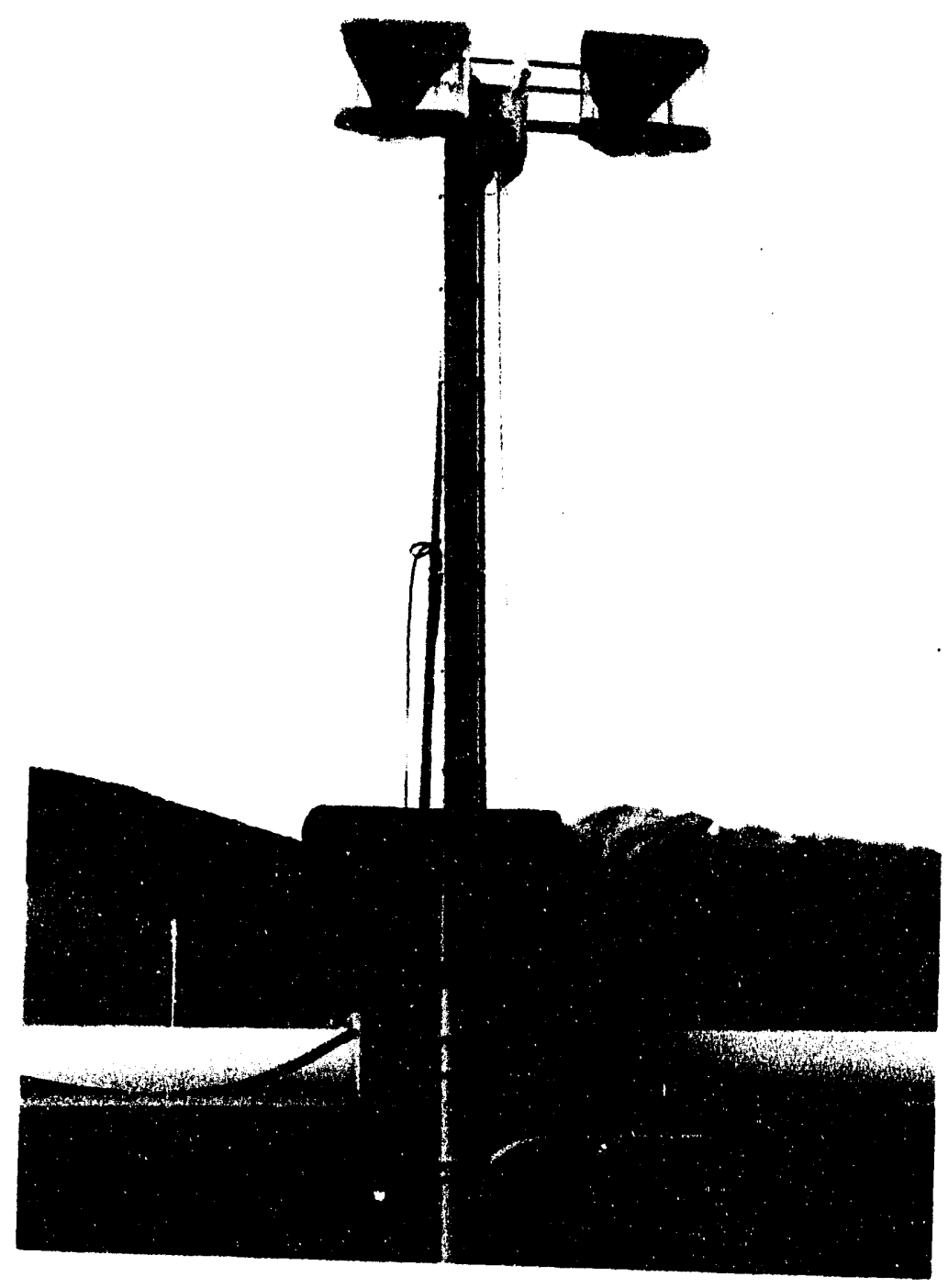

Figure 3.7. Photograph of the Antenna Pair 


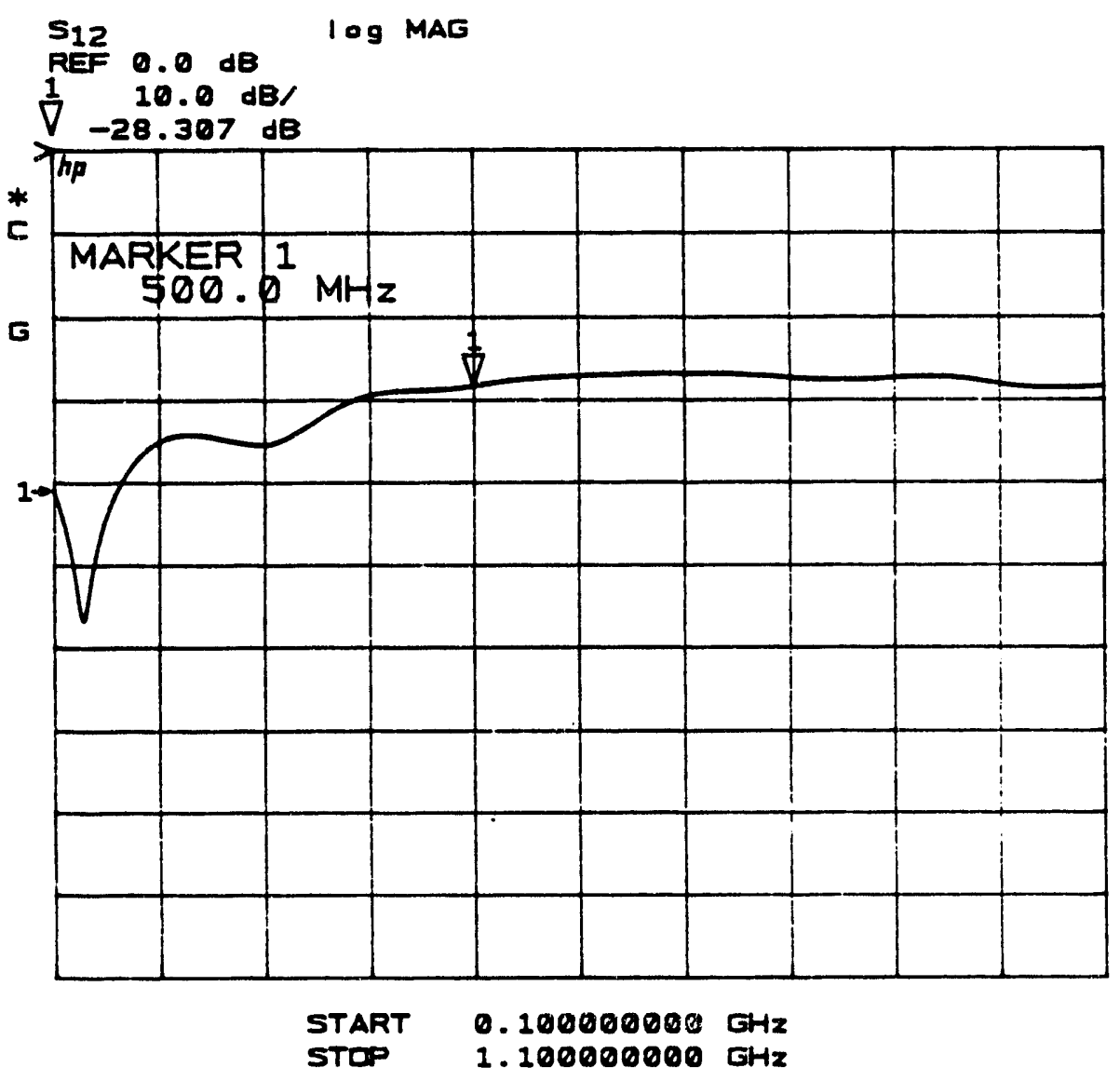

Figure 3.8. Transmission between Two Antennas (100-1100 MHz) 


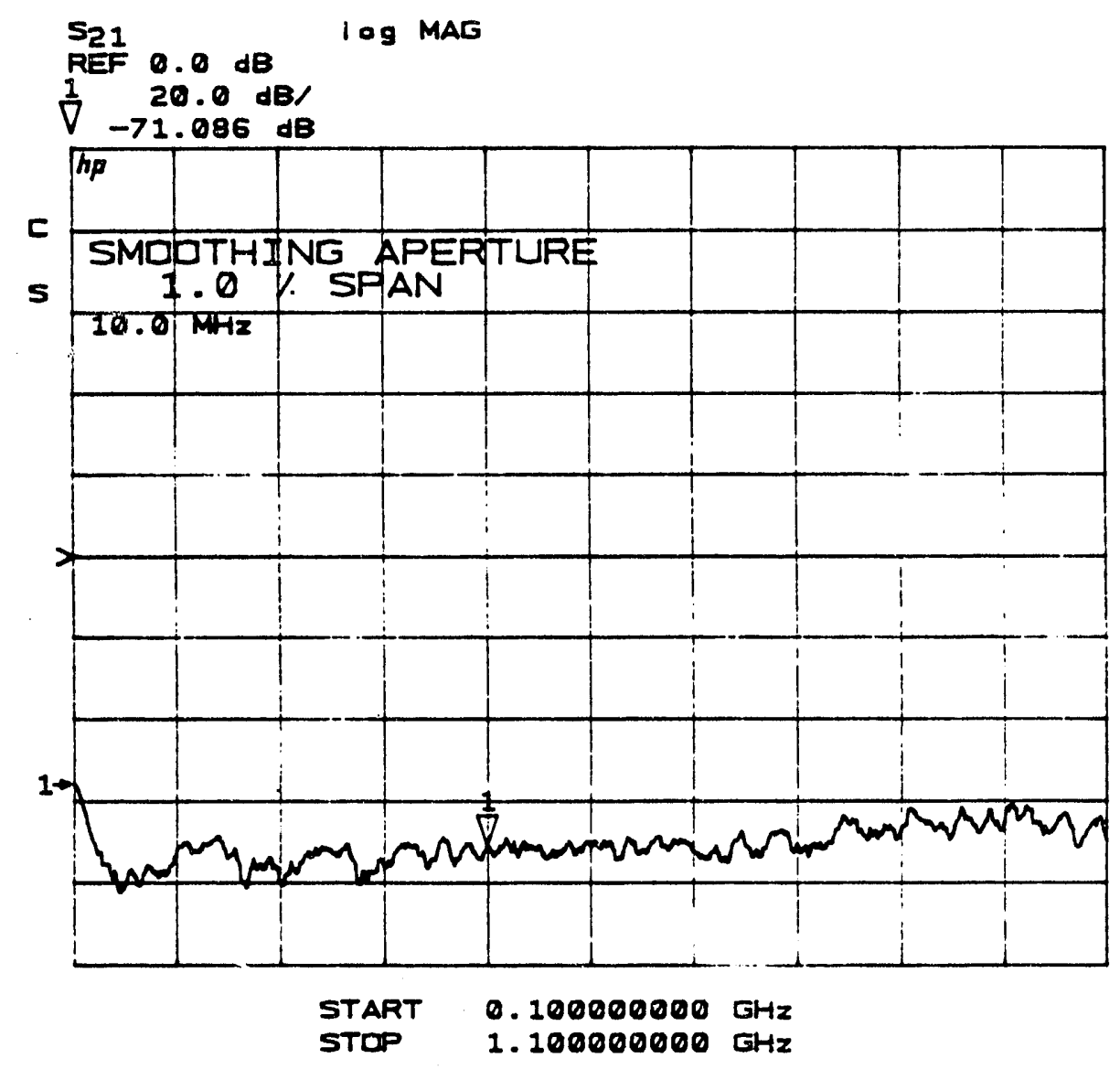

Figure 3.9. Isolation between Transmit and Receive Antennas (100-1100 MHz) 


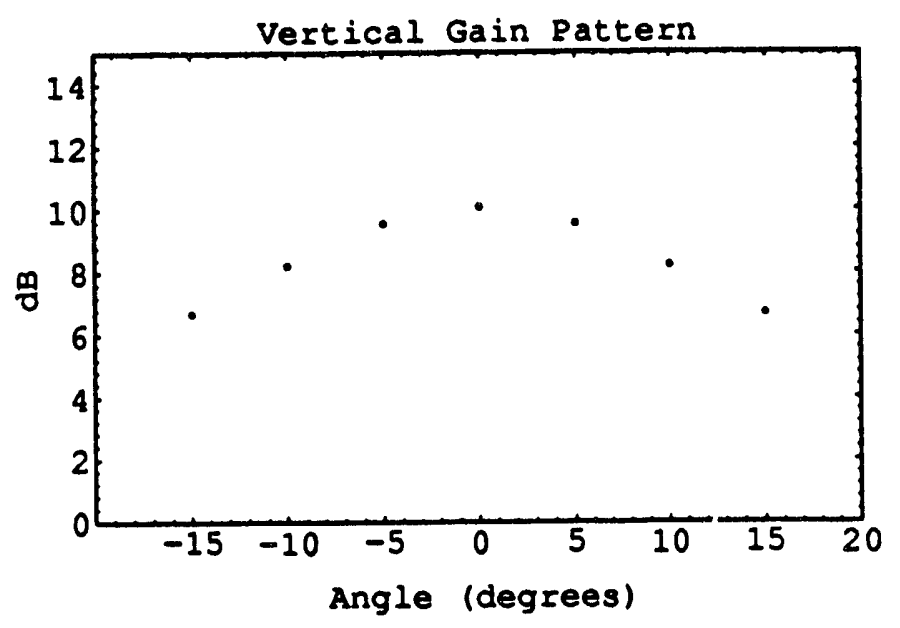

Figure 3.10. Vertical Antenna Pattern $\left( \pm 15^{\circ}\right)$ Averaged over $300-1000 \mathrm{MHz}$

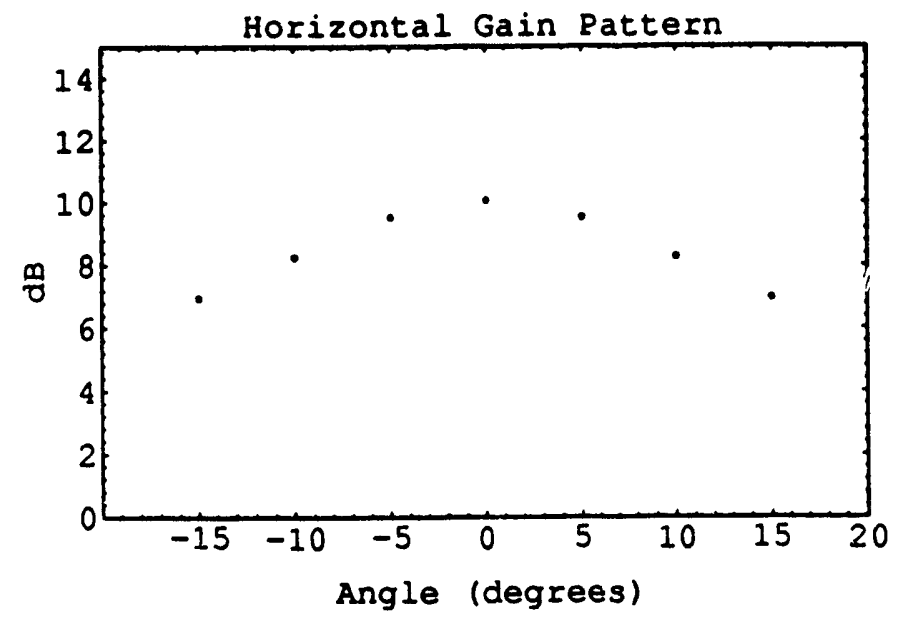

Figure 3.11. Horizontal Polarization Pattern $\left( \pm 15^{\circ}\right)$ Averaged over $300-1000 \mathrm{MHz}$ 

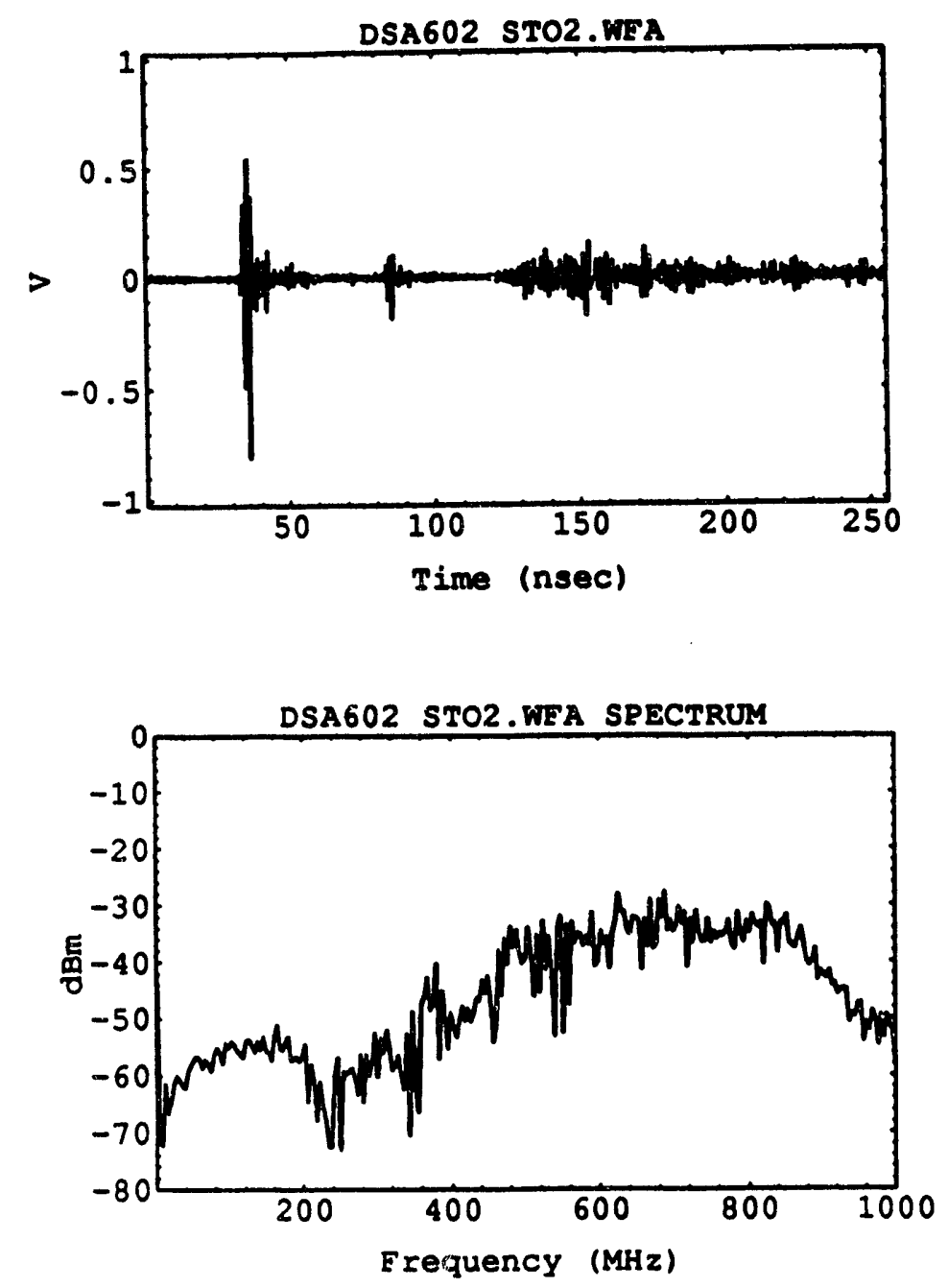

Figure 3.12. Pulse Response/Spectrum from Flat Plate Calibration Target 


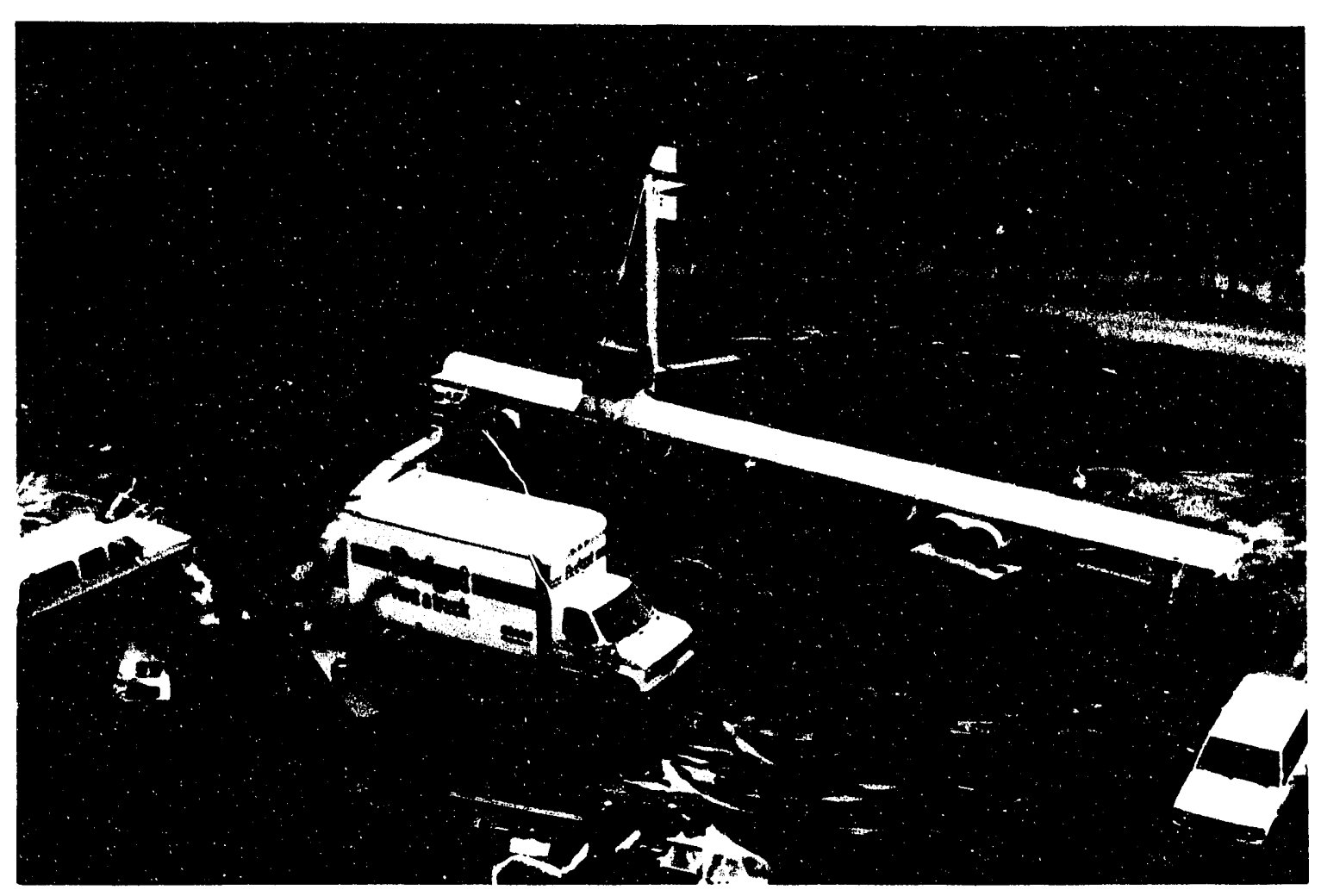

Figure 3.13. Photograph of Scanned System 


\subsection{Radar Clutter Imaging and Calibration to Radar Cross Section}

In this section, a summary of the UWB clutter processing steps is described. The following steps in the processing are summarized: data collection, time skew correction and coherent integration, apodization for constant beamwidth, synthetic beam steering, calibration to ultrawideband RCS and clutter coefficient, and a discussion of the statistics calculated on the clutter data.

\subsection{Data Collection}

The data for the ultrawideband scanned radar is collected from the transient digitizer in the following manner. The scanner, of length $L=19 \mathrm{~m}$, is moved to the extreme left to begin data collection. The radar is pulsed and the received delayed transient waveform is digitized $N_{I}$ times, where $N_{I}$ is typically equal to 100 . The transient waveform is sampled every $\Delta t=500 \mathrm{psec}$ for $N_{t}=512$ samples. The time between trigger from the time delay generator and first sample point is called the "time skew" and is denoted by $t_{s}$. Each waveform and its time skew value are downloaded over the IEEE-488 bus from the DSA 602 digitizer to a SUN Sparcstation II computer and written to hard disk. The scanner carriage is moved by $\Delta x=L /\left(N_{x}-1\right)$, where $N_{x}$ is typically 256 , and another $N_{I}$ waveforms are digitized. This procedure is repeated until the full scanner aperture has been covered.

For the 1992 measurements, internal averaging in the digitizer was used to improve the clutter data collection rate. For these measurements time skew correction was not used. This causes a minimal reduction in the high frequency content of the received waveforms due to the variation in time skew.

\subsection{Time Skew Correction and Coherent Integration}

Fourier transforms are used exclusively in the processing of the transient radar data and its calibration to RCS and clutter coefficient, $\sigma^{\mathbf{0}}$. The continuous Fourier transform pair is given by

$$
F T h(t)\} \equiv H(\omega) \equiv \int_{-\infty}^{\infty} h(t) e^{-j \omega t}
$$




$$
F T^{-1}(H(\omega)\} \equiv h(t) \equiv \frac{1}{2 \pi} \int_{-\infty}^{\infty} H(\omega) e^{j \omega t}
$$

Time shifting in the time domain is equivalent to frequency-dependent phase shifting as given by,

$$
h\left(t-t_{s}\right)=F T^{-1}\left\{H(\omega)^{-j \omega t_{c}}\right\}
$$

The Discrete Fourier Transform (DFT) pair is given by

$$
\begin{gathered}
D F T h(k \Delta t)\}=H\left(\omega_{N}\right) \equiv \sum_{k=0}^{N_{t}-1} h(k \Delta t) e^{-2 \pi k \sigma / N_{t}} \\
D F T^{-1}\left(H\left(\omega_{n}\right)\right) \equiv h(k \Delta t) \equiv \frac{1}{N} \sum_{n=0}^{N_{t}-1} H\left(\omega_{n}\right) e^{\Omega \pi k b / N_{t}}
\end{gathered}
$$

where $k$ represents the time sample index, and $n$ represents the frequency sample index, and the frequency domain samples, $\omega_{n}$, are given by,

$$
\omega_{n}=\left\{\begin{aligned}
\frac{2 \pi n}{N_{t} \Delta t} & n=0,1, \ldots, \frac{N_{t}}{2} \\
\frac{2 \pi\left(n-N_{t}\right)}{N_{t} \Delta t} & n=\frac{N_{t}}{2}+1_{s} \ldots, N_{t}-1
\end{aligned}\right.
$$

Time shifting by times less than $\Delta t$ is accomplished by phase shifting in the discrete frequency domain as in,

$$
\left.v\left(k \Delta t-t_{s}\right)=D F T^{-1}\left\{\eta \omega_{n}\right) e^{-j \omega_{n} t_{s}}\right\}
$$

The raw data $\left(N_{x}\right.$ by $N_{I}$ waveforms) is indicated by $v_{\text {raw }}(k \Delta t, l \Delta x, m)$, where $k$ represents the time sample index; $l$, represents the scanner position or $x$ index; and $m$ represents the waveform number at that position. The time sample index $k$ ranges from 1 to $N_{t}$. The spatial sample index, $l$, ranges from $-N_{x} / 2+1$ to $N_{x} / 2$. The waveform number index, $m$, ranges from 1 to $N_{I}$. The total number of waveforms taken in a scan is thus $N_{x}$ times $N_{I}$. 
The $N_{I}$ waveforms collected at each point are coherently summed by correcting for the time skew value of each waveform, as shown above, and summing the corrected waveforms,

$$
v_{c i}(k \Delta t, l \Delta x)=\frac{1}{N} \sum_{m=1}^{N_{l}} D F T^{-1}\left\{D F T\left\{v_{\text {rew }}(k \Delta t, l \Delta x, m)\right\} e^{\left.-j \omega_{0}, d, l m\right)}\right\}
$$

where $v_{c i}$ represents the coherently integrated data.

\subsection{Frequency Dependent Apodization for Constant Beamwidth}

It is desirable for this ultrawideband radar system to have a well defined clutter cell size. Therefore, the data is processed to have a constant beamwidth as a function of frequency. This is accomplished by apodizing the data in the frequency domain with a window function tha: narrows as frequency is increased. This is easily accomplished with the scanned data as follows,

$$
\begin{gathered}
\operatorname{rect}(x)= \begin{cases}1 & |x| \leq \frac{1}{2} \\
0 & |x|>\frac{1}{2}\end{cases} \\
V_{\text {apod }}\left(\omega_{n}, l \Delta x\right)=\operatorname{rect}\left(\frac{l \Delta x}{U\left(\omega_{\text {low }} J \omega_{n}\right)}\right) D F T\left\{v_{c t}(k \Delta t, l \Delta x)\right\}
\end{gathered}
$$

where $V_{\text {apod }}$ represents the apodized data in the temporal frequency domain.

\subsection{Synthetic Beam Steering/Focusing}

The scanned data is now synthetically beam-steered by time shifting and summing the $N_{x}$ waveforms in the following way. The range, $R$, to the center of the covered swath is a function of the time delay, $t_{d}$, and is given by 


$$
R=\frac{c\left(t_{d}+N_{t} \Delta t / 2\right)}{2}
$$

The time shift, $\Delta t_{\mathrm{bs}}$, necessary for each position is a function of the beam-steer angle, $\theta$, which in the far-field of the scanner is given by,

$$
\Delta t_{b s}=\frac{2 l \Delta x}{c} \sin \theta
$$

Thus the focused data, $v_{\text {foc }}$ is obtained by the following formula,

$$
v_{f o c}(k \Delta t, \theta)=\frac{1}{N} D F T^{-1}\left\{\sum_{i=1}^{N_{z}} V_{\text {spod }}\left(\omega_{n}, l \Delta x\right) e^{-j \frac{2 \omega_{n}}{c} l \Delta x \sin \theta}\right\}
$$

if the range is sufficiently far away so that the covered swath is in the far field of the scanner. If this condition is not met, a slightly more complex form will account for the curvature of the wavefront,

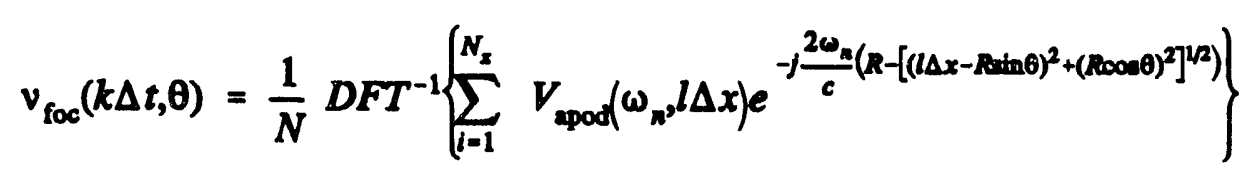

\subsection{Calibration to Ultrawideband RCS and Clutter Coefficient}

The focused data, $v_{\text {foc }}$, must now be calibrated to radar cross-section (RCS) and clutter coefficient $\left(\sigma^{0}\right)$ utilizing the response from a calibration target of known RCS. For this set of data the calibration target used was a 6 ' by $12^{\prime}$ rectangular flat plate made of metallic screen. The calibration procedure for a single frequency continuous wave system is first described and then the extension to the ultrawideband case. The power received by the radar is given by the radar equation (Skolnik 1980), 


$$
P_{r}=P_{t} \frac{G^{2} \lambda^{2} \sigma}{(4 \pi)^{3} R^{4}}
$$

where $P_{t}$ is the power transmitted, $G$ is the gain, $\lambda$ is the wavelength, $R$ is the range to the target, and $\sigma$ is the radar cross section of the target. Radar cross section is defined by,

$$
0 \equiv \lim _{R \rightarrow \infty} 4 \pi R^{2} \frac{\left|E_{r}\right|^{2}}{\left|E_{i}\right|^{2}}
$$

where $E_{r}$ is the reflected field strength at the radar, and $E_{i}$ is the strength of the incident field at the target. For a flat rectangular plate aligned normally to the radar, the RCS is,

$$
\sigma=\frac{4 \pi A^{2}}{\lambda^{2}}
$$

where $A$ is the area of the flat plate, and the physical optics approximation is assumed to be valid. The power from a calibration target, with known RCS $=\sigma_{1}$ and known range $R_{1}$, is measured and is also assumed to follow the radar equation,

$$
P_{1}=P_{t} \frac{G^{2} \lambda^{2} \sigma_{1}}{(4 \pi)^{3} R_{1}^{4}}
$$

The power from a second target or clutter, with unknown RCS $=\sigma_{2}$ and known range $R_{2}$, is measured and is also assumed to follow the radar equation,

$$
P_{2}=P_{8} \frac{G^{2} \lambda^{2} \sigma_{2}}{(4 \pi)^{3} R_{2}^{4}}
$$

Power at the receiver is related to voltage by,

$$
P=\frac{1}{2} \frac{V^{2}}{Z_{0}}
$$


Taking the ratio of the powers from the unknown and known targets, the transmitted power, wavelength, and system gain cancel to yield,

$$
\frac{P_{2}}{P_{1}}=\frac{\sigma_{2} R_{1}^{4}}{\sigma_{1} R_{2}^{4}}
$$

Solving for the unknown RCS yields,

$$
\sigma_{2}=\sigma_{1}\left(\frac{\left|V_{2}\right| R_{2}^{2}}{\left|V_{1}\right| R_{1}^{2}}\right)^{2}
$$

The transient waveform may be calibrated in a similar way to the above continuous wave calibration by Discrete Fourier Transform of the transient voltage waveform and calibrating the system at each discrete frequency. A discrete calibration spectrum, $S\left(\omega_{n}\right)$, is defined by,

$$
\left|S\left(\omega_{n}\right)\right|=\frac{\left|V_{1}\left(\omega_{n}\right)\right|}{\sqrt{\sigma_{1}\left(\omega_{n}\right)}}\left(\frac{R_{1}}{R_{0}}\right)^{2}
$$

where $V_{1}\left(\omega_{n}\right)$ is the DFT of the transient waveform received from the calibration target (known RCS $=\sigma_{1}\left(\omega_{n}\right)$ ) and $R_{0}$ is an arbitrary reference range. The RCS of the unknown target as a function of frequency is thus,

$$
\sigma_{2}\left(\omega_{n}\right)=\frac{\left|V_{2}\left(\omega_{n}\right)\right|^{2}}{\mid S\left(\omega_{n}\right)^{2}}\left(\frac{R_{2}}{R_{0}}\right)^{4}
$$

where $V_{2}\left(\omega_{n}\right)$ is the DFT of the transient waveform received from another target or clutter (unknown RCS $=\sigma_{2}\left(\omega_{n}\right)$ ). The system frequency response is band limited so that a low frequency cutoff $\left(\omega_{\text {low }}\right)$ and high frequency cutoff $\left(\omega_{\text {high }}\right)$ are specified so that calibration will be enforced only over this frequency band. The low end and high end cutoff frequencies for this system are typically $300 \mathrm{MHz}$ and $1000 \mathrm{MHz}$, respectively. The band limited, calibrated response is given by, 


$$
\sqrt{\sigma_{2}}\left(\omega_{n}\right)=\left\{\begin{array}{cc}
\frac{V_{2}\left(\omega_{n}\right)}{\left|S\left(\omega_{n}\right)\right|}\left(\frac{R_{2}}{R_{1}}\right)^{2} & \omega_{\text {low }} \leqslant \omega_{n} \leqslant \omega_{\text {high }} \\
0 & \text { elsewhere }
\end{array}\right.
$$

where the negative frequency side of the spectrum has been set to zero. The spectrum is then translated, so that the center frequency, e.f. $\omega_{c}=650 \mathrm{MHz}$, is shifted to DC. This process will yield a transient waveform in the time domain with approximately the theoretical range resolution of,

$$
\Delta R=\frac{C}{2 B}
$$

where $B=\left(\omega_{\text {high }}-\omega_{\text {low }}\right) / 2 \pi$ is the bandwidth of the system. The high resolution (ultrawideband) square-root RCS is thus given by,

$$
\left|\sqrt{\sigma_{2}}(k \Delta t)\right|=\frac{2(\pi / \Delta t)}{\omega_{\text {high }}-\omega_{\text {low }}}\left|D F T^{-1}\left\{\sqrt{\sigma_{2}}\left(\omega_{n}+\omega_{c}\right)\right\}\right|
$$

The ultrawideband RCS is defined

$$
\sigma_{2}(k \Delta t)=\left|\sqrt{\sigma_{2}}(k \Delta t)\right|^{2}
$$

The UWB clutter coefficient, $\sigma^{\mathbf{0}}$, is calculated simply from the UWB RCS by dividing by the area of a clutter cell, $A$,

$$
\begin{gathered}
\sigma_{0} \equiv \frac{\sigma}{A} \\
A=R \theta_{b w} \Delta R \\
R=\frac{c\left(t_{d}+N_{t} \Delta t / 2\right)}{2}
\end{gathered}
$$

where $R$ is the range to the clutter cell and $\theta_{\mathrm{bw}}$ is the synthesized beamwidth (approximately equal to $1.5^{\circ}$ for a rectangular window). This high resolution calibration to 
clutter coefficient is applied to the $v_{\text {foc }}(\dot{k} \Delta t, \theta)$ data to obtain high resolution two dimensional (range, angle) images of clutter coefficient.

\subsection{Clutter Statistics}

The high resolution calibrated clutter coefficient images are then sampled every clutter cell and statistics of the clutter are calculated. The number of samples, minimum, maximum, mean, modian, standard deviation, skewness, kurtosis, histogram, and cumulative distribution are calculated.

To allow comparison of this data to existing clutter data and models, the cumulative distribution is plottc? on "Weibull paper" as described below. The Weibull probability density function for clutter coefficient, $\sigma^{0}$, is given by,

$$
w\left(\frac{\sigma^{\circ}}{\sigma^{M}}\right)=\ln (2) m\left(\frac{\sigma^{o}}{\sigma^{M}}\right)^{m-1} e^{-\ln (2)}\left(\frac{\sigma^{\circ}}{\sigma^{M}}\right)^{m}
$$

whe e $\sigma^{M}$ is the median clutter coefficient value, and $m$ is called the slope parameter. The Weibull cumulative proh' jility distribution function is given bv,

$$
W\left(\sigma^{\circ}\right)=1-e^{\ln (2)\left(\frac{0_{0}}{\sigma^{\mu}}\right)^{m}}
$$

A measured distribution function, $W\left(\sigma^{n}\right)$, may be mapped so that it will appear as a straight line with slope, $m$, if it matches the Weibull distribution, by the following formulas,

$$
\begin{gathered}
y={ }^{10 \log _{10}}\left(\left[\frac{1}{1-W\left(\sigma^{9}\right)}\right)\right) \\
x=10 \log _{10}\left(0^{\circ}\right)
\end{gathered}
$$

where $x$ represents the horizontal axis of the plot and equals the clutter coefficient value in $\mathrm{dB}$, and $y$ represents the vertical axis of the plot and is related to the cumulative distribution function as shown. The Weibull slope parameter is typically expressed by its inverse, the Weibull spread parameter. 
The statistical parameters are defined in the same manner as in Reference (Billingsley and Larrabee 1991). The mean is defined by

$$
\bar{x}=\frac{1}{N} \sum_{i=1}^{N} x_{i}
$$

which will typically be converted to decibels. The median is defined to be the $50 \%$ level in the cumulative distribution. The standard deviation (sd), skewness, and kurtosis are defined by

$$
\begin{gathered}
\text { sd }(x)=\left[\frac{1}{N-1} \sum_{i=1}^{N}\left(x_{i}-x\right)^{2}\right]^{1 / 2} \\
\text { skewness (x; }=\frac{M_{3}(x)}{\left[M_{2}(x)\right]^{3 / 2}} \\
\text { kurtosis }(x)=\frac{M_{4}(x)}{\left[M_{2}(x)\right]^{2}}
\end{gathered}
$$

where

$$
M_{q}(x)=\frac{1}{N} \sum_{i=1}^{N}\left(x_{i}-\bar{x}\right)^{q}
$$

The standard deviation will typically be divided by the mean and converted to decibels. The skewness and kurtosis will typically be converted to decibels.

\subsection{Long Record Lengths}

One of the impulse radar system :mprovements used in the 1992 clutter measurements was longer digitizer record lengths in the DSA 602. The record length used was 8192 (8K) for clutter data and 512 for calibration and noise measurements. The beam steering/focusing algorithm has a range dependence if the far-field assumption is not met. This range dependence can be ignored for the 512 record length (range swath of $38 \mathrm{~m}$ ) but cannot be ignored for a 8192 record length (range swath of $600 \mathrm{~m}$ ). There- 
fore, the clutter data was processed in overlapping increments of 512 to provide analysis over the full $8 \mathrm{~K}$ record.

\subsection{Clutter Imaging Example}

To illustrate the data collection and analysis procedure an example of the clutter imaging measurements and processing is discussed below. The scanner is moved to 256 uniformly spaced positions across the 19-meter aperture. At each position typically 100 waveforms are gathered. These waveforms are either averaged in the DSA 602A or using time skew correction in the computer. This data can be represented as an image in which the scanner position is the horizontal axis and time is the vertical axis. Voltage amplitude is then scaled to gray-scale or pseudo-color for display in the image. In this data, strong targets will appear as lines across the image. Targets lying along a line normal to the scanner axis will appear as horizontal lines in the image. Targets off axis will appear as left or right slanted lines. Figure 4.1 shows an unprocessed image of the calibration target at a range of approximately $1 \mathrm{~km}$. This data was then calibrated to clutter coefficient using the methods described above to generate the image in Figure 4.2. Note that this image is a range-angle image. The horizontal axis is angle $\left(-15^{\circ}\right.$ to $\left.+15^{\circ}\right)$ and the vertical axis is range ( $38 \mathrm{~m}$ total swath). 
256 nsec

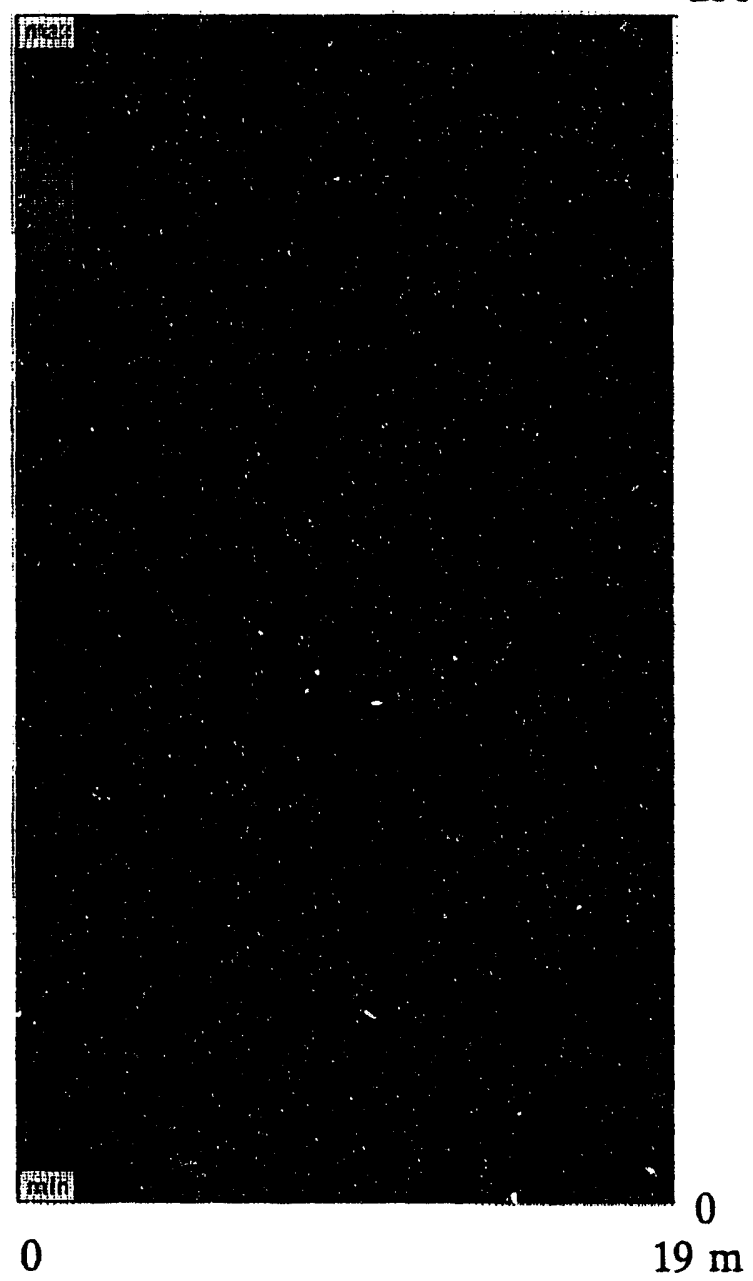

Figure 4.1. Unprocessed Calibration Target Response Image 


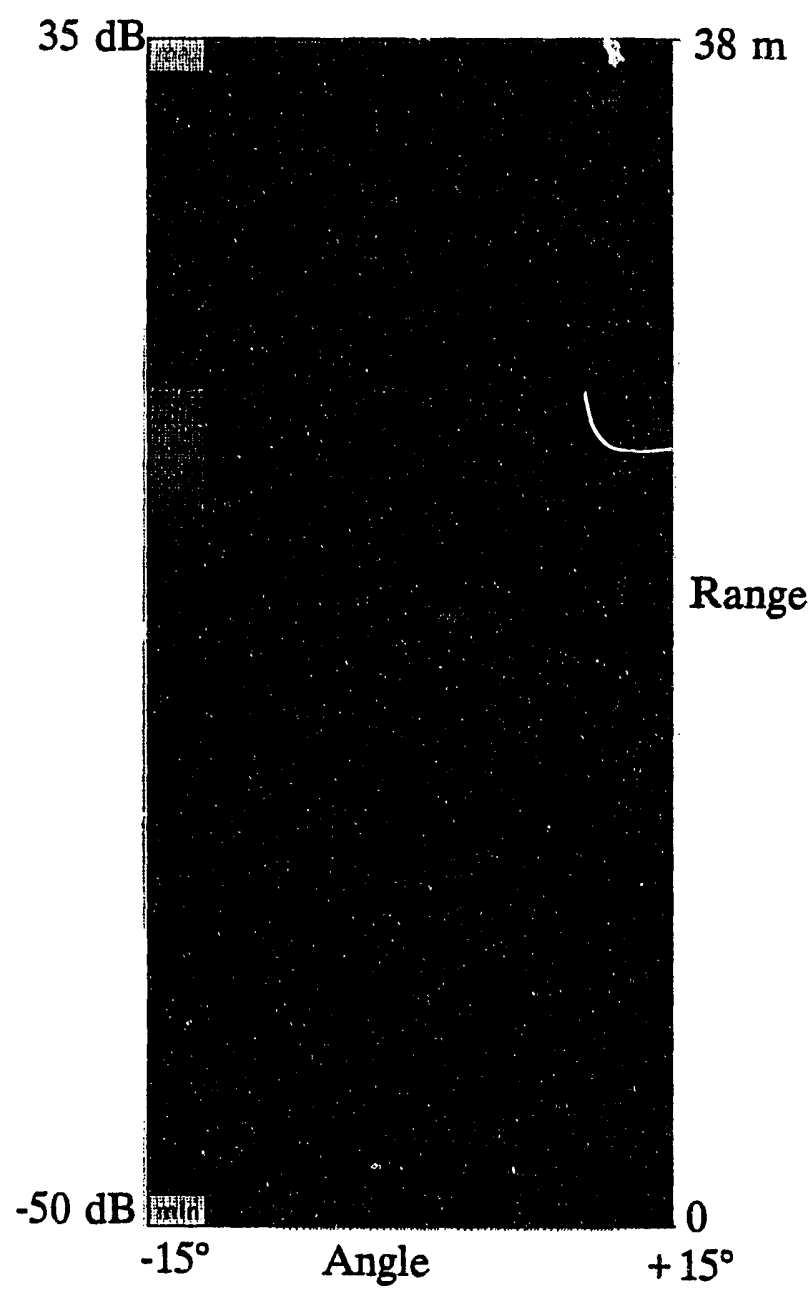

Figure 4.2. Calibration Target Image (Range-Angle) Calibrated to RCS 


\subsection{Site Selection and RFI Measurements}

Choosing a site for the clutter measurements involved a number of often conflicting criteria. These criteria included suitable radar illumination of desirable clutter, low RFI levels, and accessibility to the 19-meter scanner.

\subsection{Physical Site Requirements}

During 1991, a search for potential sites for the forest and desert clutter measurements was conducted. A convenient forested site was found in the Olympic National Forest near Sequim, WA. A desert site was found in Badger Canyon located near PNL's Richland, WA facility.

During June and July 1992, an extensive search was undertaken for potential new sites for the 1992 impulse radar clutter measurements. A number of criteria were used for determining the suitability of prospective measurement sites. First the radar should illuminate the areas of clutter to be measured. Typically, this means the radar must be located on the side or top of a hill. Second, the site must accommodate a level lot approximately 30 meters in diameter to allow for positioning of the 20 meter scanner. Third, the angular and range swaths available at the site should be as large as possible in order to obtain the largest set of clutter data.

Physical examination of the accessible terrain near Sequim has established three sites that meet the criteria listed above. The three sites are identified as the "Original Site," which is the site of the 1991 impulse clutter measurements; the "Maynard Site," which is near Maynard Peak; and the "Road 150 Site," which is near Road 150. These sites are shown on the topographic map in Figure 5.1.

\subsection{RFI Survey}

On July 16, 1992, the three prospective forested sites were examined for suitability for the impulse radar clutter measurements. In addition to the physical requirements discussed above, the prospective sites should have low levels of radio frequency interference (RFI), the dominant source of noise for these measurements.

To determine the suitability of these sites for the impulse radar clutter measurements, RFI measurements were made at each of the three sites. One of these sites is the site of the 1991 impulse clutter measurements. This site is known to have relatively low levels of RFI and is used as the reference for the other two potential sites. 
The system used to make the RFI measurements consists of a log-periodic antenna (Electro-Mechanics Co. Model 3146A), 15 feet of RG142B cable, an Avantek UT60491M amplifier, a Mini-Circuits ZFL-1000LN amplifier, and a Tektronix 2784 Spectrum Analyzer all connected in series. The gain of the Avantek amplifier is approximately 20 $\mathrm{dB}$ from 0.1 to $1.1 \mathrm{GHz}$. The gain of the Mini-Circuits amplifier is approximately $24 \mathrm{~dB}$ over the same band. The gain of the two amplifiers and the cable is shown in Figure 5.2. Note that a $40-\mathrm{dB}$ attenuator has been placed before the input to the amplifiers in this measurement. Thus, the gain at the center frequency is about $42 \mathrm{~dB}$. The gain of the log-periodic antenna is shown in Figure 5.3. The average gain over the 300-1000 $\mathrm{GHz}$ band is approximately $6 \mathrm{dBi}$.

The spectrum analyzer was configured to have a resolution bandwidth of $1 \mathrm{MHz}$ and a video bandwidth of $100 \mathrm{~Hz}$. The power levels shown on the spectrum analyzer and plots are the power levels observed at the spectrum analyzer input. The gain of the antenna and amplifiers has not been removed. For all measurements the antenna was polarized half way between vertical and horizontal polarizations. Results for two antenna orientations at the Original Site are shown in Figures 5.4 and 5.5. Results for two antenna orientations at the Maynard Site are shown in Figures 5.6 and 5.7. Results for both antenna orientations at the Road 150 Site are shown in Figures 5.8 and 5.9.

Analysis of these results indicates that the qualitatively lowest levels of RFI are present at the Original Site. The Maynard Site shows peak RFI levels comparable to the Original Site with more carriers evident for a somewhat higher average level. The $334^{\circ}$ orientation at the Maynard Site shows higher levels of RFI, due most likely to cellular phone transmitters and television stations in the Port Angeles area. Both RFI measurements at the Road 150 Site show RFI levels significantly higher than the other two sites. This site is line of sight to a number of transmitting antennas located on nearby Blyn Mountain. The $58^{\circ}$ orientation is looking directly at the transmitting antennas and therefore shows the highest levels. The other orientation is subdued, but still much higher than the other two sites.

These RFI measurements indicate that for clutter measurements with noise levels similar to the 1991 clutter measurements only the Original Site and the Maynard Site are acceptable.

\subsection{Characteristics of the Chosen Sites}

Given the stringent site requirements outlined above only two good prospective sites were found. One of which is the site of the original clutter measurements in 1991. The other site is located near Maynard Peak. Measurements from both of these sites look in the general direction of Bear Mountain although from different sides. 
The original site is located near Bear mountain in the Olympic National Forest near Sequim, WA. This site has an available has an available range swath of $500 \mathrm{~m}$ to over $2500 \mathrm{~m}$, and an angular swath of $150^{\circ}$. The radar site is located on a clearing on a hillside looking out over a valley onto opposing hillsides. A calibration site is located on a bare knoll approximately $1 \mathrm{~km}$ from the radar position. This site is well protected from RFI transmitters by surrounding mountains.

The Maynard Site is located approximately $2.2 \mathrm{~km}$ southwest from the peak of Bear Mountain. This site has a sharp drop-off for the first $0.5 \mathrm{~km}$ and reasonable illumination of the terrain beyond this range. The available angular swath is approximately $150^{\circ}$ with a possible extension to $180^{\circ}$. The last $30^{\circ}$ sector is shadowed somewhat by the terrain close to the scanner position. The available range swath is limited by nearby peaks located 2-3.5 km from the site Over most of the angular swath the available range should be in excess of $2.5 \mathrm{~km}$. Given the sharp drop-off near the scanner site the total available range swath is approximately from $0.5 \mathrm{~km}$ to $2.5 \mathrm{~km}$. There are two excellent sites to place the 6' by $12^{\prime}$ calibration target. Both are in clear cut areas approximately 1 kilometer from the radar site.

A significant (perhaps 20\%) percentage of this site is composed of clear cuts or smaller trees. Given the extensive logging that has been done in recent years in the Olympic National Forest, this is an unavoidable feature of the terrain in this area. Therefore it is reasonable to include it in the clutter measurements. 


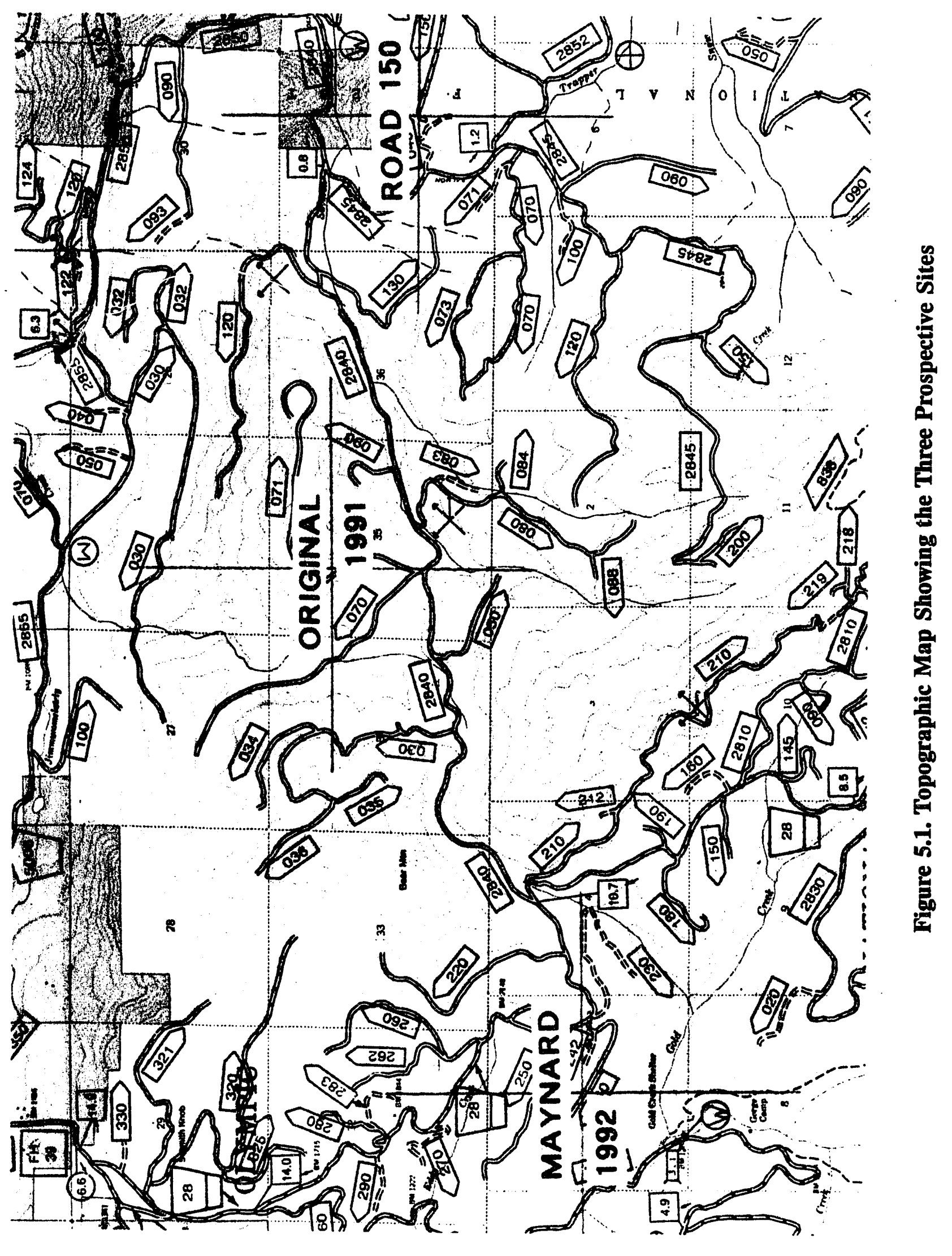




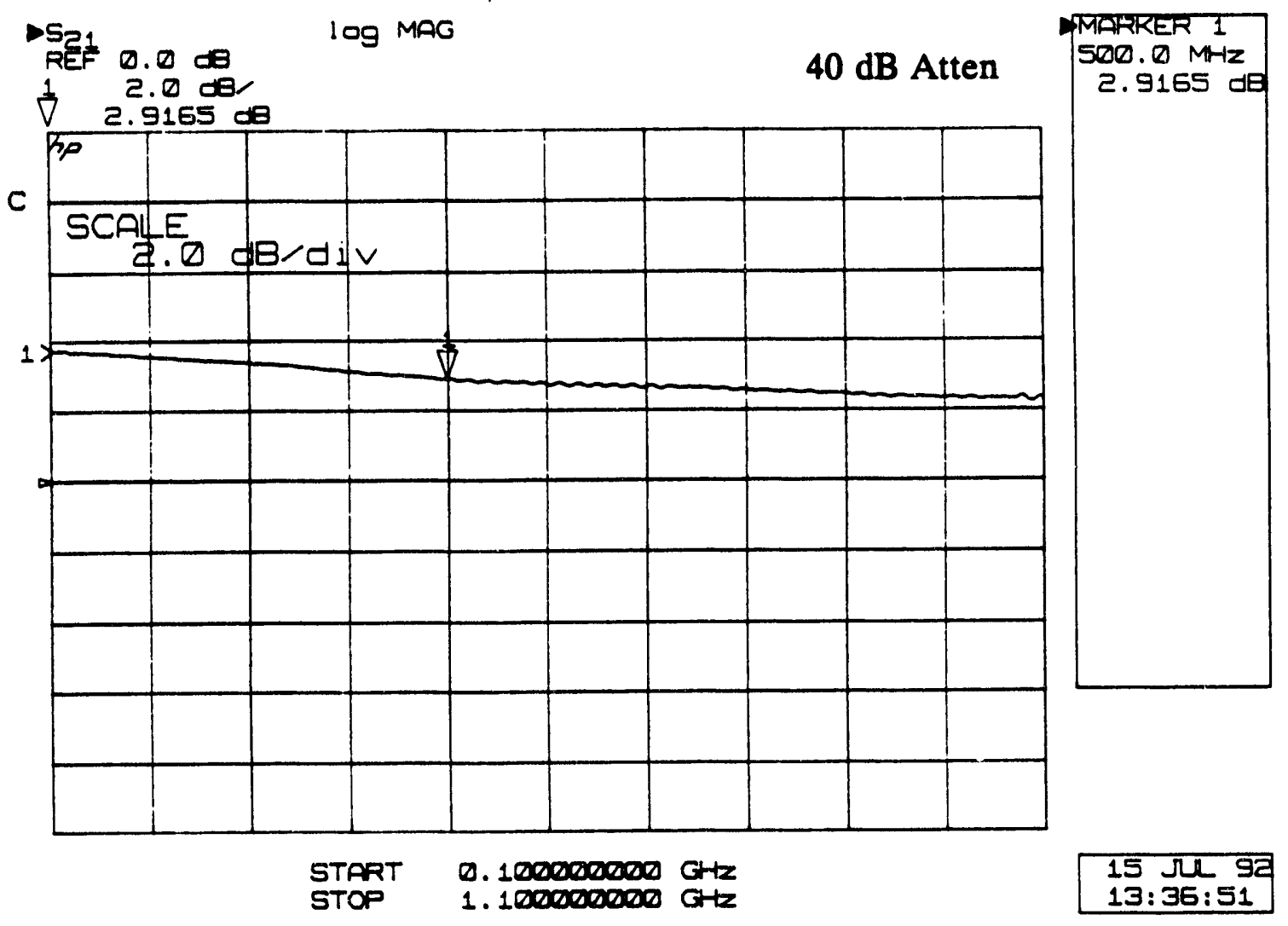

Figure 5.2. Gain of the RFI Measurement System

A series connection of the Avantek UT6-0491M amplifier, a Mini-Circuits ZFL-1000LN amplifier, 15 feet of RG142B cable, and a $40 \mathrm{~dB}$ attenuator connected to the input of the Avantek amplifier. 


\begin{tabular}{|c|c|c|c|}
\hline $\begin{array}{l}\text { FREOUENGY } \\
\text { (MHE) }\end{array}$ & $\begin{array}{c}\text { ANTEMM } \\
\text { FACTOR (d8) }\end{array}$ & $\begin{array}{c}\text { CAIM } \\
\text { MUERRIC }\end{array}$ & $\begin{array}{l}\text { GAIN } \\
\text { dBI }\end{array}$ \\
\hline $\begin{array}{l}300 \\
325 \\
350 \\
375 \\
400 \\
425 \\
450 \\
475 \\
500 \\
525 \\
550 \\
575 \\
600 \\
625 \\
650 \\
675 \\
700 \\
725 \\
750 \\
775 \\
800 \\
825 \\
850 \\
875 \\
900 \\
925 \\
950 \\
975 \\
1008\end{array}$ & 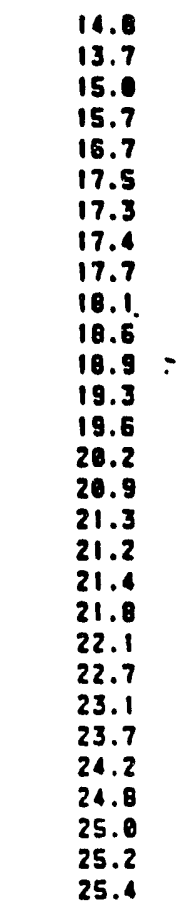 & $\begin{array}{l}3.16 \\
4.72 \\
4.03 \\
3.99 \\
3.59 \\
3.36 \\
3.91 \\
4.34 \\
4.50 \\
1.50 \\
4.10 \\
4.43 \\
4.46 \\
4.49 \\
4.20 \\
3.88 \\
3.80 \\
4.21 \\
4.26 \\
4.15 \\
4.18 \\
3.84 \\
3.69 \\
3.42 \\
3.21 \\
3.01 \\
2.99 \\
3.03 \\
3.03\end{array}$ & $\begin{array}{l}5.0 \\
6.7 \\
6.1 \\
6.0 \\
5.5 \\
5.3 \\
6.0 \\
6.4 \\
6.5 \\
6.5 \\
6.4 \\
6.5 \\
6.5 \\
6.5 \\
6.2 \\
5.9 \\
5.8 \\
6.2 \\
6.3 \\
6.2 \\
6.2 \\
5.8 \\
5.7 \\
5.3 \\
5.1 \\
4.8 \\
4.8 \\
4.8 \\
4.8\end{array}$ \\
\hline
\end{tabular}

Figure 5.3. Gain of the Log-Periodic Antenna 


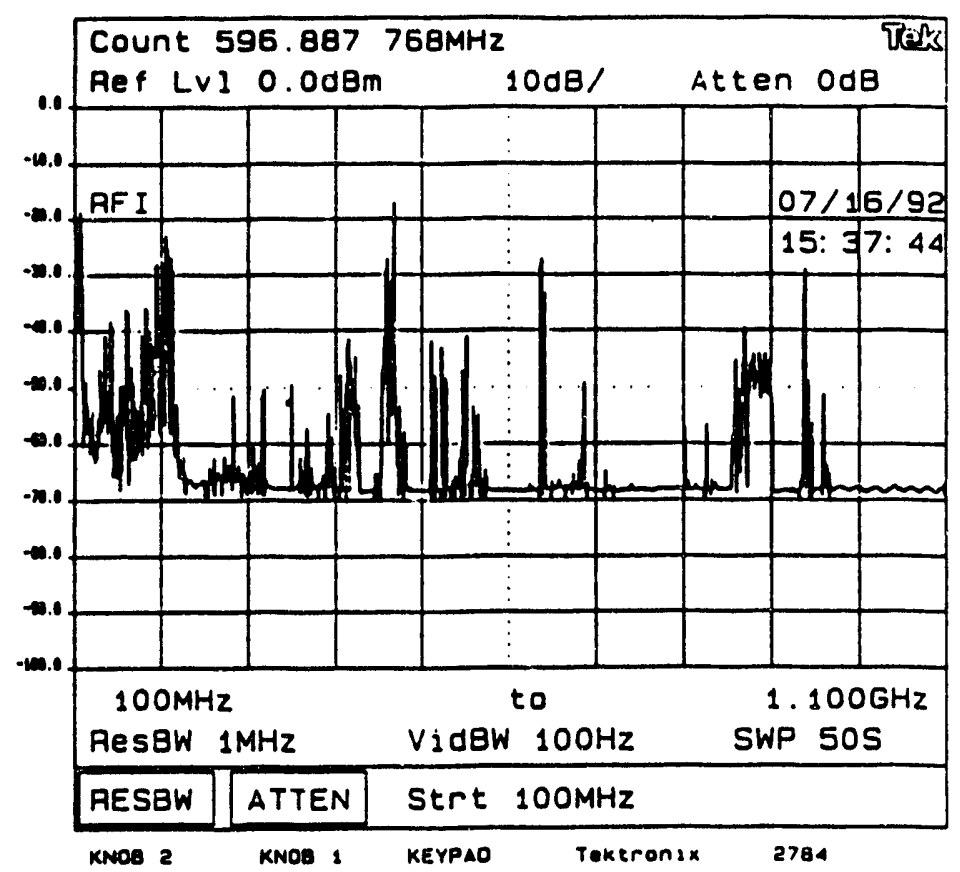

Figure 5.4. RFI Measurement at the Original Site, $212^{\circ}$ Orientation

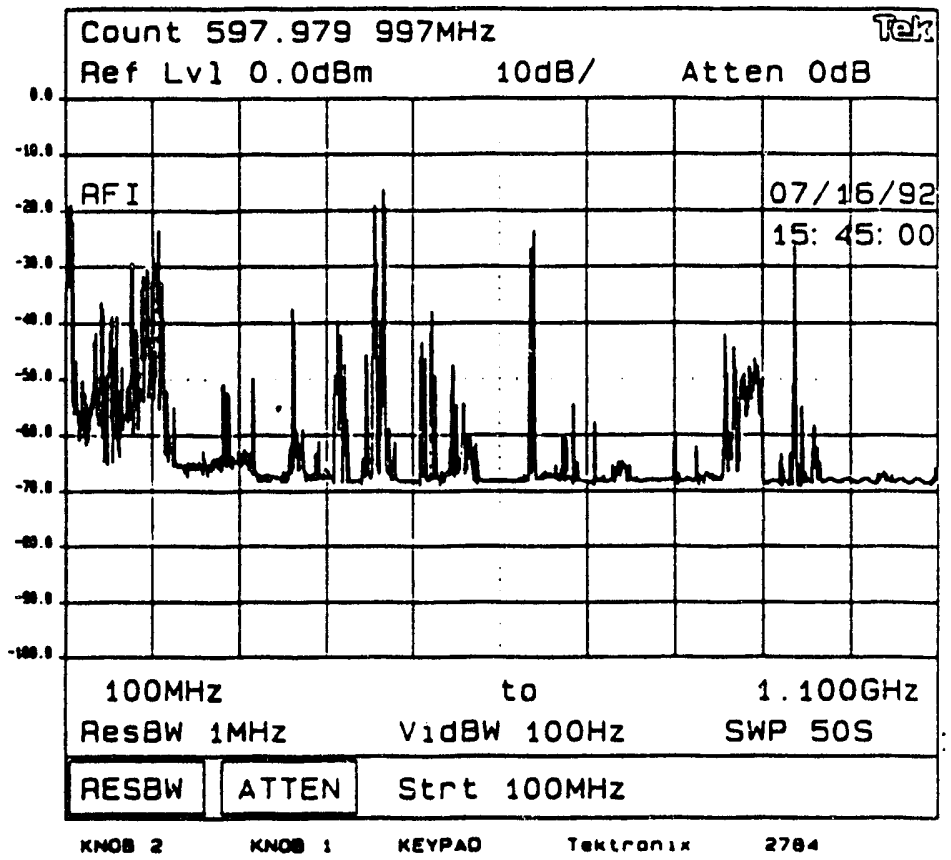

Figure 5.5. RFI Measurement at the Original Site, $304^{\circ}$ Orientation 


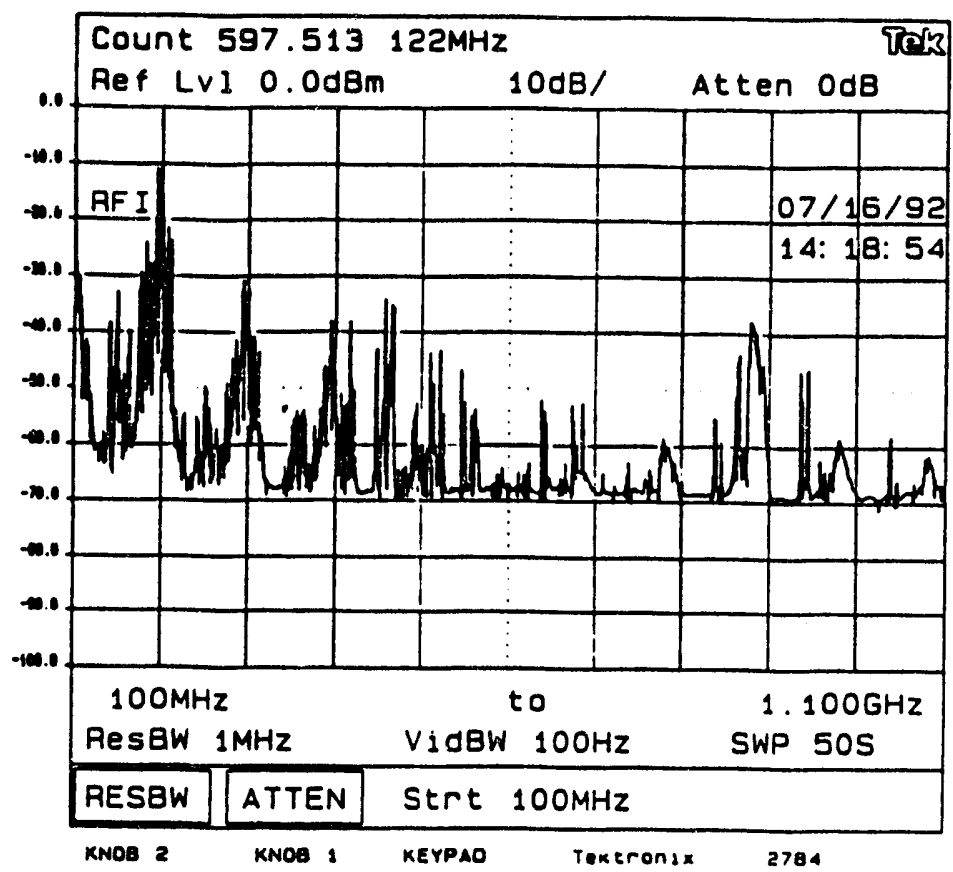

Figure 5.6. RFI Measurement at the Maynard Site, $72^{\circ}$ Orientation

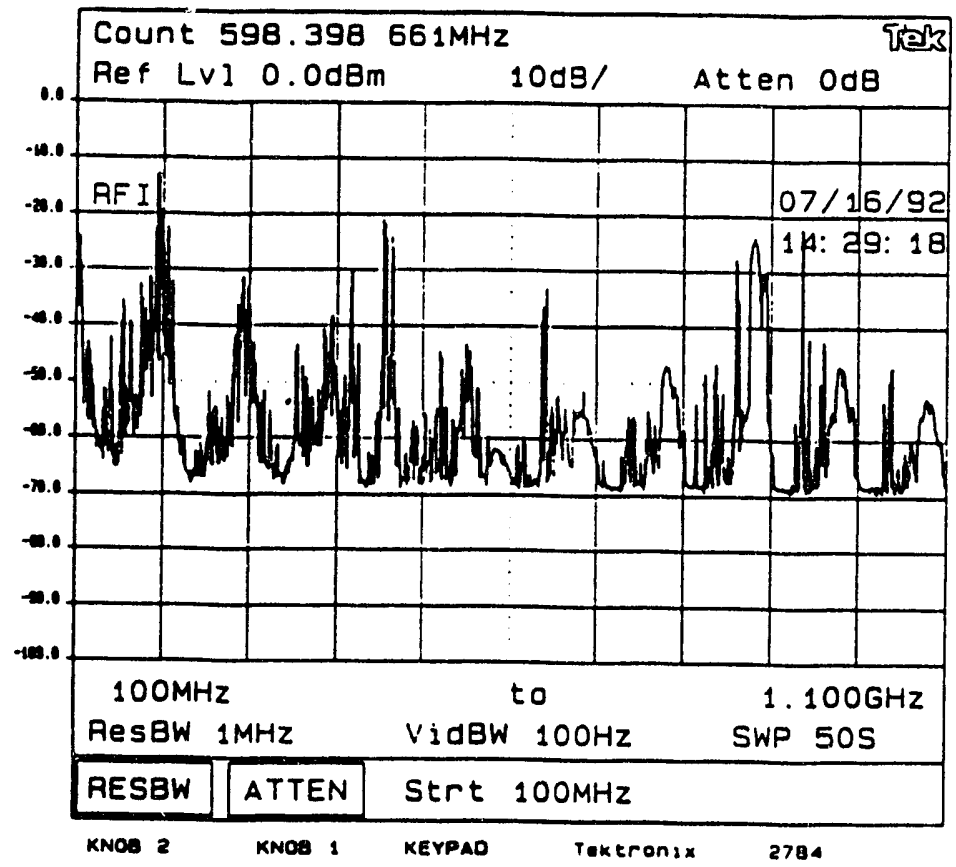

Figure 5.7. RFI Measurement at the Maynard Site, $334^{\circ}$ Orientation 


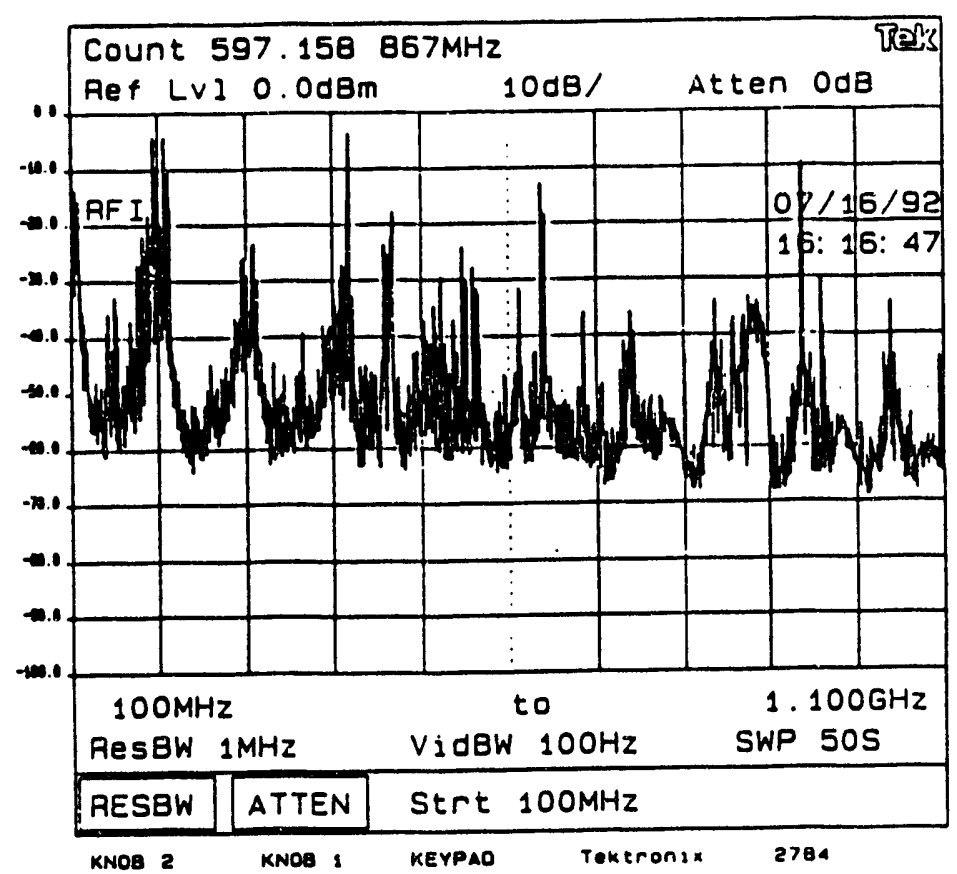

Figure 5.8. RFI Measurement at the Road 150 Site, $58^{\circ}$ Orientation Pointed directly at transmitters on Blyn Mountain. 


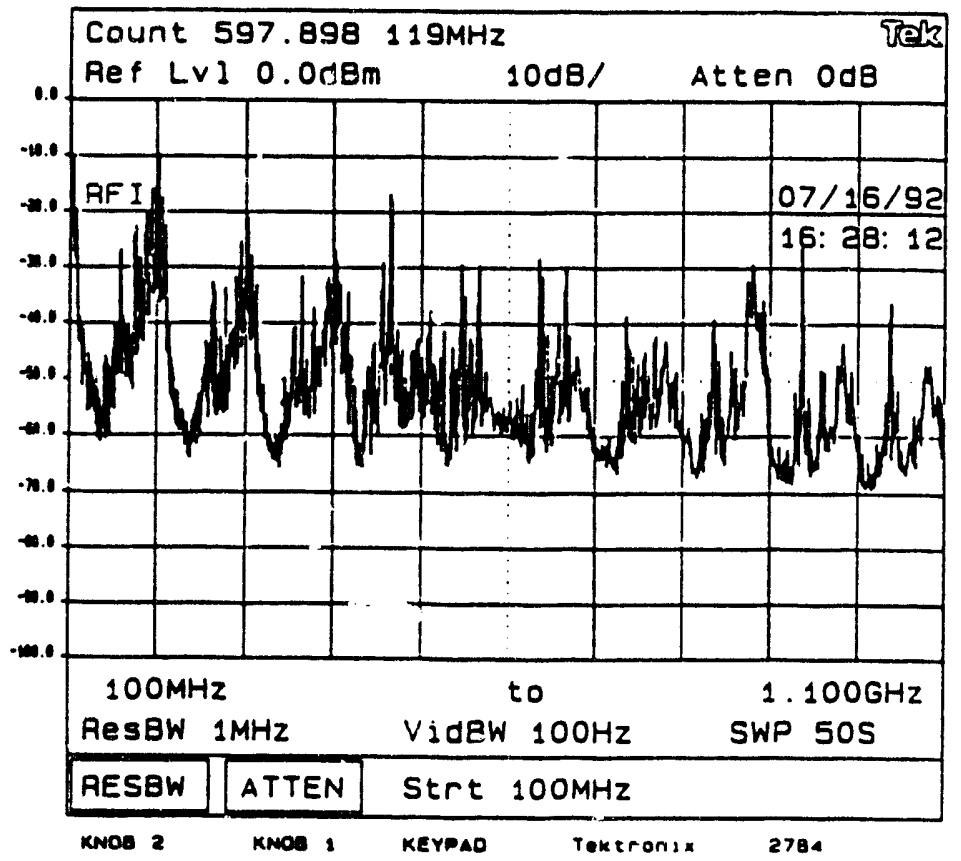

Figure 5.9. RFI Measurentist at the Road 150 Site, $224^{\circ}$ Orientation 


\subsection{Forest and Desert Measurements}

At the beginning of November 1991, the PNL impulse radar, the 19-meter scanner, and System Planning Corporation's mobile Mark IV instrumentation radar were set up at the Sequim clutter measurement site. Operations were conducted there for two weeks.

\subsection{Impulse Forest Measurements (Sequim)}

The PNL impulse radar measured clutter coefficients for approximately 120,000 cells covering a total of approximately $0.7 \mathrm{~km}^{2}$ for both $\mathrm{VV}$ and $\mathrm{HH}$ polarizations. The SPC Mark IV measured an area covering approximately $6 \mathrm{~km}^{2}$, in both polarizations. The step-chirp area included all that covered by the impulse measurements.

Measurements were made at three scanner orientations spaced $30^{\circ}$ apart. In each orientation scans were performed for 13 slightly overlapping range increments covering 0.75 to $1.2 \mathrm{~km}$ in both $\mathrm{VV}$ and $\mathrm{HH}$ polarizations, for a total of 78 scans.

Each scan collected 100 received waveforms at each of 256 positions in the 19 meter aperture, for a total of 25,600 waveforms. Each scan provided clutter measurements in 155 cells (covering approximately 35 meters total range) in each of 20 synthesized beams for a total of 3100 cells per scan. Time required to complete a scan was 40 to 45 minutes.

A flat plate calibration target was included in the clutter scene on a substantially bare knoll at approximately $1 \mathrm{~km}$ iange. The target area was rescanned several times during the two week period to check the impulse radar system stability. Figure 6.1 is a panoramic view of the general scene at the Sequim site from the radar scanner location. Figure 6.2 shows the radar setup at the Sequim site. Figure 6.3 is an aerial photograph of the site, and Figure 6.4 is a topographic map of the area.

\subsubsection{Calibration}

The calibration procedure used follows the analysis in Section 4.5. A flat plate calibration target was placed on a bare knoll approximately $1 \mathrm{~km}$ from the radar. The target consisted of two 6 by 6 foot mesh plates assembled as a 6 foot wide by 12 foot high rectangle. The plate was manually oriented for maximum return amplitude while observing the impulse radar voltage waveform output.

Calibration waveforms appeared significantly cleaner in the synthetic aperture data. This is to be expected for two reasons. The narrower synthesized beam would give roughly a $10 \mathrm{~dB}$ improvement in target to clutter ratio. Also 25,600 waveforms, rather than 2,000 
were averaged suggesting approximately $10 \mathrm{~dB}$ further improvement in target to RFI ratio from coherent processing.

A slightly processed B-scan version of a data set collected from the calibration target area is shown in Figure 6.5. This pseudo-color image is representative of the voltage waveforms returned from the target area. Each column in the image represents a coherent summation of 100 waveforms from the target area at that scanner position. Thus, a target located directly ahead of the scanner (perpendicular to the scanner axis) would generate a response at approximately equal time delay from each scanner position, and shows up as a horizontal line in the image. Off axis discrete targets show up in the image as angled lines. The processing described in Section 4.4 converts this data into high resolution focused range-angle images which are calibrated to clutter coefficient, as shown in Figure 6.6. The angular extent of the range-angle images is $-15^{\circ}$ to $+15^{\circ}$ with $0.2^{\circ}$ increments. The range extent of the images is approximately 38 meters.

The voltage waveform used for calibration was obtained from the focused data by choosing the angle at which the peak response was observed in the focused, uncalibrated data. Therefore, the target did not need to be placed exactly perpendicular to the scanner axis. The voltage waveform used for calibration is shown in Figure 6.7 along with its spectrum. For calibration, this waveform was windowed using a raised cosine window with a total width of $16 \mathrm{nsec}$. This windowing was done to remove the effects of clutter away from the calibration position. The windowed waveform and its spectrum are shown in Figure 6.8. The windowed waveform was used in the calibration procedure described in Section 4.5 to calibrate the unwindowed response to high resolution UWB radar cross section. The results of the this calibration are shown in Figure 6.9. Note that the peak response is approximately forced to equal the expected RCS from the 6 ' by 12' calibration target $(34.2 \mathrm{dBsm})$. The expected UWB RCS of the calibration target is exactly equal to the single-frequency RCS at the center frequency. This is because the flat plate square root RCS varies linearly with frequency, and the UWB processing essentially takes an average of the square root of RCS in the transformation back to the time/range domain. If the unwindowed response were processed as though unknown, then the result would be exactly $34.2 \mathrm{dBsm}$. The clutter present in the waveform causes the result to be slightly different.

The range resolution of the system may be degraded by limiting the bandwidth. This is readily done using the calibration procedure, discussed in Section 4.5 , by changing the low and high frequency cutoff points. For example, the resolution of the calibration waveform (Figure 6.7) was reduced by limiting the bandwidth to $100 \mathrm{MHz}$ (600 to 700 $\mathrm{MHz}$ ), with the resulting RCS vs. range shown in Figure 6.10.

The calibration target was revisited a number of times during the two weeks of measurements to determine if the system was stable. Also, a 3' by 4' flat plate target was also deployed a number of times to verify that the calibration procedure would measure a known target's RCS correctly. The 3' by 4' target was a good choice for a secondary 
target as its RCS was large enough that it could be seen directly by the system (without scanning) at more than a kilometer. Also, unlike the large target, the 3' by 4' target is not extremely sensitive to alignment errors. This is important because, if the 6' by $12^{\prime}$ target were misaligned, then the calibrated RCS measurements of other targets would be too high. Thus, deploying the small target and verifying near-correct results was a valuable tool in verifying the measurement system, calibration algorithms, and target alignment.

Results of the ultrawideband impulse RCS measurements of known targets are summarized in Table 6.1. For these measurements the targets were located at a range of approximately $1.07 \mathrm{~km}$. The targets were approximately normal to the scanner axis and at nearly the same elevation. The table entry under Day 0 was the scan used to calibrate all of the other target and clutter measurements, and is therefore not an indication that the system is yielding the correct results. Two of the other results are within approximately $2 \mathrm{~dB}$ of the expected RCS of the 6 ' by 12 ' flat plate. The third measurement is somewhat lower than the other two, indicating that the target was probably not as well aligned. The 3' by 4' target was also scanned, with a measured RCS of $17.2 \mathrm{dBsm}$ and an expected value of $18.6 \mathrm{dBsm}$. These results indicate that the measurement and calibration techniques were yielding reasonably accurate results.

Table 6.1. On-Axis RCS Measurements (UWB) of Known Targets Including the 6' by 12' Flat Plate and a 3' by 4' Flat Plate

\begin{tabular}{|c|c|c|c|c|}
\hline \multicolumn{5}{|c|}{ Target UWB RCS Measurements (on-axis) } \\
\hline & Pol & Range (km) & RCS (dBsm) & Notes \\
\hline \multicolumn{5}{|c|}{ 6' by 12' Flat Plate Calibration Target } \\
\hline Expected & & & 34.2 & \\
\hline Day 0 & VV & 1.07 & 33.3 & calibration \\
\hline Day 1 & VV & 1.07 & 29.8 & not aligned \\
\hline Day 2 & HH & 1.07 & 32.2 & \\
\hline Day 2 & VV & 1.07 & 32.1 & \\
\hline \multicolumn{5}{|c|}{ 3' by 4' Flat Plate Target } \\
\hline Expected & & & 18.6 & \\
\hline Day 2 & VV & 1.07 & 17.2 & \\
\hline
\end{tabular}




\subsubsection{Clutter Measurements}

As indicated above, clutter was measured over a sector with a range from $750 \mathrm{~m}$ to 1200 $\mathrm{m}$ and an angular extent of $90^{\circ}$. Covering this sector took 39 scans for each polarization for a total of 78 scans. Several typical high resolution calibrated images of clutter are shown in Figures 6.11 to 6.13 .

Weather during the measurement period was generally cool and overcast with occasional light drizzle. In the week preceding the measurements rain gauges in the clutter scene collected 0.6 to 1.1 inches of total precipitation (see Appendix B). The impulse radar operating schedule was typically $3 \mathrm{pm}$ to midnight. Temperatures were generally falling during this time, frequently reaching dew point as indicated by typical formation of evening fog.

\subsubsection{Forest Clutter Analysis}

In this section, extensive statistical results of the impulse measurements from the forested site at Sequim are presented. Table 6.2 summarizes the vertical (VV) and horizontal $(\mathrm{HH})$ polarization data taken for the three lines of sight, $186^{\circ}, 216^{\circ}$, and $246^{\circ}$. Figures 6.10 and 6.11 show the probability density functions, or histograms, of this data along with a Weibull plots of the cumulative distribution functions. The Weibull plotting technique is discussed in Section 4.6. Above the noise floor, the distributions approximately match Weibull distributions with spread parameters of 2.17 for VV and 2.44 for $\mathrm{HH}$. Below the noise floor, the spread parameter is close to unity which is expected for noise. The distributions may be biased upward somewhat relative to other clutter measurements, since the measured area contained primarily slopes facing the radar with few shadowed regions.

Table 6.2. Summary of VV and HH Polarization Clutter Data Taken in Three Lines of Sight: $186^{\circ}, 216^{\circ}$, and $246^{\circ}$

\begin{tabular}{||l|l|l||}
\hline Polarization & VV & HH \\
\hline Frequency Band & $300-1000 \mathrm{MHz}$ & $300-1000 \mathrm{MHz}$ \\
\hline Aperture Window & Rectangular & Rectangular \\
\hline Angle Coverage & $171^{\circ}-261^{\circ}$ & $171^{\circ}-261^{\circ}$ \\
\hline Beamwidth (constant) & $1.5^{\circ}$ & $1.5^{\circ}$ \\
\hline Range Coverage & $750 \mathrm{~m}-1200 \mathrm{~m}$ & $750 \mathrm{~m}-1200 \mathrm{~m}$ \\
\hline Range Resolution & $0.214 \mathrm{~m}$ & $0.214 \mathrm{~m}$ \\
\hline
\end{tabular}




\begin{tabular}{|l|l|l|}
\hline Polarization & VV & HH \\
\hline Number of Cells & 117,800 & 120,900 \\
\hline Mean $\sigma^{\circ}$ & $-5.4 \mathrm{~dB}$ & $-9.0 \mathrm{~dB}$ \\
\hline Median $\sigma^{\circ}$ & $-12.4 \mathrm{~dB}$ & $-16.8 \mathrm{~dB}$ \\
\hline Max $\sigma^{\circ}$ & $14.1 \mathrm{~dB}$ & $12.4 \mathrm{~dB}$ \\
\hline Weibull Spread & 2.17 & 2.44 \\
\hline
\end{tabular}

A single scan was taken with the transmitter turned off in order to assess the noise equivalent clutter at this sight, with the results summarized in Table 6.3. The distributions of this noise data are shown in Figure 6.16. The mean noise equivalent clutter coefficient observed was $-40 \mathrm{~dB}$ and is predominantly due to RFI. This represents the approximate noise floor of the impulse clutter measurements.

Table 6.3. Summary of Noise Equivalent Clutter Data

\begin{tabular}{|l|l|}
\hline Polarization & $\mathrm{VV}$ \\
\hline Frequency Band & $300-1000 \mathrm{MHz}$ \\
\hline Aperture Window & Rectangular \\
\hline Range & $1000 \mathrm{~m}$ \\
\hline Number of Waveforms & 25,600 \\
\hline Number of Cells & 3,100 \\
\hline Mean $\sigma^{\mathrm{o}}$ & $-40.1 \mathrm{~dB}$ \\
\hline Median $\sigma^{\mathrm{o}}$ & $-42.1 \mathrm{~dB}$ \\
\hline Max $\sigma^{\mathrm{o}}$ & $-30.2 \mathrm{~dB}$ \\
\hline
\end{tabular}

Figures 6.17 and 6.18 are composite clutter maps, presented to show the correlation of measured clutter coefficient to scene topography. A topographic map of the region covered is given as Figure 6.4. The cells shown are mean values for the 35 meter range blocks measured in each scan. (Each element plotted contains the mean of the 155 range resolved cells.) Cross range resolution is the $1.5^{\circ}$ synthesized beamwidth. 


\subsection{Step-chirp Forest Measurements (Sequim)}

The 1991 step-chirp measurements were conducted in parallel with the impulse measurement by Systems Planning Corporation under subcontract to PNL. Their measurement techniques and results are detailed in SPC Final Technical Report 1432 [Sager and Schultheis 1992). The summary portion of this report is reproduced in Appendix A.

\subsection{Impulse Desert Measurements (Badger Canyon)}

Synthetic aperture clutter measurements were also attempted at a desert location in Badger Canyon, near Richland, Washington. This site was much closer to an urban area with several local UHF TV stations and cellular telephone service. Although the site was selected for low local RFI, interference was substantially more severe than at the rural Sequim location. A photograph of operations and terrain at the Badger Canyon site is shown in Figure 6.19 along with a topographic map in Figure 6.20.

Measurements were terminated when it became clear that clutter coefficients in most of the scene were not significantly above the RFI imposed noise floor. The RFI spectrum at the receiver output is shown in Figure 6.21.

Further complicating the results at the Badger site was the fact that the impulse antennas suffered some damage after the Sequim measurements. Humidity caused the foamcore supporting structure of the antennas to shrink, which caused one of the antenna feeds to short circuit. This short was fixed, however, the observed voltage waveforms had substantially more ringing, as shown in Figure 6.22. This is the waveform/spectrum returned from the $6^{\prime}$ by $12^{\prime}$ calibration target placed at approximately $1.3 \mathrm{~km}$. Possible explanations for the ringing include multipath effects and the damage that the antennas incurred. A windowed version of this waveform and its spectrum are shown in Figure 6.23 .

Due to the unusual target return, the calibration from the Sequ'm data was used to calibrate the Badger Canyon data. This calibration may not be valid if the behavior of the antennas was significantly changed by the damage. Figure 6.24 shows the focused image of the calibration target area calibrated to clutter coefficient. Figure 6.25 shows a typical calibrated clutter image. The signal levels in this image are mostly due to RFI. Therefore, this data is not representative of the true clutter levels at this site. Figure 6.26 shows a clutter scene in which some bright clutter regions are visible above the RFI background. Table 6.4 summarizes a noise equivalent clutter coefficient measurement, in which the transmitter was turned off. A mean noise level of approximately $-27 \mathrm{~dB}$ was observed. The distributions of this data are shown in Figure 6.27. 
Table 6.4. Summary of Noise Equivalent Clutter Coefficient Measured at Badger

\begin{tabular}{|l|l|}
\hline Polarization & $\mathrm{VV}$ \\
\hline Frequency Band & $300-1000 \mathrm{MHz}$ \\
\hline Aperture Window & Rectangular \\
\hline Range & $1000 \mathrm{~m}$ \\
\hline Number of Waveforms & 25,600 \\
\hline Number of Cells & 3,100 \\
\hline Mean $\sigma^{\circ}$ & $-27.2 \mathrm{~dB}$ \\
\hline Median $\sigma^{\circ}$ & $-29.0 \mathrm{~dB}$ \\
\hline Max $\sigma^{\circ}$ & $-13.8 \mathrm{~dB}$ \\
\hline
\end{tabular}

Table 6.5 summarizes the clutter data taken at the desert site. The distributions of this data are shown in Figure 6.28. Again, it should be emphasized that these measurements are contaminated by significant RFI levels, and are therefore not accurate measurements of the true clutter levels. These results are presented only to docunient the measurements that were made. The Weibull plot of the cumulative distribution function clearly shows that most of the data is noise, which should have a slope parameter of unity. A small fraction of the data is, however, above the noise floor.

Table 6.5. Summary of the RFI Dominated Clutter Data Taken at Badger Canyon

\begin{tabular}{|l|l||}
\hline Polarization & $\mathrm{VV}$ \\
\hline Frequency Band & $300-1000 \mathrm{MHz}$ \\
\hline Aperture Window & Rectangular \\
\hline Angle Coverage & $180^{\circ}-240^{\circ}$ \\
\hline Beamwidth (constant) & $1.5^{\circ}$ \\
\hline Range Coverage & $990 \mathrm{~m}-1330 \mathrm{~m}$ \\
\hline Range Resolution & $0.214 \mathrm{~m}$ \\
\hline Number of Cells & 55,800 \\
\hline Mean $\sigma^{\circ}$ & $-20.5 \mathrm{~dB}$ \\
\hline
\end{tabular}




\begin{tabular}{|l|l|}
\hline Polarization & $\mathrm{VV}$ \\
\hline Median $\sigma^{\circ}$ & $-25.7 \mathrm{~dB}$ \\
\hline Max $\sigma^{\circ}$ & $1.9 \mathrm{~dB}$ \\
\hline Weibull Spread & -- \\
\hline
\end{tabular}




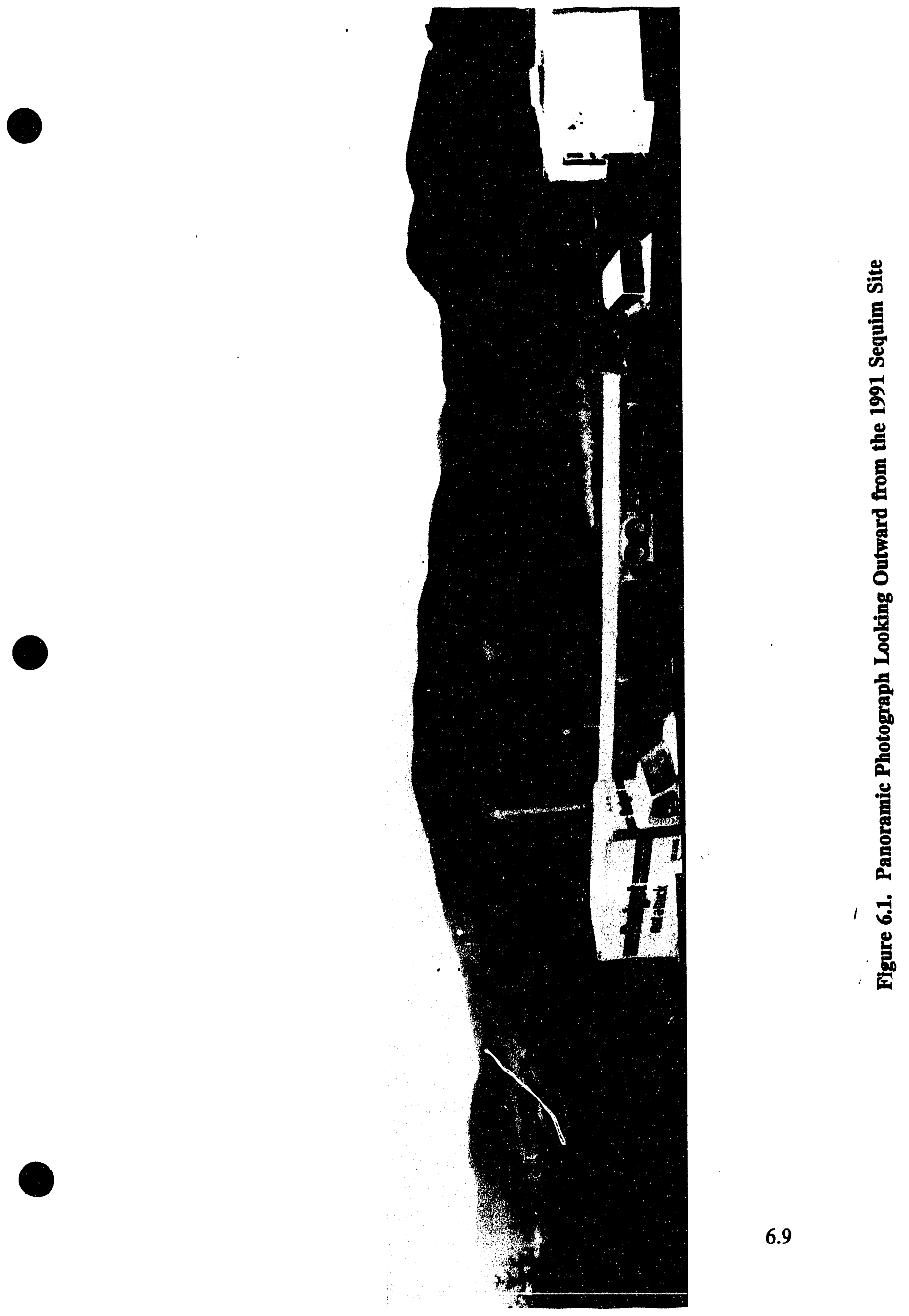




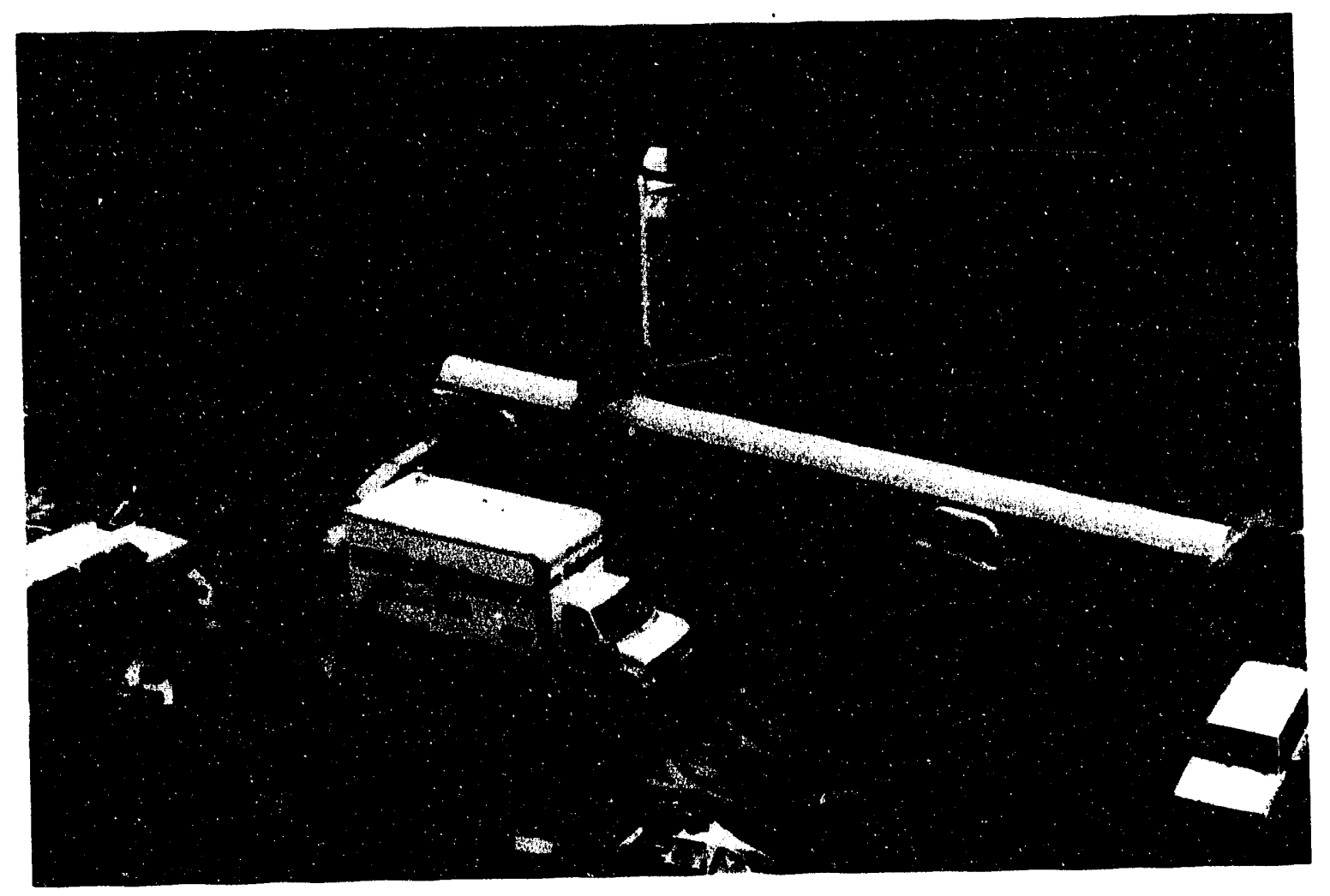

Figure 6.2. Operations at the 1991 Sequim Site 


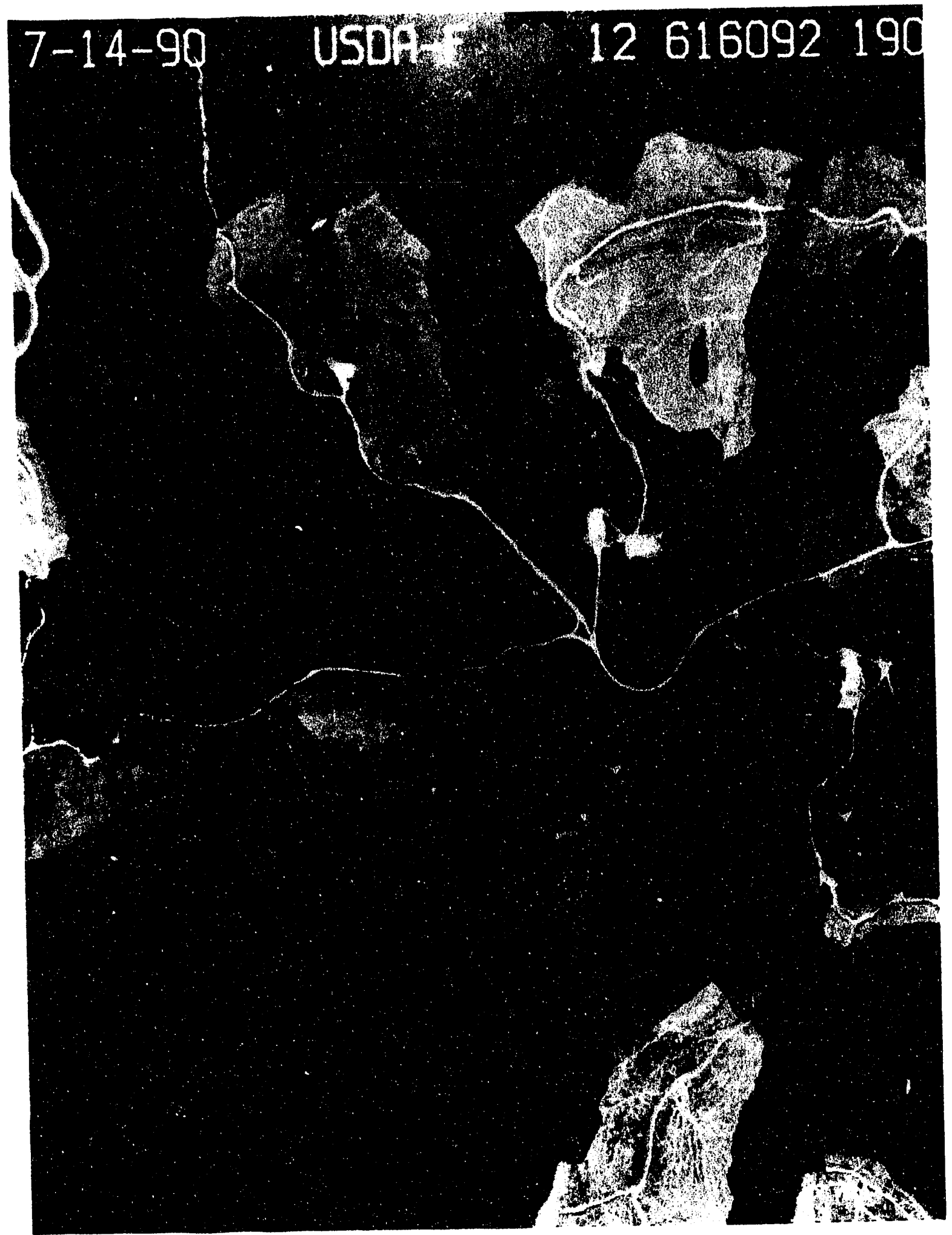

Figure 6.3. Aerial Photograph of the 1991 Sequim Site 


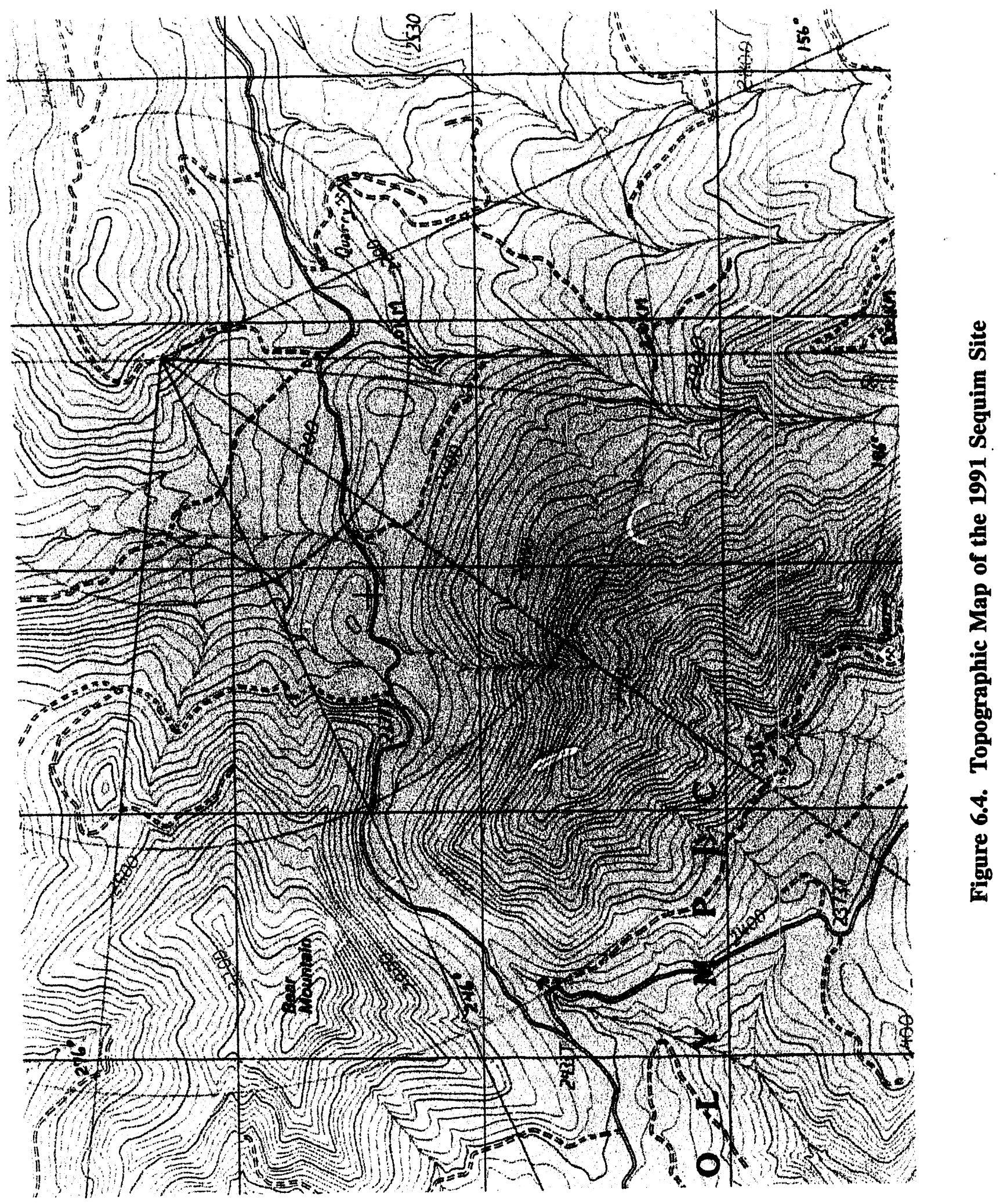




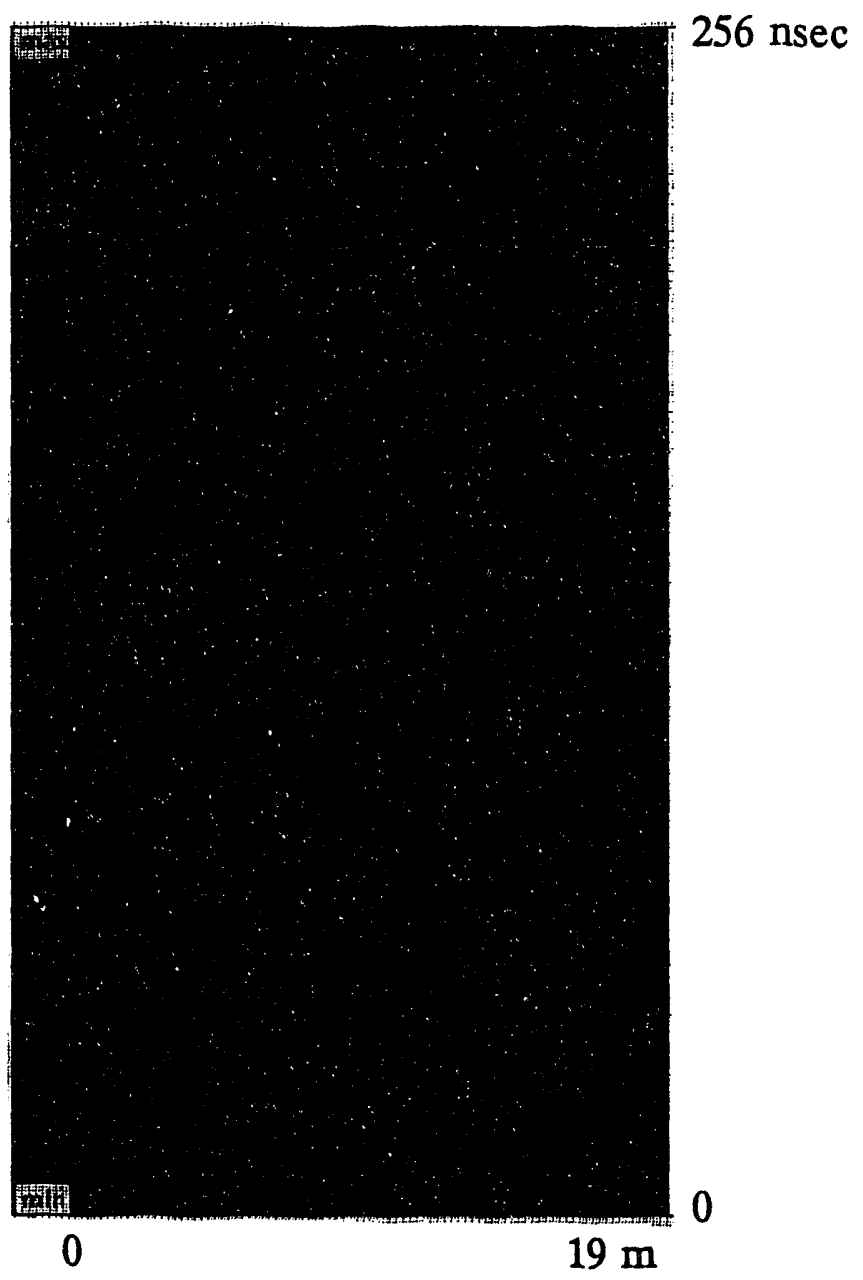

Figure 6.5. Pseudo-Color Image of the A-scans Collected at the 256 Scanner Positions of the Calibration Target 


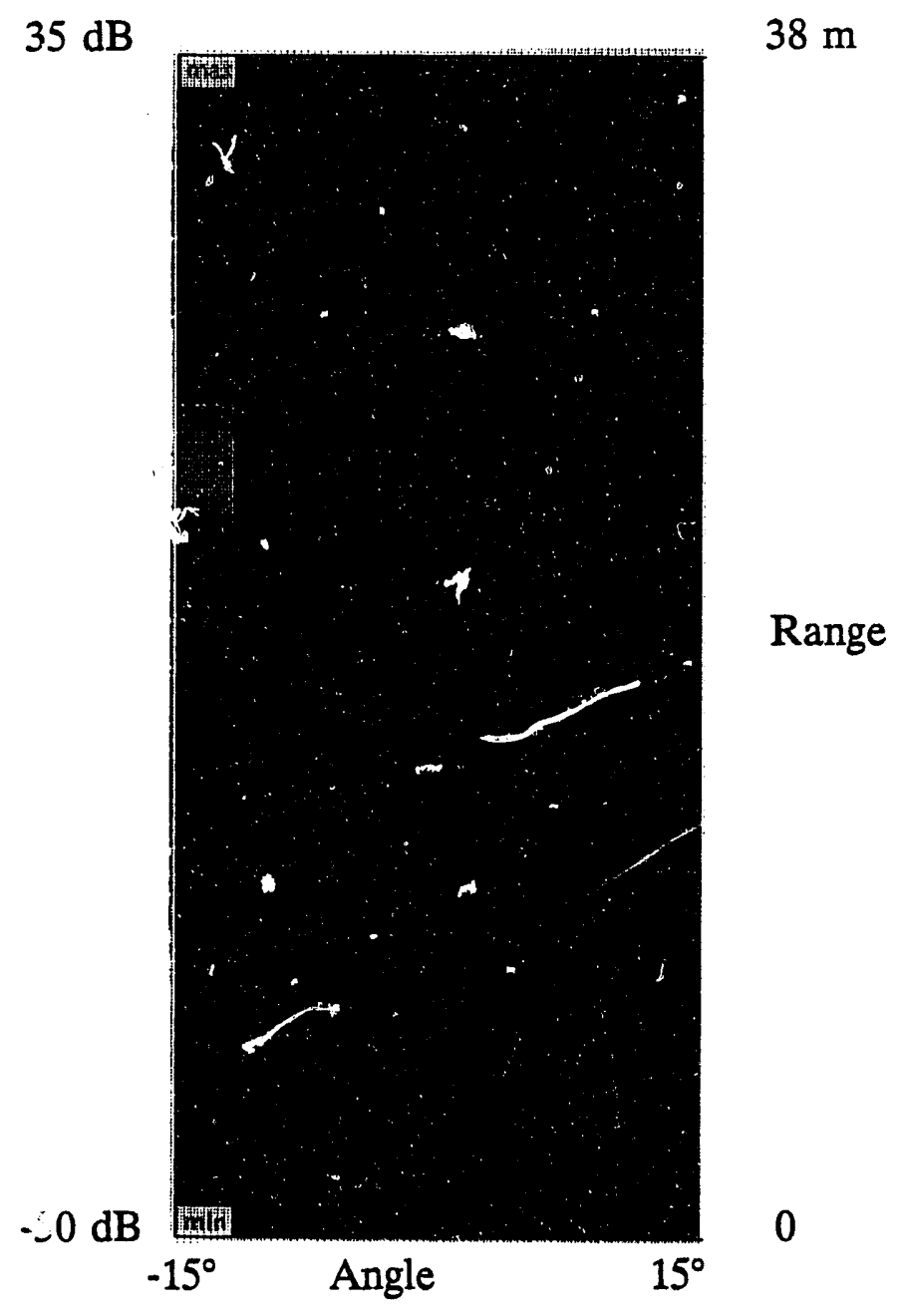

Figure 6.6. Pseudo-Color SAR Image of Calibration Targét Area Calibrated to Clutter Coefficient 

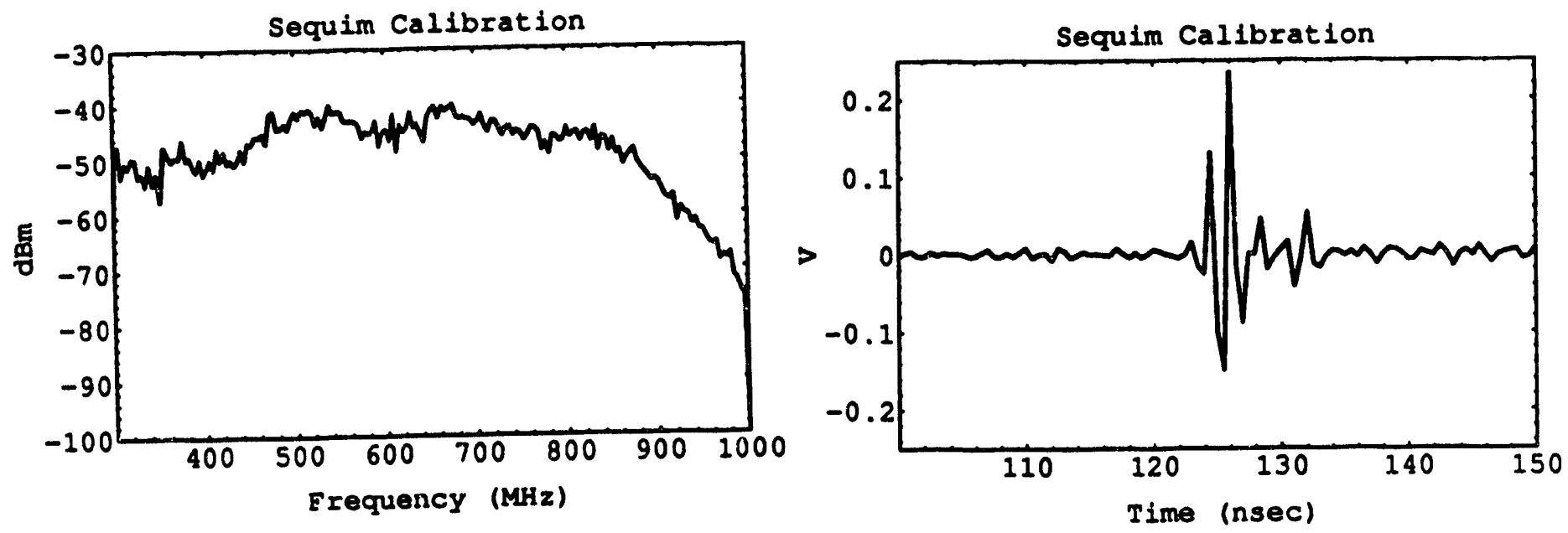

Figure 6.7. Voltage Waveform/Spectrum for Calibration Target
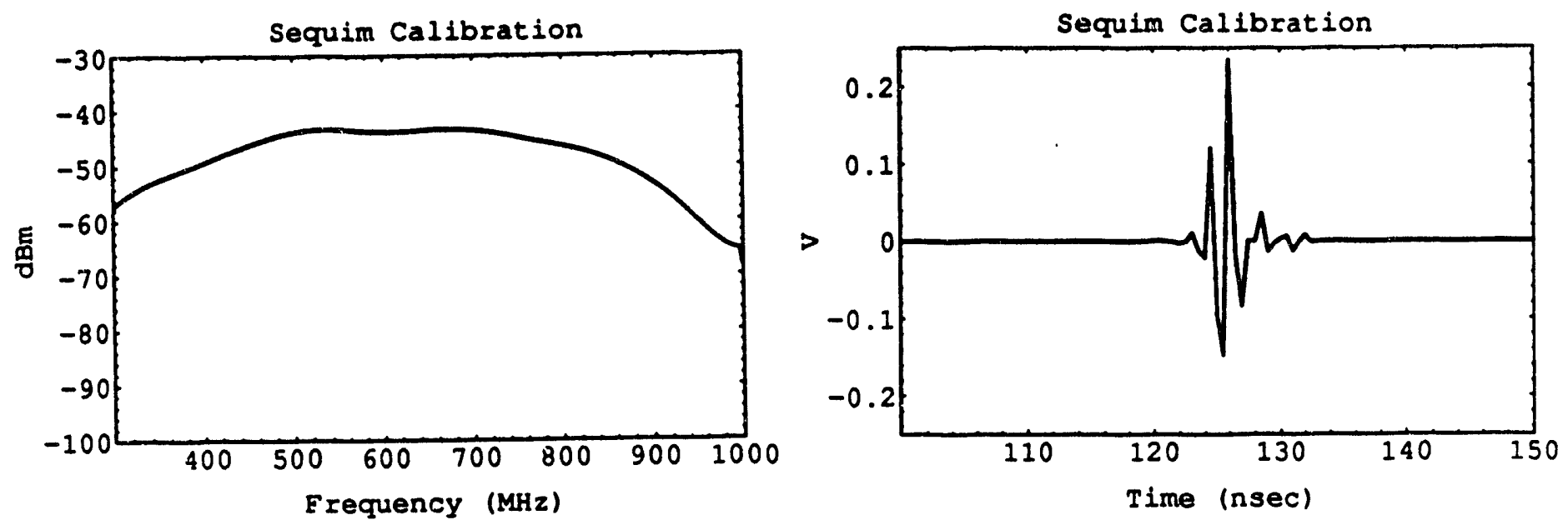

Figure 6.8. Windowed Voltage Waveform/Spectrum for Calibration Target 


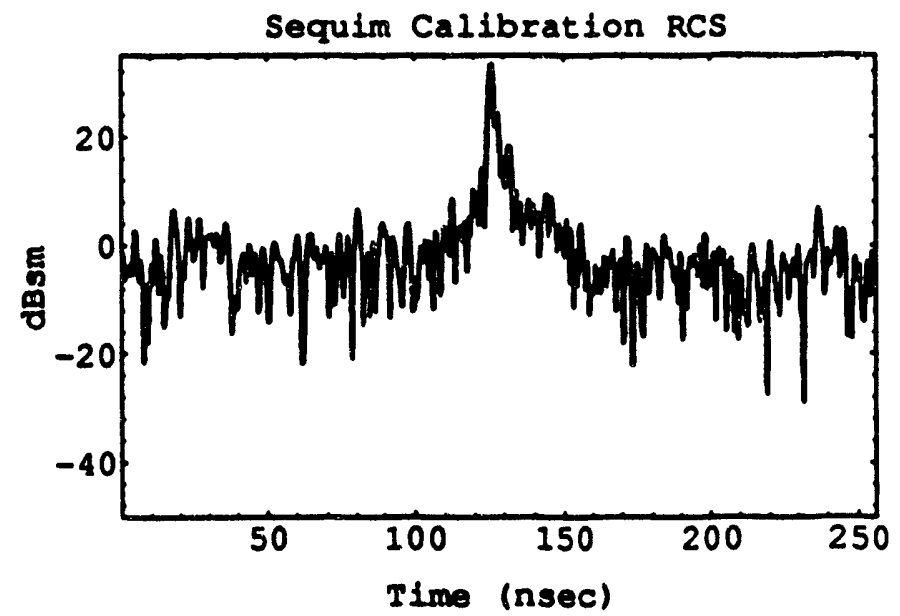

Figure 6.9. RCS Versus Range for the Calibration Target

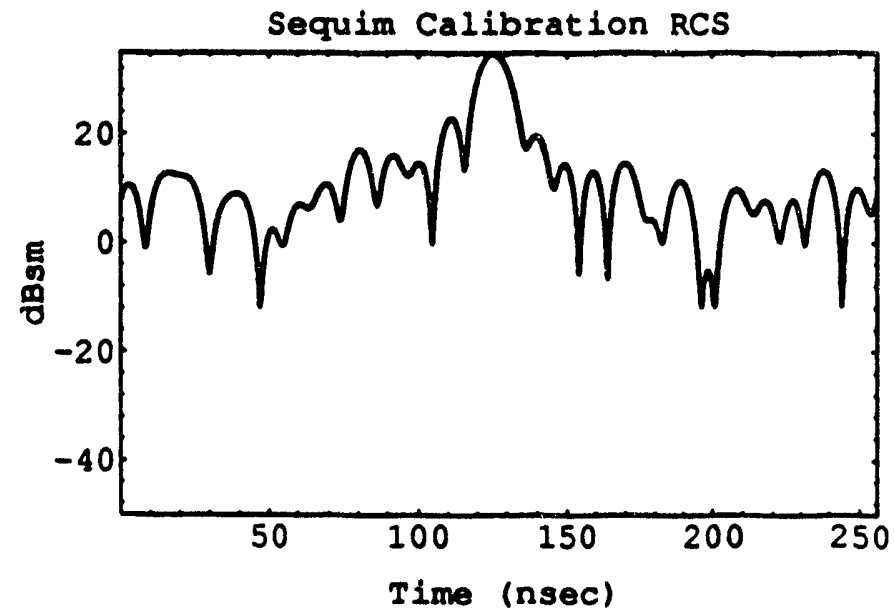

Figure 6.10. Reduced Resolution (100 MHz bandwidth) RCS Versus Range for the Calibration Target 


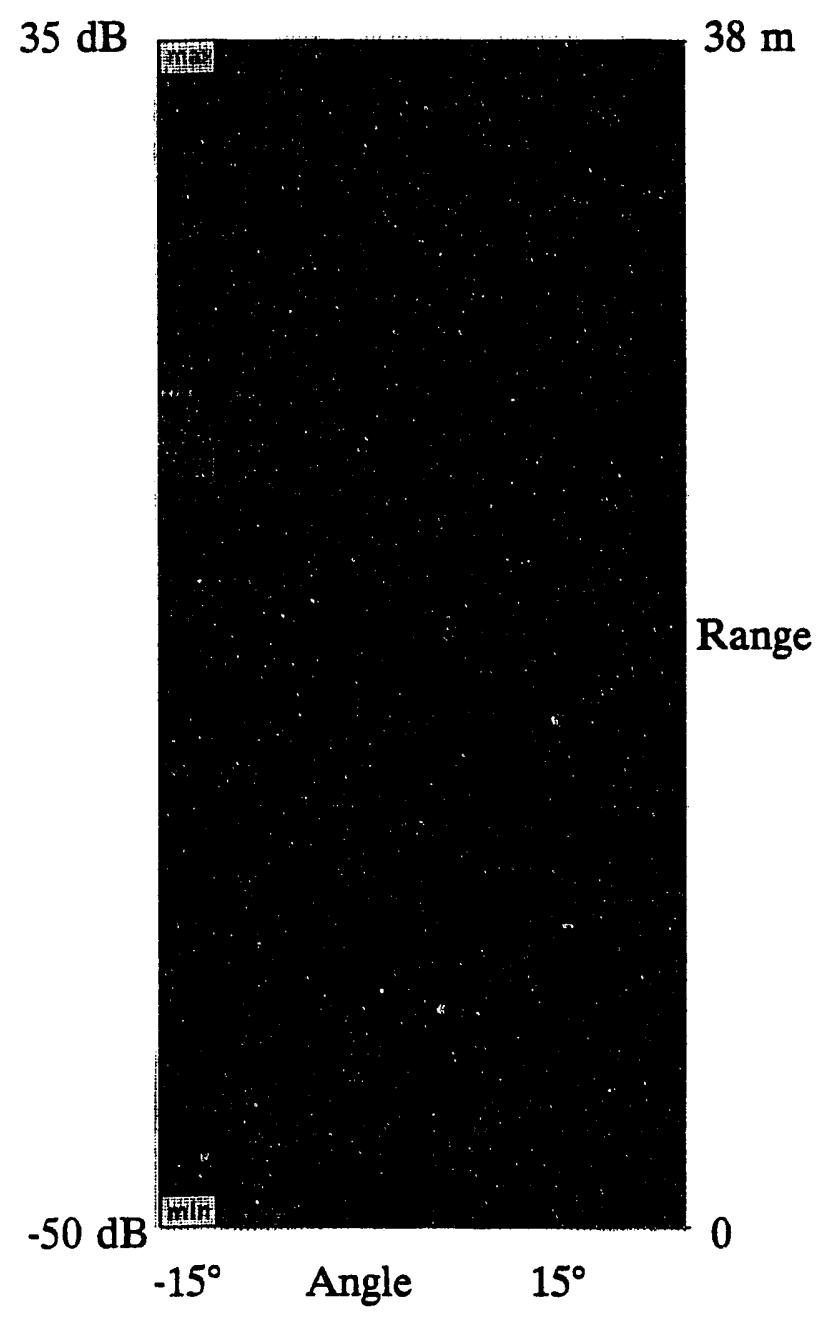

Figure 6.11. Pseudo-Color Calibrated SAR Image of a Relatively Low Clutter Region

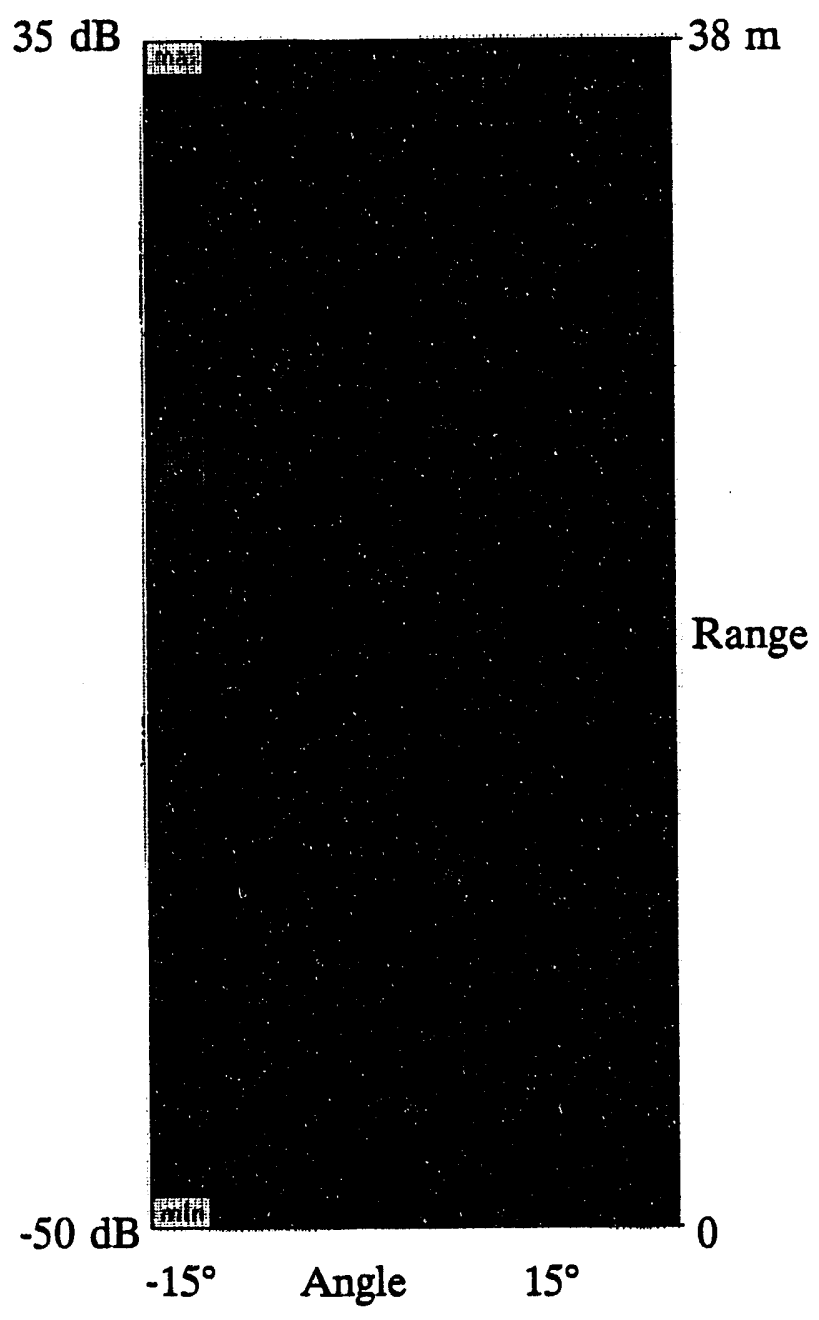

Figure 6.12. Pseudo-Color Calibrated SAR Image of a Relatively Typical Clutter Region 


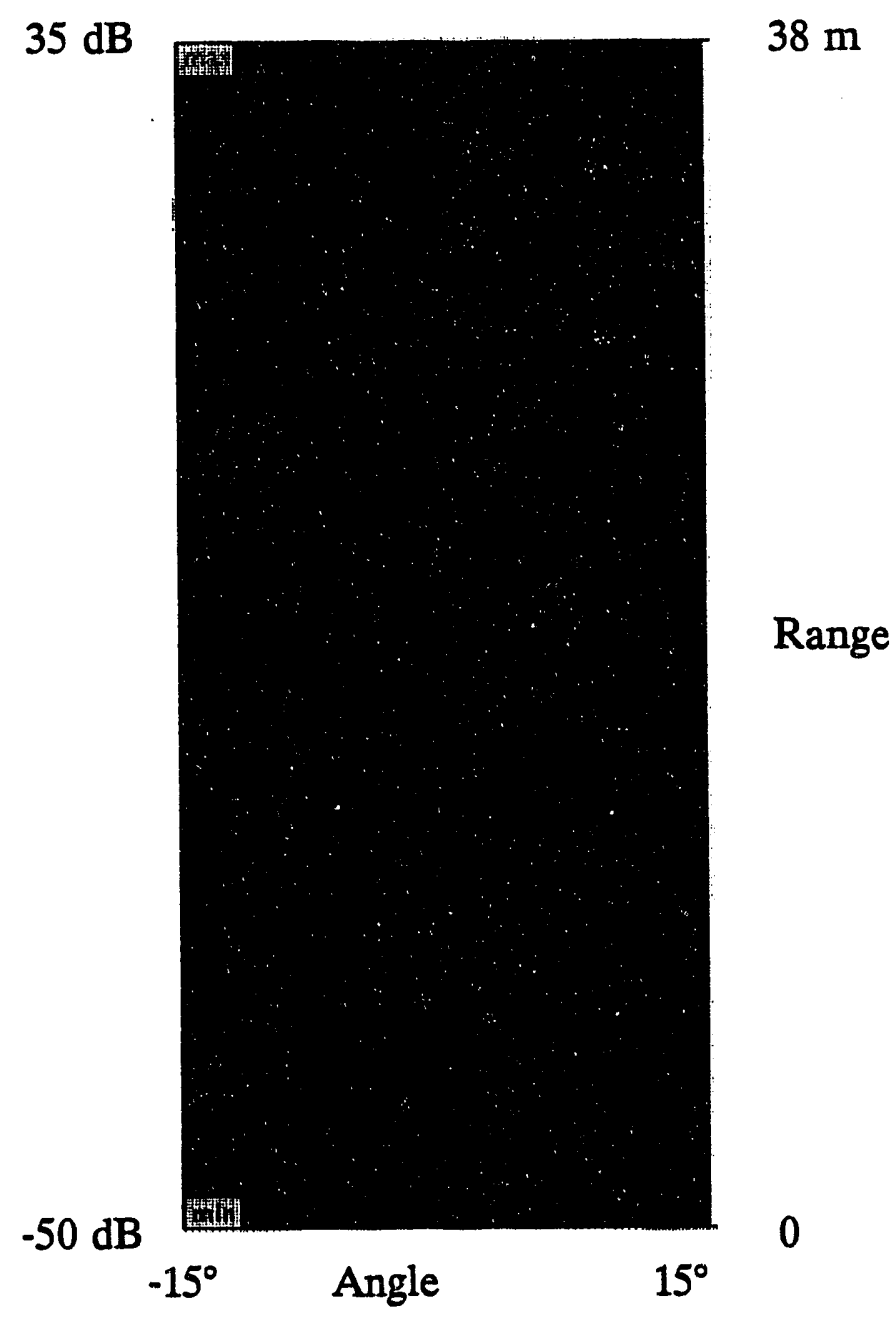

Figure 6.13. Pseudo-Color Calibrated SAR Image of a Relatively High Clutter Region 

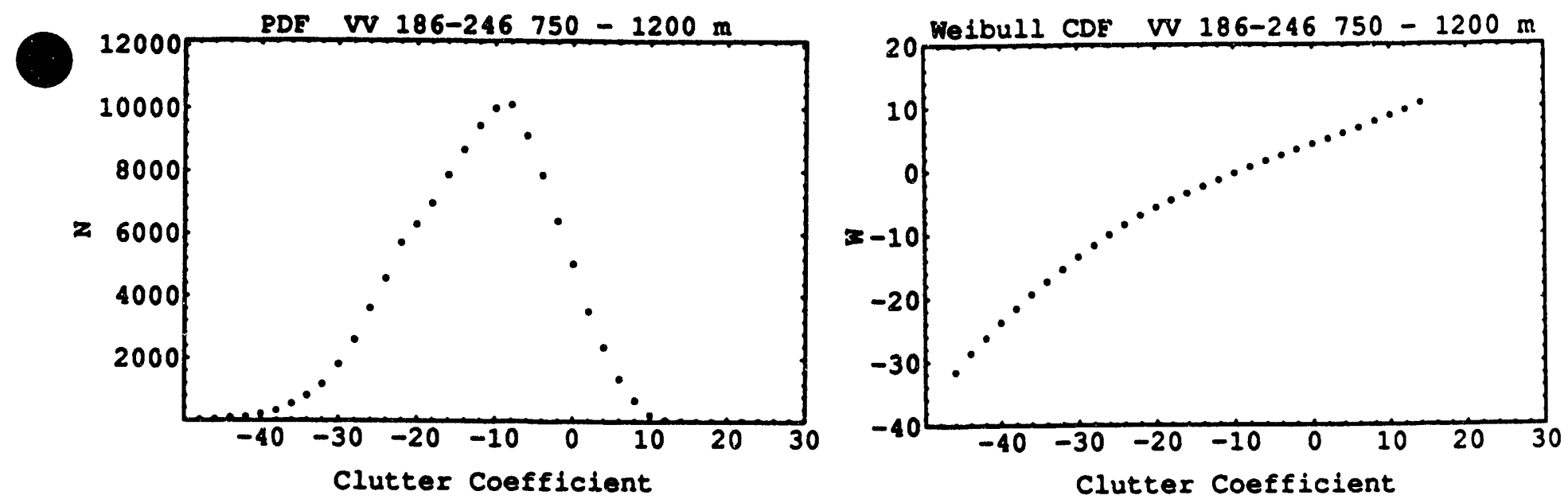

Figure 6.14. Distributions of VV Polarization Clutter Data Taken in Three Lines of Sight: $186^{\circ}, 216^{\circ}$, and $246^{\circ}$
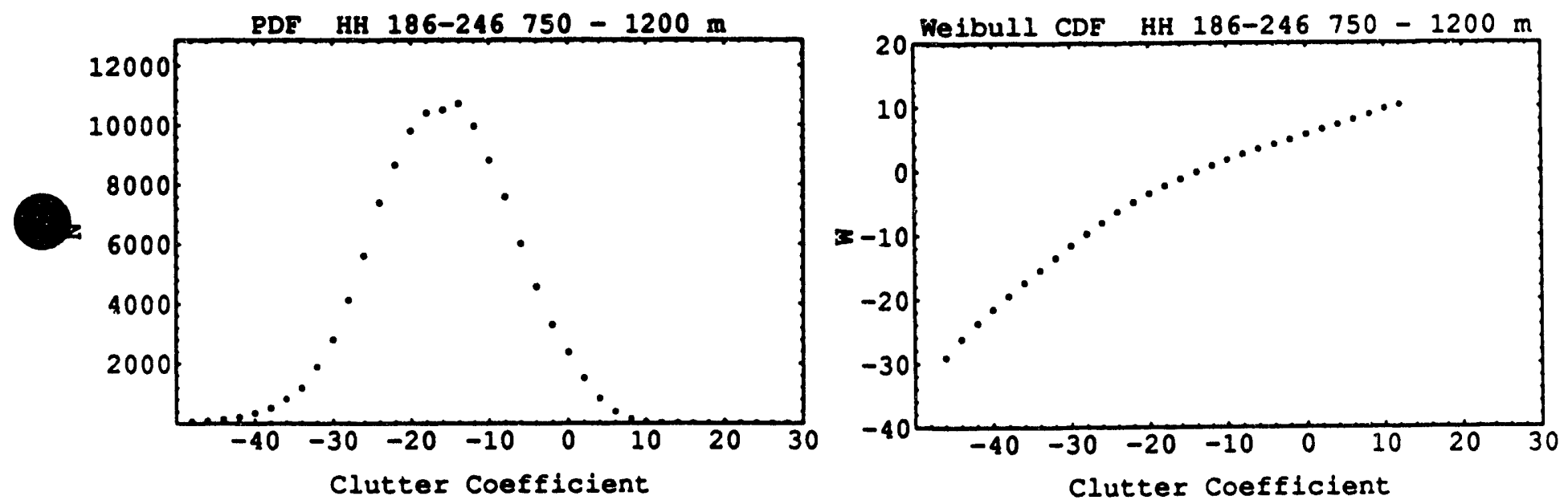

Figure 6.15. Distributions of HH Polarization Clutter Data Taken in Three Lines of Sight: $186^{\circ}, 216^{\circ}$, and $246^{\circ}$ 

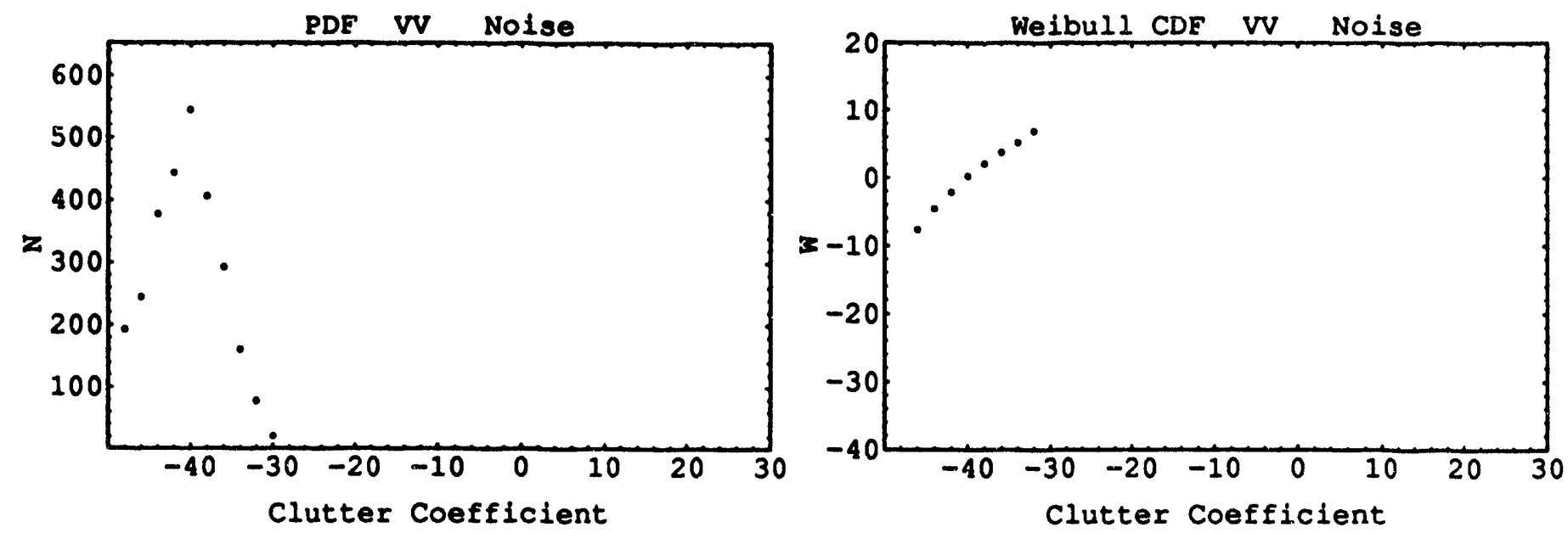

Figure 6.16. Distributions of Noise Equivalent Clutter Data

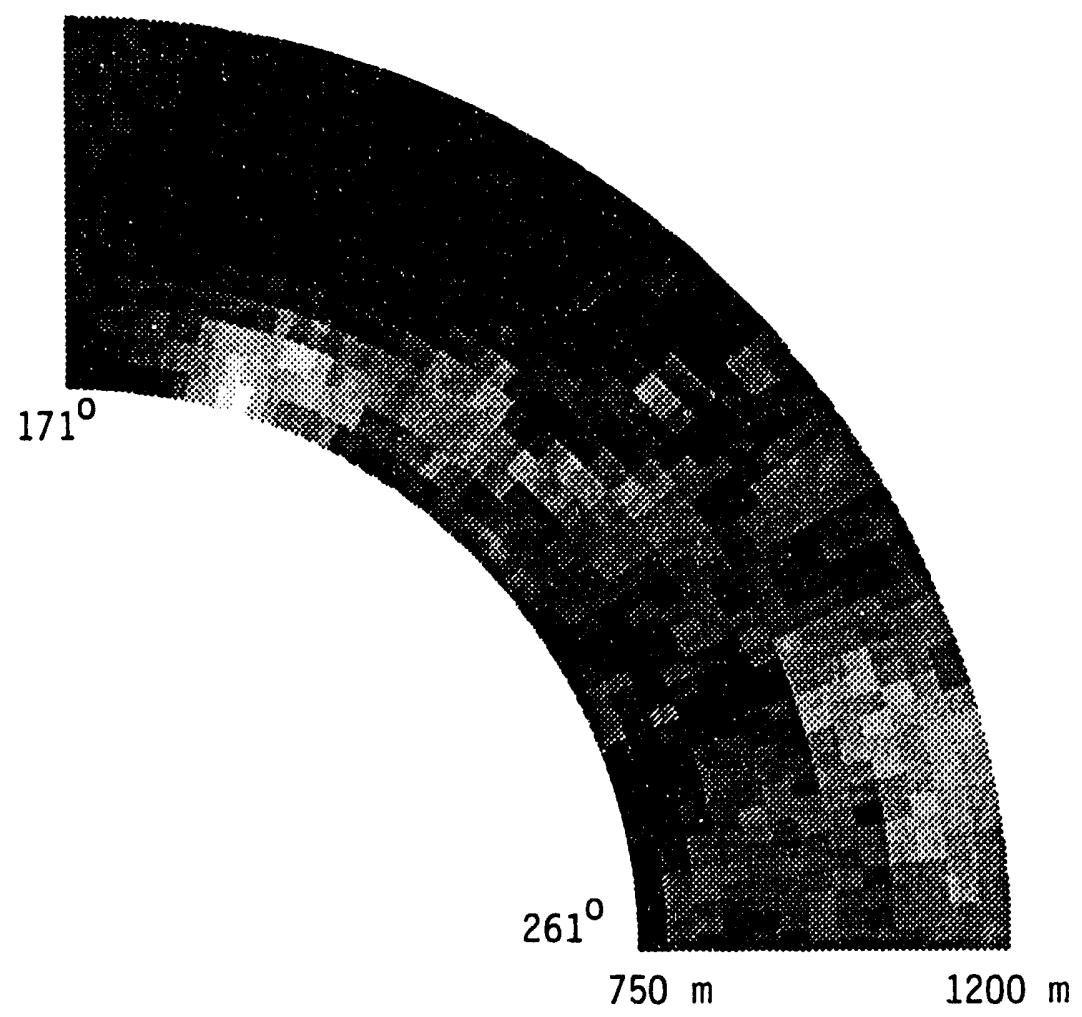

Figure 6.17. Composite Clutter Map of the VV Data 


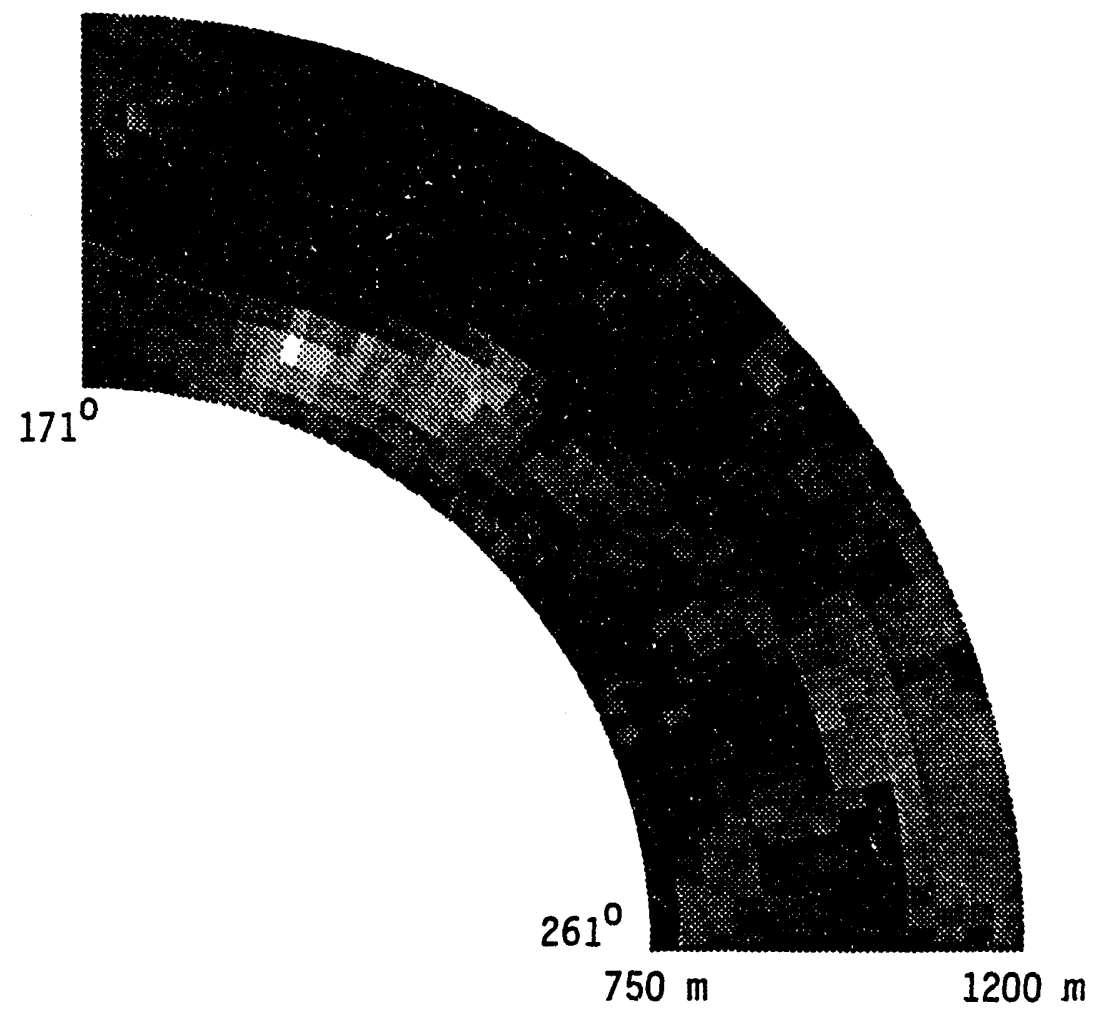

Figure 6.18. Composite Clutter Map of the HH Data

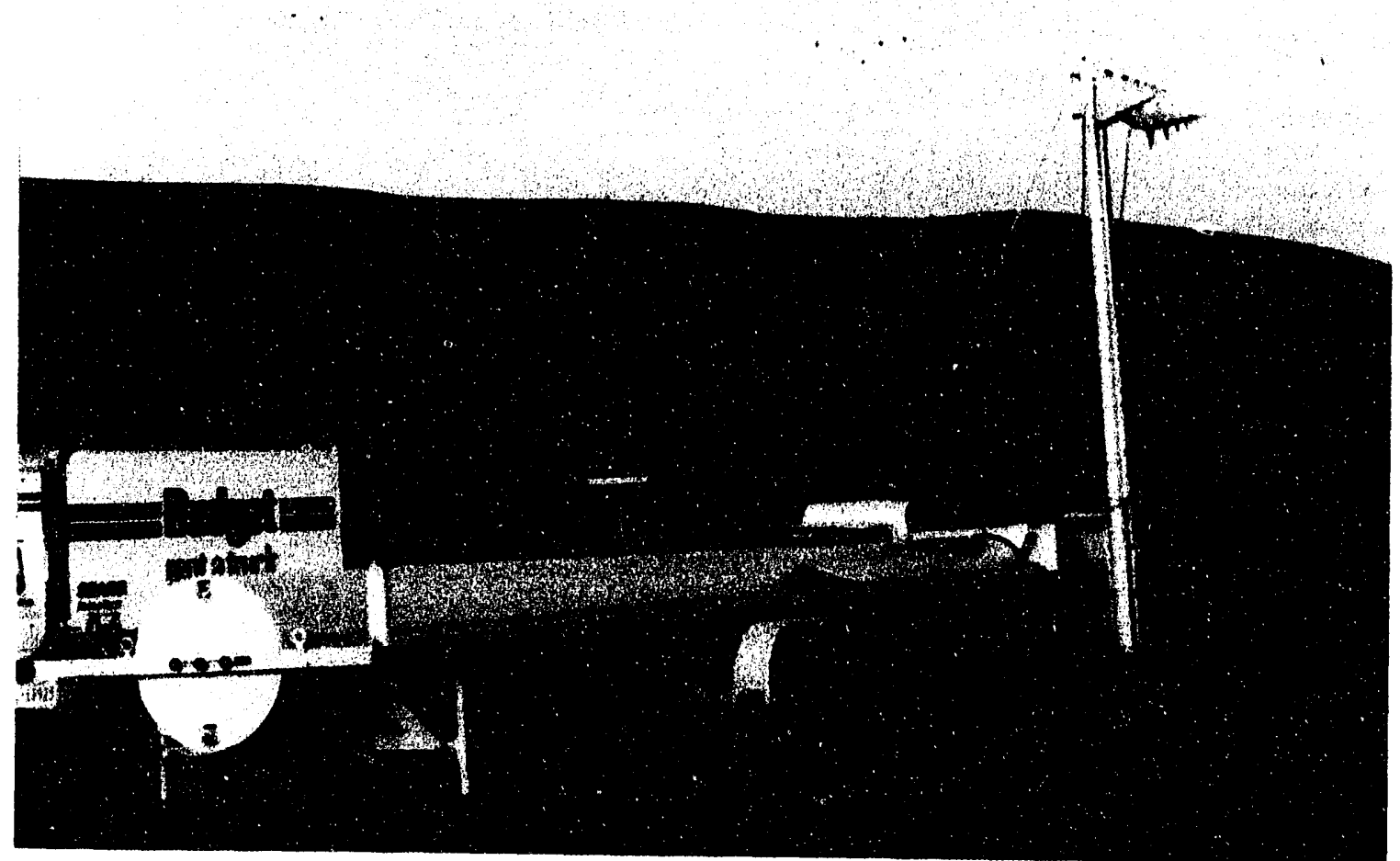

Figure 6.19. Operations and Terrain at Badger Canyon Site 


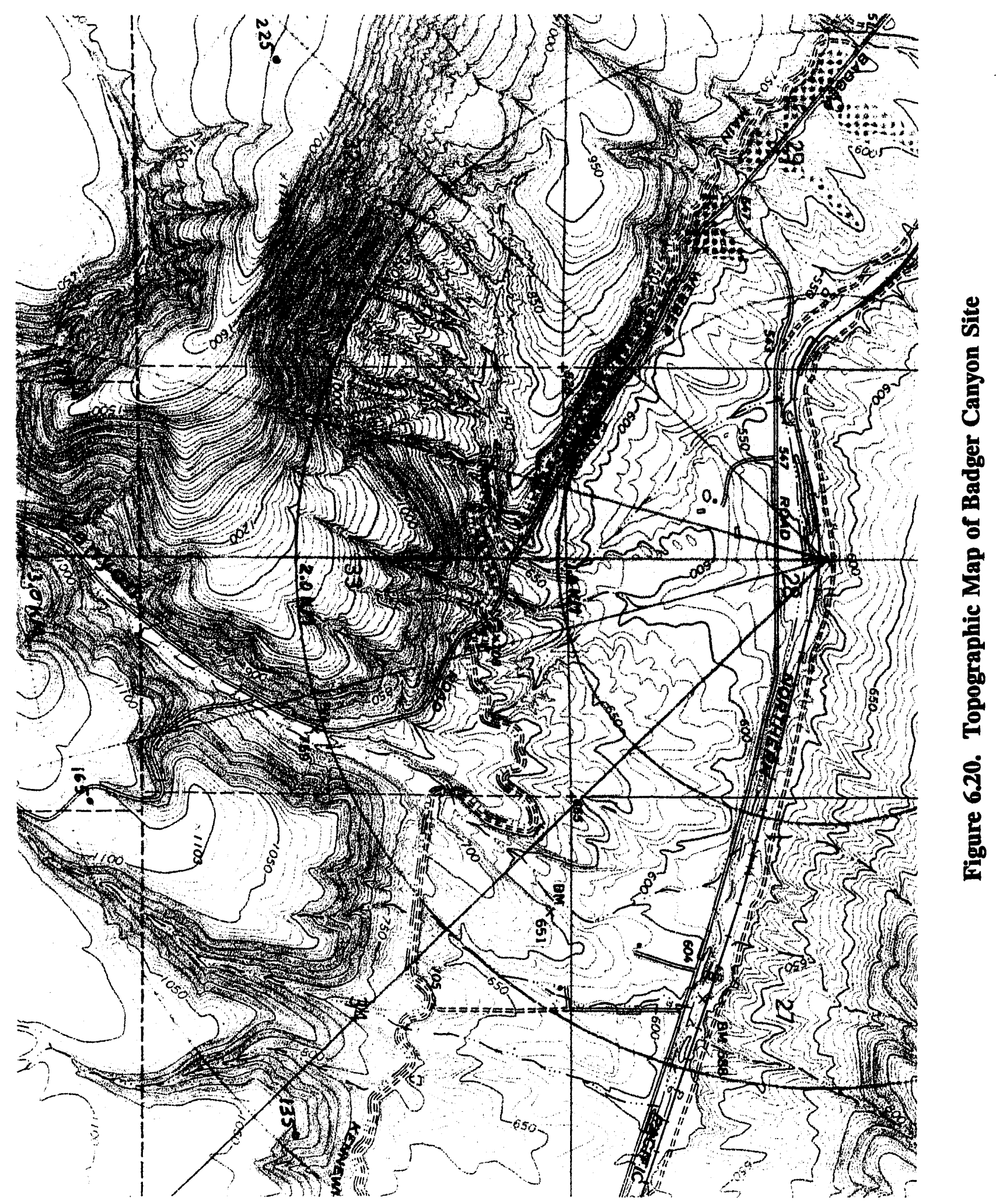




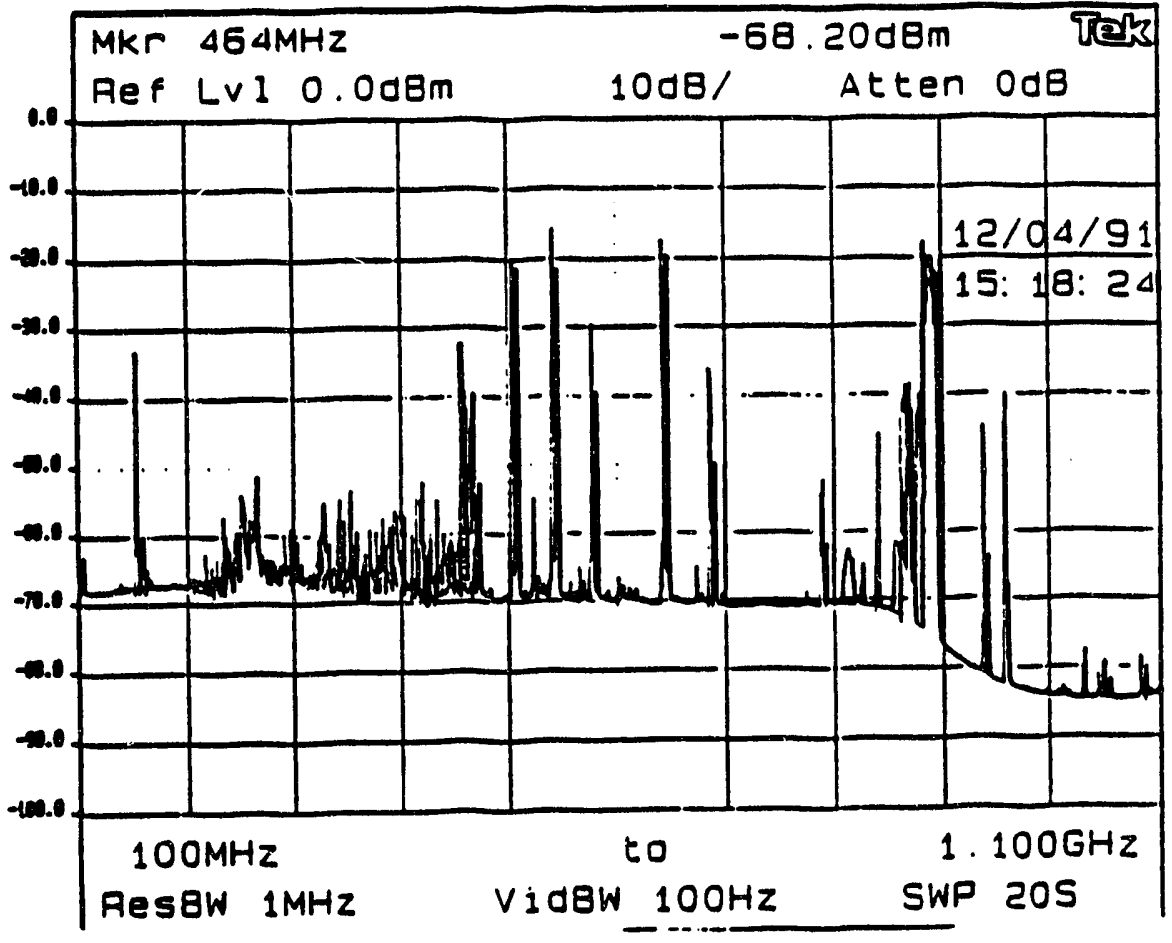

Figure 6.21. Received RFI Spectrum at Badger Canyon 

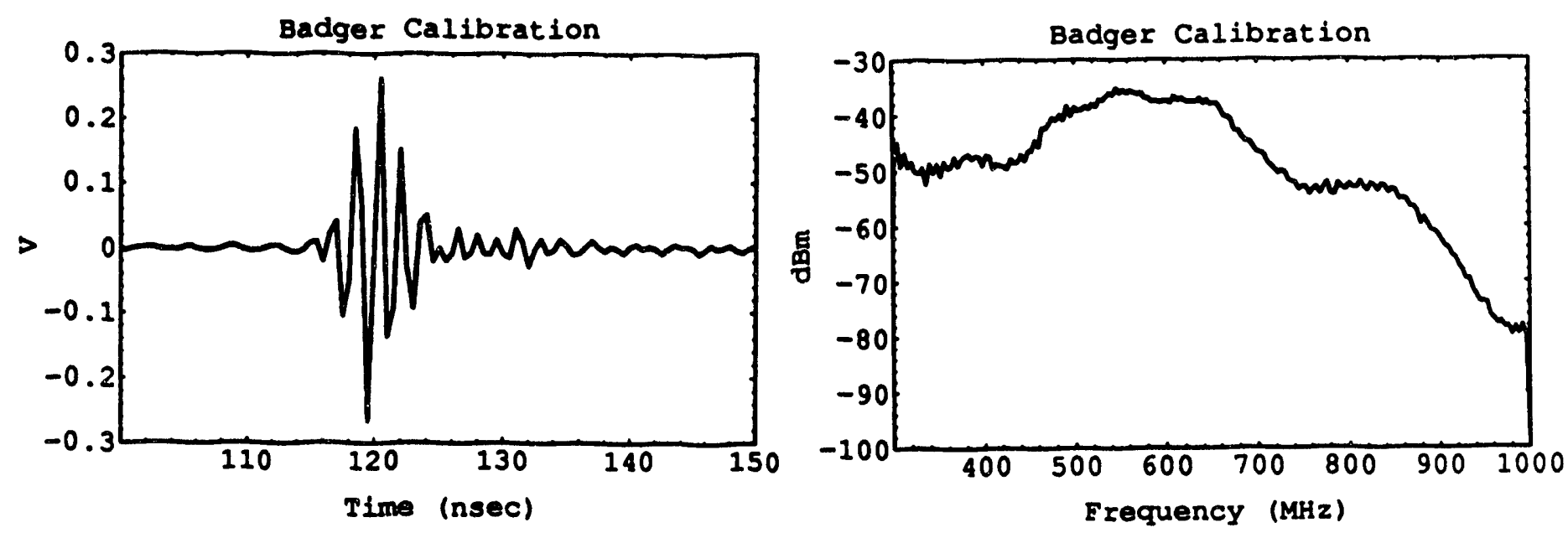

Figure 6.22. Voltage Waveform/Spectrum for Badger Calibration Target
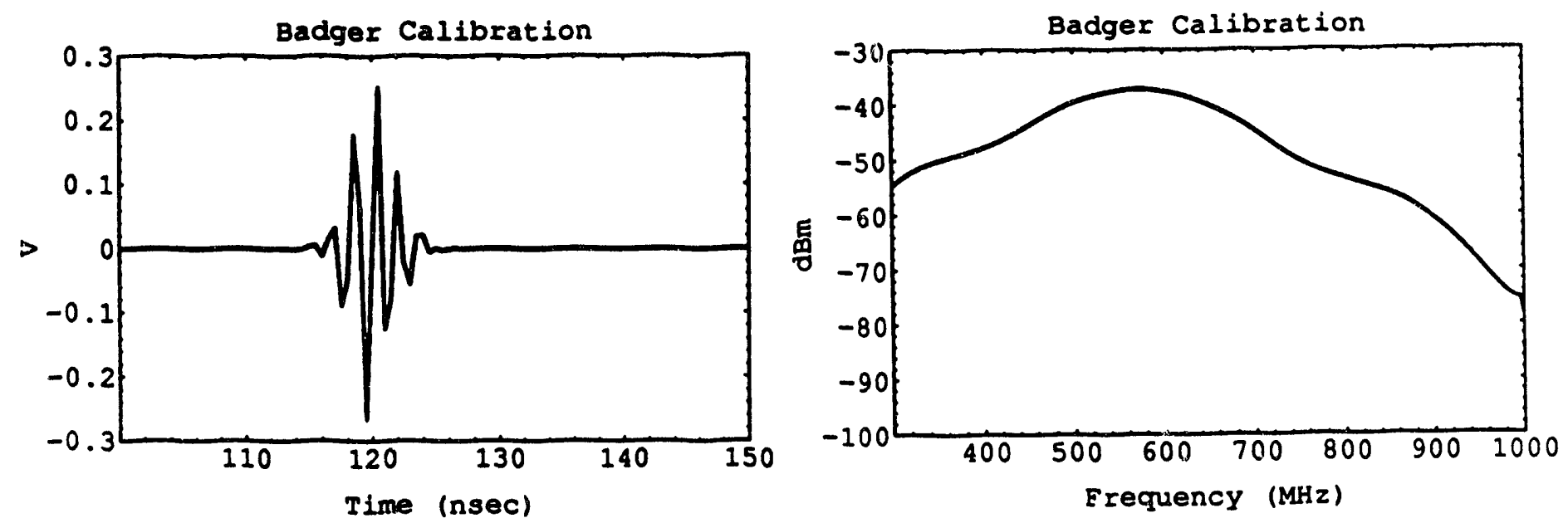

Figure 6.23. Windowed Voltage Waveform/Spectrum for Badger Calibration Target 


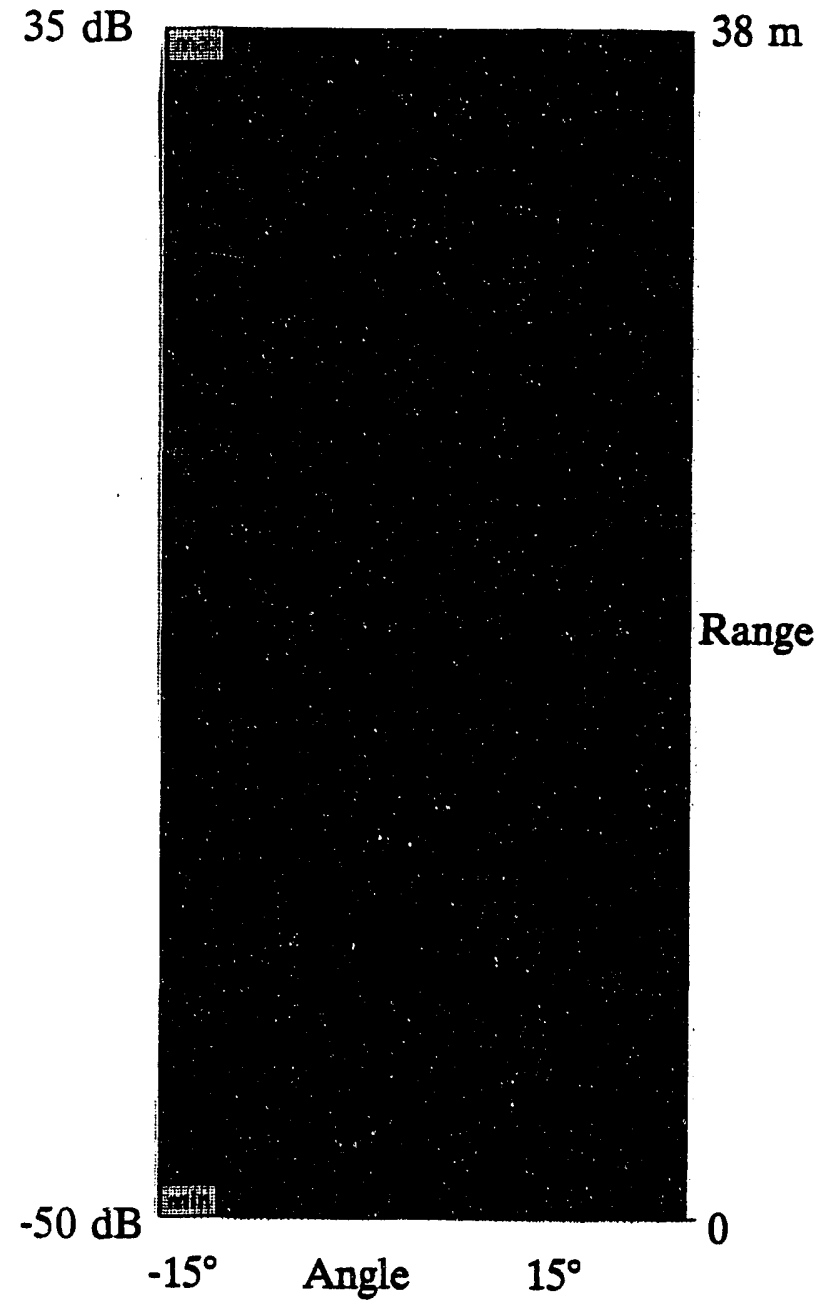

Figure 6.24. Pseudo-Color Calibrated SAR Image of Badger Calibration Target Area

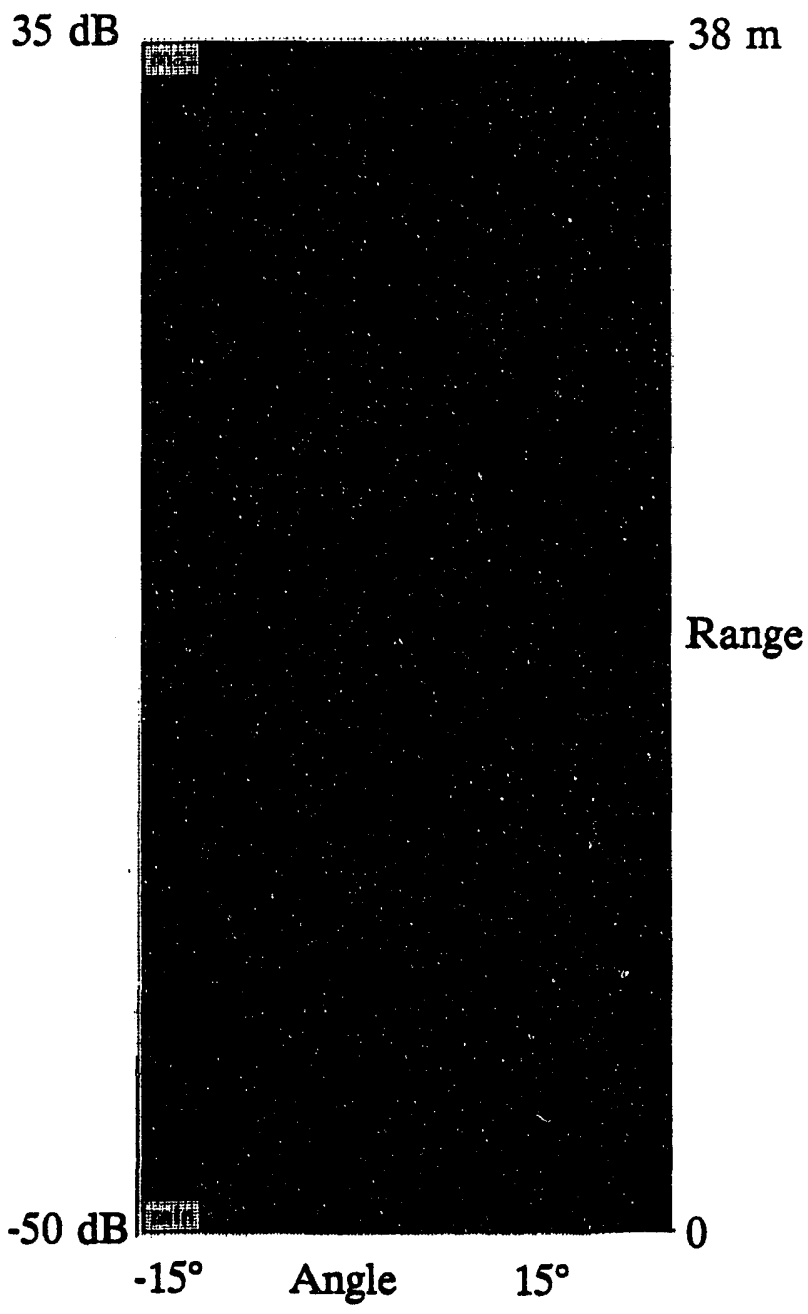

Figure 6.25. Pseudo-Color Calibrated SAR Image of Badger Clutter Region Showing Essentially Noise (RFI) 


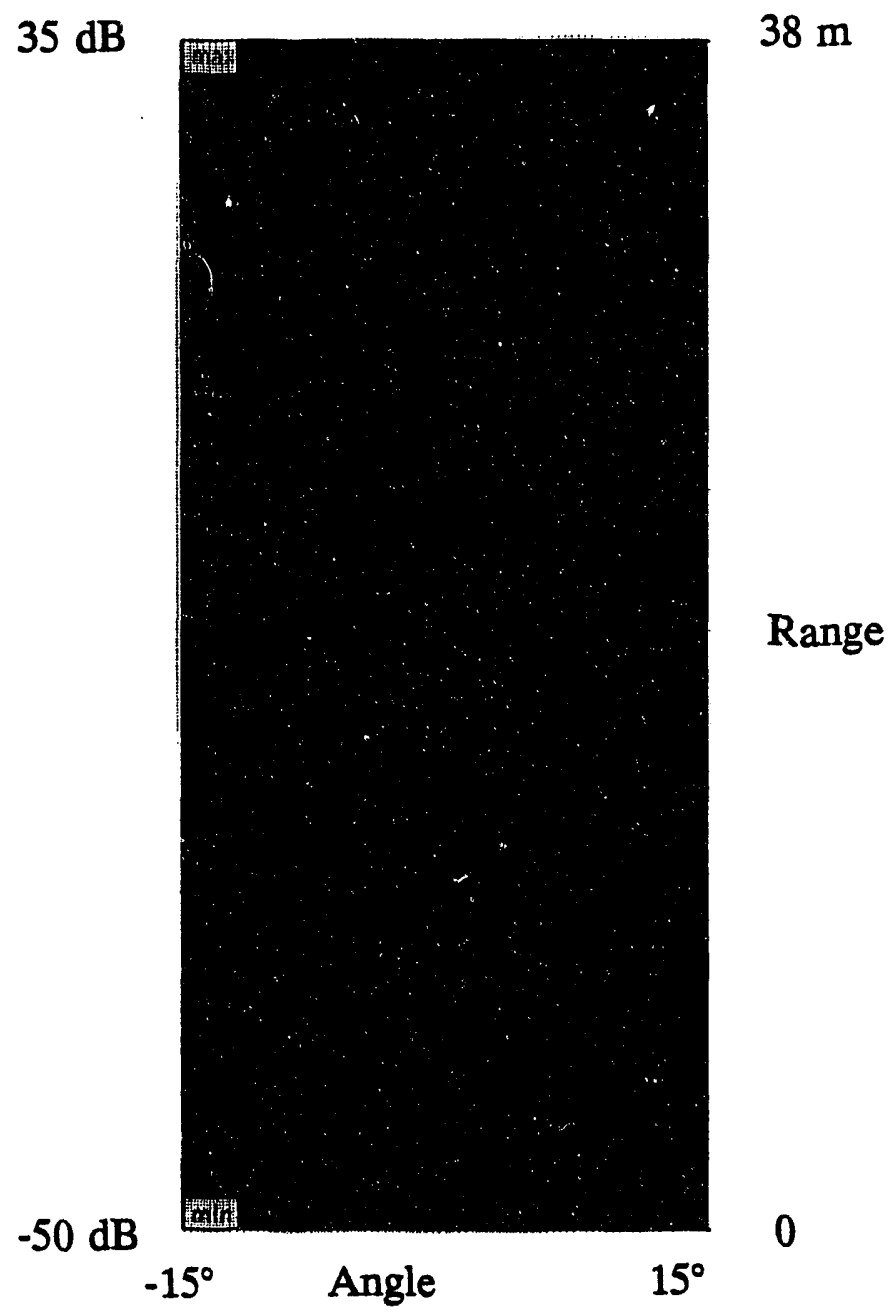

Figure 6.26. Pseudo-Color Calibrated SAR Image of Badger Clutter Region Showing Discrete Scatterers over a Noise (RFI) Dominated Background 

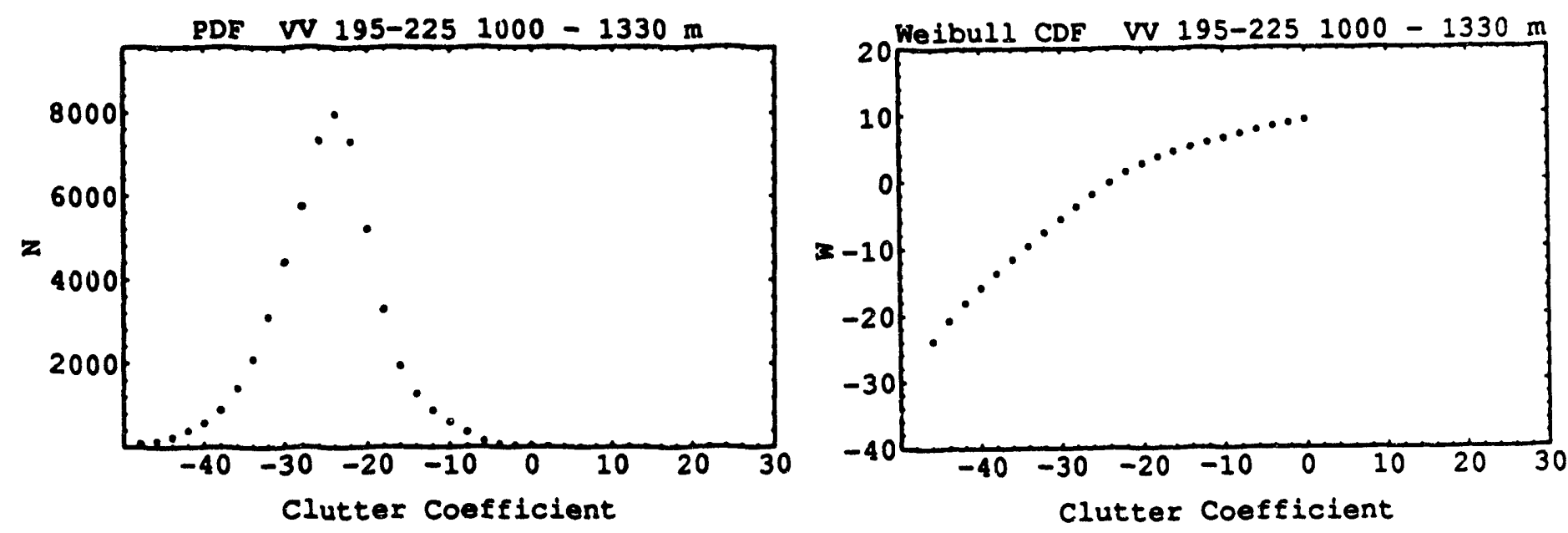

Figure 6.27. Distributions of the RFI Dominated Clutter Coefficient Measured at Badger Canyon
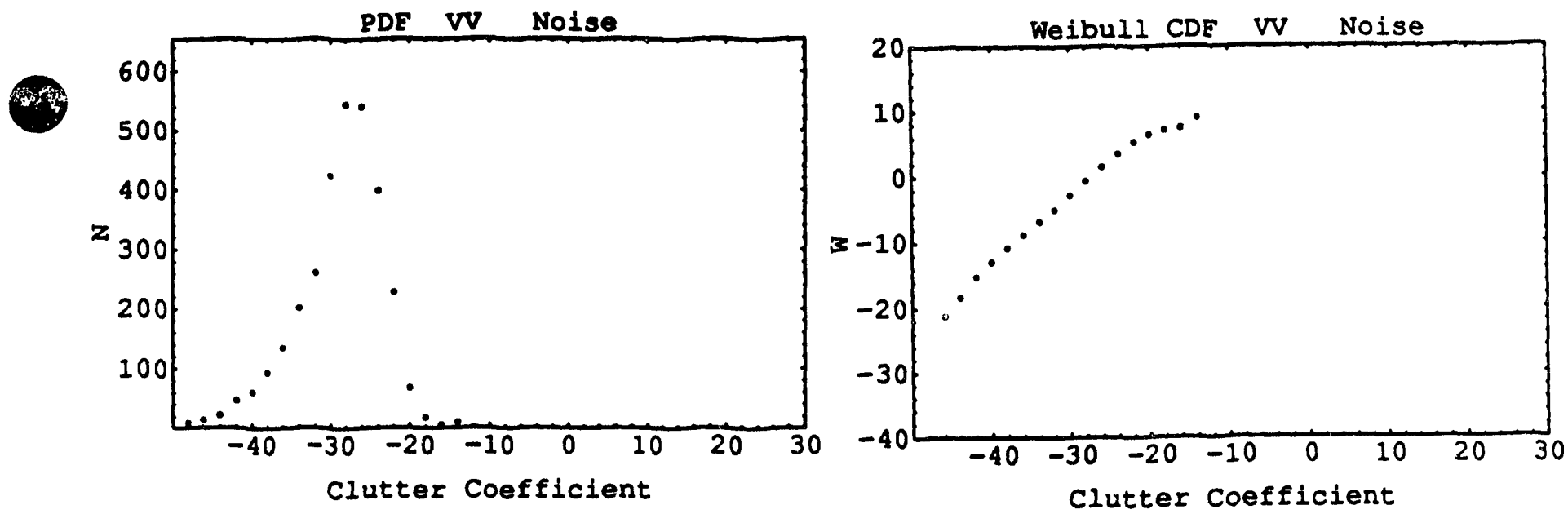

Figure 6.28. Distributions of the Noise Equivalent Clutter Coefincient Measured at Badger Canyon 


\subsection{Impulse Forest Measurements}

Forest clutter measurements were also taken using the impulse radar system at an additional site near Sequim, WA. This site is referred to as the Maynard Site and is described in more detail in Section 5.3. This site is located approximately $2.2 \mathrm{~km}$ southwest of Bear Mountain in the Olympic National Forest near Sequim, WA. Figure 7.1 is a panoramic collage of photographs looking outward from the scanner position. Figure 7.2 is a p stograph of the scanner and radar set-up at the Maynard Site. Figure 7.3 shows a topographic map of the area surrounding the site. Figure 7.4 is an aerial photograph of the site and surrounding terrain.

\subsection{Calibration and Verification}

To ensure that the radar system was operating as expected, a radar equation closure experiment was conducted at PNL prior to the 1992 measurements. A typical impulse waveform from the DSA 602A digitizer was captured to disk and its Fourier spectrum was computed as shown in 'i gure 7.5. A small (3' by 4' flat plate ) calibration target was then placed 3 meters above twe ground at a range of 35 meters from the scanner. The received waveform was then digitized and stored as shown in Figure 7.6. The transient waveform in this figure was then time gated to reduce multipath using a raised cosine window with full width of $7.2 \mathrm{nsec}$. The gated waveform and its spectrum are shown in Figure 7.7. Closure with the radar equation is shown in Table 7.1 at 400, 600, and 800 MHz. Note that closure is reasonable given that the multipath signal cannot be completely removeri by time gating. The area of the 3' by 4' flat plate target is $1.115 \mathrm{~m}^{2}$. The gain of the antennas is assumed to be $10(10 \mathrm{dBi})$. The range to the target is 35 meters. Note that the assumed gain of the antennas may be as low as $8 \mathrm{dBi}$ which would improve the closure error.

Table 7.1. Radar Equation Closures (3' by 4' Target at 35 Meters)

\begin{tabular}{||l|l|l|l||}
\hline & $400 \mathrm{MHz}$ & $600 \mathrm{MHz}$ & $800 \mathrm{MHz}$ \\
\hline$P_{r} / P_{t}(\mathrm{~dB})$ calc & $-62.8 \mathrm{~dB}$ & $-62.8 \mathrm{~dB}$ & $-62.8 \mathrm{~dB}$ \\
\hline$P_{r}(\mathrm{dBm})$ meas & -20 & -15 & -23 \\
\hline$P_{t}(\mathrm{dBm})$ & 41 & 39 & 37 \\
\hline
\end{tabular}




\begin{tabular}{|c|c|c|c|c|c|c|}
\hline & \multicolumn{2}{|c|}{$400 \mathrm{MHz}$} & \multicolumn{2}{|c|}{$600 \mathrm{MHz}$} & \multicolumn{2}{|c|}{$800 \mathrm{MHz}$} \\
\hline $\begin{array}{l}\text { Net Receiver } \\
\text { Gain }(\mathrm{dB})\end{array}$ & $\begin{array}{l}\text { Recvr } \\
\text { Cable } \\
\text { Attn } \\
\end{array}$ & $\begin{array}{l}53.3 \\
-5.6 \\
-40 \\
\end{array}$ & $\begin{array}{l}\text { Recv } \\
\text { Cable } \\
\text { Attn }\end{array}$ & $\begin{array}{l}54 \\
-6.9 \\
-40 \\
\end{array}$ & $\begin{array}{l}\text { Recvr } \\
\text { Cable } \\
\text { Attn }\end{array}$ & $\begin{array}{l}54.4 \\
-8.3 \\
-40 \\
\end{array}$ \\
\hline & Net & 7.7 & Net & 7.1 & Net & 6.1 \\
\hline$P_{r} / P_{t}(d B)$ meas & -68.7 & & -61.1 & & -66.1 & \\
\hline Closure Error (dB) & 5.9 & & 1.7 & & 3.3 & \\
\hline
\end{tabular}

At the Maynard site a simpler means of checking for closure with the radar equation was desired. Experience has shown that calculations using the peak transient amplitude yield reasonable results. For this calculation the center frequency $(650 \mathrm{MHz})$ is assumed in the radar equation. The first calibration measurement was conducted with the large target placed at a range of 940 meters with the small target placed approximately 30 meters to the right at a range of approximately 928 meters. The HVTP pulser generates a peak amplitude of approximately $2000 \mathrm{~V}$ at the output of 35 feet of coaxial cable used to connect the pulser to the transmit antenna. This corresponds to a peak transmitted power of approximately $80 \mathrm{~kW}$. The RCS of the 6' by 12' flat plate calibration target is $34.2 \mathrm{dBsm}\left(2654 \mathrm{~m}^{2}\right)$ at $650 \mathrm{MHz}$. The gain of the antennas is approximated at $10 \mathrm{~dB}$ (10). The wavelength is 0.461 meters at the center frequency. The expected power at the receive antenna output is

$$
P_{\varepsilon}=P_{t} \frac{G^{2} \lambda^{2} \sigma}{(4 \pi)^{3} R^{4}}=800 \frac{(10)^{2}(0.461)^{2}(2654)}{(4 \pi)^{3}(940)^{4}}=2.9 \times 10^{-6} \mathrm{~W}
$$

The gain of the receiver is $54 \mathrm{~dB}$ and cables losses are $8 \mathrm{~dB}$. Thus, the power at the input of the digitizer is $2.9 \mu \mathrm{W}$ times 39800 which equals $0.115 \mathrm{~W}$. This represents a peak voltage of 2.4 volts. The peak voltage observed from the 6' by 12 ' target at 940 meters is approximately 1.25 volts. This iepresents a difference of approximately $5.6 \mathrm{~dB}$ between the expected voltage and the measured voltage. This level of difference is expected since the pulse spectrum is much more broad than the radar systems $300-850$ $\mathrm{MHz}$ bandwidth. If the pulse were filtered its peak amplitude would decrease accordingly. Additionally, the gain of the antennas is not precisely known. The assumed gain of $10 \mathrm{dBi}$ might in fact be as low as $8 \mathrm{dBi}$, which would cause the agreement to improve by $4 \mathrm{~dB}$. This radar equation closure test is not highly accurate, however, it is very useful for immediate determination of proper operation of the radar system. Operational errors such as peaking on a sidelobe of the calibration target or a failure of a receiver component would be readily determined using this type of analysis. 
At the Maynard Site, two calibration target positions were chosen. Both of these positions were at approximately the same elevation as the radar system and had a valley in between. The valley floor was roughly centered between the radar and the target positions. The height of the radar and target positions above the floor was approximately 100 meters. This height difference roughly corresponds to a one-way time delay on the order of $67 \mathrm{nsec}$ at a range of $1 \mathrm{~km}$. Furthermore, the valley floor was largely covered with foliage and in no way represented an ideal ground plane for multipath signals. Given these considerations, multipath was not expected to be a problem at either calibration position.

The validity of the calibration procedure is highly dependent on the propagation characteristics between the radar and the target. A free space model is assumed in the calibration. At real sites, this will never be strictly correct. Multipath is the dominant issue concerning calibration accuracy. Due to the very short transmitted pulse and high range resolution of the system, most multipath signals can be time gated from the calibration waveform prior to calibration.

An inage of the raw A-scan data gathered from the calibration target is shown in Figure 7.8. Each vertical line in the image represents the average of 100 waveforms taken at each scanner position. The horizontal aperture is 19 meters, and the vertical scale represents 512 waveform samples for $256 \mathrm{nsec}$ or 38 meters of range.

The calibration process described in Section 4.5 is shown graphically in Figures 7.9 to 7.11. The focused waveform and is spectrum at the angle of the calibration target peak are shown in Figure 7.9. This waveform is time gated and calibrated to RCS and is shown in Figure 7.10. A full calibrated range-angle image of the target and its surrounding clutter is shown in Figure 7.11.

Thorough measurements were taken to ensure that the free-space calibration model was accurate at both calibration positions. Two calibration targets were deployed at each position. A 6' by 12' flat plate target was used as the main target. A 3' by 4' target was deployed simultaneously with the larger target. The small target was positioned approximately 10-15 meters closer to the radar and off to the right approximately 20-40 meters. A photograph of the target placement along the $28^{\circ}$ line of sight at a range of approximately 1000 meters is shown in Figure 7.12. This placement ensured that the small target response could be isolated from the large target response and yet would be present in the same calibration image. The large target has an expected RCS of 34.2 $\mathrm{dBsm}$. The small target has an expected RCS of $18.6 \mathrm{dBsm}$. Examination of four different calibration scans of the two targets at both positions $\left(28^{\circ}\right.$ and $\left.70^{\circ}\right)$, and conversion from clutter coefficient to RCS yields a table of RCS measurements of known targets. This data is shown in Table 7.2 and is in agreement with the expected RCS values to within approximately $2 \mathrm{~dB}$. The 6' by 12 ' target response in the "cal_e" file was used to calibrate the other measurements and is therefore not an independent measurement. The consistency of RCS measurements using two different targets at two different 
positions demonstrates that multipath effects are not present significantly in the calibration data.

Table 7.2. RCS Measurements of Known Targets

\begin{tabular}{|c|c|c|c|c|c|c|c|c|c|}
\hline File & Pol & Angle & Range, & Target & $\begin{array}{l}\sigma^{\circ} \\
\mathrm{dB}\end{array}$ & $\begin{array}{l}\text { Area, } \\
\mathrm{m}^{2}\end{array}$ & $\begin{array}{l}\sigma_{\text {meas }} \\
\text { dBsm }\end{array}$ & $\begin{array}{l}\sigma_{\text {calc, }} \\
\mathrm{dBsm}\end{array}$ & $\begin{array}{r}\text { Diff; } \\
\mathrm{dB}\end{array}$ \\
\hline cal_d & VV & $70^{\circ}$ & 940 & $6 \times 12$ & 24.8 & 6.64 & 33.0 & 34.2 & 1.2 \\
\hline cal_d & VV & $70^{\circ}$ & 928 & $3 \times 4$ & 9.1 & 6.56 & 17.3 & 18.6 & 1.3 \\
\hline cal_e & $\mathrm{HH}$ & $70^{\circ}$ & 940 & $6 \times 12$ & 24.6 & 6.64 & 32.8 & 34.2 & 1.4 \\
\hline cal_e & $\mathrm{HH}$ & $70^{\circ}$ & 928 & $3 \times 4$ & 9.2 & 6.56 & 17.4 & 18.6 & 1.2 \\
\hline $\mathrm{cal2} b$ & VV & $28^{\circ}$ & 1277 & $6 \times 12$ & 23.9 & 9.03 & 33.5 & 34.2 & 0.7 \\
\hline $\mathrm{cal2} \mathrm{b}$ & VV & $28^{\circ}$ & 1266 & $3 \times 4$ & 7.7 & 8.95 & 17.2 & 18.6 & 1.4 \\
\hline cal2_c & $\mathrm{HH}$ & $28^{\circ}$ & 1277 & $6 \times 12$ & 23.7 & 9.03 & 33.3 & 34.2 & 0.9 \\
\hline cal2_c & $\mathbf{H H}$ & $28^{\circ}$ & 1266 & $3 \times 4$ & 7.9 & 8.95 & 17.4 & 18.6 & 1.2 \\
\hline
\end{tabular}

\subsection{Clutter Measurements}

Improvements to the radar system since the 1991 measurements have resulted in greatly increased data collection rates. Longer record lengths (8192 samples) have reduced the number of scans necessary to cover the illuminated area. Higher pulser power levels increased the effective range of the system. Internal averaging in the DSA602 also increased the data collection rate by removing the data transfer bottleneck.

Measurable terrain at the Maynard Site consists of an angular swath of $180^{\circ}$ and a range swath up to 4 kilometers. This area was subdivided into six $30^{\circ}$ sectors and five 600 meter range sections. Each range swath consists of 8192 sample points for 4096 nsec or 604.8 meters. The nearest range is approximately $0.3 \mathrm{~km}$ and the furthest range is approximately $3.3 \mathrm{~km}$.

Vertical and horizontal polarization data were taken at each sector and range for a total of 60 clutter data scans. Additional calibration and noise measurement scans were also taken. Table 7.3 shows the filenames of each set of data taken and the sector and starting ranges covered. Each scan covers an angular swath of $30^{\circ}$ and a range swath of $604.8 \mathrm{~m}$. 
Table 7.3. Sectors and Ranges Covered $\left(30^{\circ}\right.$ by $604.8 \mathrm{~m}$ per scan)

\begin{tabular}{|c|c|c|c|c|c|c|}
\hline Fichane & singlo $100 \%$ & sector 2 & Sector 3 & $\begin{array}{l}\text { Sector } 4 \\
\text { Angle. } 10^{\circ}\end{array}$ & Sector 5 & $\begin{array}{l}\text { Sector } 6 \\
\text { Angle: } 310^{\circ}\end{array}$ \\
\hline $\begin{array}{l}\text { Range } 1 \\
300 \mathrm{~m}\end{array}$ & s1_r1 & $s 2$ r1 & s3_r1 & s4_r1 & s5_r1 & $\mathrm{s6}$ \\
\hline $\begin{array}{l}\text { Range } 2 \\
904.8 \mathrm{ml}\end{array}$ & $s 1$ r2 & $s 2+2$ & 83 r 2 & $s 4$ r2 & s5_r2 & s6_r2 \\
\hline $\begin{array}{l}\text { Range } 3 \\
1509.6 \mathrm{~m}\end{array}$ & s1_r3 & s2_r3 & s3_r3 & s4_r3 & s5_r3 & s6_r3 \\
\hline $\begin{array}{l}\text { Range } 4 \\
2114.4 \mathrm{~m}\end{array}$ & s1_r4 & s2_r4 & s3_r4 & s4_r4 & s5_r4 & $\mathrm{s6 \_} \mathrm{r} 4$ \\
\hline $\begin{array}{l}\text { Range } 5 \\
2719.2 \mathrm{~m}\end{array}$ & s1_r5 & s2_r5 & s3_r5 & s4_r5 & s5_r5 & s6_r5 \\
\hline
\end{tabular}

\subsection{Clutter Imaging Samples}

Clutter range-angle images as shown in Figure 7.12 are not easily viewed for the full 8K record length clutter data files since the number of angles is relatively small (200) and the number of samples is high (8192). For examination on the computer screen, scrolling is used to allow examination of the data set at full resolution. For correlation of the data to the landscape or for a simple overview image of the clutter data, the range resolution must be effectively reduced. Furthermore a two-dimensional image in meters by meters ( $x-y$ image) is more useful that the range-angle images for this purpose. A data reduction/interpolation computer program was developed that reduces that data by computing the mean over typically 64 sample points, and interpolates the range-angle data onto a regular $x$-y image grid. Typical images including the calibration target from sector 2 range 2 are shown in Figures 7.13 and 7.14. Additional clutter images from sector 3 range 2 are shown in Figures 7.15 and 7.16.

\subsection{Noise (RFI) Measurements}

Noise measurements were taken at both calibration target positions by turning off the transmitter and gathering full scans. This data is then processed as though it were clutter data at a range of $1 \mathrm{~km}$. The result of this processing is referred to as the "noise equivalent clutter coefficient." Typical statistical results are shown in Tables 7.4 and 7.5. Distributions are shown in Figures 7.17 and 7.18. 
Table 7.4. Noise Equivalent Clutter Coefficient Statistics at $1 \mathrm{~km}$ for 300-800 MHz Processing Bandwidth and $70^{\circ}$ Orientation

\begin{tabular}{||c|c|c|}
\hline Polarization & $\mathrm{VV}$ & $\mathrm{HH}$ \\
\hline Frequency Band & $300-800 \mathrm{MHz}$ & $300-800 \mathrm{MHz}$ \\
\hline Aperture Window & Rectangular & Rectangular \\
\hline Range & $1000 \mathrm{~m}$ & $1000 \mathrm{~m}$ \\
\hline Number of Waveforms & 25,600 & 25,600 \\
\hline Number of Cells & 2208 & 2208 \\
\hline Mean $\sigma^{\circ}$ & $-50.8 \mathrm{~dB}$ & $-48.7 \mathrm{~dB}$ \\
\hline Median $\sigma^{\circ}$ & $-52.3 \mathrm{~dB}$ & $-50.3 \mathrm{~dB}$ \\
\hline Max $\sigma^{\circ}$ & $-41.4 \mathrm{~dB}$ & $-40.0 \mathrm{~dB}$ \\
\hline
\end{tabular}

Table 7.5. Noise Equivalent Clutter Coefficient Statistics at $1 \mathrm{~km}$ for 300-800 MHz Processing Bandwidth and $28^{\circ}$ Orientation

\begin{tabular}{|l|c|c|}
\hline Polarization & $\mathrm{VV}$ & HH \\
\hline Frequency Band & $300-800 \mathrm{MHz}$ & $300-800 \mathrm{MHz}$ \\
\hline Aperture Window & Rectangular & Rectangular \\
\hline Range & $1000 \mathrm{~m}$ & $1000 \mathrm{~m}$ \\
\hline Number of Waveforms & 25,600 & 25,600 \\
\hline Number of Cells & 2208 & 2208 \\
\hline Mean $\sigma^{\circ}$ & $-47.7 \mathrm{~dB}$ & $-42.5 \mathrm{~dB}$ \\
\hline Median $\sigma^{\circ}$ & $-49.2 \mathrm{~dB}$ & $-44.2 \mathrm{~dB}$ \\
\hline Max $\sigma^{\circ}$ & $-39.2 \mathrm{~dB}$ & $-33.5 \mathrm{~dB}$ \\
\hline
\end{tabular}


Composite images clutter data were formed using all 60 data scans (6 angular swaths * 5 range swaths 2 polarizations). These images appeared somewhat different than similar images formed soon after returning from Sequim, especially the vertically polarized data. In particular sectors 4 and 5 appeared to have a significant noise floor increase. Earlier the data had been processed using a $300-850 \mathrm{MHz}$ bandwidth, so it was suspected that RFI from cellular phones in the $800-900 \mathrm{MHz}$ frequency range was responsible for the increased noise floor. Further evidence of this is that sectors 4 and 5 are pointing in the general direction of Port Angeles, WA and Victoria, B.C. Noise data taken from two directions and two polarizations further confirms this result. Table 7.6 gives the noise equivalent clutter means values for different processing bandwidths.

Table 7.6. Noise Equivalent Clutter Coefincient at $1 \mathrm{~km}$ for Different Processing Bandwidths

\begin{tabular}{|c|c|c|c||}
\hline Frequency Band & $\begin{array}{c}\text { Mean Noise } \sigma^{\circ} \\
\text { V pol }(\mathrm{dB})\end{array}$ & $\begin{array}{c}\text { Mean Noise } \sigma^{\circ} \\
\text { H pol (dB) }\end{array}$ & Orientation \\
\hline $300-800 \mathrm{MHz}$ & -50.8 & -48.7 & $70^{\circ}$ \\
\hline $300-900 \mathrm{MHz}$ & -34.8 & -42.2 & $70^{\circ}$ \\
\hline $300-800 \mathrm{MHz}$ & -47.7 & -42.5 & $28^{\circ}$ \\
\hline $300-900 \mathrm{MHz}$ & -31.4 & -38.3 & $28^{\circ}$ \\
\hline
\end{tabular}

Note that the vertical polarization noise floor is increased by about $15 \mathrm{~dB}$ by including the $800-900 \mathrm{MHz}$ frequency band. Given this higher noise floor, the 1992 measurements have been processed using a $300-800 \mathrm{MHz}$ bandwidth, which results in a significantly higher clutter to noise ratio. The data has also been processed with $300-900 \mathrm{MHz}$ and 300-1000 MHz frequency bands for compatibility with the earlier 1991 measurements.

\subsection{Forest Clutter Analysis}

Due to improvements in the data collection rate of the impulse radar system for the 1992 measurements, a significantly larger amount of forest clutter data was obtained. Five range gates were used to cover 300 meters to 3300 meters. Six $30^{\circ}$ sectors were used to cover a $180^{\circ}$ angular swath. Both horizontal and vertical polarizations were used over the entire region.

A composite imaging program was used to combine all of the data from each polarization into composite images. Images were formed for the entire data sets for each 
polarization and are shown in Figures 7.19 and 7.20. The range resolution in these images was compressed using the mean of the clutter values over 64 sample points. The angular resolution of the clutter data is relatively coarse and did not need to be reduced. The gray scale in the images is scaled to be black at the minimum mean clutter level and white at the maximum mean clutter levei. In between the minimum and maximum, the clutter coefficient levels (in $\mathrm{dB}$ ) are mapped linearly to gray levels.

These composite images are of much higher resolution than those presented in Figure 6.17 and 6.18 , although the technique used to generate the images is very similar. Examination of the composite clutter images shows strong correlation with the topography in the aerial photos and topographic maps. In particular, roads, clear-cut/tree lines, mountain sides, and ridges are discernible in the images.

Examination of the composite clutter images also shows which of the data scans are well illuminated. In forming the statistical data set certain sectors/ranges should probably not be used. The sectors are numbered from 1 to 6 counterclockwise from the bottom right side of the image. Ranges are numbered from 1 to 5 from near to far. The data set used to compute the overall statistics is: Sector 1 ranges 1 to 5 , Sector 2 ranges 1 to 4 , Sector 3 ranges 1 to 3, Sector 4 ranges 1 to 4 , and Sector 5 ranges 1 to 5 . Sector 6 was not used since it was largely shadowed by a low ridge near the radar site.

The overall statistics of the $300-800 \mathrm{MHz}$ vertically and horizontally polarized clutter data were computed and are given in Table 7.7 and the distributions are shown in Figures 7.21 and 7.22. In Table 7.7 the statistics were computed in accordance with the formulas given in Section 4.6. The Weibull spread was calculated by numerically fitting a line to the Weibull distribution plots over the clutter values from $-20 \mathrm{~dB}$ to $+14 \mathrm{~dB}$.

Table 7.7. Summary of 300-800 MHz VV and HH Polarization Clutter Data Taken in 6 Lines of Sight: $100^{\circ}, 70^{\circ}, 40^{\circ}, 10^{\circ}, 340^{\circ}$, and $310^{\circ}$

\begin{tabular}{|l|l|l||}
\hline Polarization & $\mathrm{VV}$ & $\mathrm{HH}$ \\
\hline Frequency Band & $300-800 \mathrm{MHz}$ & $300-800 \mathrm{MHz}$ \\
\hline Aperture Window & Rectangular & Rectangular \\
\hline Angle Coverage & $115^{\circ}$ to $0^{\circ}$ to $295^{\circ}$ & $115^{\circ}$ to $0^{\circ}$ to $295^{\circ}$ \\
\hline Bandwidth (constant) & $1.35^{\circ}$ & $1.35^{\circ}$ \\
\hline Range Coverage & $300 \mathrm{~m}-3300 \mathrm{~m}$ & $300 \mathrm{~m}-3300 \mathrm{~m}$ \\
\hline Range Resolution & $0.3 \mathrm{~m}$ & $0.3 \mathrm{~m}$ \\
\hline
\end{tabular}




\begin{tabular}{||l|l|l|}
\hline Polarization & $\mathrm{VV}$ & $\mathrm{HH}$ \\
\hline Number of Cells & 973,728 & 973,728 \\
\hline Mean & $-6.4 \mathrm{~dB}$ & $-9.3 \mathrm{~dB}$ \\
\hline Median & $-18.4 \mathrm{~dB}$ & $-19.1 \mathrm{~dB}$ \\
\hline Mean/Median Ratio & $12.0 \mathrm{~dB}$ & $9.8 \mathrm{~dB}$ \\
\hline Std Dev/Mean & $6.1 \mathrm{~dB}$ & $6.5 \mathrm{~dB}$ \\
\hline Skewness & $13.4 \mathrm{~dB}$ & $18.6 \mathrm{~dB}$ \\
\hline Kurtosis & $33.7 \mathrm{~dB}$ & $43.5 \mathrm{~dB}$ \\
\hline Max & $22.9 \mathrm{~dB}$ & $23.0 \mathrm{~dB}$ \\
\hline Weibull Spread & 2.97 & 2.83 \\
\hline
\end{tabular}

The overall statistics of the $300-1000 \mathrm{MHz}$ vertically and horizontally polarized clutter data were computed and are given in Table 7.8, and the distributions are shown in Figure 7.23 and 7.24 .

Table 7.8. Summary of 300-1000 MHz VV and HH Polarization Clutter Data Taken in 6 Lines of Sight: $100^{\circ}, 70^{\circ}, 40^{\circ}, 10^{\circ}, 340^{\circ}$, and $310^{\circ}$

\begin{tabular}{||l|l|l||}
\hline Polarization & $\mathrm{VV}$ & $\mathrm{HH}$ \\
\hline Frequency Band & $300-1000 \mathrm{MHz}$ & $300-1000 \mathrm{MHz}$ \\
\hline Aperture Window & Rectangular & Rectangular \\
\hline Angle Coverage & $115^{\circ}$ to $0^{\circ}$ to $295^{\circ}$ & $115^{\circ}$ to $0^{\circ}$ to $295^{\circ}$ \\
\hline Bandwidth (constant) & $1.35^{\circ}$ & $1.35^{\circ}$ \\
\hline Range Coverage & $300 \mathrm{~m}-3300 \mathrm{~m}$ & $300 \mathrm{~m}-3300 \mathrm{~m}$ \\
\hline Range Resolution & $0.214 \mathrm{~m}$ & $0.214 \mathrm{~m}$ \\
\hline Number of Cells & $1,298,304$ & $1,298,304$ \\
\hline Mean & $-6.5 \mathrm{~dB}$ & $-8.9 \mathrm{~dB}$ \\
\hline Median & $-14.2 \mathrm{~dB}$ & $-15.5 \mathrm{~dB}$ \\
\hline Mean/Median Ratio & $7.7 \mathrm{~dB}$ & $6.6 \mathrm{~dB}$ \\
\hline
\end{tabular}




\begin{tabular}{|l|l|l||}
\hline Polarization & VV & HH \\
\hline Std Dev/Mean & $5.7 \mathrm{~dB}$ & $6.2 \mathrm{~dB}$ \\
\hline Skewness & $20.8 \mathrm{~dB}$ & $23.2 \mathrm{~dB}$ \\
\hline Kurtosis & $47.7 \mathrm{~dB}$ & $50.9 \mathrm{~dB}$ \\
\hline Max & $26.4 \mathrm{~dB}$ & $25.3 \mathrm{~dB}$ \\
\hline Weibull Spread & 2.39 & 2.40 \\
\hline
\end{tabular}




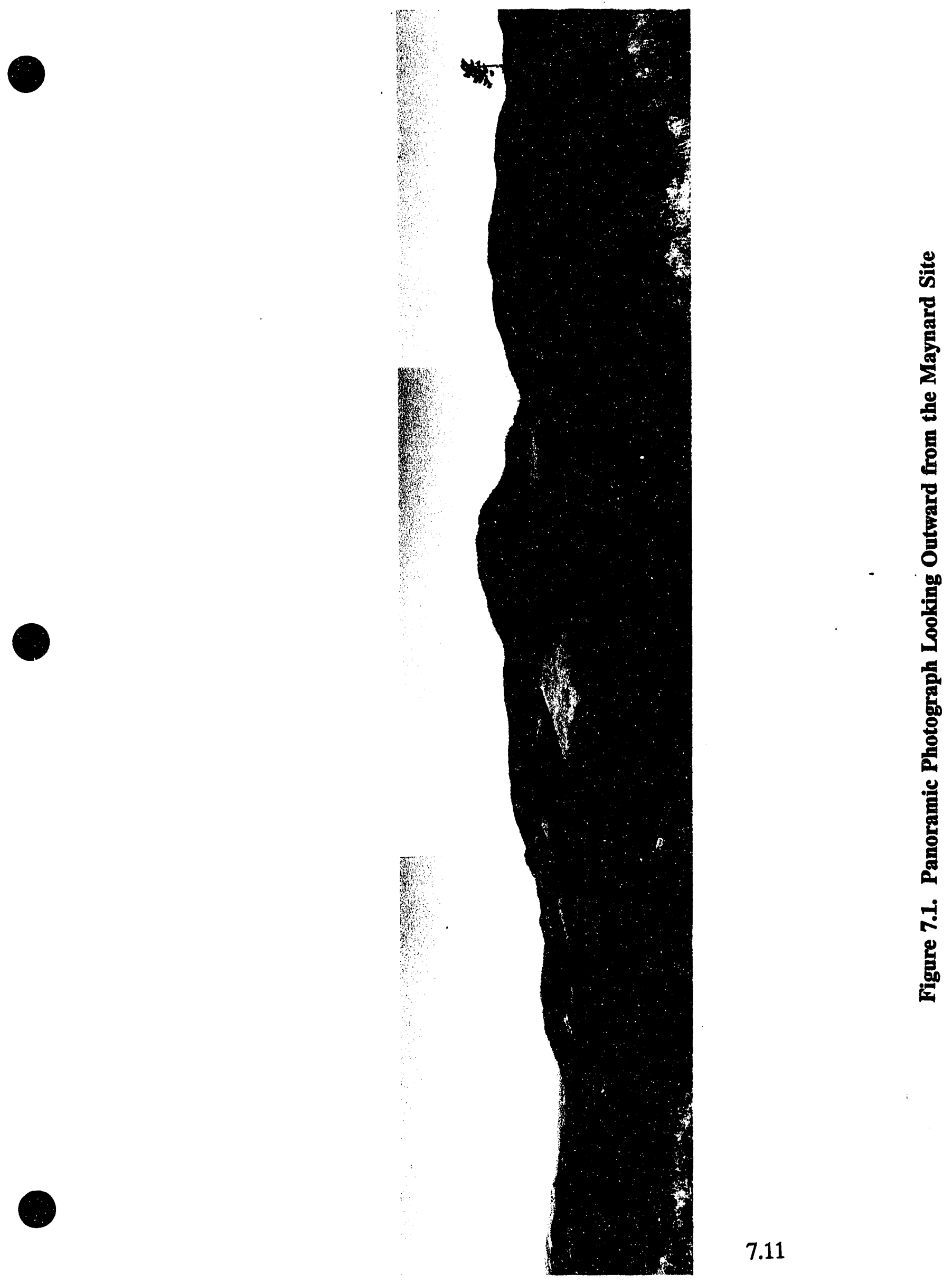




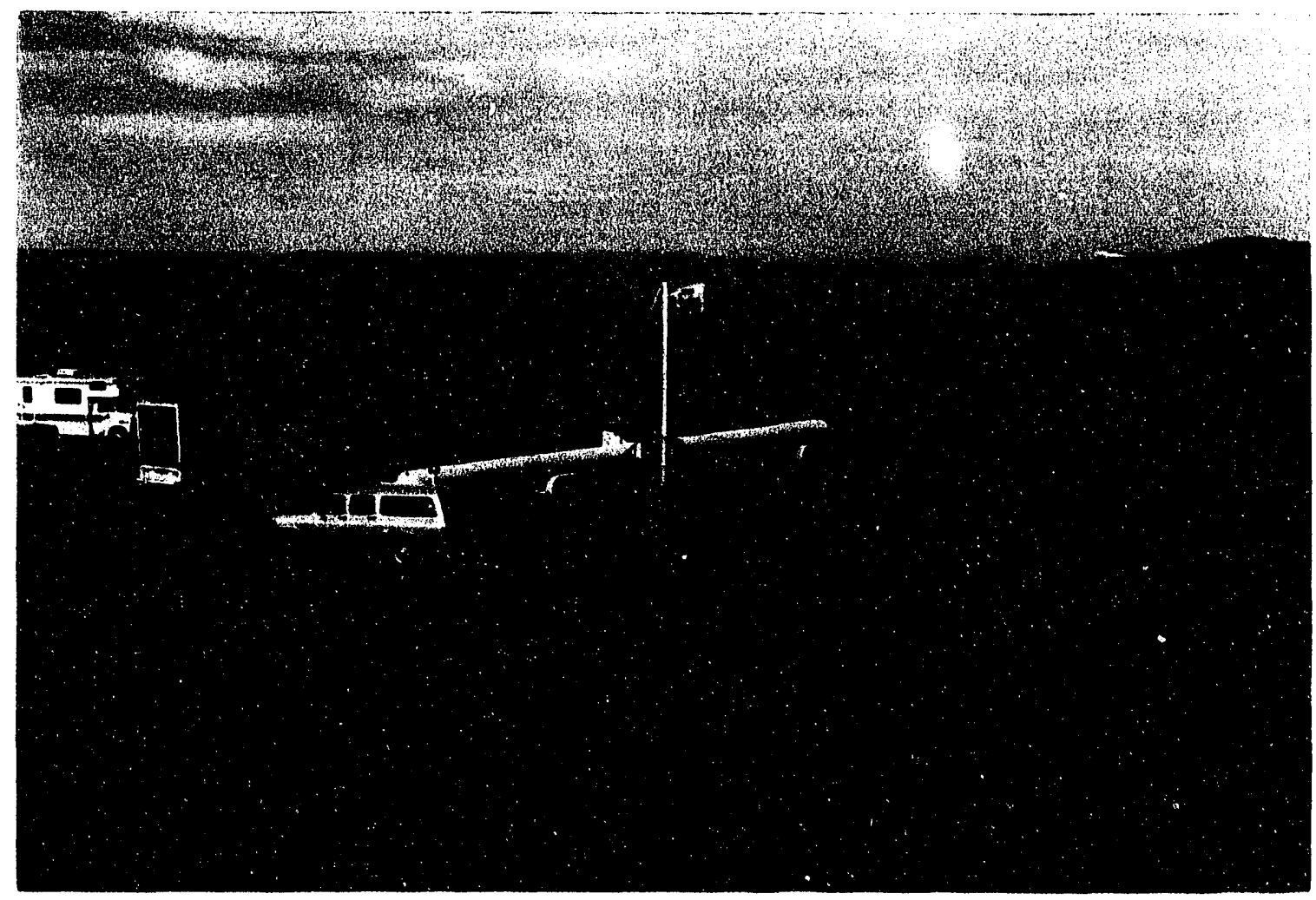

Figure 7.2. Photograph of the Scanner and Radar System at the Maynard Site 


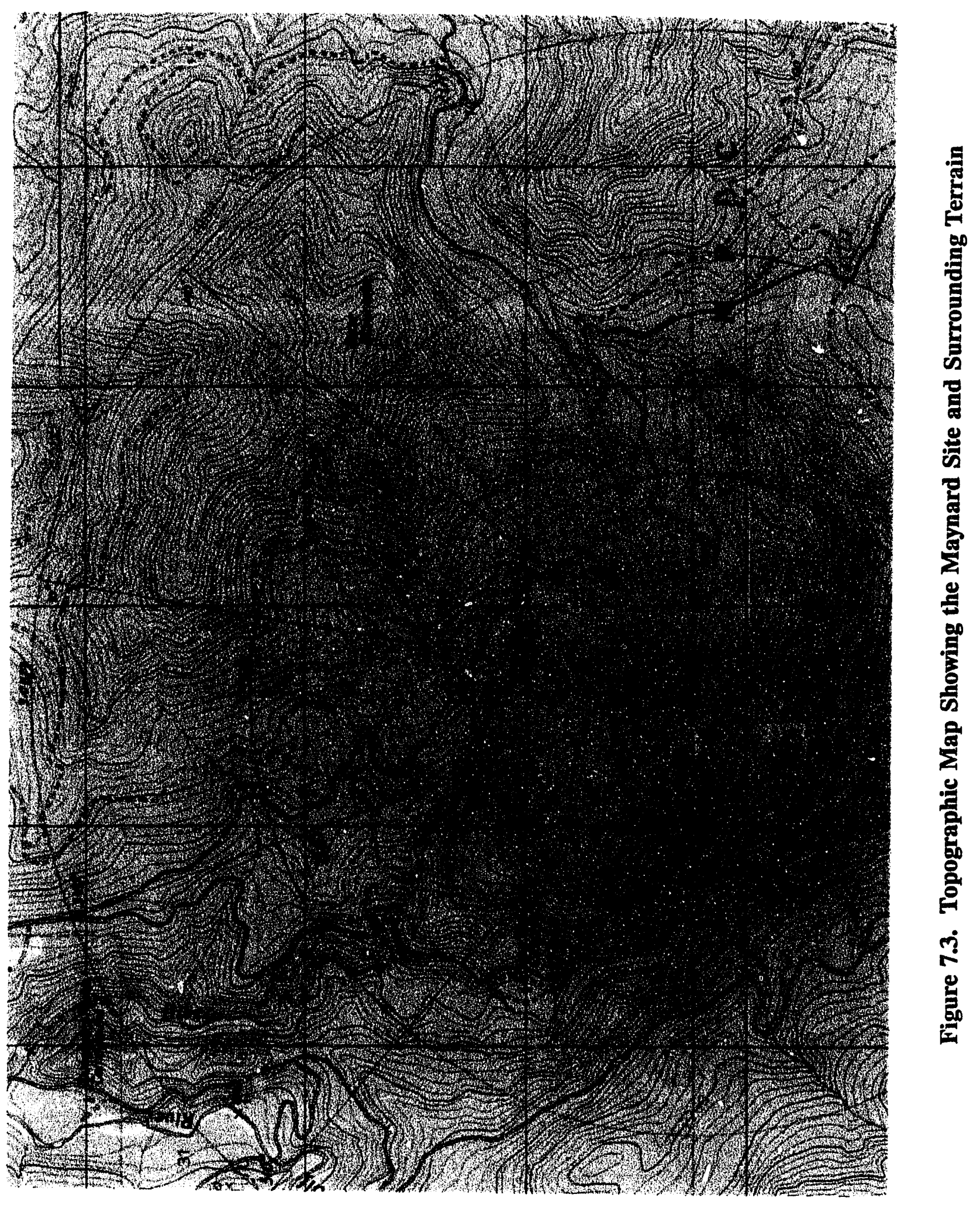




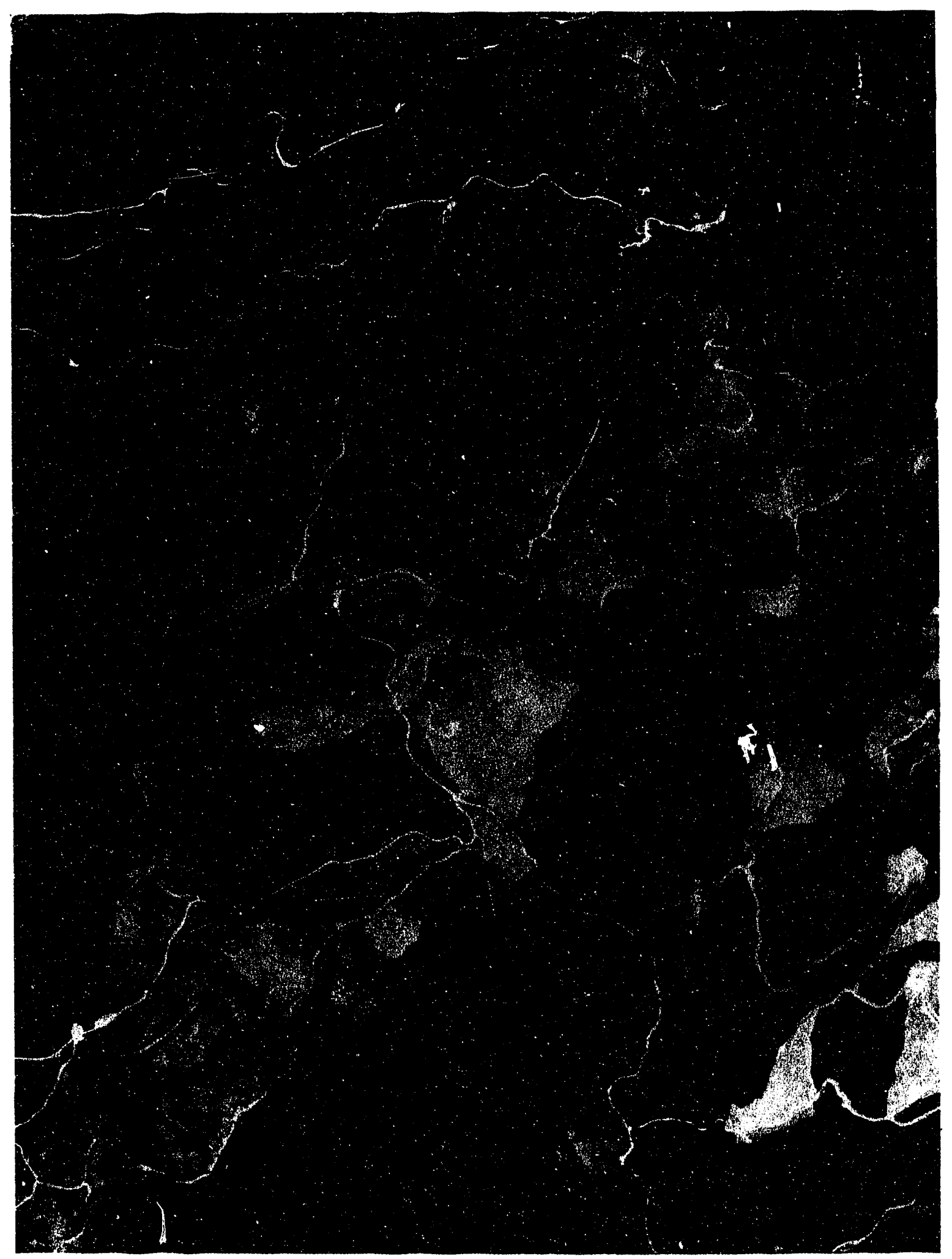

Figure 7.4. Aerial Photograph of the Maynard Site and Surrounding Terrain 

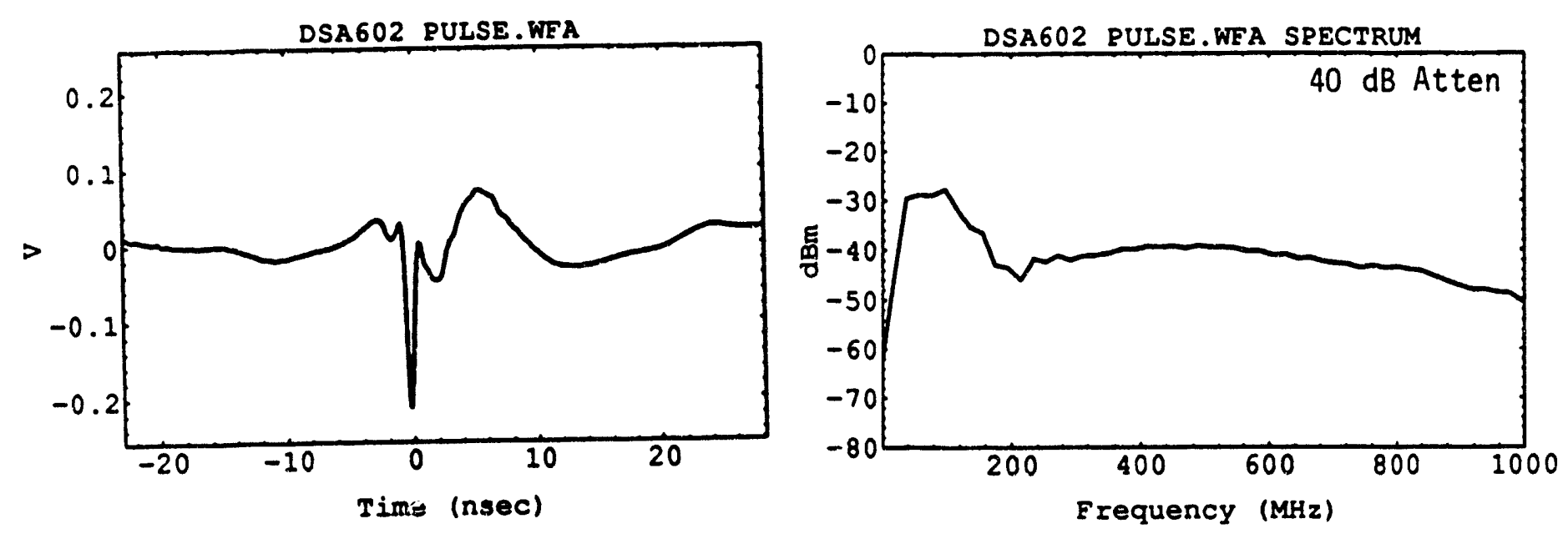

Figure 7.5. Pulser Output Waveform and Spectrum Attenuated by $\mathbf{4 0} \mathrm{dB}$

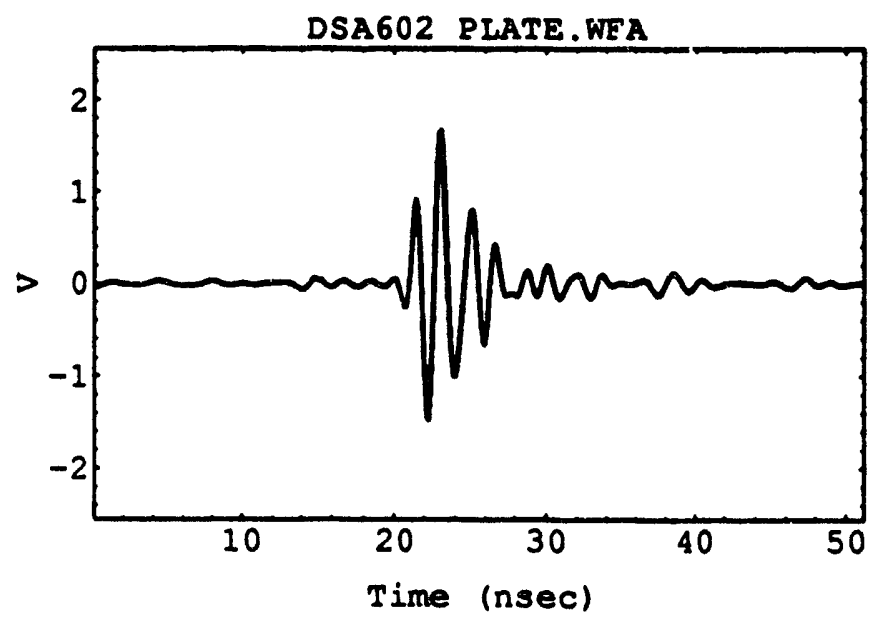

Figure 7.6. Waveform Received from 3' by 4' Target at 35 Meters 

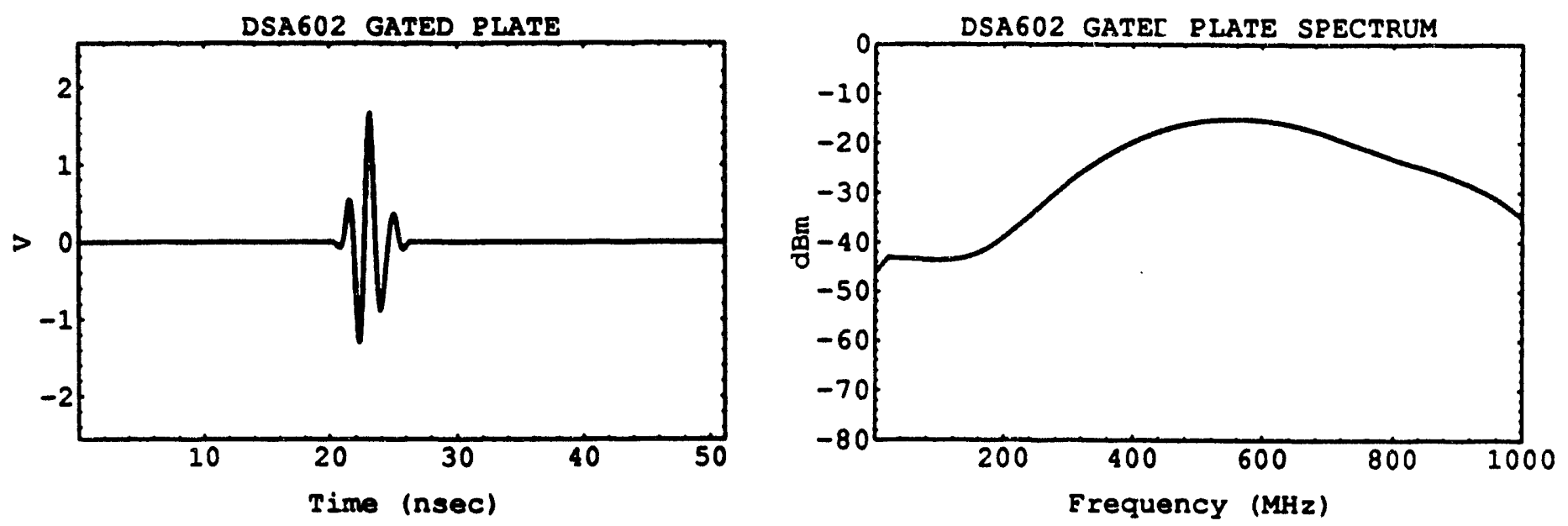

Figure 7.7. Gated Waveform and Spectrum Received from 3' by 4' Target at 35 Meters 


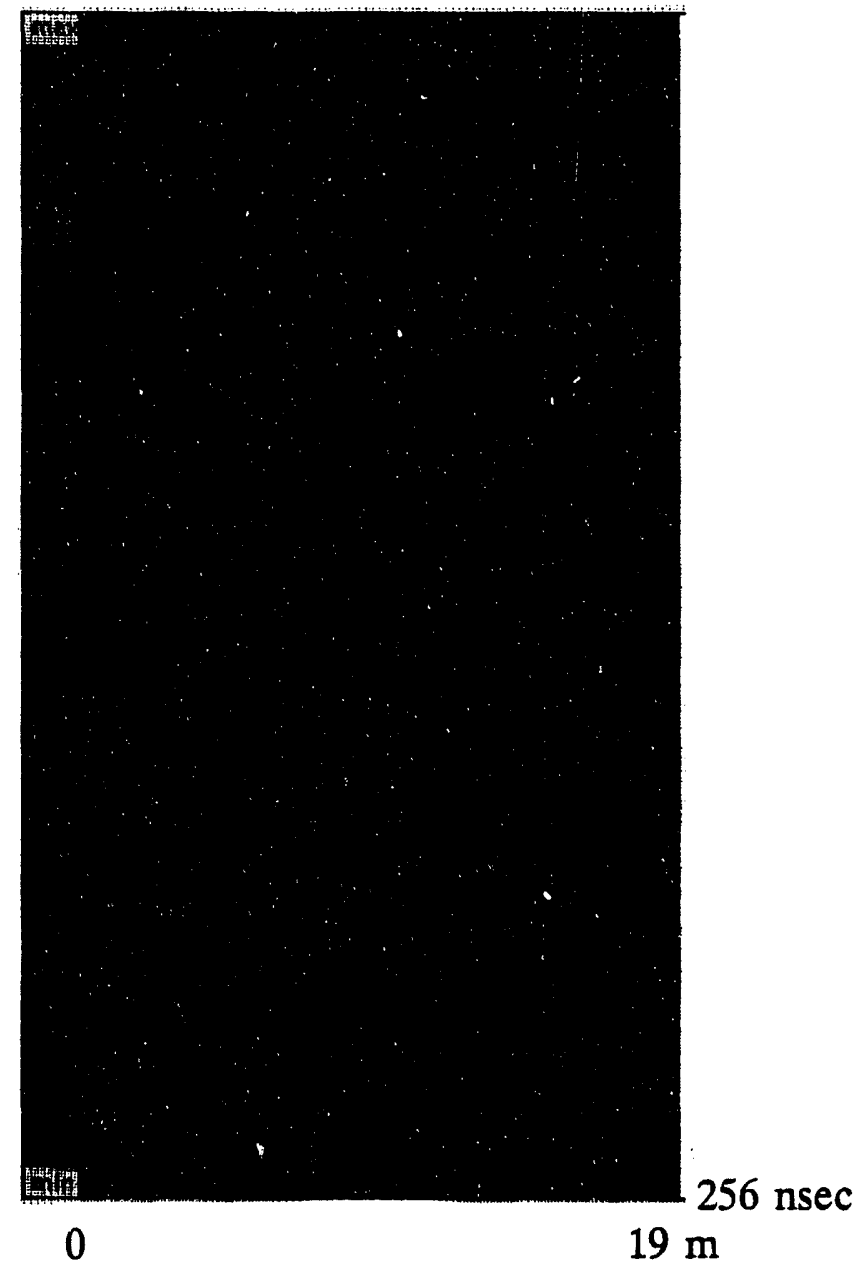

Figure 7.8. Pseudo-Color Image of the A-scans Collected at the 256 Scanner Positions of the Calibration Target Area 

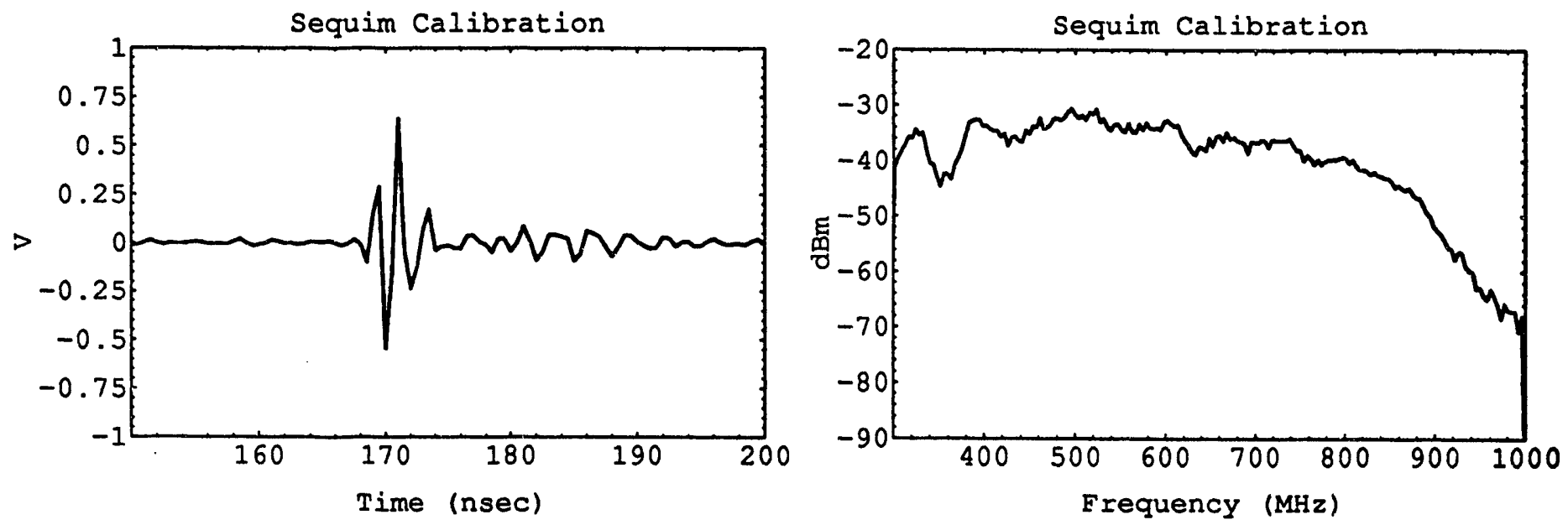

Figure 7.9. Focused Calibration Target Waveform and Spectrum

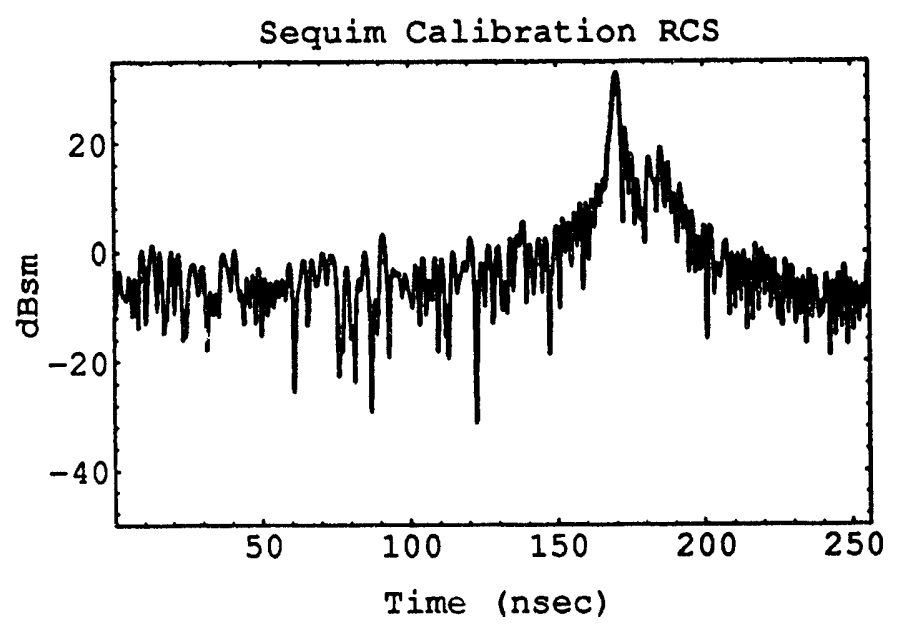

Figure 7.10. Focused Calibration Target Waveform Calibrated to RCS 


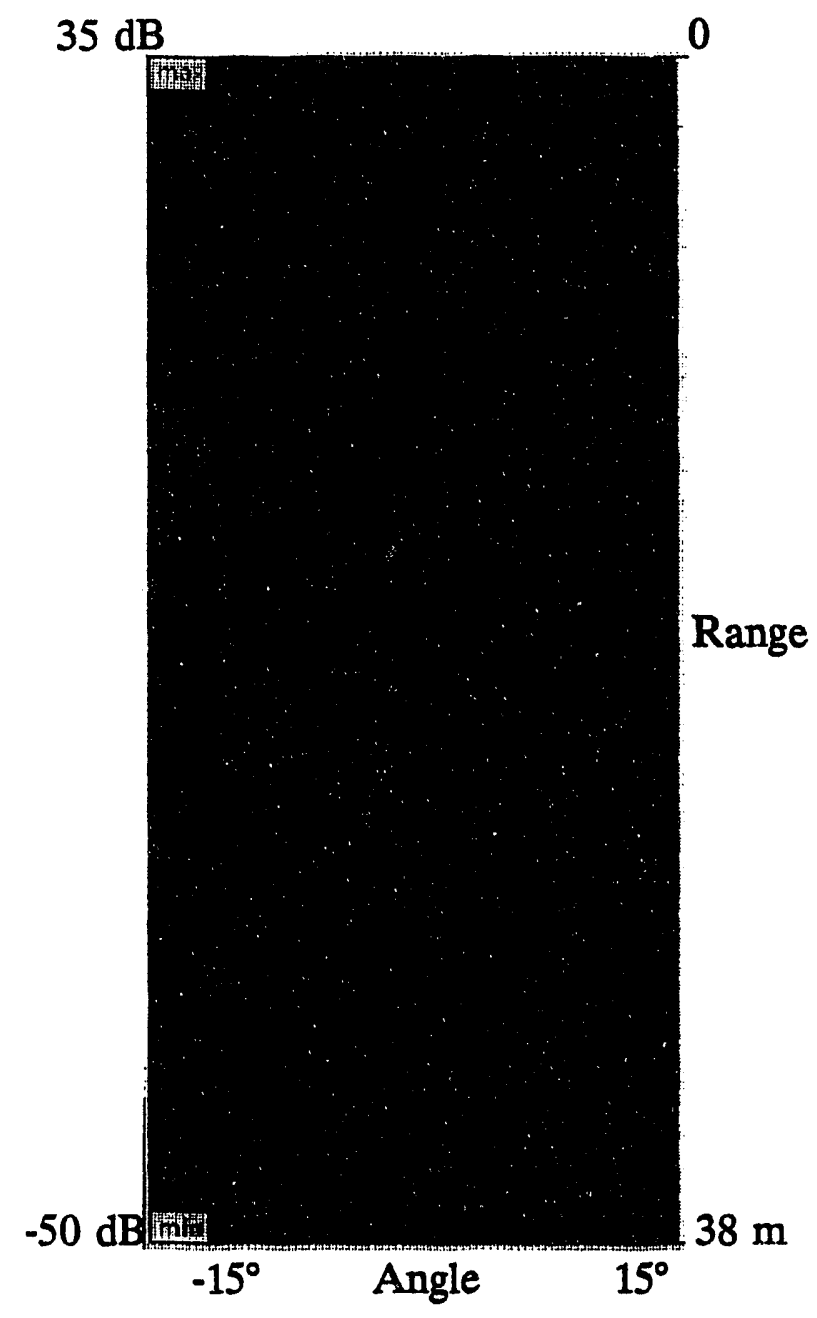

Figure 7.11. Calibration Target Image (located in clutter) Calibrated to RCS 


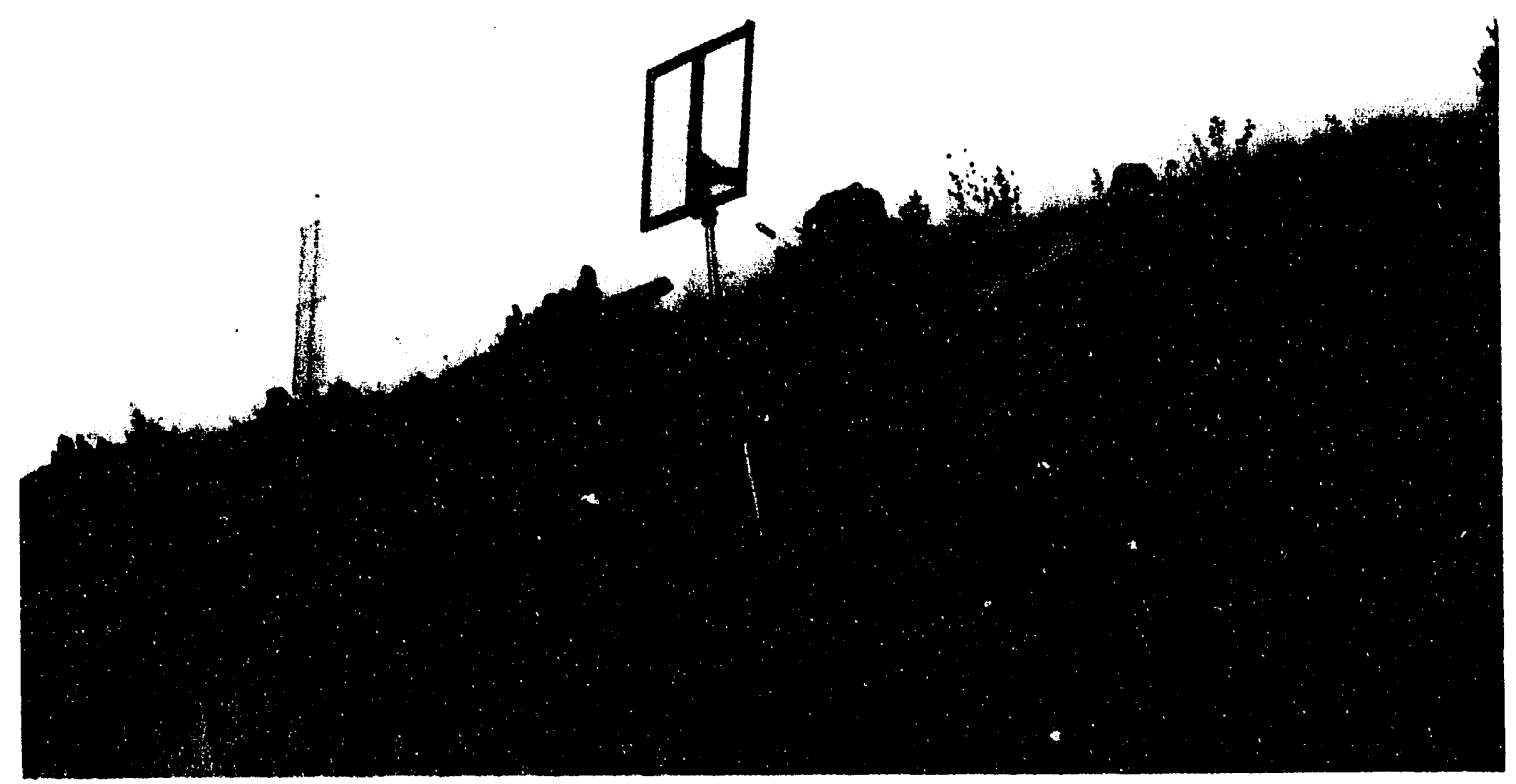

Figure 7.12. Photograph of $6^{\prime}$ by $1^{\prime}$ and $3^{\prime}$ by $4^{\prime}$ Calibration Targets along the $28^{\circ}$ Line of Sight 
$1500 \mathrm{~m}$

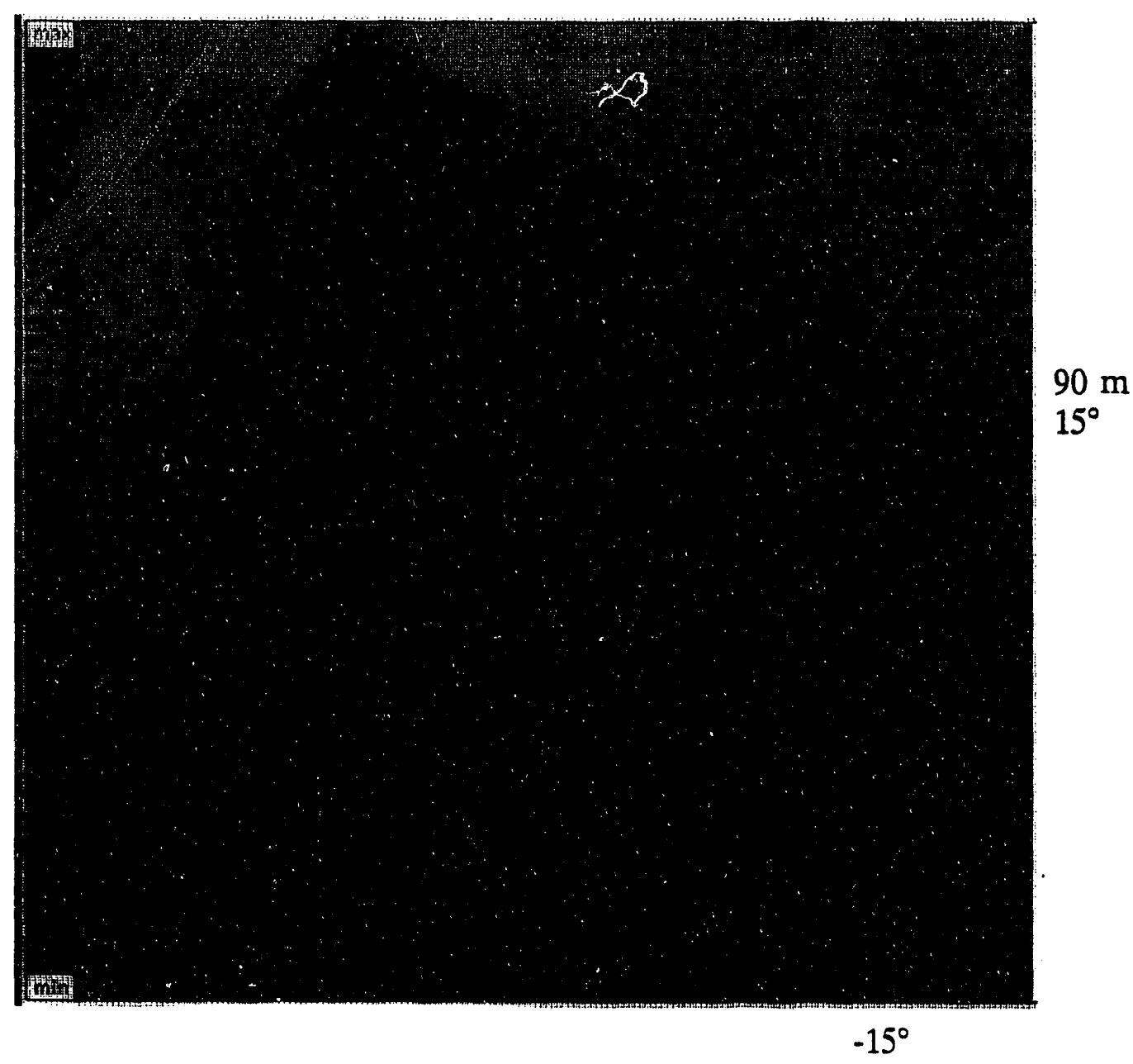

Figure 7.13. RCS Image of Clutter in Sector 2 (V pol.) 
$1500 \mathrm{~m}$

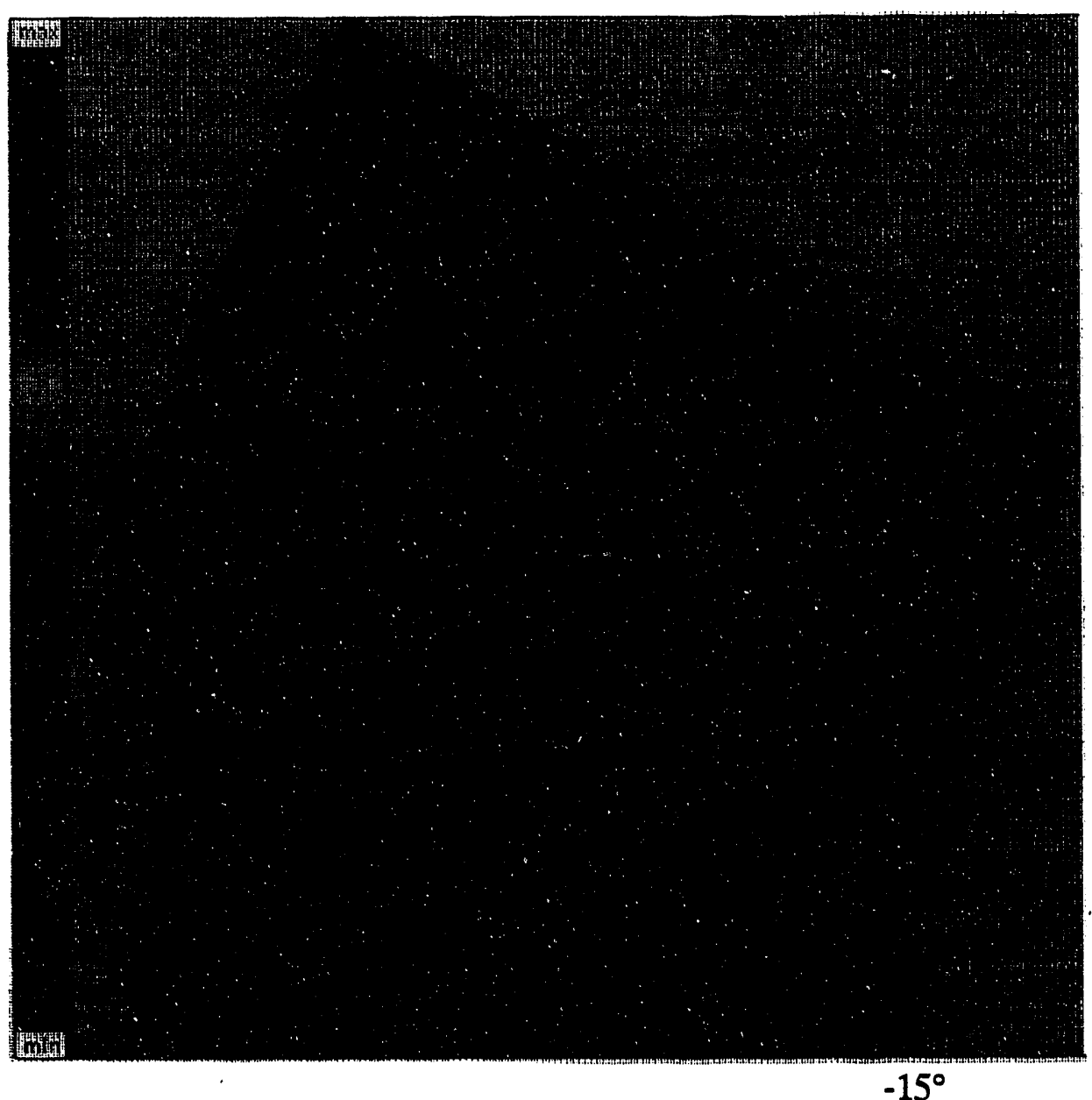

$900 \mathrm{~m}$

$15^{\circ}$

Figure 7.14. RCS Image of Clutter in Sector 2 (H pol.) 
$1500 \mathrm{~m}$

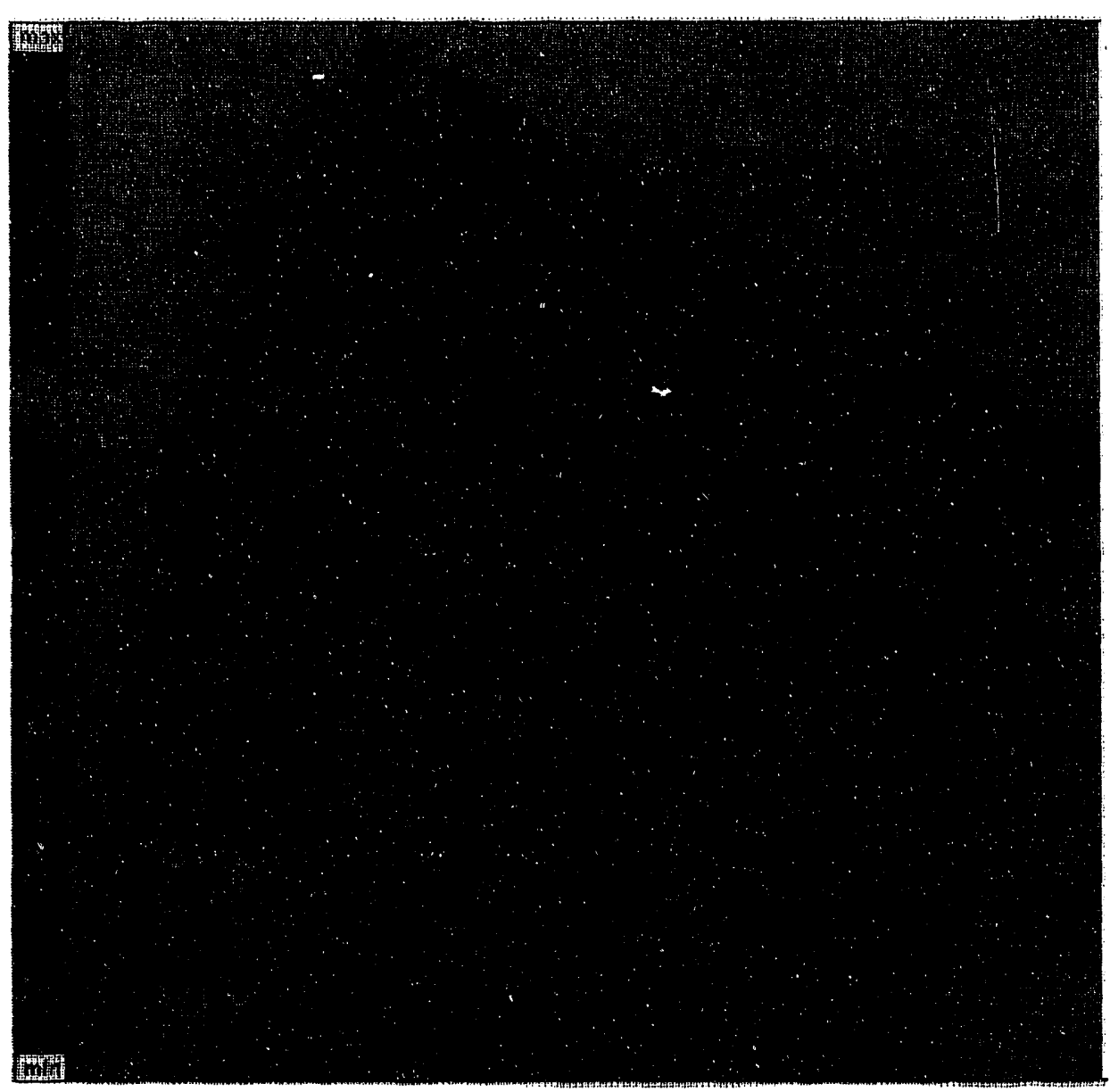

$-15^{\circ}$

$900 \mathrm{~m}$

$15^{\circ}$

Figure 7.15. RCS Image of Clutter in Sector 3 (V pol.) 
$1500 \mathrm{~m}$

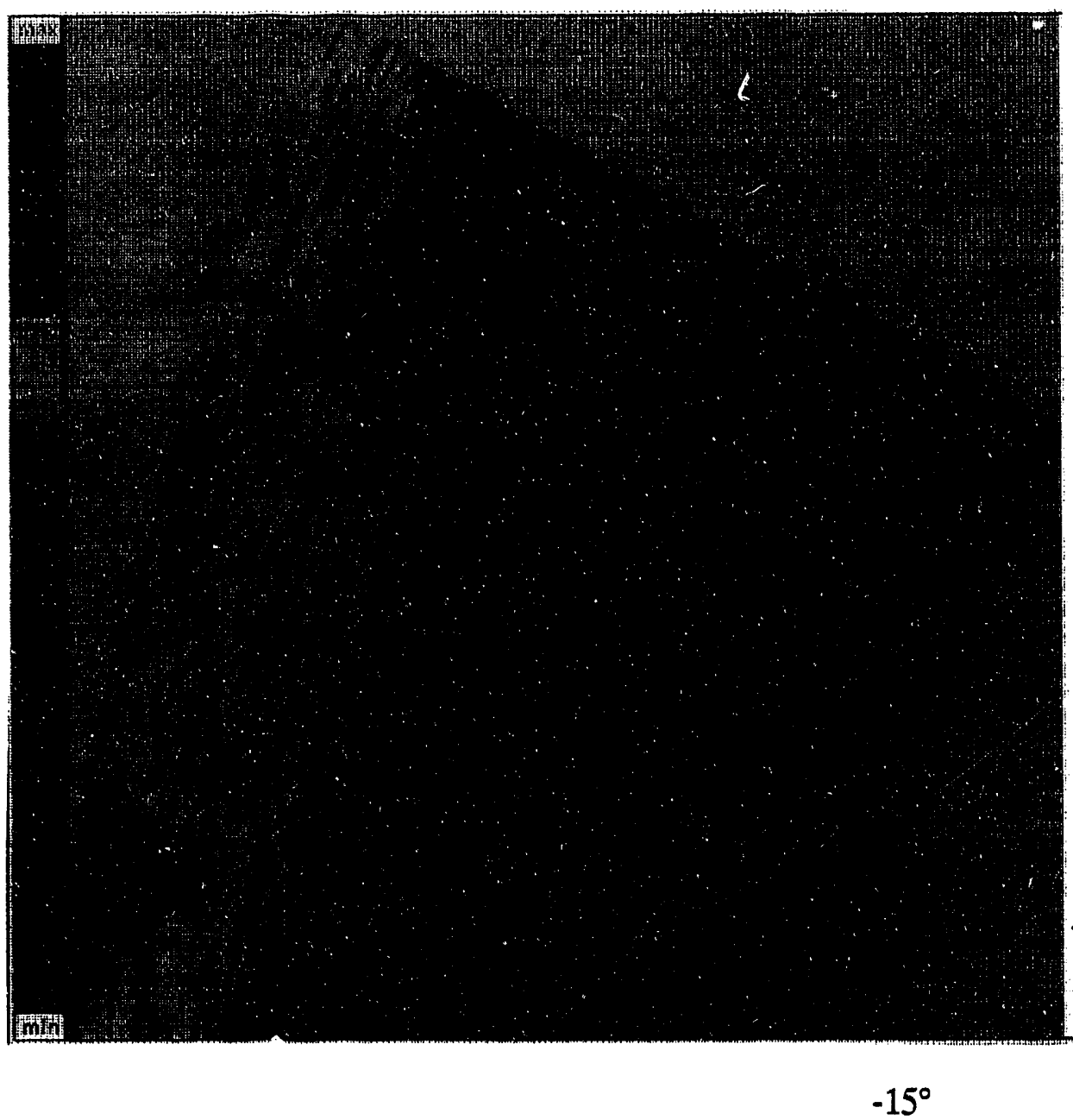

$900 \mathrm{~m}$

$15^{\circ}$

Figure 7.16. RCS Image of Clutter in Sector 3 (H pol.) 

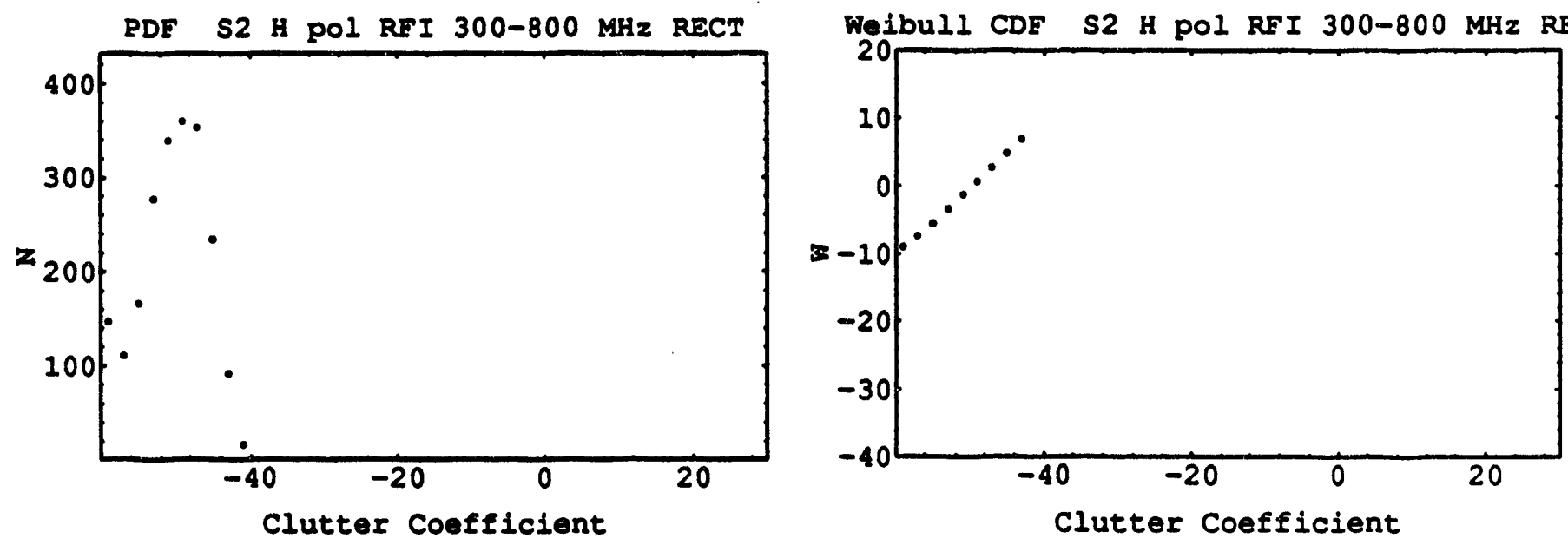

Figure 7.17. Noise Equivalent Clutter Coefncient Distributions for $\mathbf{H}$ Pol at $70^{\circ}$ Orientation and at $1 \mathrm{~km}$ for $300-800 \mathrm{MHz}$ Processing Bandwidth
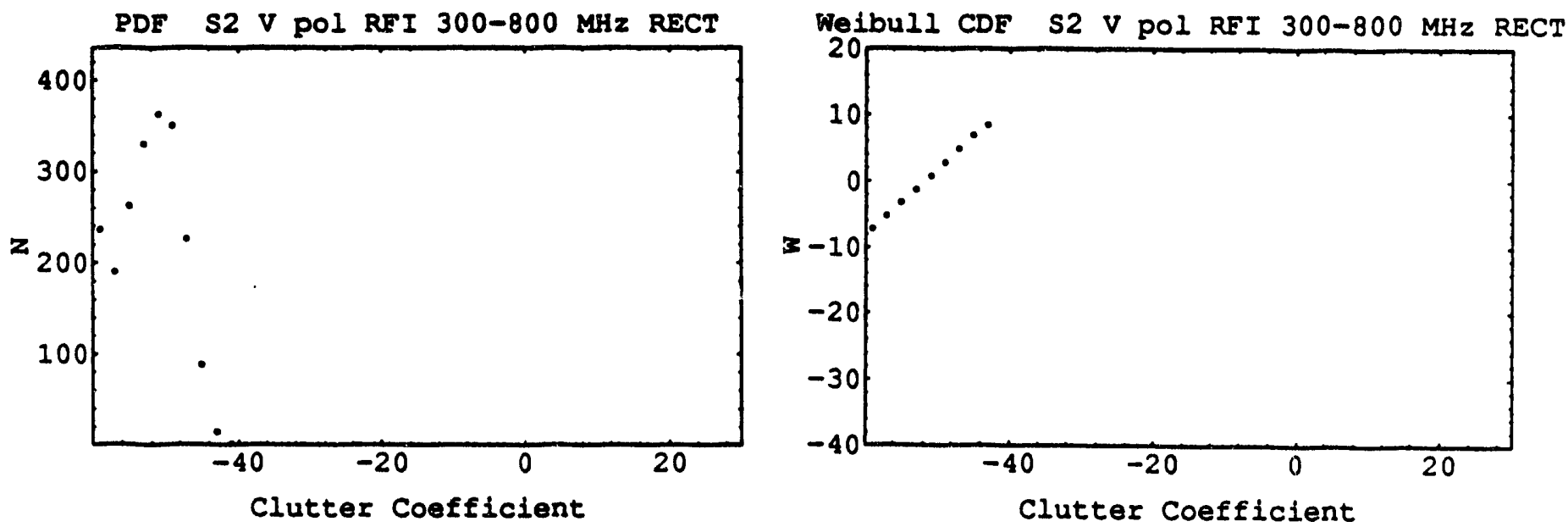

Figure 7.18. Noise Equivalent Clutter Coefficient Distributions for V Pol at $70^{\circ}$ Orientation and at $1 \mathrm{~km}$ for $300-800 \mathrm{MHz}$ Processing Bandwidth 


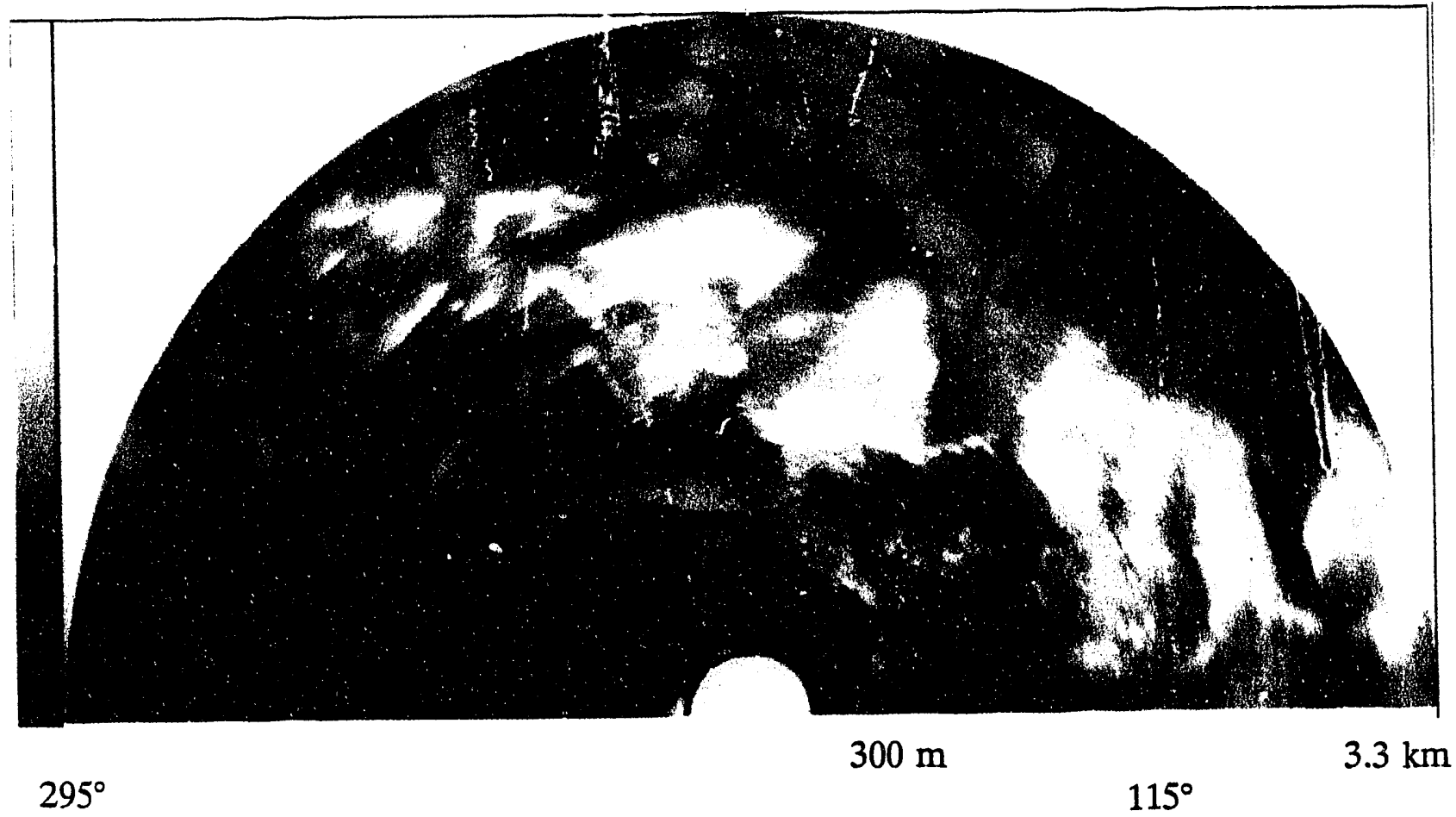

Figure 7.19. Composite Clutter Image of the VV Data

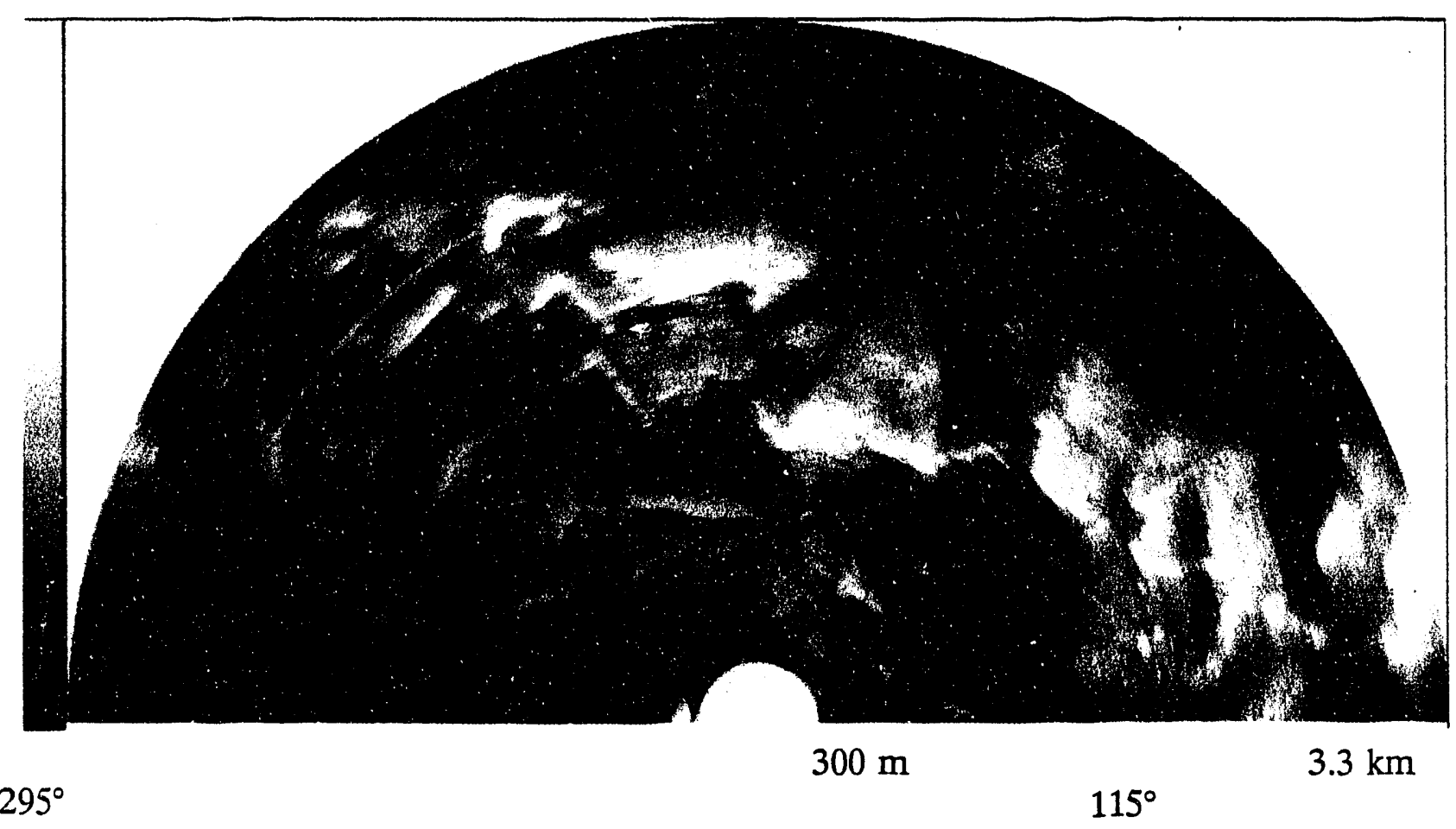

Figure 7.20. Composite Clutter Image of the HH Data 

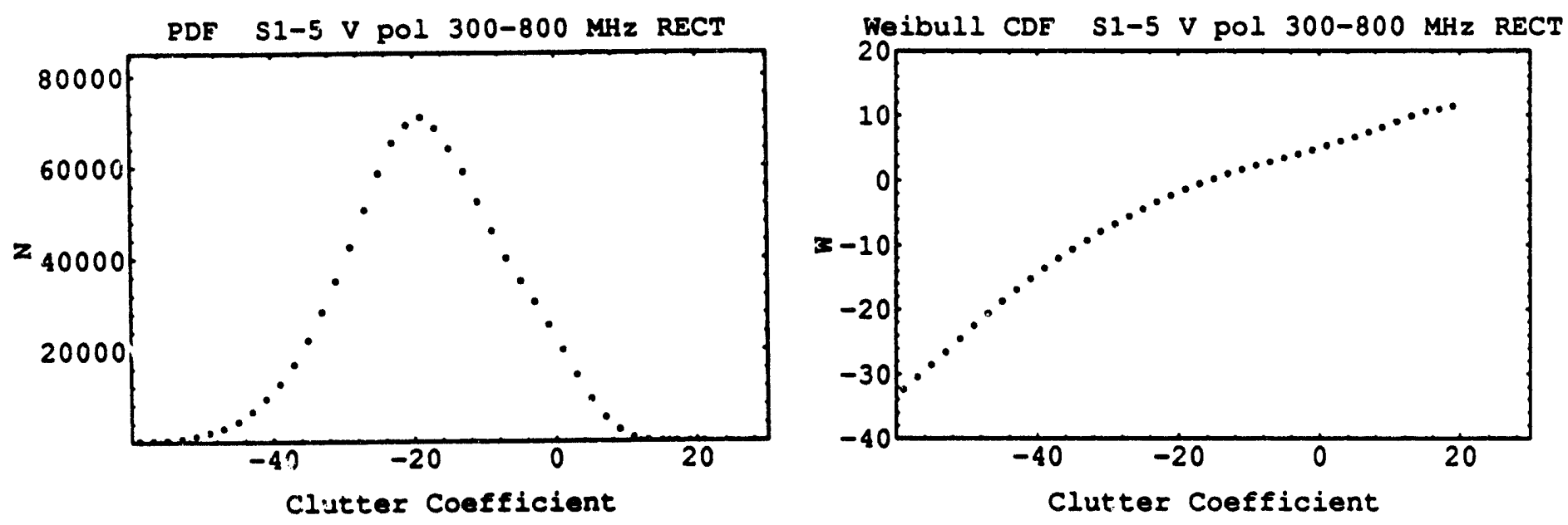

Figure 7.21. Distributions of $300-800 \mathrm{MHz}$ VV Polarization Clutter Data Taken in 6 Lines of Sight: $100^{\circ}, 70^{\circ}, 40^{\circ}, 10^{\circ}, 340^{\circ}$, and $310^{\circ}$
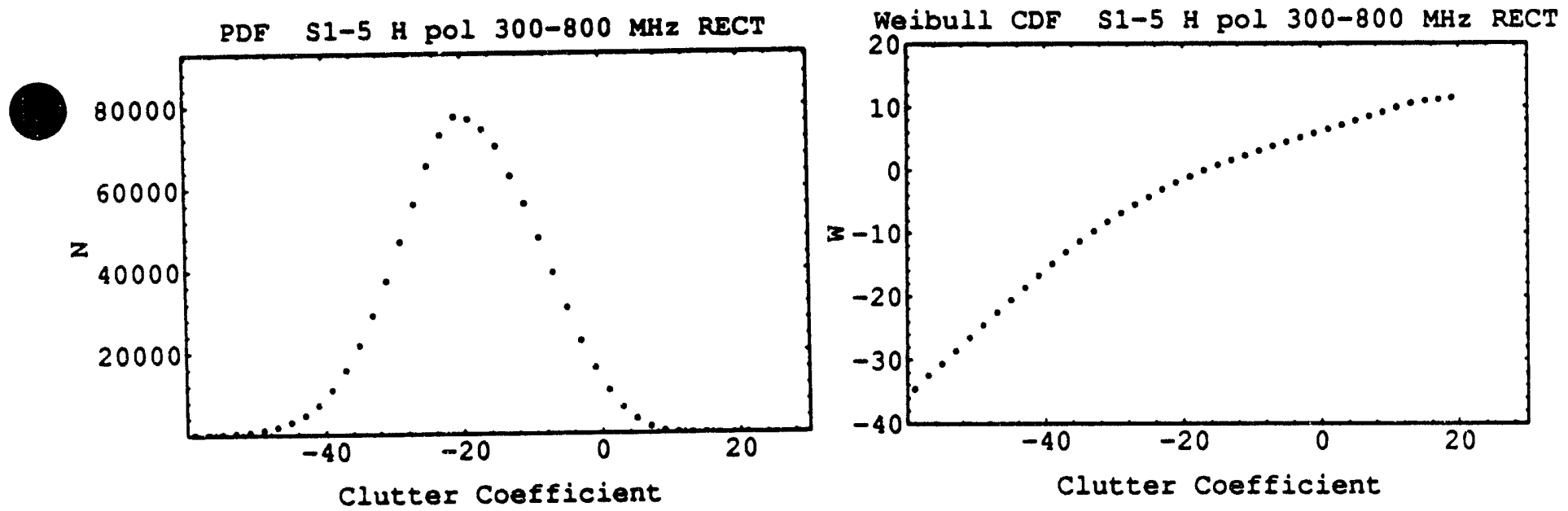

Figure 7.22. Distributions of $300-800 \mathrm{MHz}$ HH Polarization Clutter Data Taken in 6 Lines of Sight: $100^{\circ}, 70^{\circ}, 40^{\circ}, 10^{\circ}, 340^{\circ}$, and $310^{\circ}$ 

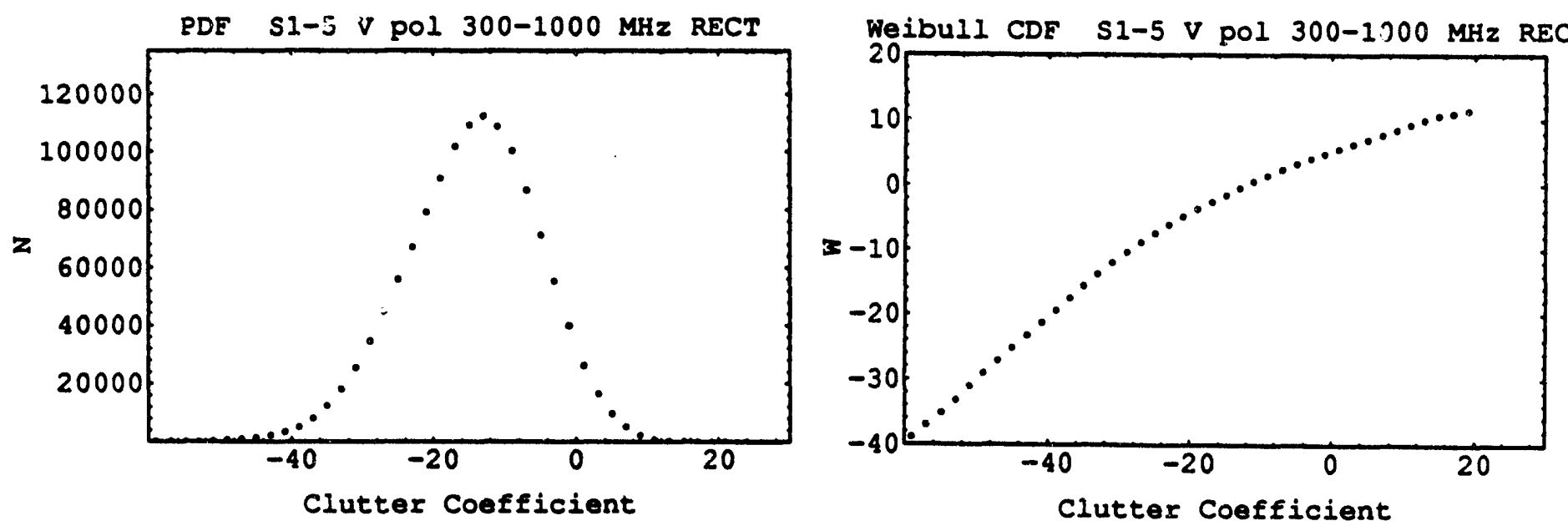

Figure 7.23. Distributions of 300-1000 MHz VV Polarization Clutter Data

Taken in 6 Lines of Sight: $100^{\circ}, 70^{\circ}, 40^{\circ}, 10^{\circ}, 340^{\circ}$, and $310^{\circ}$
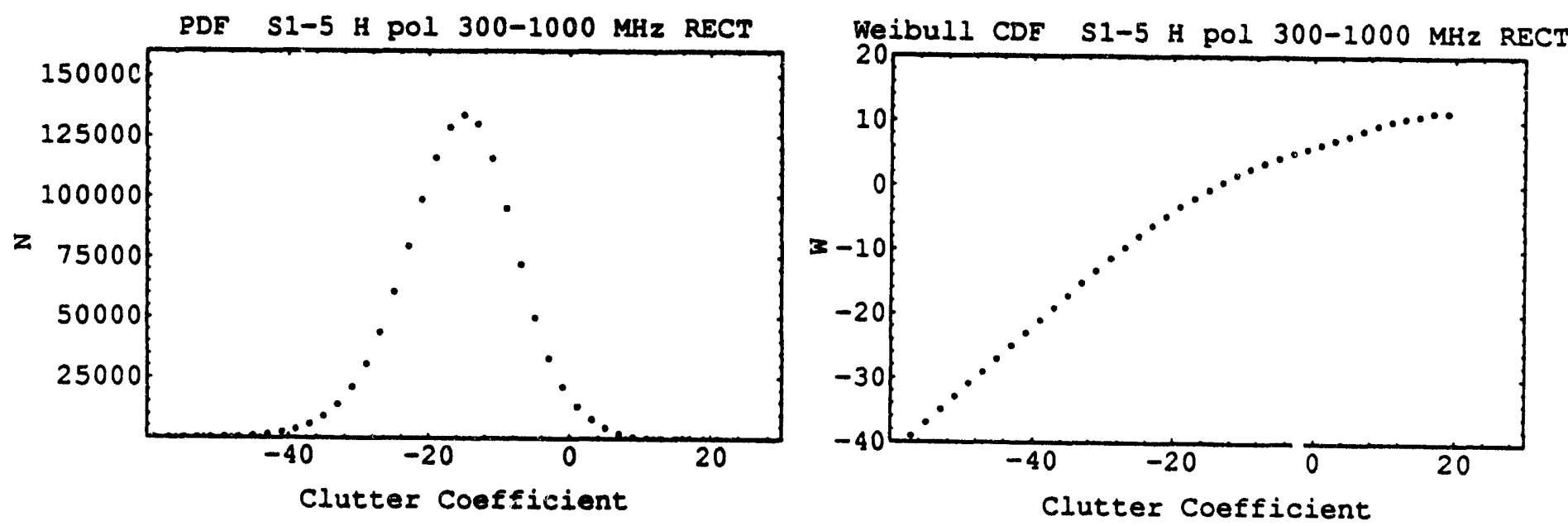

Figure 724. Distributions of 300-1000 $\mathrm{MHz}$ HH Polarization Clutter

Data Taken in 6 Lines of Sight: $100^{\circ}, 70^{\circ}, 40^{\circ}, 10^{\circ}, 340^{\circ}$, and $310^{\circ}$ 


\subsection{Comparison with Existing Data and Conclusions}

One of the most important aspects of the UWB clutter project was to determine if more widely available narrowband clutter data could be successfully used in the UWB case. An additional goal was to determine the dependence of the clutter statistics on the frequency content and resolution of the UWB data. The following sections summarize the clutter statistics obtained in the 1991 and 1992 measurements and compare these results with existing narrowband data.

\subsection{Overall Summary of Clutter Statistics}

Three separate sets of UWB forest clutter data have been obtained. The first two sets are from the 1991 measurements using both the impulse and the step-chirp systems. These measurements both used the 300-1000 $\mathrm{MHz}$ frequency band and were taken simultaneously. The step-chirp measurements covered a significantly larger area than the impulse measurements. The 1992 impulse measurements were taken at a similar site to the 1991 measurements and yielded similar results. The 1992 measurements covered a. vastly larger area than did the 1991 impulse measurements. Mean clutter values obtained from these three sets of data agree to within $3 \mathrm{~dB}$. This is exceptional agreement, but may be somewhat coincidental since the terrain covered is different in each case. A summary of the UWB clutter data is given in Table 8.1.

Table 8.1. Summary of UWB Clutter Values

\begin{tabular}{|c|c|c|c|c|}
\hline Polarization & $\begin{array}{l}\text { Frequency } \\
\text { Band, MHz }\end{array}$ & Mean, dB & Median, dB & $\begin{array}{l}\text { Std Dev/ } \\
\text { Mean, dB } \\
\end{array}$ \\
\hline \multicolumn{5}{|c|}{1991 Impulse UWB Forest Clutter Measurements } \\
\hline $\begin{array}{l}\mathrm{HH} \\
\mathrm{VV}\end{array}$ & $\begin{array}{l}300-1000 \\
300-1000\end{array}$ & $\begin{array}{l}-9.0 \\
-5.4 \\
\end{array}$ & $\begin{array}{l}-16.8 \\
-12.4 \\
\end{array}$ & -- \\
\hline \multicolumn{5}{|c|}{1991 Step Dhirp UWB Forest Clutter Measurements } \\
\hline $\begin{array}{l}\mathrm{HH} \\
\mathrm{VV}\end{array}$ & $\begin{array}{l}300-1000 \\
300-1000\end{array}$ & $\begin{array}{l}-11.5 \\
-7.4\end{array}$ & $\begin{array}{l}-18.8 \\
-14.0\end{array}$ & $\begin{array}{l}4.7 \\
4.2\end{array}$ \\
\hline \multicolumn{5}{|c|}{1992 Impulse UWB Forest Clutter Measurements } \\
\hline $\begin{array}{l}\mathrm{HH} \\
\mathrm{VV}\end{array}$ & $\begin{array}{l}300-800 \\
300-800\end{array}$ & $\begin{array}{l}-9.3 \\
-6.4\end{array}$ & $\begin{array}{l}-19.1 \\
-18.4\end{array}$ & $\begin{array}{l}6.5 \\
6.1\end{array}$ \\
\hline
\end{tabular}




\subsection{Range Resolution and Frequency Content Effects}

The step-chirp data set from the 1991 forest measurements was also processed to determine the effects of range resolution reduction by decreasing the bandwidth (Appendix A). Note that the narrower frequency range could be defined anywhere within the $300-1000 \mathrm{MHz}$ total bandwidth. Typically the narrower bandwidths were chosen for a constant center frequency of $650 \mathrm{MHz}$. Table 8.2 shows the, result of resolution (bandwidth) reduction for $x 1, \times 2, \times 4$, and $\times 8$ for the $186^{\circ}$ sector of data. Note that there is a significant decrease in clutter levels from the 0.214 meter resolution to the $0.429 \mathrm{~m}$ resolution with little subsequent change. This appears to be due to the elimination of the low frequency content of the $300-1000 \mathrm{MHz}$ frequency band. This was determined by rep:ocessing the $x 2$ data using the center frequency of the lower and upper halves of the 300-1000 MHz spectrum, which showed that the lower frequency content has signific . atly higher reflectivity (Sager and Schultheis 1992).

Table 8.2. Range Resolution Effects on $\sigma^{0}$ Statistics (Sager and Schultheis and Appendix A)

\begin{tabular}{||c|c|c|c|c||}
\hline \hline Polarization & Range Res, $\mathrm{m}$ & Mean, $\mathrm{dB}$ & Median, dB & Std Dev/ \\
\hline $\mathrm{HH}$ & 0.214 & -11.5 & -18.8 & 4.7 \\
$\mathrm{VV}$ & 0.214 & -7.4 & -14.0 & 4.2 \\
\hline $\mathrm{HH}$ & 0.429 & -15.4 & -22.6 & 4.7 \\
$\mathrm{VV}$ & 0.429 & -11.1 & -18.0 & 4.6 \\
\hline HH & 0.857 & -16.5 & -23.4 & 4.5 \\
$\mathrm{VV}$ & 0.857 & -12.0 & -19.0 & 4.7 \\
\hline HH & 1.714 & -16.6 & -23.0 & 4.4 \\
VV & 1.714 & -12.0 & -18.9 & 4.7 \\
\hline
\end{tabular}

\subsection{Comparison with Existing Narrow Band Data}

An analysis comparing the UWB clutter data gathered during the 1991 measurements was written by Mike Tuley and was presented in Tuley et al. (1993) and is summarized here. The UWB clutter data was compared with existing narrowband data primarily from two sources. The first source is Nathanson (1991). The constant gamma model was used in which $\sigma^{0}=\gamma \sin (\psi)$, where $\gamma$ is a constant and $\psi$ is the grazing angle. Nathanson provides a value of $-16 \mathrm{~dB}$ for $\gamma$ for wooded hills with grazing angles of $15^{\circ}$ to $70^{\circ}$. Assuming an average local grazing angle of $20^{\circ}$ for the 1991 Sequim measurements 
results in a predicted median $\sigma^{\circ}$ of $-20 \mathrm{~dB}$. This is on the order of $5 \mathrm{~dB}$ below the median levels (average of HH and VV) observed for the 1991 measurements. The predicted value agrees quite well with the 1992 impulse measurements which have a median $\sigma^{0}$ values of approximately $-19 \mathrm{~dB}$.

The main source of nai row band clutter data is the MIT Lincoln Laboratory data (Billingsley and Larrabee 1991). This data was gathered using five radar systems operating over narrow bandwidths. Three of these frequencies are of interest to the UWB measurements. These include a VHF system operating a $167 \mathrm{MHz}\left(13^{\circ}\right.$ azimuth beamwidth and $36 \mathrm{~m}$ or $150 \mathrm{~m}$ range resolution), a UHF system operating at $435 \mathrm{MHz}$ ( $5^{\circ}$ azimuth beamwidtil and $36 \mathrm{~m}$ or $150 \mathrm{~m}$ range resolution), and an L-band system operating at $1230 \mathrm{MHz}$ ( $3^{\circ}$ azimuth beamwidth and $15 \mathrm{~m}$ or $150 \mathrm{~m}$ range resolution). Table 8.3 provides a summary of the MIT/LL data of interest for the UWB forest and desert clutter measurements. Comparison of the UWB clutter data from the 1991 and 1992 measurements with the MIT/LL UHF data shows that mean and median clutter levels are consistent with the Mountains terrain data set. The agreement with the Forest/High Relief data set is not nearly as close. This is likely due to lower slopies for the Forest/High Relie? data set than for the Sequim data.

Table 8.3. MIT/LL Narrowband Radar Data (Billingsley and Larrabee 1991)

\begin{tabular}{||l|c|c|c||}
\hline \multicolumn{5}{||c|}{} & Mountains & $\begin{array}{c}\text { Forest/ } \\
\text { High Relief }\end{array}$ & $\begin{array}{c}\text { Desert/Marsh/ } \\
\text { Grasslands }\end{array}$ \\
\hline VHF & -7.6 & -10.5 & -38.2 \\
\hline UHF & -10.6 & -16.1 & -39.4 \\
\hline L-band & -17.5 & -18.2 & -39.6 \\
\hline & \multicolumn{3}{|c|}{ Median (dB) } \\
\hline VHF & -13.0 & -15.0 & -49.0 \\
\hline UHF & -16.0 & -26.0 & -59.5 \\
\hline L-band & -28.0 & -25.5 & -48.5 \\
\hline \multicolumn{5}{|c|}{ Std Dev/Mean (dB) } \\
\hline VHF & 3.4 & 4.2 & 5.5 \\
\hline UHF & 5.4 & 4.3 & 8.2 \\
\hline L-band & 2.8 & 6.1 & 9.2 \\
\hline
\end{tabular}




\subsection{Conclusions}

The results from the 1991 and 1992 UWB forest clutter measurements and subsequent analyses lead to a number of conclusions, as drawn in Tuley et al. 1993.

The calibrations of these experiments are believed to be accurate to within $2 \mathrm{~dB}$. The impulse and step-chirp systems gathered data that is essentially equivalent which was shown by a detailed comparison of data from one sector (Tuley et al. 1993)

Mean clutter coefficient values are typically $-5 \mathrm{~dB}$ to $-7 \mathrm{~dB}$ for vertical polarization and $9 \mathrm{~dB}$ to $-11 \mathrm{~dB}$ for horizontal polarization. Median clutter values are typically $-12 \mathrm{~dB}$ to $-18 \mathrm{~dB}$ for vertical polarization and -17 to -19 for horizontal polarization. Thus, mean and median values are typically 3-5 dB higher for $\mathrm{VV}$ than for $\mathrm{HH}$ polarization.

The clutter statistics do not depend strongly on range resolution for the range resolutions considered $(0.214 \mathrm{~m}$ to $1.714 \mathrm{~m})$. Note that this conclusion can only be drawn for the system configurations and terrain types that were examined.

Mean and median values are similar to the MIT/LL UHF (435 MHz) mountain terrain data (Billingsley and Larrabee 1991). 


\subsection{References}

Billingsley, J. B., and J. F. Larrabee, "Multifrequency Measurements of Radar Ground Clutter at 42 Sites," Lincoln Laboratory Technical Report 916, November 15, 1991.

Nathanson, F. E., Radar Design Principles, Second Edition, McGraw-Hill, New York, 1991.

OSD/DARPA Ultra-Wideband Radar Review Panel, "Assessment of Ultra-Wideband (UWB) Technology," July 13, 1990.

Sager, E. V., and A. C. Schultheis, "Description of Clutter Data Collected at a Forested Site," SPC Final Technical Report 1432, October 1992.

Skolnik, M. L., Introduction to Radar Systems, McGraw-Hill, New York, 1980.

Tuley, M. T., D. M. Sheen, H. D. Collins, E. V. Sager, and A. C. Schultheis, "Ultrawideband Radar Clutter Measurements and Analysis," Proceedings - Ultrawideband Radar, SPIE, January 1993. 


\section{APPENDIX A:}

\section{SPC Report on 1991 Sequim Measurements}


SPC Log No. 9-1722

cyooi

\title{
DESCRIPTION OF CLUTTER DATA COLLECTED AT A FORESTED SITE
}

SPC REPORT 1432

October 1992

Earl V. Sager

Andreas C. Schultheis

\author{
Prepared for \\ Battelle Pacific Northwest Laboratories \\ Battelle Boulevard \\ P.O. Box 999 \\ Richland, WA 99352
}

Subcontract 127158-A-T2

A. 1 


\section{CONTENTS}

I. TEST OBJECTIVE

II. TEST DESCRIPTION

III. CALIBRATION

IV. RF ENVIRONMENT

V. DATA COLLECTION

VI. DATA PROCESSING

VII. CORRELATION OF CHIRP AND IMPULSE DATA

APPENDIX A - Beam MapS

APPENDIX B - Reflectivity Distribution Plots

APPENDIX C - Reflectivity Cumulative Plots

APPENDIX D - Reflectivity statistical Listings 
In November of 1991, system Planning corporation (SPC) participated with Battelle Pacific Northwest Laboratories (PNL) in collecting high range resolution clutter RCS data. The main purpose for using the SPC MKIV step-chirp radar was to provide a complementary set of data to compare to results obtained from the PNL impulse radar. Data sets for both radar systems were collected from the same clutter scenes at closely spaced periods in time. The MKIV was operated over a bandwidth consistent with the range resolution of the impulse system and high range resolution was obtained by Fourier processing the step chirp data. Synthetic aperture beam forming techniques were applied to both data sets to generate narrow azimuth beams. The body of data collected by the MKIV vas larger than that of the impulse system because of better throughput and longer range sensitivity. Because of this, the data set produced with the MKIV is a valuable asset for clutter statistics. In addition, the step chirp waveform permits the use of data processing to reduce the radar bandwidth to study the effects of variable range resolution. Interference from narrow band RFI could also be conceivably filtered from the data.

PNL was responsible for the collection and processing of all impulse radar data. SPC was similarly responsible for the step chirp radar data.

Dr. Michael Tuley of Georgia Tech Research Institute (GTRI) was responsible for assessing the correlation between the step chirp radar and impulse radar sets of data based on contributions provided by SPC and PNL.

II.

TEST DESCRIPTION

Data was collected from a forested site near sequim, Washington in November of 1991. The radar was sited at a clearing on the side of a hill overlooking a valley and across to tree covered slopes. The trees were pines in the 30 to 50 foot height range. The weather was generaliy humid with temperatures in the 50-70 degree $F$ range during the daytime data collection periods.

Data was collected as follows. A horizontal antenna positioner (scanner) 19 meters in length was located .5 to $2.5 \mathrm{~km}$ from the clutter areas of interest. Horizontally and vertically polarized log-periodic antennas were mounted on the mast of the scanner. The two-way horizontal $3 \mathrm{~dB}$ beamwidth of the antennas was predicted to be 26 degrees at .3 GHz and 20 degrees at $1 . \mathrm{GHz}$. The antenna mast moved continuously along the track so that 127 azimuth positions were sampled at each of the 1024 step chirp frequencies that were collected from .3 to $1.0 \mathrm{GHz}$. The objective is to process the data so that high range resolution clutter statistics can be obtained from a frequency independent patch size. The use

$$
\text { A. } 3
$$


of a fixed 19 meter synthetic aperture antenna results in a beam profile that would diminish by a factor of about three from the low frequency to the high frequency ends of the chirp. Synthetic aperture reduction techniques were used to process the data so that a constant beam profile (equivalent to the low frequency end) is maintained.

For RCS backscatter measurements, the two-way 3 dB beam profile is related to frequency $f$ and aperture size $D$ by:

$$
\theta_{\text {beam }}=\frac{C}{2 D}
$$

where:

$C=$ speed of Iisist

$D$-aperture width

$f$-frequency

In order to maintain a constant beam width, the synthesized aperture at $1.0 \mathrm{GHz}$ must be .3 the size at $.3 \mathrm{GHz}$. To form equivalent beams at $1.0 \mathrm{GHz}$ and at .3 $\mathrm{GHz}$, only (.3)(127) contiguous elements (a subaperture) are used at the high end while the ful. 127 elements are used at the low end. once a constant beam size is synthesized at each frequency (1024 of them), an FFT is performed to generate a high resolution profile for each subaperture. Prior to the FFT, weighting can be applied to reduce sidelobes. A phase calibration is required of the 1024 frequency elements prior to the FFT to correct for dispersion and to properly align the output range bins. The calibration constants are obtained from a calibration target erected at a converient location relative to the radar. This calibration procedure assumes that $a$ uniform frequency response is desired for the chirp data.

A data set is described by the following parameters:

$$
\begin{aligned}
& N_{c}=\text { number of chirp frequencies } \\
& N_{a}=\text { number of aperture samples } \\
& D=\text { aperture length } \\
& R_{0}=\text { center range } \\
& f_{0}=\text { base frequency } \\
& B=\text { chirp bandwidth } \\
& P R F=\text { constant }
\end{aligned}
$$

A complete data set consists of $\mathrm{N}_{c} \times \mathrm{N}_{a}$ data points. The antenna was continuously moved at a slow rate while the data was collected. The PRF of the radar, the number of coherent integrations at each frequency in the step chirp, and the scan speed of the positioner were selected to coincide with the required spatial sampling interval. A typical run took about 11 minutes to complete. The run was duplicated for both $\mathrm{HH}$ and VV polarization.

All data points were extracted from the file and stored in an $\mathrm{N}_{c} \times \mathrm{N}_{\mathrm{a}}$ array, where $\mathrm{N}_{\mathrm{c}}=1024$ and $\mathrm{N}_{\mathrm{a}}=127$. Every lement was 
amplitude and phase calibrated according to normal chirp calibration procedures. The data analysis program takes as input the aperture spacing $d$, the number of aperture points $N_{a}$, the operating range $R_{0}$, and a set of angles at which beams are to be formed. Complex beamforming weights were determined by the trigonometry of the problem which depends on $D$ and $R_{0}$. The output is a file consisting of RCS (amplitude and phase) versus range versus beam steering angle. This file can be processed for statistical analysis of the clutter cells.

The aperture function to steer the array to a particular angle for a particular frequency is given by:

$$
A\left(\theta_{s}, f\right)-\Sigma_{i}\left[a\left(x_{i}, f\right) e^{i \delta \phi\left(x_{i}, \theta_{s}, f\right)}\right]
$$

The phase shifts at each aperture position $x$ used to steer the array are:

$$
\delta \phi\left(x, \theta_{s}, f\right)=-\left[R\left(x, \theta_{s}\right)-R_{0}\right]\left[4 \pi \frac{f}{C}\right]
$$

where:

$$
R(x, \theta)=\sqrt{R_{0}^{2}+x^{2}-2 x R_{0} \sin (\theta)}
$$

At each frequency, a single complex data value will be generated from a subset of the $\mathrm{N}_{\mathrm{a}}$ collected values. A different value will be computed for every required steering angle.

At higher frequencies the beam width created by this aperture function will be narrower than at lower frequencies. In order to maintain a constant beam width for all frequencies which will give a constant clutter patch size, the beam formed at higher frequencies will use fewer elements in proportion to the ratio $\left(f_{\text {low }} / f\right) \mathrm{N}_{\mathrm{a}}$. If a smaller array is created around the center of the full array, the fewer elements result in less gain (reducing the SNR). In order to obtain high range resolution, an FFT is applied to chirp sets representing each synthesized beam angle.

The results of the beam steering and range compression operation is a matrix of RCS values associated with discrete clutter patches determined by the range and angle resolution of the processing. The RCS of each patch is normalized by the area of the patch to produce the clutter reflectivity coefficient. The array 
of reflectivity values spanning the range azimuth sector can be displayed as a beam map and processed for statistics.

III.

CALIBRATION

Calibration could not be conducted within one of the range azimuth sectors viewed by the scanner. Insufficient signal-toclutter power was available to properly peak the calibration target and to provide a meaningful amplitude and phase calibration. Instead the calibration target was positioned in a cleared area at about 1000 feet from the antenna. Because of irregularities in the frequency response of the calibration target, significant multipath effects were indicated. As a result, calibration data collected from another site at near Richland, Washington was used instead for a calibration reference to process the Sequiil clutter data.

Calibration was performed using a rectangular screen 6 feet wide by 12 feet high mounted with the center seven feet above ground. The antenna horn was dismounted from the scanner and mounted on a tripod at a seven foot height so that the antenna could view the screen at a convenient location. A sighting scope was mounted on the screen so that the face could be approximately pointed at the antenna. The return from the screen was peaked at the highest frequency by hand in elevation and azimuth. The screen was secured with ropes while the data was collected. No capability existed to ascertain the multi-path propagation factor. The cable path to the horn was maintained at a constant length for data collection and calibration. An RF cable segment equal in length to the piece fixed to the scanner was made use of during the calibration.

The principal uncertainties deal with the multipath propagation factor. The relief of the ground between the antenna and target was generally gently rolling with irregularities of the order of a few inches. There was a downslope to the left of the target and an upslope to the right. No dramatic nulls were observed in the response of the target as the frequency was swept across the band. The external response of the plate was very similar to the internal loop mode response of the radar.

The output of the RF converter was measured at SPC and an estimated power to be received from the cal target based on gains and losses was calculated as a function of frequency.

Table 1

Factors Affecting Calibration

\begin{tabular}{||l|l|l|l|l||}
\hline polarization & H & V & H & V \\
\hline frequency $(\mathrm{GHz})$ & .3 & .3 & 1. & 1. \\
\hline
\end{tabular}




\begin{tabular}{||l|l|l|l|l||}
\hline measured power in $(\mathrm{dBm})$ & -77.85 & -76.05 & -60.35 & -62.75 \\
\hline estimated power in $(\mathrm{dBm})$ & -78.12 & -77.12 & -71.75 & -73.55 \\
\hline measured - estimated $(\mathrm{dB})$ & .28 & 1.08 & 11.41 & 10.81 \\
\hline
\end{tabular}

There appears to be a jubstantial power excess. A difference of 10 $\mathrm{dB}$ in power received between .3 and $1.0 \mathrm{GHz}$ can originate from the propagation factor. However, the propagation factor cannot account for a $10 \mathrm{~dB}$ excess over the estimated value at the cal target range of about 950 feet for the antenna and target heights that were involved. No enhancement should be possible at 950 feet. As the ground reflection coefficient decreases from 1 , the differences between the propagation factors for .3 and 1 . GHz converge from a maximum of about $20 \mathrm{~dB}$. At this point there is no clue as to the source of the apparent excess power. However, since the calibration is a relative one and multipath does not appear to be a significant contributor, the calibration performed on the clutter data should be valid.

IV.

RF ENVIRONMENT

RF contamination was readily detectable at multiple locations within the .3 to 1 . GH 2 spectrum. This contamination is shown in Figure 1 relative to the noise fioor. As can be seen in Figure 2, which compares the RF contamination to the typical clutter levels, the measurements of clutter reflectivity are not significantly degraded by the amount of RF contamination that is present.

v.

\section{LATA COLLECTION}

The scanner was manually moved to view four different sector angles: $186,216,246$, and 276 degrees. At each sector angle the scanner made four passes as the MKIV radar collected data at HH and VV polarization at lear and far ram,es. The reax and far ranges covered .5 to $2.5 \mathrm{~km}$ in two segments. Each data consisted of 5 collected range delays with a spacing increment of $1330 \mathrm{~ns}$. Tue basic radar collection parameters are listed in Table 2. Coherent integration was used to improve SNR. At each of the 1024 frequency steps, 256 pulses were summed before storing to tape. Pseudorandom coding was applied to the waveform to avoid contributions from range ambiguous clutter.

Table 2

SPC MRIV Radar Parameters

\begin{tabular}{||l|c|c||}
\hline & CAPABILITY & USED \\
\hline Frequency & .3 to $18 \mathrm{GHz}$ & .3 to I GHz \\
\hline Power & $2 \mathrm{w}$ to $1 \mathrm{~kW}$ & $2 \mathrm{w}$ \\
\hline PRF & $<1 \mathrm{MHz}$ & $55 \mathrm{kHz}$ \\
\hline Pulsewidth & $>1 \mathrm{~ns}$ & $1330 \mathrm{~ns}$ \\
\hline
\end{tabular}

A.7 


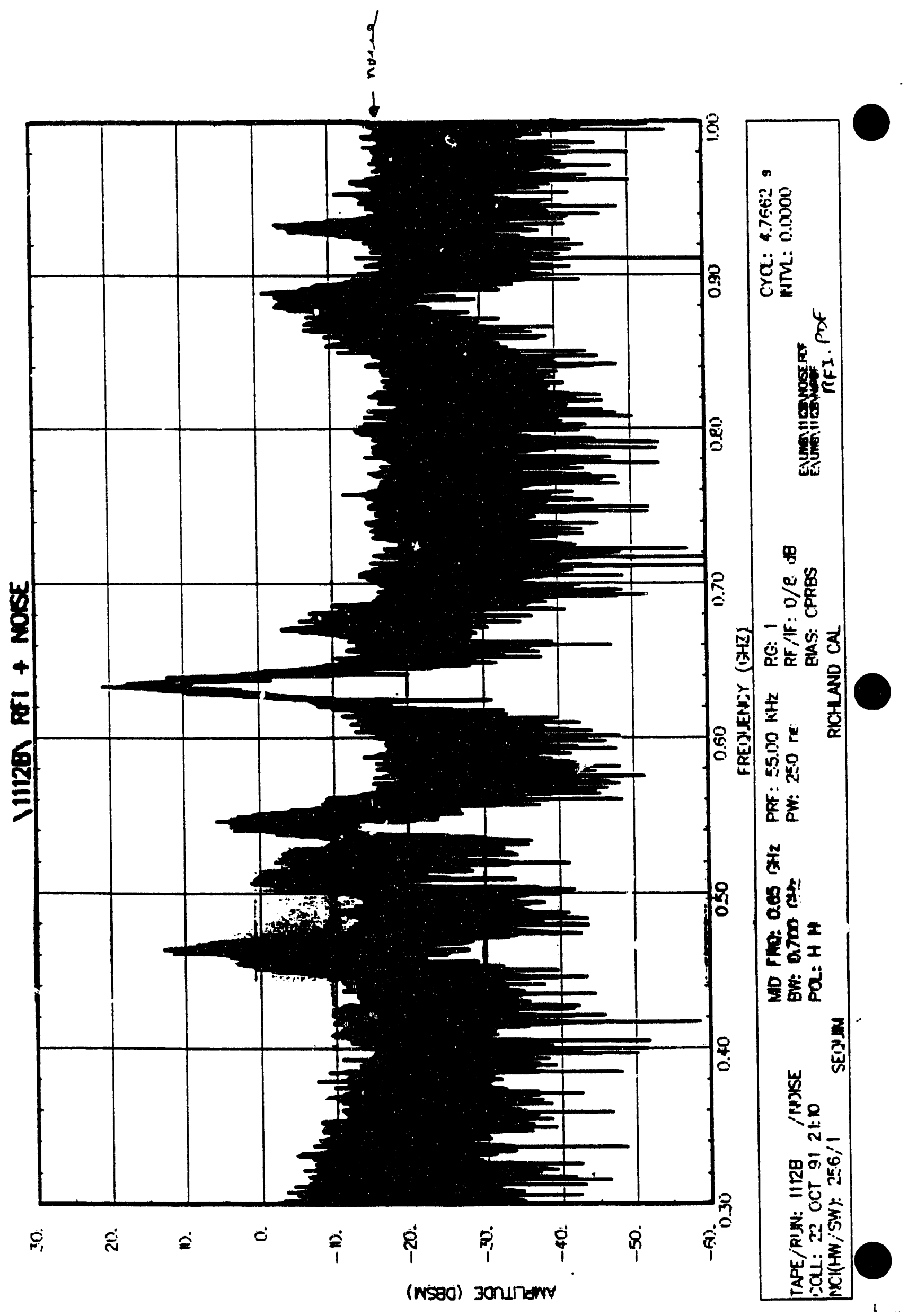

Figuie 1

RFI + Noise

A. 8 


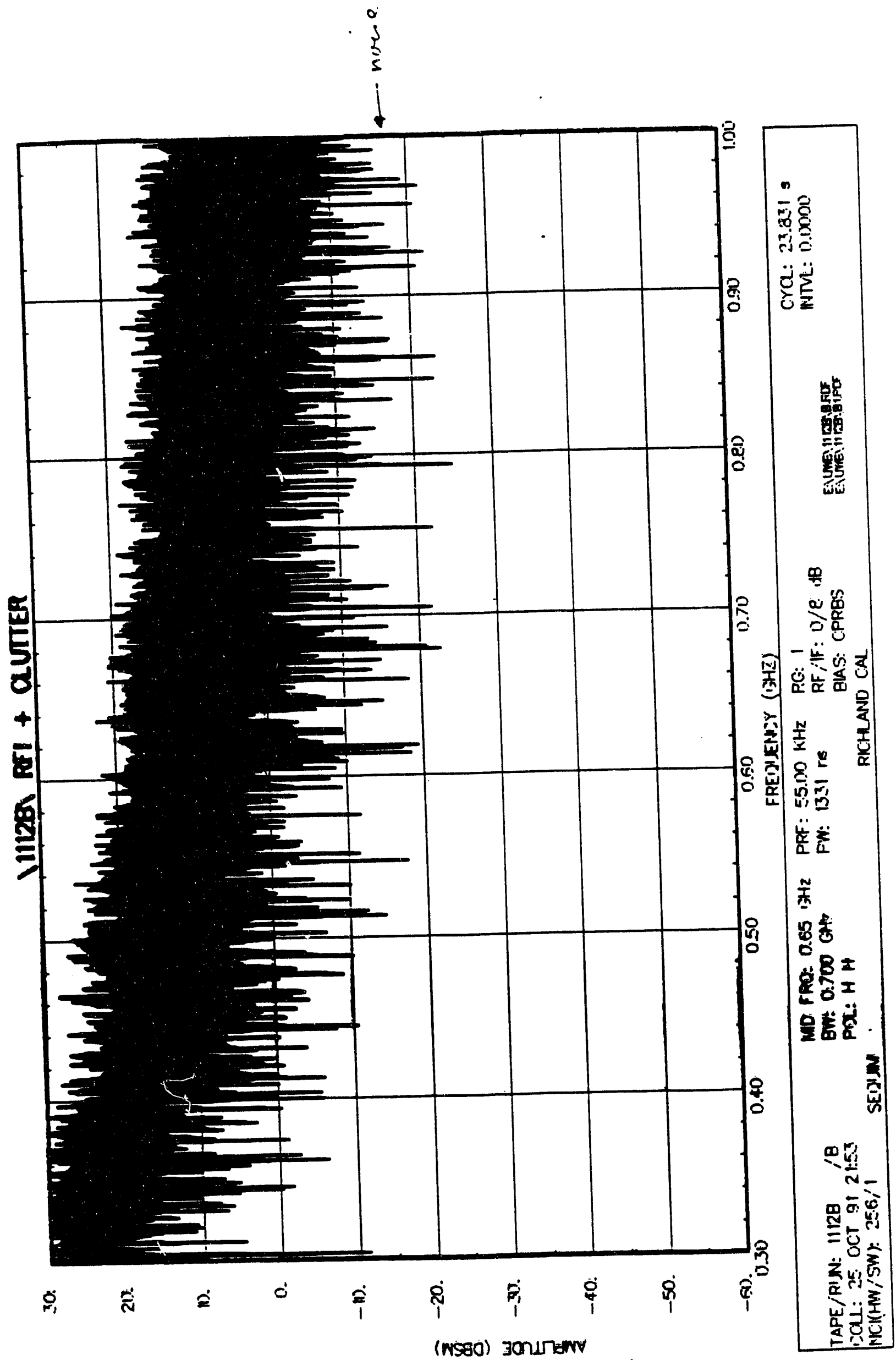

Figure 2

RFI + Clutter

A. 9 


\begin{tabular}{||l|c|c||}
\hline & CAPABILITY & USED \\
\hline Polarization & HH VV HV VH & HH VV \\
\hline A/D Resolution & 12 bits & 12 bits \\
\hline Coherent Integration & $<64,000$ & 256 \\
\hline Bias Compensation & Pseudorandom & Pseudorandom \\
\hline
\end{tabular}

\section{DATA PROCESSING}

Data was collected and processed over a range interval of 500 meters to 2500 meters. The cell size is given by $R(d R)(d A)$. The processed beam angle $d A$ is .0255 radians. The fundamental range resolution of .214 meters is obtained for $700 \mathrm{MHz}$ of bandwidth. cell area as a function of range for different range resolutions is shown in Figure 3 .

\section{File designation -}

Histogram files are identified with six characters as illustrated below:

AAAPRC - six character file name

$$
\begin{aligned}
& \text { AAA - sector angle [ } 186,216,246,276 \text { or ALI ] } \\
& \text { F- polarization H or V } \\
& \text { R- range resolution } \\
& \text { B: .214m } \\
& \text { C: . } 214 \mathrm{~m} \times 4=.86 \mathrm{~m} \\
& \text { D: .214m X2=.43m } \\
& \text { E: . } 214 \mathrm{~m} \times 8=1.71 \mathrm{~m} \\
& \text { F: } .214 \mathrm{~m} \times 16=3.42 \mathrm{~m} \\
& \text { G: } 214 \mathrm{~m} \times 32=6.85 \mathrm{~m} \\
& \text { C- a processing code }
\end{aligned}
$$

\begin{tabular}{|c|c|c|c|}
\hline Character & sector & Pol & Range \\
\hline A & 186 & $\mathrm{H}$ & far \\
\hline B & 186 & V & far \\
\hline c & 186 & $\mathrm{H}$ & near \\
\hline D & 186 & $\mathrm{~V}$ & near \\
\hline A & 216 & $\mathrm{H}$ & far \\
\hline B & 216 & $\mathrm{H}$ & near \\
\hline C & 216 & V & far \\
\hline
\end{tabular}

Beam map files are identified with five character file names as illustrated below:

TDRCA - five character file name

$\mathrm{T}$ - tape file identifying principal range and polarization as follows 


\section{CLUTTER CELL AREA}

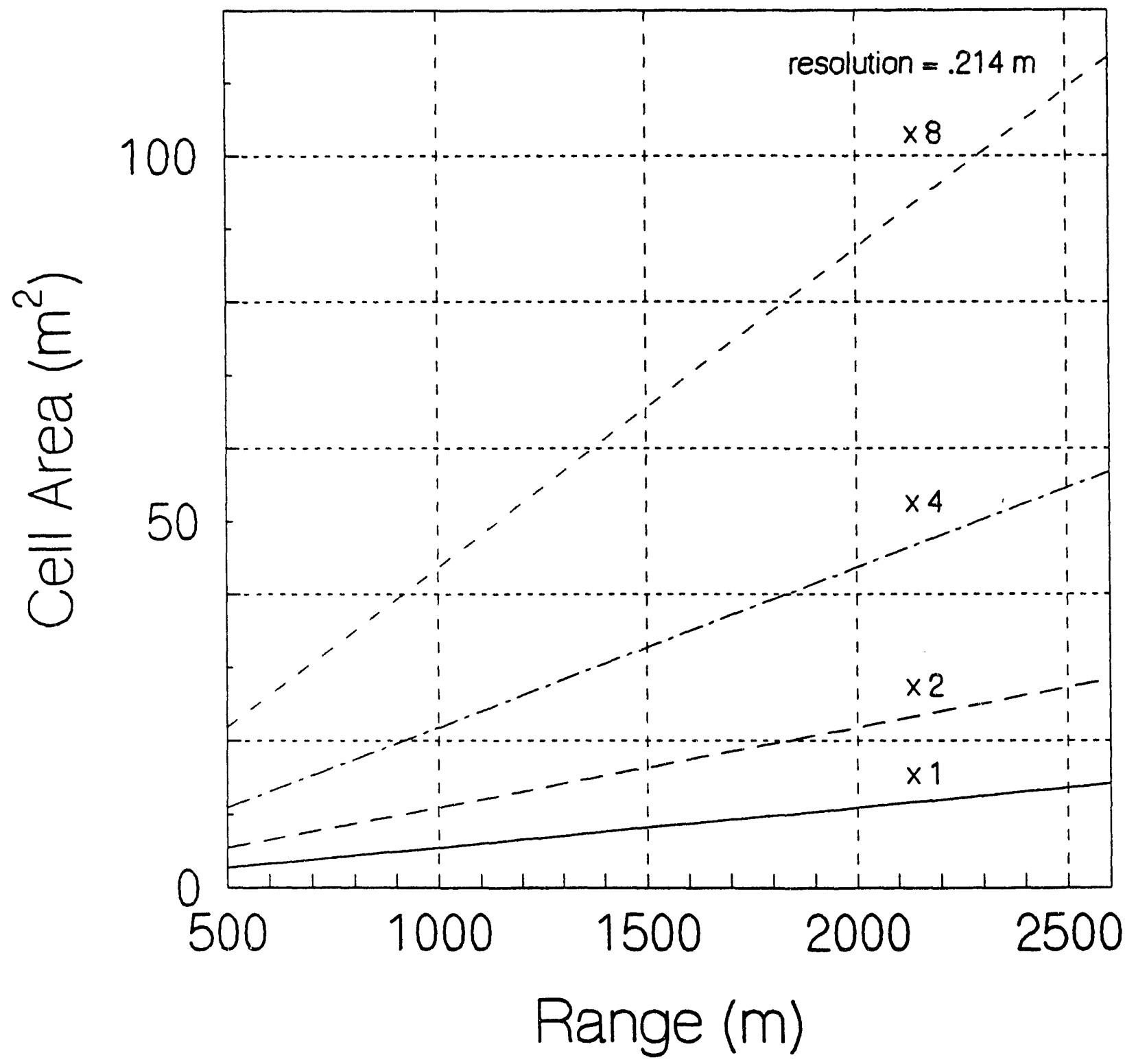

Figure 3

clutter Cell Area vs Range 


$\begin{array}{llll}\text { E } & 216 & \text { V } & \text { near } \\ \text { A } & 246,276 & \text { H } & \text { far } \\ \text { B } & 246,276 & \text { H } & \text { near } \\ \text { C } & 246,276 & \text { V } & \text { far } \\ \text { D } & 246,276 & \text { V } & \text { near }\end{array}$

D - range delay adjustment

$\begin{array}{ll}\text { 1: } & 0 \mathrm{~ns} \\ 2: & -1330 \mathrm{~ns} \\ 3: & -2660 \mathrm{~ns} \\ \text { 4: } & -3990 \mathrm{~ns} \\ \text { 5: } & -5320 \mathrm{~ns}\end{array}$

$\mathrm{R}$ - range resolution (as indicated above)

C - processing code

A - type of output (D for displayable in $d B$, I for linear)

\section{High resolution}

Data for each of the 10 range intervals at each of the four sector angles were processed individually for both $\mathrm{HH}$ and $\mathrm{VV}$ polarization. The result of the first stage of processing was a beam map composed of 21 azimuth beams of nominal 1.5 degree beamwidth covering the 30 degree sector. Each beam contained 929 range cells. The difference between the 1024 input frequencies and the 929 output range cells results from deleting those processed range cells not covered by the radar pulse. No weighting function was used to generate the range cells. Thus, the nominal range resolution is .214 meters. Each beam map was prepared as a linear ASCII file for further statistical processing and as a separate file suitable for display.

The second stage of the processing consisted of collecting all range intervals within a given sector and preparing a set of statistics. The statistical measures consist of:

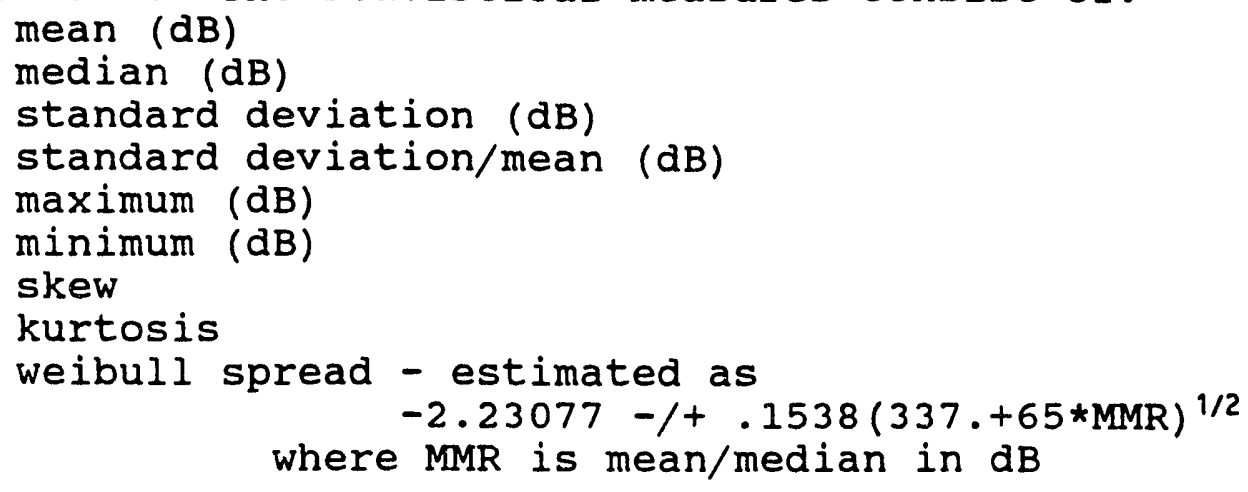


Values were histogrammed in $1 \mathrm{~dB}$ bins from -50 to $+30 \mathrm{~dB}$. In addition, all clutter cells were aggregated as a group for each polarization and the same set of statistics gerierated. Distribution and cumulative plots were prepared.

High range resolution color beam maps displaying reflectivity as a function of range and beam angle are to be found in Appendix A. Each sector angle contains ten maps for each polarization. Each map represents approximately 200 meters and 30 degrees.

\section{Variable resolution}

The maximum bandwidth of $700 \mathrm{MHz}$ was collected in 1024 step frequencies. Resolution was degraded by reducing the processed bandwidth with a constant center frequency of $650 \mathrm{MHz}$. Degradation was performed at steps of $1,2,4$ and 8 for the complete data set. A summary of the varied resolution characteristics is given in Table 3. In addition, the data for the 186 degree sector was further degraded to 16 and 32 . The results of the degradation on means and medians is plotted in Figure 4 and Figure 5 for the aggregate data and in Figures 6 and 7 for the four separate sector angles. The plots appear to show a steep drop off when degrading by a factor of two. Further steps show a rapid leveling off. Figures 8 to 19 jio seam maps for a particular segment of the data within the 186 ciegree sector. This segment was selected for the presence of high levels and low levels within the map. The number of high levels, identified as red, are sharply reduced as resolution is degraded. However, the change in levels is not really due to the change in resolution, but is due to the diff:? parts of the frequency spectrum included to produce the necessiry bandwidth. The same range-angle sector was reprocessed to utilize the same bandwidth, but instead of centering the frequency at the center of the full bandwidth, the center of the lower and upper halves was used. The results are shown in the beam maps of Figures 20 to 23. Obviously the reflectivity is much greater for the map produced from the lower spectral half than from the higher spectral half.

Table 3

Composition of a Processed Data set

\begin{tabular}{|c|c|c|c|c|}
\hline $\begin{array}{c}\text { Resolution } \\
(\mathrm{m})\end{array}$ & $\begin{array}{c}\text { Bandwidth } \\
(\mathrm{MHz})\end{array}$ & $\begin{array}{c}\# \text { of } \\
\text { frequencies }\end{array}$ & $\begin{array}{c}\text { of clutter } \\
\text { cells }\end{array}$ & $\begin{array}{l}\text { \# of } \\
\text { cells } \\
\text { in data }\end{array}$ \\
\hline .214 & 700 & 1024 & 929 & $19.5 \mathrm{~K}$ \\
\hline
\end{tabular}




\begin{tabular}{||c|c|c|c|c||}
\hline .428 & 350 & 512 & 464 & $9.7 \mathrm{~K}$ \\
\hline .856 & 175 & 256 & 233 & $4.9 \mathrm{~K}$ \\
\hline 1.71 & 87.5 & 128 & 116 & $2.4 \mathrm{~K}$ \\
\hline 3.42 & 43.75 & 64 & 58 & $1.2 \mathrm{~K}$ \\
\hline 6.84 & 21.88 & 32 & 29 & $.6 \mathrm{~K}$ \\
\hline
\end{tabular}

Summary

A summary of the statistical parameters obtained for the aggregated data is provided in Table 4. A similar summary for the data segregated by sector is found in Table 5. Plots of distributions and cumulatives along with histogram and statistical listings are provided in Appendices B, C and D.

Table 4

STATISTICAL SUMMARY Of REFLECTIVITY at SEQUIM

\begin{tabular}{||l|l|l|l|l|l|l|l|l||}
\hline File & Pol & Res & $\begin{array}{l}\text { Mean } \\
(\mathrm{dB})\end{array}$ & $\begin{array}{l}\text { Median } \\
(\mathrm{dB})\end{array}$ & $\begin{array}{l}\text { SD/Mn } \\
(\mathrm{dB})\end{array}$ & $\begin{array}{l}\text { Max } \\
(\mathrm{dB})\end{array}$ & Weib & Num \\
\hline ALLHB1 & HH & 1 & -11.5 & -18.8 & 4.7 & 10 & 2.14 & $780 \mathrm{~K}$ \\
\hline ALLVB1 & WV & 1 & -7.4 & -14. & 4.23 & 16 & 2.02 & $780 \mathrm{~K}$ \\
\hline ALLHD1 & HH & 2 & -15.4 & -22.6 & 4.66 & 7 & 2.13 & $390 \mathrm{~K}$ \\
\hline ALLVD1 & WV & 2 & -11.1 & -18. & 4.57 & 11 & 2.08 & $390 \mathrm{~K}$ \\
\hline ALLHC1 & HH & 4 & -16.5 & -23.4 & 4.52 & 40 & 2.08 & $195 \mathrm{~K}$ \\
\hline ALLVC1 & W & 4 & -12.0 & -19.0 & 4.67 & 9 & 2.10 & $195 \mathrm{~K}$ \\
\hline ALLHE1 & HH & 8 & -16.6 & -23.0 & 4.39 & 4 & 2.00 & $97 \mathrm{~K}$ \\
\hline ALLVE1 & WV & 8 & -12. & -18.9 & 4.69 & 90 & 2.08 & $97 \mathrm{~K}$ \\
\hline
\end{tabular}


Table 5

STATISTICAL SUMMARY of

REFLECTIVITY at SEQUIM

SEPARATED BY SECTOR

\begin{tabular}{|c|c|c|c|c|c|c|c|c|c|}
\hline File & Pol & Res & $\begin{array}{l}\text { Mean } \\
(\mathrm{dB}) \\
\end{array}$ & $\begin{array}{l}\text { Median } \\
(\mathrm{dB})\end{array}$ & $\begin{array}{l}\mathrm{SD} / \mathrm{Mn} \\
\text { (dB) }\end{array}$ & $\begin{array}{l}\text { Max } \\
\text { (dB) }\end{array}$ & Weib & $\begin{array}{l}\text { Shad } \\
(x) \\
\end{array}$ & Num \\
\hline $186 \mathrm{HB1}$ & HH & 1 & -11. & -18.1 & 5.1 & 10 & 2.12 & 10 & 195K \\
\hline $186 \mathrm{VB} 1$ & wv & 1 & -6.9 & -13.4 & 4.2 & 13 & 2.01 & 10 & $195 K$ \\
\hline $216 \mathrm{HB1}$ & HH & 1 & -13. & -17.3 & 3.3 & 5 & 1.69 & 5 & 195K \\
\hline 216VB1 & vv & 1 & -8.5 & -12.9 & 2.9 & 9 & 1.62 & 5 & $195 \mathrm{~K}$ \\
\hline 246HB1 & HH & 1 & -10.8 & -17.7 & 3.8 & 10 & 2.08 & 25 & 195K \\
\hline 246VB 1 & vv & 1 & -7.2 & -13.5 & 3.5 & 12 & 1.97 & 25 & $195 K$ \\
\hline 276 HB1 & $\mathrm{HH}$ & 1 & -11.5 & -23.3 & 5.2 & 9 & 2.89 & 50 & 195K \\
\hline 276VB1 & vV & 1 & -7.2 & -17.1 & 5.1 & 16 & 2.58 & 50 & $195 K$ \\
\hline 186HD 1 & $\mathrm{HH}$ & 2 & -15.4 & -22.2 & 4.68 & 7 & 2.07 & 10 & $97 K$ \\
\hline 186V01 & VV & 2 & -10.5 & -17.4 & 4.26 & 10 & 2.02 & 10 & $97 K$ \\
\hline $216 \mathrm{HO} 1$ & $\mathrm{HH}$ & 2 & -16.6 & -21.3 & 3.23 & 2 & 1.65 & 5 & $97 K$ \\
\hline 216V01 & vV & 2 & -12.1 & -16.8 & 3.2 & 6 & 1.66 & 5 & $97 K$ \\
\hline $246 \mathrm{HD} 1$ & $\mathrm{HH}$ & 2 & -14.9 & -21.8 & 3.89 & 3 & 2.09 & 25 & $97 \mathrm{~K}$ \\
\hline $246 \mathrm{V0} 1$ & vV & 2 & -11.1 & -17.6 & 3.68 & 9 & 2.02 & 25 & $97 K$ \\
\hline $276 \mathrm{HD} 1$ & HH & 2 & -14.9 & -26.6 & 5.44 & 6 & 2.78 & 50 & $97 \mathrm{~K}$ \\
\hline 276 VD1 & vv & 2 & -10.8 & -21.4 & 5.63 & 11 & 2.78 & 50 & $97 K$ \\
\hline $186 \mathrm{HCl}$ & $H H$ & 4 & -16.4 & .23 .4 & 4.56 & 4 & 2.1 & 10 & $49 \mathrm{~K}$ \\
\hline $186 \mathrm{VCl}$ & vV & 4 & -11.3 & -18.2 & 4.68 & 9 & 2.07 & 10 & $49 \mathrm{~K}$ \\
\hline $216 \mathrm{HC1}$ & HH & 4 & -17.6 & -22.2 & 3.2 & 1 & 1.64 & 5 & $49 K$ \\
\hline $216 \mathrm{VC} 1$ & vv & 4 & -12.9 & -17.7 & 3.3 & 5 & 1.69 & 5 & $49 K$ \\
\hline $246 \mathrm{HCl}$ & HH & 4 & -16 & -22.6 & 3.89 & 3 & 2.04 & 25 & $49 K$ \\
\hline 246VC1 & w & 4 & -12 & -18.7 & 3.81 & 6 & 2.04 & 25 & $49 K$ \\
\hline $276 \mathrm{HCl}$ & $H H$ & 4 & -16.1 & -25.8 & 5.27 & 4 & 2.59 & 50 & $49 K$ \\
\hline $276 \mathrm{VCl}$ & w & 4 & -11.9 & -22.9 & 5.58 & 8 & 2.76 & 50 & $49 K$ \\
\hline 186HE 1 & HH & 8 & -16.5 & -23.6 & 4.46 & 2 & 2.11 & 10 & $24 k$ \\
\hline 186VE 1 & vv & 9 & -11.4 & -18.2 & 4.65 & 9 & 2.06 & 10 & $24 K$ \\
\hline 216HE 1 & $\mathrm{HH}$ & 8 & -17.8 & -22.2 & 2.94 & -1 & 1.62 & 5 & $24 K$ \\
\hline 216VE1 & vV & 8 & -12.9 & -17.6 & 3.25 & 3 & 1.68 & 5 & $24 K$ \\
\hline 246HE 1 & $\mathrm{HH}$ & 8 & -16.1 & -22.3 & 3.75 & 2 & 1.95 & 25 & $24 k$ \\
\hline 246VE & vV & 8 & -12. & -18.4 & 3.7 & 5 & 2. & 25 & $24 x$ \\
\hline 276HE 1 & $H H$ & 8 & -16.2 & .24 .4 & 5.1 & 4 & 2.3 & 50 & $24 k$ \\
\hline
\end{tabular}


VARIATION OF MEAN

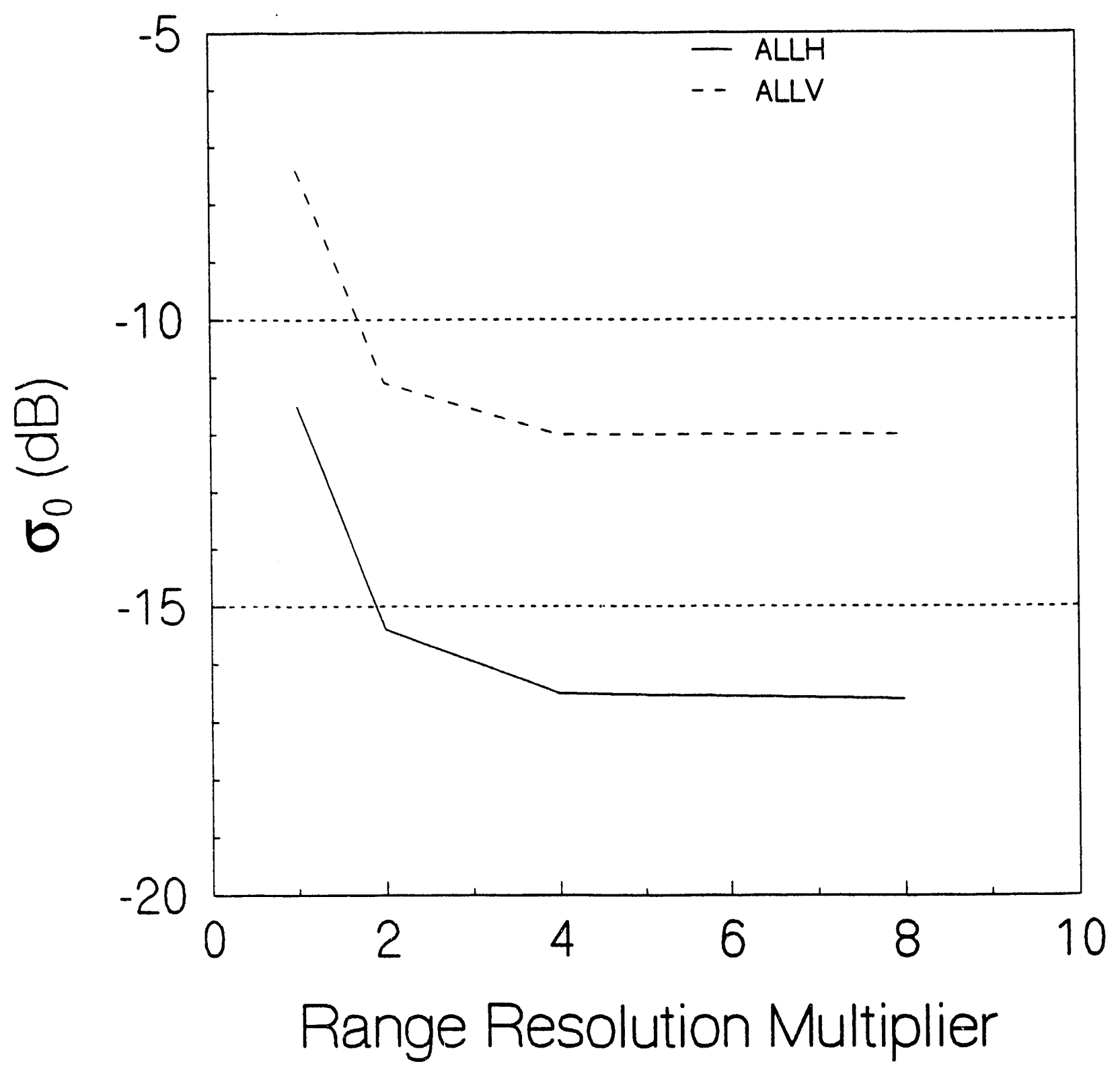

Figure 4
Variation of Aggregate Mean with Range Resolution

A. 16 


\section{VARIATION OF MEDIAN}

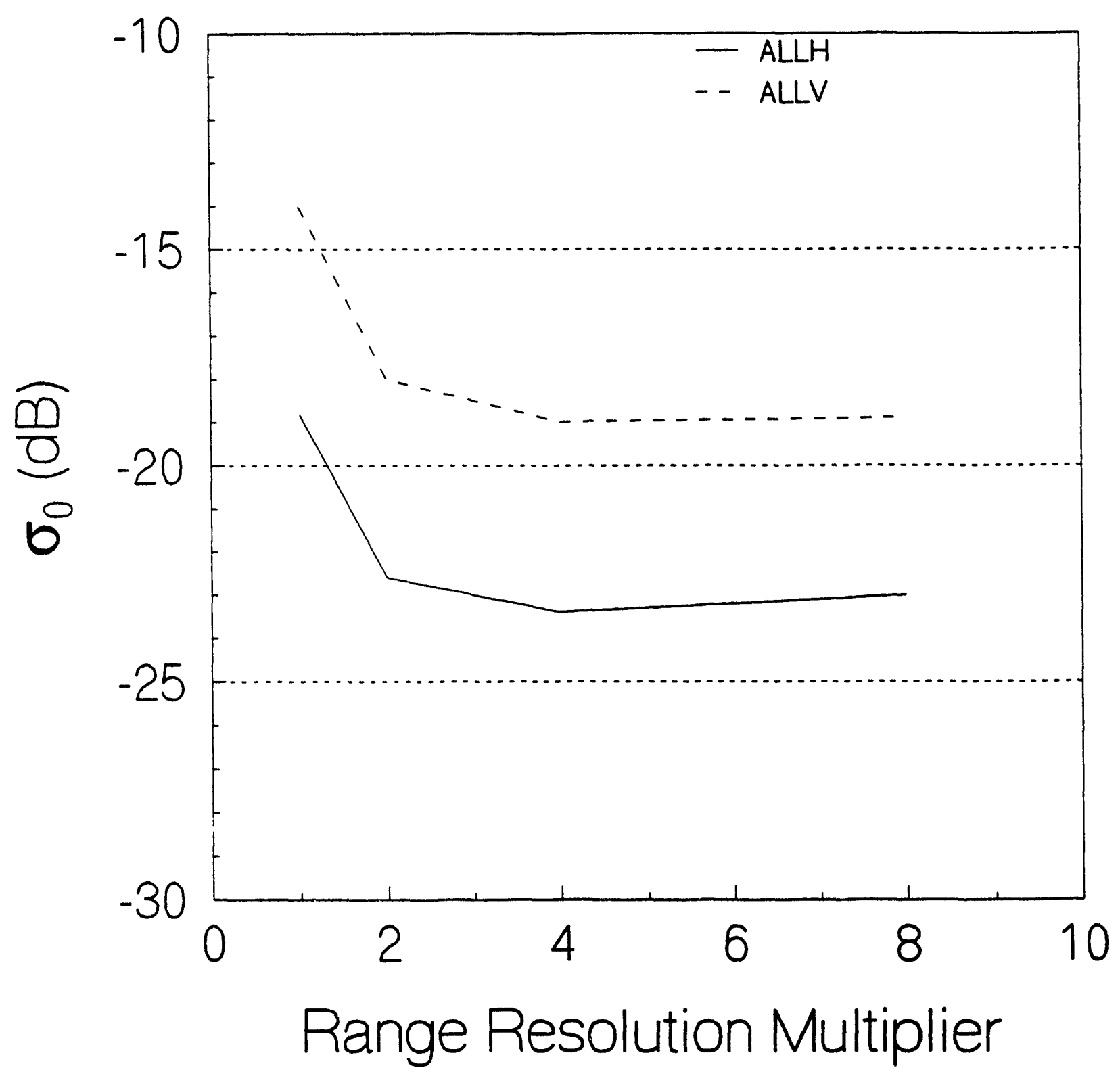

Figure 5

Variation of Aggregate Median with Range Resolution 


\section{VARIATION OF MEAN}

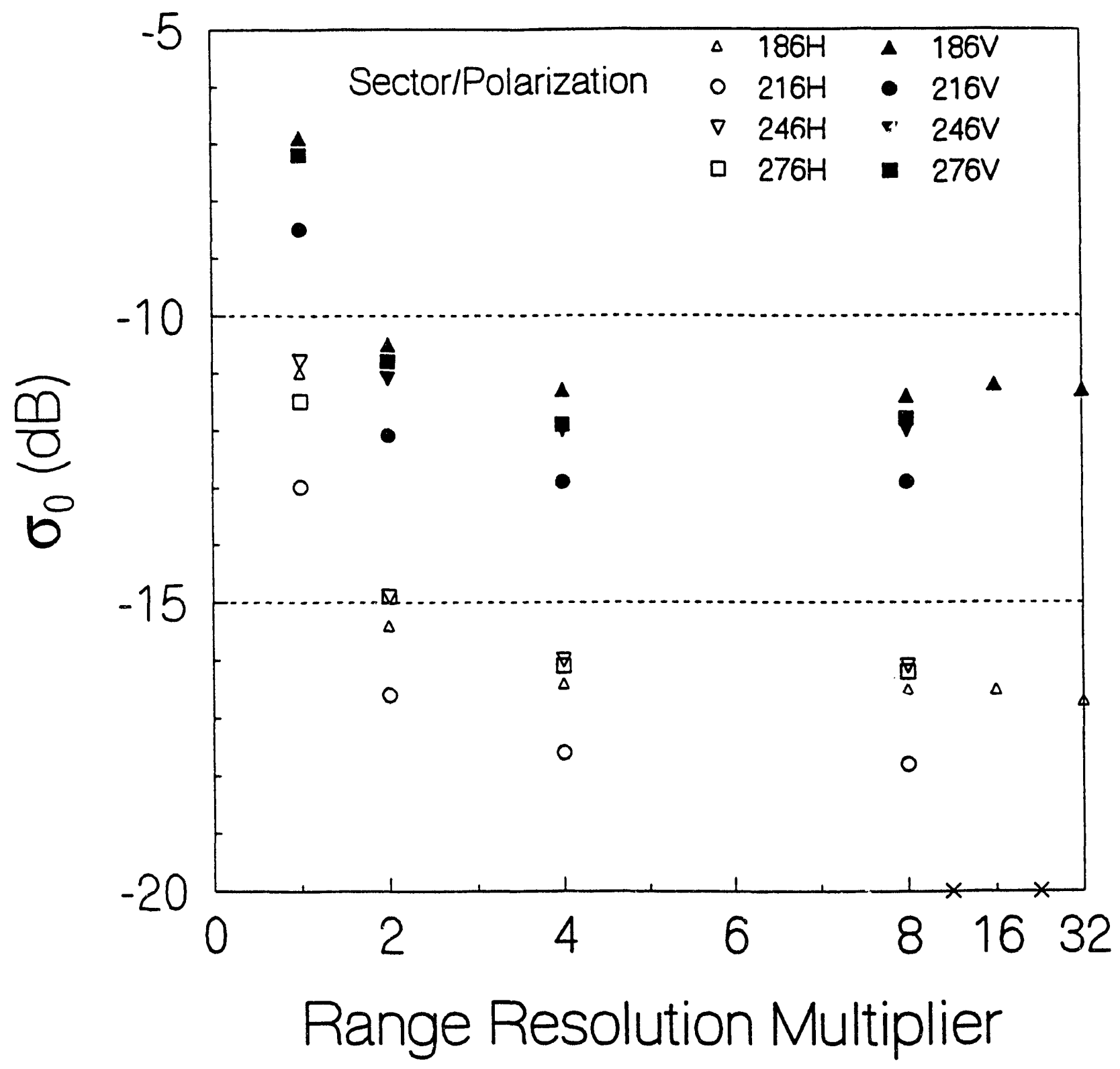

Figure 6

Variation of Sector Mean with Range Resolution

A. 18 


\section{VARIATION OF MEDIAN}

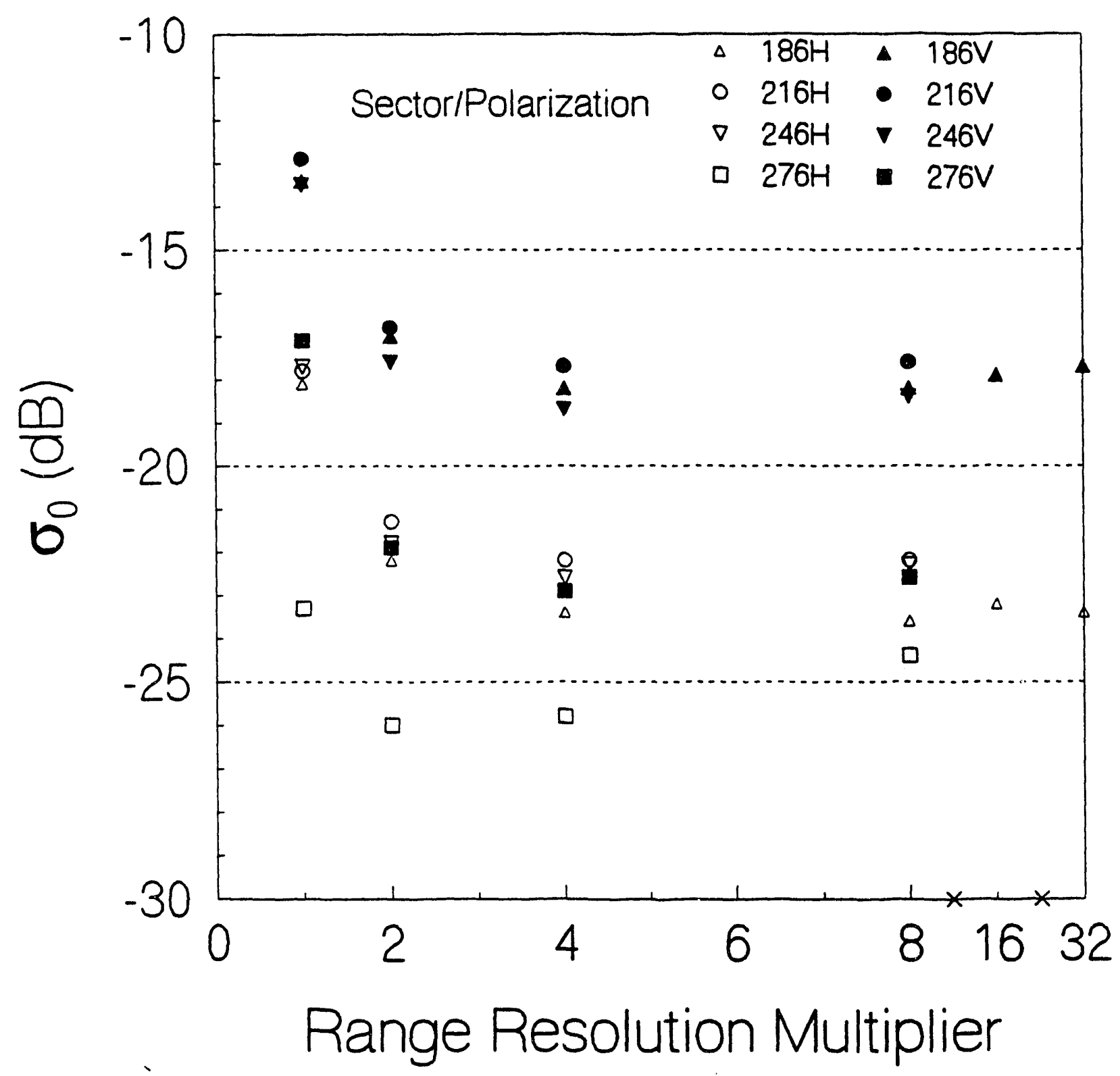

Figure 7

Variation of Sector Median with Range Resolution

A. 19 


\begin{tabular}{|l|l|l|l|l|l|l|l|l|l|}
\hline 276VE1 & VV & 8 & -11.8 & -22.6 & 5.76 & 9 & 2.72 & 50 & $24 \mathrm{~K}$ \\
\hline
\end{tabular}

\section{CORRELATION OF CHIRP AND IMPULSE DATA}

A portion of the data from the 186 degree sector was processed to produce a file of high resolution range-azimuth reflectivity values. This file was provided to $\mathrm{Dr}$. Michael Tuley of GTRI to correlate with the PNL processed data collected for the same general region. His work indicated a high degree of correlation with an offset of 72.4 meters. The means and median values, when scaled for the apparent offset, were within about 1 dB. A subsequent examination of the SPC processing algorithms uncovered an iliproper range slide of about 200 feet. Removal of that range brings the spatial assignments of the two data sets within close agreement. All data was processed with the corrected range. 

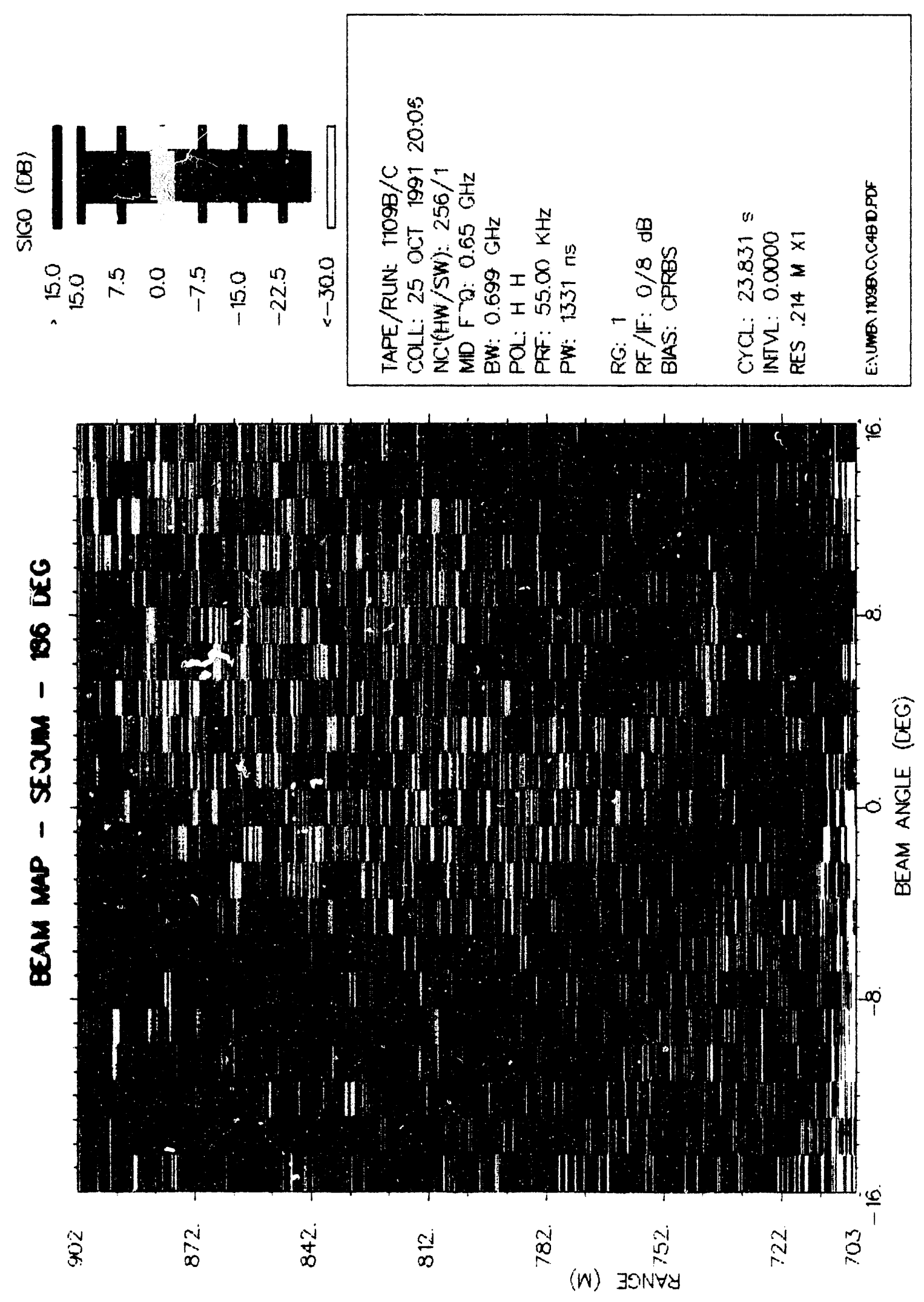

Figure 8.

Resolution: .214m $\times 1$ Center Frequencies - H polarization

A. 21 

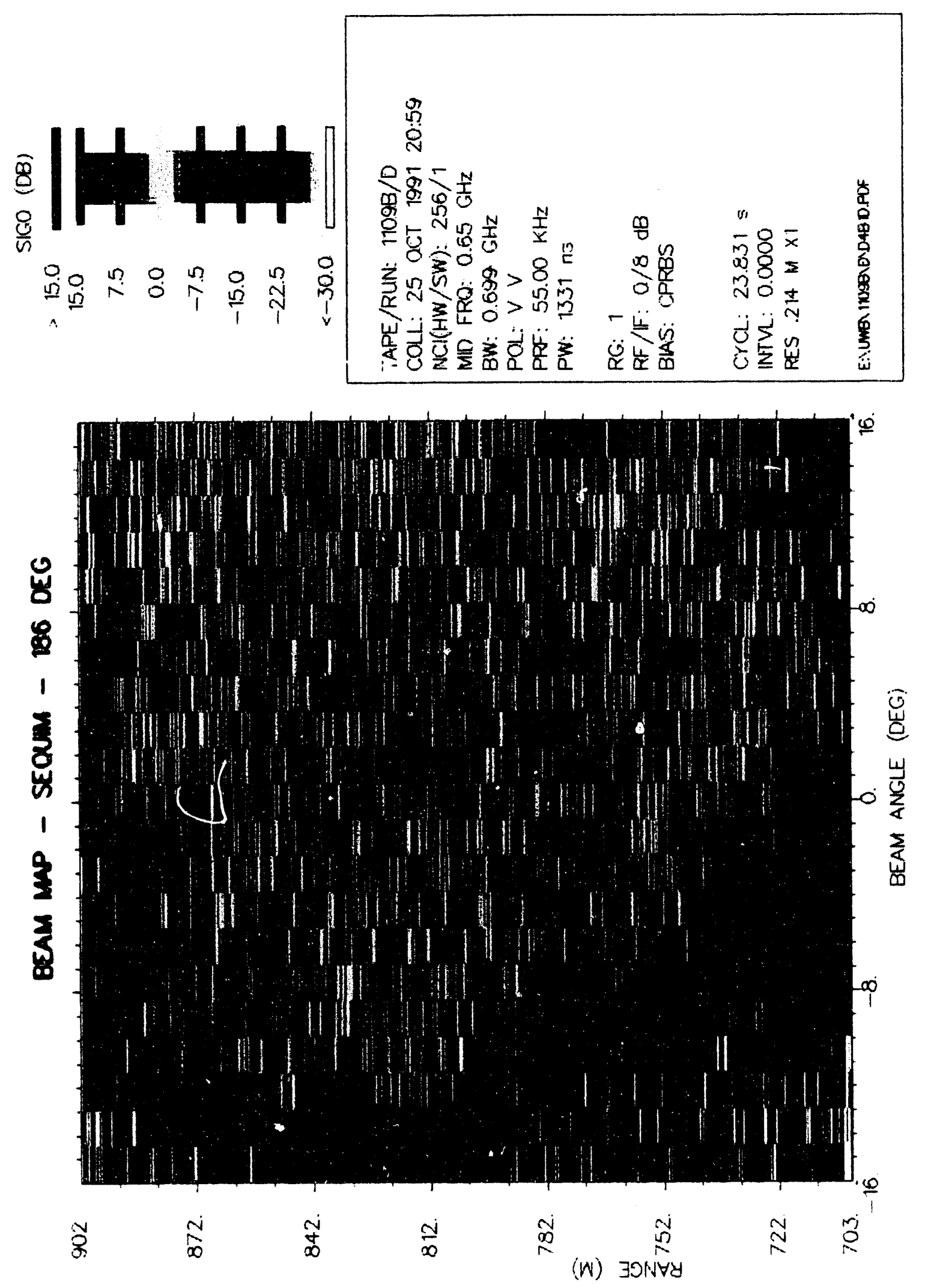

Figure 9.

Resolution: .214m $\times 1$ Center Frequencies - V polarization 

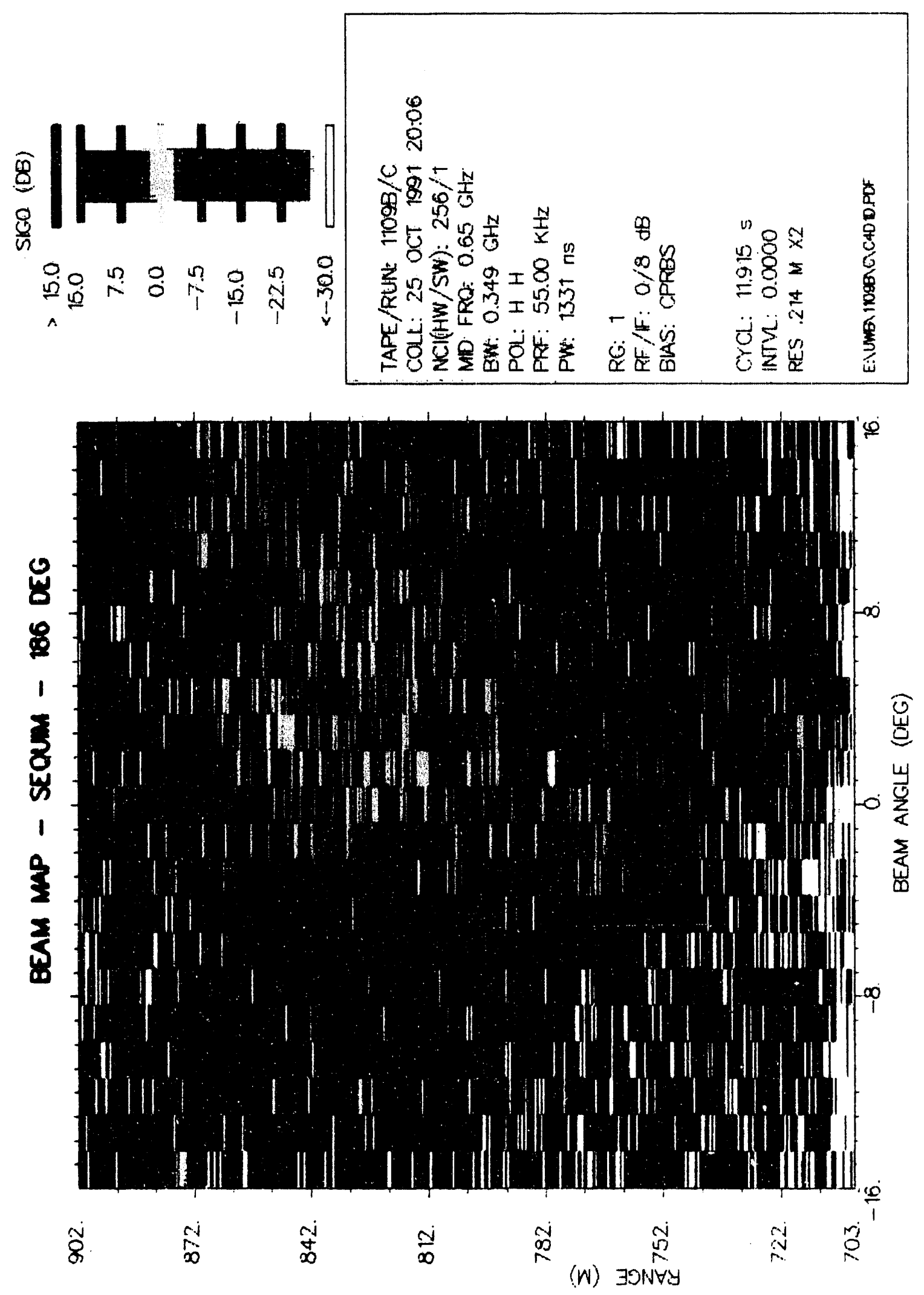

Figure 10.

Resolution: .214m $\times 2$ Center Frequencies - H polarization 

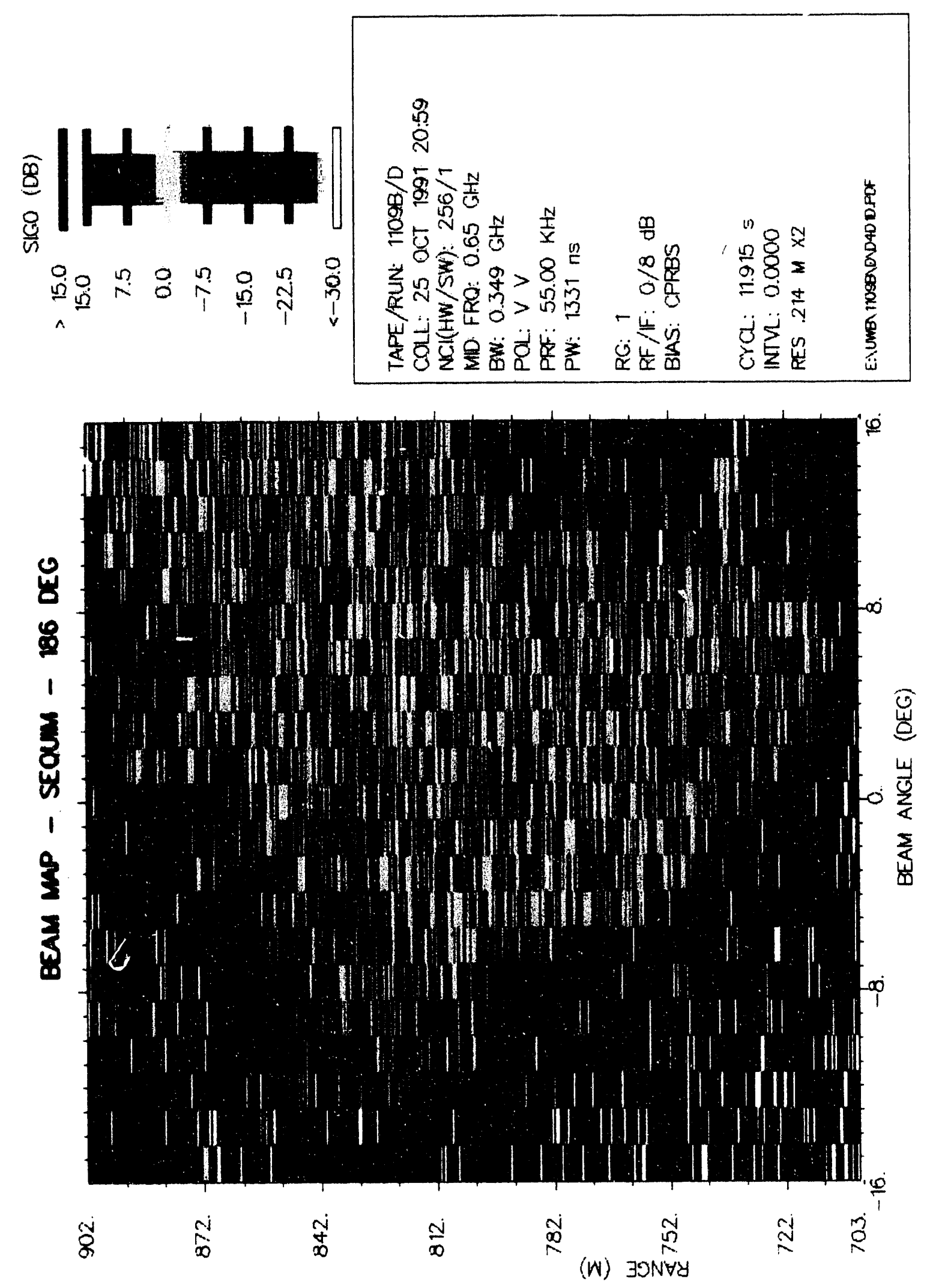

Figure 11.

Resolution: .214m $\times 2$ Center Frequencies - V polarization 

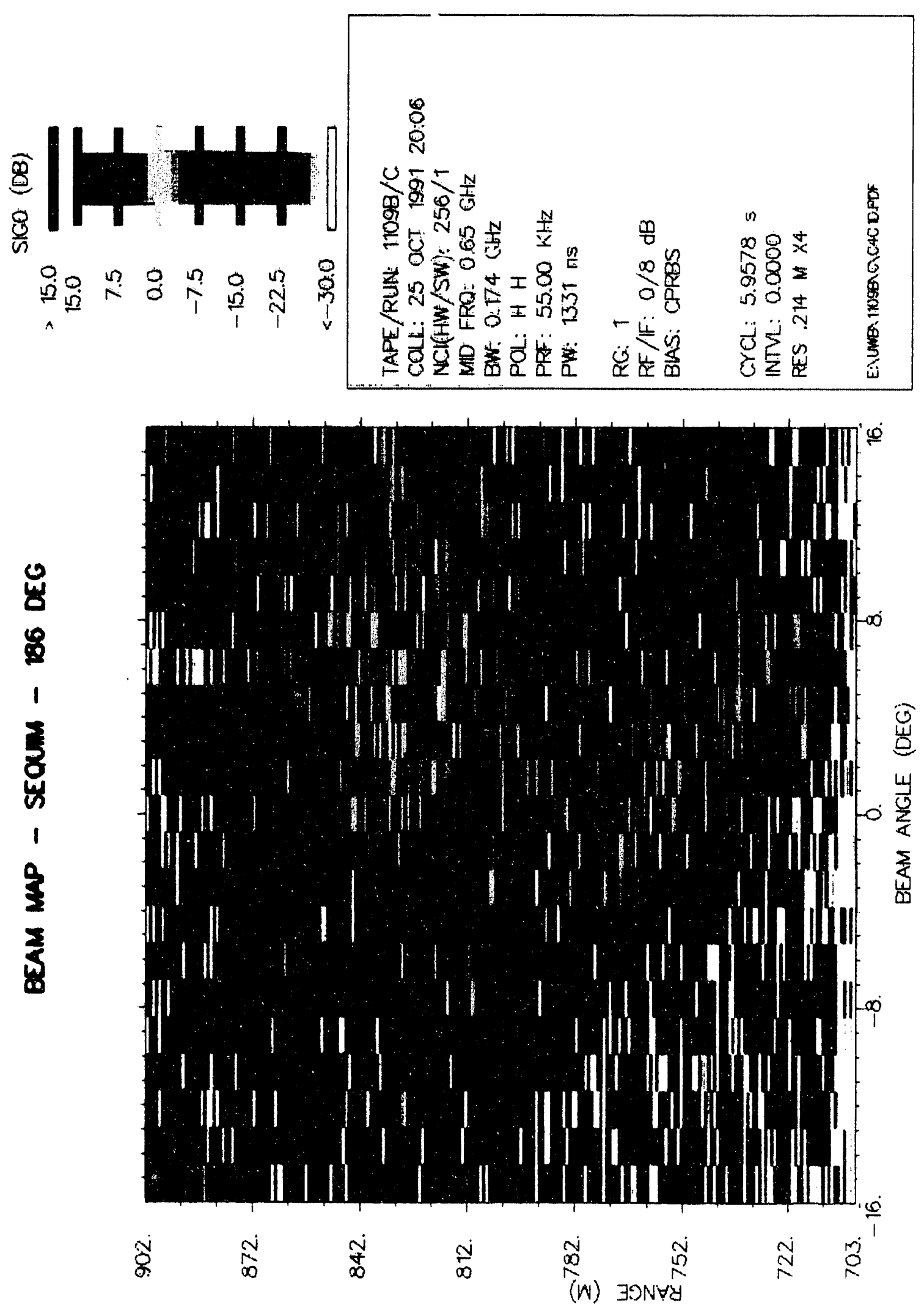

Figure 12.

Resolution: .214m $\times 4$ Center Frequencies - H polarization

A. 25 

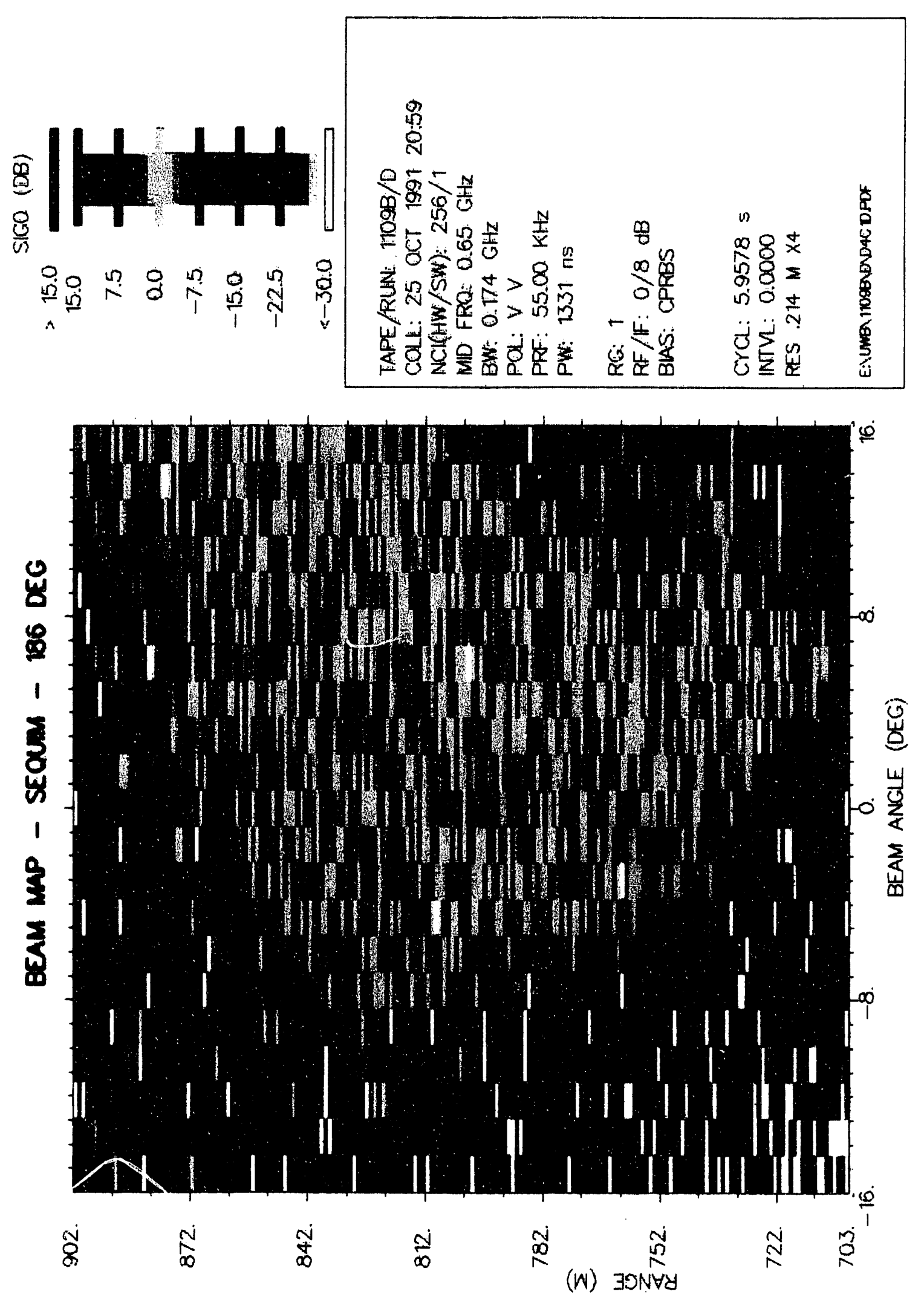

Figure 13.

Resolution: .214m $\times 4$ Center Frequencies - V polarization 

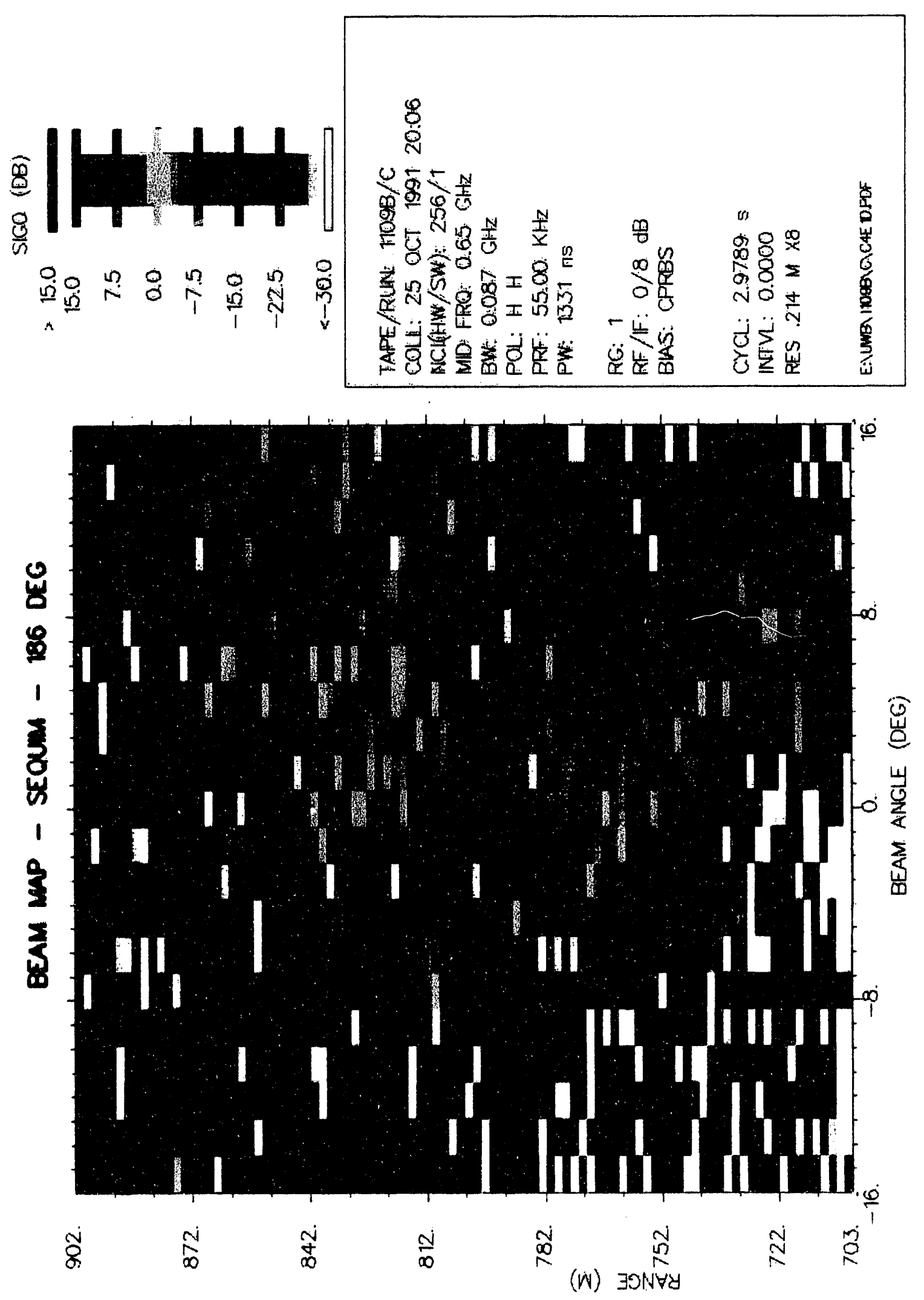

Figure 14.

Resolution: .214m $\times 8$ Center Frequencies - H polarization 

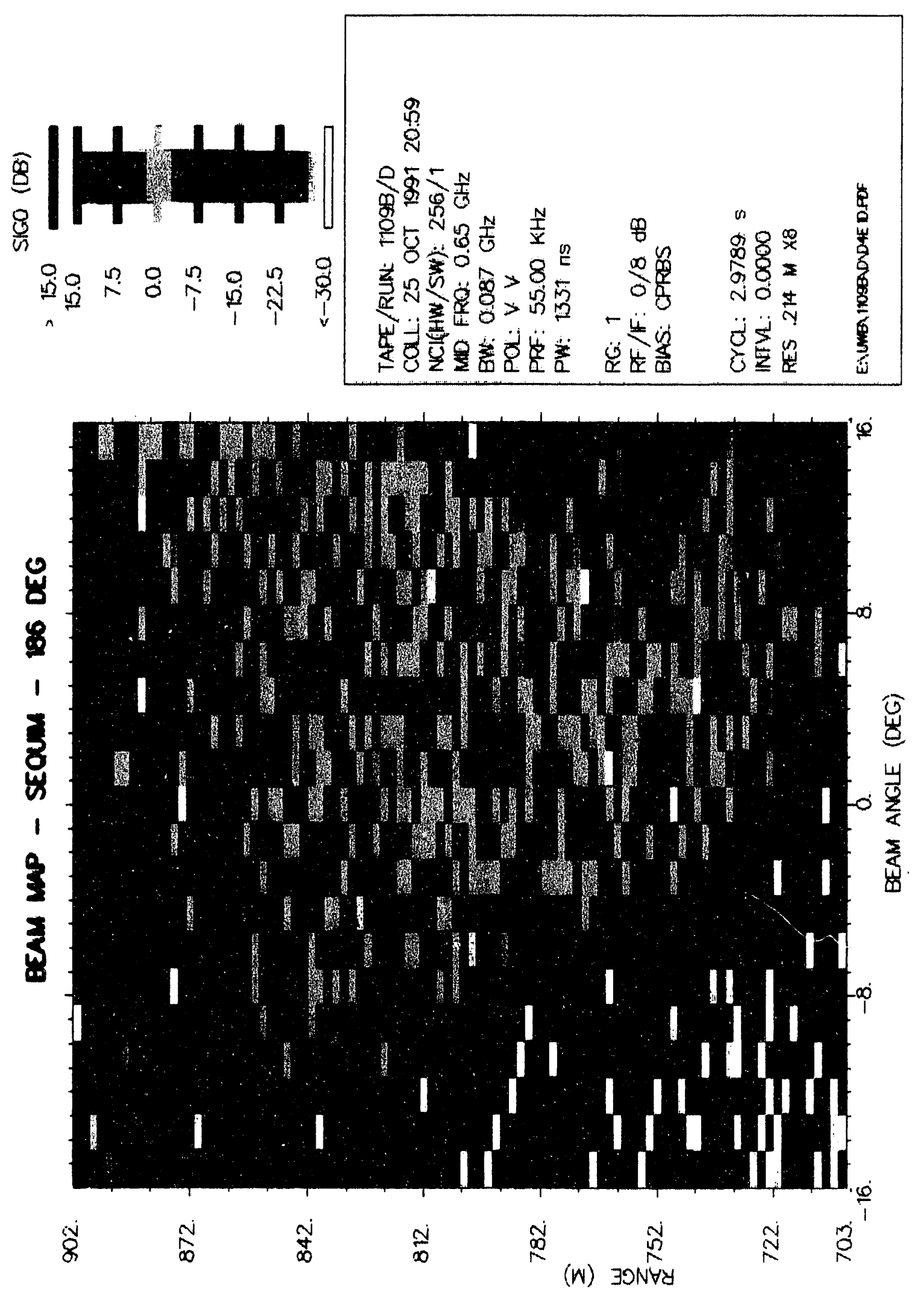

Figure 15.

Resolution: .214m $\times 8$ Center Frequencies - V polarization

A. 28 

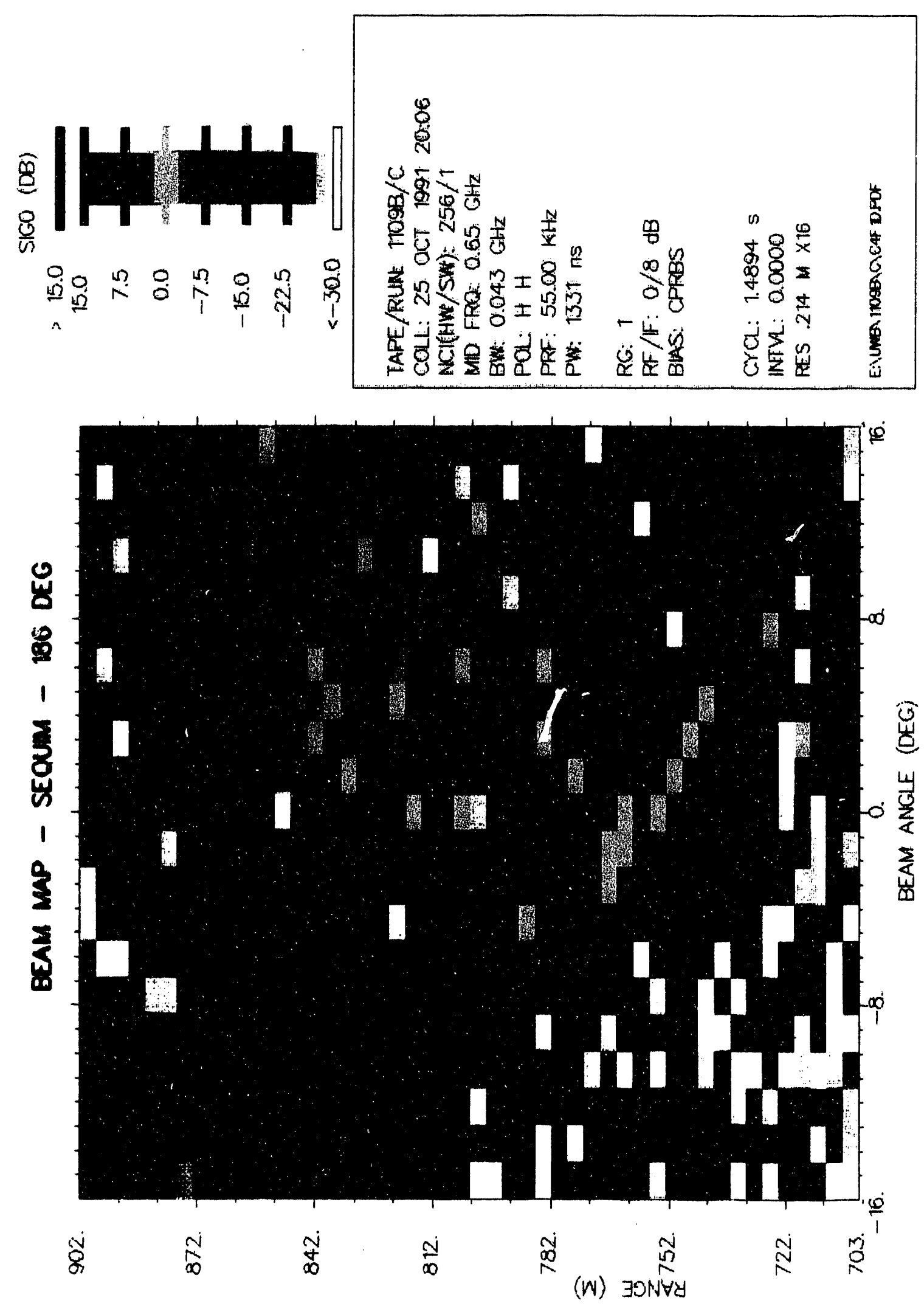

Figure 16.

Resolution: . $214 \mathrm{~m} \times 16$ Center Frequencies - H polarization

A. 29 

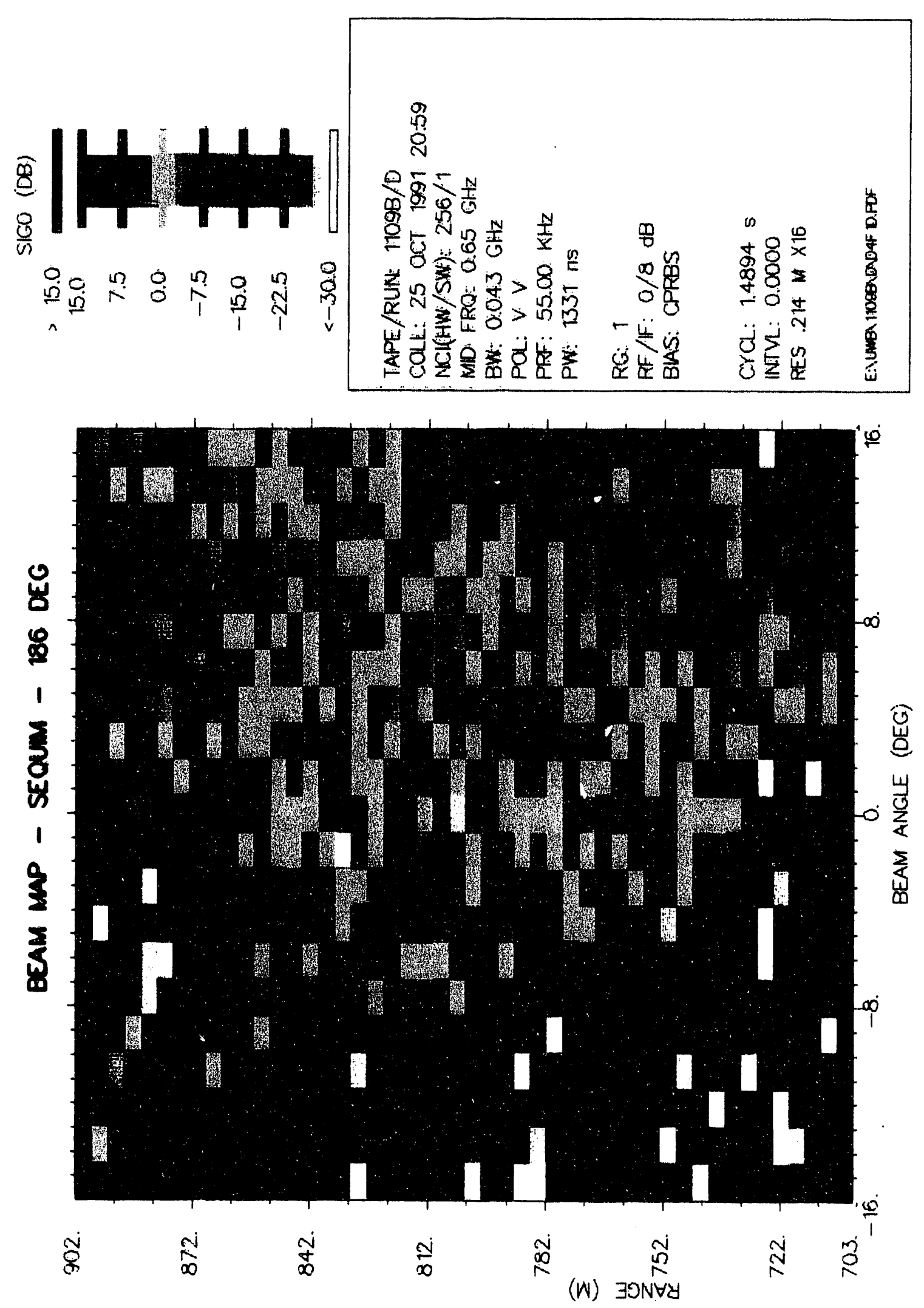

Figure 17.

Resolution: .214m $\times 16$ Center Frequencies $-V$ polarization

A. 30 

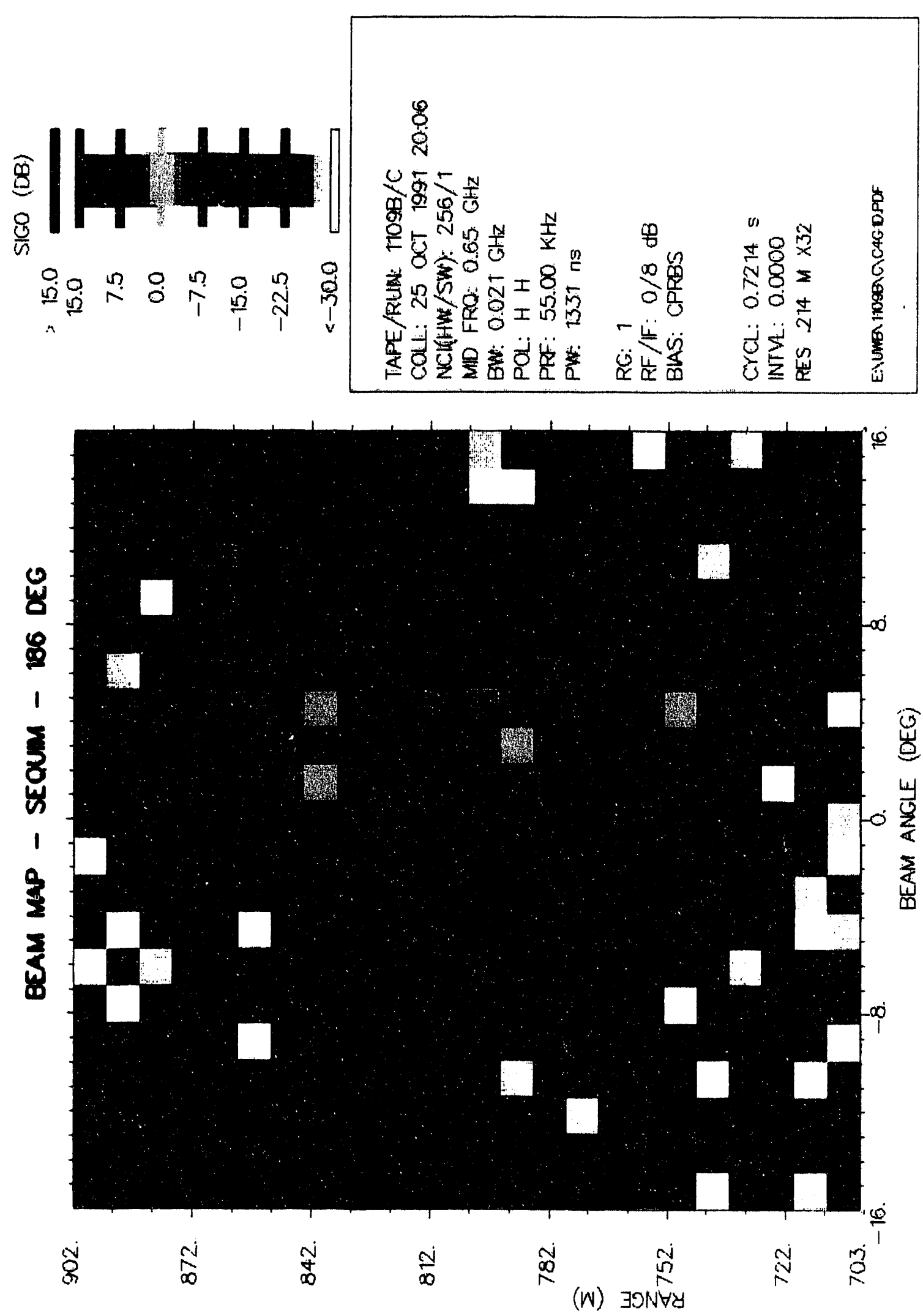

Figure 18.

Resolution: . 214m x32 Center Frequencies - H polarization

A. 31 

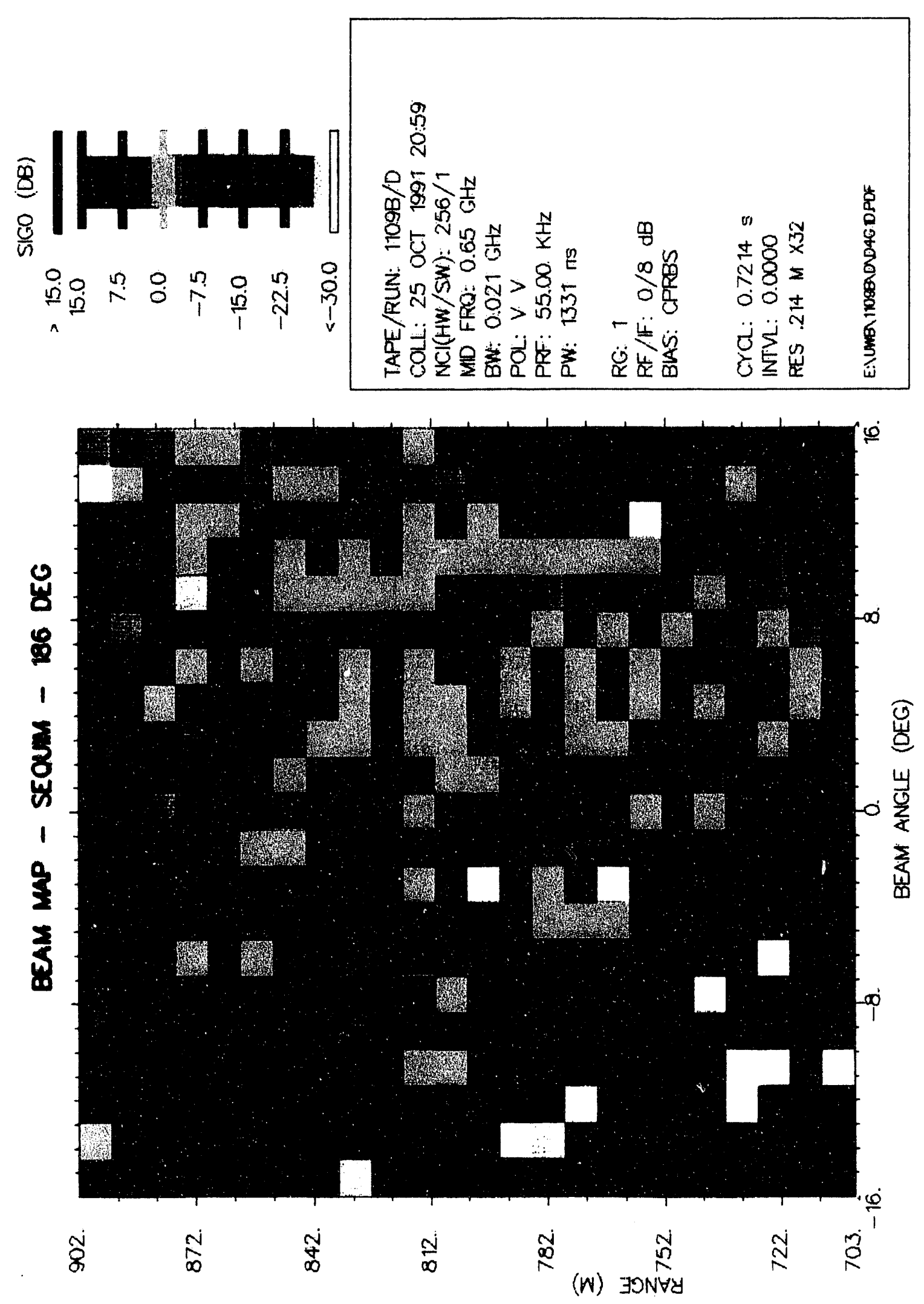

Figure 19.

Resolution: .214m x32 Center Frequencies - V polarization

A. 32 

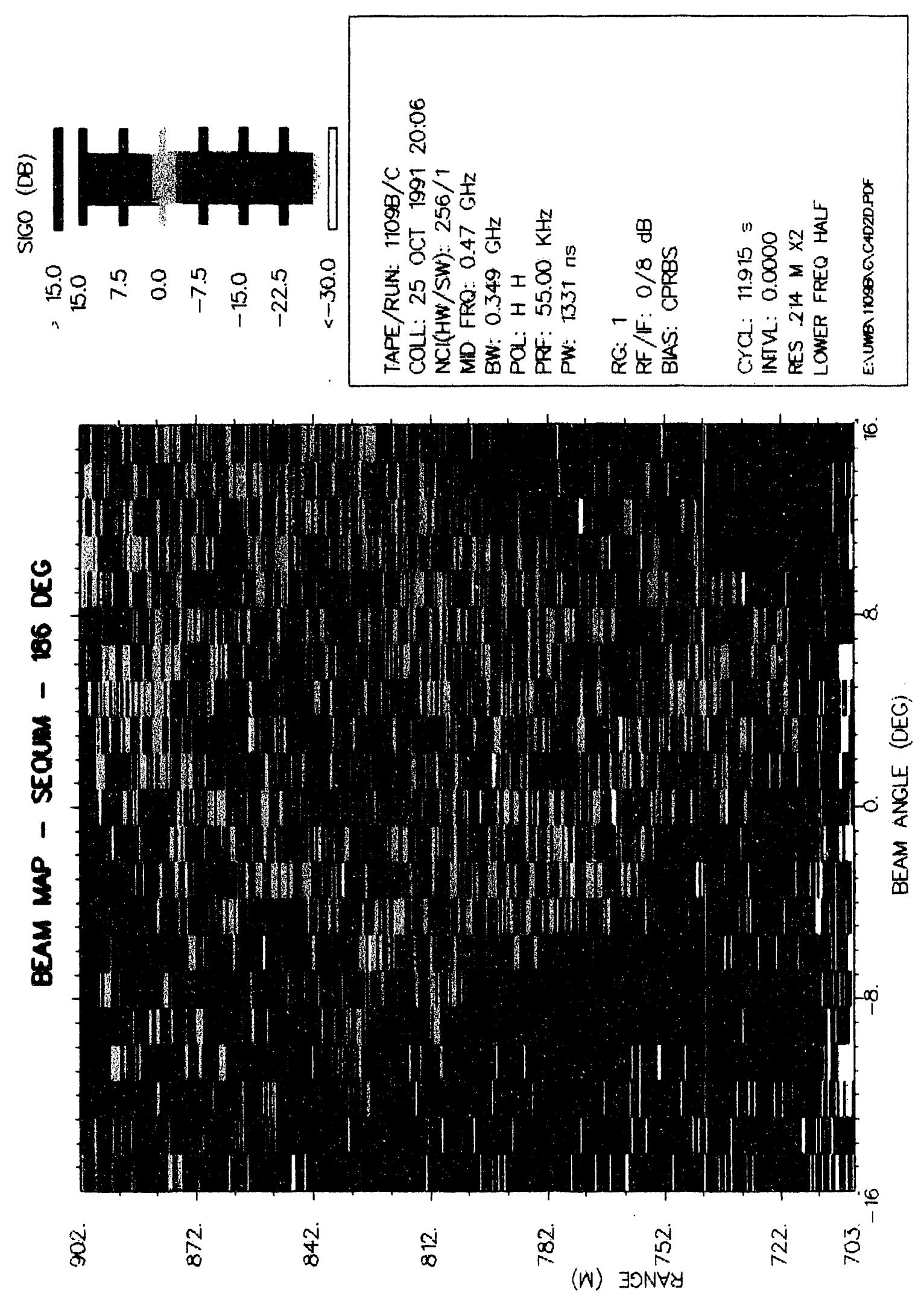

Figure 20.

Resolution: .214m $\times 2$ Lower Frequencies - H polarization

A. 33 

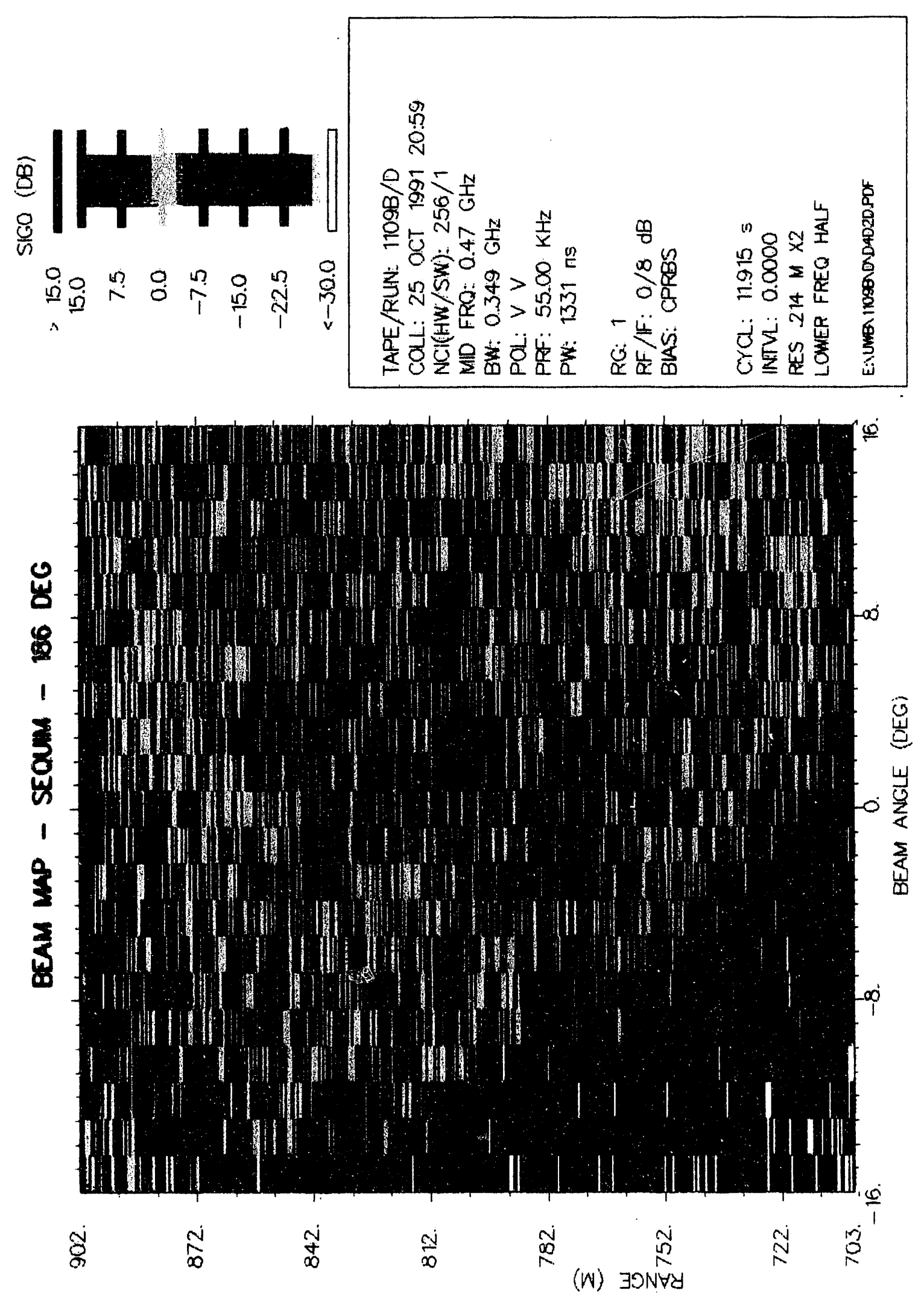

Figure 21.

Resolution: .214m x2 Lower Frequencies - V polarization

A. 34 

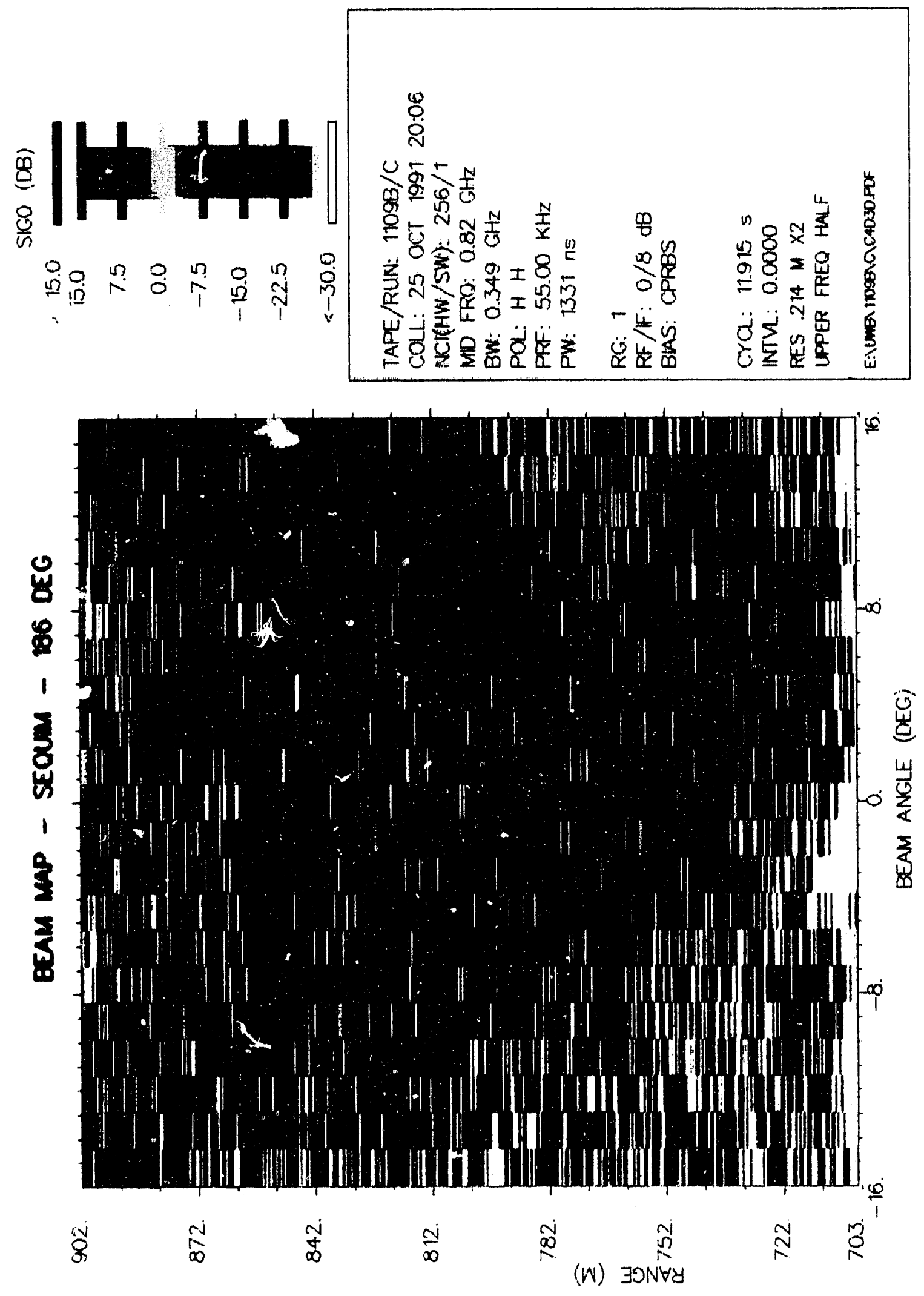

Figure 22.

Resolution: .214m $\times 2$ Upper Frequencies - H polarization A. 35 

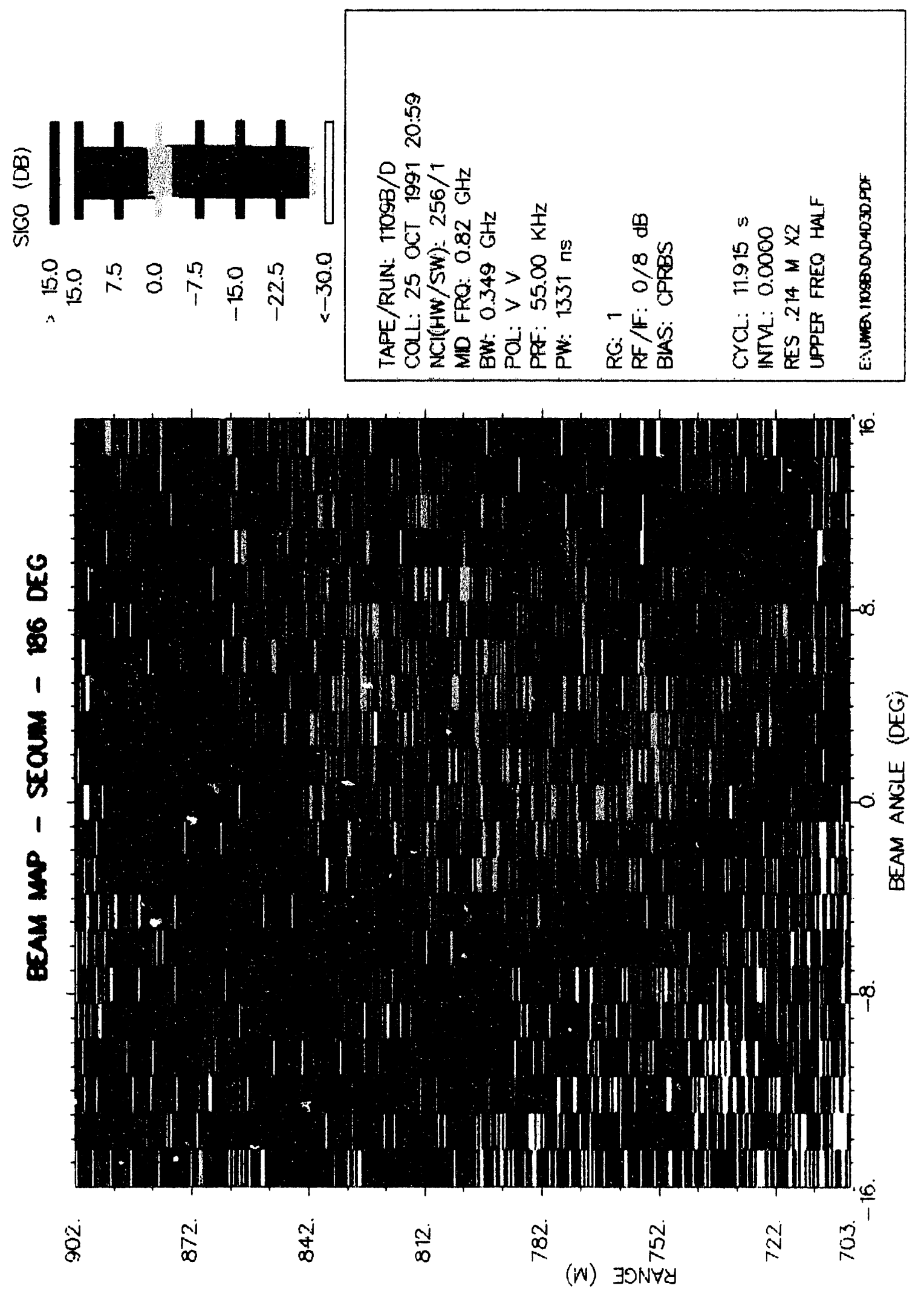

Figure 23.

Resolution: $.214 \mathrm{~m} \times 2$ Upper Frequencies - V polarization

A. 36 


\section{APPENDIX B:}

Ground Truth for Original Site 1991 Sequim

Measurements 
UWB CLUTTER EXPERIMENT GROUND

TRUTH DATA FOR A FORESTED SITE

\author{
V. I. Cullinan \\ E. Telenick
}

November 1991

Letter Report prepared for

Pacific Northwest Laboratories

B. 1 


\section{INTRODUCTION}

Battelle, Marine Sciences Laboratory was requested to participate in the collection of ground truth data in association with the UWB Clutter Radar Experiment conducted for the Defense Advanced Research Projects Agency through a contract with the Department of Energy. The data collection criteria for the radar experiment were to determine the general vegetative and environmental characteristics along 3 transect lines of illumination from a pre-selected site in the Quilcene Ranger District, Olympic National Forest, Washington.

Historically, radar clutter measurement efforts have been planned and sized so that large areas have fallen within the measurement zone.

Consequently, ground truth measurements have often consisted only of general descriptions of terrain type (e.g., wheat fields, forest canopy, desert). This experiment however, was designed to target a much smaller area, thereby allowing the scope of the ground truth data to be expanded from the historical level of data acquisition. The goal of data collection in this experiment was to balance the qualitative and quantitative environmental descriptions to allow for a greater understanding of the reflective radar scatter without providing excessive detail superfluous to the radar designer.

\section{METHODS}

Field surveys were conducted at a pre-selected "forested" site within the 0lympic National Forest. Data collection was designed to characterize the landscape in a general manner for the following parameters: 1) stand type including size, spacing, and dominant species; 2) canopy profile and coverage; 3) understory vegetation type and amount; 4) forest litter accumulation and description; and 5) moisture level. Details of the survey including transect location, field methods, statistical analysis, and photographic records of the specific sites have been included and provide a database useful to groundtruth the forest cover types within the site. Ancillary documentation in the form of aerial photographs plus Geographical Information System (GIS) data on specific timber stands within the radar illumination path will be included as a supplement to this document (Supplement 1 ). 


\section{Iransect Location}

The ground truth sampling area was 1 imited to a $2 \mathrm{~km}$ radius from the radar site, eliminating the area of negative slope which extends approximately $0.5 \mathrm{~km}$ from the radar site counterclockwise in a north to east direction. Within the sampling area three transect line azimuths were predetermined as potential lines of radar illumination and were used for the ground truth data collection. These transects, as viewed from the radar site from south to west, are referred to as the Mount Zion, One-K, and Bear Mountain transects and face 167, 216, and 261 degrees, respectively (Figure 1) (Supplement 2).

Location of the transect lines was accomplished with a hand held compass, aerial photographs, helium balloons, and an observer at the radar site. Using two-way radios, the observer guided a second technician equipped with the balloons to points along the transects which intersected accessible roads. The center lines of illumination were approximated with two balloons per transect plus a final target zone. Photographs were used to document the location of the three transects as seen from the radar site (Appendix $A$ ).

Once the transect lines were located, color aerial photographs were used to delineate potential timber stands and clearcuts for sampling. Stand types were verified along each transect during an initial field survey, and sample points were selected based on gross differences in stand composition. A total of 14 sample plots were selected for the three transects, with 4 to 5 sample plots per transect (Figure 1).

\section{Field Methods}

Due to the cursory nature of the stand surveys, a single sample plot was chosen to describe each stand. Each plot was carefully selected to be representative of that stand type. For example, plot centers were placed away from the edges of clearcuts or logging roads to minimize the effects of blowdowin or logging construction. A plot radius of $16.7 \mathrm{ft}$, which represents $1 / 50$ of an acre on level ground, was selected because it was large enough to accommodate minor site variability yet small enough to allow a single surveyor to efficiently inventory the site. Both general stand conditions and specific site conditions as defined by the boundaries of the plot were described for each sampling plot on a field form (Figure 2 ). 
Figure 1. UWB Experiment Ground Truth Sampling Plot Locations as Adapted from A Custom Correct Map, Little River Enterprises, 1990

B. 4 


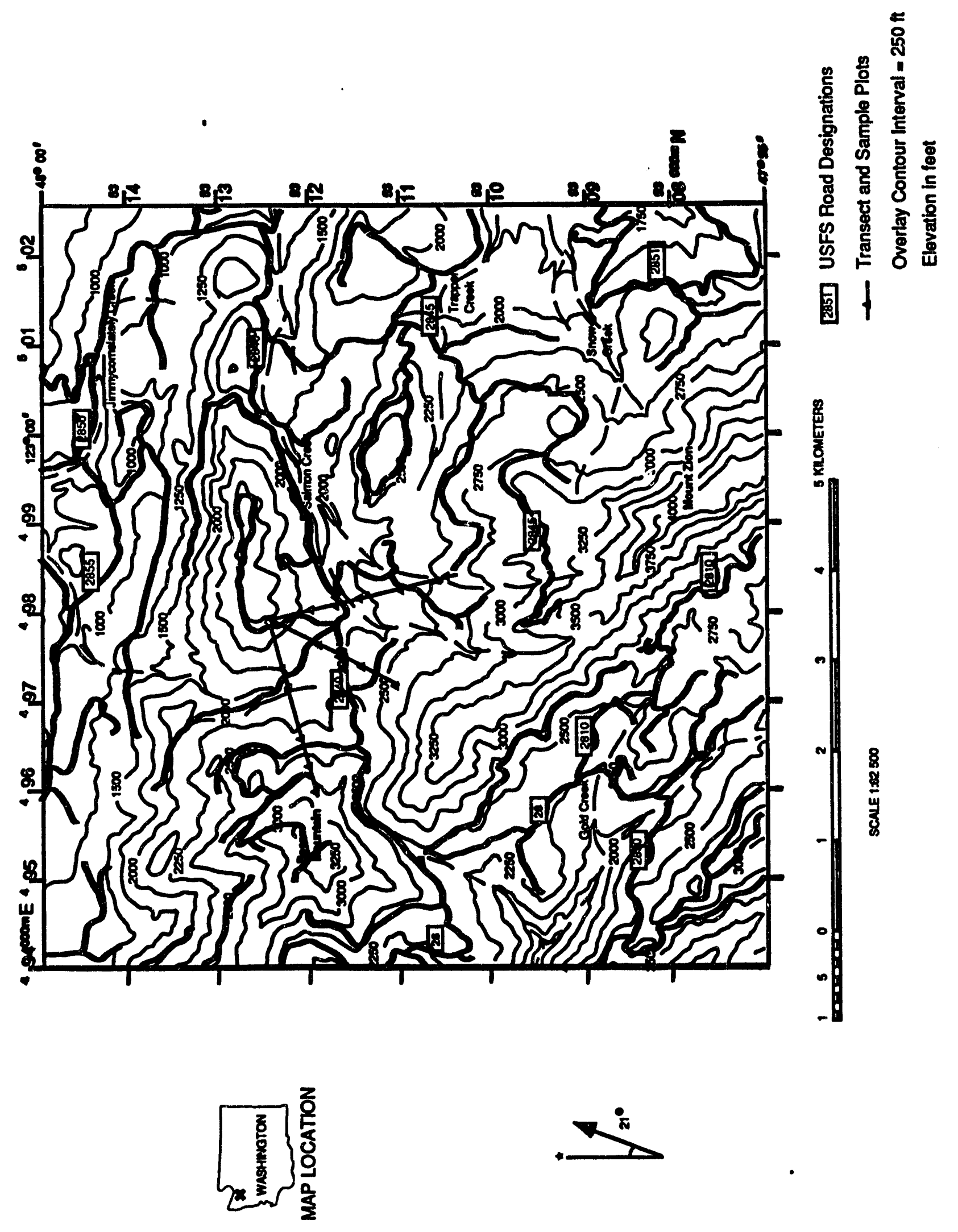




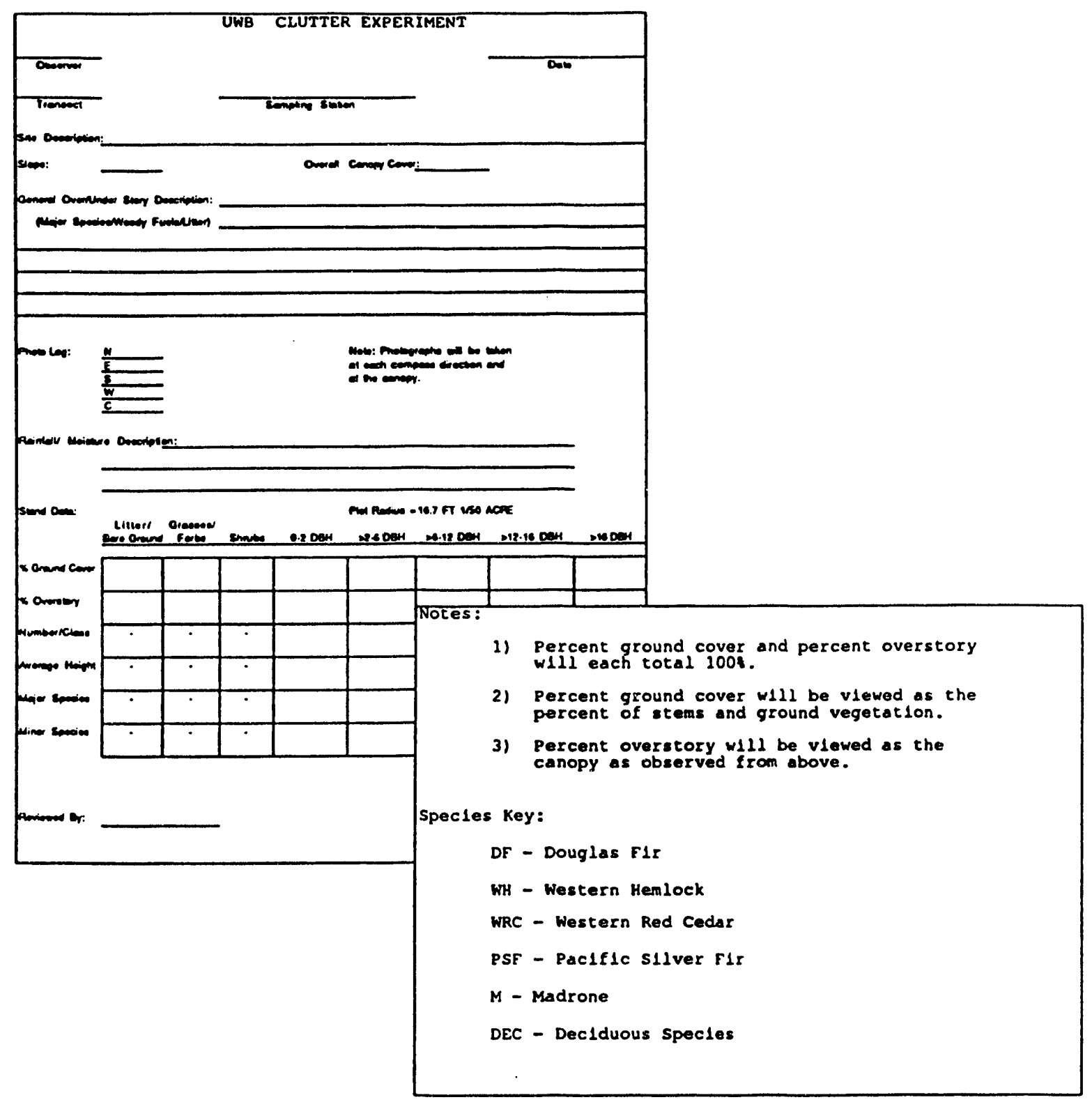

Figure 2. UWB Clutter Experiment Ground Truth Data Collection Form 
The data taken at each plot included general stand characteristics of the site and photographs. The stand type at each sample plot was described in terms of its overall composition, slope, canopy cover, litter accumulation, and moisture characteristics. These descriptions provide an overview of the general area, not necessarily restricted to the plot perimeter. Photographs were taken from the center of each sample plot toward the cardinal compass points (North, East, South, West) plus the canopy to provide a visual record of the various sample plots (Appendix B).

Specific data was collected within the confines of the circular plot. The center point of each plot was marked with colored flagging, and plot perimeters were marked with tree marking paint. Overstory vegetation was categorized using 5 stem diameter classifications: 0-2, >2-6, >6-12, >12-16, and $>16$ inches. All diameters were measured at a standard height of $4.5 \mathrm{ft}$. Trees which did not have a measurable stem at this height were tallied as shrubs. Major and minor species represented in the plot were recorded along with an ocular estimate of the average tree height by stem size classification. Due to the variability of heights and multiple trees per class in many of the sample plots, these estimates should be considered very coarse. Occasional tree heights were measured using a clinometer to provide a "calibration" for the ocular estimates.

Each site was further described in terms of the vegetation for both ground cover and overstory coverage. Vegetation was classified as either litter/bare ground, grasses/forbs, shrubs, or one of the 5 tree stem classifications. The ground cover survey was defined as the percentage of the circular plot covered by each of these vegetative classifications. Because this survey dealt primarily with the ground cover composition, only the crosssectional diameters of the woody stems of trees were evaluated as a percentage of the overall plot for this calculation. Shrubs were tallied as ground cover unless they were tall enough to be considered as a factor in the overstory. In these cases the shrubs were considered small trees and categorized by stem diameters. The percent overstory survey was conducted as if the plot was viewed from above. In areas where there was multiple overstory layering, the uppermost canopy was recorded in the appropriate stem diameter classification. Thus, for both surveys the overall coverage totalled, but did not exceed $100 \%$. 
Moisture conditions were described for each site in terms of overstory shading, aspect, and litter accumulation and their influence on the relative "wetness" of a stand. Rain gauges were set up at three locations along each transect, and at the radar site, in an effort to quantify microclimate variability within the study area. These gauges were monitored periodically throughout the duration of the radar fieid experiment.

\section{Statistical Analysis}

Data from the field survey forms were entered into an Excel spreadsheet (Excel Version 3.0, MicroSoft Corporation, One Microsoft Way, Redmond, WA 98052) for analysis. Plots were generated using both Excel and DeltaGraph software (DeltaGraph Version 1.5, DeltaPoint, Inc., 200 Heritage Harbor, Suite G, Monterey, CA 93940). Data were summarized by both stand classification and by individual transect. Individual sample plot data are listed in Appendix B.

For the purpose of analysis, three stand classes were used to characterize the 14 sampling plots. Stands were classified as Class 1 if the major tree component was absent or could be characterized as seediing/sapling with a diameter of $\leq 2$ inches, Class 2 if the major tree component could be harvested as pole timber, or Class 3 if the major tree component could be harvested as saw timber. Pole and saw timber stands were identified as having trees with a diameter of $\leq 12$ and $>12$ inches, respectively.

All sampling plots were categorized within one of the stand classes in order to estimate the mean and standard deviation for each of the stand parameters measured. Weighted means, using the number of trees observed in each stem diameter class as the weights, were calculated to estimate the mean tree spacing, tree diameter, and tree height. The moisture level at each site was ranked without ties from 1 (driest) to 5 (wettest) to produce an average relative moisture for each stand class.

\section{RESULTS AND DISCUSSION}

Using the individual plot and stand data summaries, transect vegetative and environmental parameters were described along with the general stand characteristics associated with the three stand classifications (Table 1). 


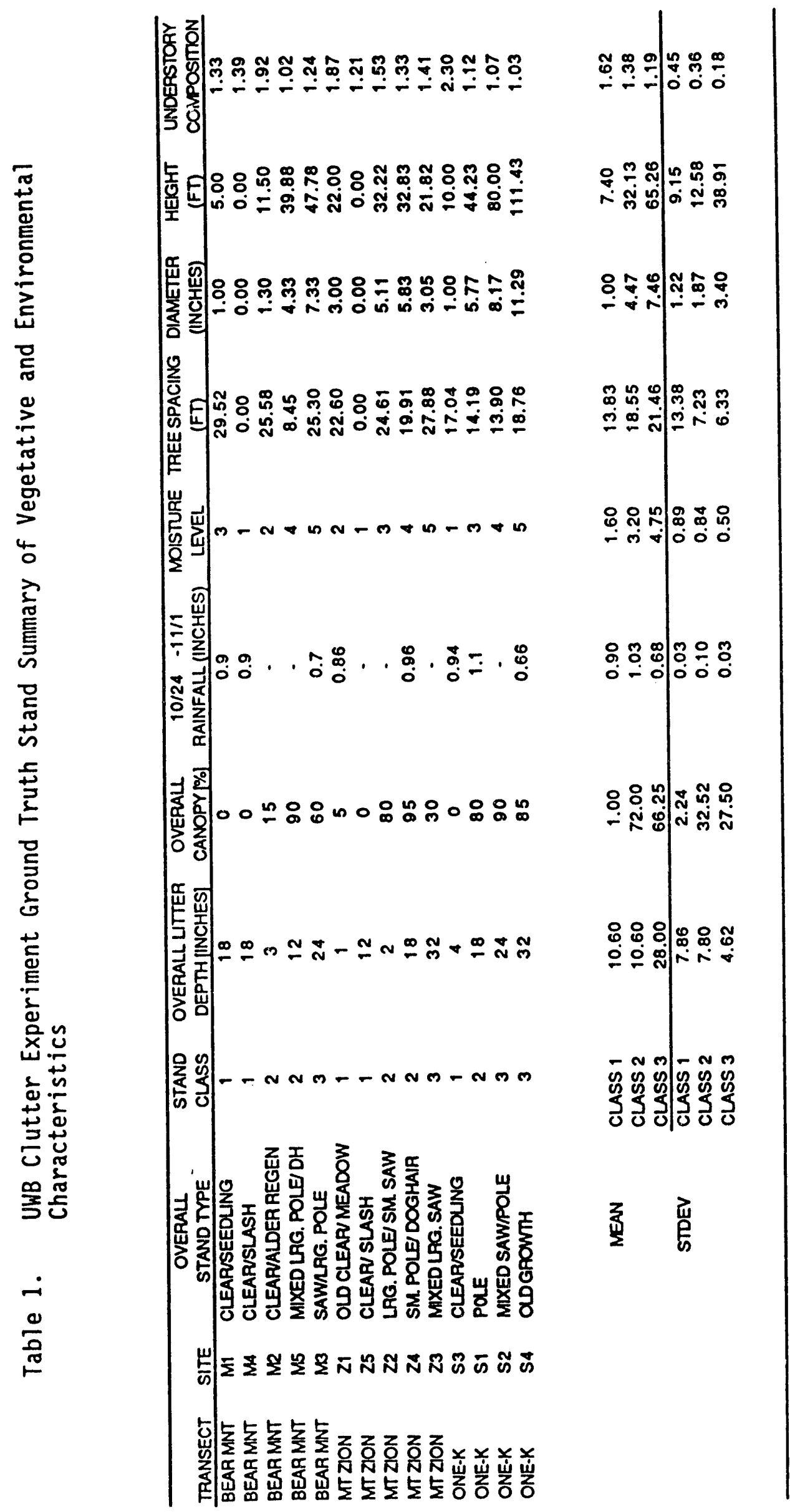

B. 9 
Profiles of each stand class along the transect lines are shown in Figure 3. Distances within each stand type were calculated from aerial photographs using two points at a defined distance and estimated slope correction factors to compensate for uneven terrain (Table 2). Figure 4 and depicts the composition of each transect in terms of the three primary stand classifications.

General stand characteristics were averaged for all sample plots within a common stand class. Summary statistics are presented for litter depth, percent canopy, current rainfall, and relative moisture (Figure 5). As expected, the average litter depth, canopy cover, and relative moisture increased as the tree sizes increased. Increased canopy cover and litter depths tend to prevent sites from drying as fast. The litter depth was greater than expected in the class 1 areas because of residual debris from recent logging on several of the plots. Percent canopy cover was highest within the class 2 stands (pole) because of closer spacing and more fully developed crowns on several of the sample plots. Rainfall levels were based solely on rain gauge locations and could have been influenced by local variation as well as canopy obstructions preventing rainfall penetration.

Additional stand information, including average tree spacing, diameter, height, and the composition of the understory component, was also calculated by stand class (Figure 6 ). Tree spacing increased with stand class, indicating a trend toward wider spacing as trees matured. This trend is expected due to natural thinning as a result of competition for nutrients and available sunlight and due to commercial thinning operations. Tree diameters follow a similar trend; however, the overall averages are considerably smaller than the defined size classifications for pole and saw timber. This reduction in diameter can be explained by the few number of larger trees in each sample plot and many smaller trees downweighting the larger diameters. Average tree heights were calculated using the same weighting method; therefore, while the trends are representative, the actual height averages reflect mixed tree sizes within a class type. The average understory composition portrays the relative contribution of bare ground/litter, grasses/forbs, or understory shrubs (coded as 1,2 , and 3 respectively) ignoring the stem diameter classes. Less understory foliage (grasses, forbs, and shrubs) was represented in the larger 
diameter stands, primarily due to the heavy litter accumulation in these sites. 

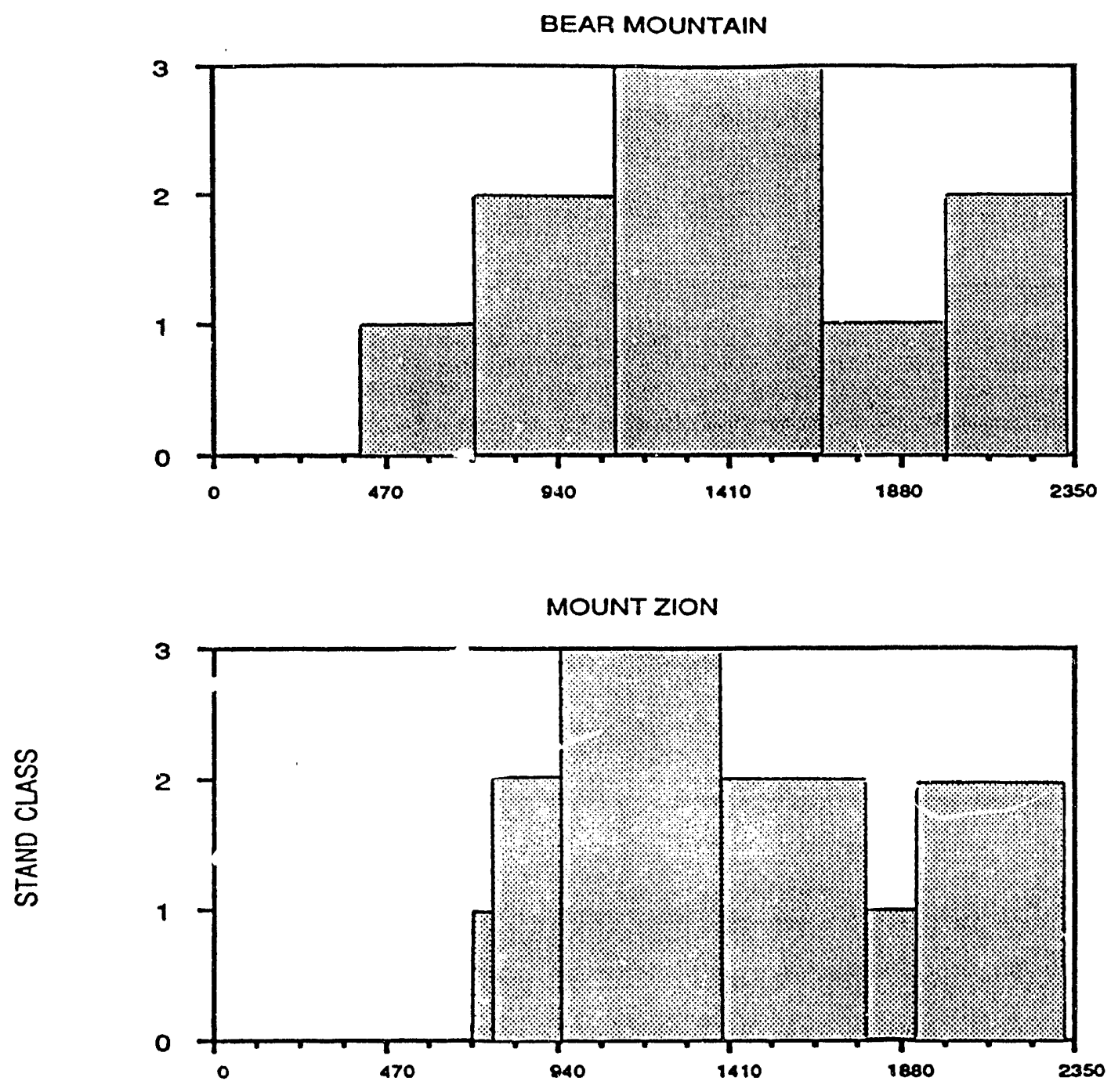

ONE - K

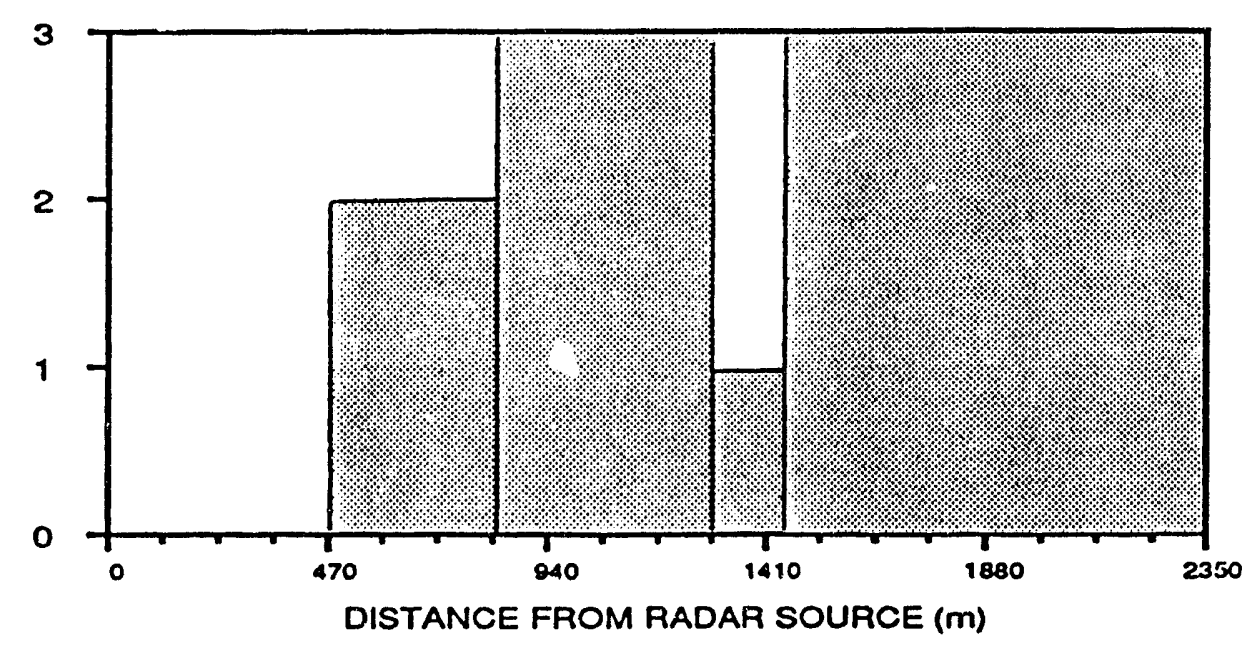

Figure 3. UWB Clutter Experiment Ground Truth Transect Profile by Stand Classification

$$
\text { B. } 12
$$


Table 2. UWB Clutter Experiment Ground Truth Sample Plot Summary for Transect Profile

\begin{tabular}{|c|c|c|c|c|c|c|c|}
\hline TRANSECT & STTE & $\begin{array}{l}\text { OVERALI } \\
\text { STAND TYPE }\end{array}$ & $\begin{array}{l}\text { STAND } \\
\text { CLASS }\end{array}$ & $\begin{array}{l}\text { DISTANCE FPOM } \\
\text { RADAR }(m)\end{array}$ & $\begin{array}{l}\text { STAND CLASS } \\
\% \text { OF TRANSECT }\end{array}$ & SLOPE $[\%]$ & ASPECT \\
\hline BEARMNT & $M 1$ & CLEARUSEEDUNG & $T$ & 393 & 13.52 & NEG 5 & SW \\
\hline BEARMNT & $M 4$ & CLEARSLASH & 1 & 1662 & 14.21 & 80 & $E$ \\
\hline BEARMNT & M2 & CLEAPUALDER REGEN & 2 & 707 & 16.75 & 5 & E \\
\hline BEARMNT & M5 & MIXED URG. POLE DH & 2 & 1992 & 14.21 & 45 & ESE \\
\hline BEARKINT & M3 & SAWRRG. POLE & 3 & 1096 & 24.38 & 70 & $E$ \\
\hline MT ZION & $\mathbf{Z 1}$ & OL CLEAR MEADOW & 1 & 707 & 2.04 & 0 & N/A \\
\hline MT ZION & $\mathbf{Z 5}$ & CLEAR/ SLASH & 1 & 1814 & 4.93 & 15 & w \\
\hline MT ZION & $\mathbf{Z 2}$ & LRG. POLE SM. SAW & 2 & 746 & 10.27 & 5 & WWW \\
\hline MT ZION & $\mathbf{Z 4}$ & SM. POLEJ DOGHAIR & 2 & 1382 & 22.64 & 15 & WNW \\
\hline MT ZION & 23 & MIXED LRG. SAW & 3 & 942 & 23.06 & 15 & WNW \\
\hline ONE-K & S3 & CLEAPUSEEDLING & 1 & 1277 & 7.36 & 85 & $N E$ \\
\hline ONE-K & s1 & POLE & 2 & 471 & 14.72 & 5 & NE \\
\hline ONE-K & s2 & MIXED SAW/POLE & 3 & 817 & 19.57 & 70 & $N E$ \\
\hline ONE-K & 54 & ODGPOWTH & 3 & 1450 & 38.30 & 50 & BE \\
\hline
\end{tabular}

B. 13 


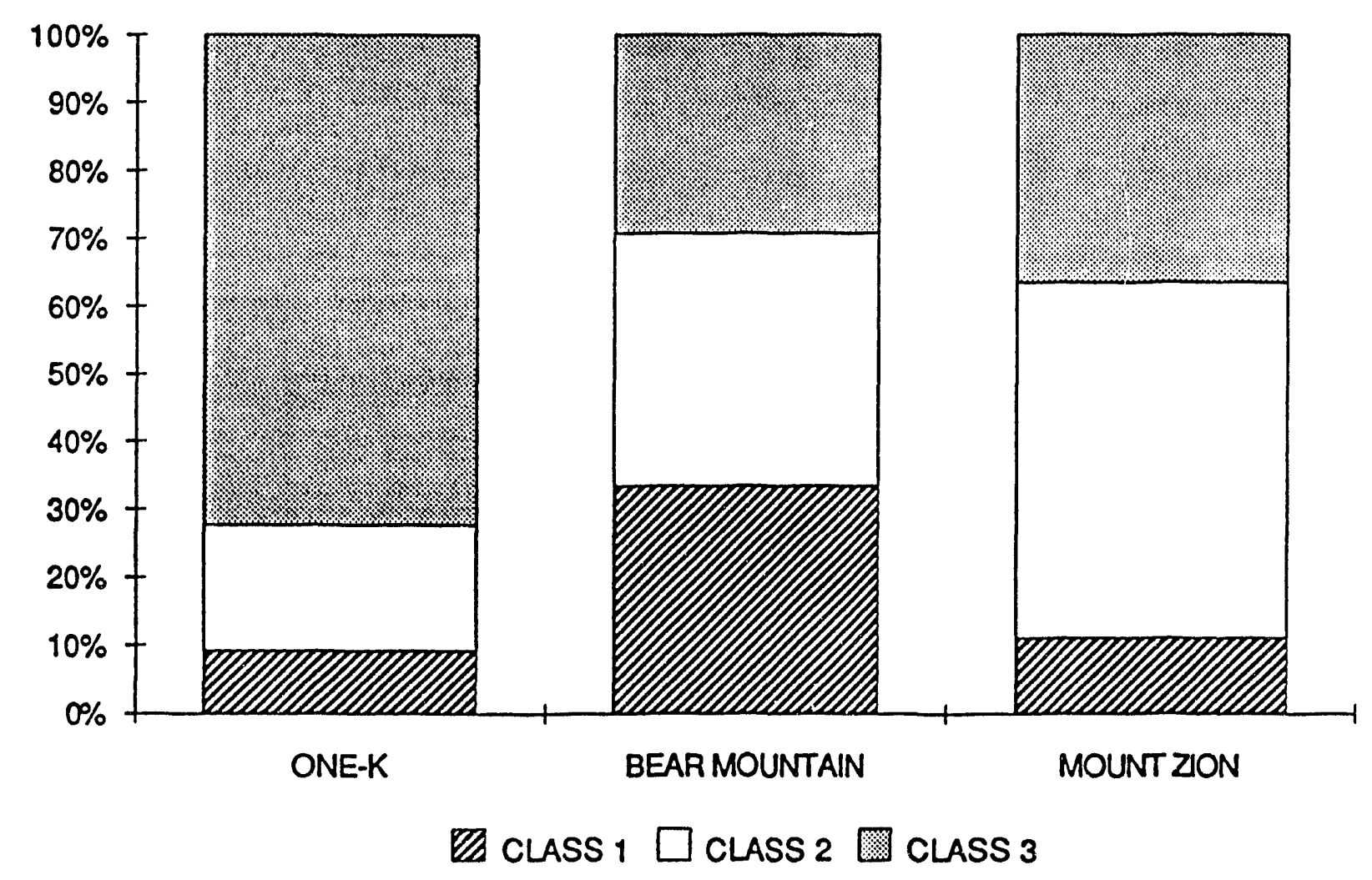

Figure 4. Stand Class Composition of Each Transect for the UWB Clutter Experiment Forested Site

B. 14 
A

B
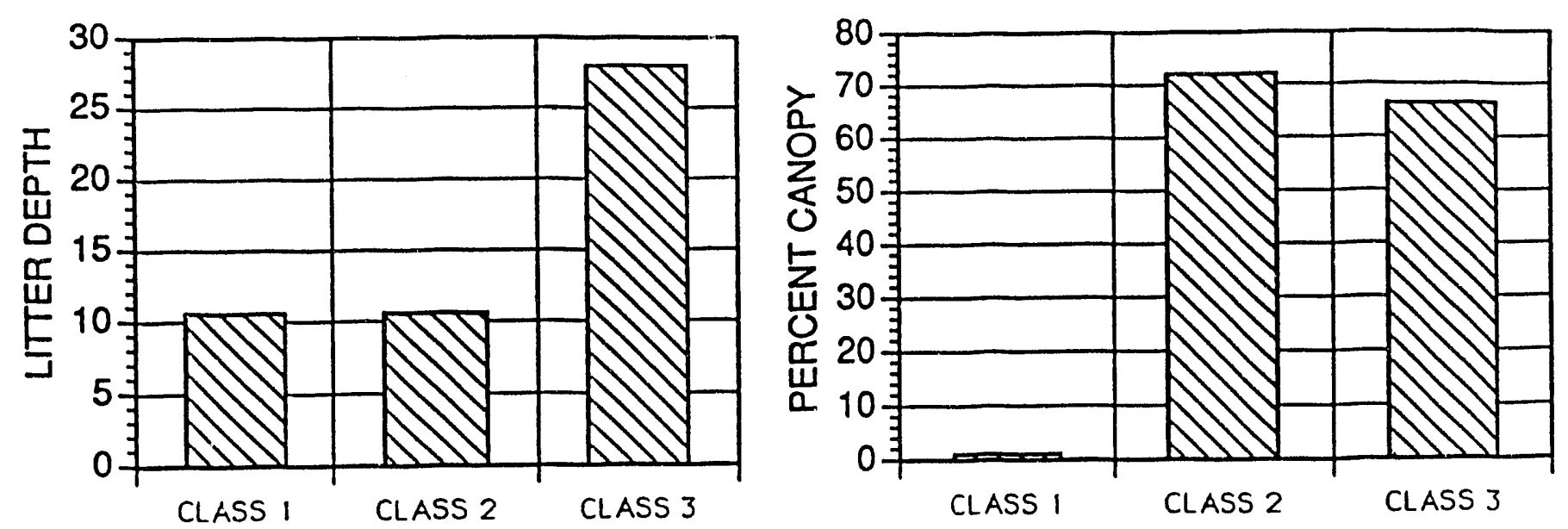

C
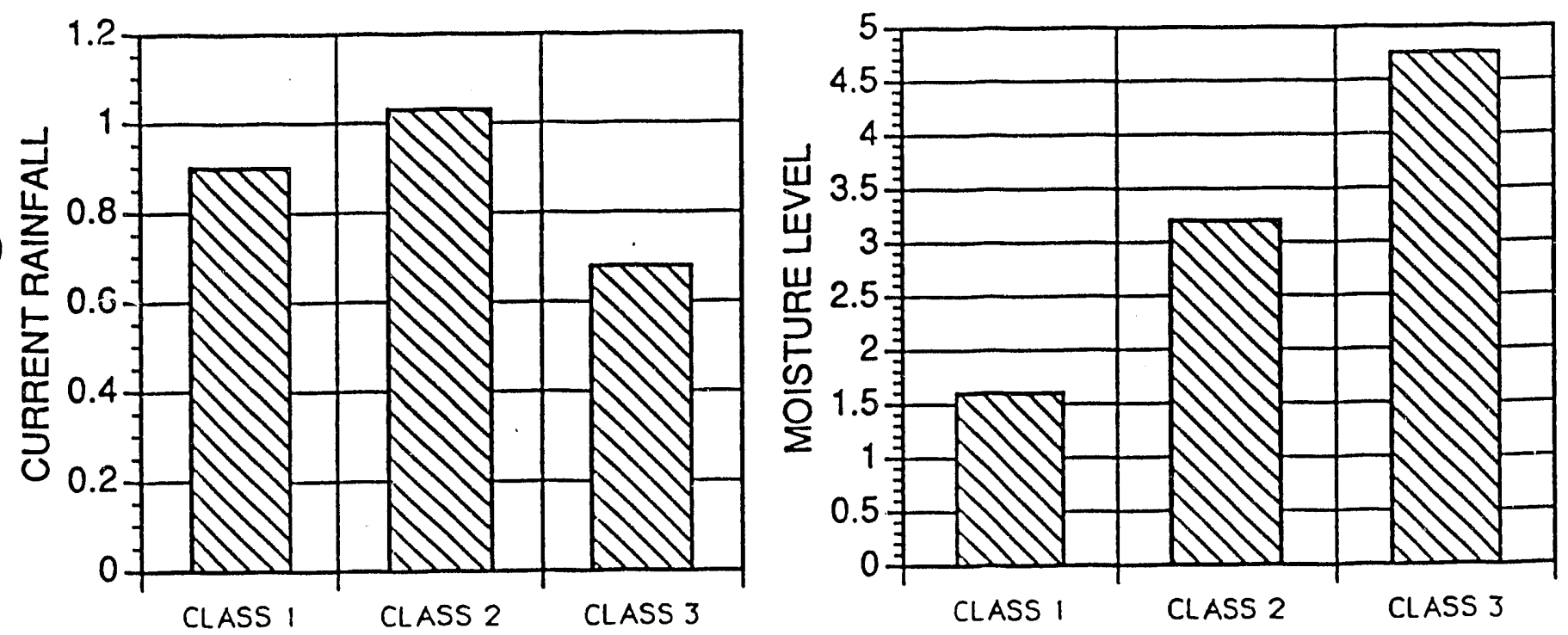

Figure 5. Average Stand Characteristics by Overstory Classification Including (A) Litter Depth (inches), (B) Percent Canopy Closure, (C) Current Rainfall (inches), and (D) Average Moisture Level Based on Circular Plots with a $16.7 \mathrm{ft}$ Radius 

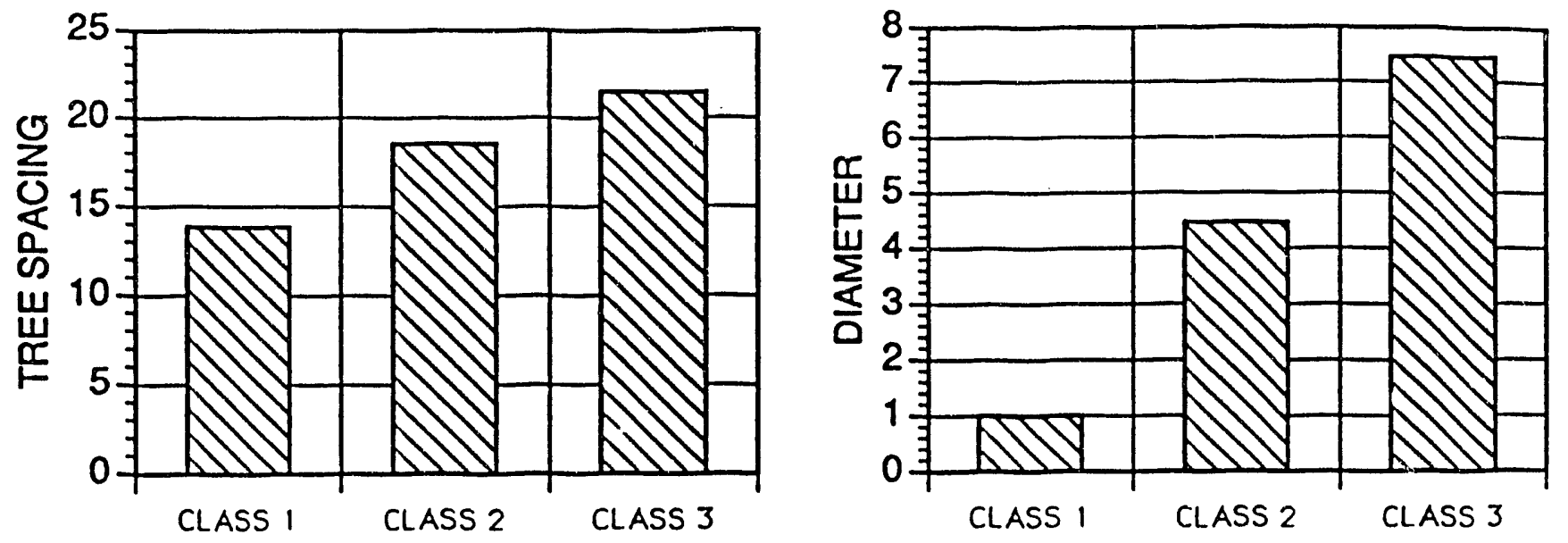

C
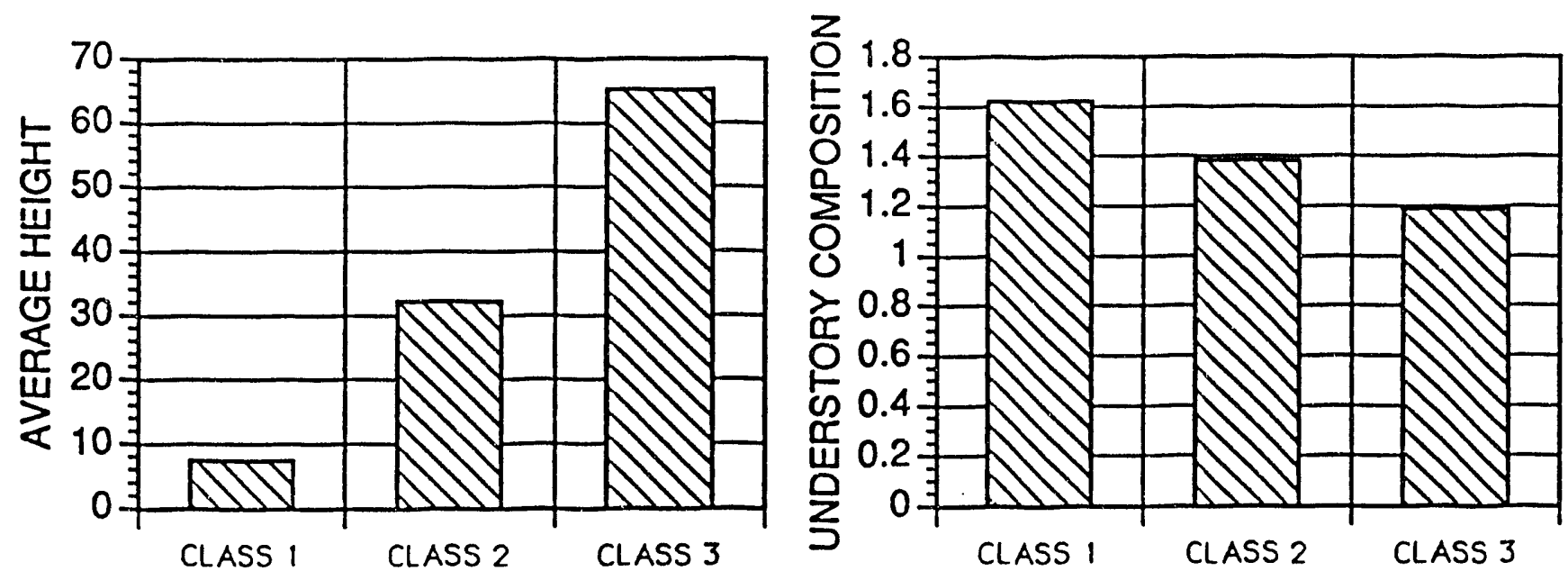

Figure 6. Average Stand Characteristics by Overstory Classification Including (A) Tree Spacing ( $\mathrm{ft}$ ), (B) Average Tree Diameter at Breast Height (inches), (C) Average Tree Height (ft), and (D) Average Understory Composition Based on Circular Plots with a $16.7 \mathrm{ft}$ Radius

B. 16 


\section{APPENDIX A}

Appendix A contains photographs of the three transects; One-K, Mount Zion, and Bear Mountain as viewed from the radar site.

B. 17 
ONEK TRANSECT
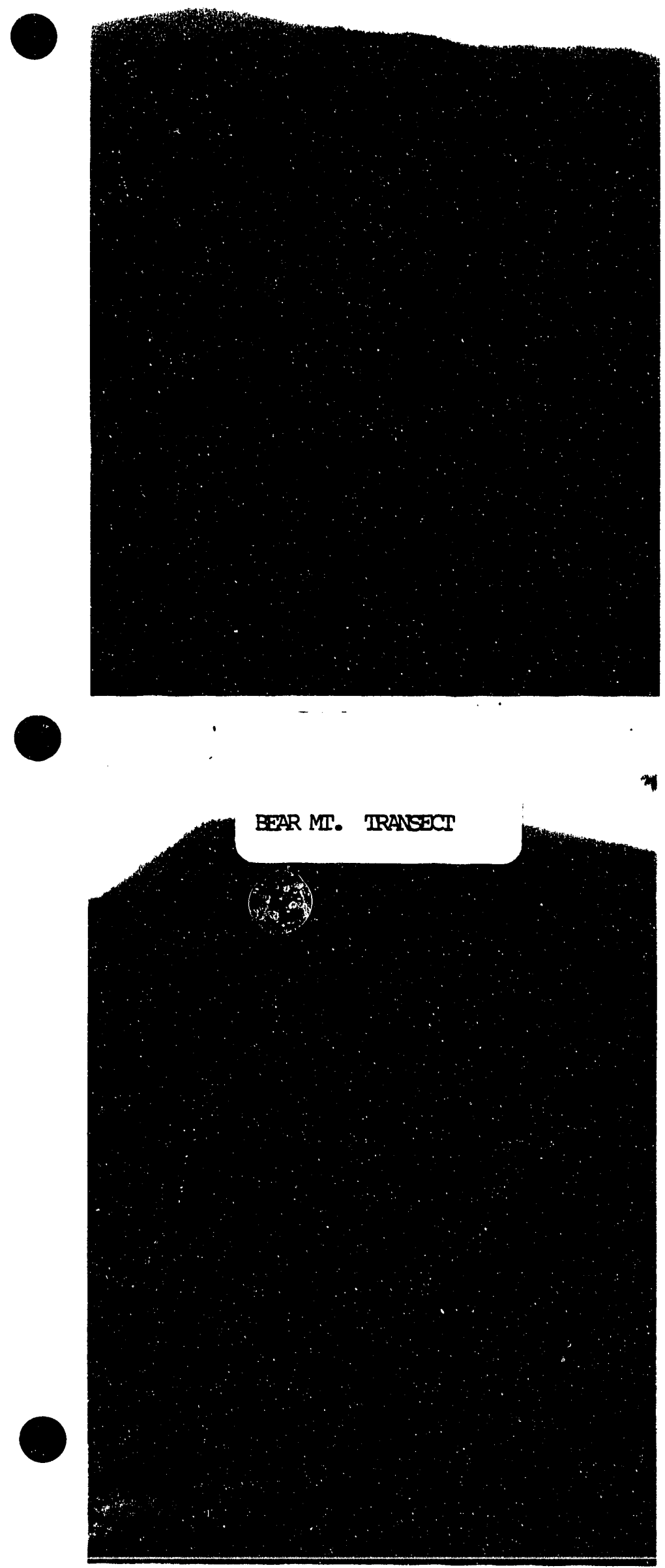

MI. ZION TRANSECT
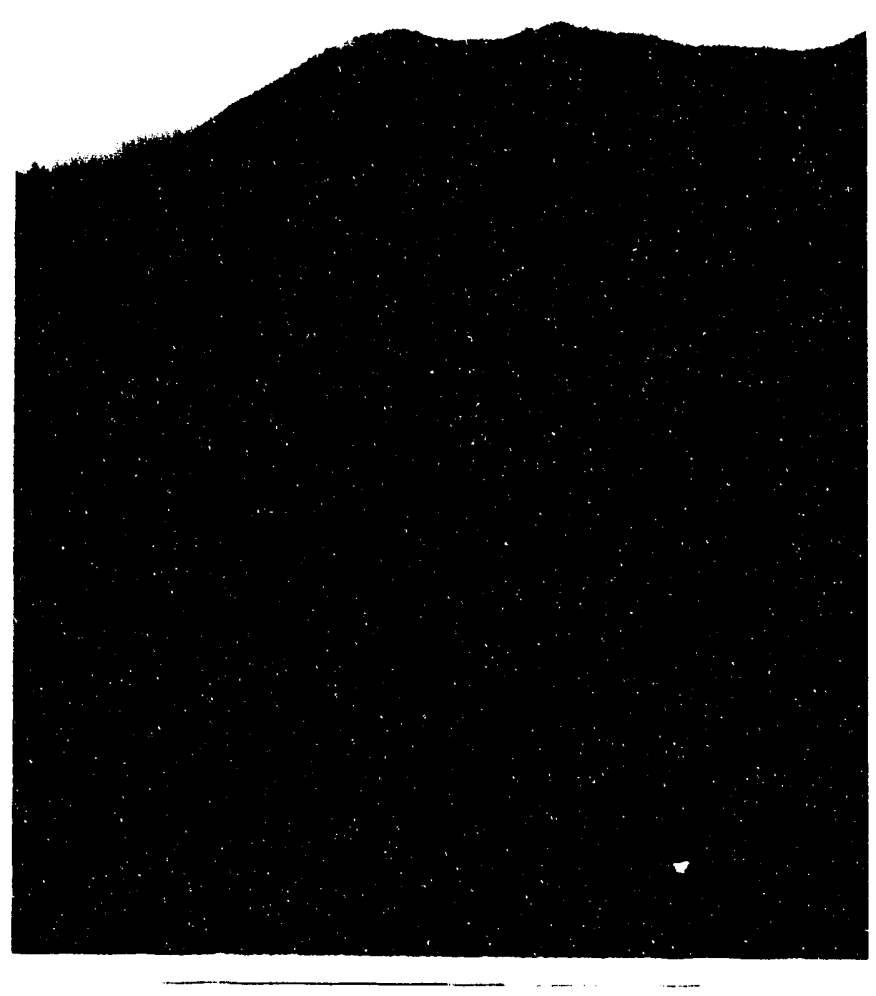


\section{APPENDIX B}

Appendix B contains photographs and field data sheets for the individual sample plots. The sites are numbered with the lowest numbered plot closest to the radar site for each transect. Photographs of the canopy are on the reverse side of the photograph holder for each site. 

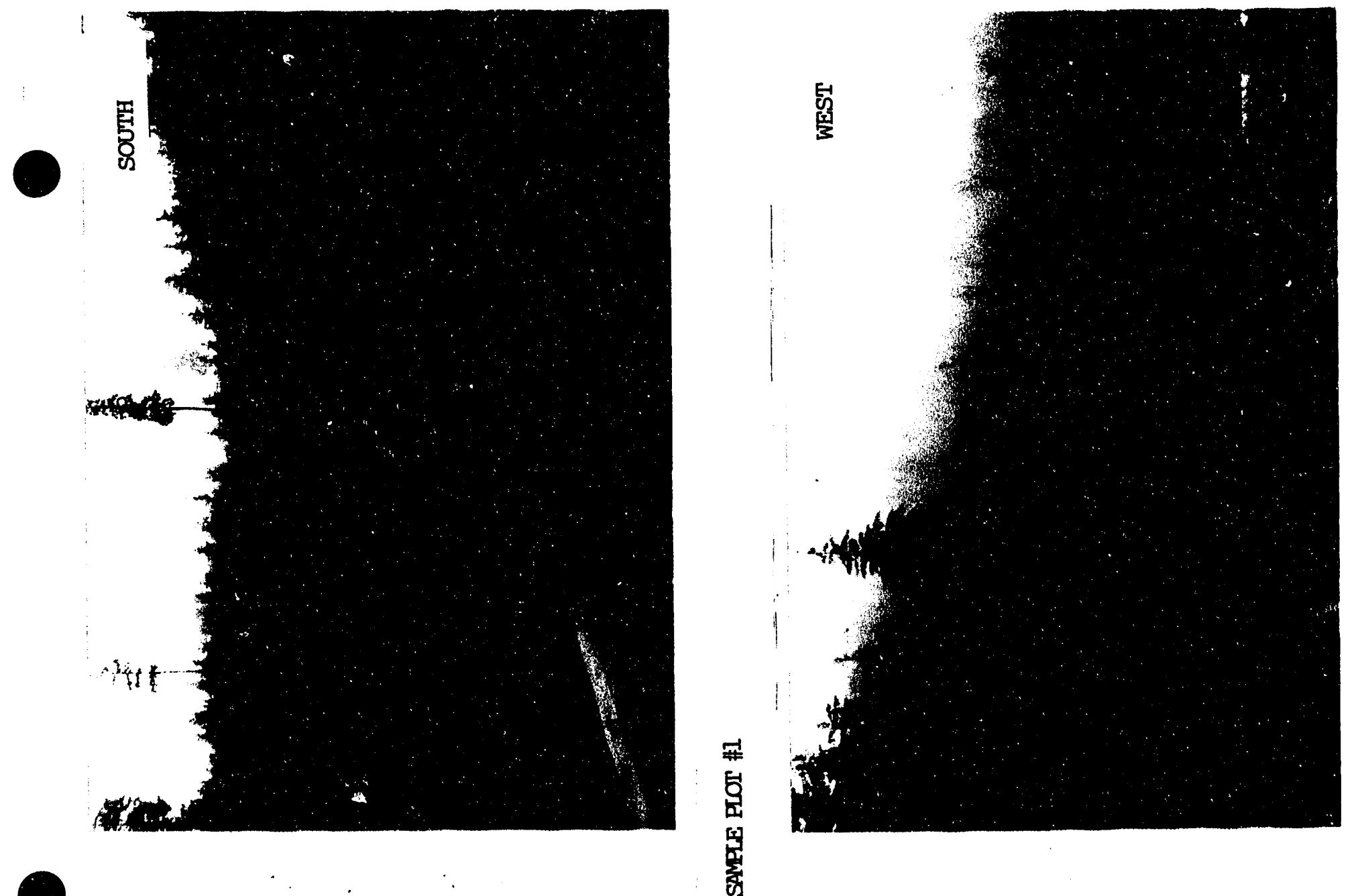

$\bullet$
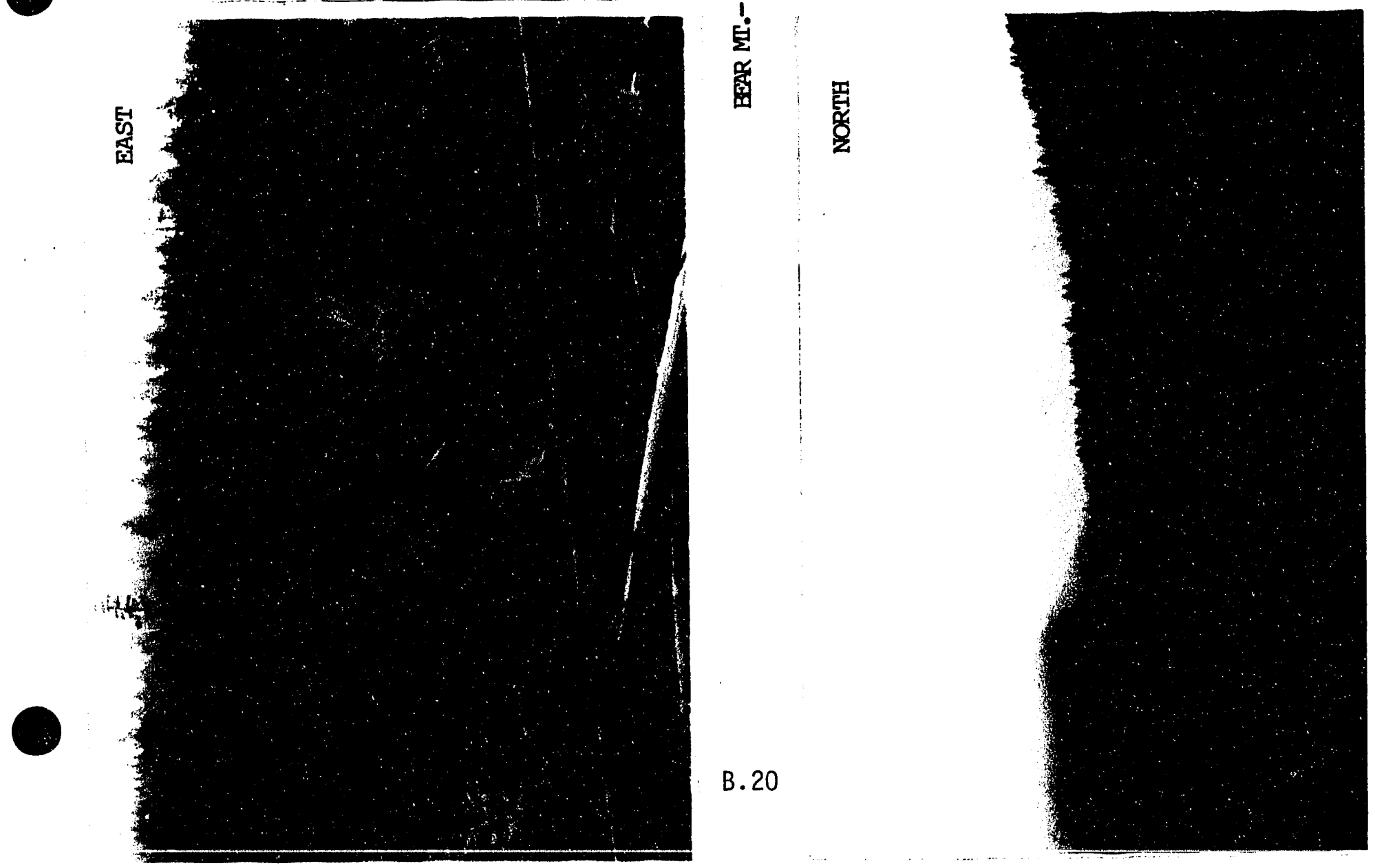
UWB CLUTTER EXPERIMENT

TELENICK

Observer

$\frac{10 / 24 / 91 \quad 15: 00}{\text { Date }}$

BEAR MTN.

Transect

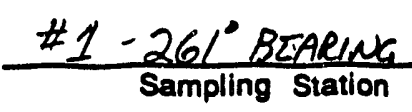

Site Description: APPROX. 50 VDS FPOM IST BALOON THIS TRANSECT (79 BEARWK). S. EDEE OF CLCARCUT OUCRALL 5-10\%

Slope: SITE $5 \%$-SIOESLOPE MORE - Overall Canopy Cover: OL DPEN

TREM RACAR SITE

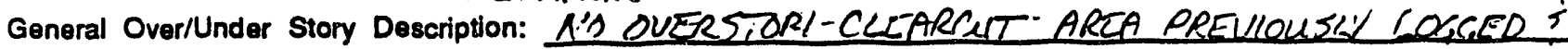

(Major Spocies/Woody Fuols/Litter) BUPNOA - IS SLESH PILED - S12E UE CLEARCLT 20-40A (EST)

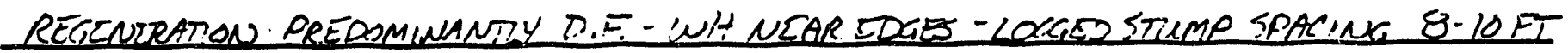

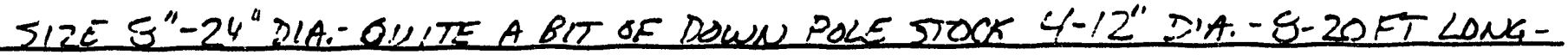

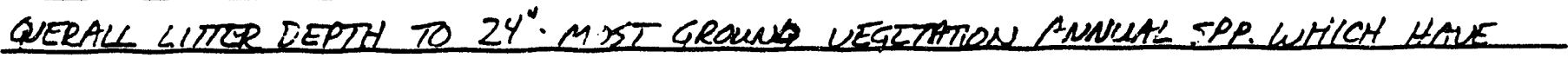

TURNED BROWN-SOME SALAL, RUBUS, OTETR - MORE PUBBISN THAN ZLOU CLEARCLT. SLASH WOT PILED HERE-SCATERED

Photo Log: $\quad \frac{N}{5} / 35$ RoLL/Pitoto

$$
\begin{aligned}
& \hline \text { I } 1 / 36 \\
& \hline S 2 / 1 \\
& \hline W 2 / 2 \\
& \hline C 2 / 3
\end{aligned}
$$

Note: Photographs will be taken

at each compass direction and

at the canopy.

Rainfall Moisture Description: HARP TO ASSESS LCCAL UARIATON BENAEEN MT. ZLN CLEARCUT

-SEEMS DRIER - NU OUERSTORY TO RERUCE EUAPSRATION-WDODY MATLTIAL

LESS ROTTED THEN GTHER SITES-NO MOSS-DRIZZLWG NOW - SET RAW GAUGE $13: 10$

Stand Data:

Plot Radius $=16.7 \mathrm{FT} 1 / 50$ ACRE

Litter/ Grasses/

Bare Ground Forbs Shrubs $0.2 \mathrm{DBH}>2.6 \mathrm{DBH}>6.12 \mathrm{DBH}>12.16 \mathrm{DBH}>16 \mathrm{DBH}$

\begin{tabular}{|c|c|c|c|c|c|c|c|c|}
\hline$\%$ Ground Cover & 70 & 25 & 4 & $<1$ & 0 & 0 & 0 & 0 \\
\hline \% Overstory & 70 & 25 & 4 & $<1$ & 0 & 0 & 0 & 0 \\
\hline Number/Class & - & - & - & $i^{*}$ & 0 & 0 & 0 & 0 \\
\hline Average Height & - & - & - & $5^{\prime}$ & - & - & - & - \\
\hline Major Species & - & - & - & $D F$ & - & - & - & - \\
\hline Minor Species & $\cdot$ & $\cdot$ & - & - & - & - & - & - \\
\hline
\end{tabular}

\# SEEDLINGS $\% .5$ FT (O DEH) NOT TALIED AS TREZS-COUNT AS JHRUBS

* MOSTLY BROWN ANNUALS

- Reviewed By: 11 Cllinax 
Notes:

1) Percent ground cover and percent overstory will each total $100 \%$.

2) Percent ground cover will be viewed as the percent of stems and ground vegetation.

3) Percent overstory will be viewed as the canopy as observed from above.

Species Key:

$$
\begin{aligned}
& \text { DF - Douglas Fir } \\
& \text { WH - Western Hemlock } \\
& \text { WRC - Western Red Cedar } \\
& \text { PSF - Pacific Silver Fir } \\
& \text { M - Madrone } \\
& \text { DEC - Deciduous Species }
\end{aligned}
$$




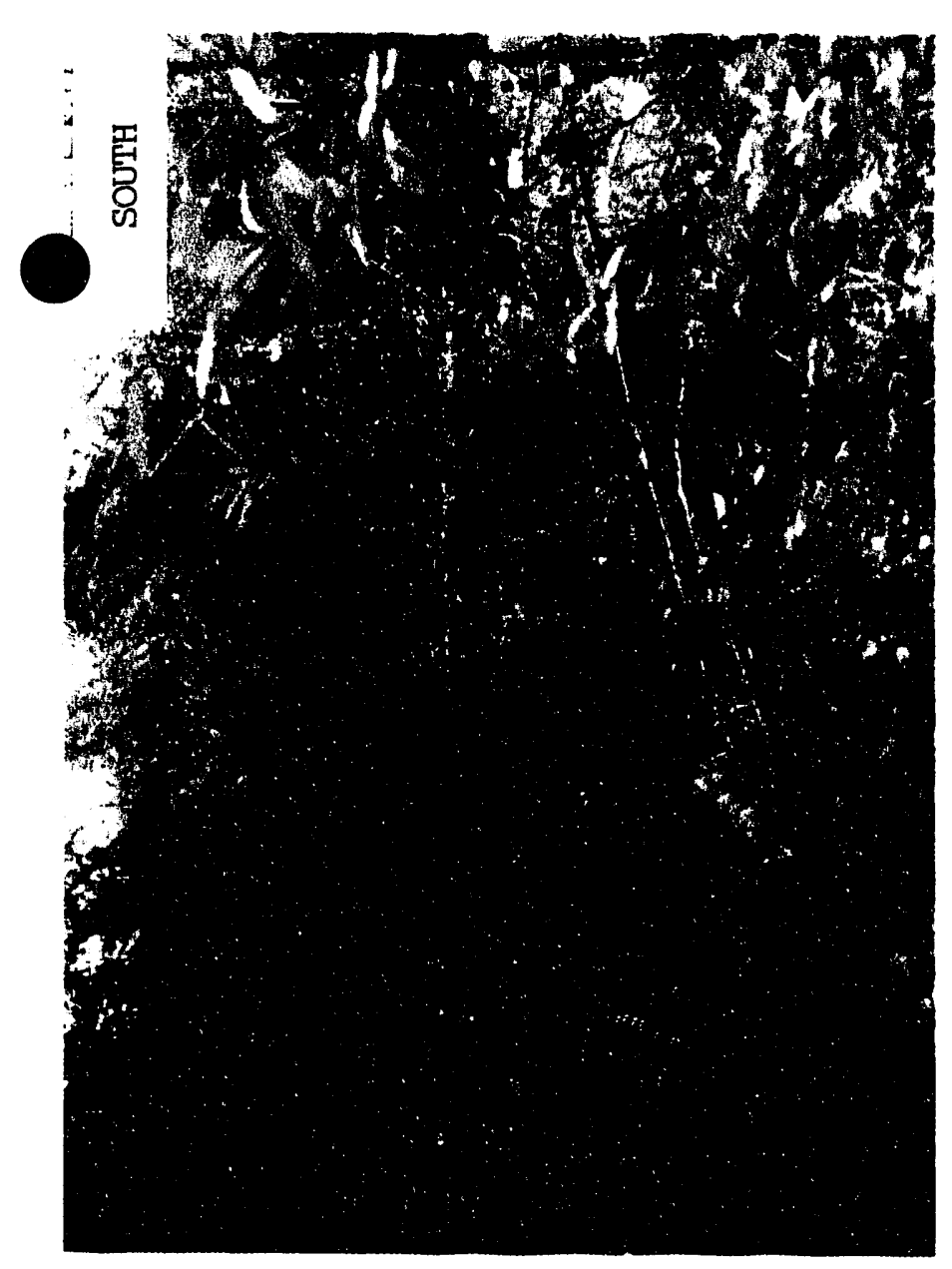

9

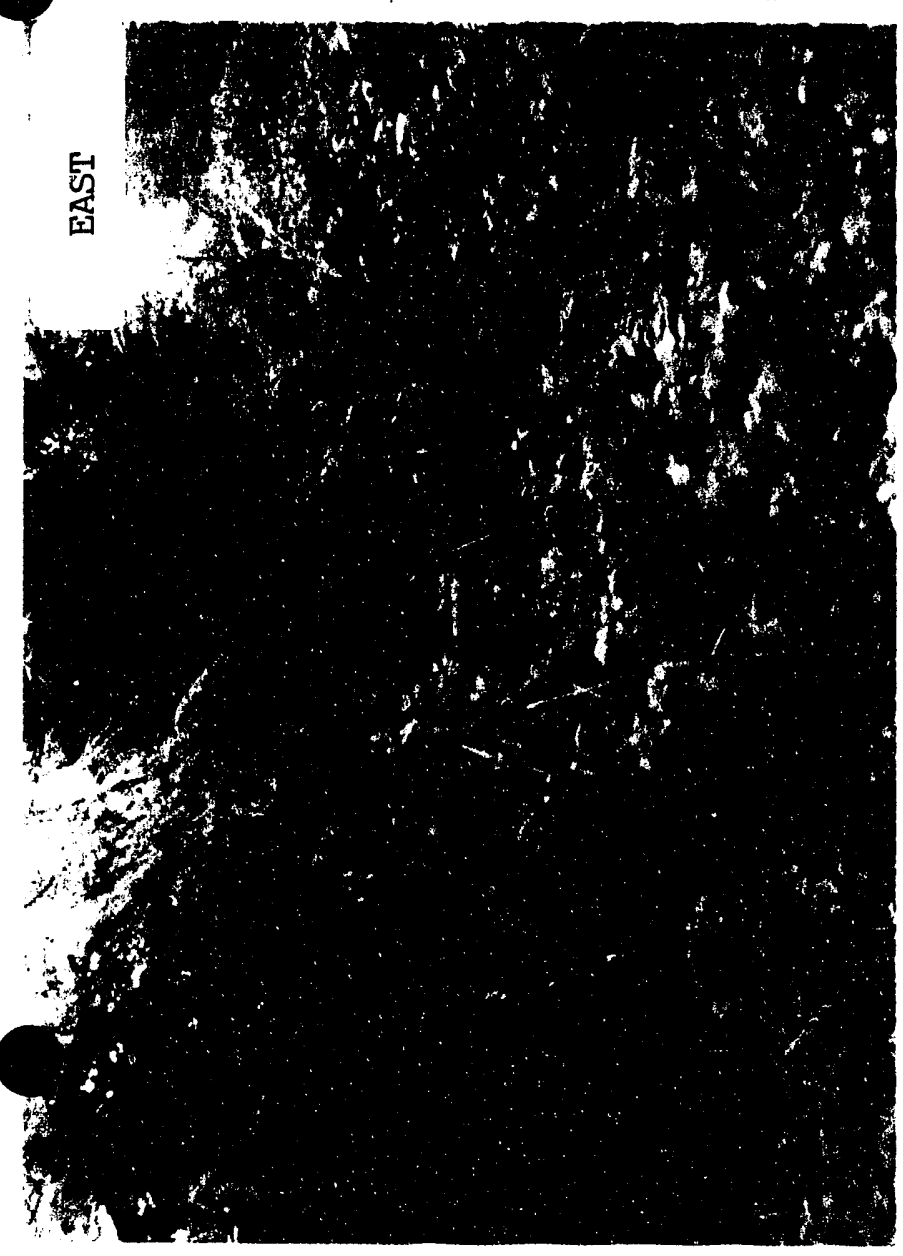

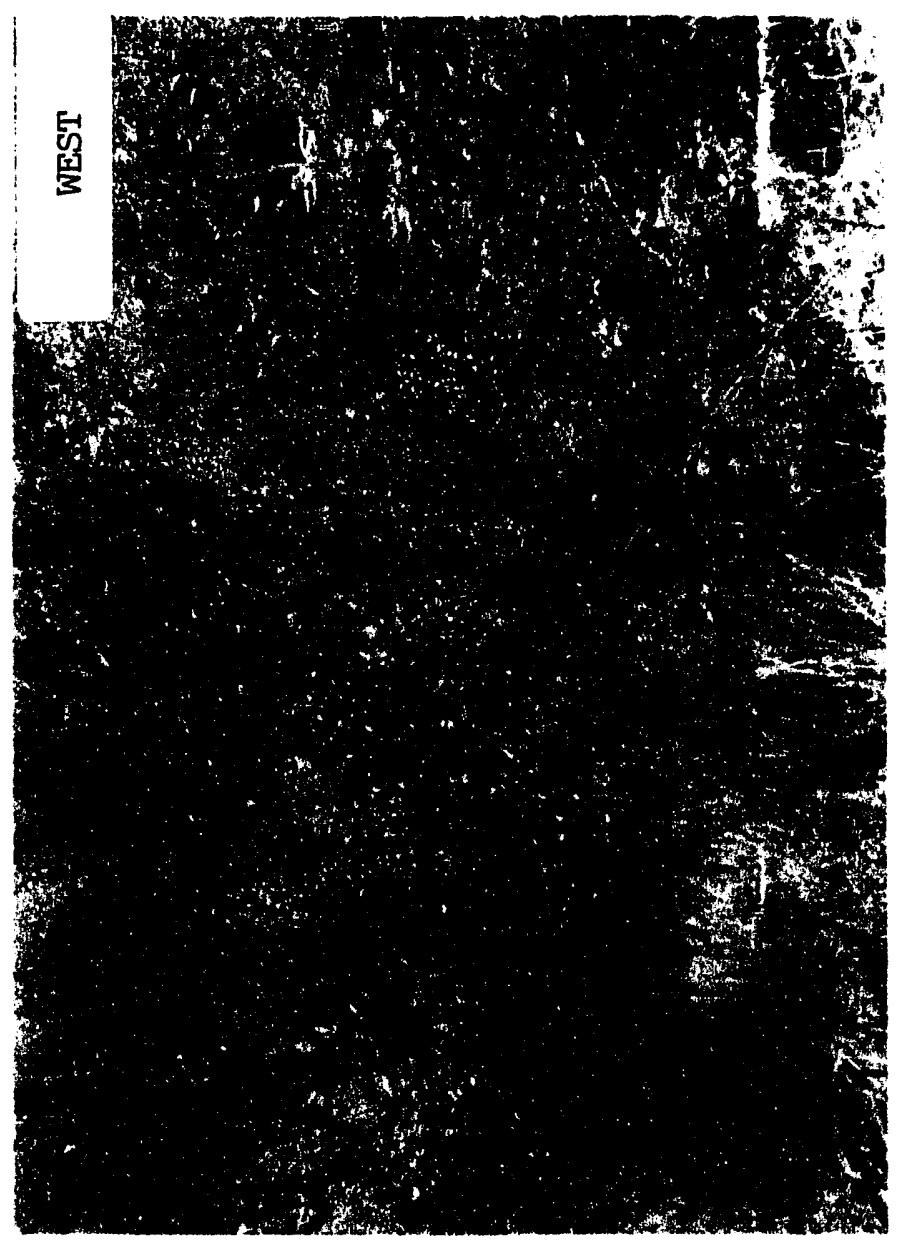

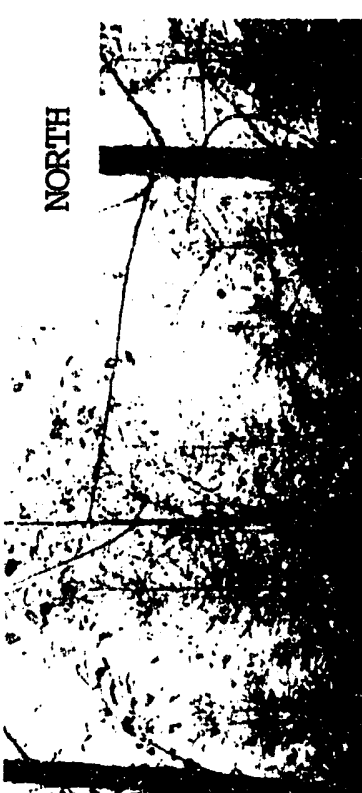

B. 23

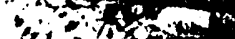

a $x^{x+1}$

1 $x+4$

- 50 ord

-fot pora

+5 a

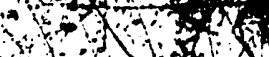

ind

$\Rightarrow$ ShN?

Yo

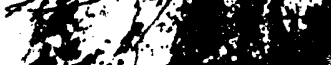



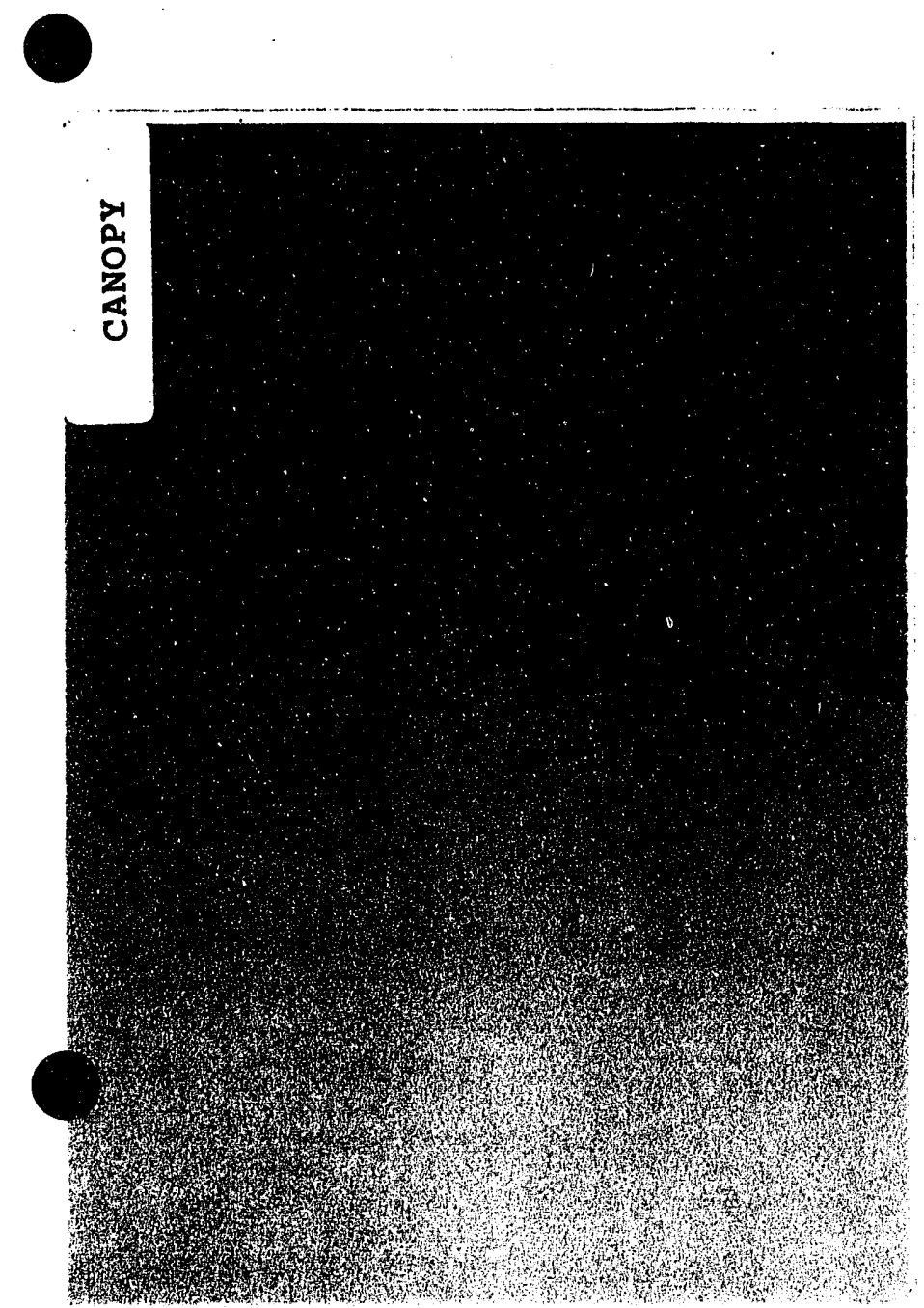

B. 24 : 
UWB CLUTTER EXPERIMENT

TELENLCK Observer

BEAR MTN

Transect $\frac{10 / 24 / 91 / 5: 30}{\text { Date }}$

\#2-261 BLARINC Sampling Station

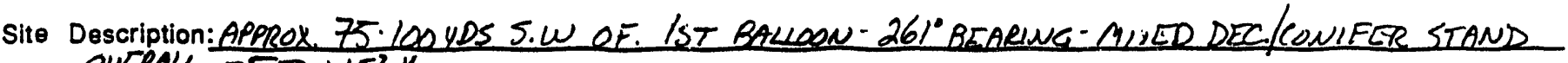
OUCRALC - $570+15 \% *$

Slope: $\angle I T E$ O-5\%

\section{* I cezatue to radarsite}

Overall Canopy Cover: $15 \%$

General Over/Under Story Description: QUERSTORY - MIXED ALDER, wllOW iOTHER DEC SPR-ALSO WH

(Major Species/Woody Fuels/Litter) DF-AVE. CONIFER HT. 20.30'STD.ECIDUOUS SPP. 4TS 20-30'ET LUNDERSTORY: SOME OPEN GRASSY ARDAS OTHER POCKETS THICK WI RUBLLS SPR PRAMBLES, SALAL MUER RHODSRENDRON - FORBS, EERUS T TRASSZS VERY MUMMON IN OPLN AREAS - LITER - MINOR STLMS: TWLGS MOSTL 2 " - OCCASIONAK OLD STUMPS - MOSTUY ROTED - RUE. BITLR DEPTH ¿3" INCLUDING THIS 'ERTS FALLEN LLAVES ANNLULS

Photo Log:

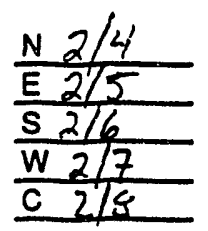

Note: Photographs will be taken at each compass direction and at the canopy.

Rainfalll Moisture Description: GREA APPEABS MODERATEZY DRY - UO BXES OR STANDING WATER, MOSTLY GRASSES. NO MOSS - HHIN OUERSTORY SHOWLD ALOW RAPID DPYINK INITH THUS LITLR ACCUMULATION ESPECIALY -NU RAIN

Stand Data: GAUGE SET.

Litter/ Grasses/

Bare Ground Forbs Shrubs $0.2 \mathrm{DBH}>2.6 \mathrm{DBH}>6.12 \mathrm{DBH}>12.16 \mathrm{DBH}>16 \mathrm{DBH}$

$\%$ Ground Cover

\begin{tabular}{|c|c|c|c|c|c|c|c|}
\hline 28 & 50 & 20 & 1 & $<1$ & 0 & 0 & 0 \\
\hline 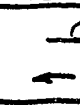 & & 5 & $!$ & 2 & 2 & 0 & 0 \\
\hline - & - & - & 9 & 1 & 0 & 0 & 0 \\
\hline - & - & - & $10^{\prime}$ & 25 & 0 & - & - \\
\hline$\cdot$ & - & - & DEC-ALDER & $\omega H$ & - & - & - \\
\hline - & . & - & $\omega H$ & - & - & - & - \\
\hline
\end{tabular}

- Reviewed By: I1 '1ublinum 
Notes:

1) Percent ground cover and percent overstory will each total $100 \%$.

2) Percent ground cover will be viewed as the percent of stems and ground vegetation.

3) Percent overstory will be viewed as the canopy as observed from above.

Species Key:

$$
\begin{aligned}
& \text { DF - Douglas Fir } \\
& \text { WH - Western Hemlock } \\
& \text { WRC - Western Red Cedar } \\
& \text { PSF - Pacific Silver Fir } \\
& \text { M - Madrone } \\
& \text { DEC - Deciduous Species }
\end{aligned}
$$



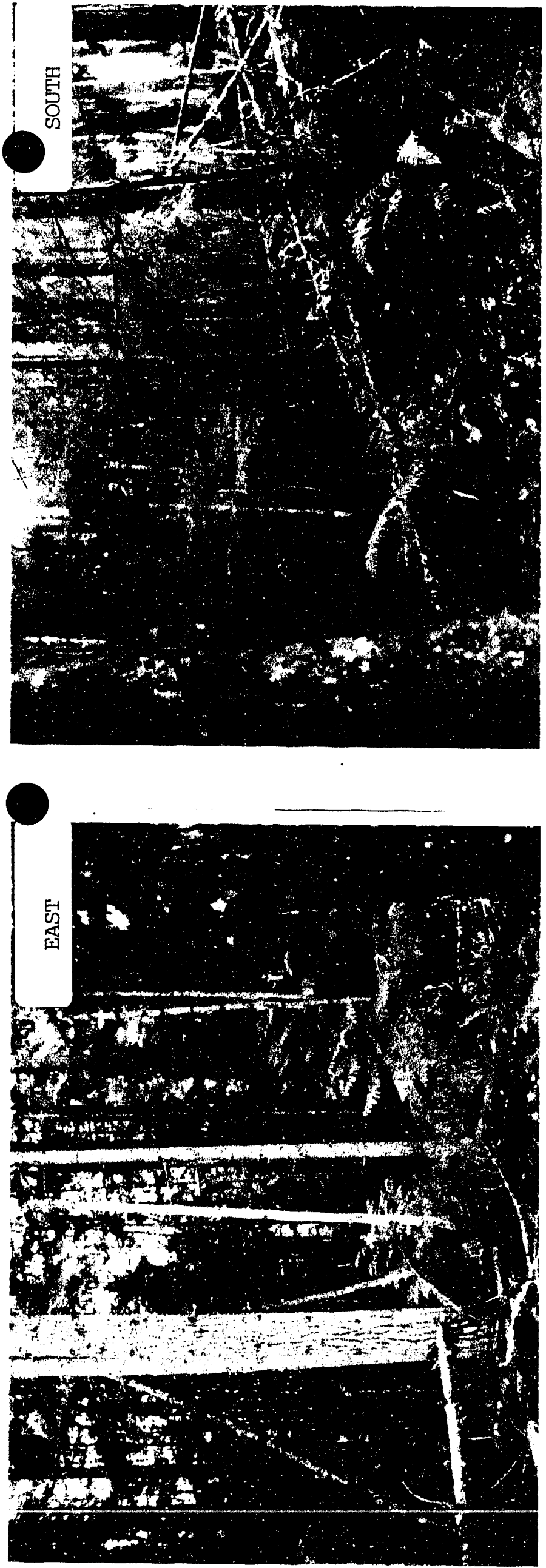

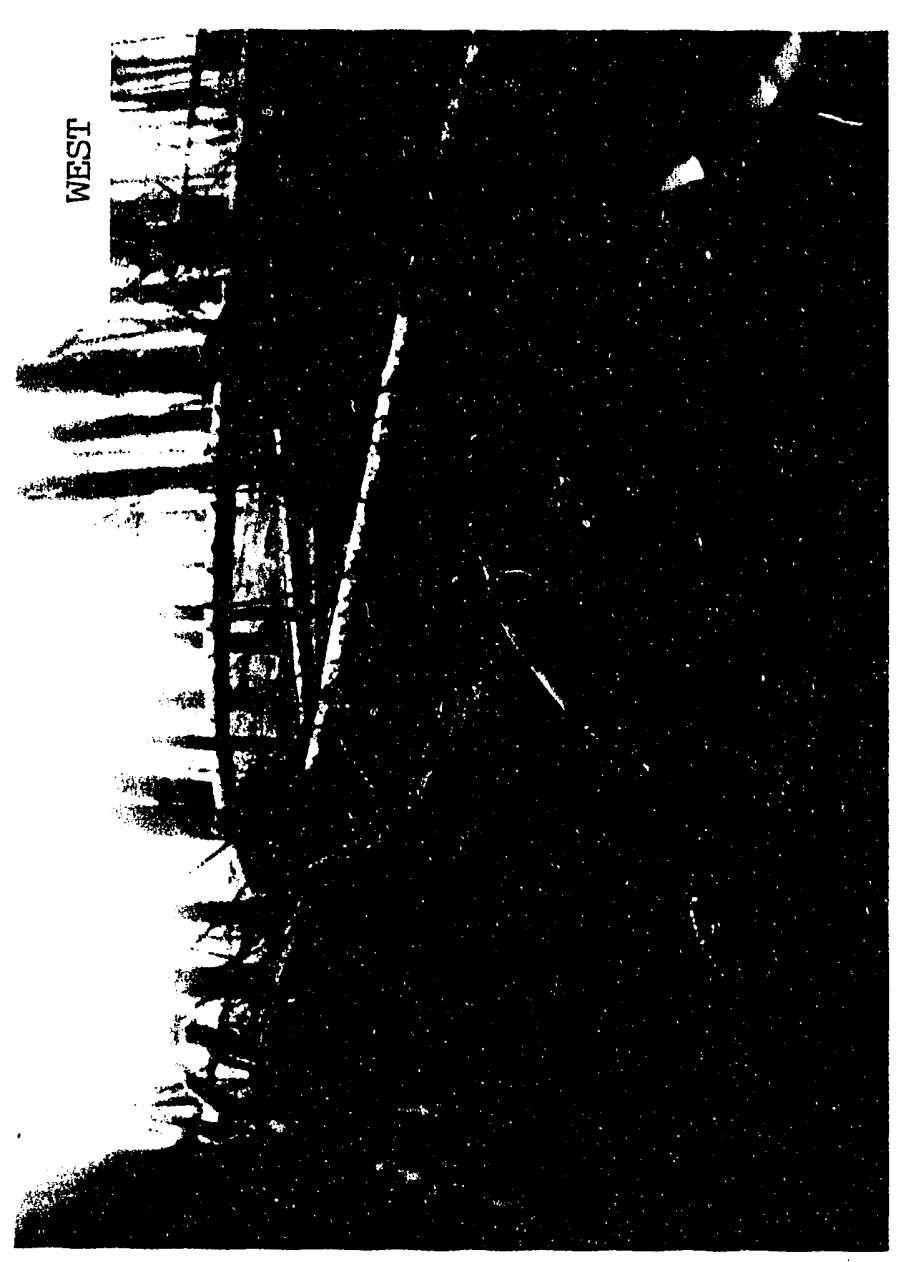

B. 27
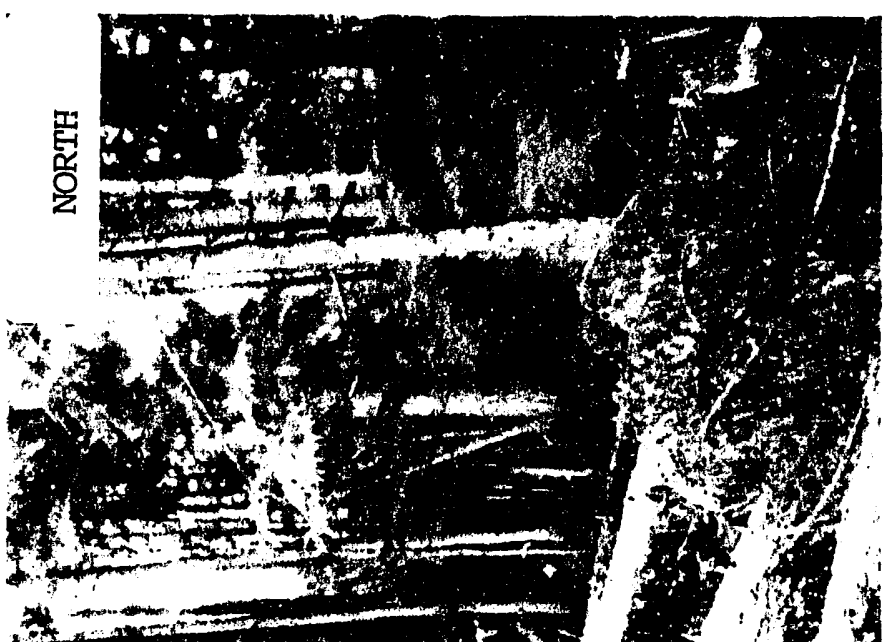

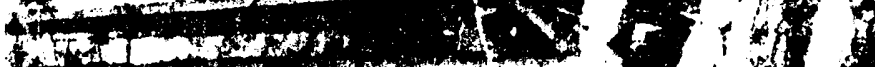

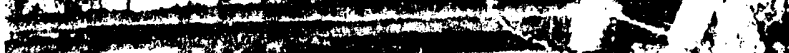

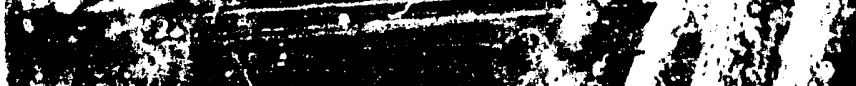

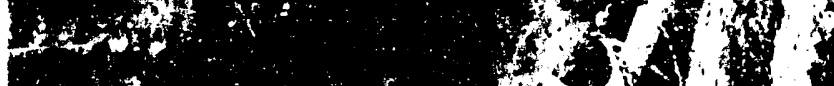

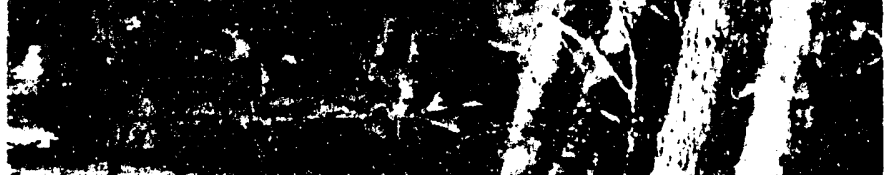

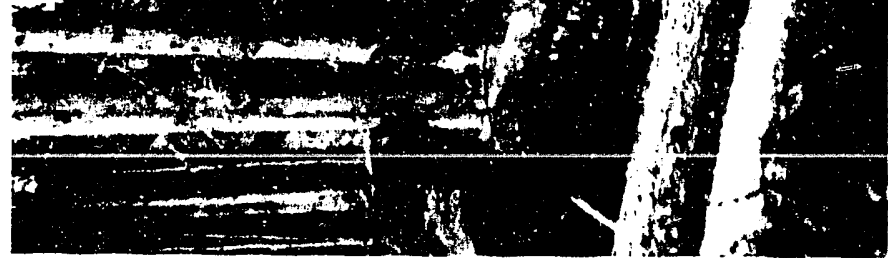

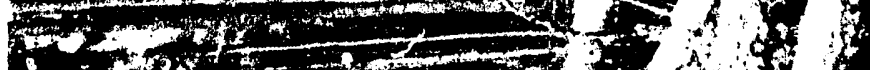




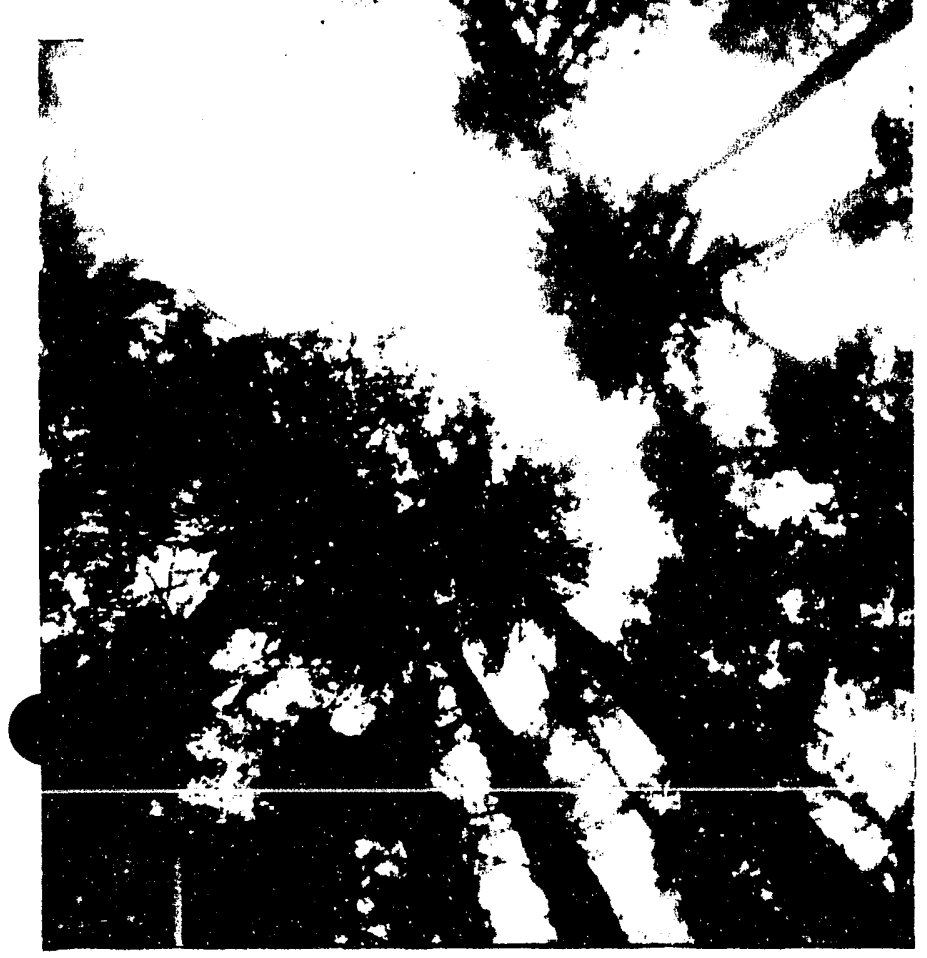


UWB CLUTTER EXPERIMENT

TELENICK

Observer

$\frac{10 / 24 / 91 \quad 16 i 45}{\text { Date }}$

BEAR MTN

\#3-261'BEARING

Transect Sampling Station

Site Description: DOWN HILLSIDE TROM CLEARCUT NEAR ZND GALLON APPRCXX lOOYDS-BEARWK $81^{\circ}$ oudeall $60-80 \%$

Slope: SITE zol.

Overall Canopy Cover: 60 !

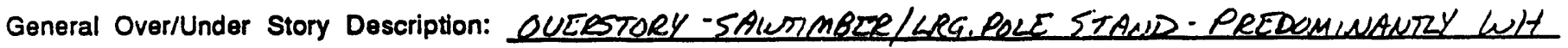

(Major Species/Woody Fuels/Litter) SOME DF. FAIRLY GOOD HT. LAYERING THROUGLWOUT. MOSTLY

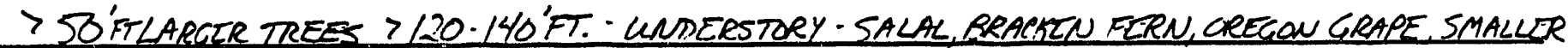

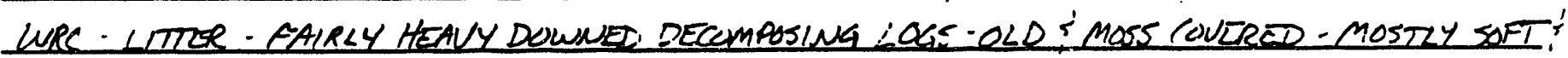
ROTING; SOME BLQWDOWN NR. PLEARCUT EOUNDORI=S ALE UTER DERTH. $24-36 "$ NR

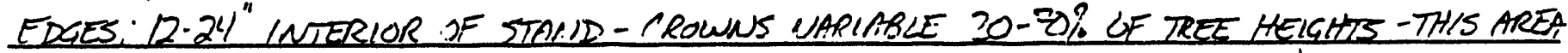
WILL PROBABLY CREATE MORE SCAMIR THAN OTHER SITES DUE TO MIXED LEUELS ' HTS.

Photo Log: $\quad \frac{N 2 / 12}{2}$ PrL: /PHOTO

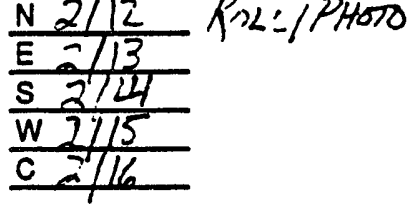

Note: Photographs will be taken at each compass direction and at the canopy.

Rainfally Moisture Description: SITE APREARS RELATUUELY WET. CANOPY COUER I DEEP LITTR KEEP IROUNS MOIST NU BOAS-QUITE A BT OF MOSS NS RAW GAUCE SEI HORE

Stand Data:

Plot Radius $=16.7$ FT 1/50 ACRE

Litter/ Grasses/ Bare Ground Forbs Shrubs $0.2 \mathrm{DBH}>2.6 \mathrm{DBH}>6.12 \mathrm{DBH}>12.16 \mathrm{DBH}>16 \mathrm{DBH}$

$\%$ Ground Cover

\begin{tabular}{|c|c|c|c|c|c|c|c|}
\hline 75 & ${ }^{1+k} 0$ & 70 & 1 & 1 & 1 & 2 & 10 \\
\hline$\frac{Q P E N}{\leftarrow 47}$ & $\rightarrow$ & 5 & 1 & 2 & 5 & 15 & 25 \\
\hline - & - & - & 3 & 2 & 1 & $1^{\left(15.2^{4}\right)}$ & $\begin{array}{r}\left(25.1^{4}\right) \\
2\left(26.0^{\prime \prime}\right) \\
\end{array}$ \\
\hline - & - & - & $10^{\prime}$ & $13^{\prime}$ & $25^{\prime}$ & $90^{\prime}-100^{\prime}$ est. & $120^{\circ}-130^{\circ}$ \\
\hline - & - & . & $\omega H$ & $\omega H$ & $D F$. & $D F$ & $D F$. \\
\hline - & - & 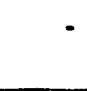 & - & - & $\omega H$ & $\omega H$ & $\omega H$ \\
\hline
\end{tabular}

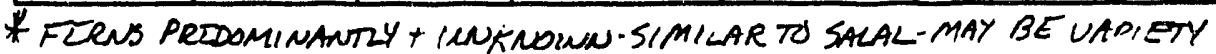

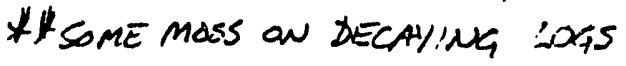

- Reviewed By: VICGeleinem 
Notes:

1) Percent ground cover and percent overstory will each total $100 \%$.

2) Percent ground cover will be viewed as the percent of stems and ground vegetation.

3) Percent overstory will be viewed as the canopy as observed from above.

Species Key:

$$
\begin{aligned}
& \text { DF - Douglas Fir } \\
& \text { WH - Western Hemlock } \\
& \text { WRC - Western Red Cedar } \\
& \text { PSF - Pacific Silver Fir } \\
& \text { M - Madrone } \\
& \text { DEC - Deciduous Species }
\end{aligned}
$$



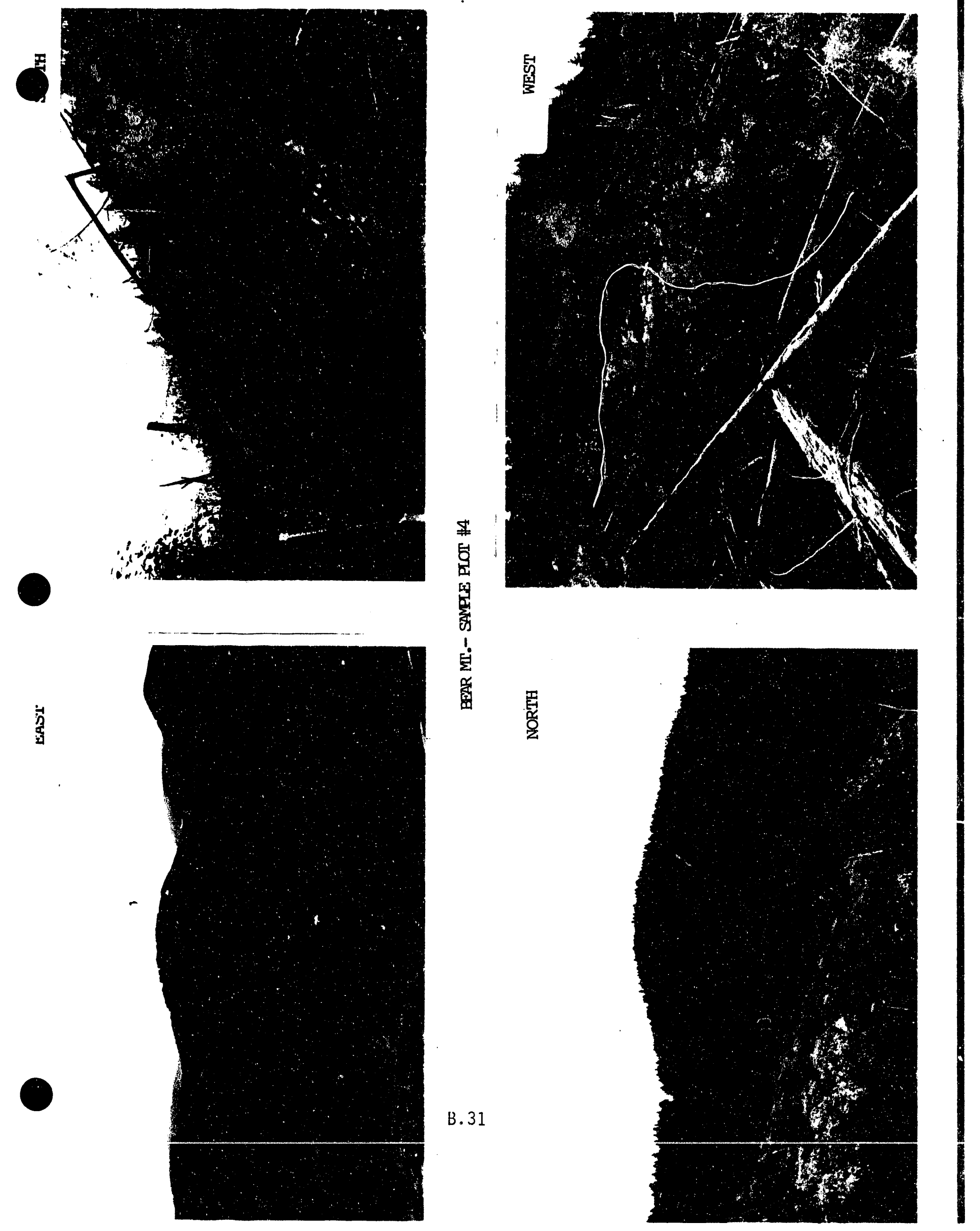


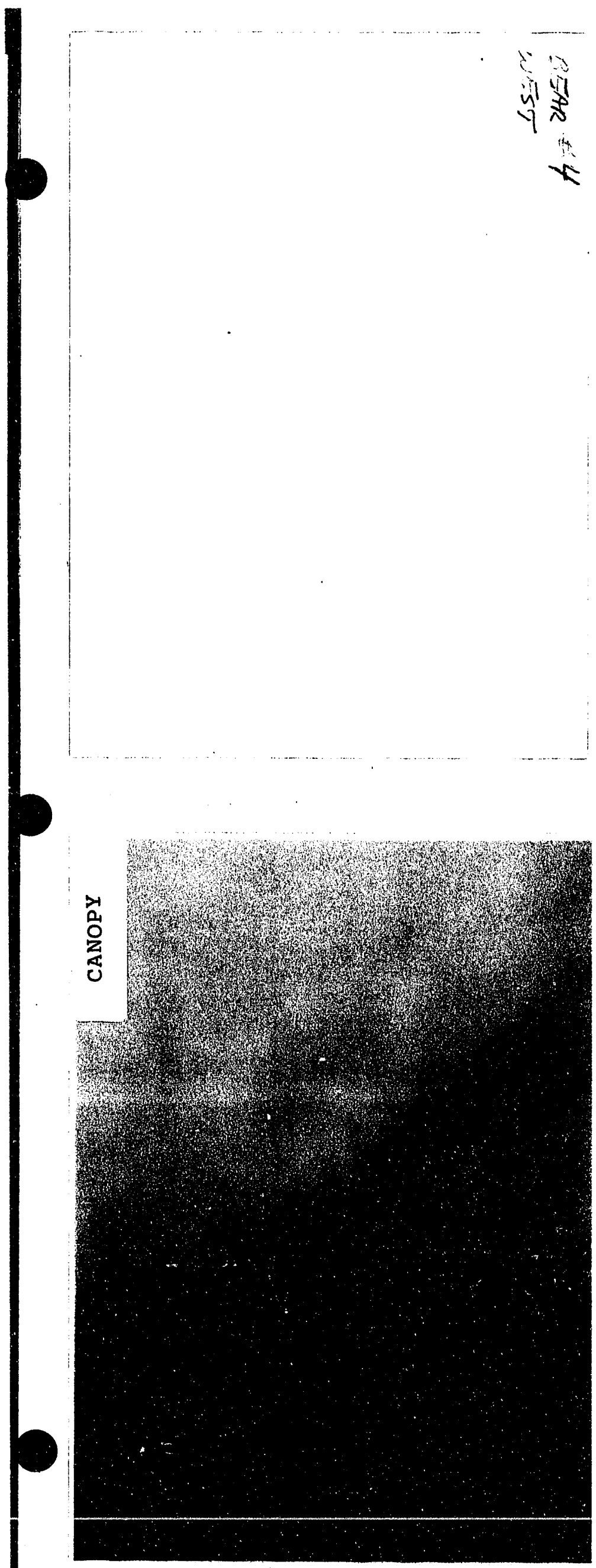

衰.

11
yi

B. 32 


\section{UWB CLUTTER EXPERIMENT}

$\frac{\text { Telenck }}{\text { Observer }}$

BEAR MTN.

Transect

UWB CLUTTER EXPERIMENT

$\frac{10 / 25 / 910900}{\text { Date }}$

\#4-261. BLARING

Sampling Station
Site Description: APPROX SO YOS DOWN HILSIOE EROM BEAR MTN. TARGET ZONE (SPUR RD) NEAR W/ END OUERALL FO-i00\%
Slope: $\quad 5 I T E 80 \%$ Overail Canopy Cover: $D \%$ CLEARCUT OF CLEARCUT- F9'BEARIUG,

General Over/Under Story Description: AUERSTOR\%-OREN, CLCARCLT-30-40A ESIIMATED SIZE-

(Major Species/Woody Fuels/Litter) LUNDERSTORY - PREDOMTNANTZY D'STURRANCE WUED SPECIES.

ANAUALS - THISRE, UARIUUS COMPOSITES - OCCASIONAL INRC OR ALOLR SFEDLINGS - VERY

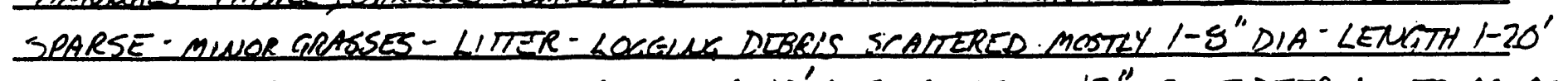
FAIRLY EUCNLY DNAEPSED-STUMP SPACIN 6-10'AVE. AVE SIIE 12"-SOME DEEP LITER AREA MOSTLY DECOMPOSED MATRRIAL. AUE 12 -24" DEPTN-AREAS OF FARE MIAIRTHLSOIL IN YARDING TRAILS

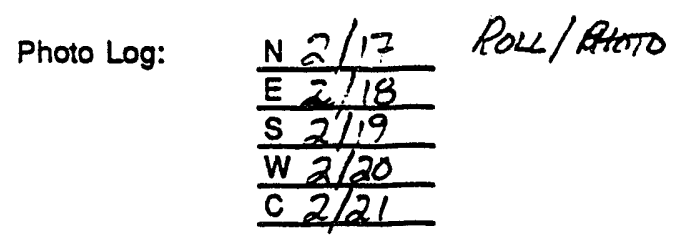

Note: Photographs will be taken at each compass direction and at the canopy.

Rainfall/ Moisture Description: S:TE AFPEARS RELATIVEYY DRY-NU CANOPY COULR TO

SHIELS SUNLIGHT-L'RER IS FAIRLY DEET HUEUER S.E. ASPECT OS SLOPE DRIES MORE TIAN OTHER CLEARCLTS - SET RAIN GAUGE OQ10

Stand Data:

Plot Radius $=16.7$ FT 1/50 ACRE

Litter/ Grasses/

Bare Ground Forbs Shrubs $0.2 \mathrm{DBH}>2.6 \mathrm{DBH}>6-12 \mathrm{DBH}>12.16 \mathrm{DBH}>16 \mathrm{DBH}$

\begin{tabular}{|c|c|c|c|c|c|c|c|c|}
\hline$\%$ Ground Cover & 63 & 35 & \begin{tabular}{|c|} 
Trimpurboed \\
2
\end{tabular} & 0 & 0 & 0 & 0 & 0 \\
\hline \% Overstory & 63 & 35 & $z$ & 0 & 0 & 0 & 0 & 0 \\
\hline Number/Class & - & - & - & 0 & 0 & 0 & 0 & 0 \\
\hline Average Height & - & - & - & - & - & - & - & - \\
\hline Major Species & - & - & - & - & - & - & - & - \\
\hline Minor Species & - & - & - & - & $=$ & - & - & - \\
\hline
\end{tabular}

X ALL LITRE is MINCRAL SOLL

- Reviewed By: VICUleinan B. Bee Back of Form for Notes 
Notes:

1) Percent ground cover and percent overstory will each total $100 \%$.

2) Percent ground cover will be viewed as the percent of stems and ground vegetation.

3) Percent overstory will be viewed as the canopy as observed from above.

Species Key:

$$
\begin{aligned}
& \text { DF - Douglas Fir } \\
& \text { WH - Western Hemlock } \\
& \text { WRC - Western Red Cedar } \\
& \text { PSF - Pacific Silver Fir } \\
& \text { M - Madrone } \\
& \text { DEC - Deciduous Species }
\end{aligned}
$$



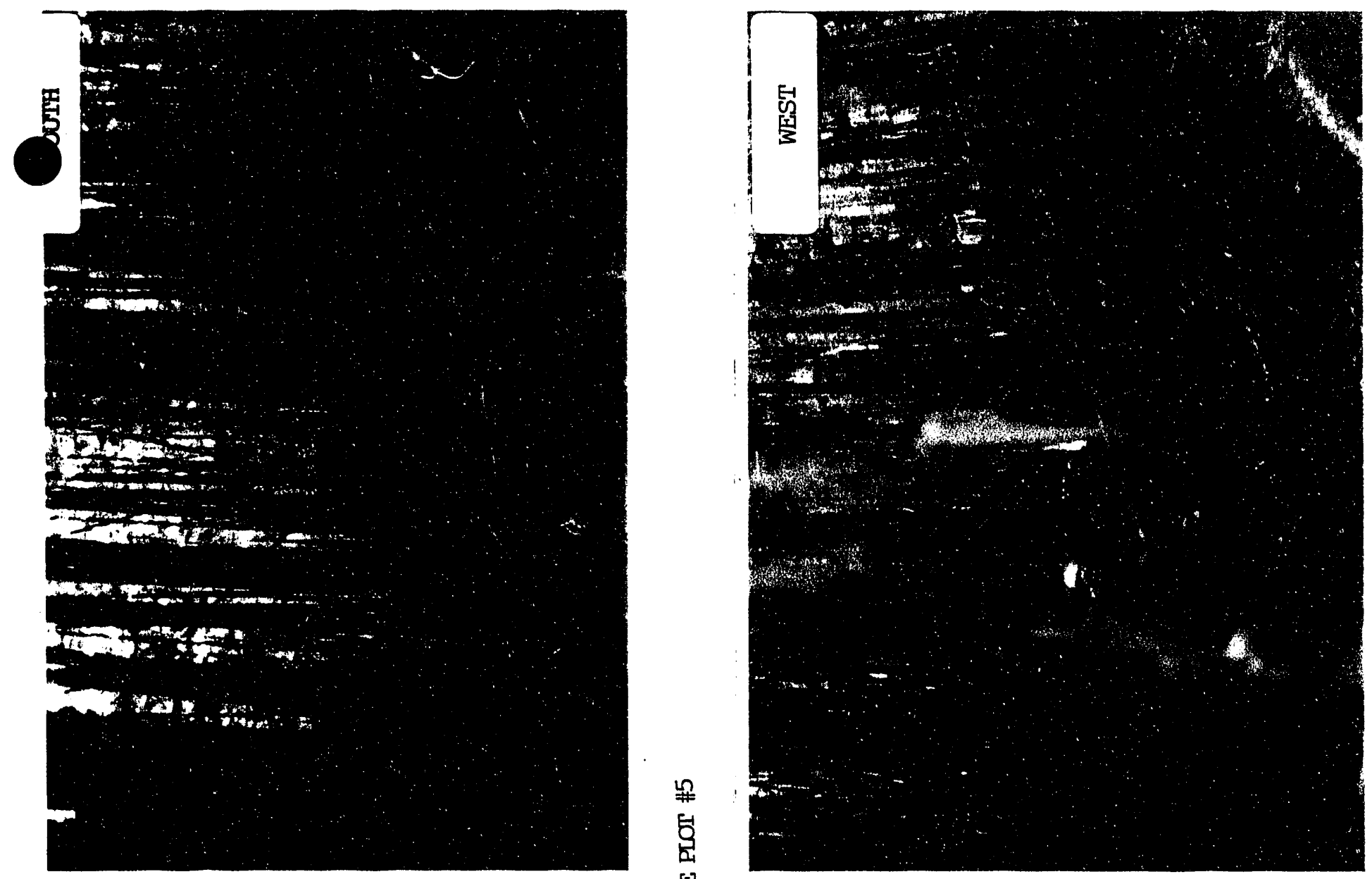

,
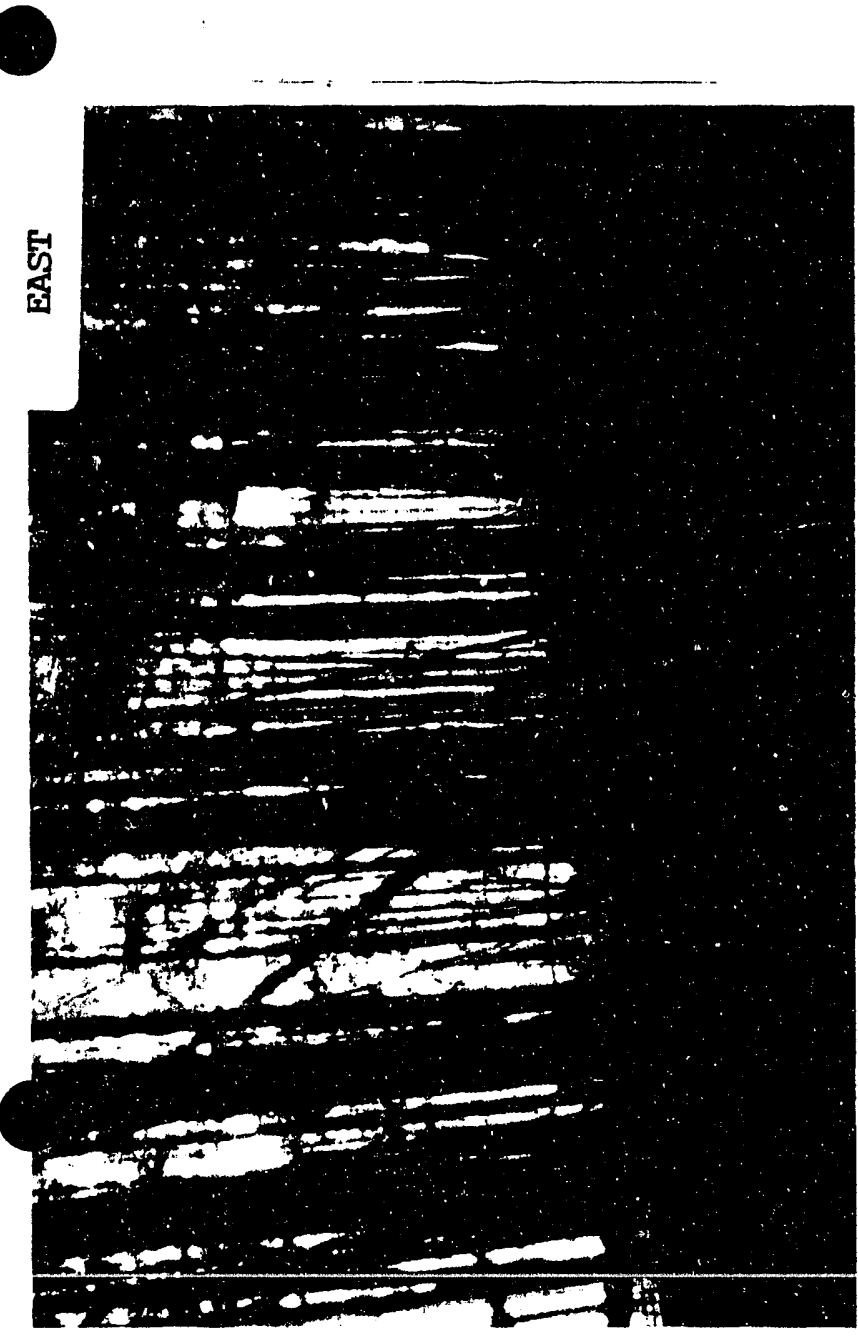

B. 35

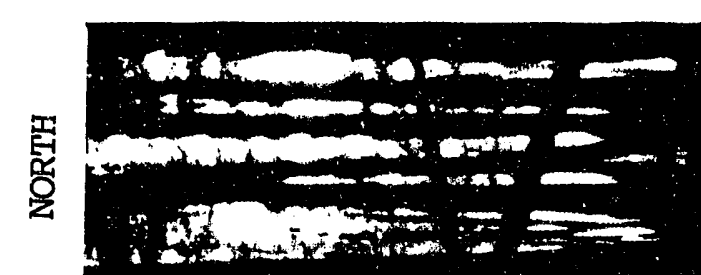

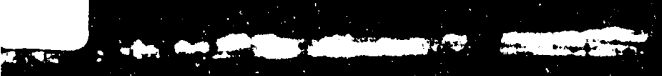

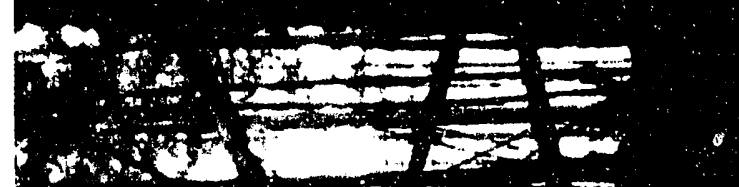

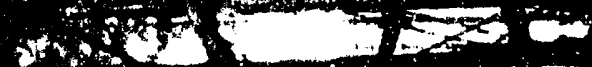

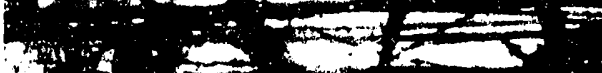

How $=0$

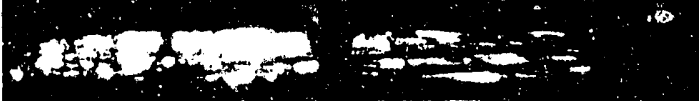

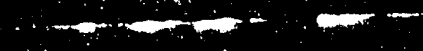

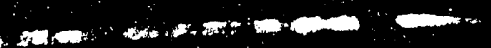

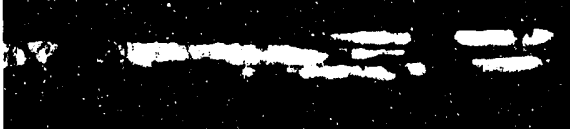

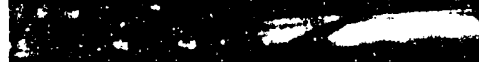




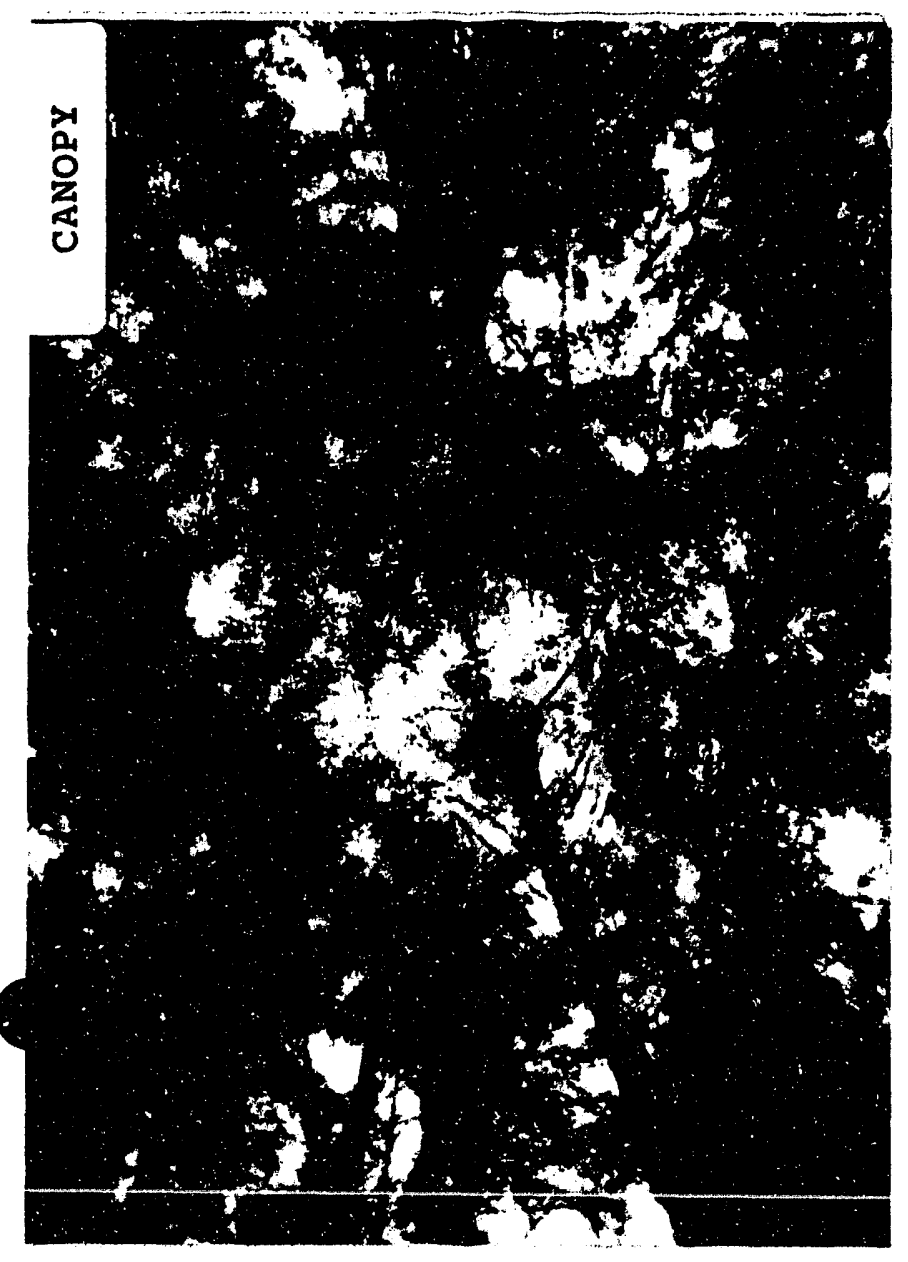

B. 36 
UWB CLUTTER EXPERIMENT

$\frac{\text { TELinick }}{\text { Observer }}$

$\frac{10 / 25 / 91 \quad 09: 35}{\text { Date }}$

BEAR MTN

\#5 261. BLARING

Transect

Sampling Station

Site Description: APPROX 40 YDS UPSLOPE FROM BEAR MTN. TARGET ZONE (SPUR RD) WN POLE STAND OUDARLL \&O-50\%

Slope: SITE $40 \%$

Overall Canopy Cover: $90-95 \%$

Z61 BLARWK

General Over/Under Story Description: QUERSTORY - PREPOMINANRY WH, DF W/ OCCASLUNAL WRC-HTS

(Major Species/Woody Fuels/Litter) QUE 70 FT. SOME TO $10^{\top}$ FT. STEM DIA. O DBH QVE \& ${ }^{4}$ POAKE 2-12" SIMILAR TO ZION E4 w/ LESS LITER - LESS DOGHAIR - UNDLRSTORY-MOSTLY

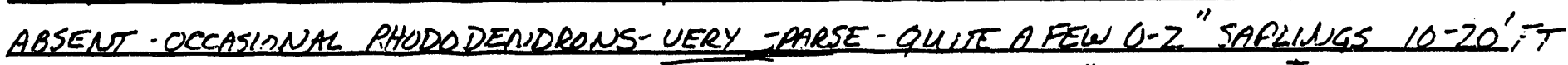
WI SPPRSE FOUTAEE - LITLR-MOD. AMT. OF DEWNED FOLES 2-6" DIA. TO $20^{\top}$ "T LEMGIT

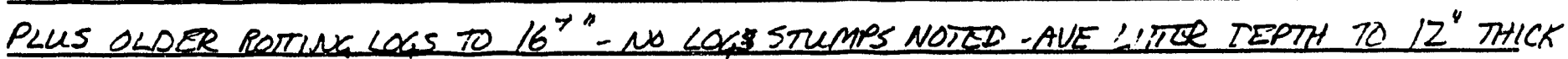

Photo Log: $\quad \mathrm{N} 2 / 22$ PoLL / PHoto

$$
\frac{\frac{N 2 / 22}{E 2 / 23}}{\frac{N 2 / 24}{S}}
$$

Note: Photographs will be taken at each compass direction and at the canopy.

Rainfall/ Moisture Description:AREA APPEARS PSCATIUELY WET-THICK CQNOPY PREIENTS DRY WG OUT + MODERATE LITTR TO RETAIN MOISTURE - SOME MOSS ON DECAYING LOS AND TREE BRANCMES-SET RAIN GAUGE - 0955

Stand Data: Plot Radius $=16.7$ FT 1/50 ACRE

Litterl Grasses/ Bare Ground Forbs Shrubs $0.2 \mathrm{DBH}>2-6 \mathrm{DBH}>6-12 \mathrm{DBH}>12-16 \mathrm{DBH}>16 \mathrm{DBH}$

\begin{tabular}{|c|c|c|c|c|c|c|c|c|}
\hline$\%$ Ground Cover & 87 & 0 & $\begin{array}{c}\text { Rhodopono. } \\
1\end{array}$ & 2 & 5 & 5 & 0 & 0 \\
\hline$\%$ Overstory & $\frac{O P_{2}}{-5 t}$ & & 1 & 4 & 30 & $60^{* * *}$ & 0 & 0 \\
\hline Number/Class & $\cdot$ & - & - & 12 & 21 & $10^{*}$ & 0 & 0 \\
\hline Average Height & - & - & - & $15^{\prime}$ & $30-40^{\prime}$ & $80^{\prime}$ & 一 & - \\
\hline Major Species & - & - & - & WRC & $\omega H$ & $\omega H$ & - & - \\
\hline Minor Species & - & - & - & $\omega H$ & WRC & $D F$ & - & - \\
\hline
\end{tabular}

I ONE TREE SPLIT TRUNK BELOW DBH - COUNTED AS 2

X* MOSTLY LITRR W/ SOME TUIGS + ROTINL LOCS HHH OUERSTORY LAYLRS TIERED - 6-12" NLASS AS DOMINANT OULRSTORY

- Reviewed By: VI C lininam 
Notes:

1) Percent ground cover and percent overstory will each total $100 \%$.

2) Percent ground cover will be viewed as the percent of stems and ground vegetation.

3) Percent overstory will be viewed as the canopy as observed from above.

Species Key:

$$
\begin{aligned}
& \text { DF - Douglas Fir } \\
& \text { WH - Western Hemlock } \\
& \text { WRC - Western Red Cedar } \\
& \text { PSF - Pacific Silver Fir } \\
& \text { M - Madrone } \\
& \text { DEC - Deciduous Species }
\end{aligned}
$$



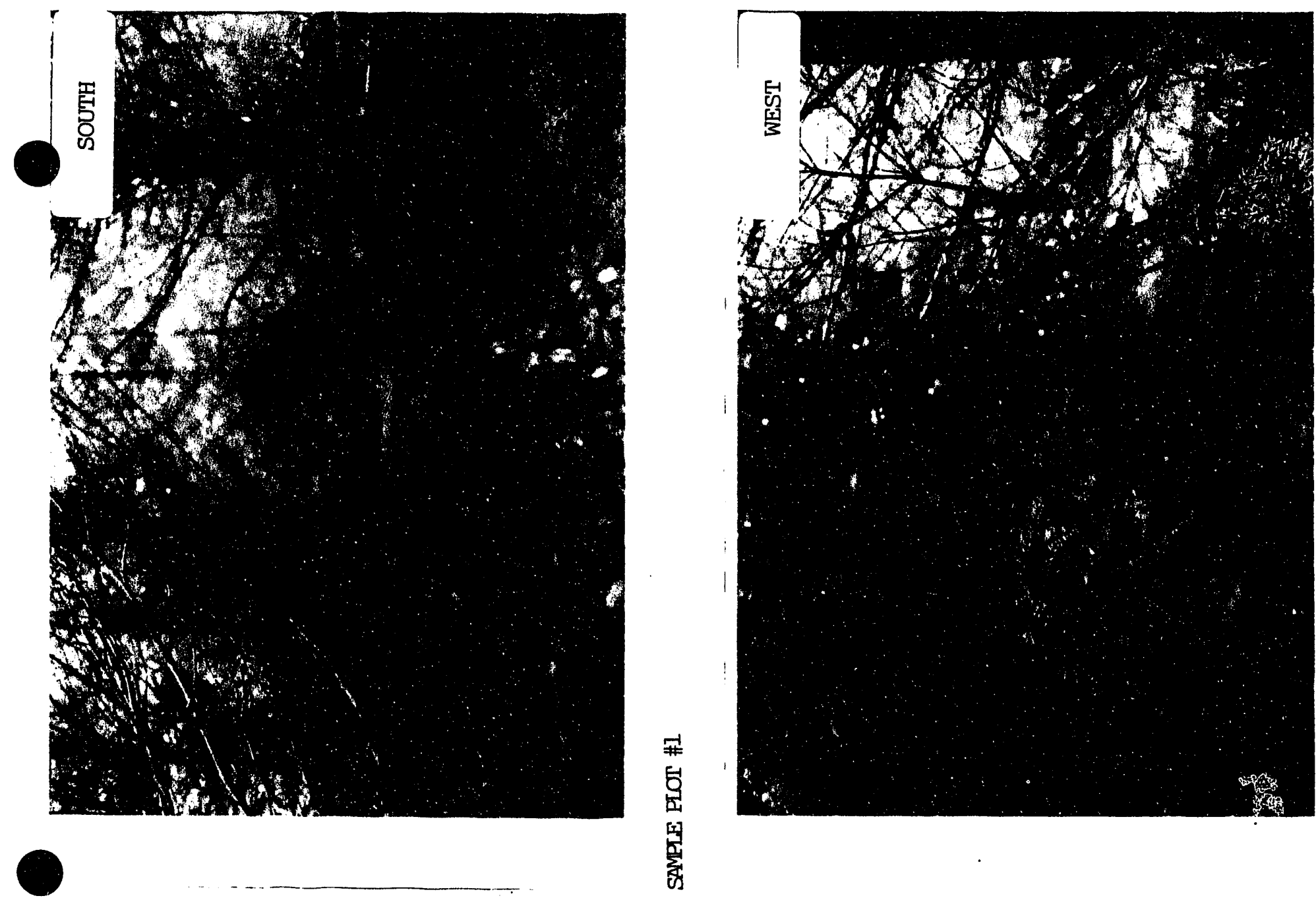

\#

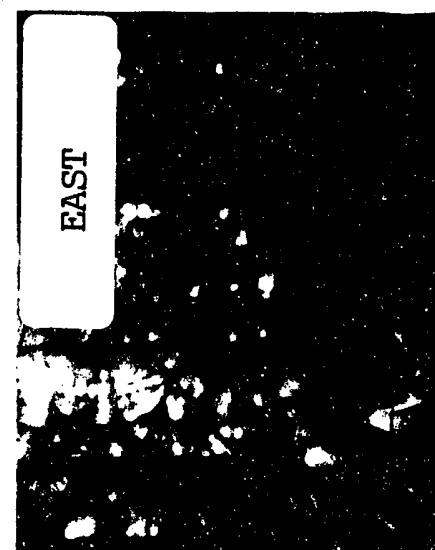

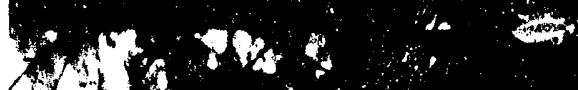
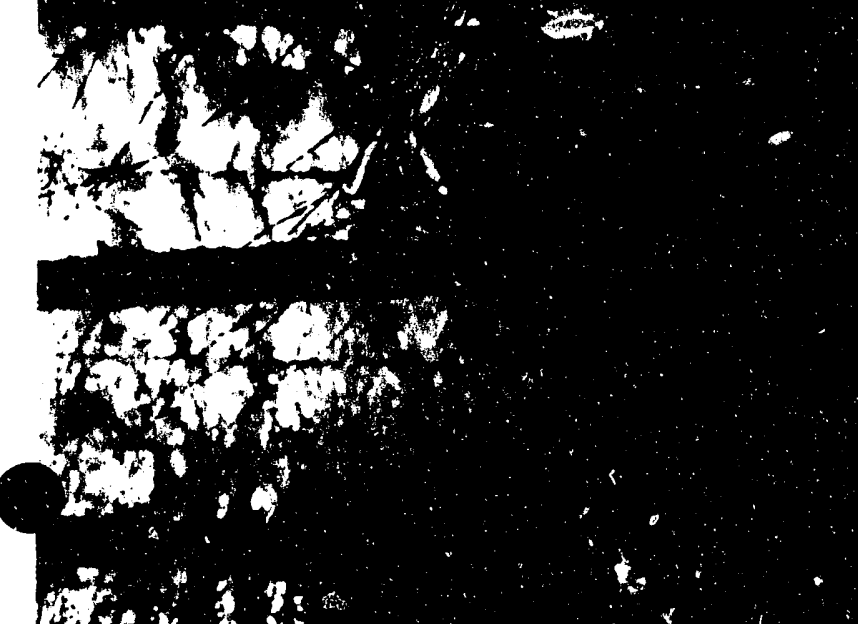

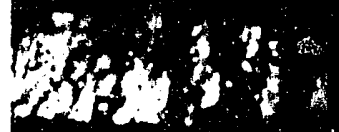

B. 39

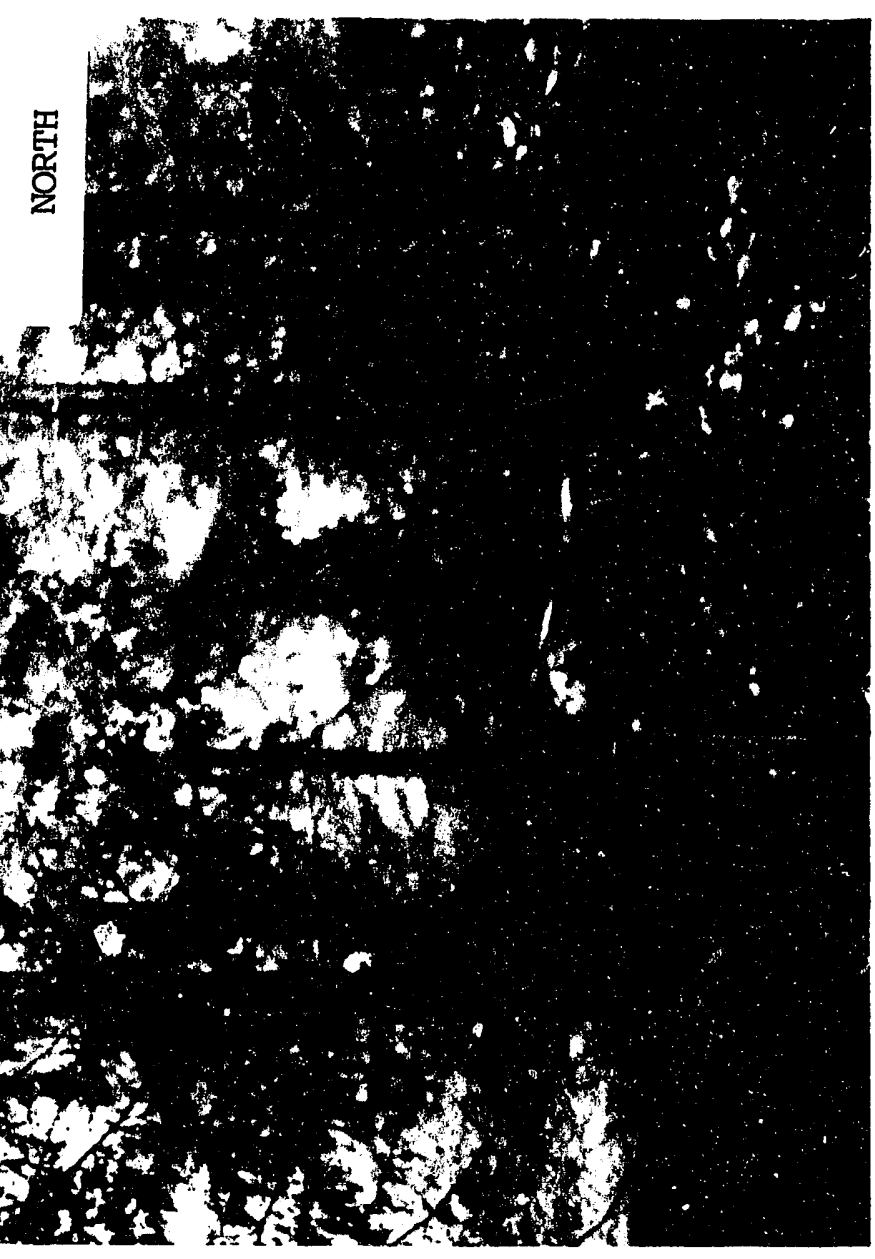




$$
\begin{aligned}
& \xi \begin{array}{l}
a \\
4
\end{array} \\
& y \\
& x
\end{aligned}
$$

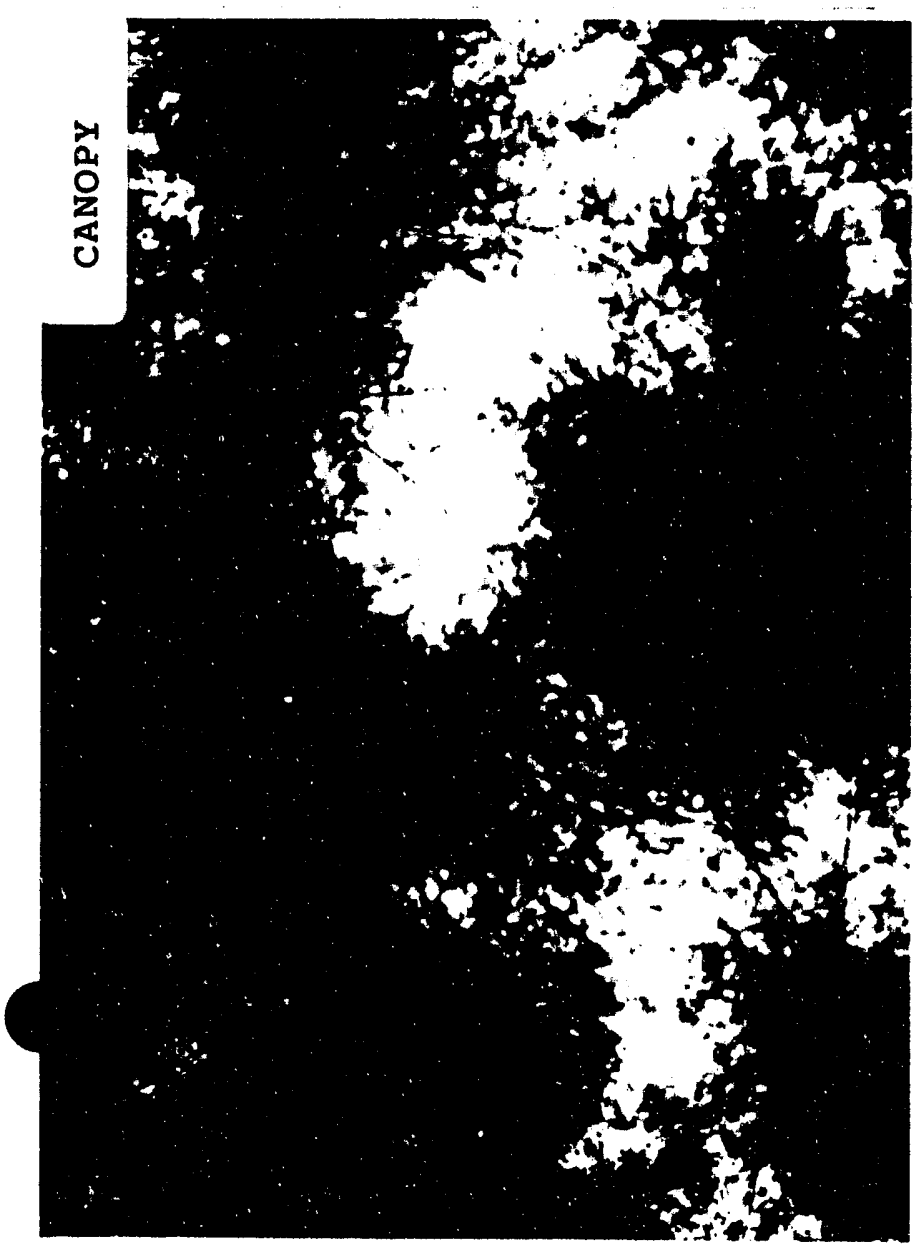


UWB CLUTTER EXPERIMENT

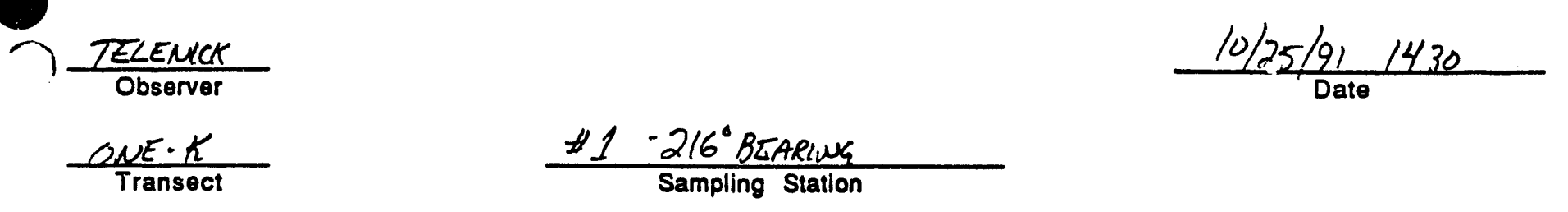

Site Description:APPRdX. 50 yOS FROM BALLOON \#1-BLARUKG $216^{\circ}$ OULRALL - 5 TO +10L ROATUE TO RADAR SITE EO\% CULRALL

Slope: SITE QS Overall Canopy Cover: 90-957, SITE

General Over/Under Story Description: OULRSTORY-PREDOMINANTZY POLE SZZEO TIMBZR-DF/WH/WRC

(Major Species/Woody Fuels/Litter) AUE HT. 40-60FT-01A.6-12" - TRESS ARE FWU CROWNED - 50 -

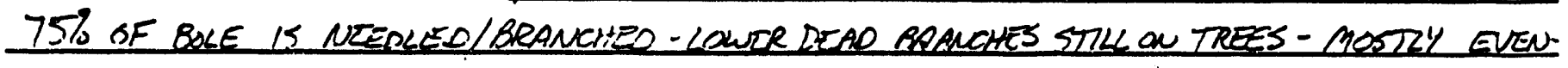

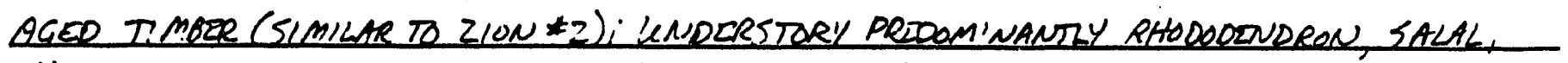
HUUCKLEBERRY, DECIDUOUSS SHRIRBS/LOSIMG LEAUES' UDT HEAVY UNDERSTORY: LIITER FAIRLY HEAVY - OLD DECOMAOSWG LOLS PUS LARE STUMRS $724^{\prime \prime}$ - MOSS COUERED - FAIRLY HEAVY - EEW FORBS- L'TTLR DEPTH TO $24^{\prime \prime}$. NO MINERAL SOIL CXPASED

Photo Log: $\frac{\frac{N 3 / 11}{E 3 / 12}}{\frac{\frac{E}{3 / 13}}{\frac{W / 14}{3 / 15}}}$

Note: Photographs will be taken at each compass direction and at the canopy.

Rainfall/ Moisturo Description: SITE APPEARS RELPTUEIY WET-SIMILAR TO $1-K \# 3$ TREES ARE SMALER BUT FULY CAMAPIED TU PREUENT SOILS FROM DRYINK - GEAVY LITER + MOSS HOLD MS:STURE WN-NCAR DRAINAEE ON AIR PHOTOS. RAIN GRUGE SET. UNDER CAMSPY $14: 45$

Stand Data: Plot Radius $=16.7$ FT 1/50 ACRE Litterl Grasses/ Bare Ground Forbs Shrubs $0.2 \mathrm{DBH}>2-6 \mathrm{DBH}>6-12 \mathrm{DBH}>12-16 \mathrm{DBH}>16 \mathrm{DBH}$

\begin{tabular}{|c|c|c|c|c|c|c|c|c|}
\hline$\%$ Ground Cover & 88 & 1 & 5 & 0 & 1 & 5 & 0 & 0 \\
\hline$\%$ Overstory & $\leftarrow$ & & 5 & $z$ & 13 & 70 & 0 & 0 \\
\hline Number/Class & - & - & - & 4 & 2 & 7 & 0 & 0 \\
\hline Average Height & $\cdot$ & - & - & $\angle 10^{\circ}$ & $40^{\prime}$ & $60.70^{\circ} \mathrm{Cs}$ & 0 & - \\
\hline Major Species & - & - & - & Wit & $\omega H$ & $D F$ & & \\
\hline Minor Species & - & - & - & WRC & - & $\omega H$ & & \\
\hline
\end{tabular}


Notes:

1) Percent ground cover and percent overstory will each total $100 \%$.

2) Percent ground cover will be viewed as the percent of stems and ground vegetation.

3) Percent overstory will be viewed as the canopy as observed from above.

Species Key:

$$
\begin{aligned}
& \text { DF - Douglas Fir } \\
& \text { WH - Western Hemlock } \\
& \text { WRC - Western Red Cedar } \\
& \text { PSF - Pacific Silver Fir } \\
& \text { M - Madrone } \\
& \text { DEC - Deciduous Species }
\end{aligned}
$$



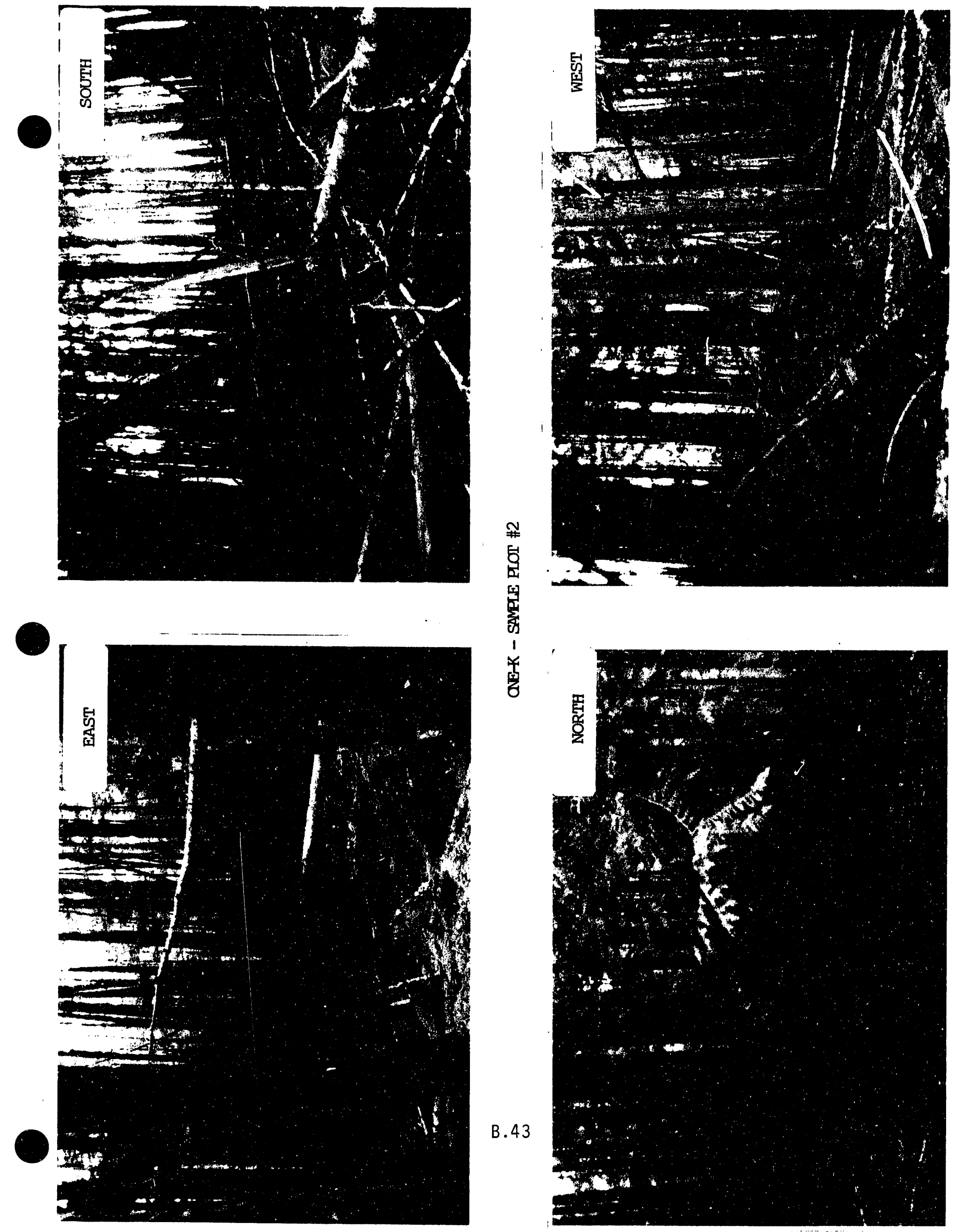

B. 43

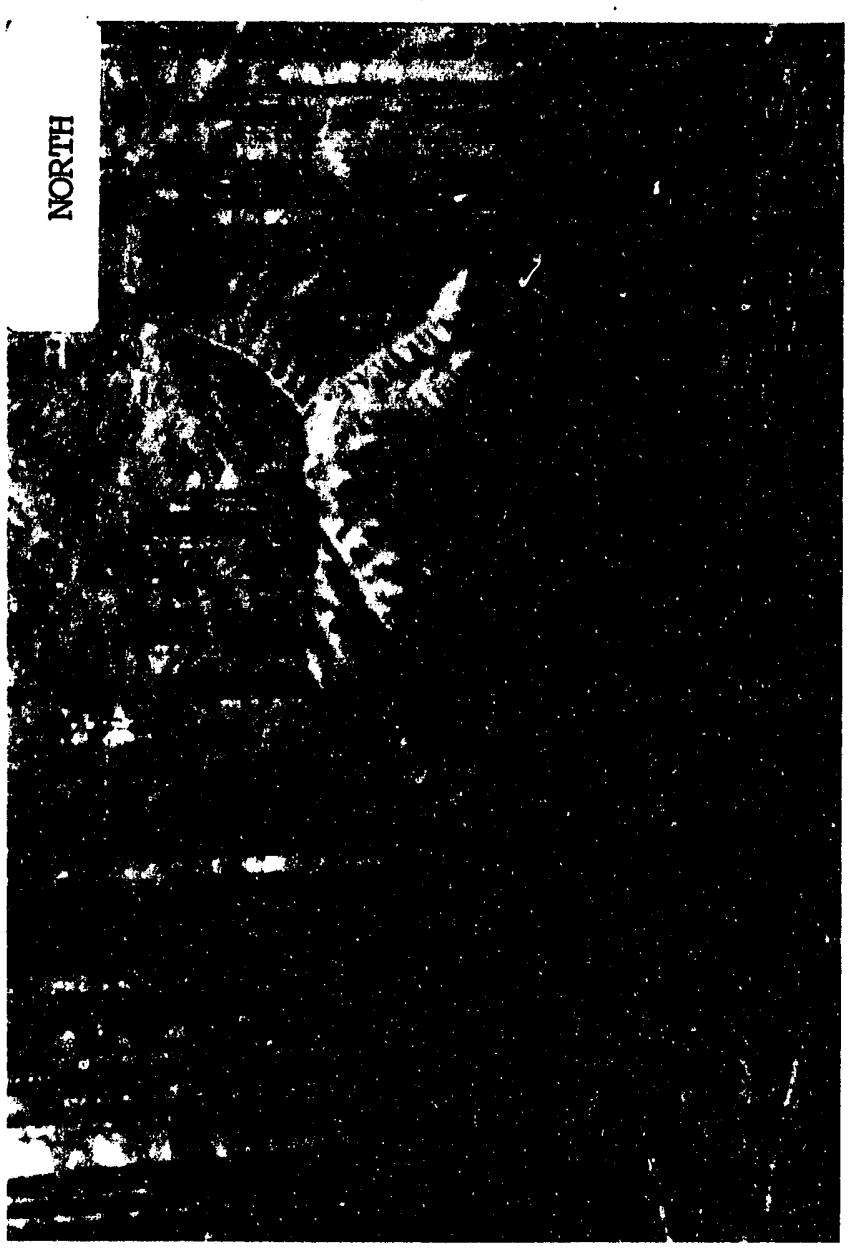




\section{UWB CLUTTER EXPERIMENT}

TELEMCE

$\frac{10 / 25 / 91 \quad 13: 20}{\text { Date }}$

ONE.K

Transect

\#2-216 BEARING

Sampling Station

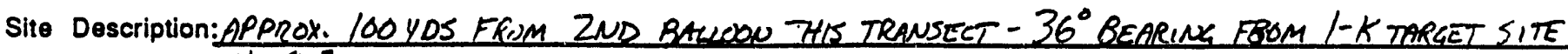
OULRALL $40.80 \%$

Slope: SITE $70 \%$ Overall Canopy Cover: $85.90 \%$

General Over/Under Story Description: QLILRSTORY. EALRWY DEUSE-SIMLAR TN BEAR MTN \#S OR

(Major Species/Woody Fuels/Litter) MT 2LOA \#4-DOMINANT SPECIES DF. 45 $130-150$ FT: DIA AVE 16-24". MOSTY 6-12 +12-16" CLASS. DF, WH W/ OCCASIONAL TALL ALDARS-THIS CLASS (CODOMINANTS) ARE 80-120FT. CROWN PROFILES UARY - OULRALL < 33\% OF TREE HT. FEW LOWER BRANCHES- UNOERSTORY - FEW SHRUBS - MOSTLY WRC - WH TO 40'ET- LITR- QUITE A EEWL DOUNED POLES 2-6" CLASS TO 30'FT LECTH FUS LARGER MOSTLY DECOMPASEO LOES 12:24" OUERALL LITLR TU 24 "THICK

Photo Log: $\frac{\frac{N 3 / 6}{E 3 / 2}}{\frac{\mathrm{E} 3 / 8}{\mathrm{~W} 3 / 9}} \frac{\text { RoL/PTior }}{\mathrm{C} 3 / 10}$

Note: Photographs will be taken

at each compass direction and

at the canopy.

Rainfally Moisture Description: SITE IS RLETTUEY WET BUT LESS THAN I-KHY - CANUPY

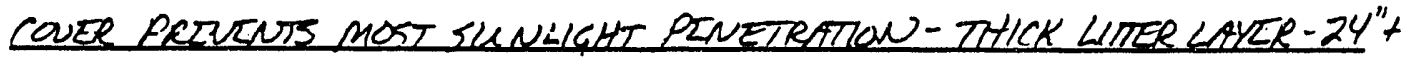

AHICK MOSS COUERED - LOTS OF DETOMPOSITZN - HOLDS MOISZURE - NU GAUCE

Stand Data:

SET- NORTH ASPECT

Plot Radius $=16.7 \mathrm{FT} 1 / 50 \mathrm{ACRE}$

Litter/ Grasses/

Bare Ground Forbs Shrubs $0.2 \mathrm{DBH}>2-6 \mathrm{DBH}>6-12 \mathrm{DBH}>12-16 \mathrm{DBH}>16 \mathrm{DBH}$

\begin{tabular}{|c|c|c|c|c|c|c|c|c|}
\hline$\%$ Ground Cover & $\begin{array}{l}1 / \mathrm{C} \text { moss } \\
855\end{array}$ & 0 & $\begin{array}{l}\text { Ge. GRant/we } \\
3\end{array}$ & 0 & 2 & 5 & 5 & 0 \\
\hline \% Overstory & $\leftarrow 15$ & $\begin{array}{l}\text { OPEN } \\
\rightarrow\end{array}$ & 0 & 1 & 4 & 30 & 30 & $20^{* * * *}$ \\
\hline Number/Class & - & - & - & ${ }^{*} 0$ & 6 & 9 & 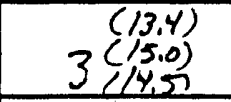 & 0 \\
\hline Average Height & - & $\cdot$ & - & - & 35 & $100^{\prime}=5$ & $120_{\text {EST }}^{\prime}$ & = \\
\hline Major Species & - & - & - & $\begin{array}{l}\text { SHIT } 1 \text { COL } \\
W H\end{array}$ & $\begin{array}{l}\mathrm{MN} \rightarrow \\
D E C \cdot A<D C R\end{array}$ & $D F$ & F & - \\
\hline Minor Species & - & - & - & WRC & $\omega H$ & $\omega H$ & $\rightarrow$ & - \\
\hline
\end{tabular}

* I SMALL WRe - us STINQ 4.5 DBH-COUNT AS SHRUB

W

* KK LARCE DF OUTSIOE PLOT BOWUDARY - CAMOPY EXTENUS INS PLOT

- Reviewed By: VIC Olhin

B. 45

See Back of Form for Notes 
Notes:

1) Percent ground cover and percent overstory will each total $100 \%$.

2) Percent ground cover will be viewed as the percent of stems and ground vegetation.

3) Percent overstory will be viewed as the canopy as observed from above.

Species Key:

$$
\begin{aligned}
& \text { DF - Douglas Fir } \\
& \text { WH - Western Hemlock } \\
& \text { WRC - Western Red Cedar } \\
& \text { PSF - Pacific Silver Fir } \\
& \text { M - Madrone } \\
& \text { DEC - Deciduous Species }
\end{aligned}
$$



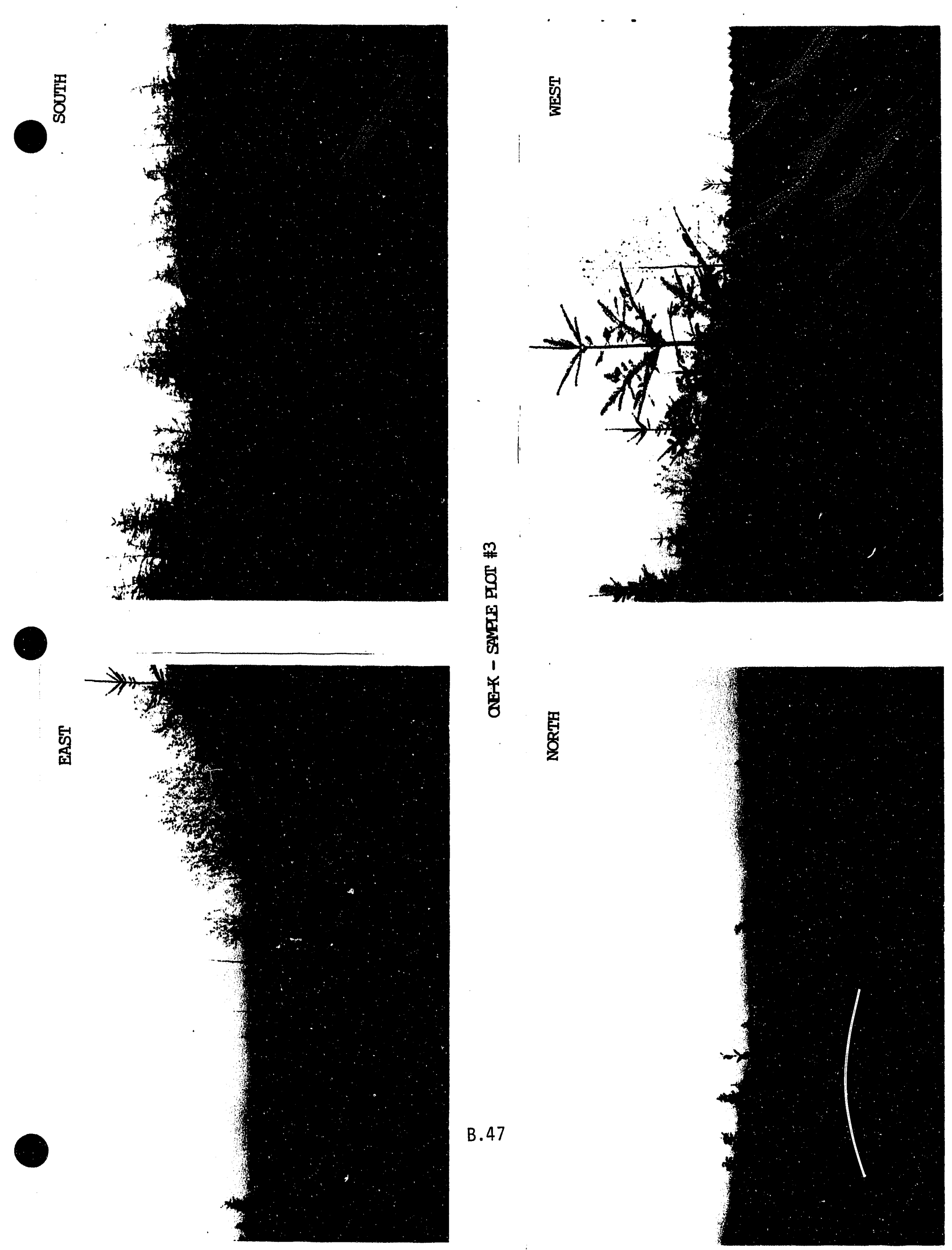

-

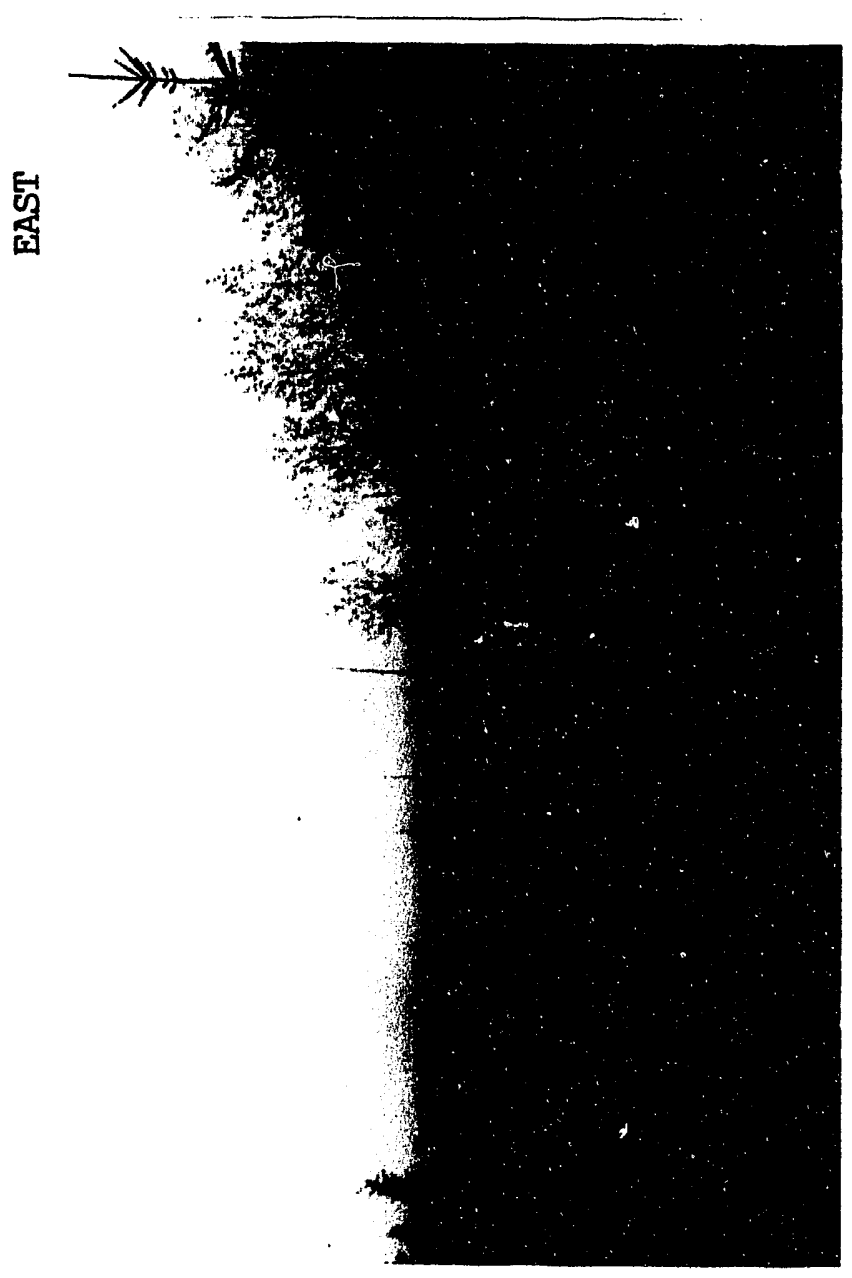

椤 


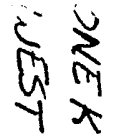

$n$
5
51
$x=1$
$x$
$x$

w

30
$y$
$x$
$x$
$x$

B. 48 


\section{UWB CLUTTER EXPERIMENT}

TELENICK

ONE-K

Transect

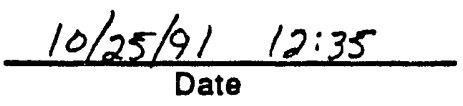

\#3-2i6 BEARUK

Sampling Station

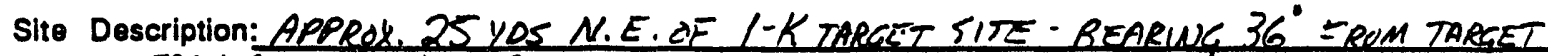
OUDRALL CLCARCUT 15-100\% TOP TO BOATOM OF HIL

Slope: SITE EST.-SMML - SLPE ON SITE-HOLE Overall Canopy Cover: 0 \%

General Over/Under Story Description: OUCRSTORY - OPEU-CLEARCUT UNDERSTORY MEAVY REPRAOUCTUN

(Major Species/Woody Fuels/Litter) PROBABLY PLATED DF SEADhMKS SPACFO 10N10'AUE- HT AUE

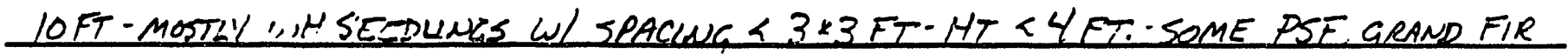
ALSO PRESENT-SOME ALDER L2SUX LEAVES 10-20ET-MOSTLY IN CWTERS - OTHER VEGETATION PRESEUT MOSTL ANNUALS, CRASSES - SOME SALAL, BEPRV - ANNUALS GRASSES DVING EACK: - LITTR-

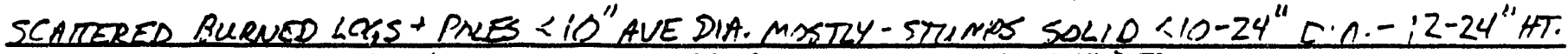

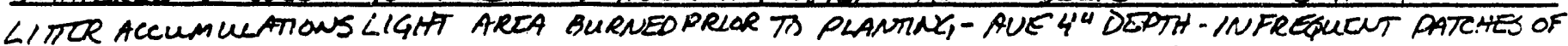
Photo Log:

\begin{tabular}{|c|}
\hline 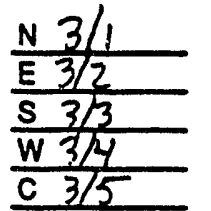 \\
\hline
\end{tabular}

Note: Photographs will be taken MINLRAL SOIL

Rainfall Moisture Description:SITE TYPICAL OF OTHER CLLARED ARTIS - PERHAPS SL. DRYLR DUE TO LIGHTER LIMER LOAOS. SAME SHADING TROM SLEDGWSGSL SAPLUKS - SET RAIN GAUGE HERE 12:45

Stand Data:

Plot Radius $=16.7$ FT $1 / 50$ ACRE

Litterl Grasses/ Bare Ground Forbs Shrubs $0.2 \mathrm{DBH}>2.6 \mathrm{DBH}>6-12 \mathrm{DBH}>12.16 \mathrm{DBH}>16 \mathrm{DBH}$

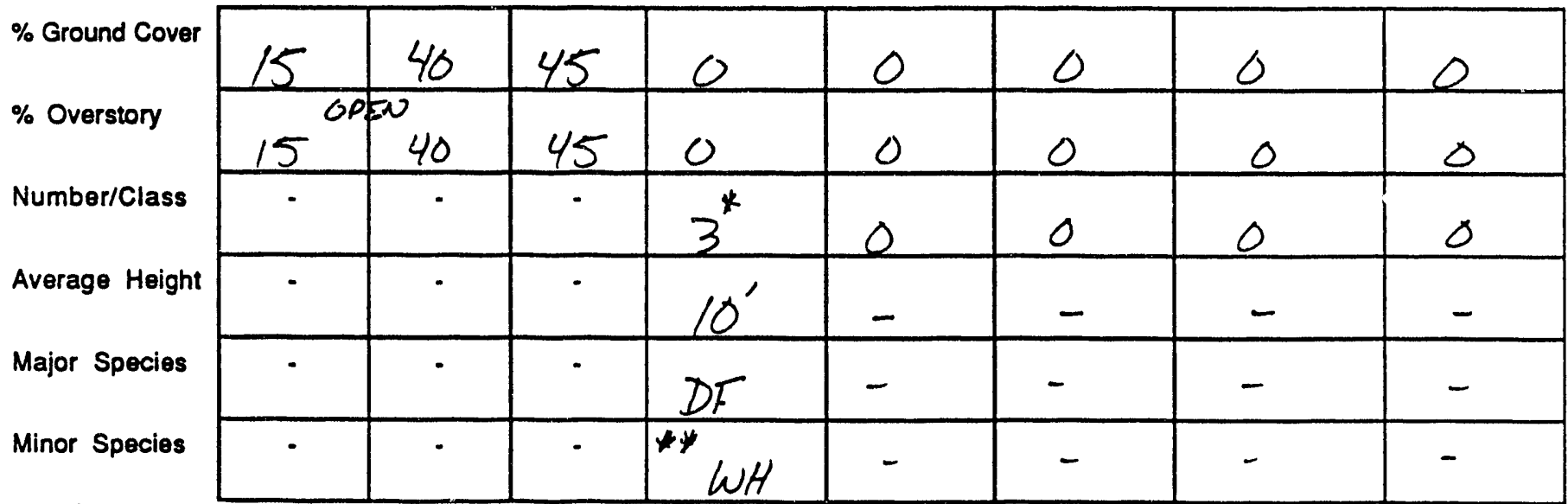

* ONLY TALLLD TREES IN/ A UISIBLE STLM C 4,5DBH. DID NOT COUNT GROWTH LCADERS AS STEMS * H MATORITH OF SEEDLMGS WH NoT LARLE ENDUGH TO TALLY

H. KEEDUMCS TALUED AS SHRUBS-THIS PLOT

- Reviewed By: vi Clewina 
Notes:

1) Percent ground cover and percent overstory will each total $100 \%$.

2) Percent ground cover will be viewed as the percent of stems and ground vegetation.

3) Percent overstory will be viewed as the canopy as observed from above.

Species Key:

DF - Douglas Fir

WH - Western Hemlock

WRC - Western Red Cedar

PSF - Pacific Silver Fir

M - Madrone

DEC - Deciduous Species 


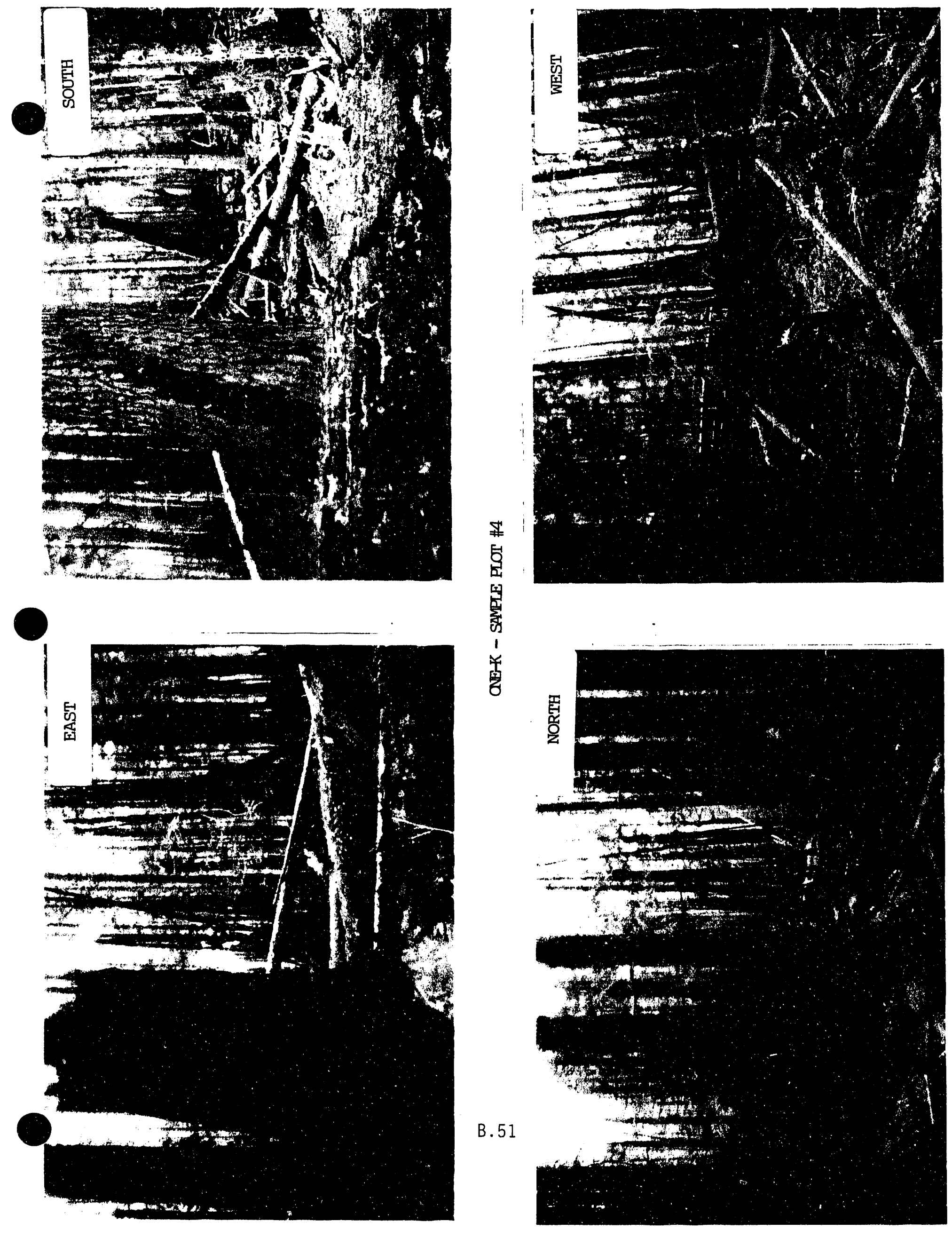




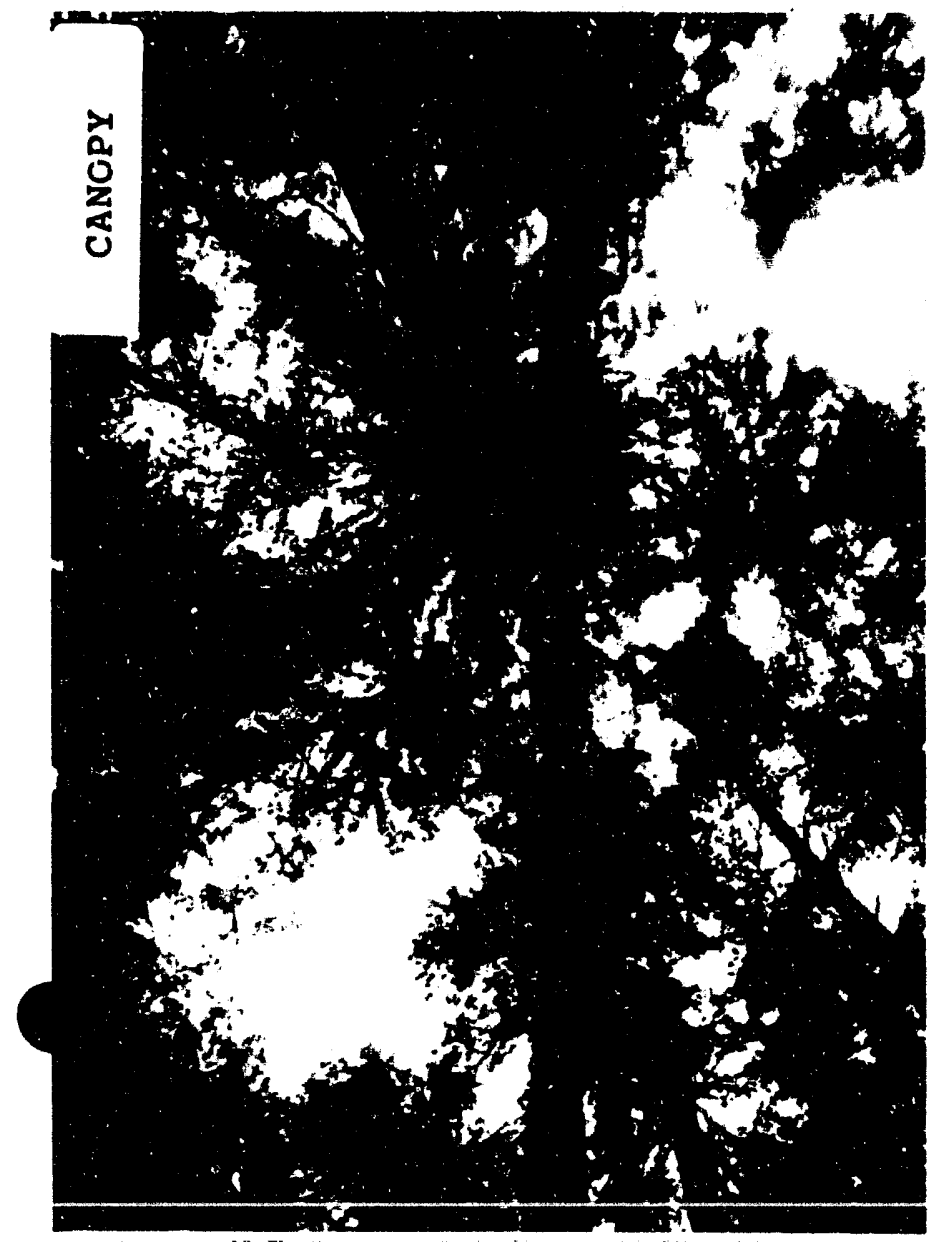

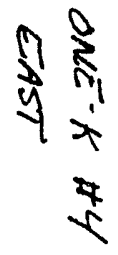


UWB CLUTTER EXPERIMENT

TELENICK

Observer

$\frac{10 / 25 / 91 / 11: 30}{\text { Date }}$

QNE-K

Transect

$\# 4-216^{\circ}$ BEARING

Sampling Station

Sito Doscription: APPROX. 200 YDS S.W OF LOGGING PRUR RD. GEYONS I-K TARGET SITE. PEGINMHE OF

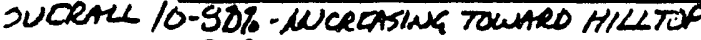

Slope: SITE 208

Overall Canopy Cover: $85 \%$

POS. ZLOPE- $216^{\circ}$ BLARUMG

General Over/Under Story Description: QUERSTORY - OLD GROUTHY TYPE STAUP-SOME UERY LARGE $724 "$

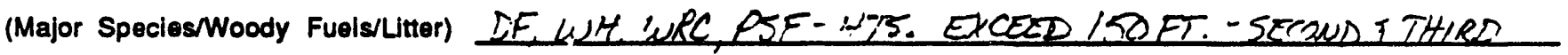
LAYERS IN CANOPY - CO DOMWNATS - 6-12" + DBH - HEICHTS TO LOET-CROWNS UMUTER TO UPPER 33\% OF BOLSS. MALLER SUPRRESSED TREES MORE SPARADC MOSTUY DEED OR AMAIMAL

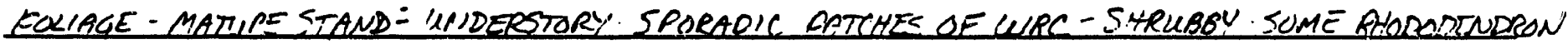

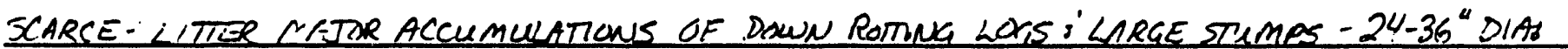

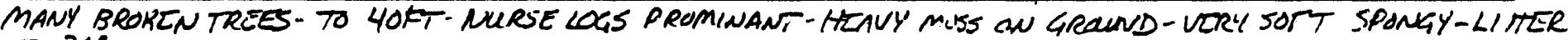
TU $36^{\circ}$

Photo Log:

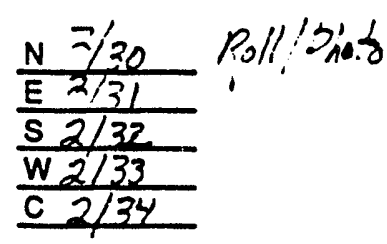

Note: Photographs will be taken

at each compass direction and

at the canopy.

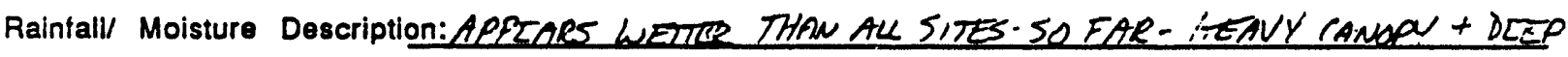
LITER KEEO GROUND VERY IAMP. MOSS ALSO RETANS MOISTURE - SET PAIN GAUGE INNDER CAMPV. $11: 45$ NOTS SMAK STREAM NR. TRANSCCT SAMPLEPT.

Stand Data: Plot Radius $=16.7$ FT 1/50 ACRE

Litterl Grasses/ Bare Ground Forbs Shrubs $0.2 \mathrm{DBH}>2.6 \mathrm{DBH}>6-12 \mathrm{DBH}>12-16 \mathrm{DBH}>16 \mathrm{DBH}$

\begin{tabular}{|c|c|c|c|c|c|c|c|c|}
\hline$\%$ Ground Cover & 79 & 1 & $\begin{array}{c}\text { 4uecklowery } \\
1\end{array}$ & 0 & 1 & $z$ & 0 & 5 \\
\hline$\%$ Overstory & $\leftarrow$ & & 0 & 0 & 0 & 5 & 30 & 60 \\
\hline Number/Class & $\cdot$ & - & - & 0 & 1 & $3^{+1 \operatorname{lnan}}$ & 0 & 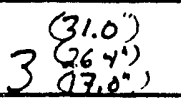 \\
\hline Average Height & - & - & - & - & $30_{\text {DYime }}^{\prime}$ & $80 \cdot 100^{\prime} \mathrm{cs}$ & 工 & $7 / 50^{\circ} \mathrm{EST}$ \\
\hline Major Species & - & - & - & - & PSF & BSF & - & $D F$ \\
\hline Minor Species & - & - & - & - & - & $\mathrm{LNH}$ & - & $\underline{\omega}$ \\
\hline
\end{tabular}

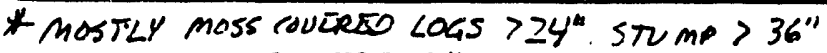

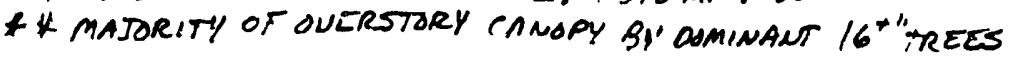

vichen 
Notes:

1) Percent ground cover and percent overstory will each total $100 \%$.

2) Percent ground cover will be viewed as the percent of stems and ground vegetation.

3) Percent overstory will be viewed as the canopy as observed from above.

Species Key:

DF - Douglas Fir

WH - Western Hemlock

WRC - Western Red Cedar

PSF - Pacific Silver Fir

M - Madrone

DEC - Deciduous Species 


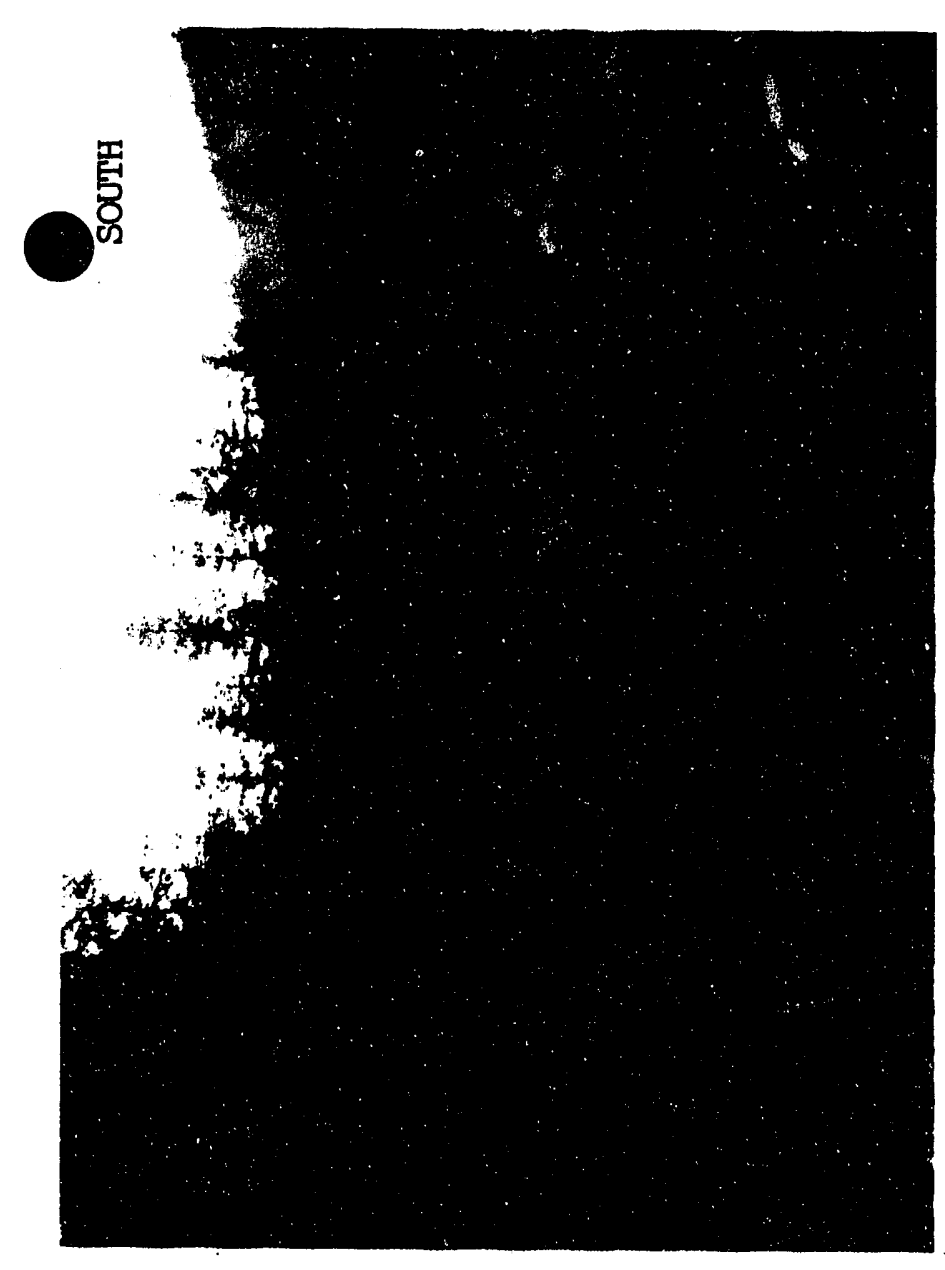

-

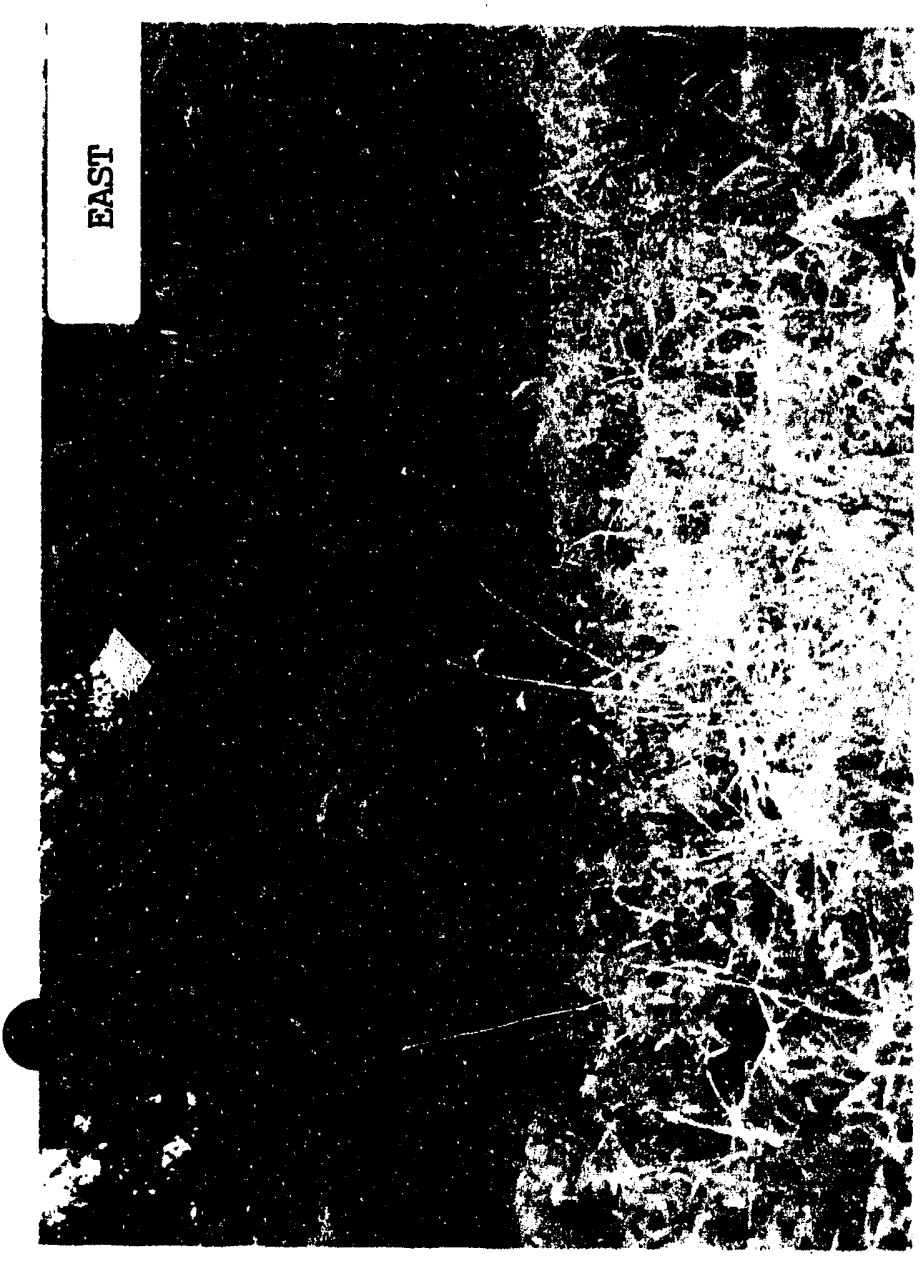

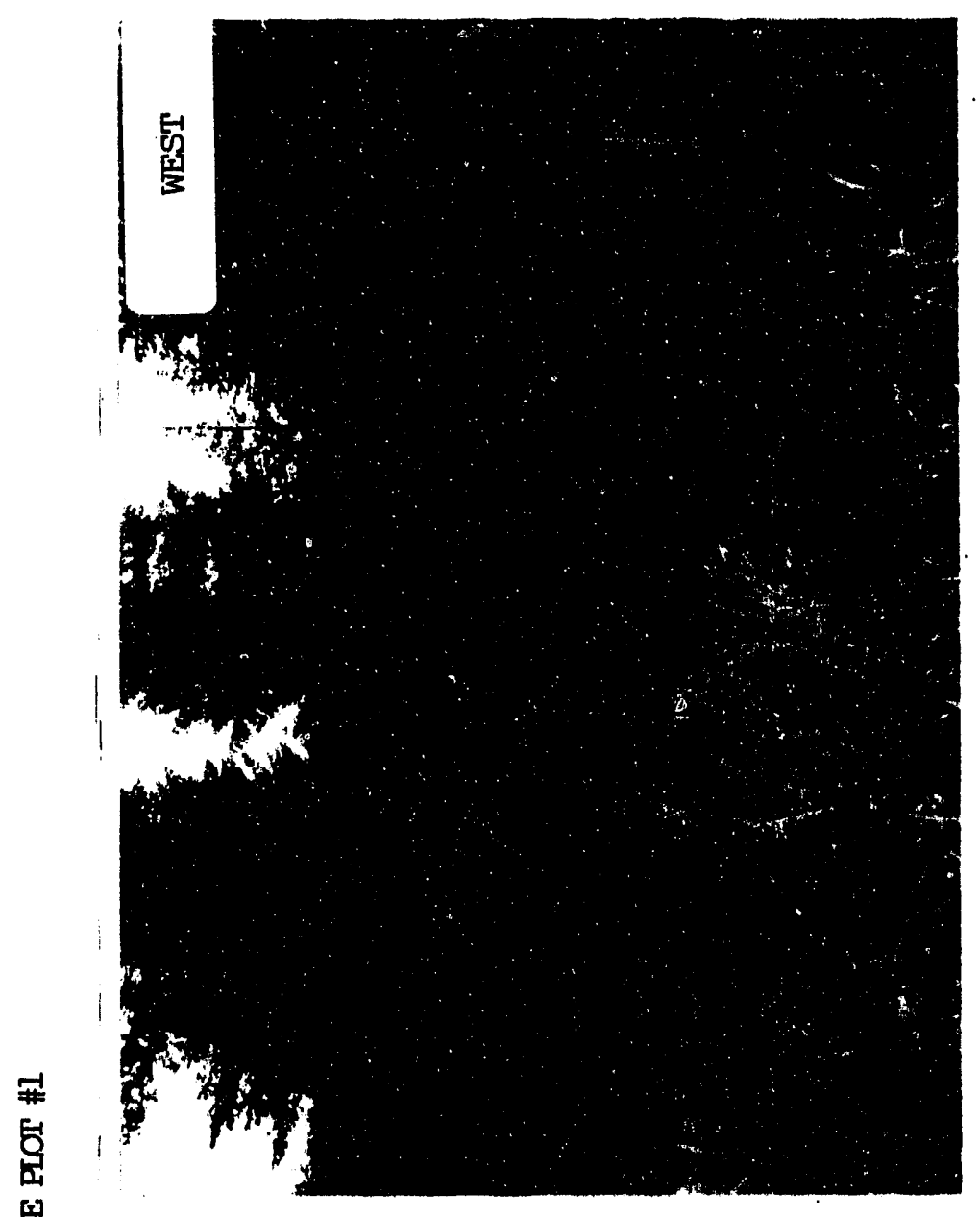

密

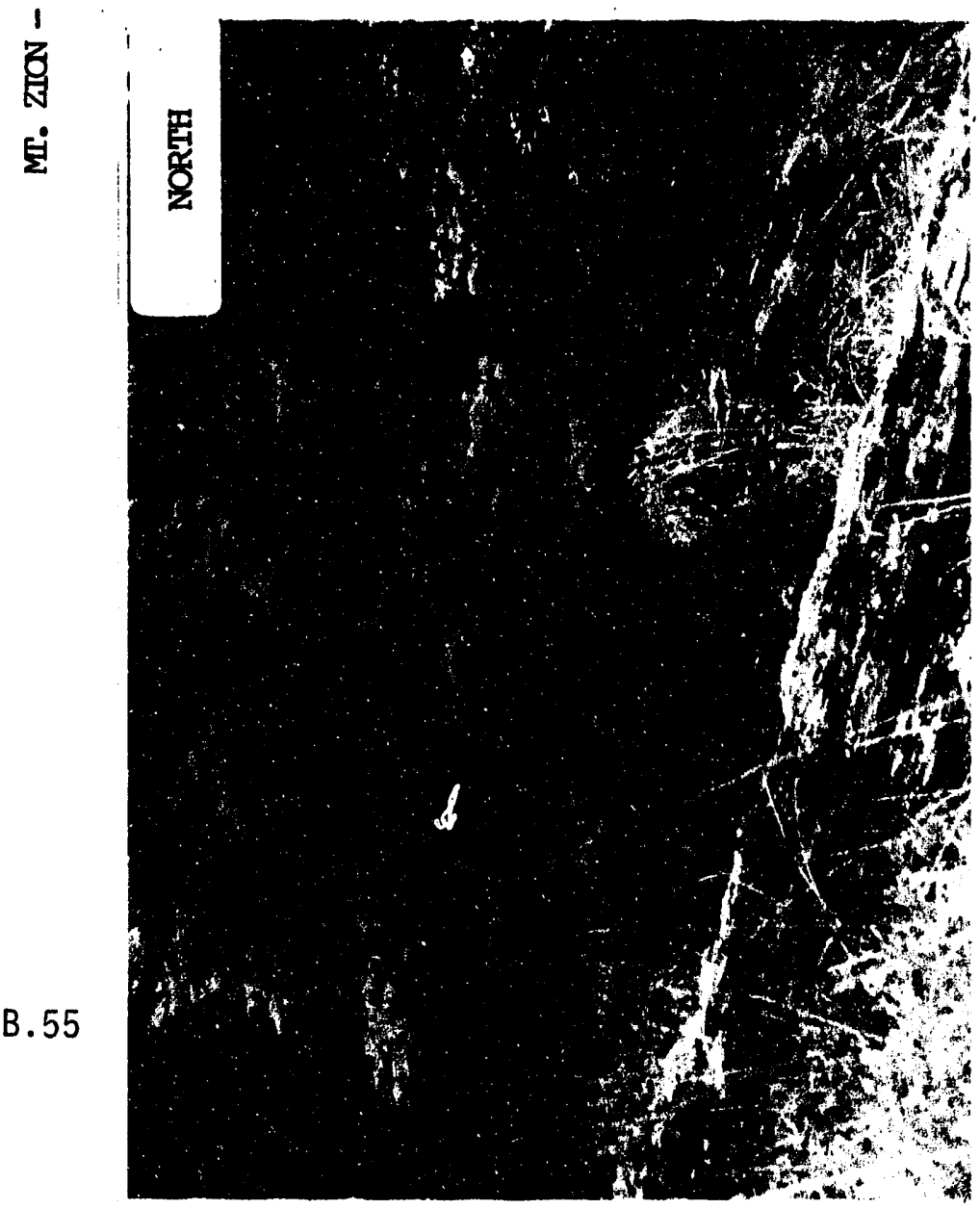




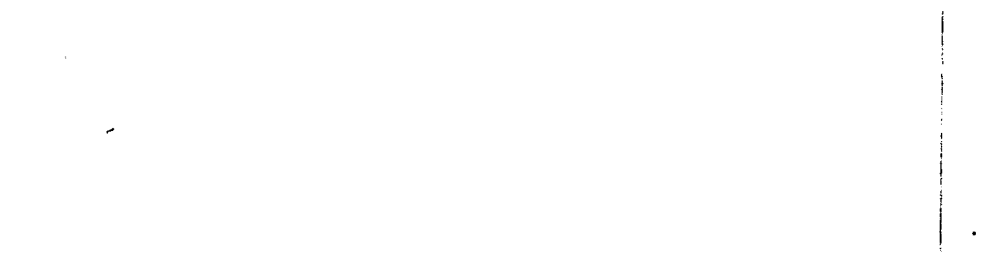

$\bullet$

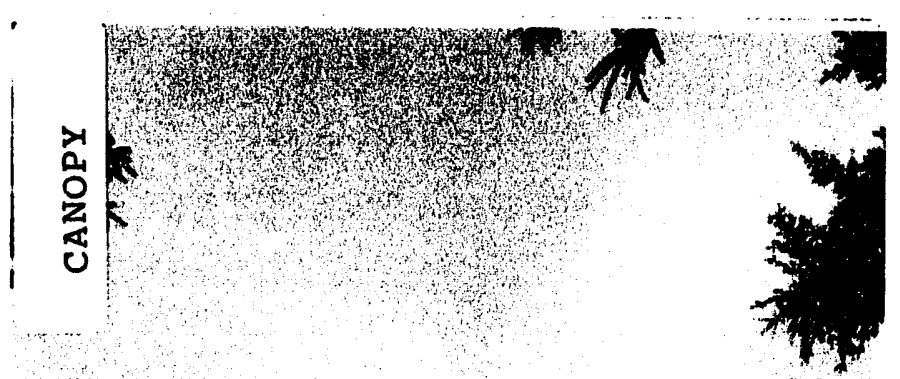


UWB CIUTTER EXPERIMENT

TELENICK

Observer

$\frac{10 / 24 / 91 / 0.55}{\text { Date }}$

MT Z10N

\#1 167 BCARIUK

Transect Sampling Station

Sits Description: APPROX 1/4MILE FROM RD. BALLOON 11 -BCARIN $347^{\circ}$ - NCAR BLND OF ROAD

Slope:

Overall Canopy Cover: $<5 \%$

General Over/Under Story Description: LUK NARROW OPEN MEADOW-RUNE SW TO NE - OLD CLEARCUT

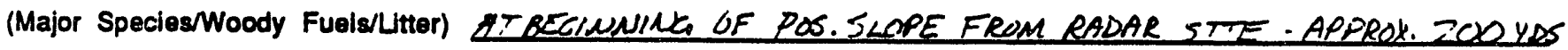
LOUC $\times 75$ YOS W'SE OULRSTORY ABSENT EXCEFT ALOMG CDGES - A FEW SMALL REPROD. IN CLEARNG L 3 FT TALL - FRCDOMONANT SURROUNDINK SPERES DF. ' INDERSTORY PREDOMINANTZY TALL GRASSES TO 3'FT. SOME FORBS. YARROW THISTLE (MOST VEG. DYIWK RACK-RROWN) BURDUSS

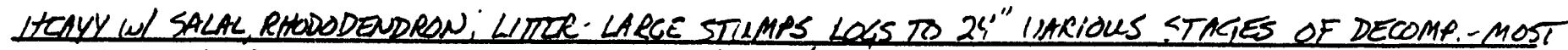
LITIER IS DYING LEAUES-FEW FIR NEELLES <I" SUERACL

Photo Log: N $1 / 15$ Rowl Fitoro Note: Photographs will be taken

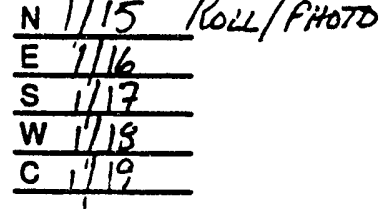
at each compass direction and at the canopy.

Rainfall/ Moisture Description: SIMILAR TO PREINOUS SITE-HOW IVER DUE TO LACK OF CANDPY THIS GRWA DRIES CONSIOLRABLY POSTER - NU SEXS, NOT AS MUCH MOSS DID NOT SET RAIN GAUGE

Stand Data: Plot Radius $=16.7$ FT 1/50 ACRE

Litter/ Grasses/ Bare Ground Forbs Shrubs $0.2 \mathrm{DBH}>2-6 \mathrm{DBH}>6.12 \mathrm{DBH}>12-16 \mathrm{DBH}>16 \mathrm{DBH}$

$\%$ Ground Cover

$\%$ Overstory

Number/Class

Average Height

Major Species

Minor Species

\begin{tabular}{|c|c|c|c|c|c|c|c|}
\hline 15 & 80 & 2 & 1 & 2 & 0 & 0 & 0 \\
\hline $\begin{array}{c}\text { OPCM } \\
\leftarrow \& 9 \rightarrow\end{array}$ & 1 & 1 & 5 & 5 & 0 & 0 \\
\hline$\cdot$ & $\cdot$ & $\cdot$ & 1 & 2 & 0 & 0 & 0 \\
\hline$\cdot$ & $\cdot$ & $\cdot$ & $6^{\prime}$ & $30^{\prime}$ & - & - & - \\
\hline$\cdot$ & $\cdot$ & $\cdot$ & $\ln$ & $D F$ & - & - & - \\
\hline$\cdot$ & - & $\cdot$ & - & - & - & - & - \\
\hline
\end{tabular}

* TREE CUT BUT SUERHAMiS PLOT RADIULS

- Reviewed By: Yl Cllima 
Notes:

1) Percent ground cover and percent overstory will each total $100 \%$.

2) Percent ground cover will be viewed as the percent of stems and ground vegetation.

3) Percent overstory will be viewed as the canopy as observed from above.

Species Key:

$$
\begin{aligned}
& \text { DF - Douglas Fir } \\
& \text { WH - Western Hemlock } \\
& \text { WRC - Western Red Cedar } \\
& \text { PSF - Pacific Silver Fir } \\
& \text { M - Madrone } \\
& \text { DEC - Deciduous Species }
\end{aligned}
$$



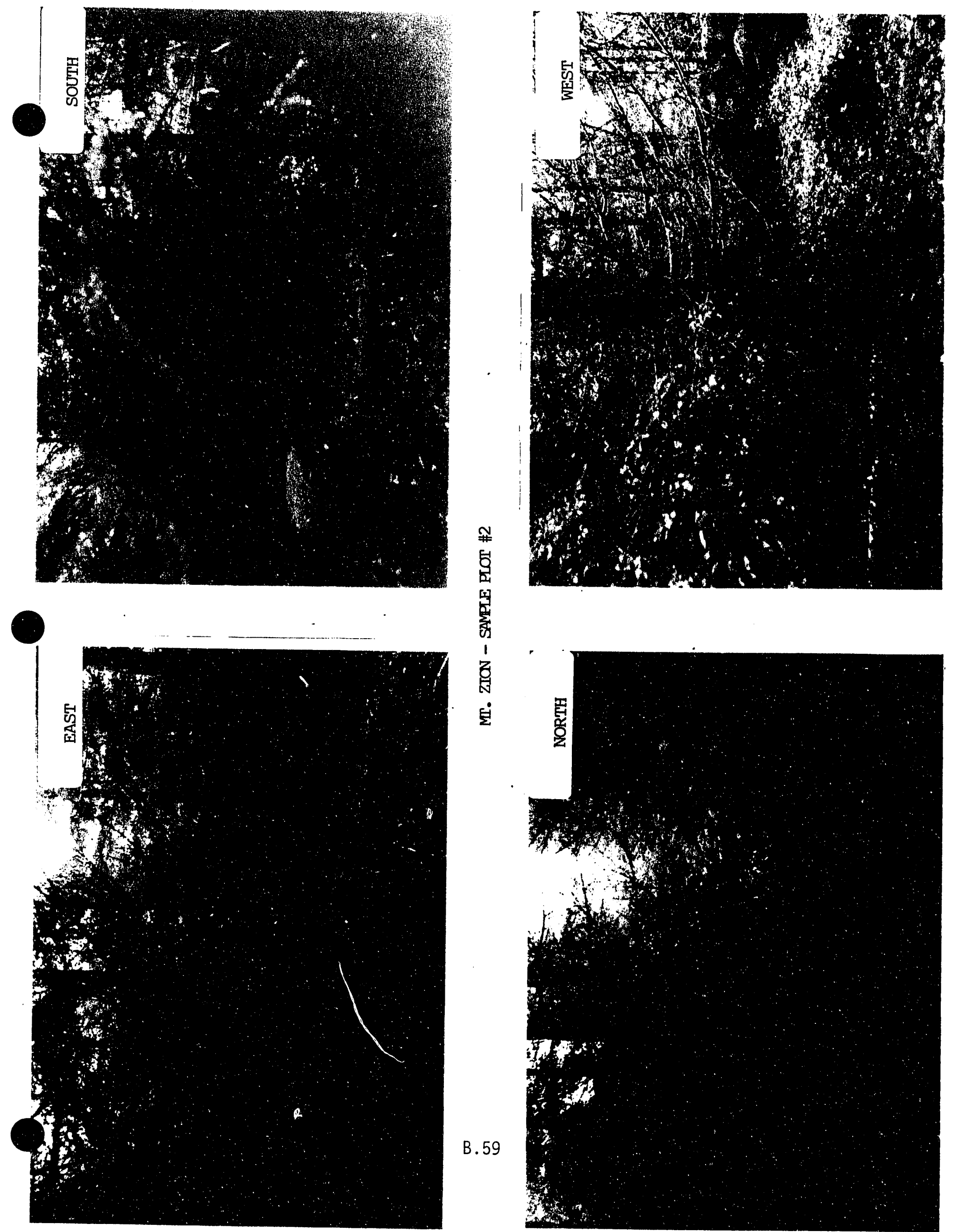

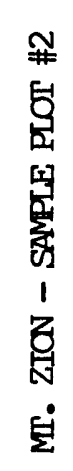

B. 59

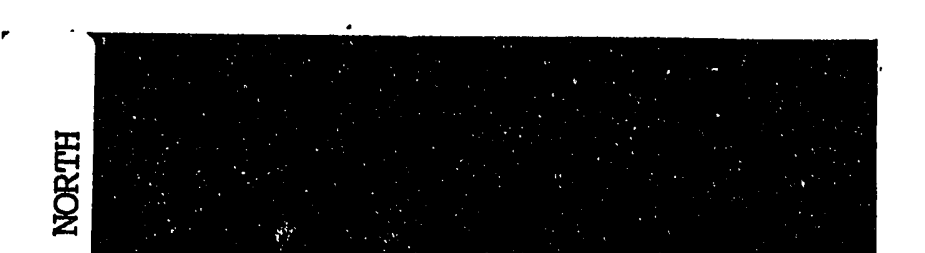




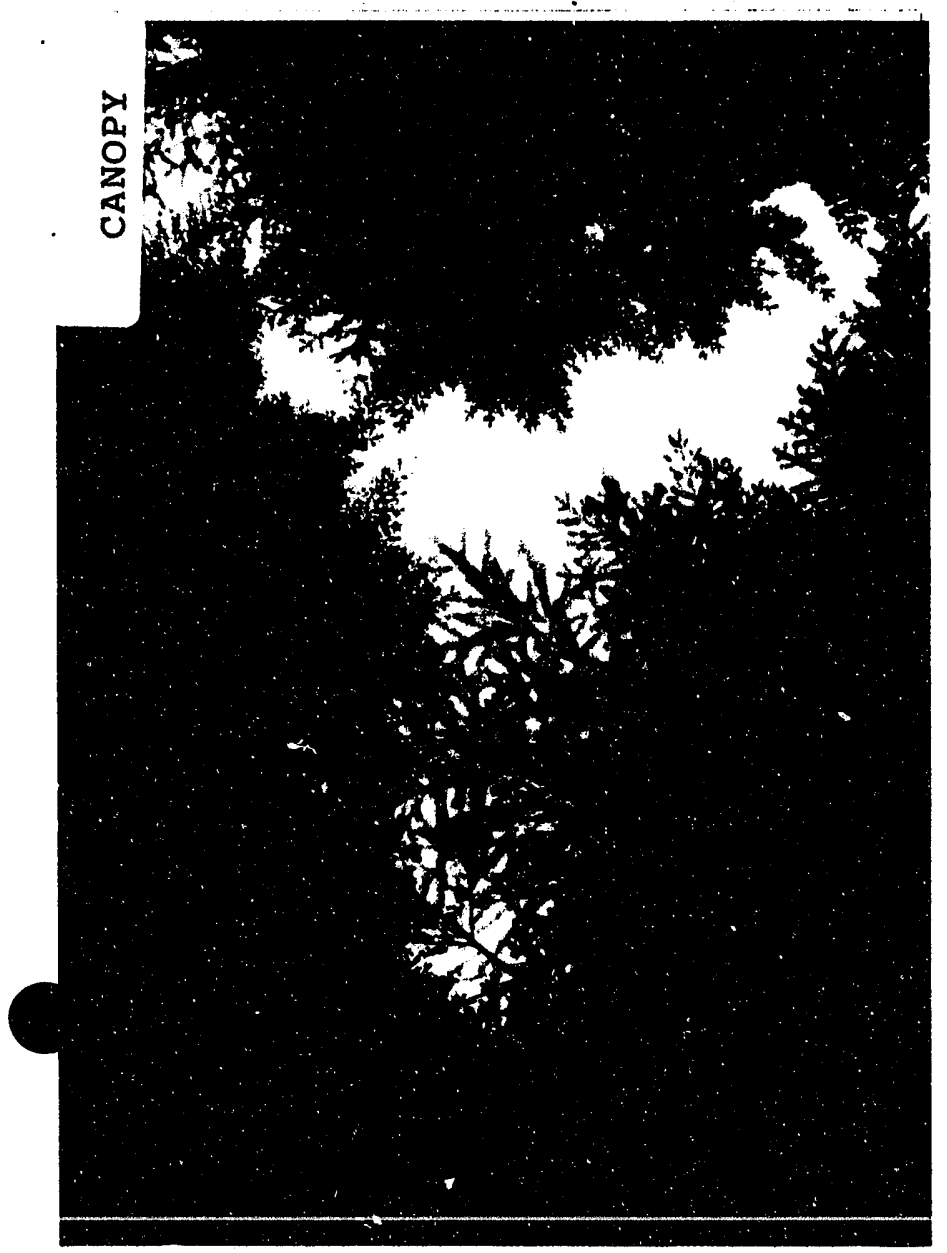


UWB CLUTTER EXPERIMENT

TELENICK

Observer

MT $210 \mathrm{~N}$

Transect

\#2-BLARING $167^{\circ}$

Sampling Station

Site Description:APPROX 125 FT FRUM ROAD-BALLOON 1-BLARIN $347^{\circ}$ - NLAR BQUD OF ROAD OUERAL $0-5 \%$

Slope: $\sin$ G-5\%

Overall Canopy Cover: $80 \%$

General Over/Under Story Description: QUERSTDRY-PPEDOMINANTLY EUEN AGEE DF SOME LدH; CROWAS

(Major Species/Woody Fuels/Litter) QULERAGE $250 \%$ OF OVERALL TREE HTT. SMALL BRANCHES ON TPEE BOLES FROM GROUND IIP (MANY DEAD) - SMALLER WH/DE W BETWETN LARGER POLES:

UNDERSTORY - MOD TO HEAVY (IN CANOPY BREAKS) - MOSTLY SOLAL, BARBZRRY TWUISTED STALK, $\angle E A F Y$ SPP. $\angle 6 "$ IALL NO GRASSES/ US MUSS : PREUIOUSLY LOCGED- STUMPS 8-24"-ROTMUK MOSS COVERED-SOME DOWNED DEBRIS-MOSS COVERED - $2-6^{\prime \prime} D I A$. 1-16"FT LONG - STUMP SPACINK AVE $20 \times 20$ FT-LITTER DEATH AVE < 2 " OUERALL

Photo Log: $\quad \mathrm{N} / / 10$ POLL/PHOTO

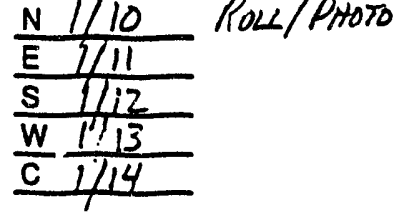

Note: Photographs will be taken at each compass direction and at the canopy.

Rainfall/ Moisture Description: AVERAGE MOISTURE - SUME MOSS ON STUMPS ' LOULR TREE

BRANGHES - NO BOGS QR STANDING WATER: RAN DOES PENETRATE CANWPY

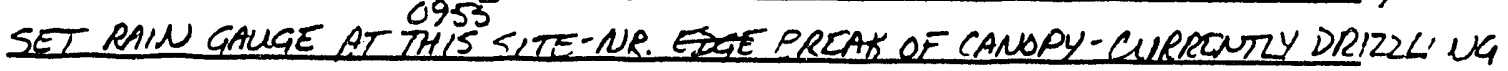

Stand Data:

Plot Radius $=16.7$ FT 1/50 ACRE

Lltierl Grasses/

Bare Ground Forbs Shrubs $0.2 \mathrm{DBH}>2.6 \mathrm{DBH}>6.12 \mathrm{DBH}>12.16 \mathrm{DBH}>16 \mathrm{DBH}$

\begin{tabular}{|c|c|c|c|c|c|c|c|c|}
\hline$\%$ Ground Cover & 50 & 40 & 5 & 1 CBS+C & $-2\left(2-6^{\prime \prime}\right)$ & 2 & $\Sigma$ & 0 \\
\hline$\%$ Overstory & $\frac{\text { OPEN }}{-33}$ & $\rightarrow$ & 5 & 5 & $z$ & 15 & 40 & 0 \\
\hline Number/Class & - & - & - & 5 & 1 & 1 & $2^{\left(12^{-13^{1}}\right)}$ & 0 \\
\hline Average Height & - & - & - & $<10^{\circ}$ & $20^{\prime}$ & $60^{\prime}$ & $70^{\circ} \cdot 90^{\circ}$ & - \\
\hline Major Species & - & - & - & WH & $\omega H$ & $D F$ & DF & - \\
\hline Minor Species & - & - & - & - & - & - & - & - \\
\hline
\end{tabular}

Reviewed By: Y1 C Chive 
Notes:

1) Percent ground cover and percent overstory will each total $100 \%$.

2) Percent ground cover will be viewed as the percent of stems and ground vegetation.

3) Percent overstory will be viewed as the canopy as observed from above.

Species Key:

$$
\begin{aligned}
& \text { DF - Douglas Fir } \\
& \text { WH - Western Hemlock } \\
& \text { NRC - Western Red Cedar } \\
& \text { PSF - Pacific Silver Fir } \\
& \text { M - Madrone } \\
& \text { DEC - Deciduous Species }
\end{aligned}
$$



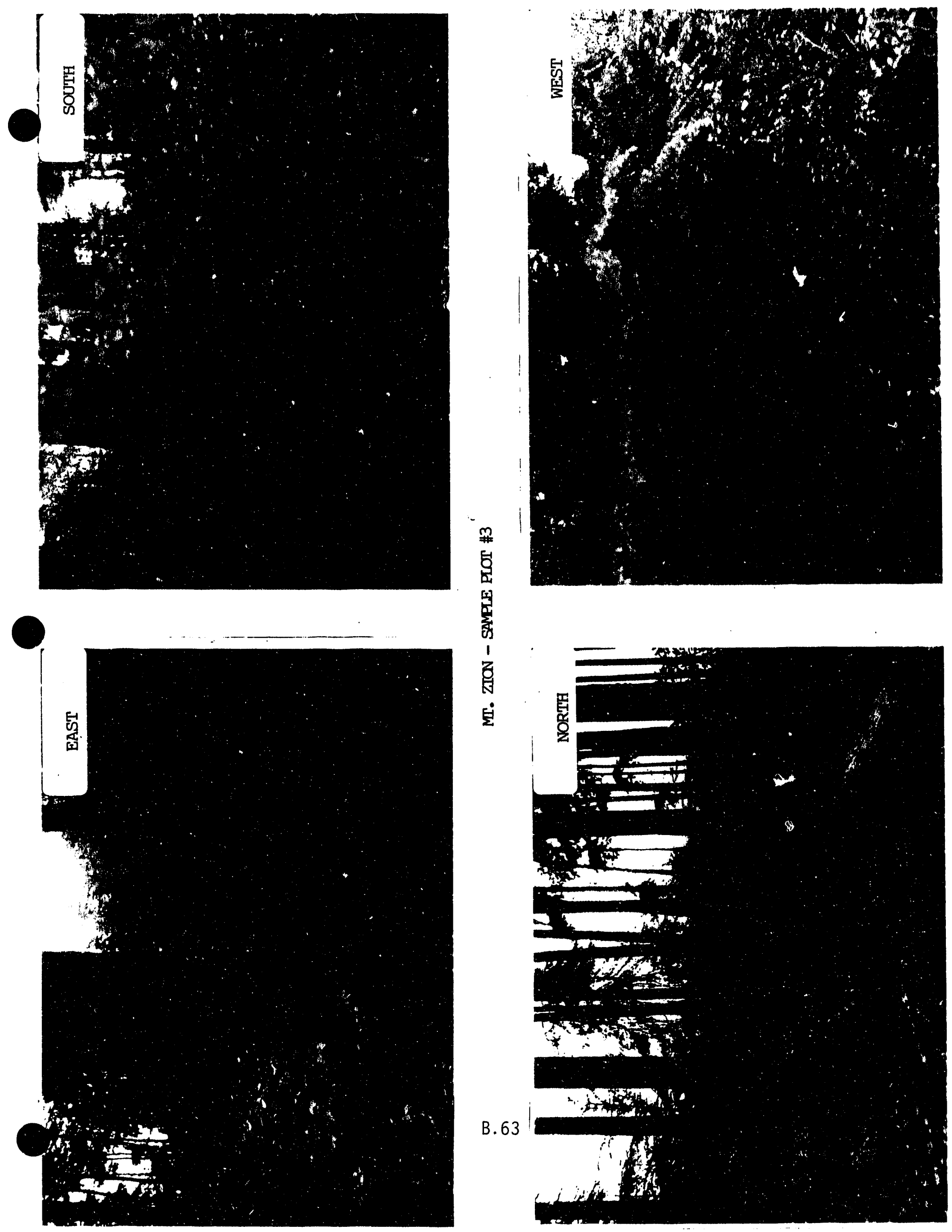


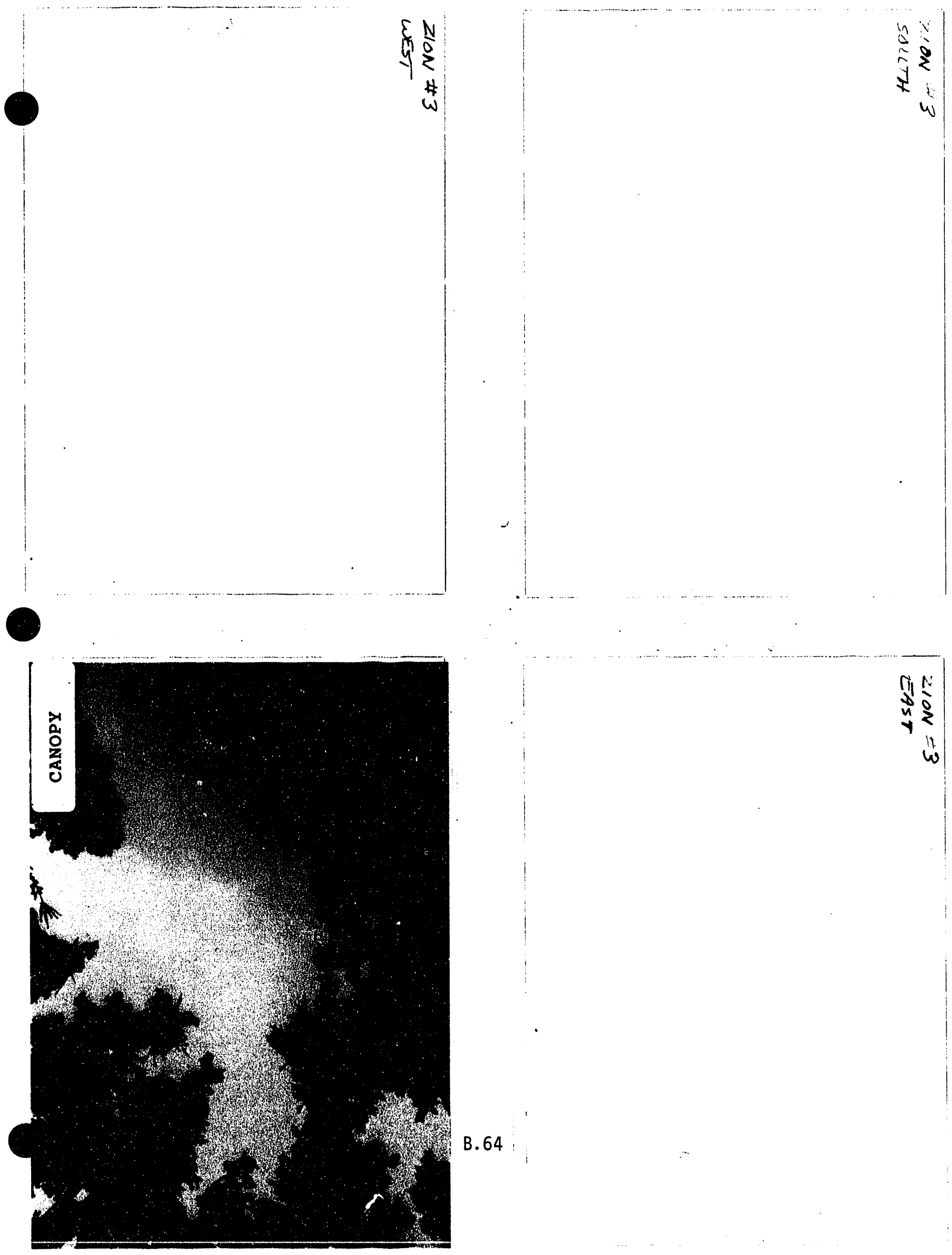




\section{UWB CLUTTER EXPERIMENT}

$\frac{\text { TELENICK }}{\text { Observer }}$

MT ZION

Transec $\frac{10 / 24 / 9111: 45}{\text { Date }}$

$\$ 3-167^{\circ}$ BEARINK

Sampling Station

Site Description: APPROK. 250 YDS FROM BALCODN \#1-BEARMK $167^{\circ}$. MTAR BEND QE RDAD PLOT SITE 5-10\%

Slope: CUIRACL-VARLABEE- STAND BISECTED BY Overall Canopy Cover: 30 ?

2 RAUNUES-SLOPES - $100 \%$ TO + $100 \%$ - AULRAGE AT SITE $10-15 \%$

General Over/Under Story Description: OVERSTOXY STAND OF EXTREMEY THL WH/DF - EYCEED $150^{\prime}$

(Major Species/Woody Fuels/Liter) CROWNS LIMTTDD TO UPPER 30-50\% OF TTIL HT - STEM DIA. AUE 12-24"PLUS - SOME WRC + DEC. ALDER WN OPEN SPACES FORM ZND CANOPY LAYER - UP $7060^{\prime}$

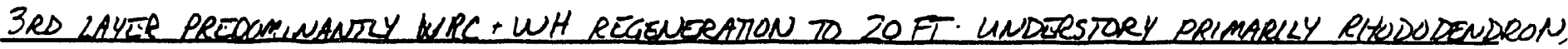
HUCKLEBERRY T MISC. DEC. SHRUBS $\left(<10^{\prime}\right)$ : LITIER - FLOOR-HEAVY WINDFALL WUL LARGE DOWNED TIMRER

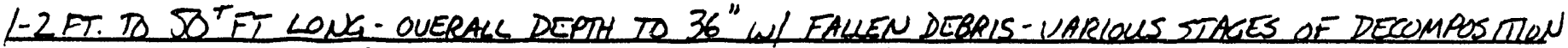
HLAVY MOSS GROWTH-SOME FORBS PRÉSENT- TWIWFLOWER, BARBERRY, WILD GINGER ETC.

Photo Log: $\frac{\frac{N i / 20}{E / / 21}}{\frac{S / 22}{W / 23}}$

Note: Photographs will be taken at each compass direction and at the canopy.

Rainfall/ Moisture Description: APPRARS TO BE FAIRLY MOIST: RUNNIAG WATER IN DEAINAGES WIN STAND. OPEN CROWN AT SUCH HEIGHTS ALOW FAIR SUNLIGHT PENETRATON: HCAVY LITER + MOSS SHOWCD RTTAIN MOISTURE -SET RAIN GAUGE@ SITE IN OPENING-12:D

Plot Radius $=16.7$ FT 1/50 ACRE

Stand Data: Litter/ Grasses/

Bare Ground Forbs Shrubs $0.2 \mathrm{DBH}>2.6 \mathrm{DBH}>6.12 \mathrm{DBH}>12.16 \mathrm{DBH}>16 \mathrm{DBH}$

\begin{tabular}{|c|c|c|c|c|c|c|c|c|}
\hline$\%$ Ground Cover & $\begin{array}{c}045 \text { MOST2 } \\
70\end{array}$ & $9^{1}$ & 15 & 1 & 1 & 1 & 1 & 2 \\
\hline$\%$ Overstory & $200^{\circ}$ & $2 *$ & 10 & 5 & 5 & 10 & 25 & 25 \\
\hline Number/Class & - & - & - & 16 & 3 & $1^{\left(143^{\prime \prime}\right)}$ & $1^{\left(12.4^{\prime \prime}\right)}$ & $/^{\left(24.5^{\circ}\right)}$ \\
\hline Average Height & - & - & - & $10^{\circ}$ & $20^{\prime}$ & $40^{\circ}$ & $90^{\prime}$ LST. & $130^{+}$esT. \\
\hline Major Species & - & - & - & $\omega H(14)$ & WH & WRC & $\omega H$ & $\omega H$ \\
\hline Minor Species & - & - & - & WRC (2) & - & - & - & - \\
\hline
\end{tabular}

* MOST moss GRounar ON DOWNED TMBER

* * DIFICULT TO ASSESS DILE TO OVLESTORY CANOPY HT.

Reviewed By:

Yichinia

B. 65

See Back of Form for Notes 
Notes:

1) Percent ground cover and percent overstory will each totai 1008 .

2) Percent ground cover will be viewed as the percent of stems and ground vegetation.

3) Percent overstory will be viewed as the canopy as observed from above.

Species Key:

DE - Dougras Fir

WH - Western Hemlock

WRC - Western Red Cedar

PSF - Pacific Silver Fir

M - Madrone

DEC - Deciduous Species 

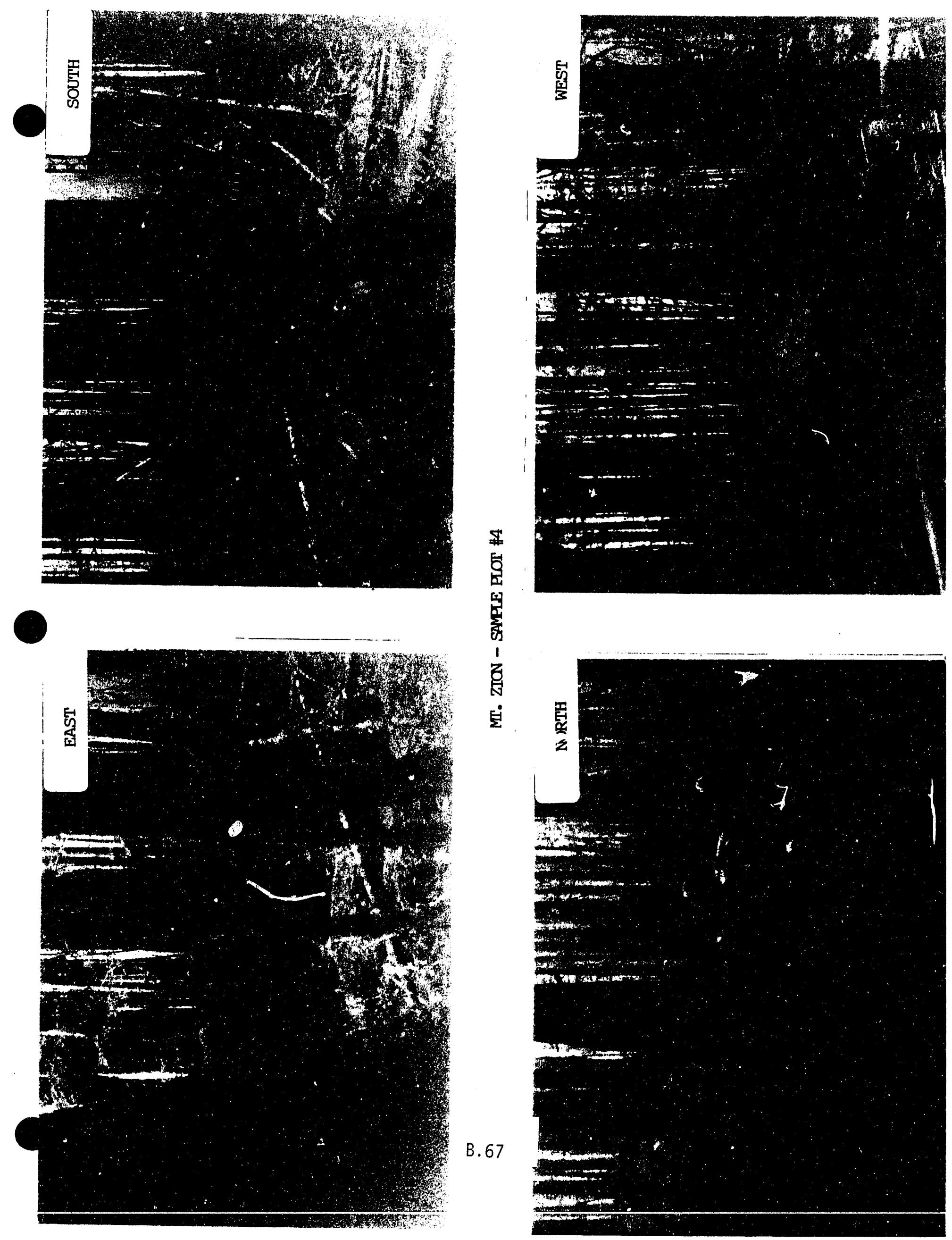
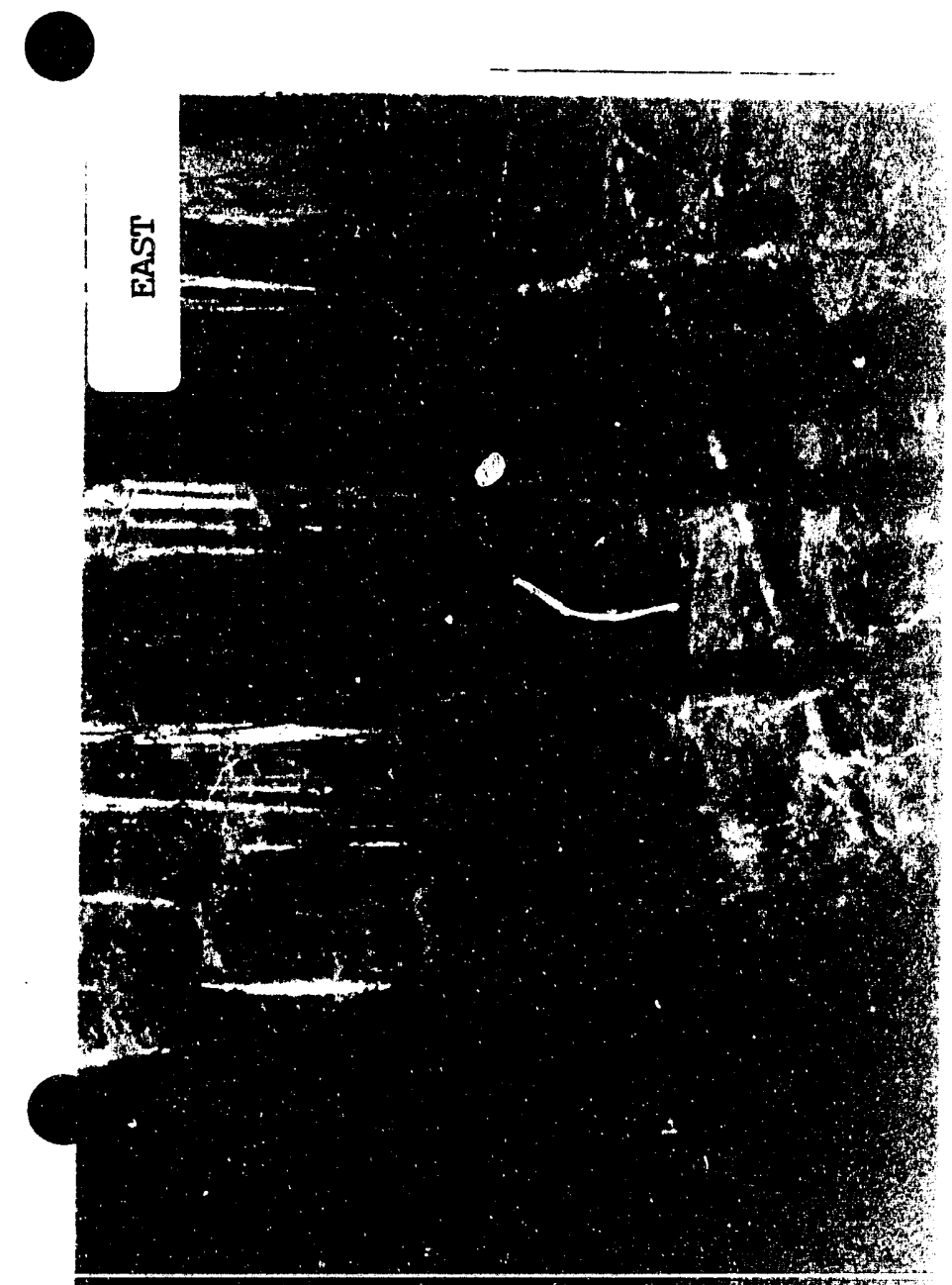

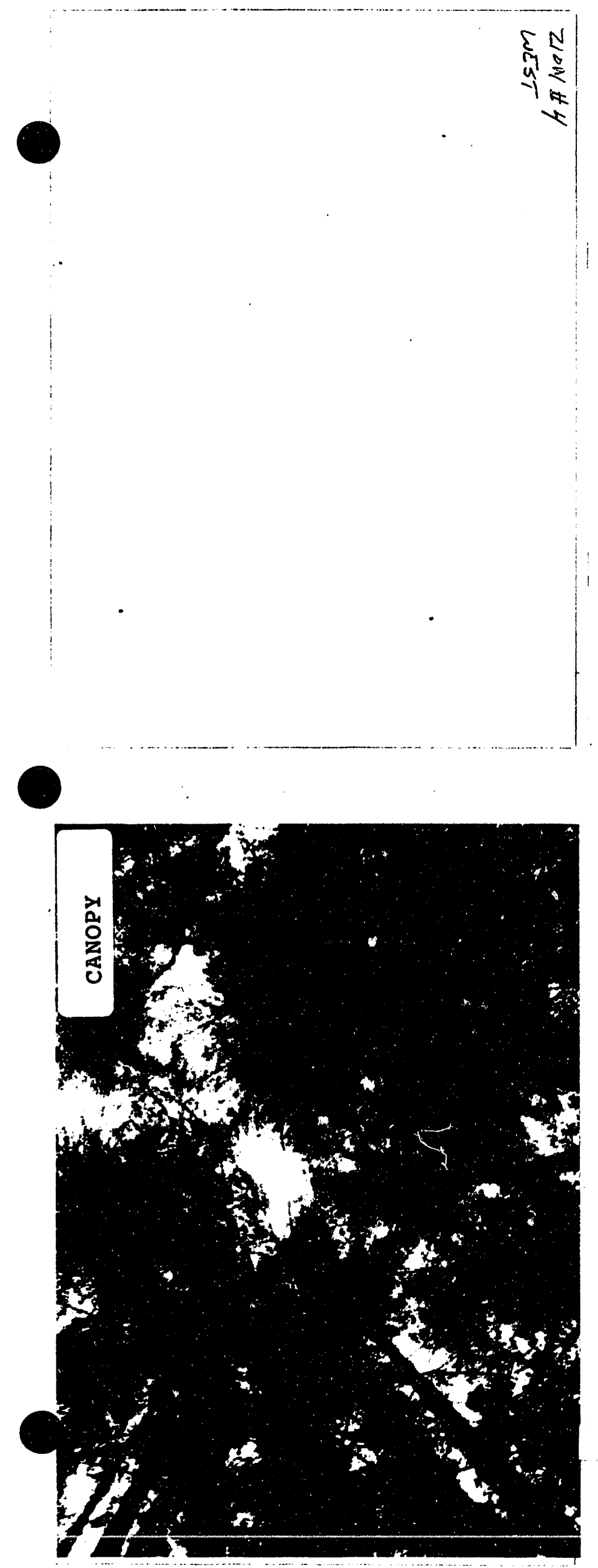

B. 68 
UWB CIUTTER EXPERIMENT

TELENICK $\frac{10 / 24 / 91 / 3: 20}{\text { Date }}$

Observer

$\frac{M T Z 210 N}{\text { Transect }}$

$\frac{\# 4-167^{\circ} \text { BEARING }}{\text { Sampling Station }}$

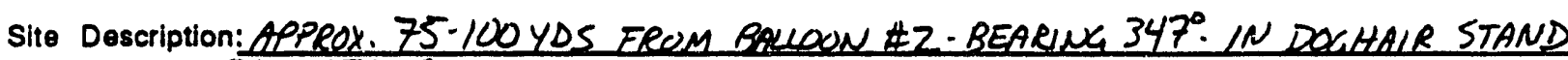

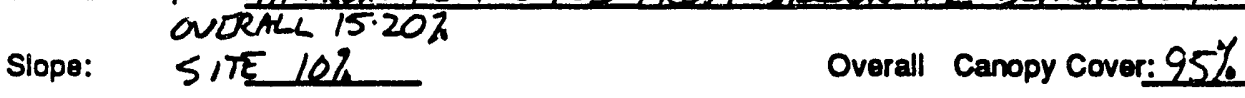

General Over/Under Story Description: GUERSTORY-GENERALGY SMALLPOL /DOAHAIR - EVEN AGED STAND

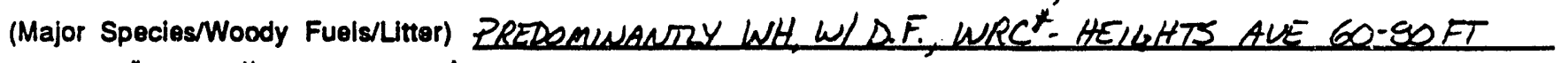
DIA. L2"TO 12 " (AVE 4-8"): UNRERSTORY MOSTZY AESENT. SCATERED RHEDSDENDYON, URC

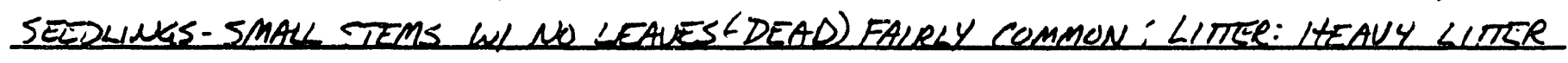
ACCUMULATONS - MOSTLY OLD DECOMPOSES LOGS + STUMPS - COVERED WU/ MOSS PLUS $\angle I G H T$ NECDLE CAST ON SUKEACE- LITLR DEPTH I-? FT AVLRAGE

*. PSF ALSO NOTED

Photo Log: $\frac{\frac{N 1 / 25}{E} \text { RoLL/PHOTO }}{\frac{\frac{E}{S} / 26}{W 1 / 28}}$

Note: Photographs will be taken

at each compass direction and

at the canopy.

Rainfall/ Moisture Description: SITE TVPICAL OF HEAVU CANOPY IOVER-SOME RAN RENETRATNG-GROUND SOFT-LITER HOLRS MOISTURE FOR CONSIDERABLE TIME WIMUNIMAL SUNLIGHT FENETRATION-CONSIDLRAGLE MOSS

Stand Data: RAIN GAUGE SET- UNDER CAMEAY - 13:30

Litterl Grasses/

Bare Ground Forbs Shrubs $0.2 \mathrm{DBH}>2.6 \mathrm{DBH}>6.12 \mathrm{DBH}>12.16 \mathrm{DBH}>16 \mathrm{DBH}$

\begin{tabular}{|c|c|c|c|c|c|c|c|c|}
\hline$\%$ Ground Cover & 61 & 25 & 2 & 1 & 5 & 5 & 1 & 0 \\
\hline \% Overstory & $\frac{O P L}{5}$ & - & 1 & 5 & 24 & 50 & 15 & 0 \\
\hline Number/Class & - & - & - & 6 & $t^{+}$ & 10 & $1^{\left(14.1^{11}\right)}$ & 0 \\
\hline Average Height & - & - & - & $10^{\prime}$ & $30^{\prime}$ & $40.50^{\circ}$ & $60-70^{\circ}$ (eot) & 0 \\
\hline Major Species & - & - & - & WH & WH & $D F$ & $\omega H$ & - \\
\hline Minor Spocies & - & - & - & WRC & WRe / PSF & $W H$ & - & - \\
\hline
\end{tabular}

+ ALMOST $1 / 2$ OF STANOMNG POLES DLAD WI NO CROWNS-THESE WORE NOT TALLLED

- Reviewed By: VIC lhimm

B. 69

See Back of Form for Notes 
Notes:

1) Percent ground cover and percent overstory will each total $100 \%$.

2) Percent ground cover will be viewed as the percent of stems and ground vegetation.

3) Percent overstory will be viewed as the canopy as observed from above.

Species Key:

$$
\begin{aligned}
& \text { DF - Douglas Fir } \\
& \text { WH - Western Hemlock } \\
& \text { WRC - Western Red Cedar } \\
& \text { PSF - Pacific Silver Fir } \\
& \text { M - Madrone } \\
& \text { DEC - Deciduous Species }
\end{aligned}
$$




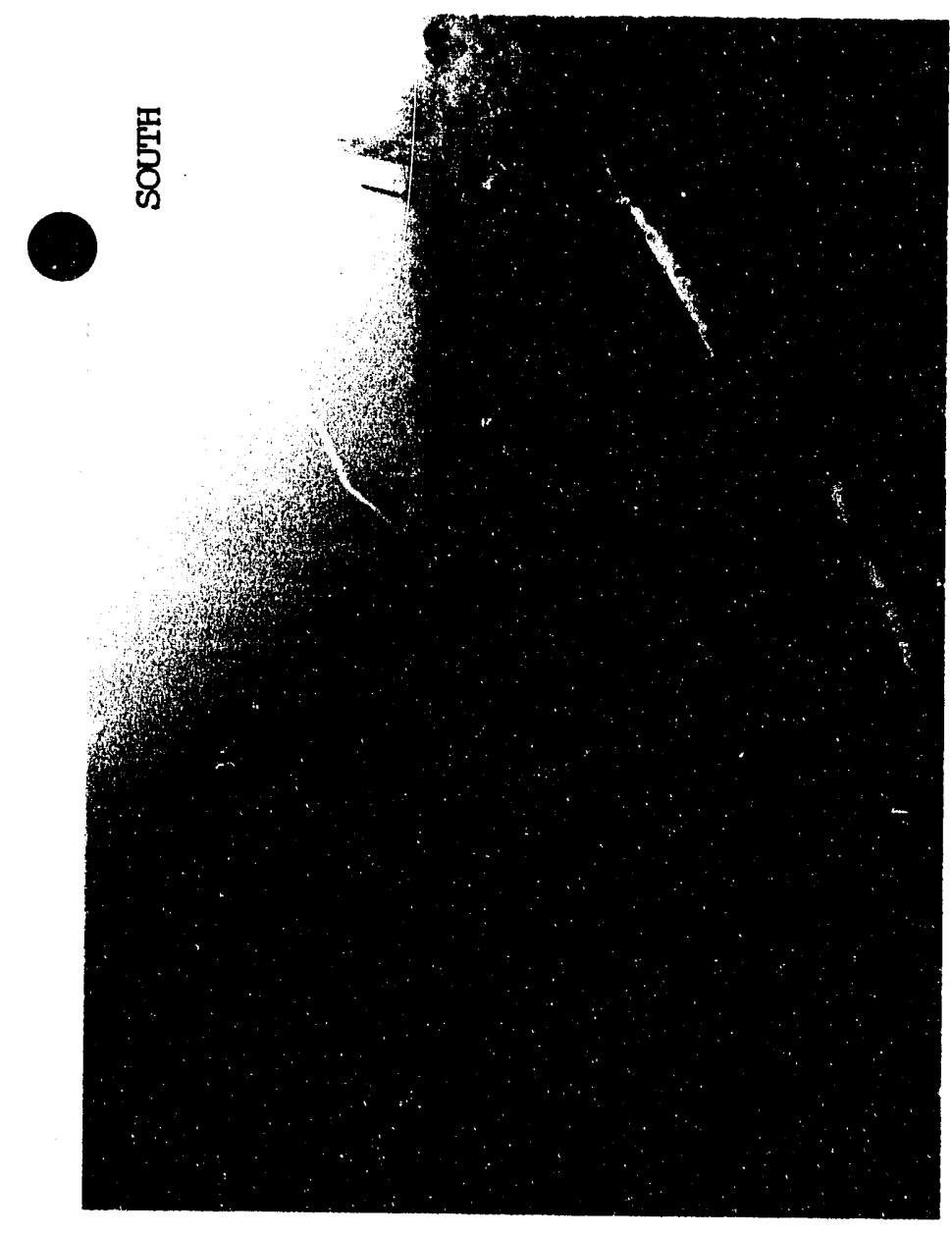

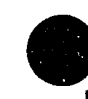

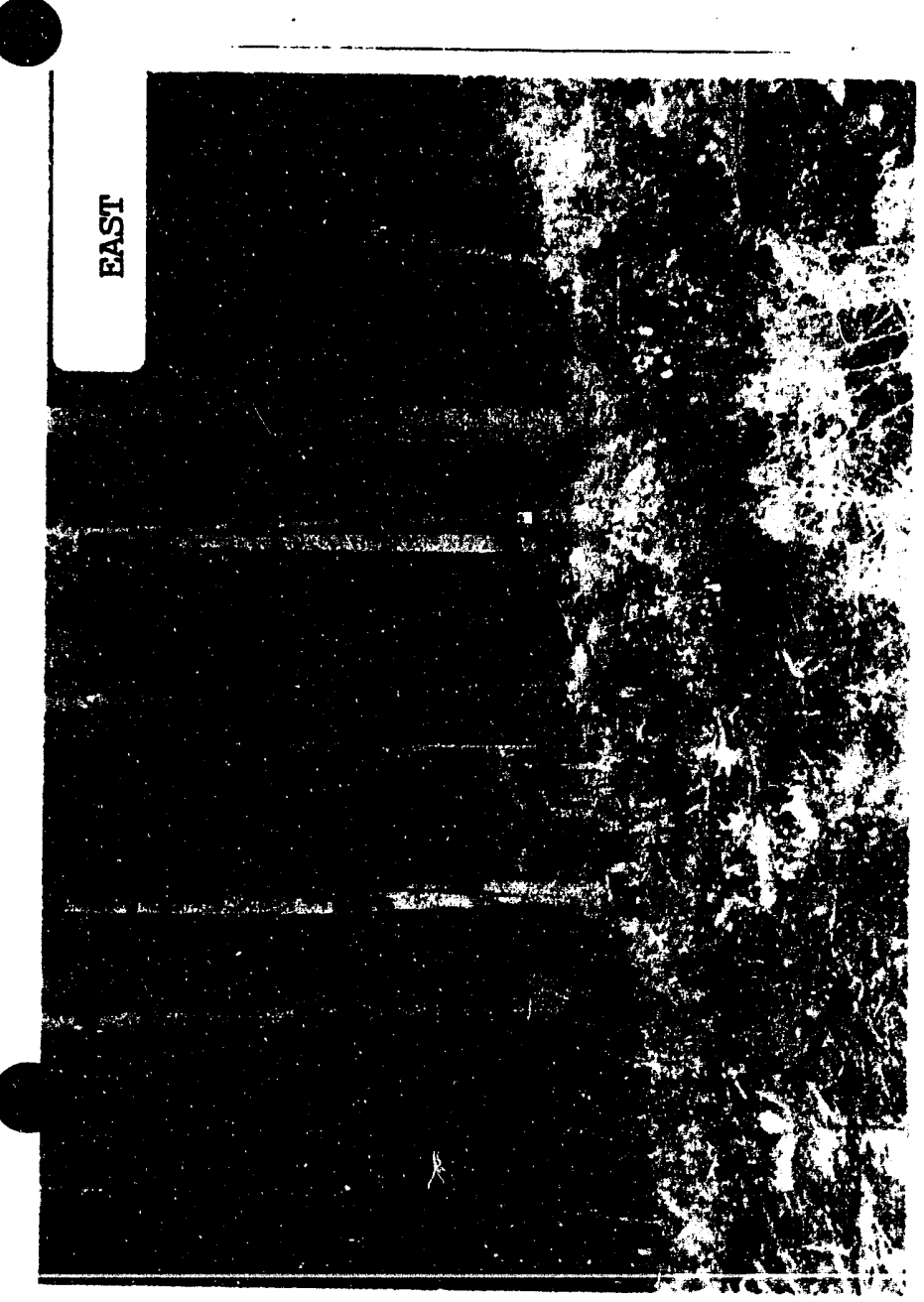

텅

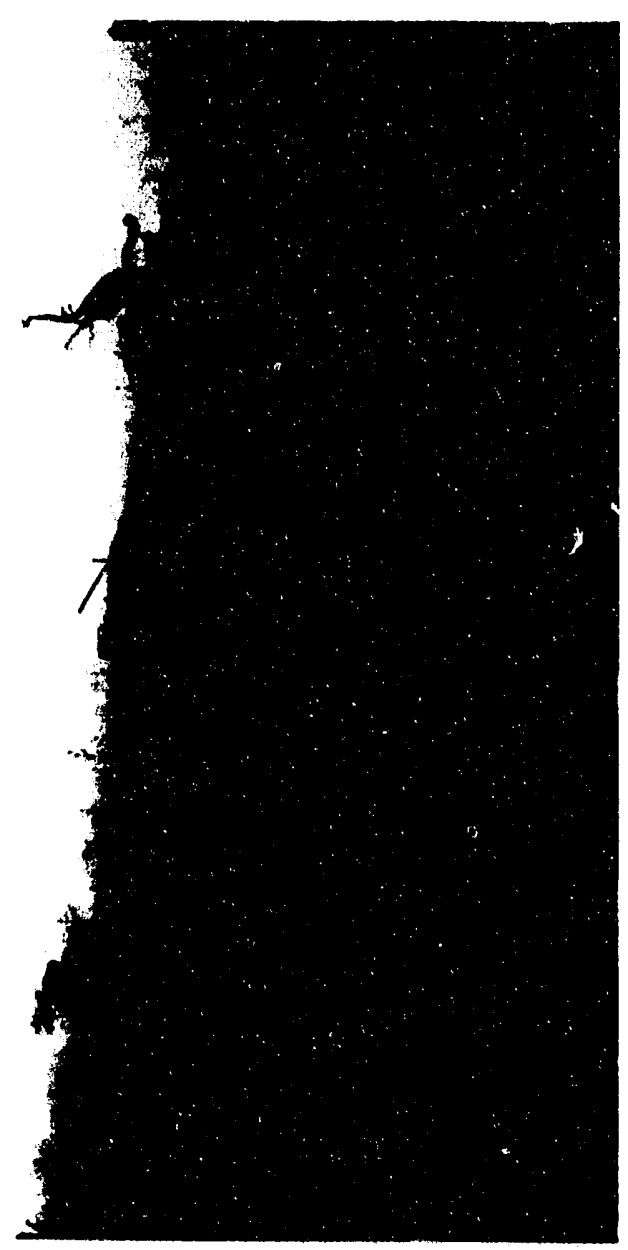

里

연

综

ह

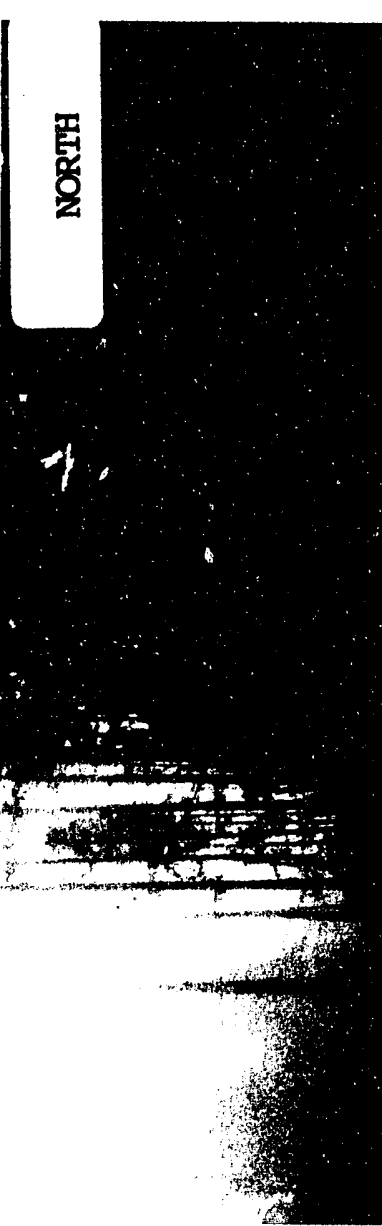

B. 71
焉

1

in

+ 


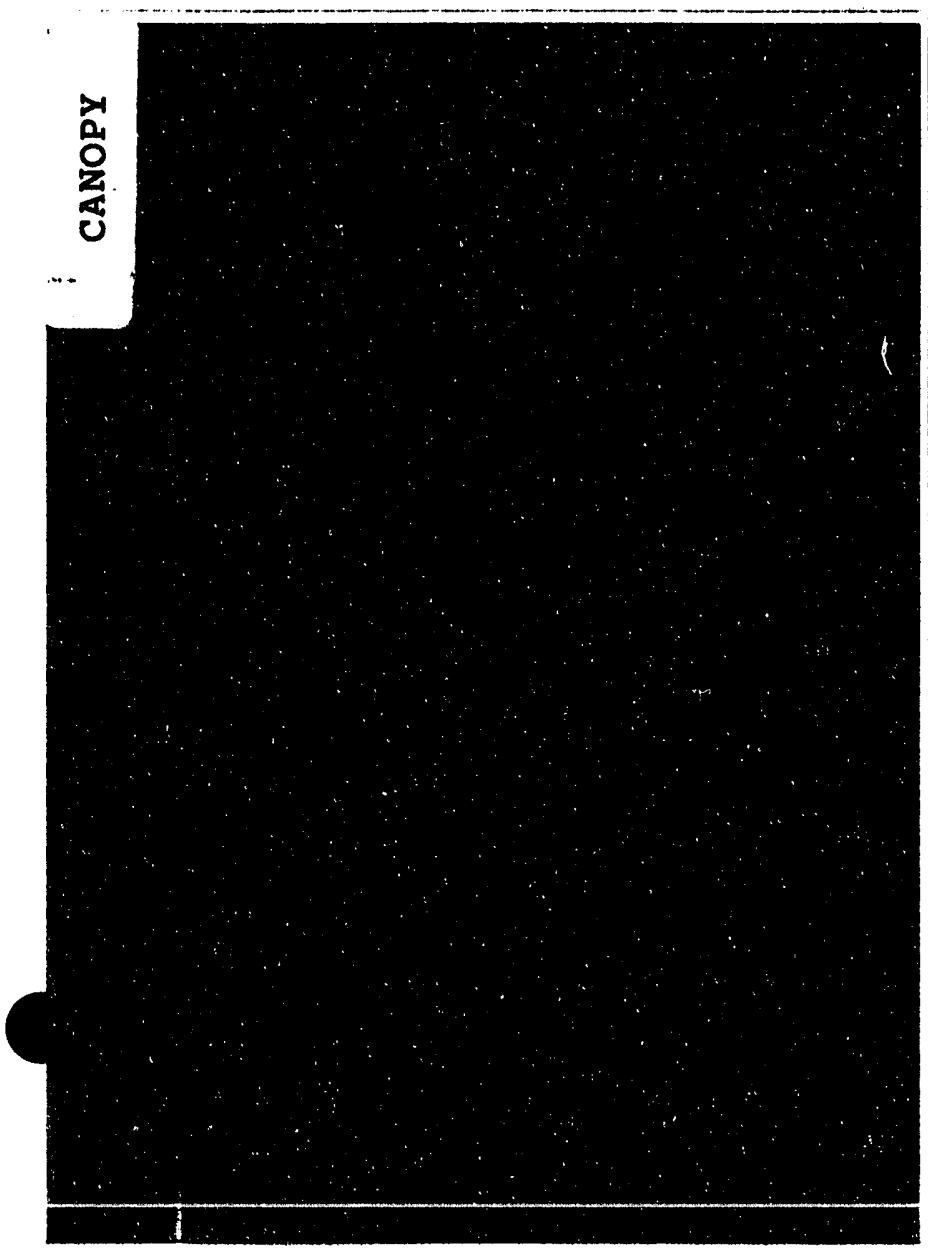


UWB CLUTTER EXPERIMENT

$\frac{T_{E} / E N I C K}{\text { Observer }}$

$\frac{M T Z 10 \mathrm{~N}}{\text { Transect }}$

$\frac{10 / 24 / 91 / 4: 15}{\text { Date }}$

$\not 5-167^{\circ}$ BEARING

Sampling Station

Site Description: CLEARCUT AKEA-S. OF BAUOON \#2 (167'BEARMG)-N.E. EDGE OF CLCARCUT = 100YOS

Slope: $\quad$ SITE. 15 R

Overall Canopy Cover: $0 \% \cdot$ OPEN

General Over/Under Story Description: RECENT CLEARCUT DEBRIS STILL SCATIERED. SUME BARE MINTERL

(Major Species/Woody Fuels/Litter) SOLL EXPOSED. MOST UNDERSTORY VEGETATION. BRACKEN EERN

THIMBLEBERRY, LACTUCA, VARIOUS COMPSSITES' MINOR VEEETATON-SEEDLINGS LI'TALL - OC.

CASIONAL ALDER 6-S'- STUMPS SPACED 10-20'AVE 12-24" DIA. - MOST LOGGING DEBRIS

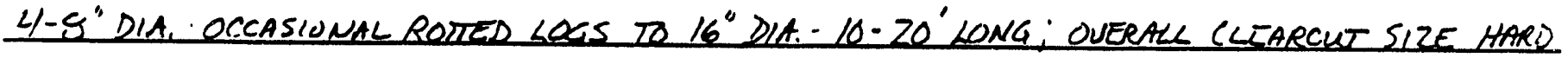

TO DCTURMUE AT LEST 10 A- LITER DEPTH AVE I ET OVERHL

Photo Log: $\quad \mathrm{N} / / 30$ ROLL/PItUTO

$$
\begin{array}{l|l|l}
N / 30 \\
\hline E / / 31 \\
\hline S / 132 \\
\hline W / 33 \\
\hline C 1 / 34
\end{array}
$$

Note: Photographs will be taken

at each compass direction and

at the canopy.

Rainfall/ Moisture Description: TYPICAL OF ARTA-NO MOSS-PROBABLY DRIER OVCRALL TUE TO EAROSURE-DRIZZLWK NOW. IN CLOUOS - NO RFIN GAUGE SET

Stand Data:

Plot Radius $=16.7$ FT 1/50 ACRE

Litter/ Grasses/

Bare Ground Forbs Shrubs $0.2 \mathrm{DBH}>2.6 \mathrm{DBH}>6-12 \mathrm{DBH}>12.16 \mathrm{DBH}>16 \mathrm{DBH}$

\begin{tabular}{|c|c|c|c|c|c|c|c|c|}
\hline$\%$ Ground Cover & 80 & 19 & 1 & $0^{*}$ & 0 & 0 & 0 & 0 \\
\hline \multirow[t]{2}{*}{ \% Overstory } & & GPEN & & & & & & \\
\hline & 80 & 19 & 1 & 0 & 0 & 0 & 0 & 0 \\
\hline Number/Class & - & - & - & 0 & 0 & 0 & 0 & 0 \\
\hline Average Height & - & - & - & - & - & - & - & - \\
\hline Major Species & - & - & - & 一 & - & - & - & - \\
\hline Minor Species & - & - & - & - & - & - & - & - \\
\hline
\end{tabular}

* SEEDLNGS S 4.5FT TALL NOT TALLIED

-. Reviewed By: Vi Clelinam

B. 73

See Back of Form for Notes 
Notes:

1) Percent ground cover and percent overstory will each total $100 \%$.

2) Percent ground cover will be viewed as the percent of stems and ground vegetation.

3) Percent overstory will be viewed as the canopy as observed from above.

Species Key:

$$
\begin{aligned}
& \text { DF - Douglas Fir } \\
& \text { WH - Western Hemlock } \\
& \text { WRC - Western Red Cedar } \\
& \text { PSF - Pacific Silver Fir } \\
& \text { M - Madrone } \\
& \text { DEC - Deciduous Species }
\end{aligned}
$$


Supplement 1. UWB Clutter Experiment Geographic Information for Ground Truth Data Collection Site

Identification Key for the Geological Information System (GIS) Data Summaries* U.S.G.S. Mount Zion Quadrangle

Item: Polygon Identification Code (Overlay)

Subject: Database Identification Code (Not Applicable)

Class: Primary Stand Classification Code

C: Crop

M: Mature

I: Immature

E: Excessive

Species: Predominant Tree Species

A: Pacific Silver Fir

AF: Subalpine Fir

$C$ : Western Redcedar

DF: Douglas Fir

iH: Western Hemlock

RA: Red Alder

Size: Size Classification Code

ND: Seedlings with no diameter (0.0-0.4" Diameter breast height (DBH))

SS: Seedlings and saplings (0.5-4.9" DBH)

PL: Poles (5.0-8.9" DBH)

MS: Small sawtimber (9.0-20.9" DBH)

LS: Large sawtimber (21.0" and larger $\mathrm{DBH})$

YRO: Year of Origin

BA: Total Basal Area per Acre

MBF : Thousand Board Feet per Acre

Area: Acres per Stand

Data has been compiled with a master key and three subdirectories, one for each primary stand classification listed above. For example, polygon number 396 on the overlay can be found under Item number 396 in the master key. This polygon is designated as Class C and is predominantly Douglas Fir with a size class of small sawtimber. The year of origin was 1880 and the average basal area per acre is $174 \mathrm{ft}$ for all tree species. The site has 14,000 board feet per acre of commercial timber in a area of 145.526 acres. The Class $C$ designation for this site can be cross referenced in the Class $C$ subdirectory. Using this subdirectory under Item number 396 gives further details of the polygon vegetative characteristics. For example, the major species is again listed as Douglas Fir. The average DBH of the Douglas Fir is $10 "$ with 216 trees/acre. The average basal area considering only the Douglas Fir is $109 \mathrm{ft}$ for a total of 13,000 board feet.

* GIS data has been provided by the U.S. Forest Service, Quilcene Ranger District. 
Supplement 2: UWB Clutter Experiment

Ground Truth Transect Location 


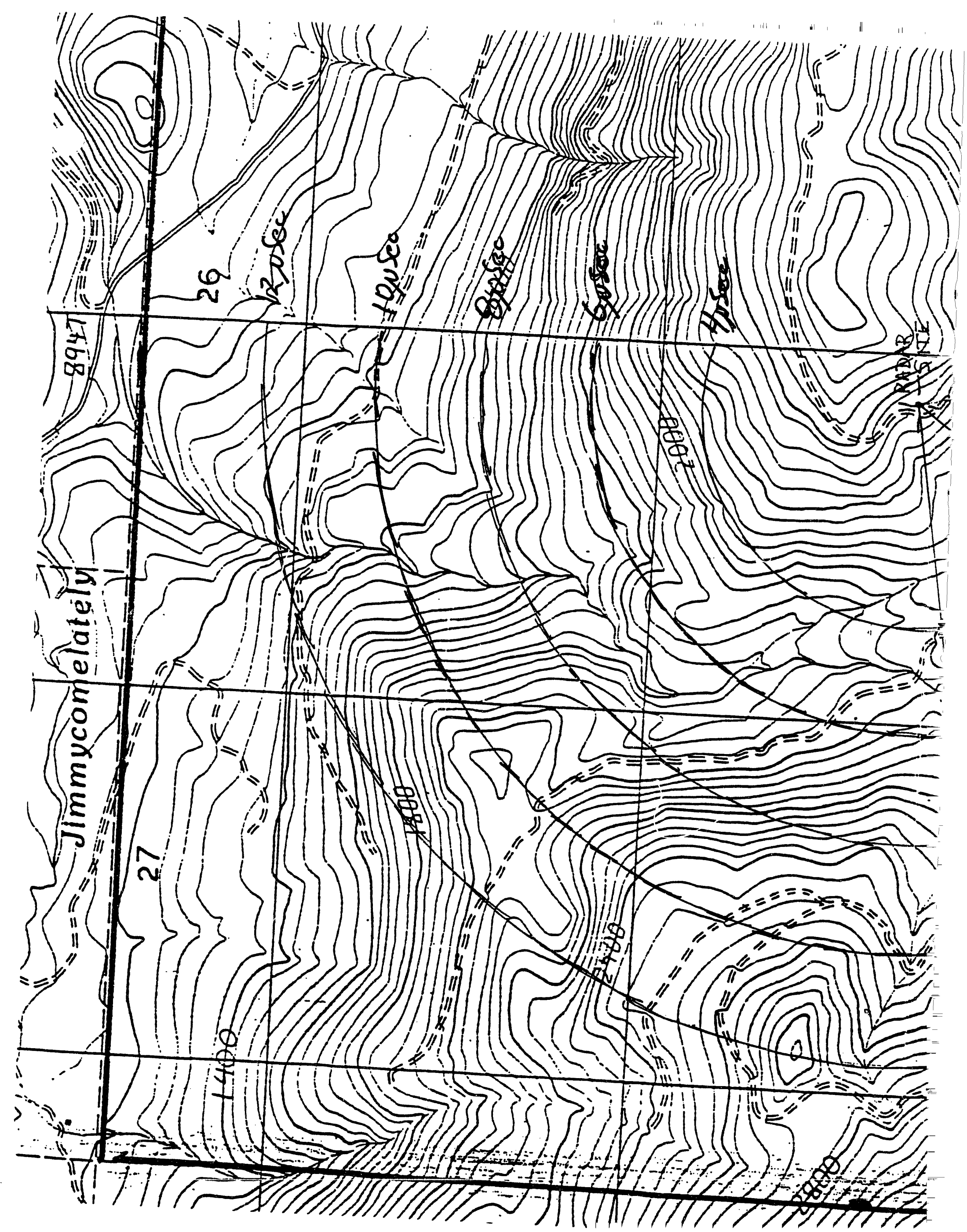



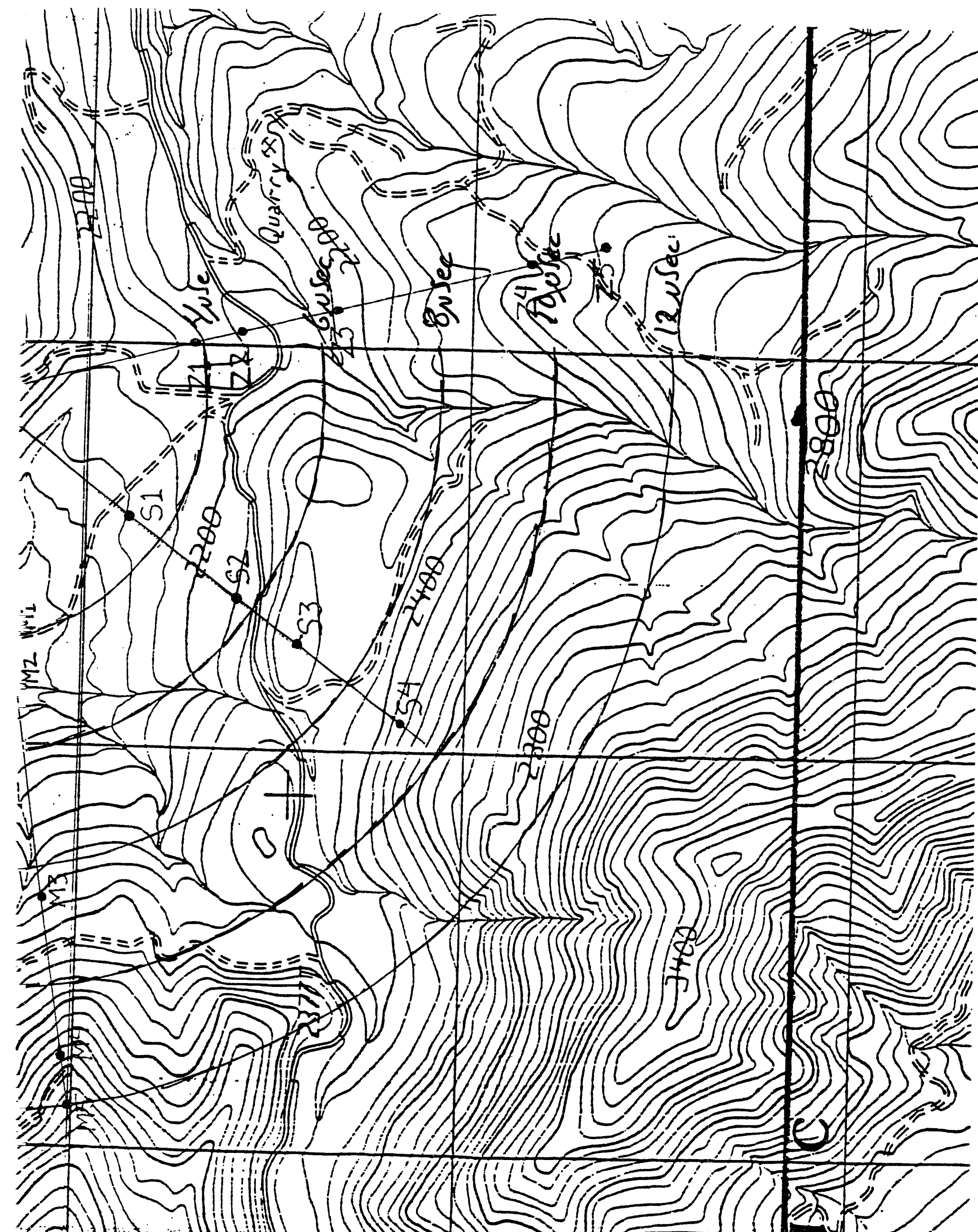

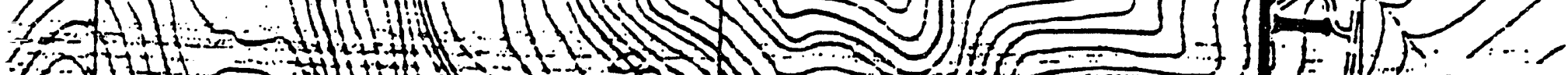

, त्रillए $\approx$ - 


\section{APPENDIX C:}

Ground Truth for Maynard Site 1992 Sequim Measurements 
1992 UWB CLUTTER EXPERIMENT GROUND TRUTH STUDY

R.W. Bienert

E. Telenick

V.I. Cullinan

November 1992

Letter Report Prepared for Pacific Northwest Laboratories

C.1 


\section{INTRODUCTION}

In October 1991, Battelle/Marine Sciences Laboratory (MSL) was requested to participate in the collection of ground truth data in support of the UWB Clutter Radar Experiment conducted for the Defense Advanced Research Project Agency (DARPA). Data collection emphasized a general characterization of the landscape and vegetation along three transect lines from a forested site within the Quilcene Ranger District, Olympic National Forest, Washington. Details of tine purpose, sampling methodologies, and results of this study have been described in Cullinan and Telenick (Letter Report, November 1991).

In September 1992, Battelle/Marine Sciences Laboratory was requested to perform an adsitional field survey at a location approximately $5 \mathrm{~km}$ southwest of the site examined in 1991. This letter report presents the methods and results for the 1992 field study.

\section{METHODS}

Field surveys were conducted during September 13 to October 11, 1992 at a pre-selected forested site within the Quilcene Ranger District of the Olympic National Forest. The objective of the field surveys was to perform a baseline characterization of the landscape and vegetation at the new location chosen for the 1992 UWB Clutter Experiment. The parameters of interest for this study were: 1) stand type including dominant species, and size and distribution of trees; 2) canopy profile and coverage; 3) cover and type of understory vegetation; 4) ground litter type and estimate of accumulation; and 5) relative moisture level.

\section{Iransect Locations}

The proposed site for the 1992 UWB Radar Clutter Experiment was located approximately $1 \mathrm{~km}$ west of the junction of Forest Service roads 28 and 240 along a ridge line overlooking the Eddy Creek drainage basin (Figure 1). Three transect lines extending $2 \mathrm{~km}$ from the radar site at angles of $30^{\circ}, 0^{\circ}$ and $330^{\circ}$ (magnetic declination $20^{\circ} \mathrm{E}$ ), bounded the "target area" selected for the ground truthing study. Areas of negative slope were excluded from examination. This included the majority 
3

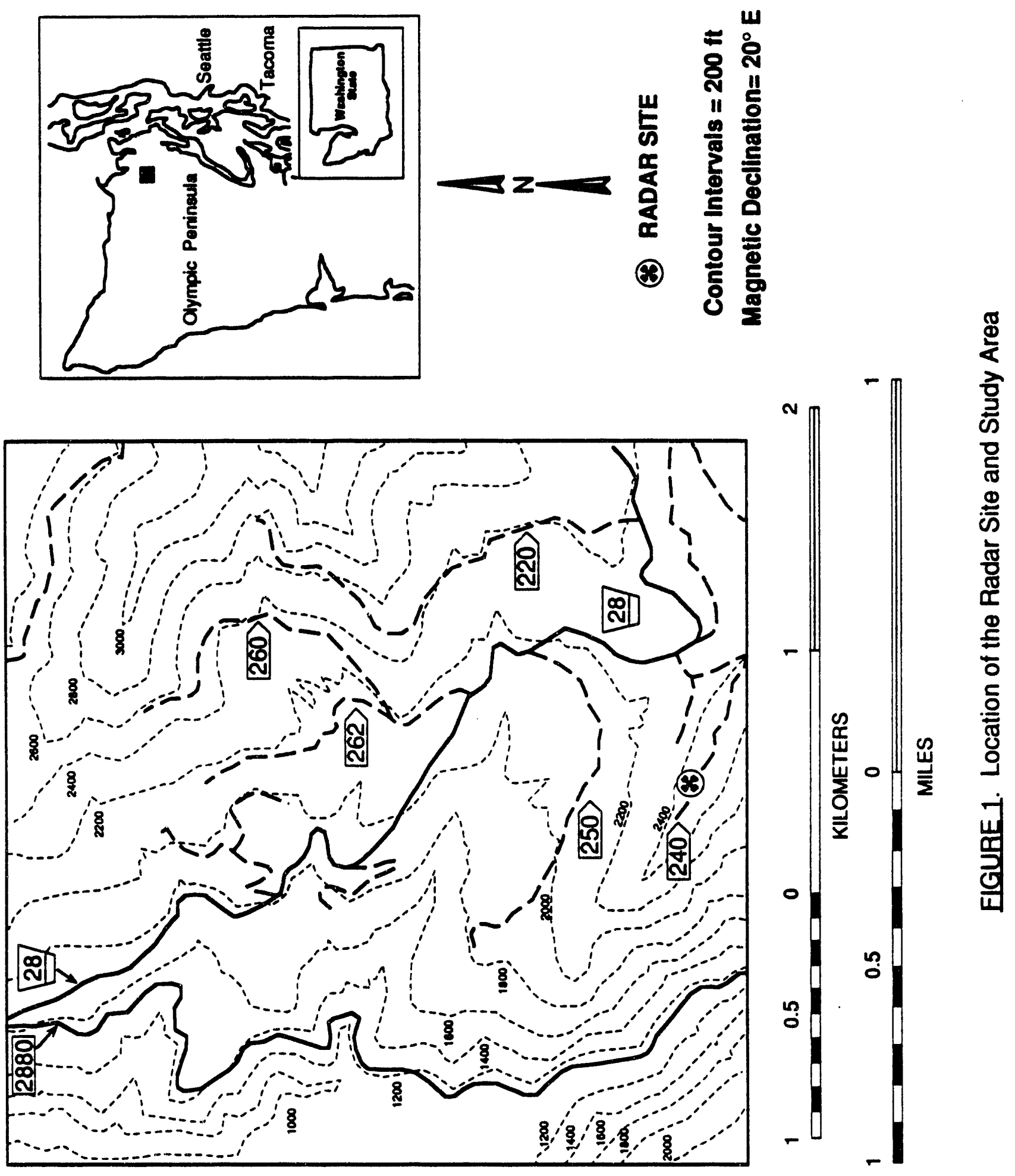

C. 3 
of the area descending toward Eddy Creek, as well as other small drainages and side slopes within the selected target area.

Location of the transects was accomplished using a hand held compass, color aerial photographs, a 7.5 minute USGS topographic map (Mount Zion quadrangle), helium balloons, and an observer located at the radar site. Using two-way radios, the observer guided a second technician equipped with the helium balloons to points along the transects which intersected accessible roads. Three balloons were used to mark the center line of each transect. The most distant balloon along each transect was located at least $2 \mathrm{~km}$ from the radar site.

Once the transects were located, color aerial photographs were used to delineate potential timber stands and clearcuts for sampling. An initial field survey was conducted to verify stand types, and potential sampling locations were identified based on gross differences in species composition between stands. A total of 13 sample plots were selected along the three transects: five each for the $30^{\circ}$ and $0^{\circ}$ transects, and four for the $330^{\circ}$ transect (Figure 2).

\section{Field Methods}

Each plot location was carefully selected to ensure that all plots were representative of the particular stands being characterized. In some cases, this involved locating plot centers away from the edges of clearcuts or logging roads to minimize the effects of blowdown or logging construction. A plot radius of $16.7 \mathrm{ft}$, which represents $1 / 50$ th of an acre on level ground, was selected because it was large enough to accommodate minor site variability yet small enough to allow a singe surveyor to efficiently inventory the site. The center of each plot was marked with a surveyor's stake and flagging tape. The perimeter of each plot was marked with a lead-free, fluorescent paint developed for construction and forestry applications. Photographic records were obtained for each of the sample plots. A total of five color photographs were taken at each site: one each facing north, south, east and west from the approximate center of the plot, and one facing straight up to record the canopy cover. 

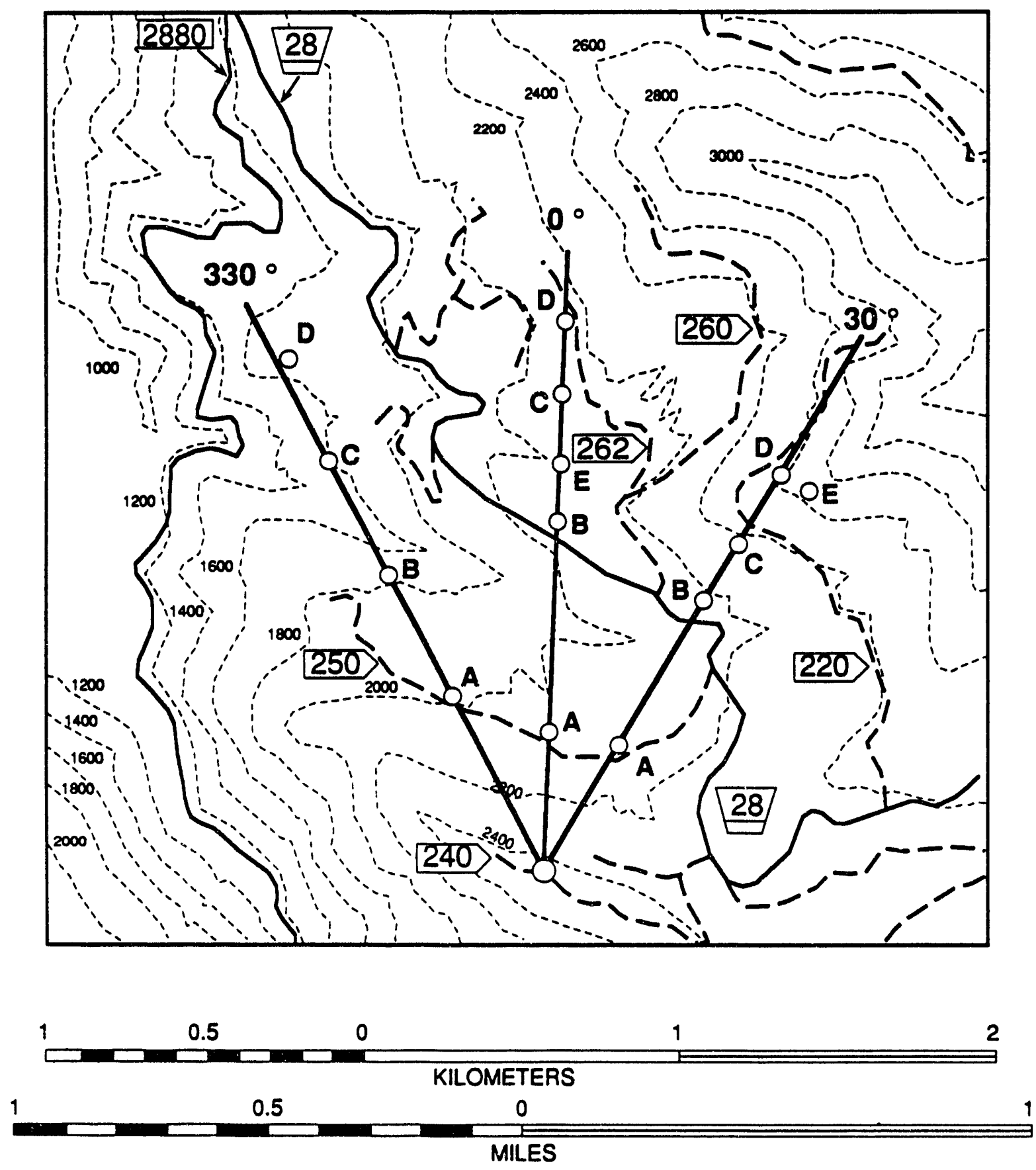

EIGURE 2. Location of Transects and Field Sampling Plots within the Study Area 
A field data form (Figure 3) was used to record general characteristics of each stand and specific vegetation characteristics of the sampling plots. Overstory vegetation was categorized using 5 stem diameter classifications: 0-2, >2-6, >6-12, and $>16$ inches. All diameters were measured at a standard height of $4.5 \mathrm{ft}$. Trees which did not have a measurable stem at his height were tallied as shrubs. Major and minor species represented in the plot were recorded along with an ocular estimate of the average tree height by stem size classification. Due to the variability of heights and multiple trees per class in many of the sampling plots, these estimates should be considered very coarse. Occasional tree heights were measured using a clinometer in order to calibrate the ocular estimates.

Each site was further described in terms of the vegetation for both ground cover and overstory coverage. Vegetation was classified as either litter/bare ground, grasses/forbs, shrubs, or one of the five tree-stem classifications. The ground cover survey described the percentage of the plot covered by each of these vegetation classifications. Only the cross-sectional diameters of the woody stems of trees were evaluated in the percentage cover estimates for this survey. Shrubs were tallied as ground cover unless they were tall enough to be included in the estimates of overstory coverage. In these cases, the shrubs were considered small trees and categorized by stem diameters. The percent overstory surveys were conducted as if the plot was viewed from above. In areas where there was multiple overstory layering, the uppermost canopy was recorded in the appropriate stem diameter classification. Thus, for both surveys the overall coverage totalled, but did not exceed, $100 \%$.

Moisture conditions were described for each site in terms of the depth and composition of accumulated litter. The objective was to obtain an estimate of the relative "wetness" of each plot. A relative score, ranging from one (driest) to five (wettest), was given to each of the plots. Rainfall during the conduct of the radar experiment was measured by placing rain gauges in the center of three plots from each transect. The rain gauges were monitored twice at weekly intervals from 27 September to 11 October. 


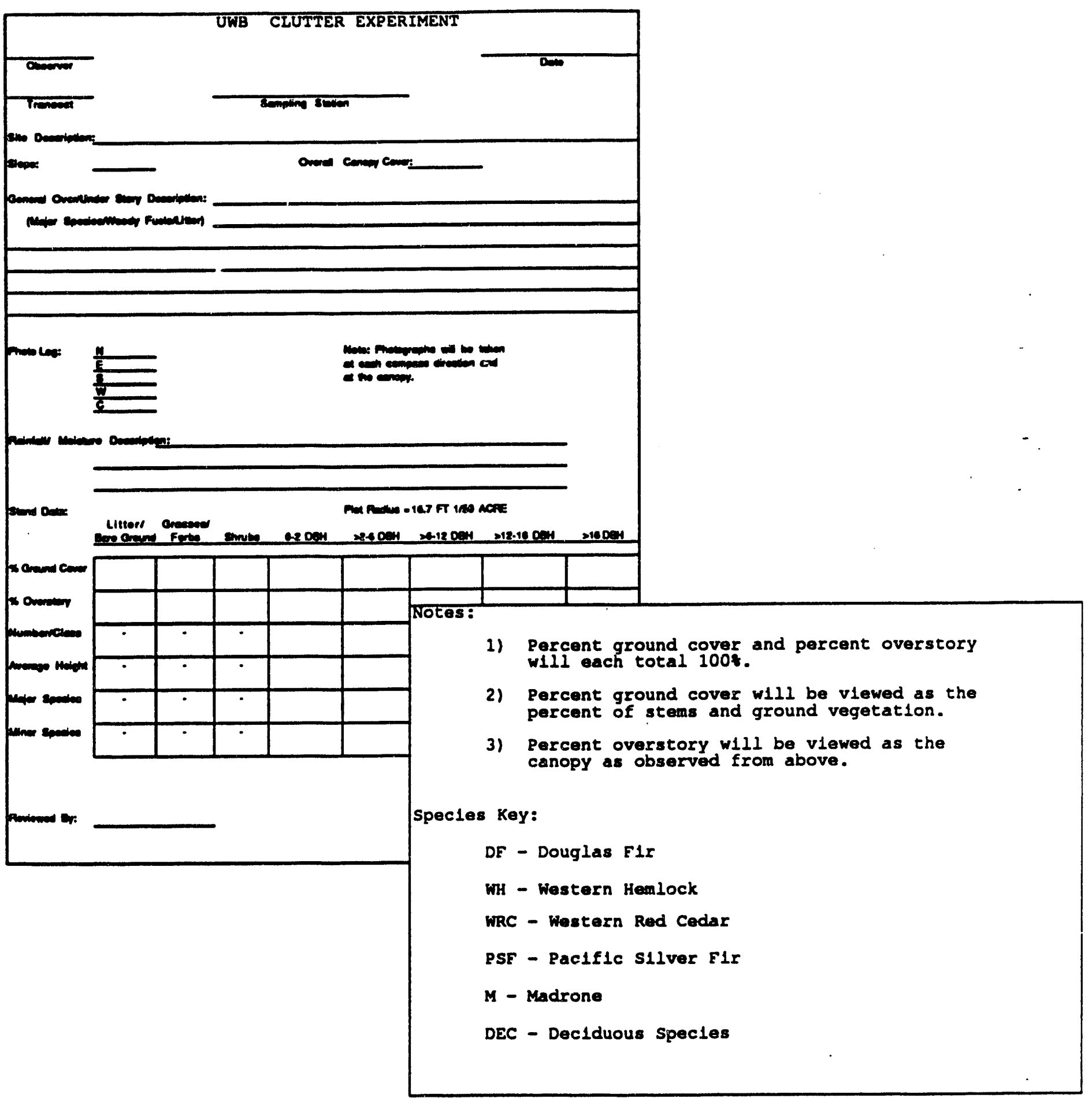

ElGURE3. Sample Field Data Form Used to Record Vegetation Characteristics

C. 7 


\section{Statistical Analysis}

Data from each of the field survey forms were entered into a commercial spreadsheet program (Microsoft Excel Version 3.0 for the Macintosh). Plots were generated using Excel and the charting program Deltagraph (Version 1.5, DelaPoint, Inc.). Data were summarized by both stand classification and by individual transect.

Three stand classes were used to characterize the 13 sample plots. Stands were classified as Class 1 if the major tree component was absent or could be characterized as seedling/sapling with a diameter of $\leq 2$ inches, Class 2 if the major tree component could be harvested as pole timber (diameters $\leq 12$ inches), or Class 3 if the major tree component could be harvested as saw timber (diameters $>12$ inches). All sampling plots were categorized within one of the stand classes in order to estimate the mean and standard deviation for each of the stand parameters measured.

\section{RESULTS AND DISCUSSION}

A spreadsheet of the raw data taken from the original field data forms has been attached as Appencix A. Photographs taken within each of the plots are provided in Appendix B. A summary of the general vegetation characteristics, litter depth, overall canopy cover, and estimates of relative moisture levels within each of the field plots, is provided in Table 1. Mean estimates of relative moisture, litter depth, and canopy cover for the three general stand classes, are provided in Figure 4.

Aerial photographs, a USGS topographic map, and ground truthing surveys were used to create a map of the general vegetation categories found within the radar target area (Figure 5). The absolute distance (uncorrected for slope) of each stand type from the radar site and the lengths of each stand type along the transect lines, were calculated from the vegetation map (Table 2). Slope-corrected lengths for each stand and distances of each stand from the radar site, were calculated according to the following formula:

corrected distance $=$ SQRT $\left.(\text { (absolute distance })^{2}+(\text { change in elevation })^{2}\right)$ If an individual stand contained areas of both positive and negative slope, then corrected distances were calculated for each upsloping and downsloping segment. 


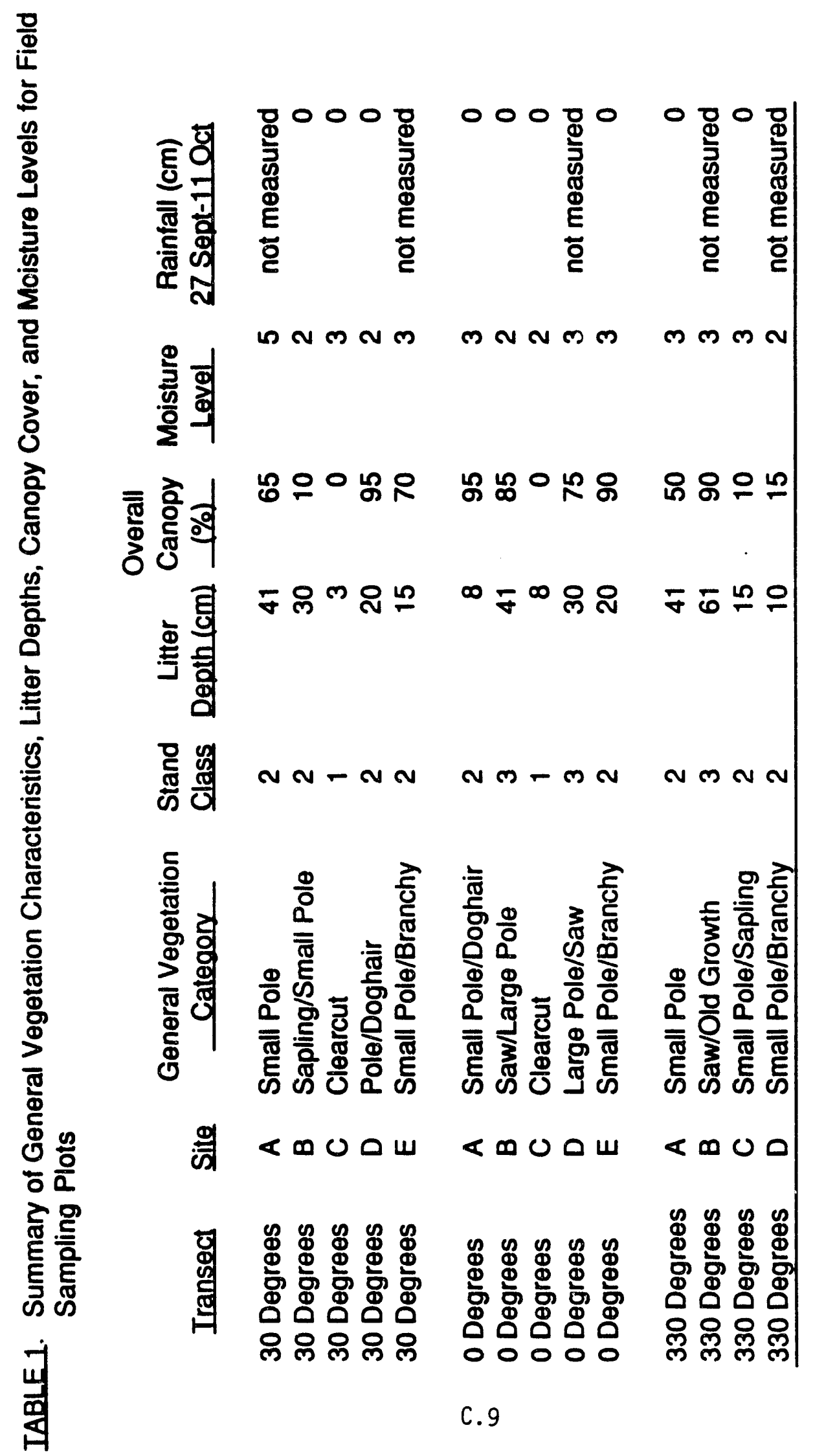


A

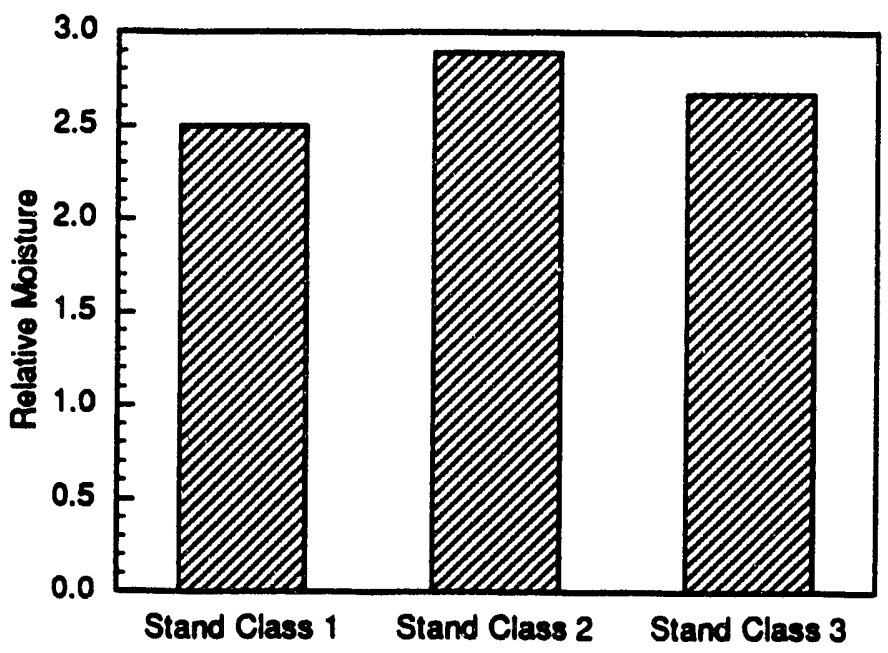

B

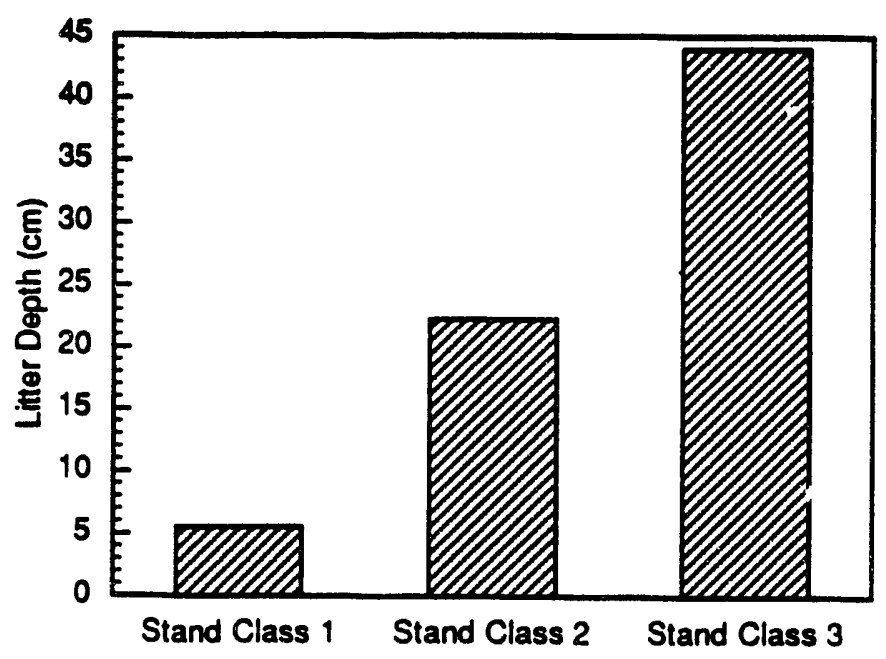

C

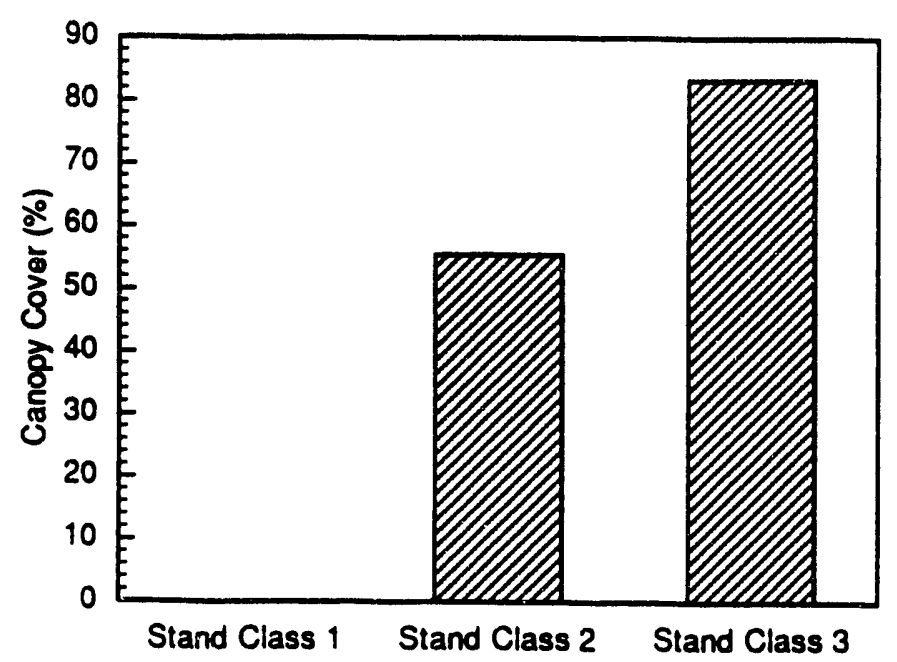

ElGURE 4. Average Stand Characteristics Including A) Relative Moisture, B) Litter Depth, and C) Canopy Cover Based on Circular Plots with a $16.7 \mathrm{ft}$ Radius 


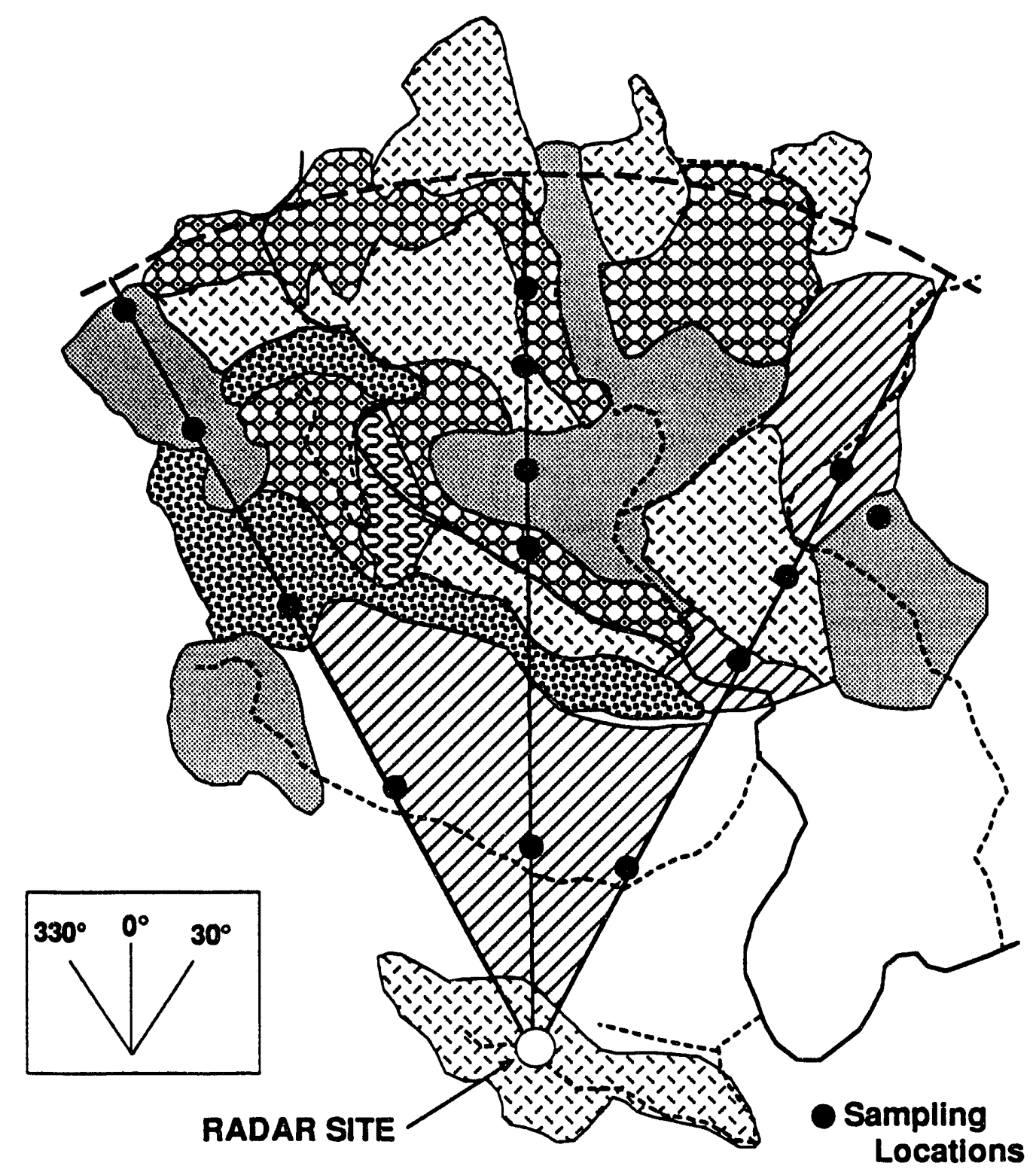

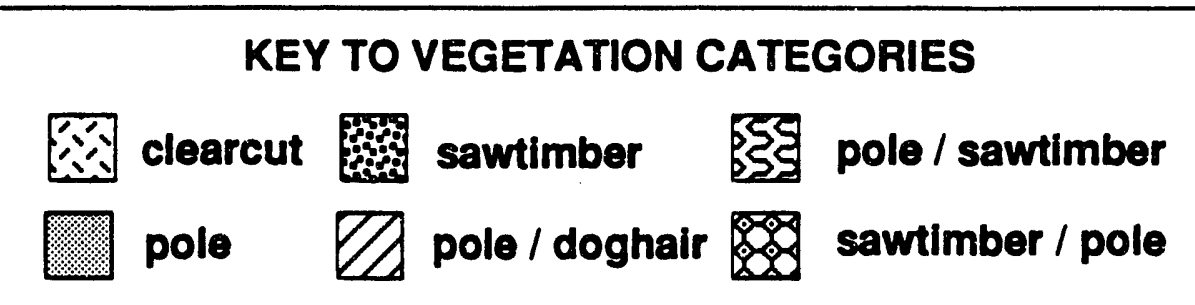

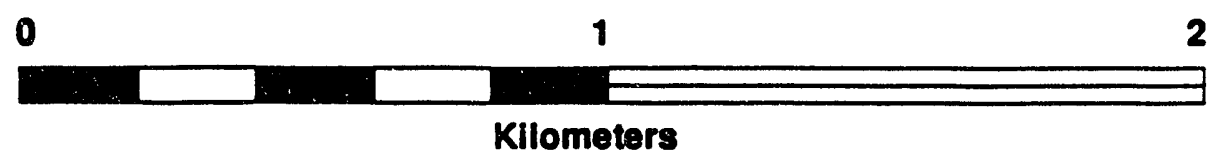

ElGURE 5. General Vegetation Zones Within the Study Area 


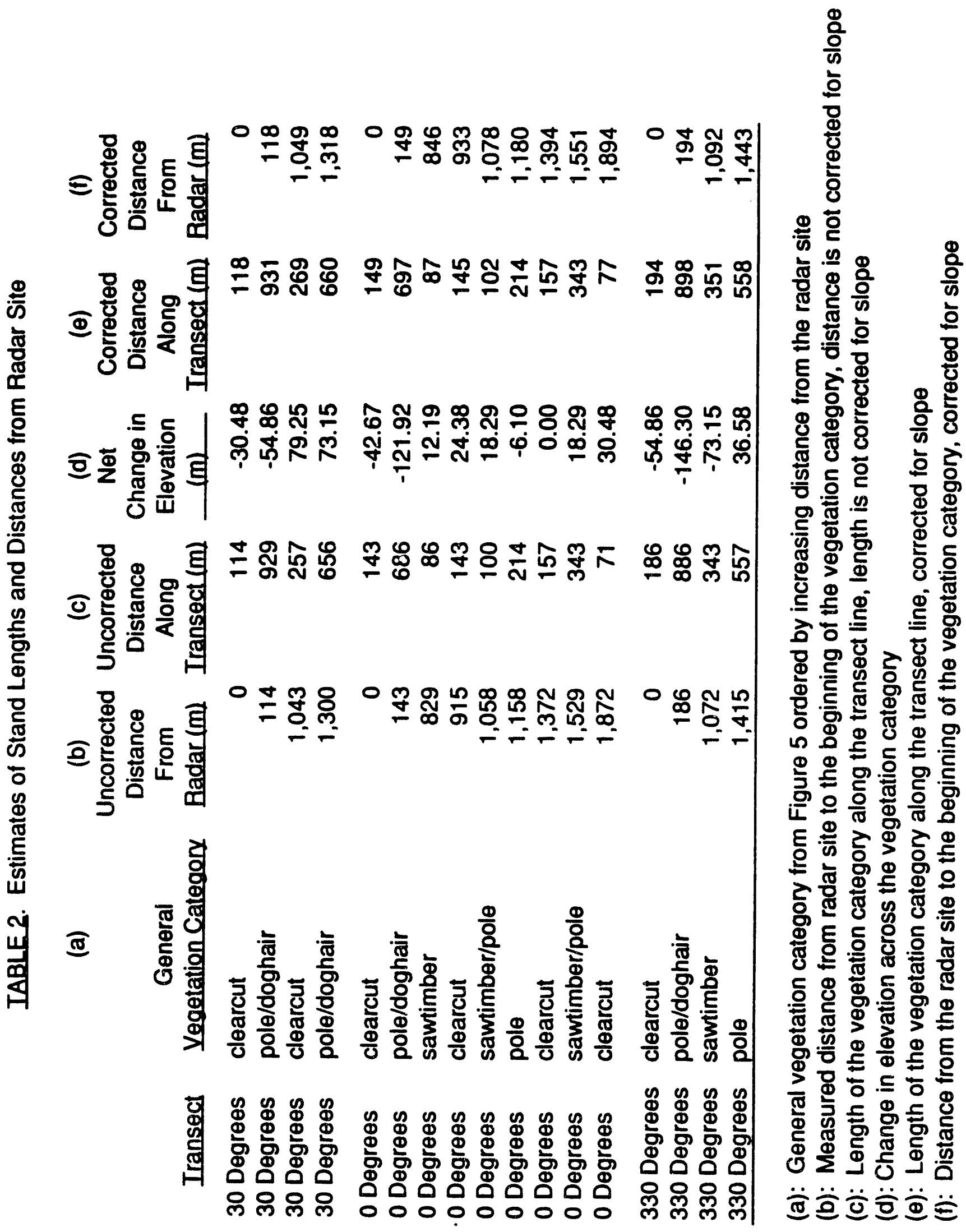$$
\text { C. } 12
$$ 
The net change in elevation was estimated by calculating a weighted mean for all segments, where the length of each segment was used as the weighting factor.

Each of the stands from Figure 5 were grouped into one of the three stand categories, and the corrected lengths from Table 2 were used to calculate the percent coverage of each stand type along each of the transects. Estimates of percent coverage of the dominant stand categories are presented in Figure 6.

The dominant stand type throughout the study area was pole timber, which is not surprising considering that much of the area has been logged recently. The pole timber stands surveyed in this study were found to be highly variable in terms of average tree size, stocking density, and the relative percentages of overstory and understory cover. Stands which were located in replanted clearcut areas tended to have trees which were more uniformly spaced, had larger diameters in relation to height, and had a higher ratio of foliage to overall biomass. In many cases, these stands had branches which extended from near ground level to the canopy, and greater development of the understory component. Other pole stands, especially those with a greater percentage of doghair, exhibited higher densities (in some cases up to 12,000 to 15,000 stems per acre), and tended to be very thin and tall with few branches at the canopy level.

The sawtimber stands were confined to narrow bands within the study area, primarily along steep slopes associated with drainages. It was generally more difficult to characterize sawtimber stands with a single sampling plot because of the low density of trees encountered and the rolatively large differences in height noted between tree species within this stand type. Sawtimber stands typically displayed the greatest canopy development and had considerably higher litter accumulation. Despite wide differences in the quality and amount of accumulated litter between stand types, differences in the average moisture content between stands were negligible. Rainfall was not recorded at any of the sampling stations while the clutter experiment was being conducted. 


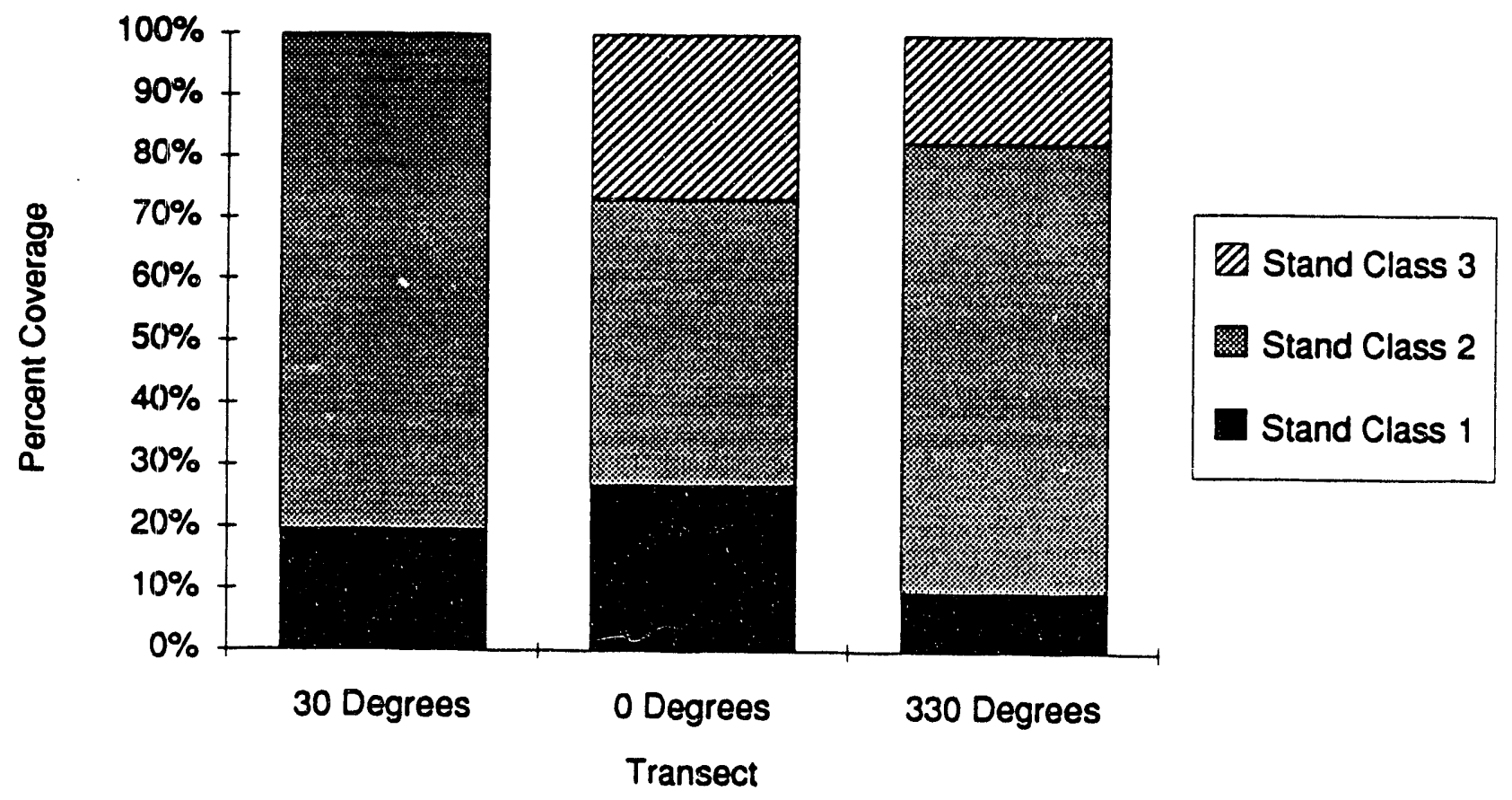

ElGURE 6. Relative Importance of Dominant Stand Classes Along Transects

C. 14 


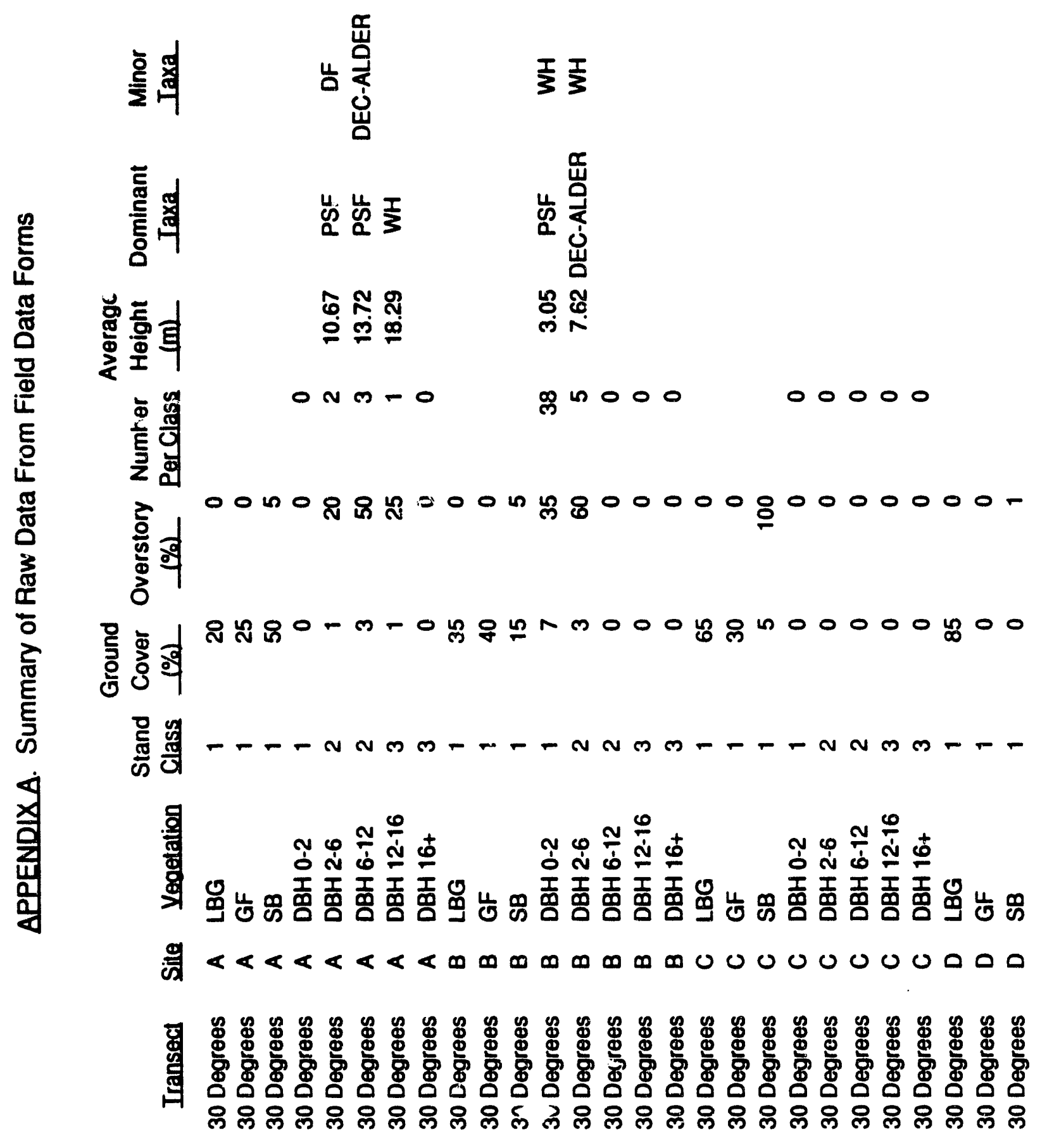




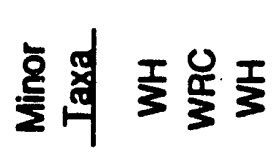

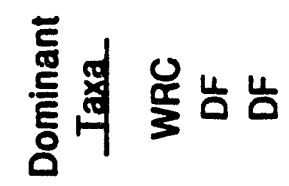

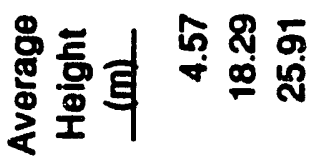

邁

㟔岇

㟔㟔

岩䓃峞

फू.

응

กับ

$\underline{\varphi} \underline{\varphi}$

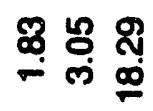

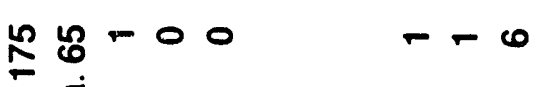

$\frac{1}{3}$

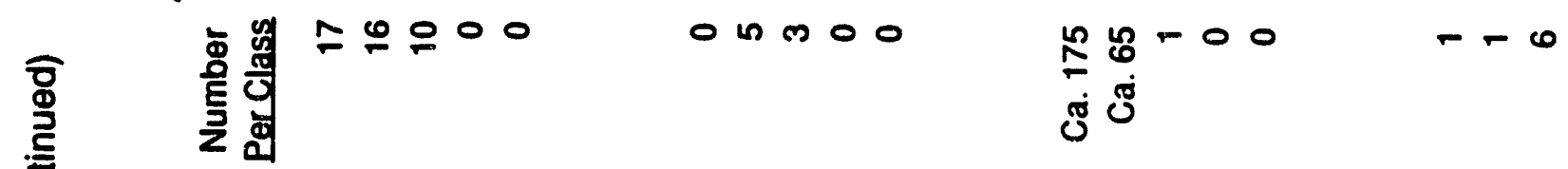

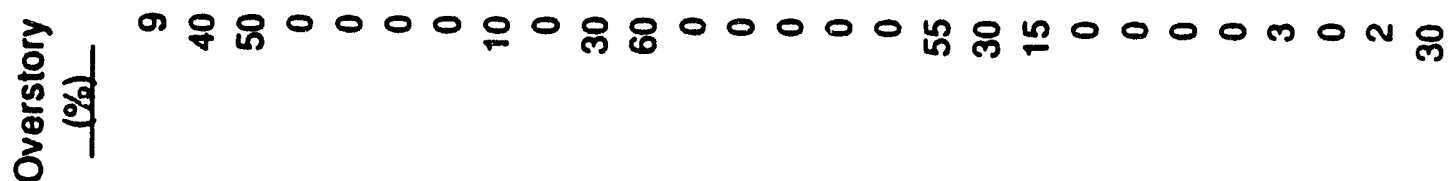

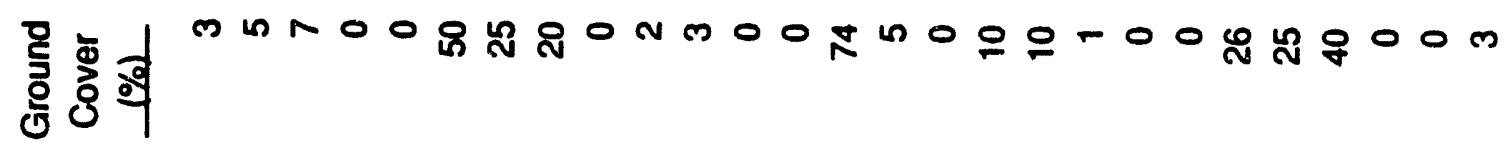

कृ

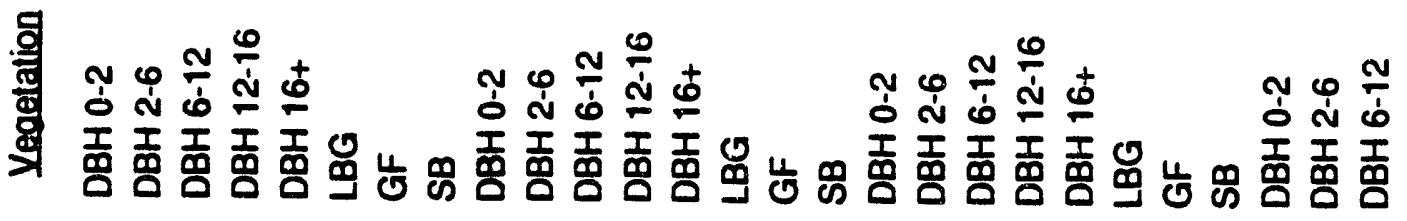
咅

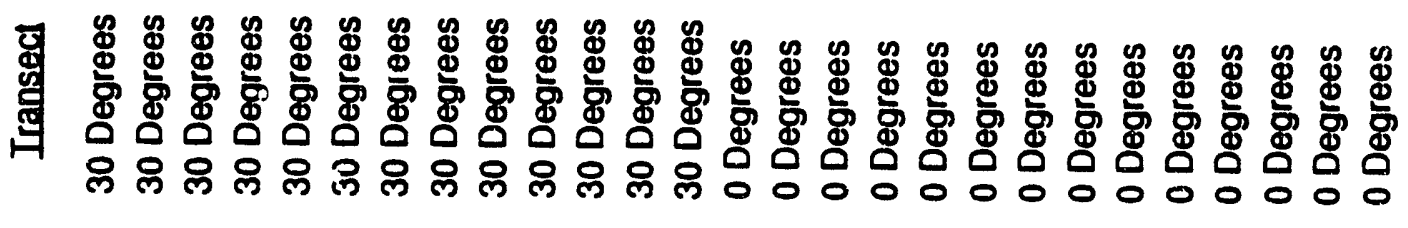

C. 16 


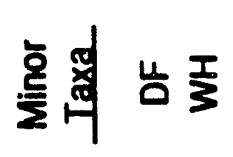

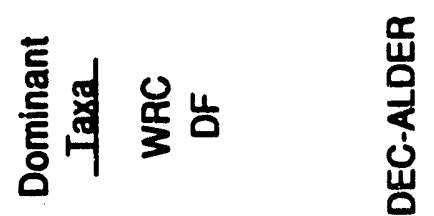

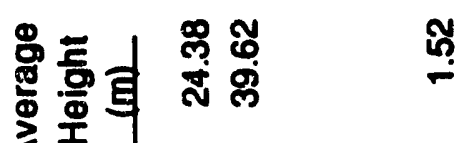

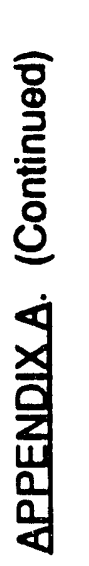

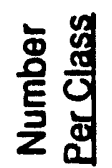

旁 $\frac{1}{5}$

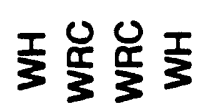

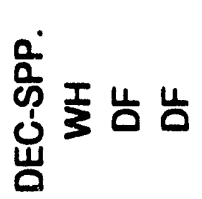

눙 \&

ก สู่ ณึ

$n \sin 0$
㟔

䍃吉

웅 능

نئ

岁 岁

$\div 6$

के으

N

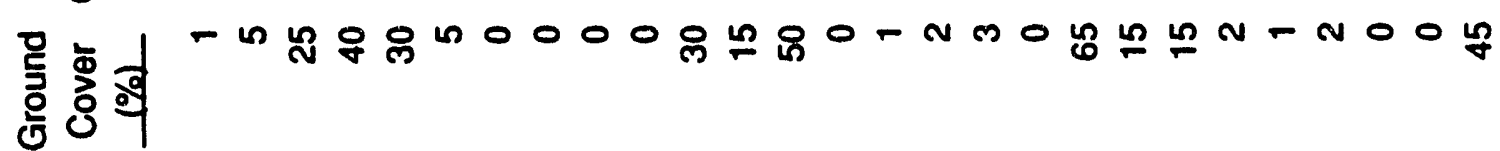

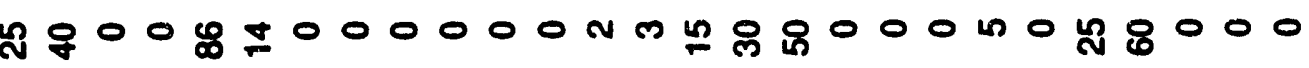

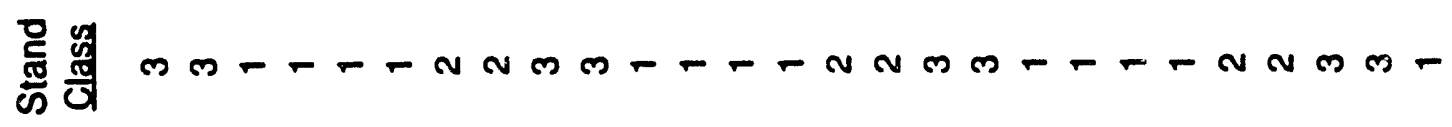

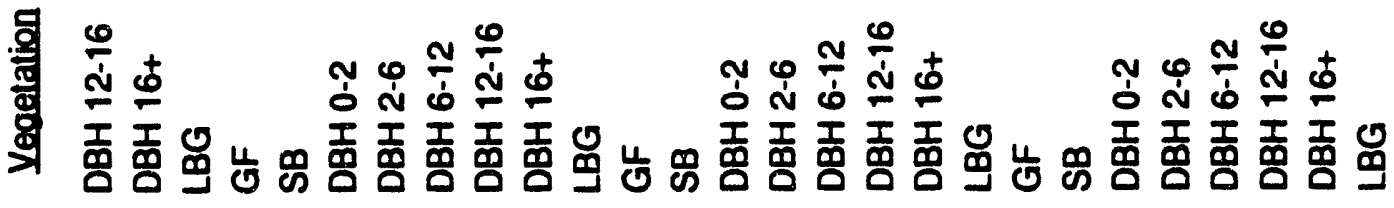

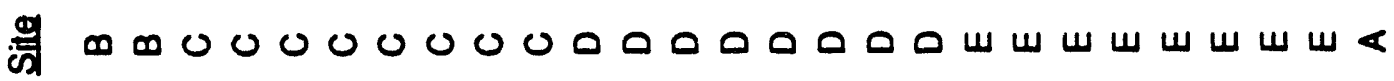

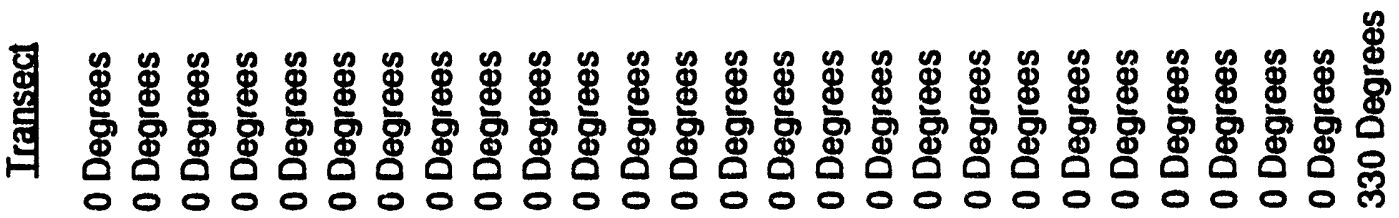




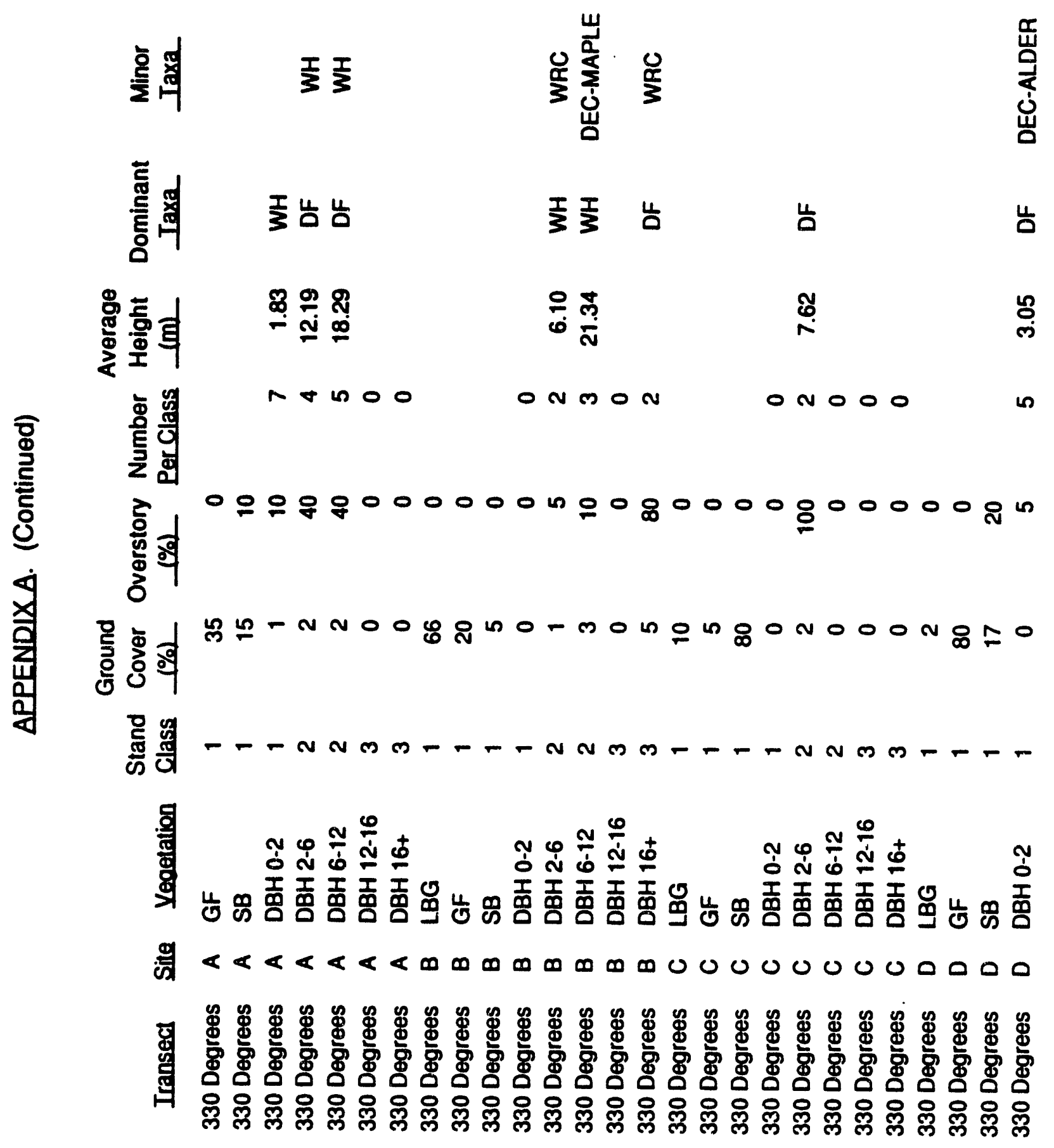




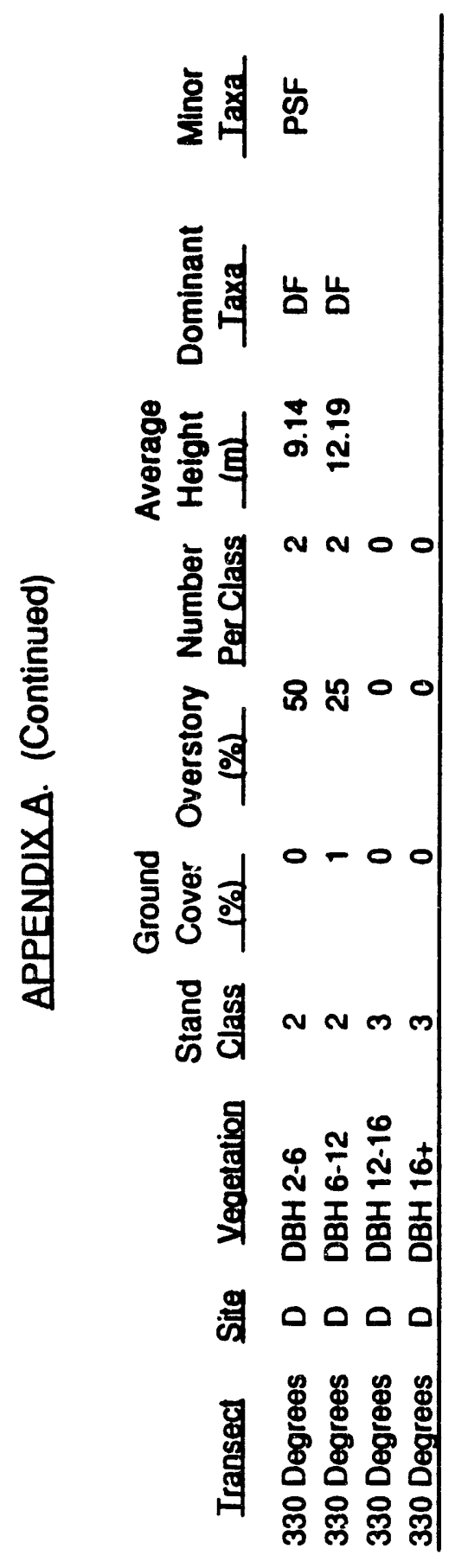

C. 19 
APPENDIX B

C. 20 
$30^{\circ}$ (A) North

$\therefore, \pi$

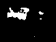

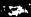

4

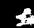

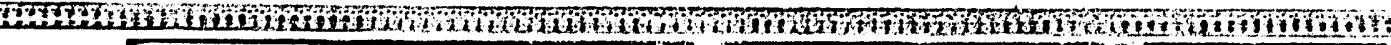

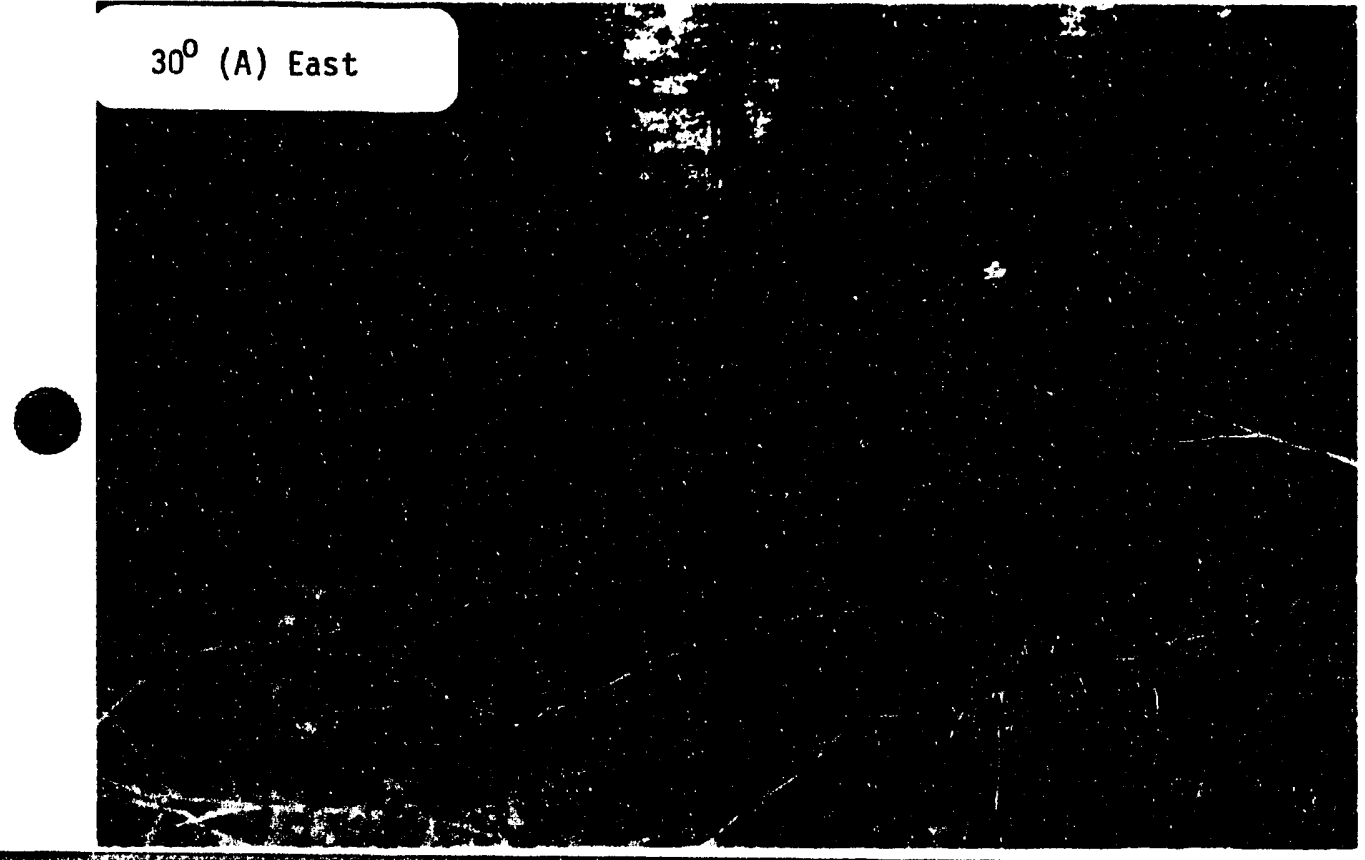

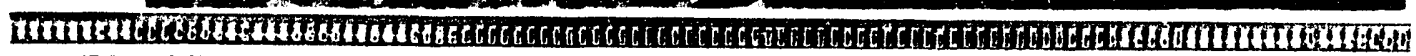

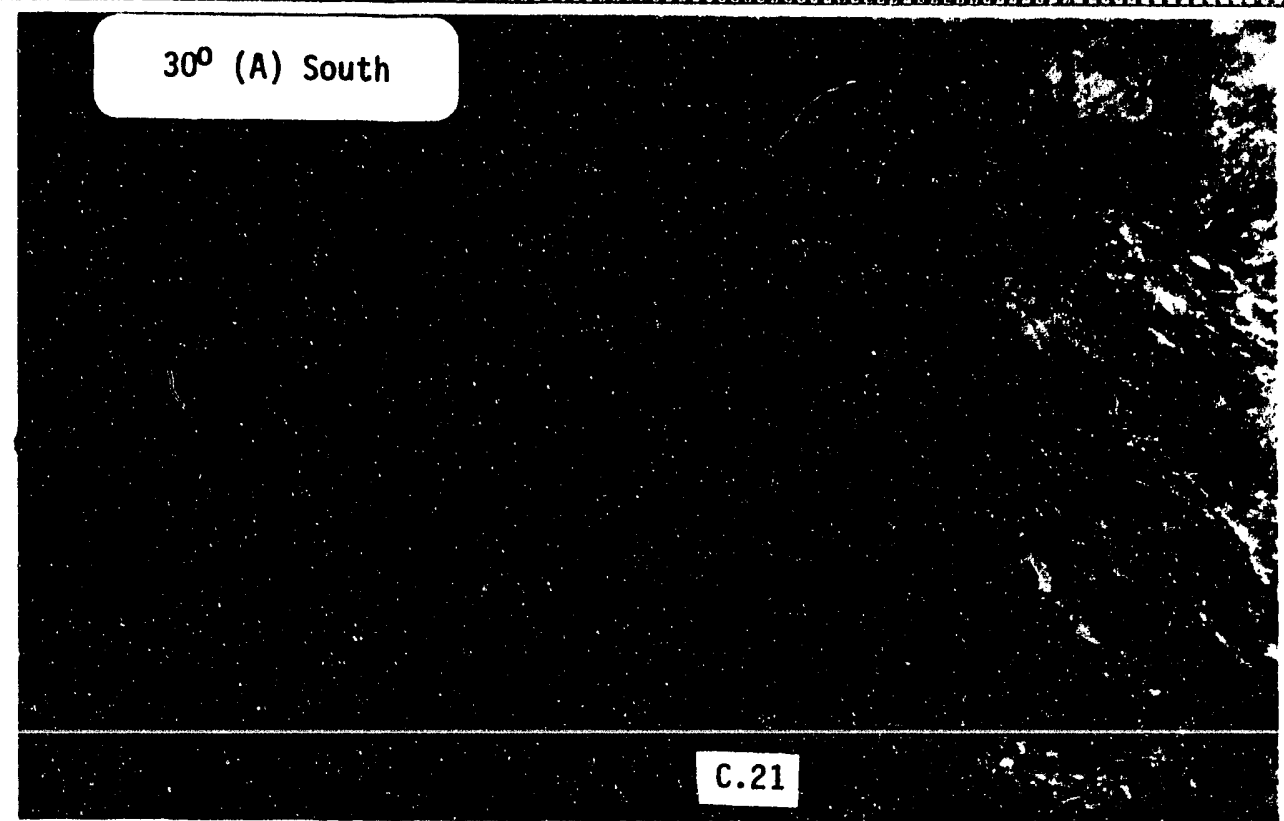



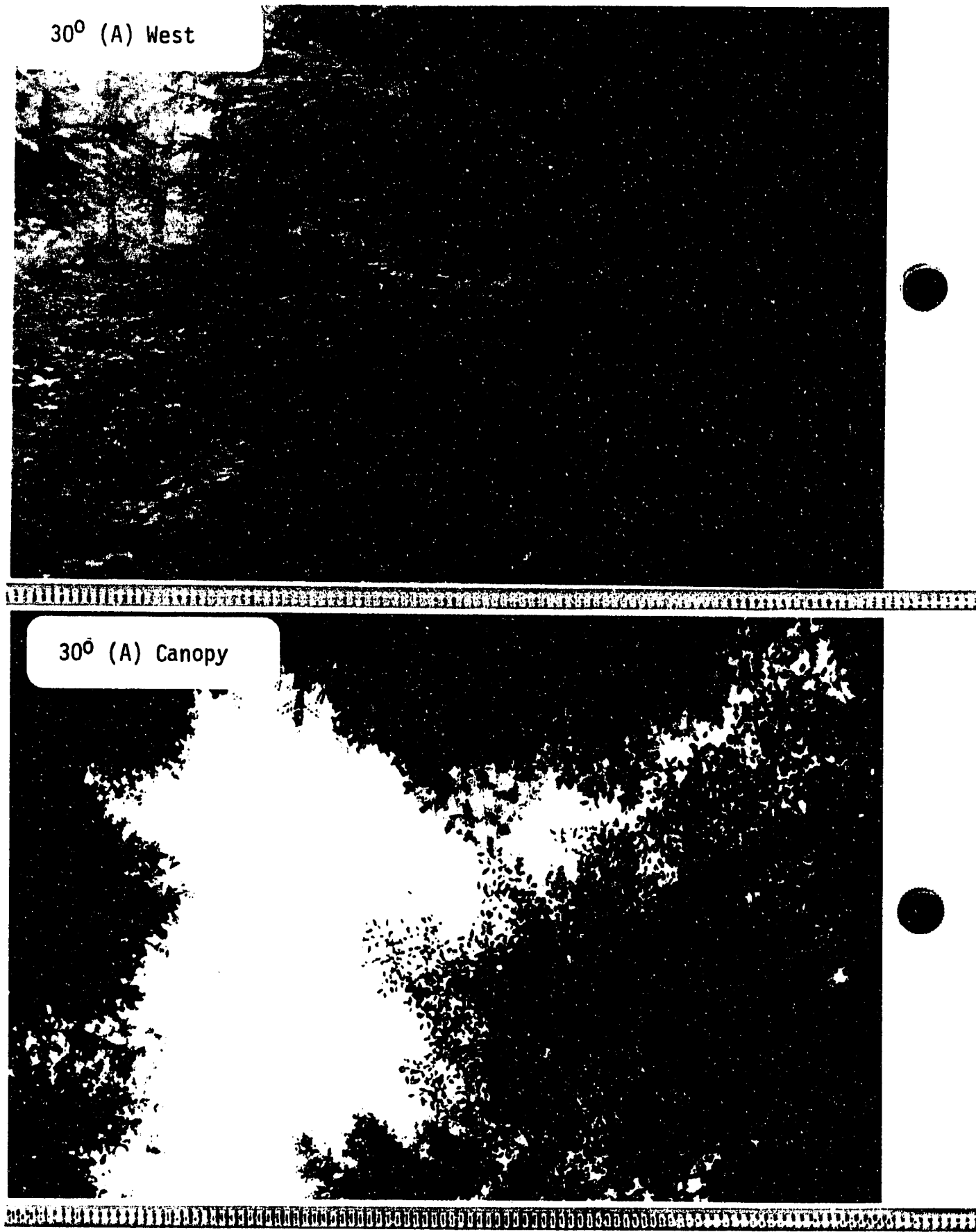


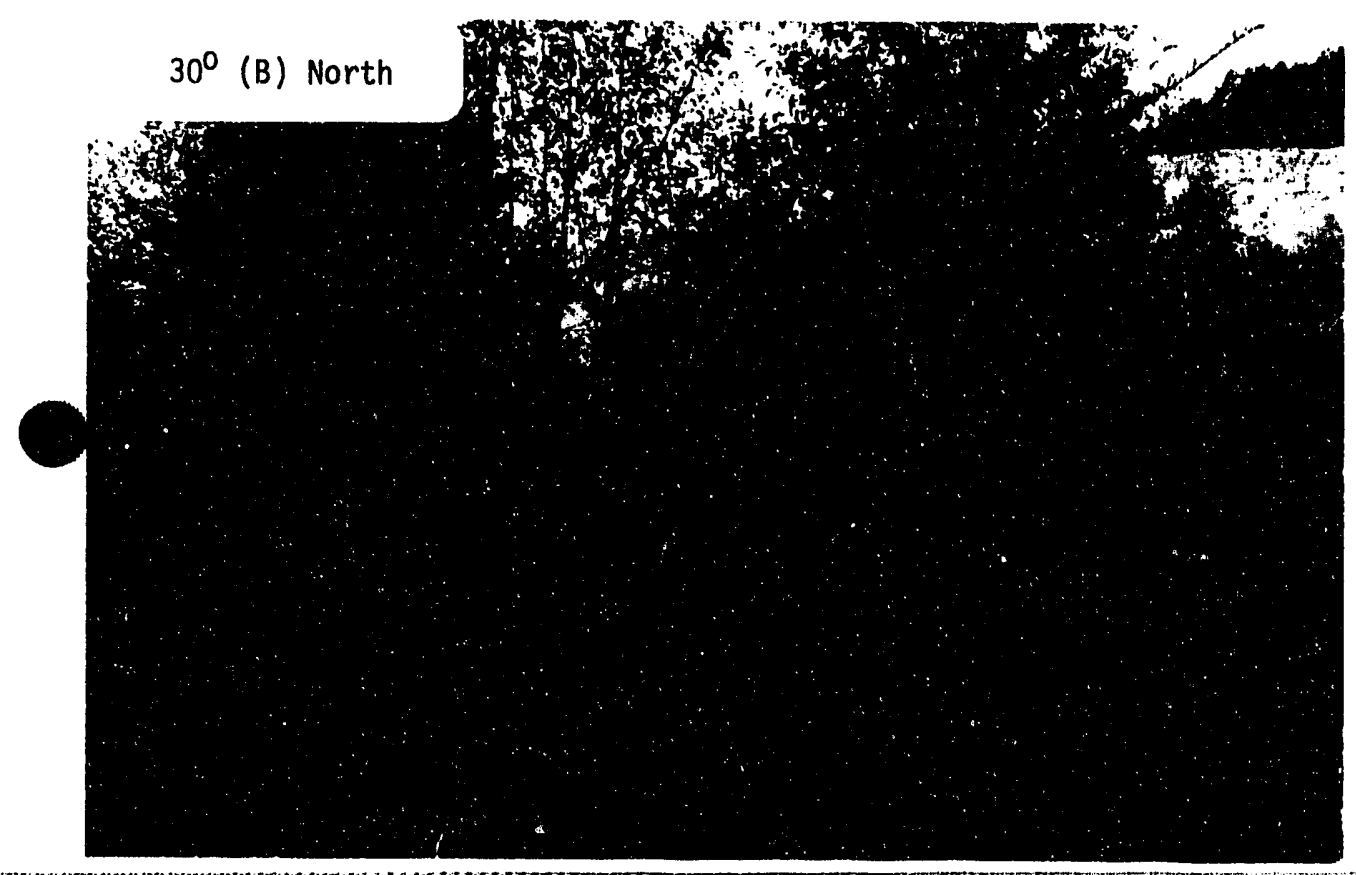

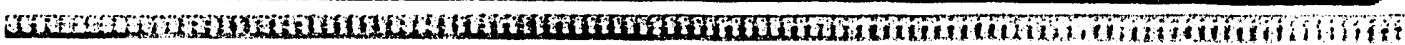

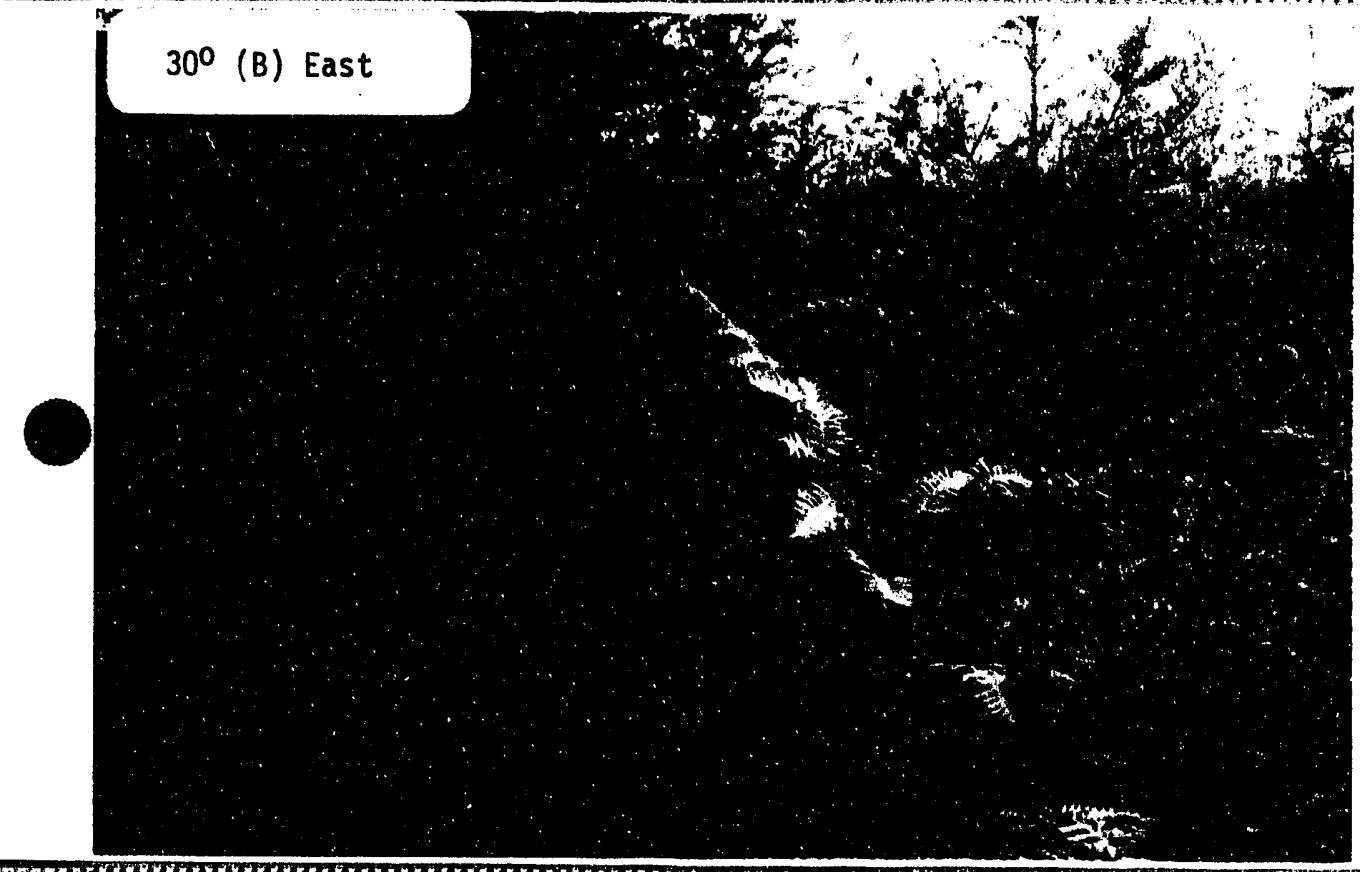

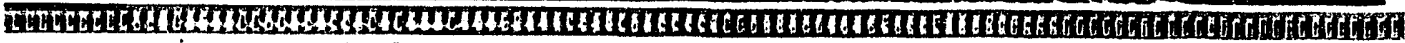

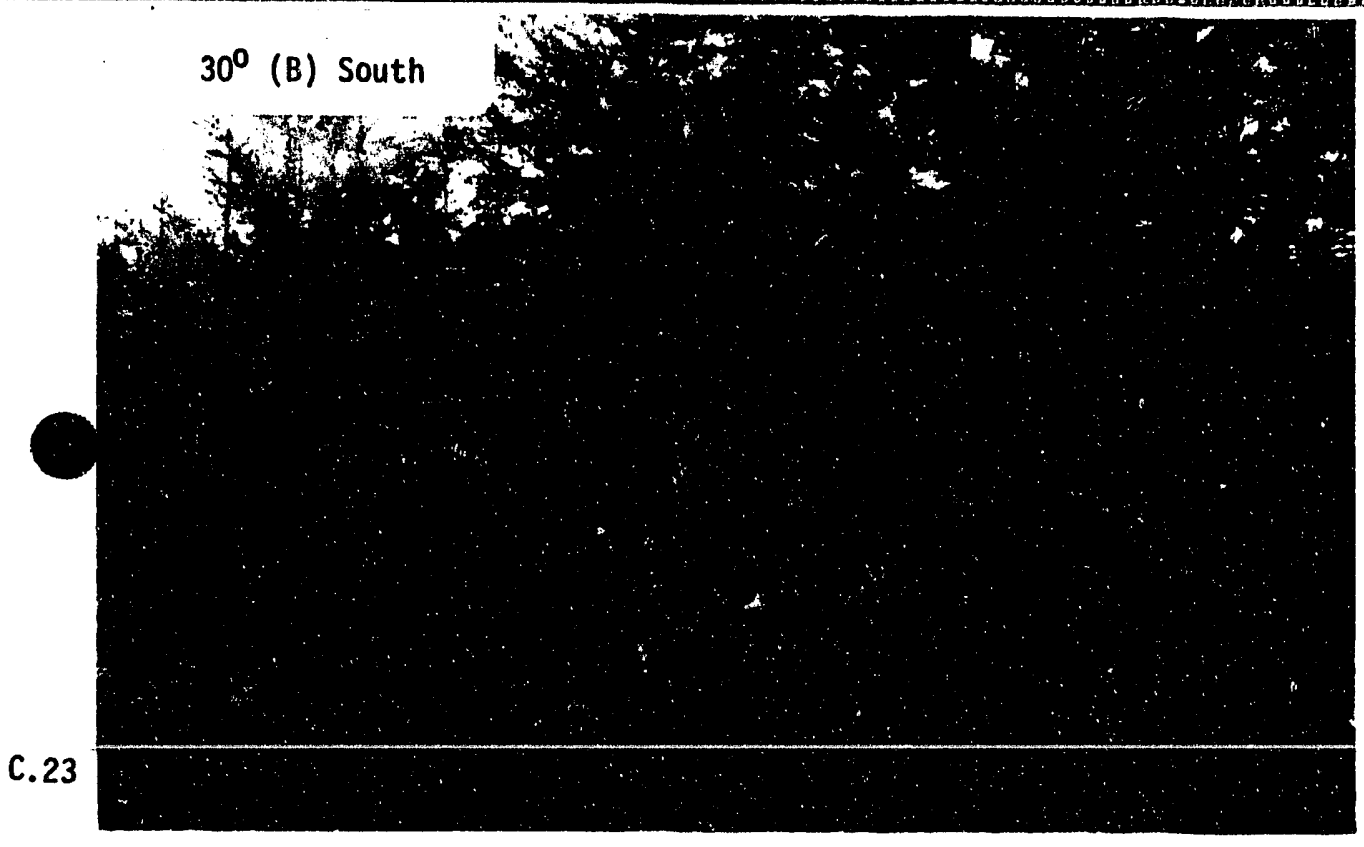




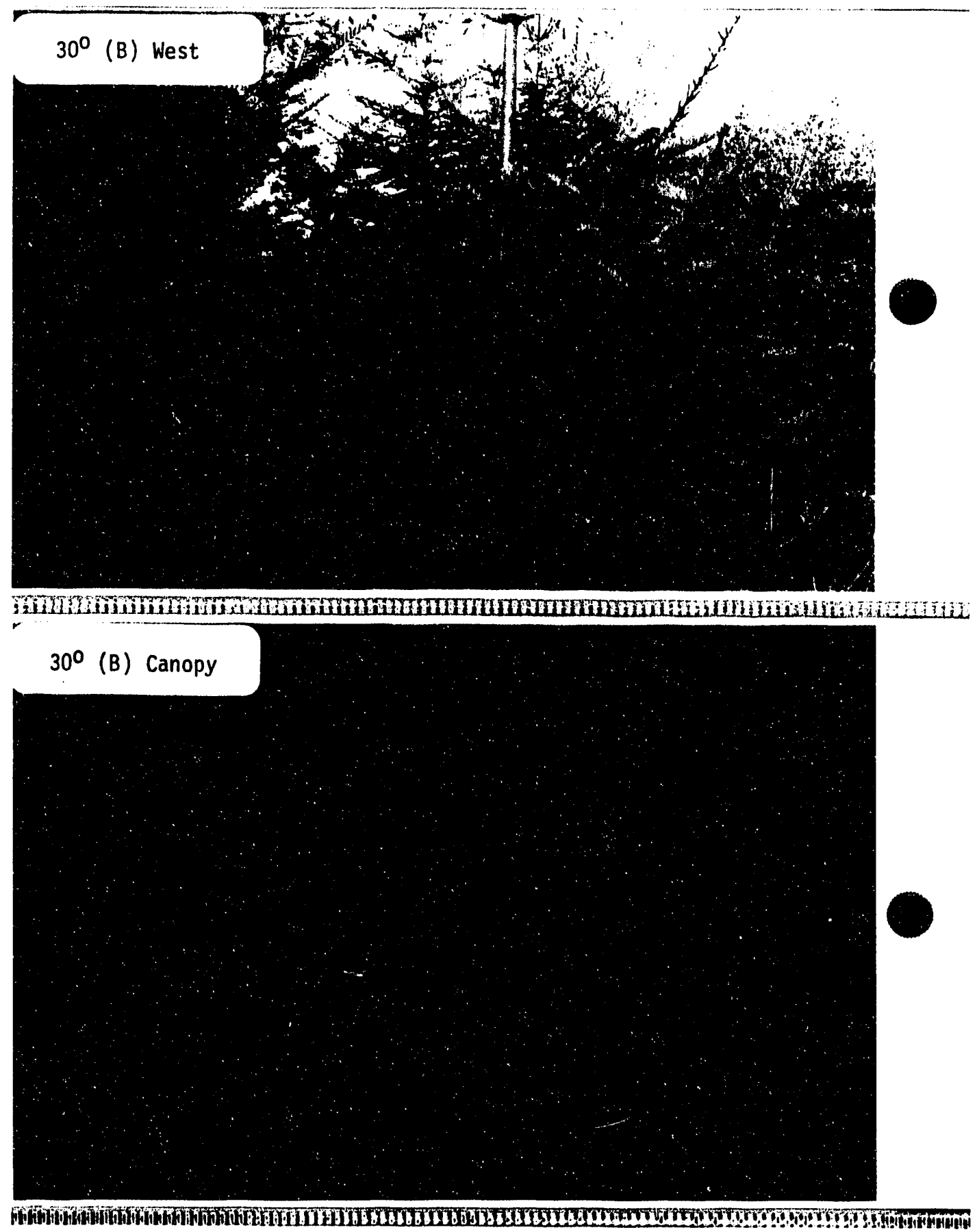

W6 th Wh thi 


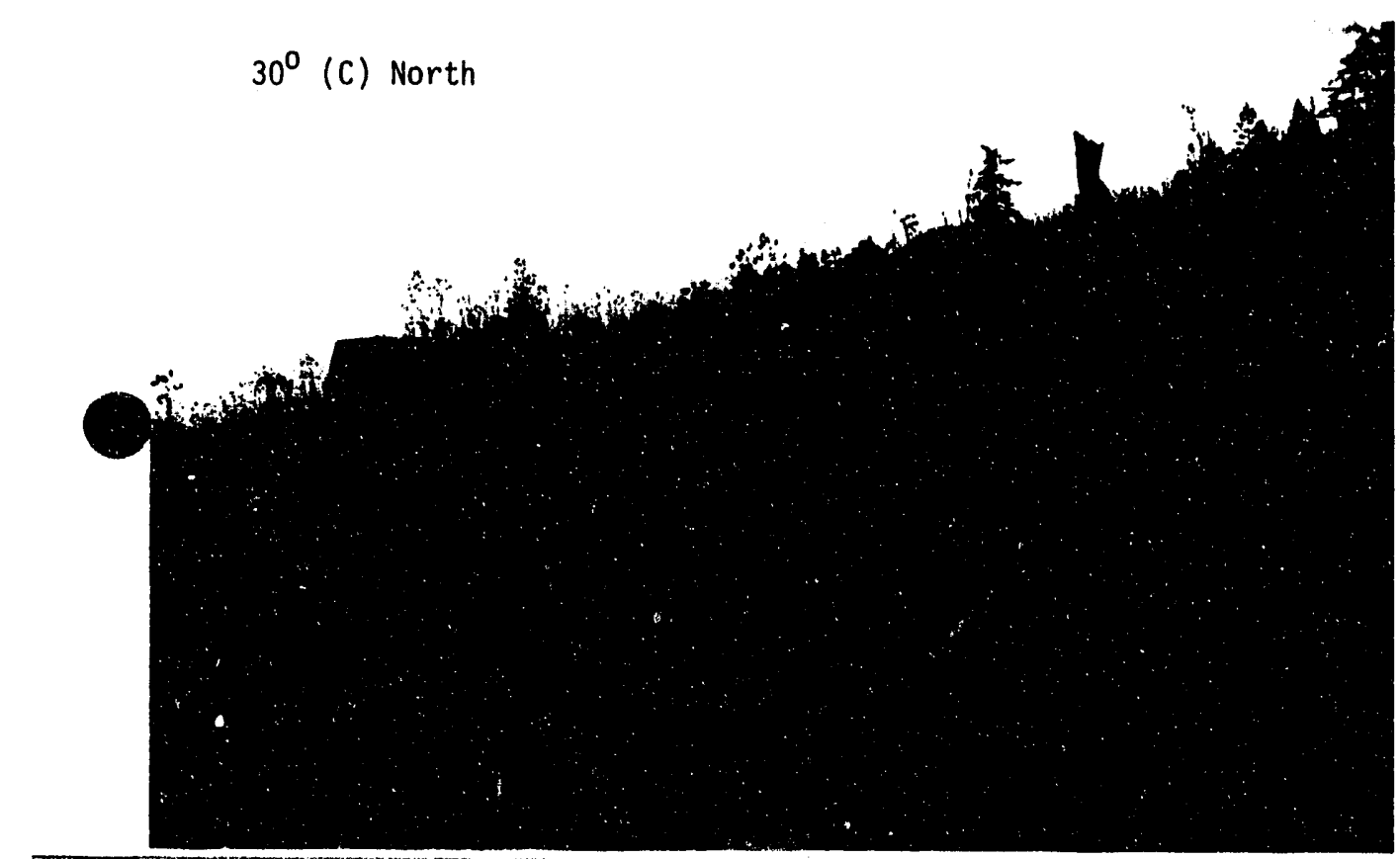

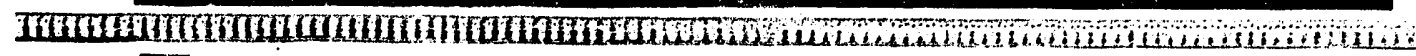

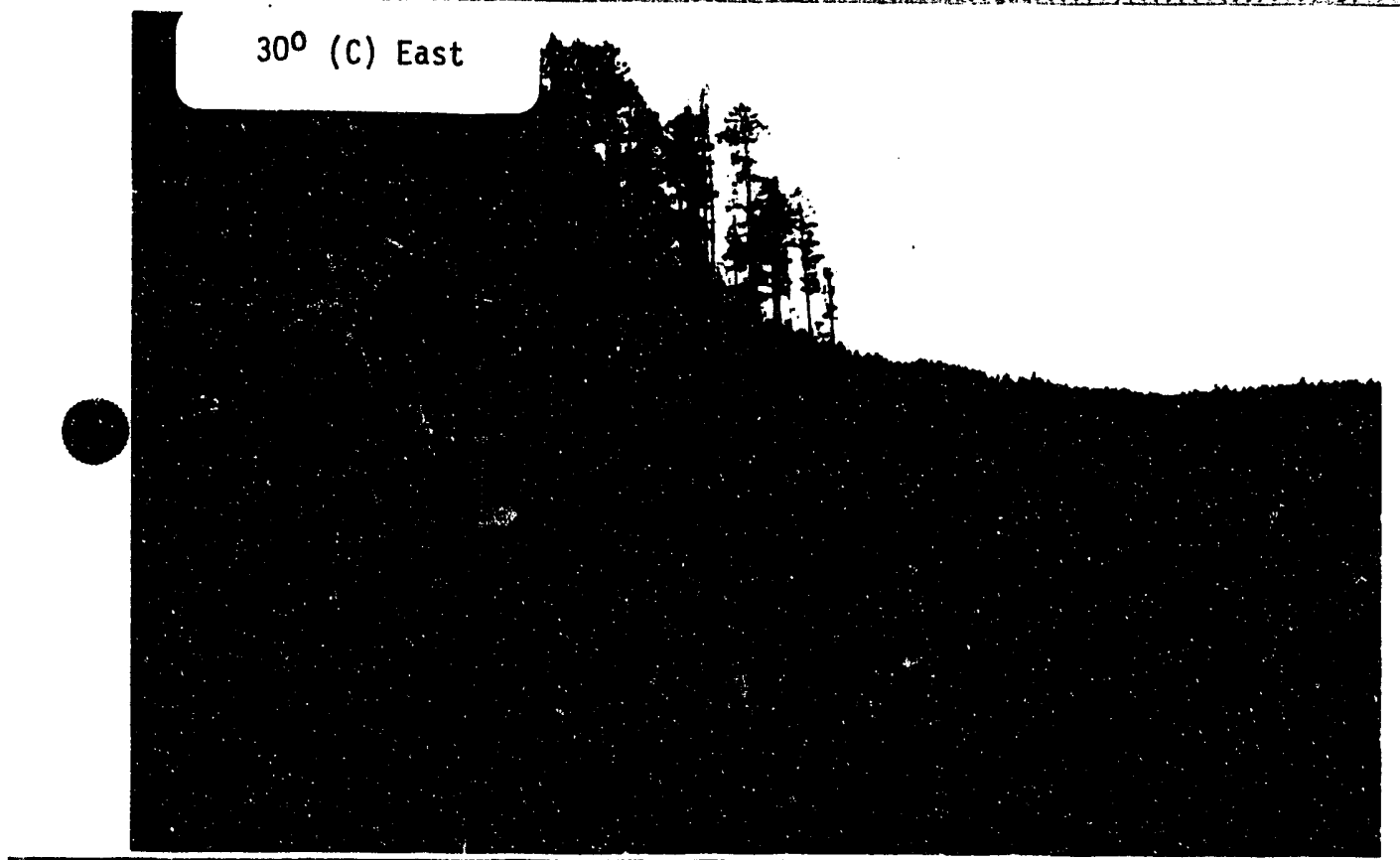

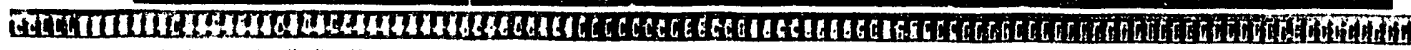
$30^{\circ}$ (C) South

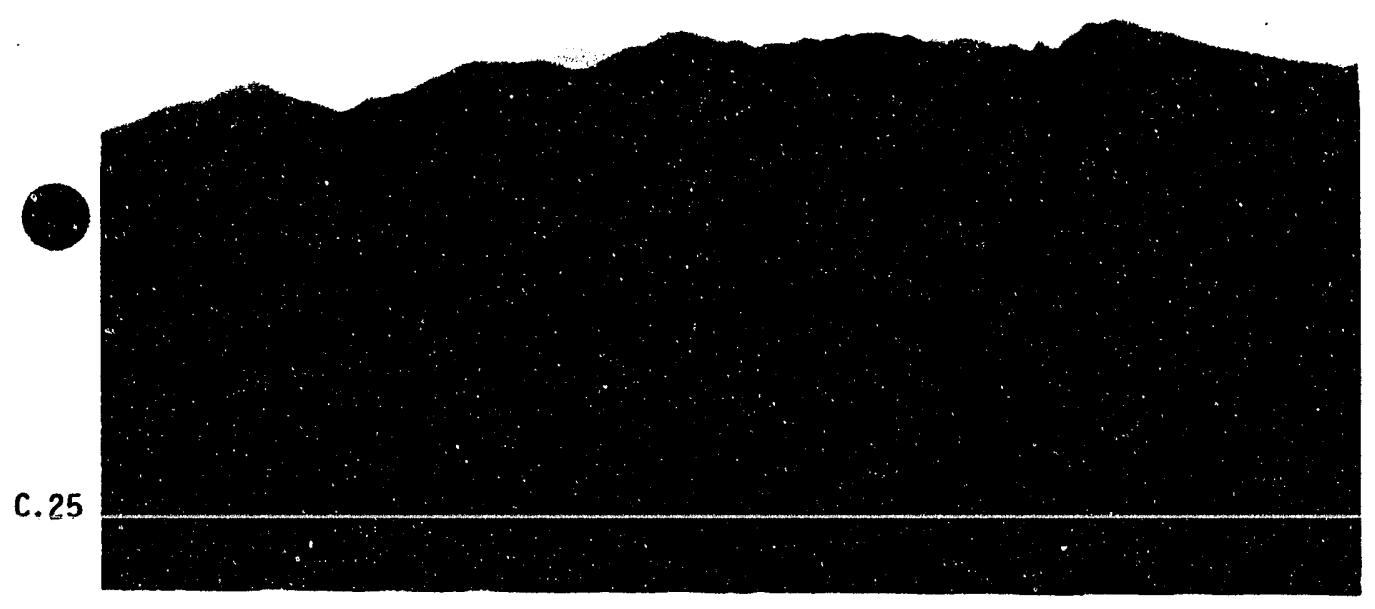


$30^{\circ}$ (C) West

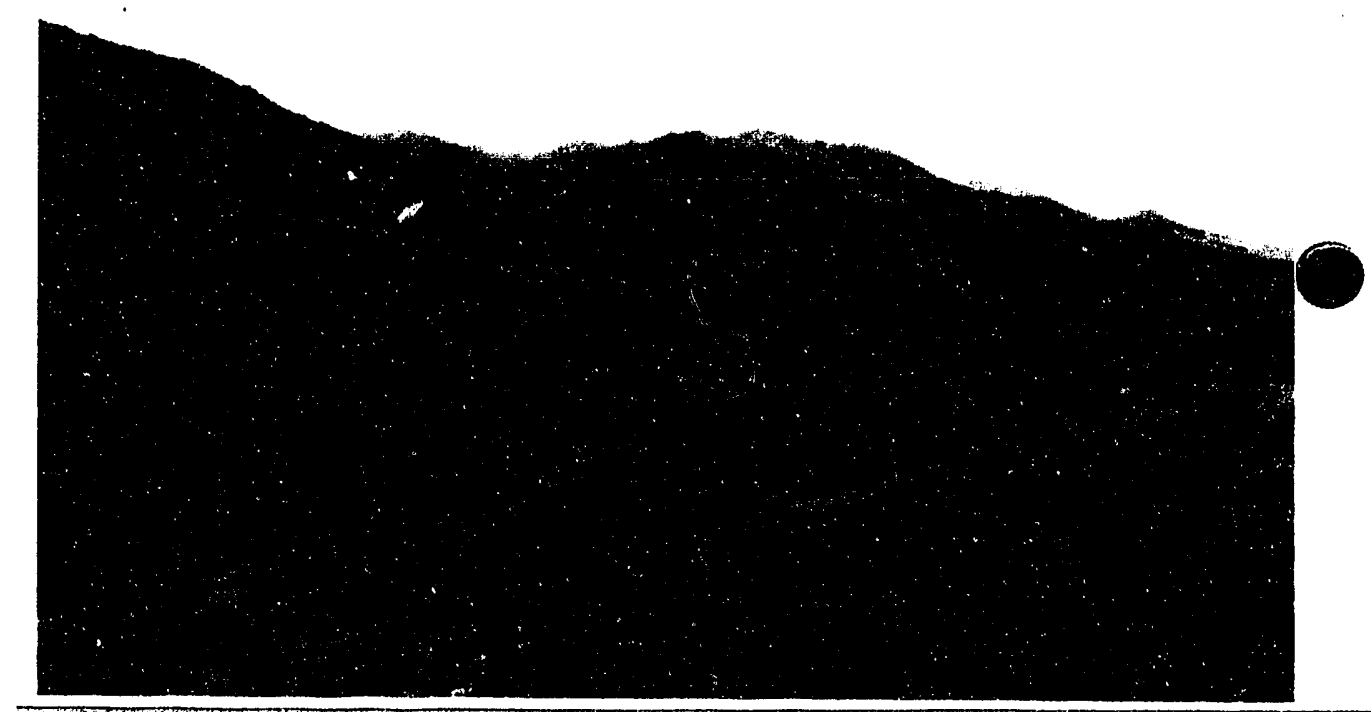

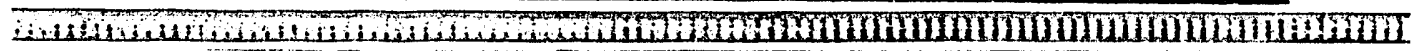
$30^{\circ}$ (C) Canopy

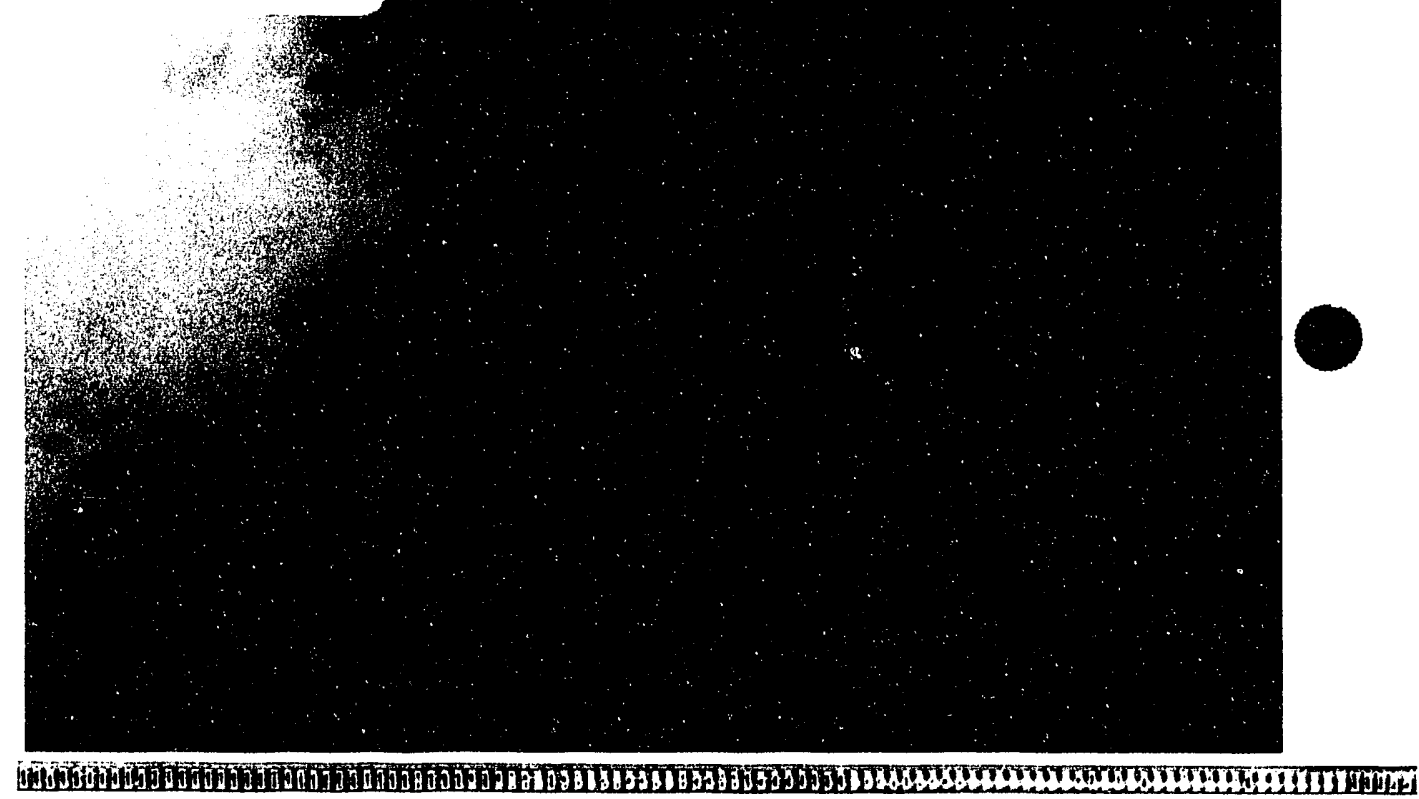

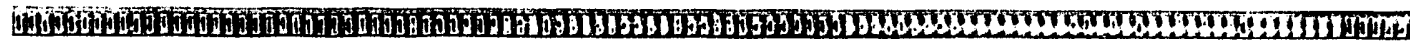




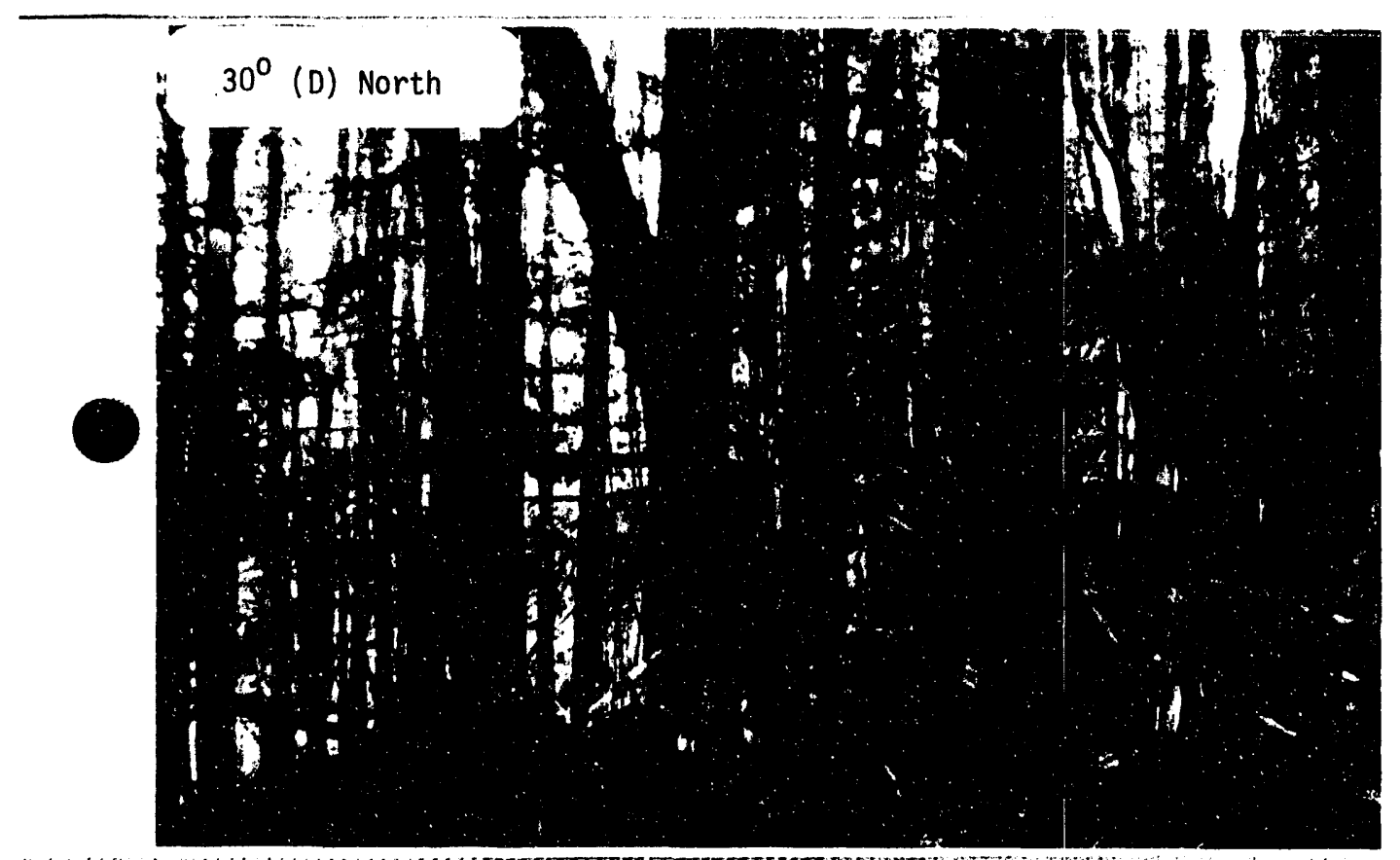

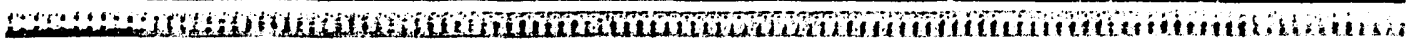

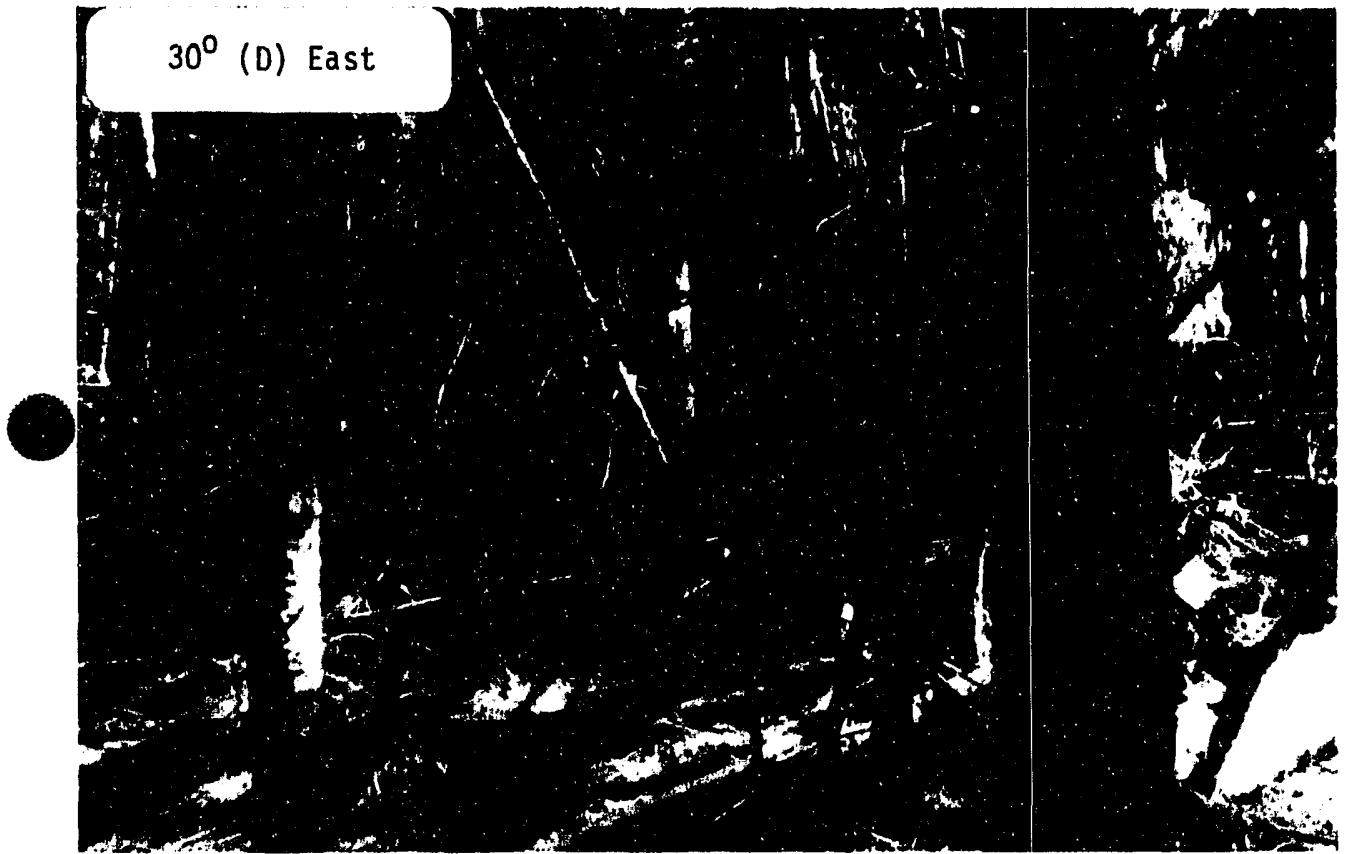

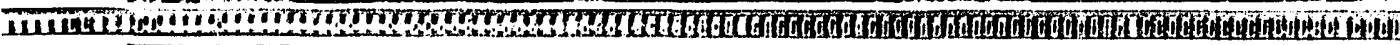

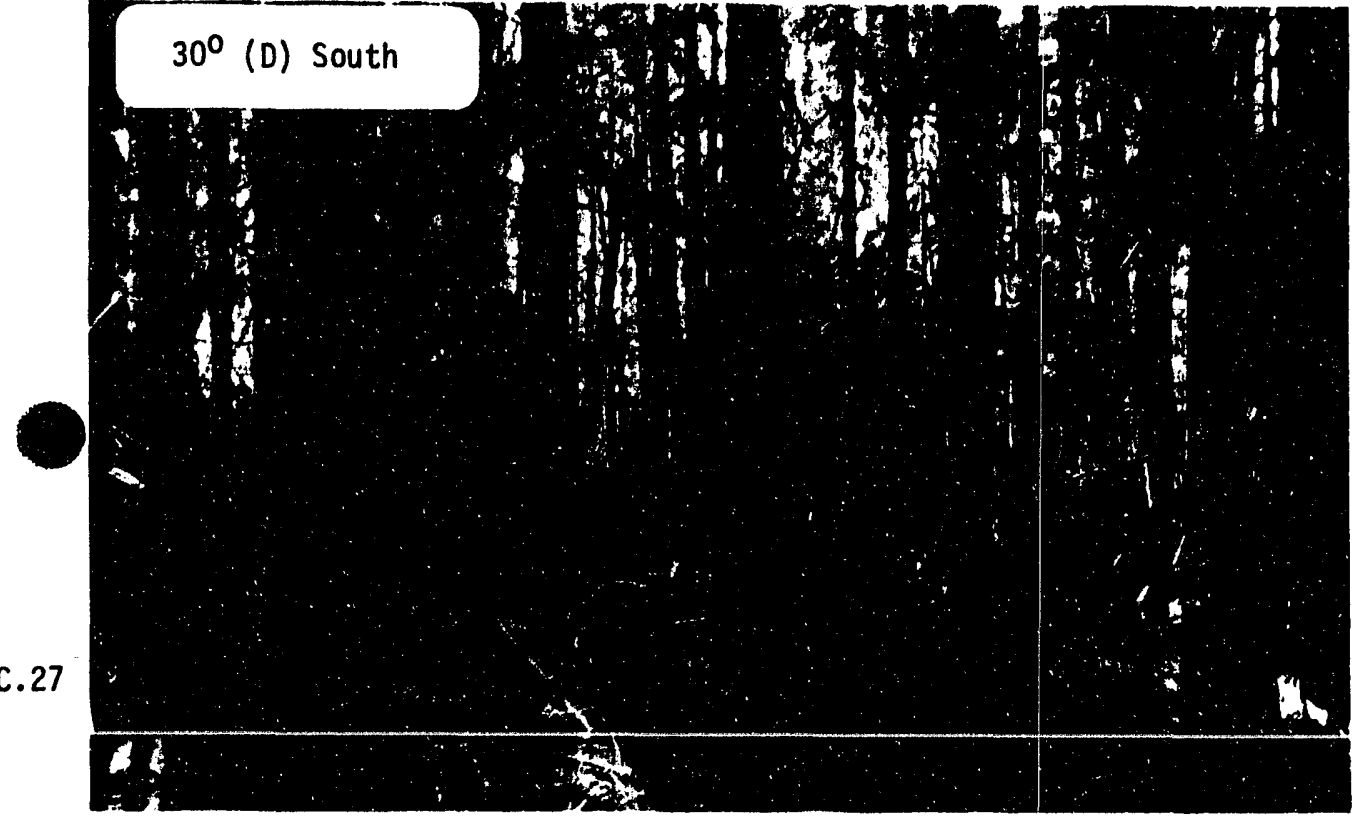




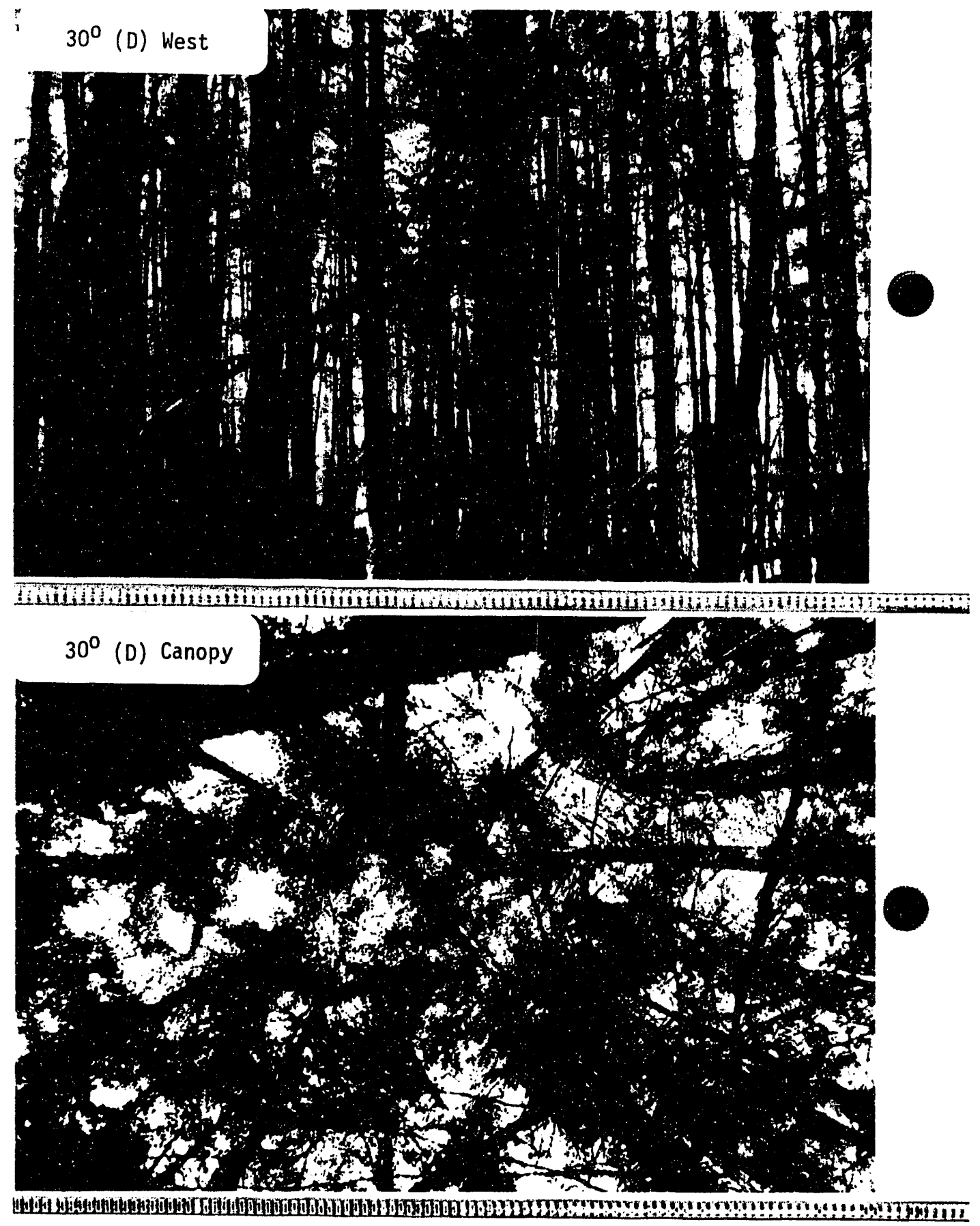

C. 28 


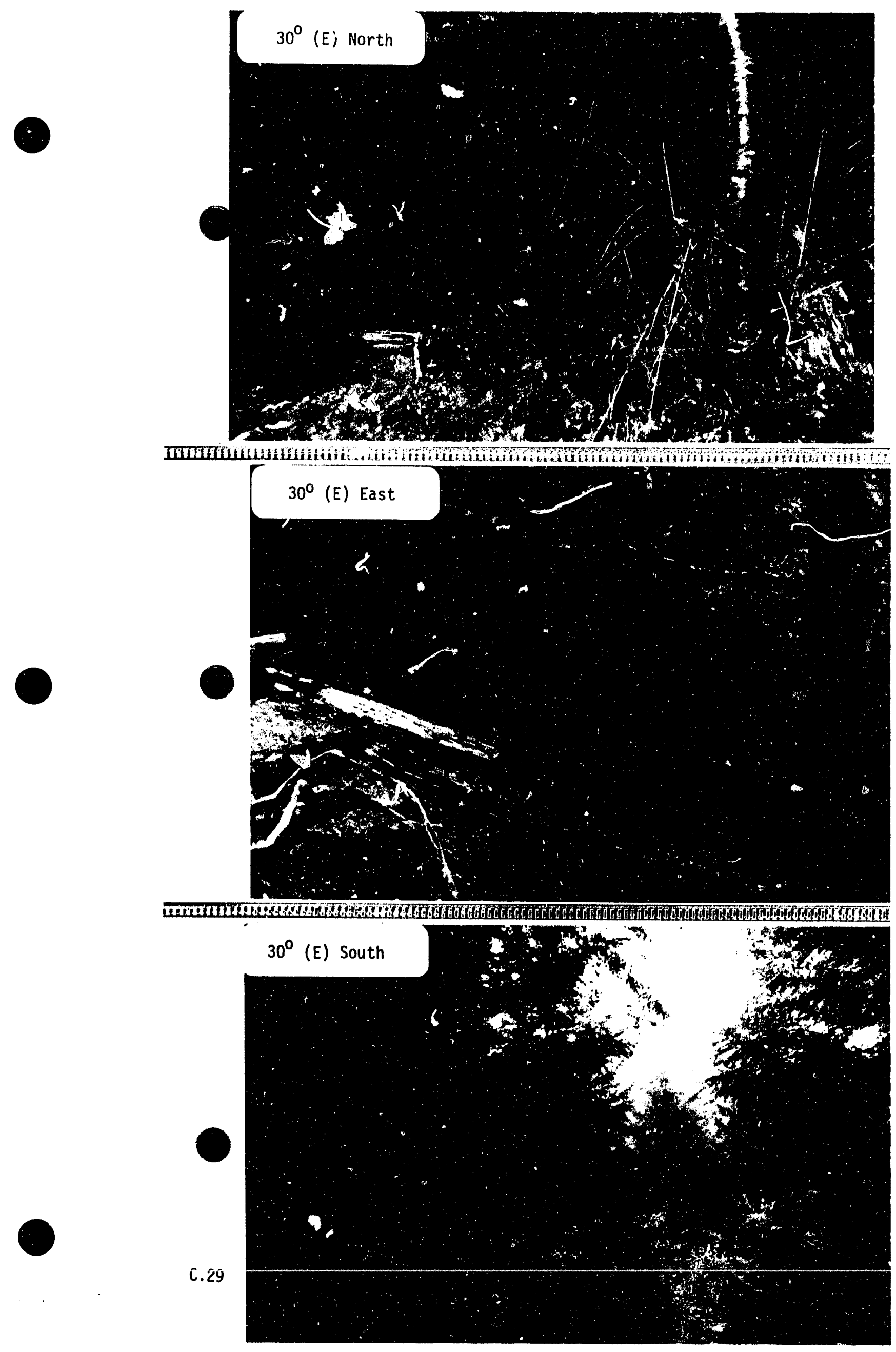




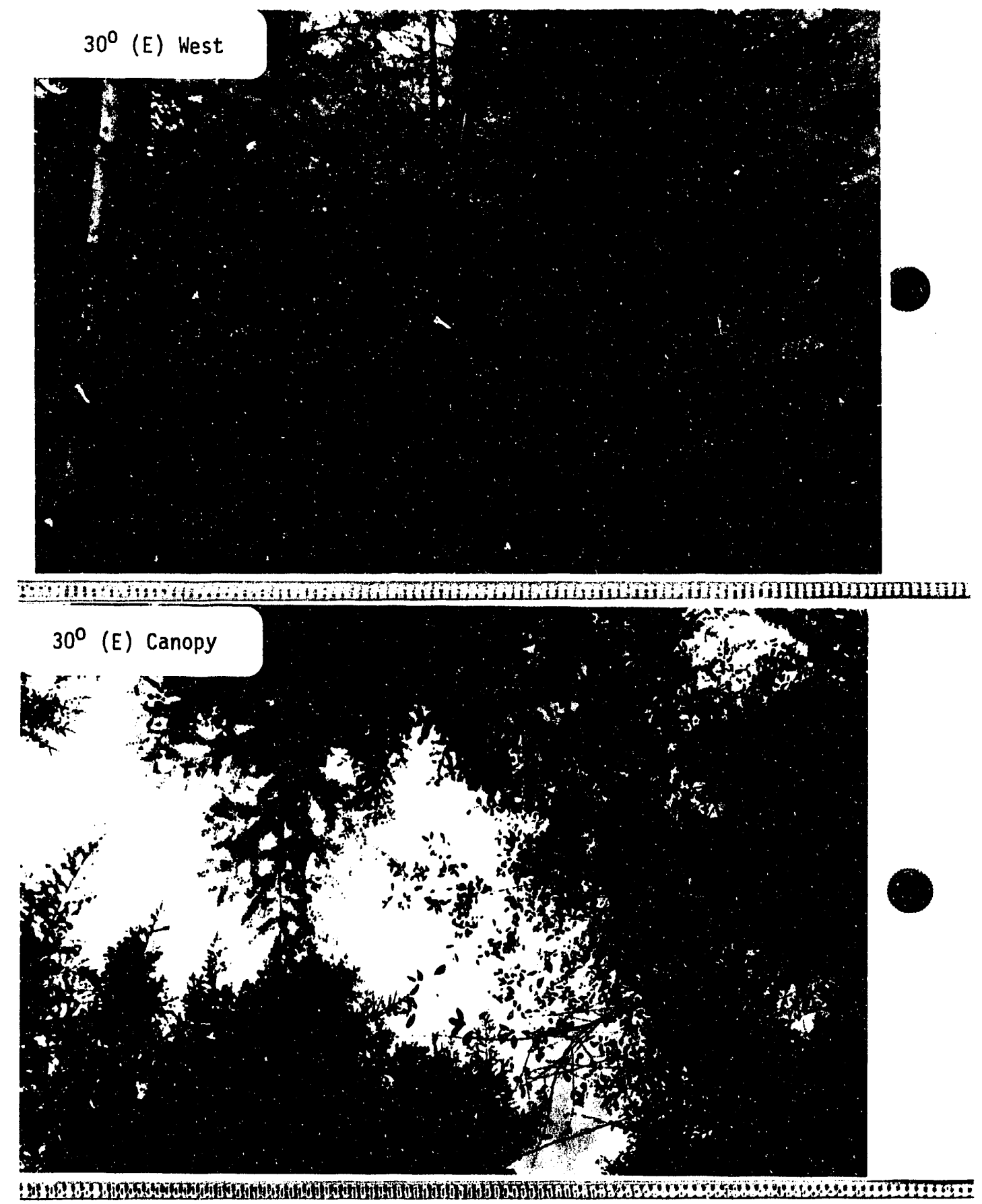

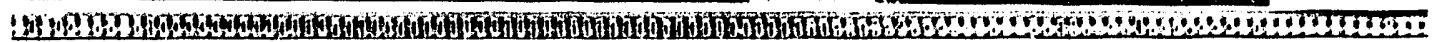




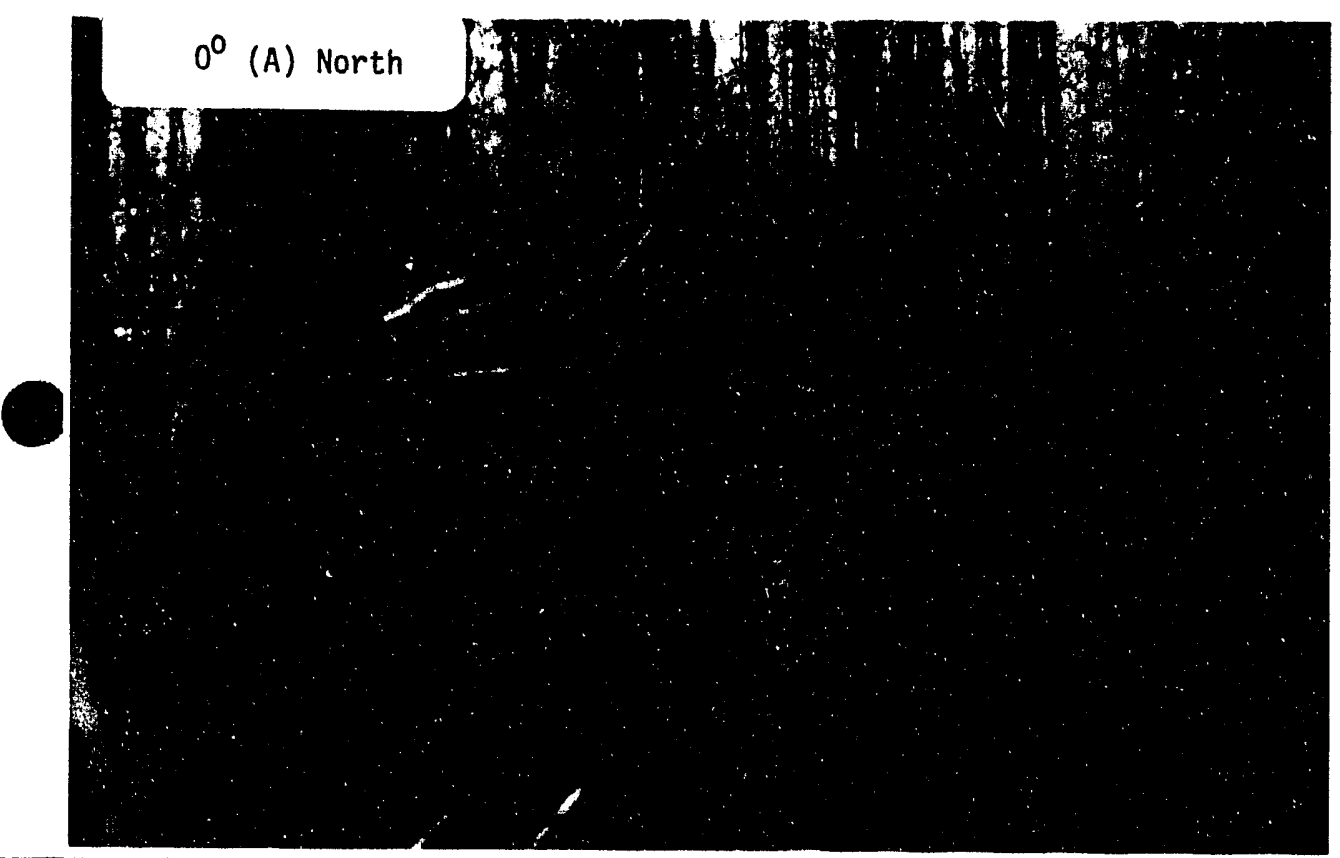

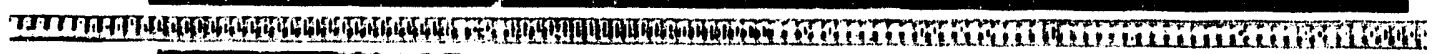

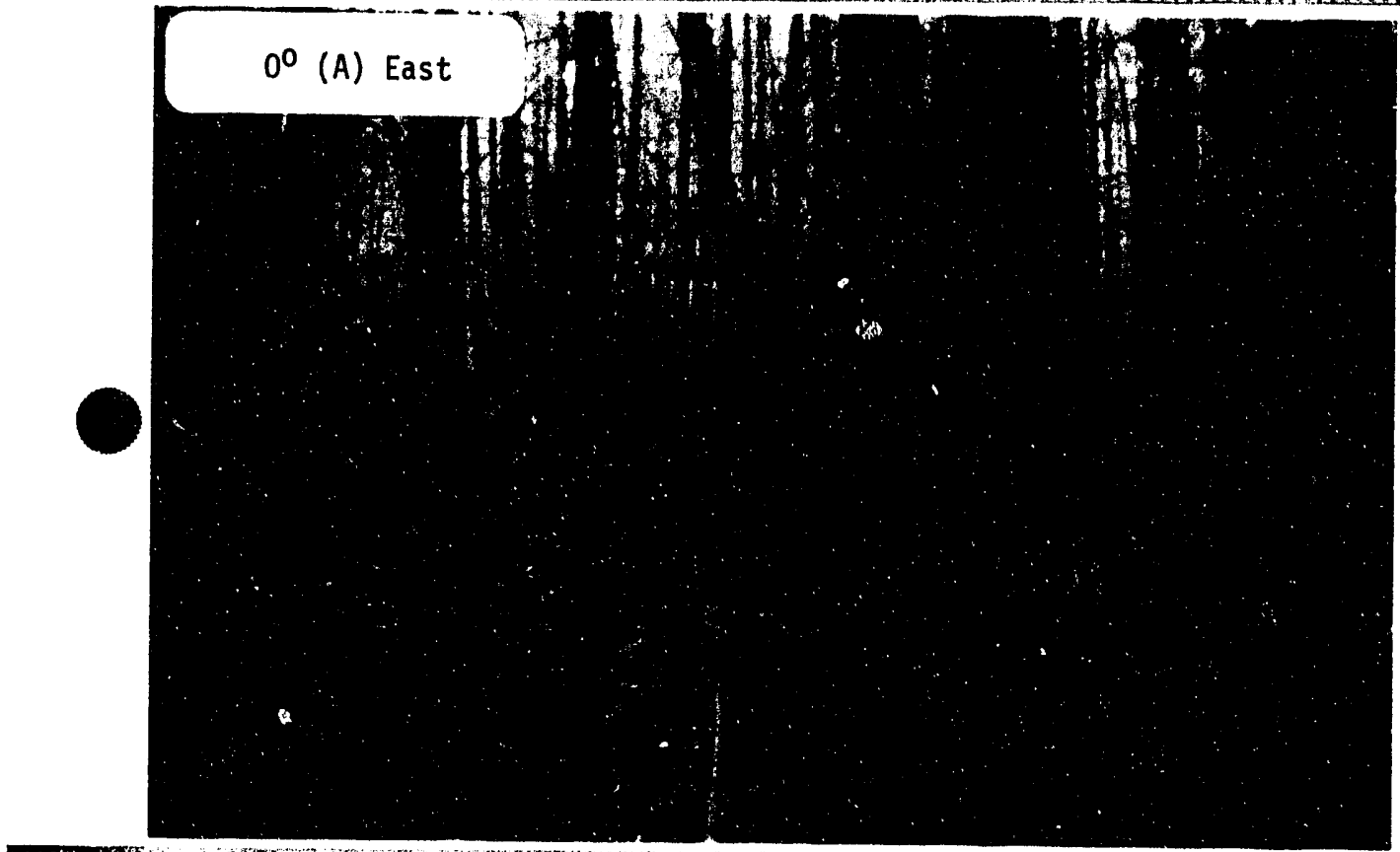

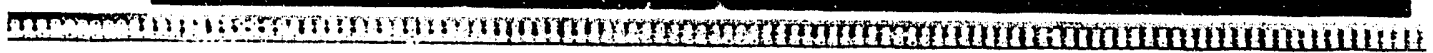

$$
0^{\circ} \text { (A) South }
$$




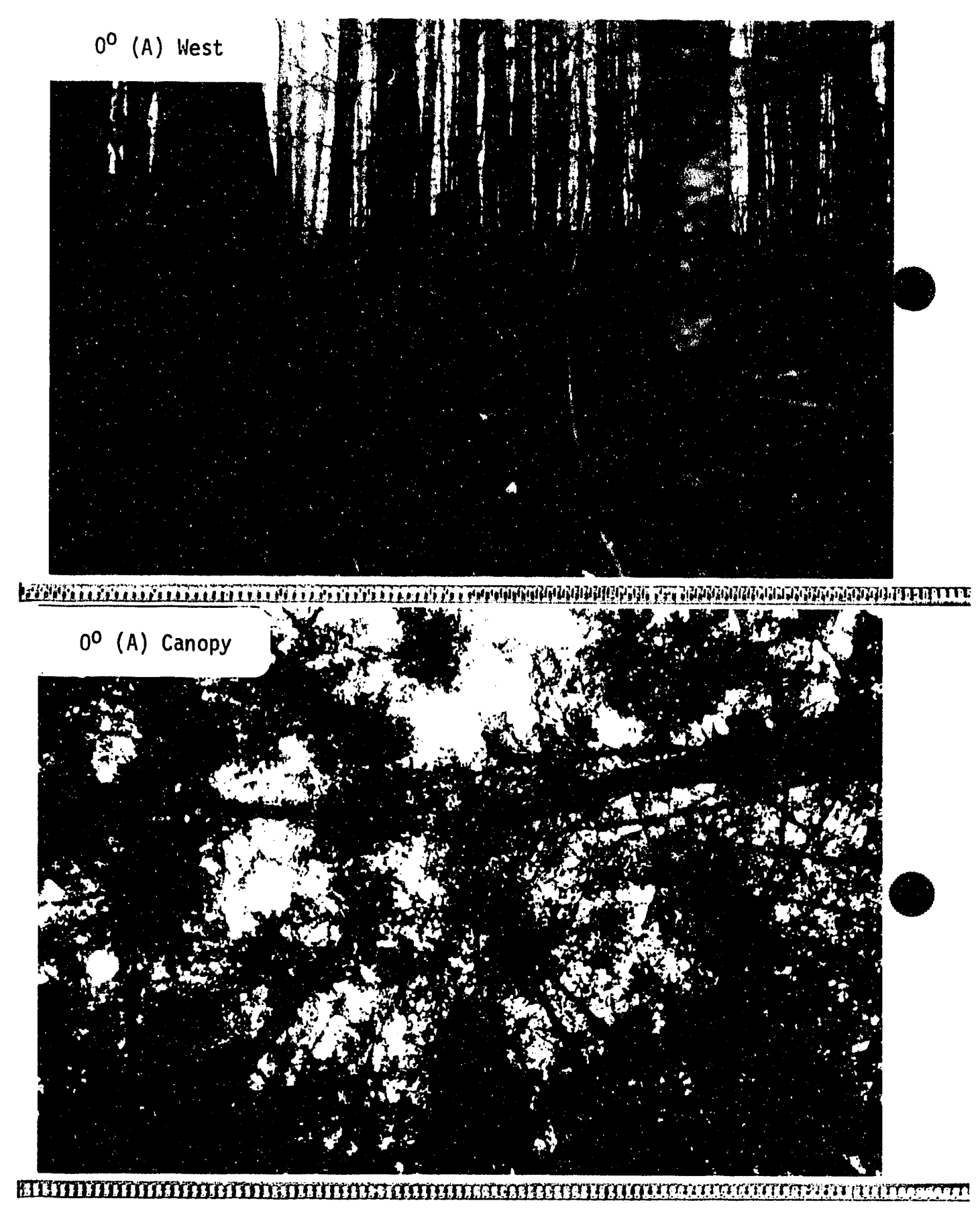

C. 32 


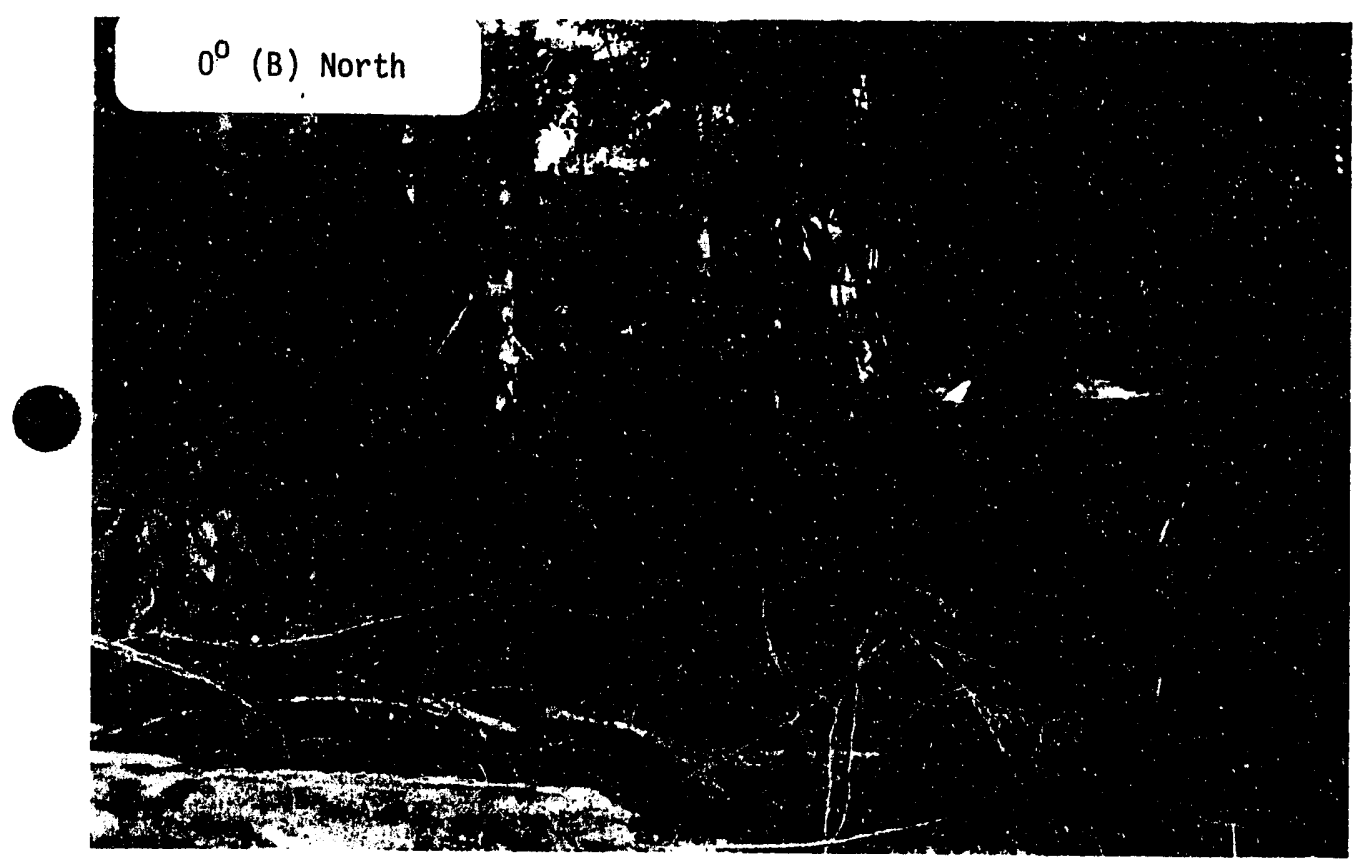

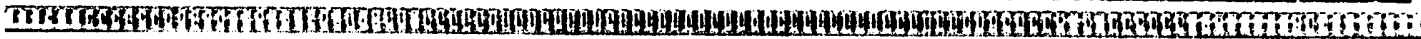

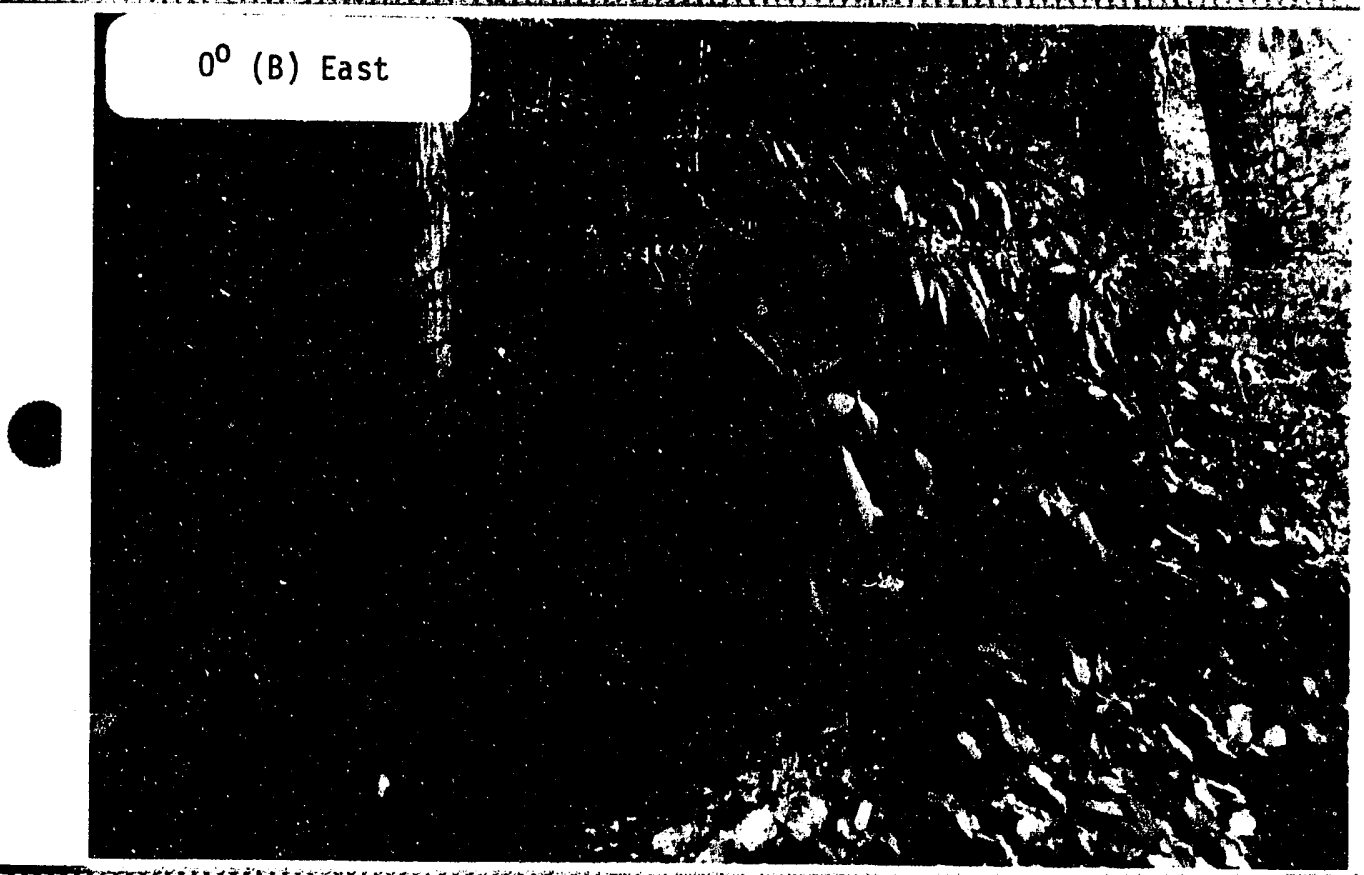

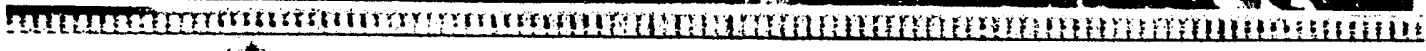

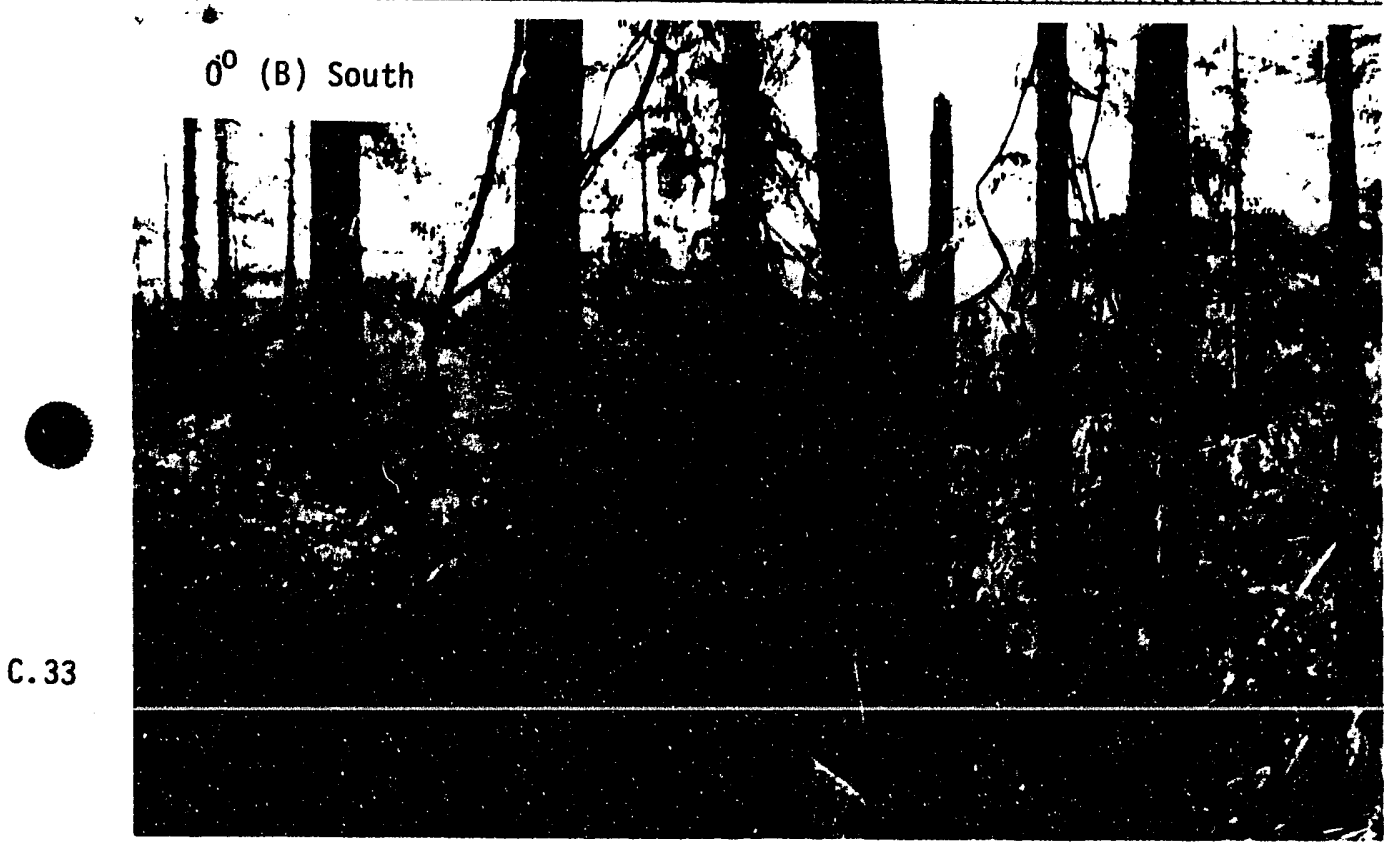




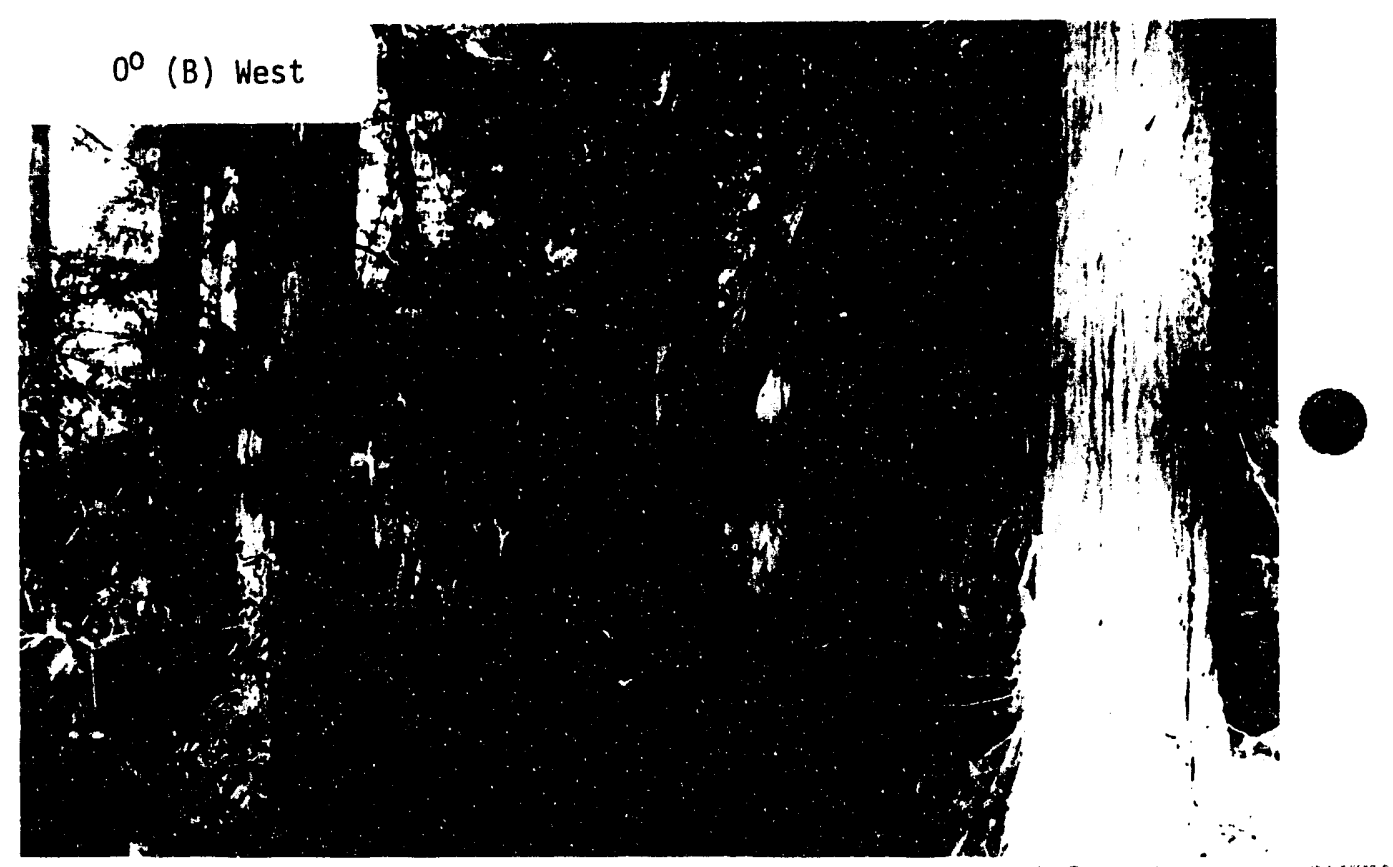

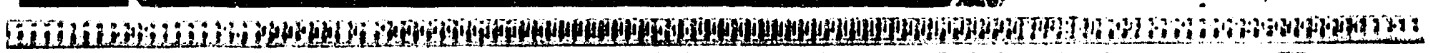

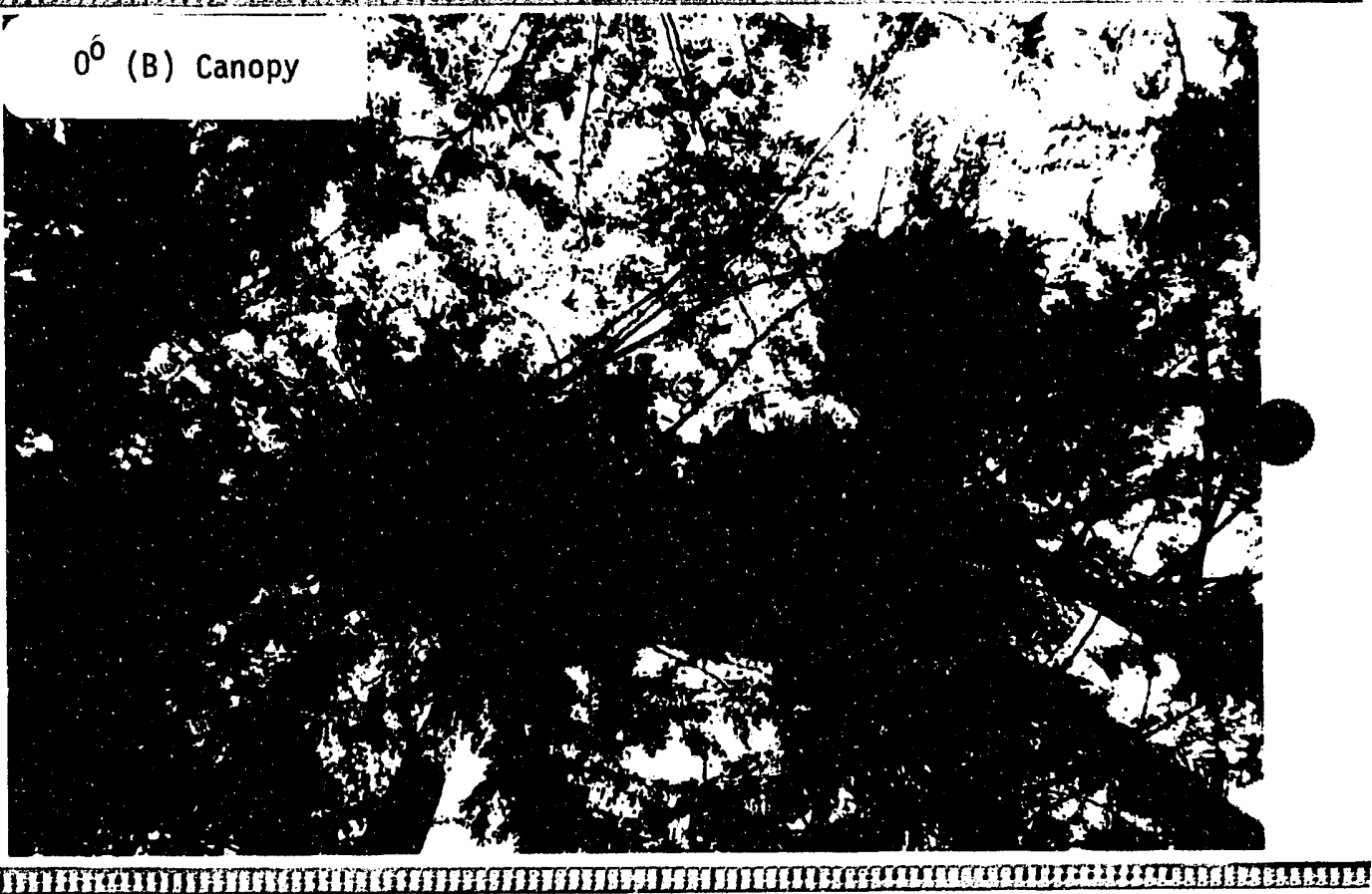

C. 34 


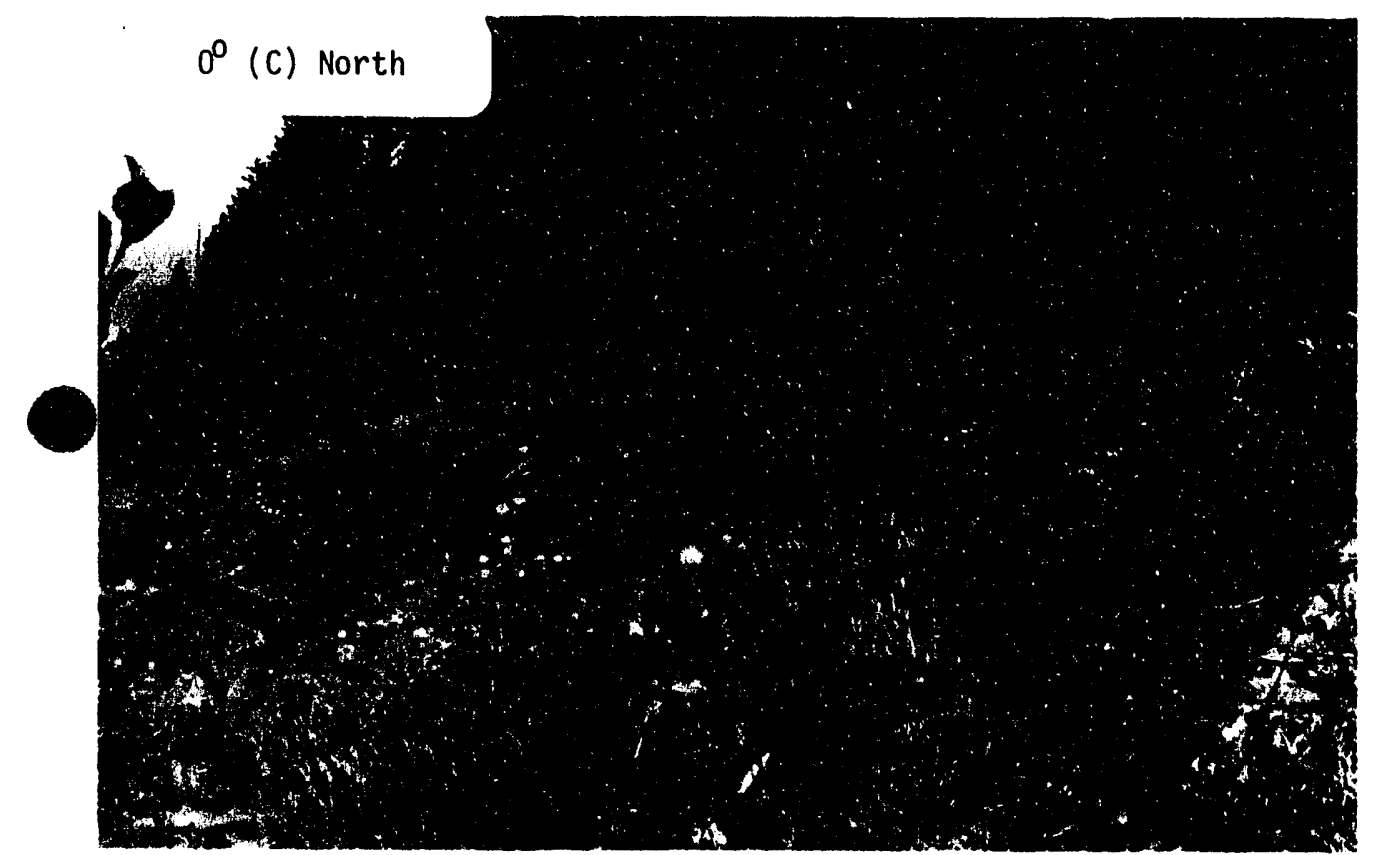

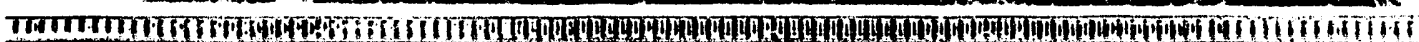

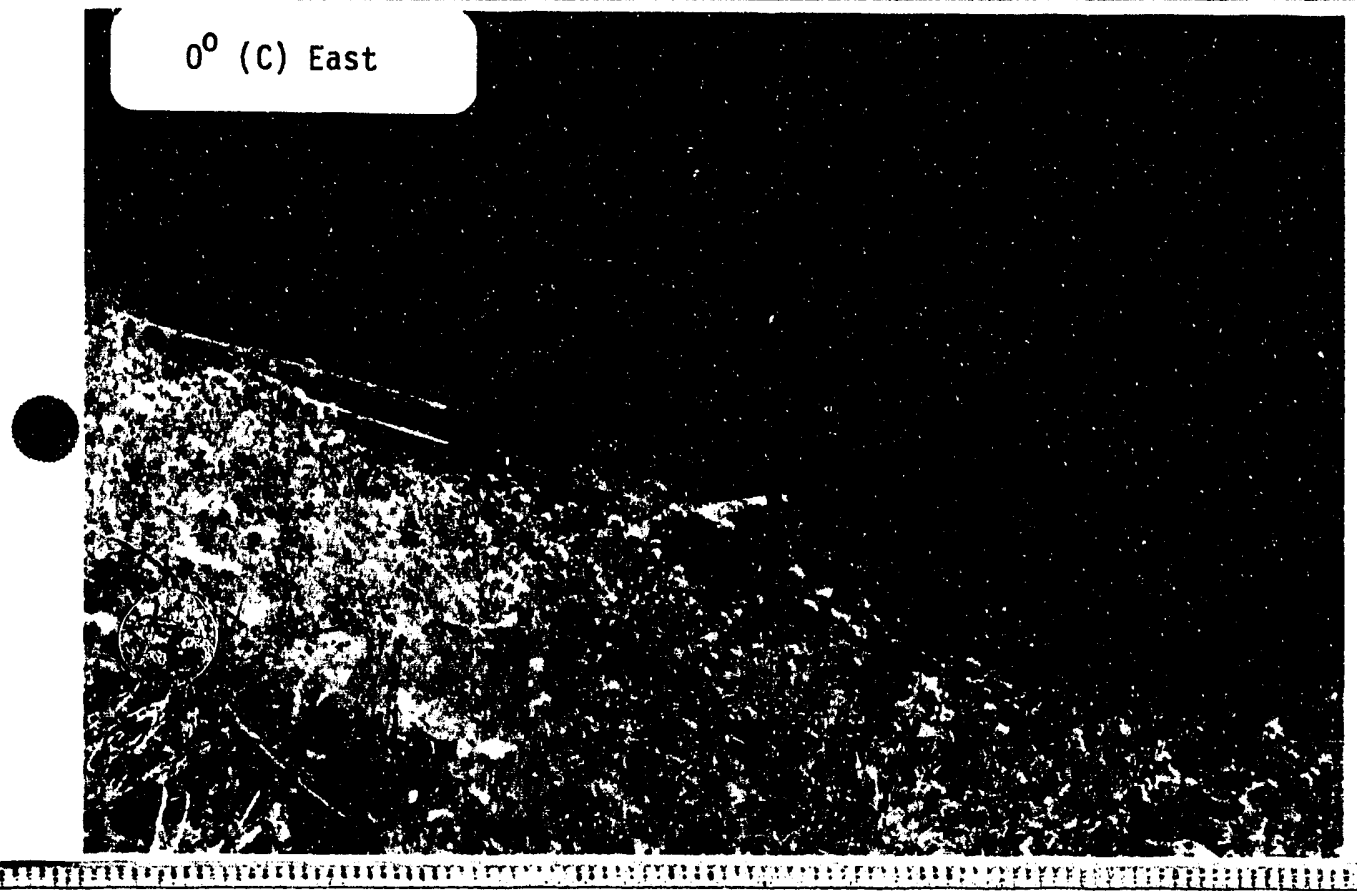

$0^{0}$ (C) South

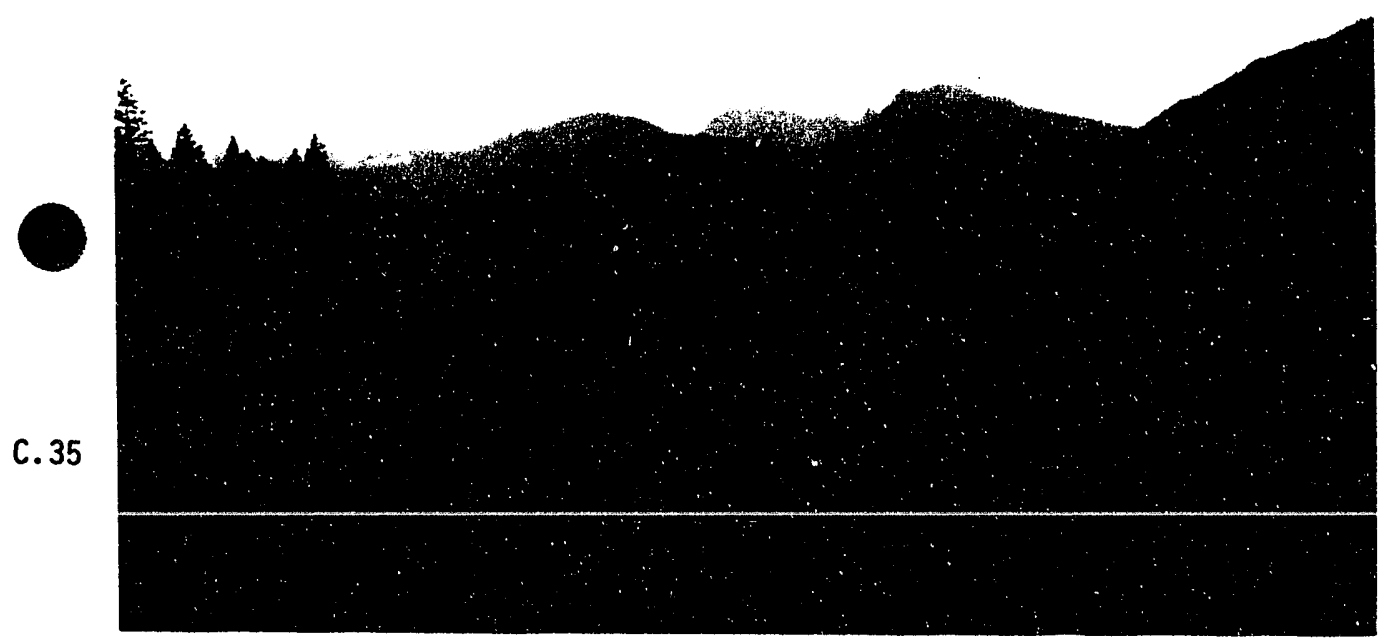


$0^{0}(\mathrm{C})$ West

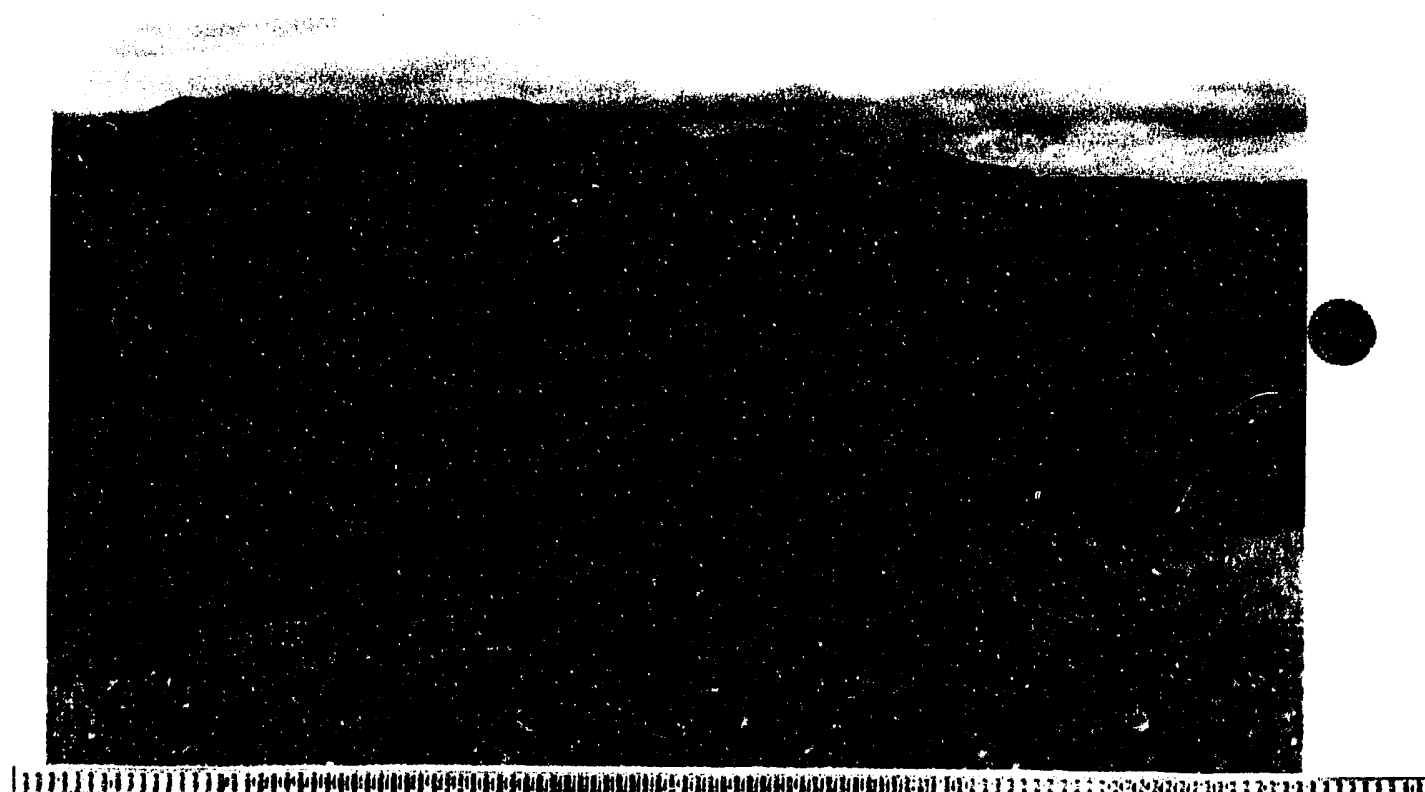

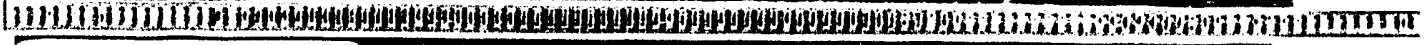

$$
0^{\circ} \text { (C) Canopy }
$$
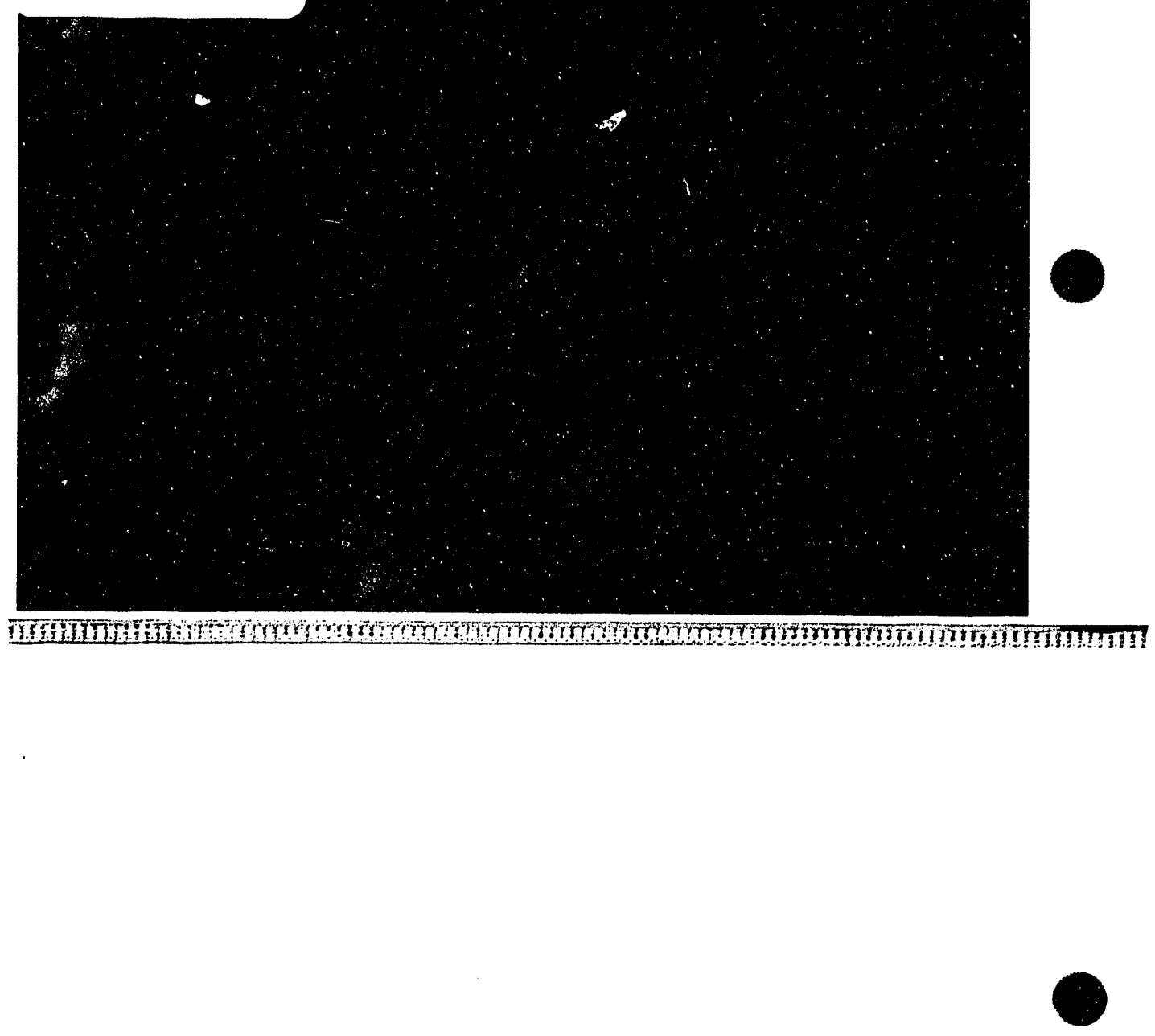

C. 36 


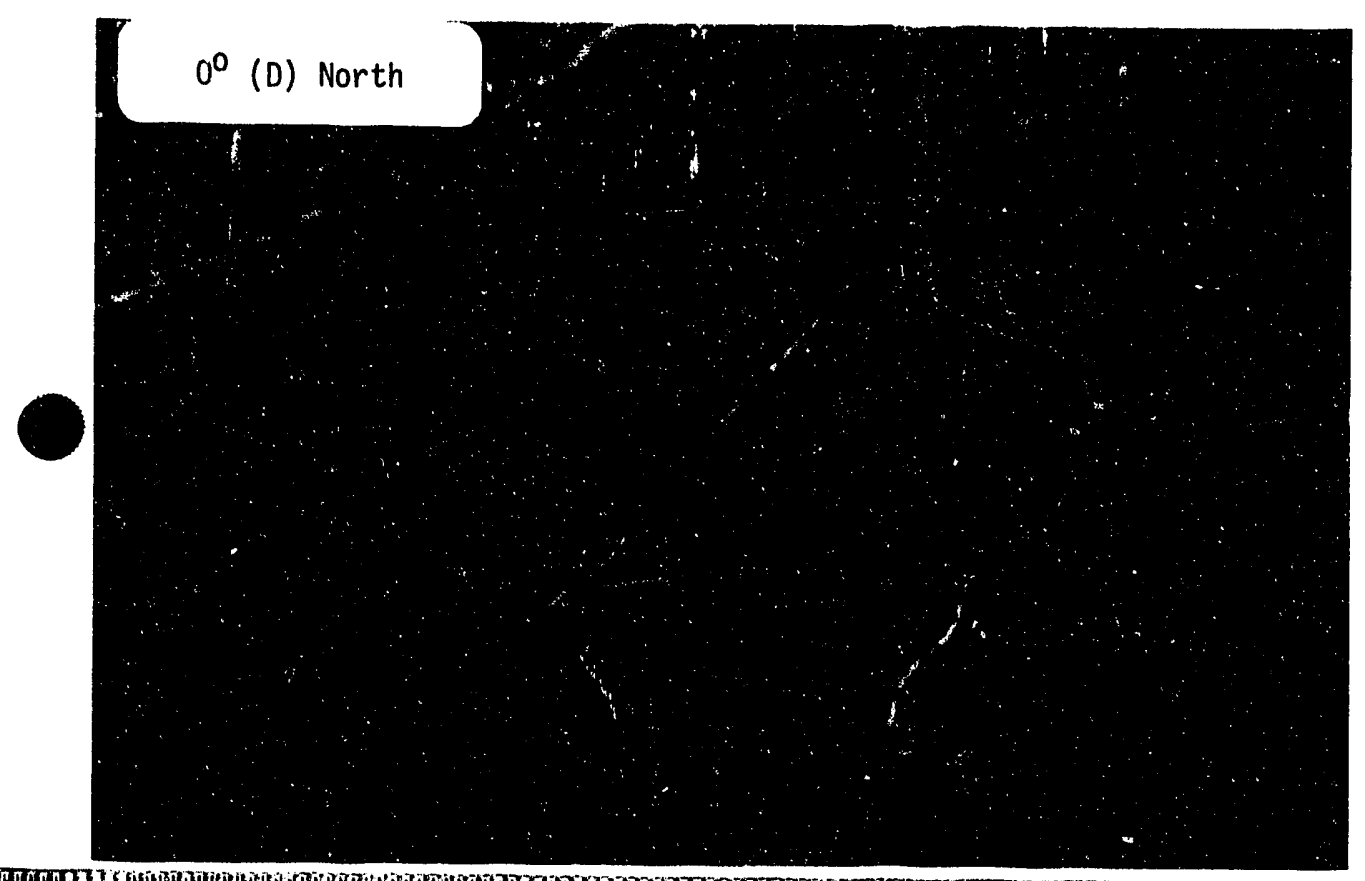

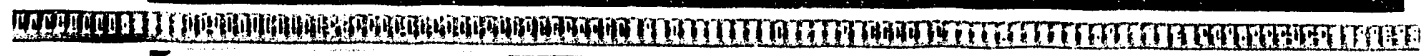

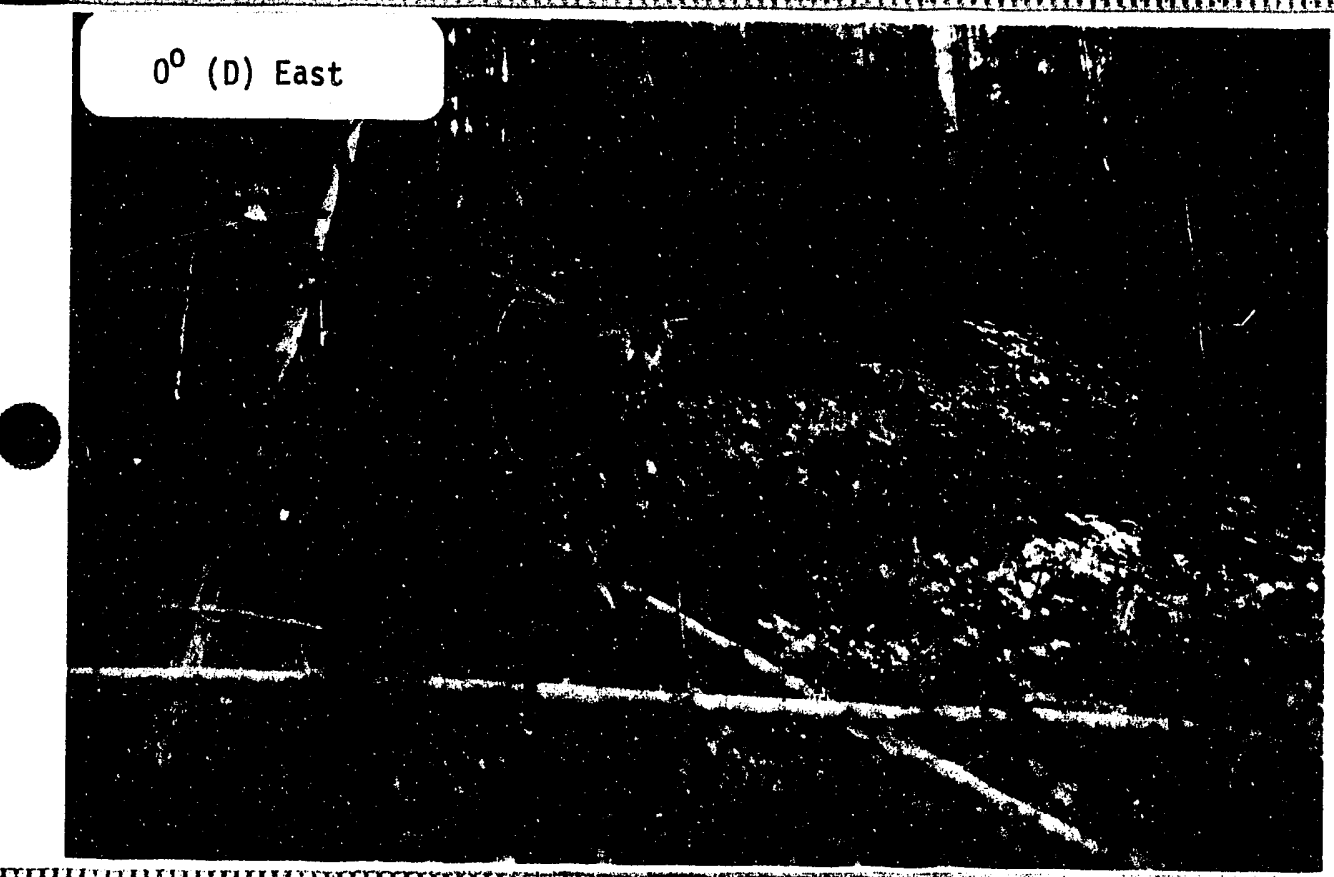

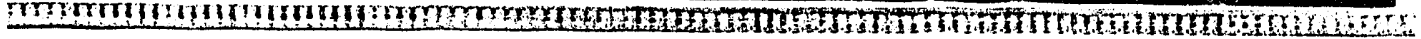

$0^{\circ}$ (D) South

C. 37

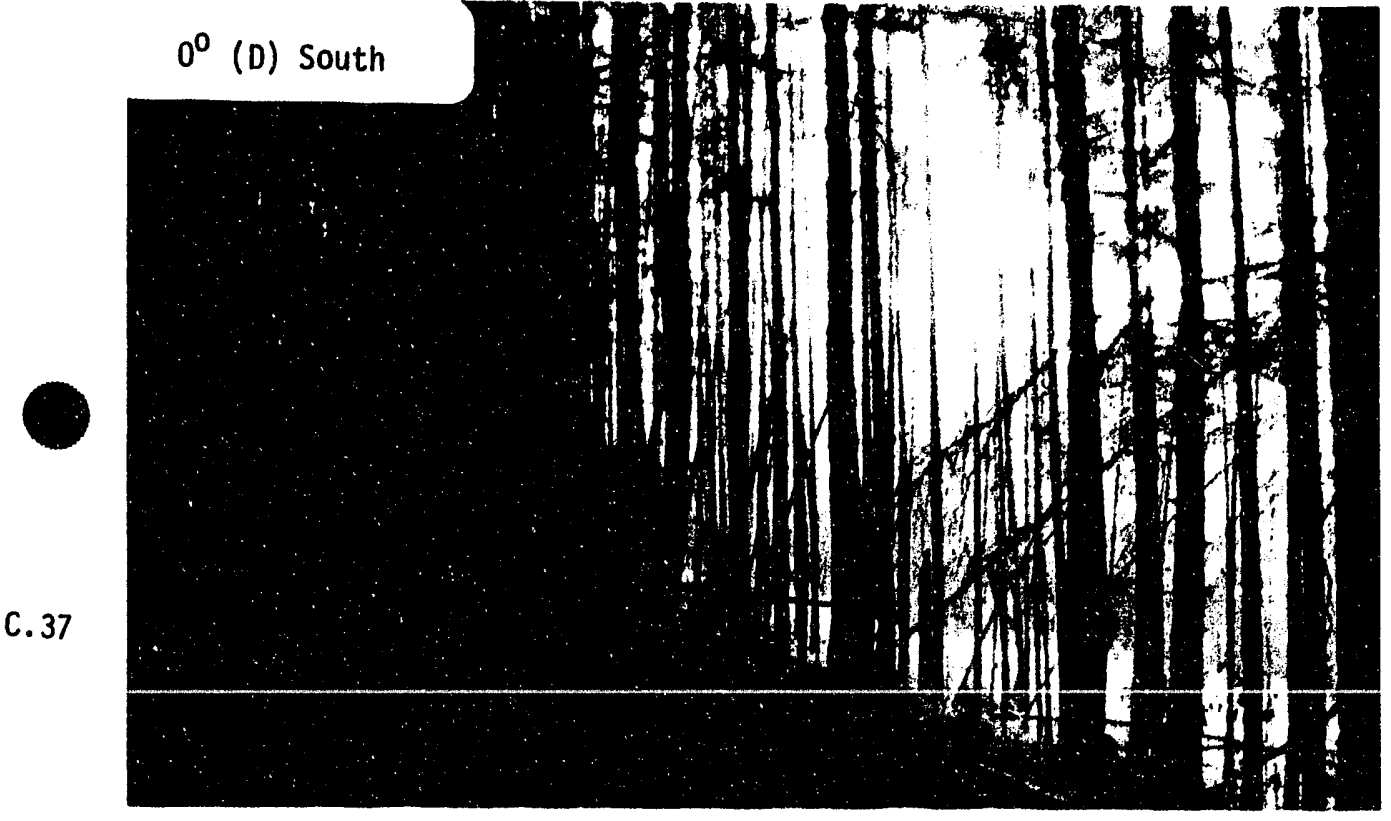




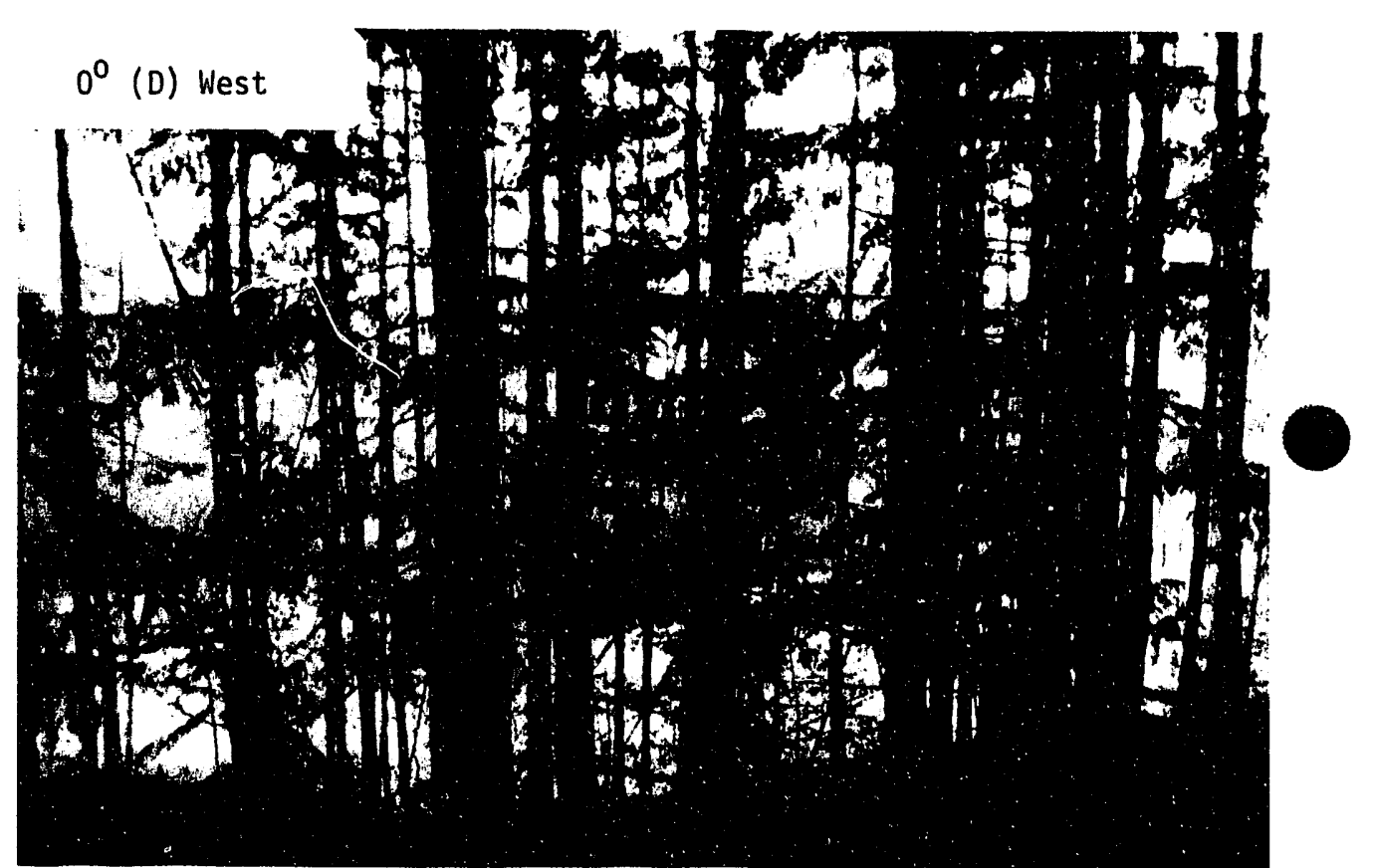

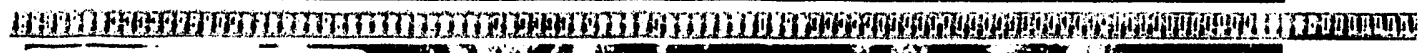

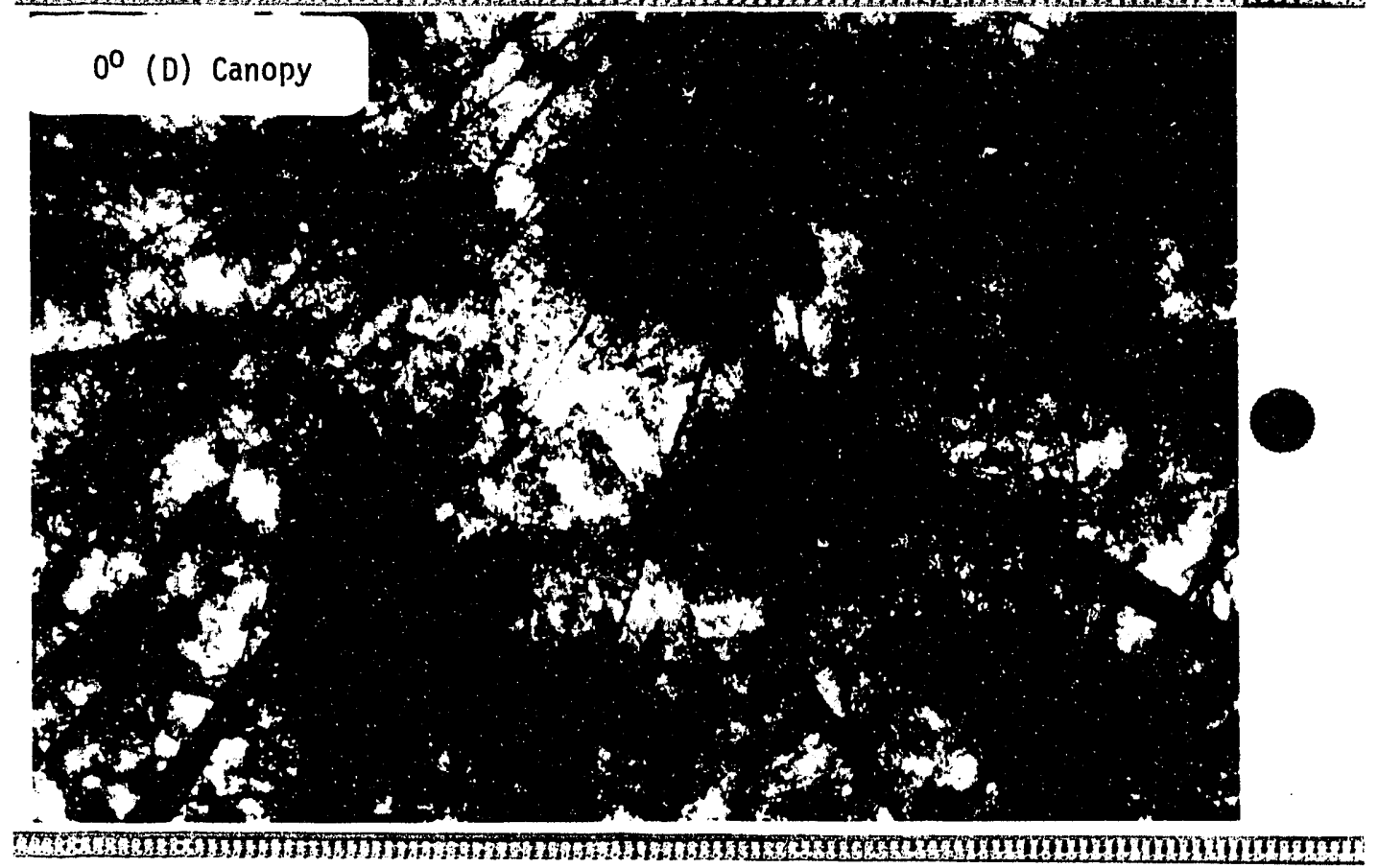

C. 38 


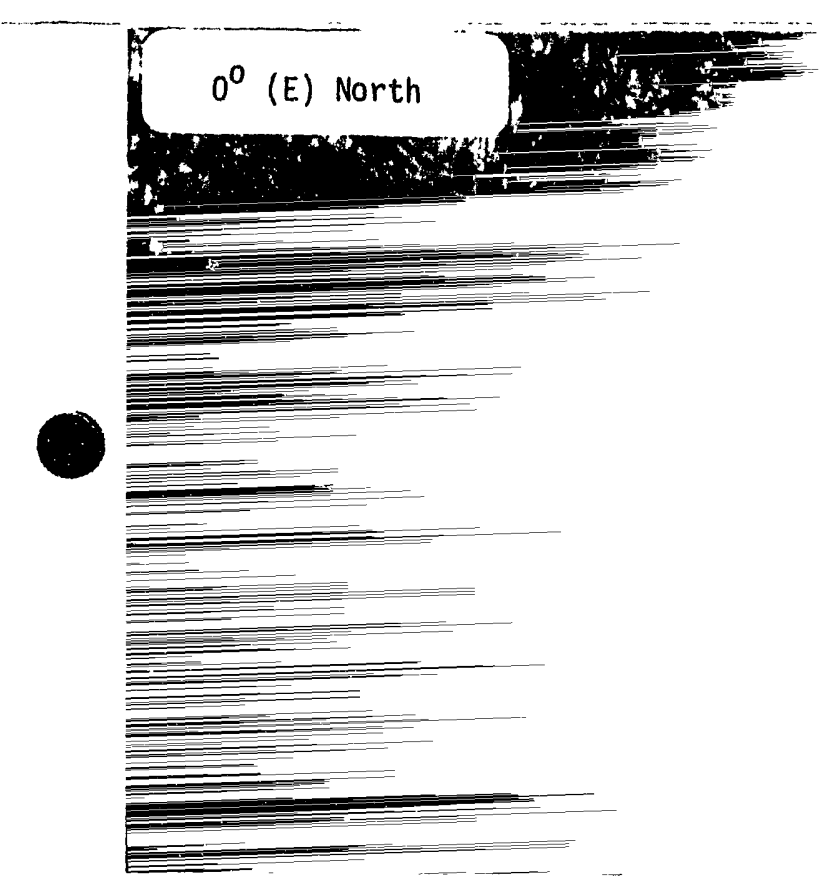

TEwiven

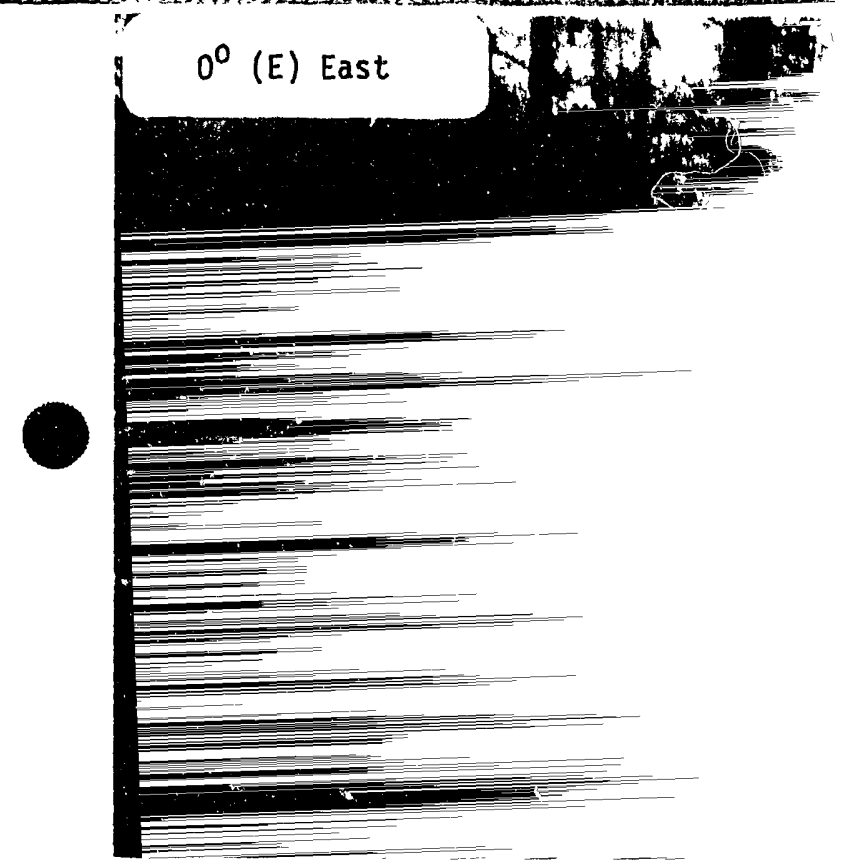

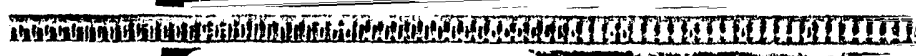

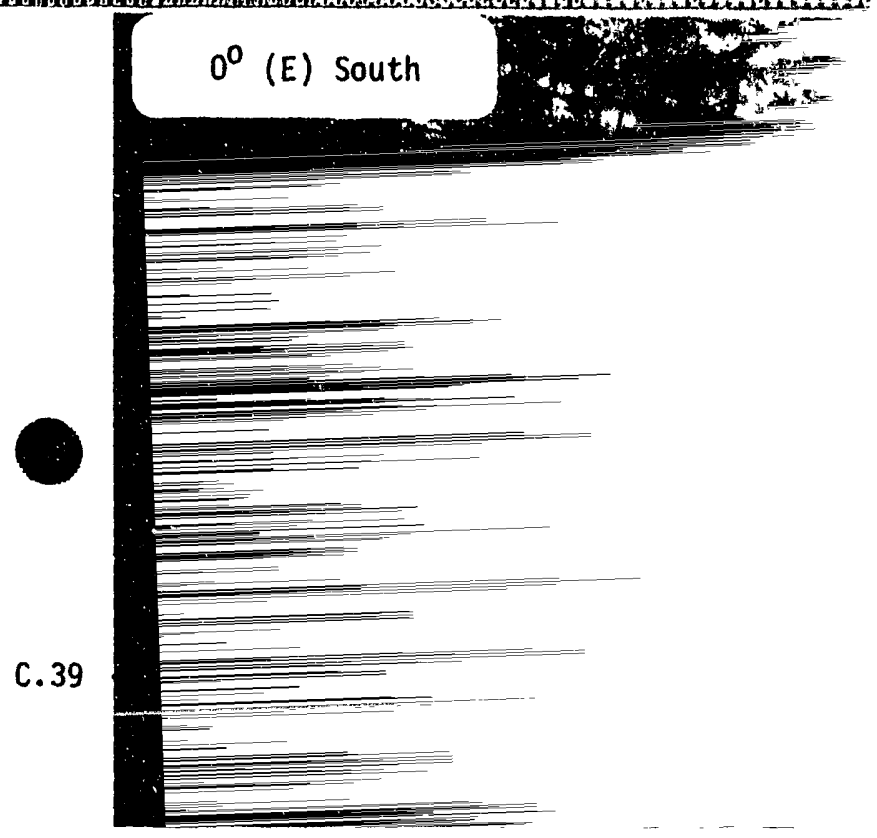




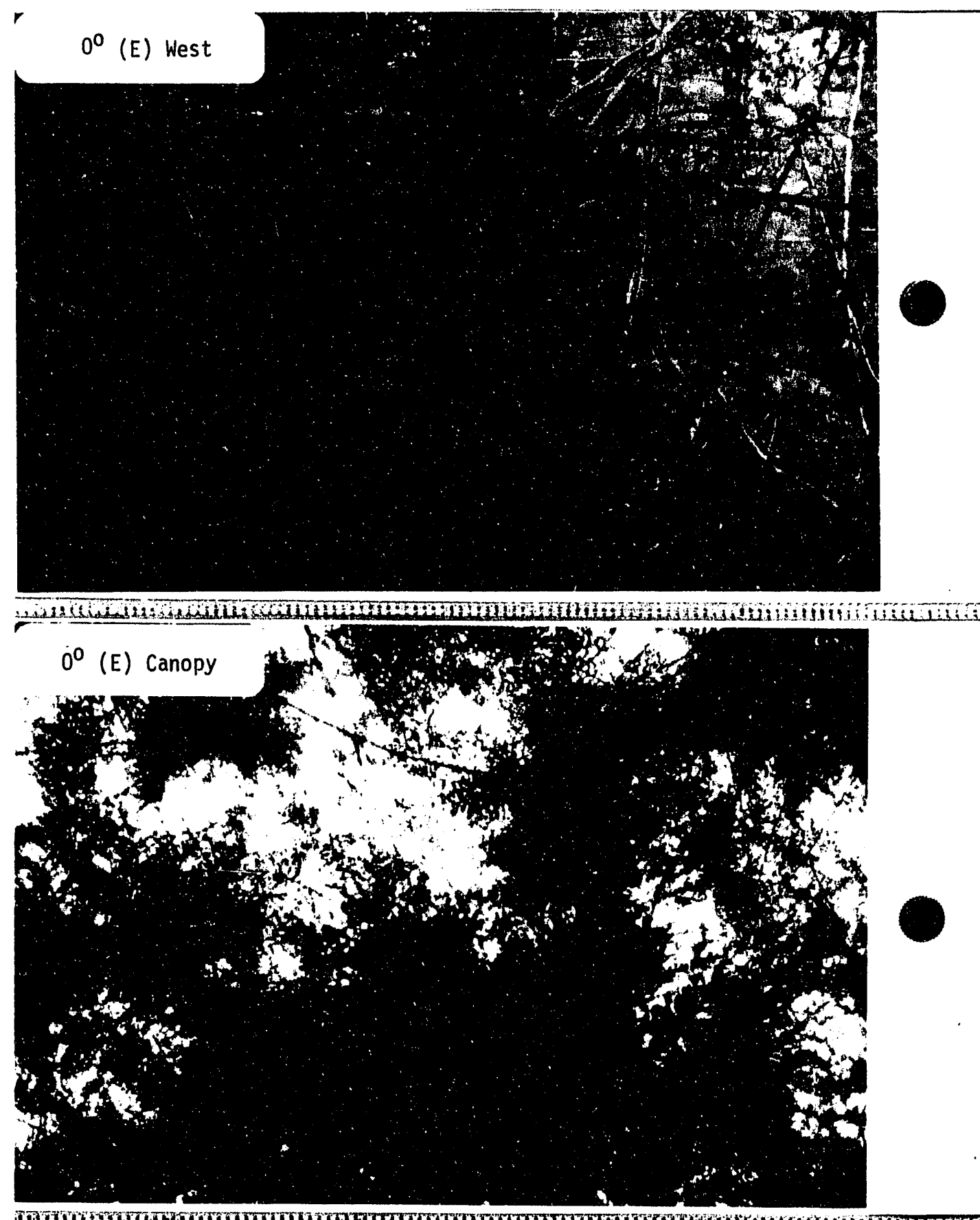

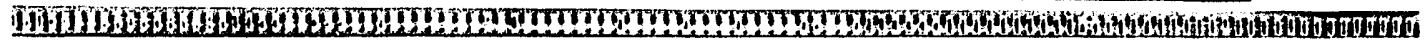




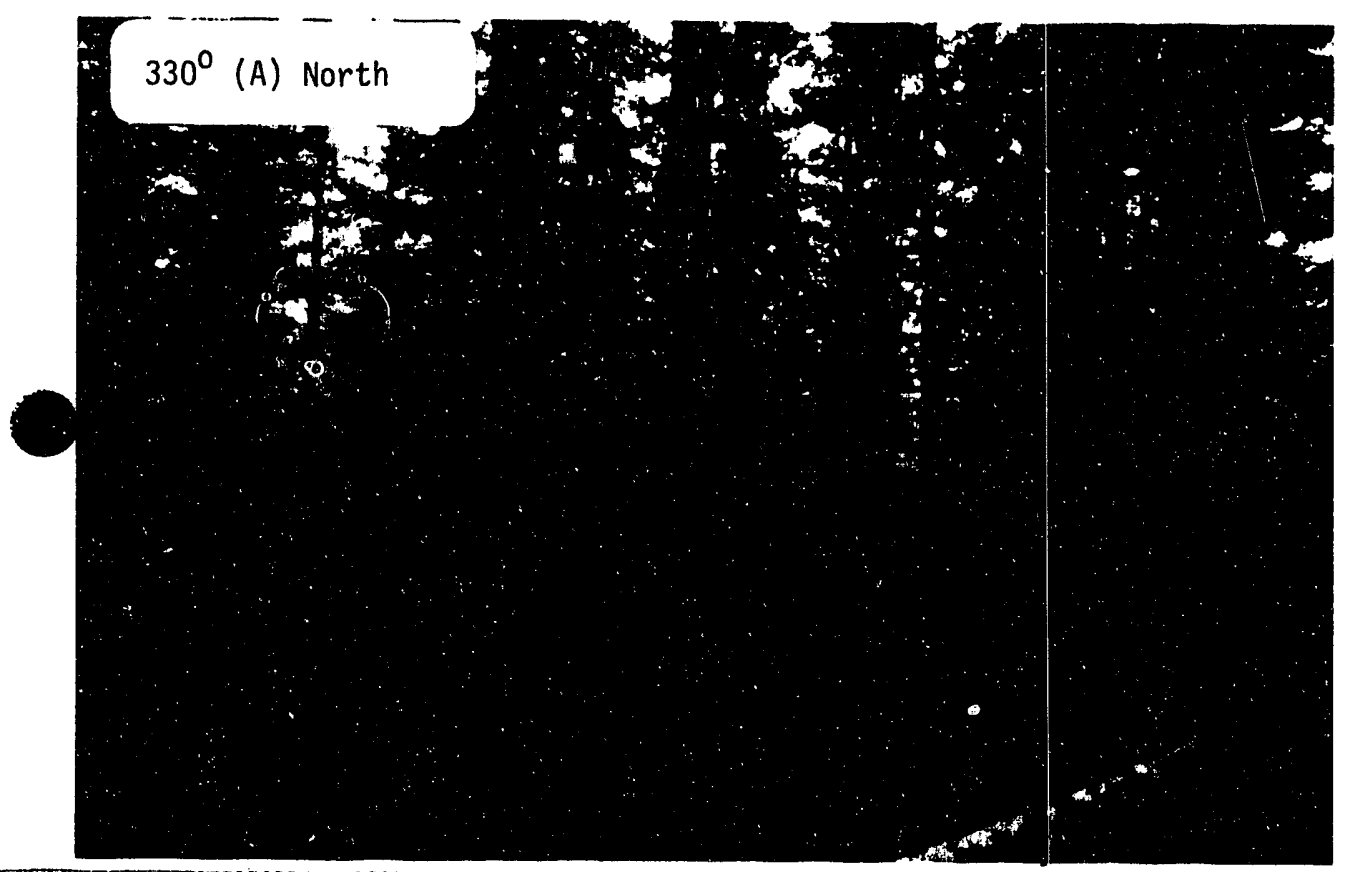

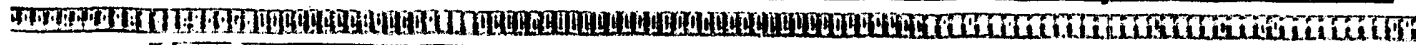

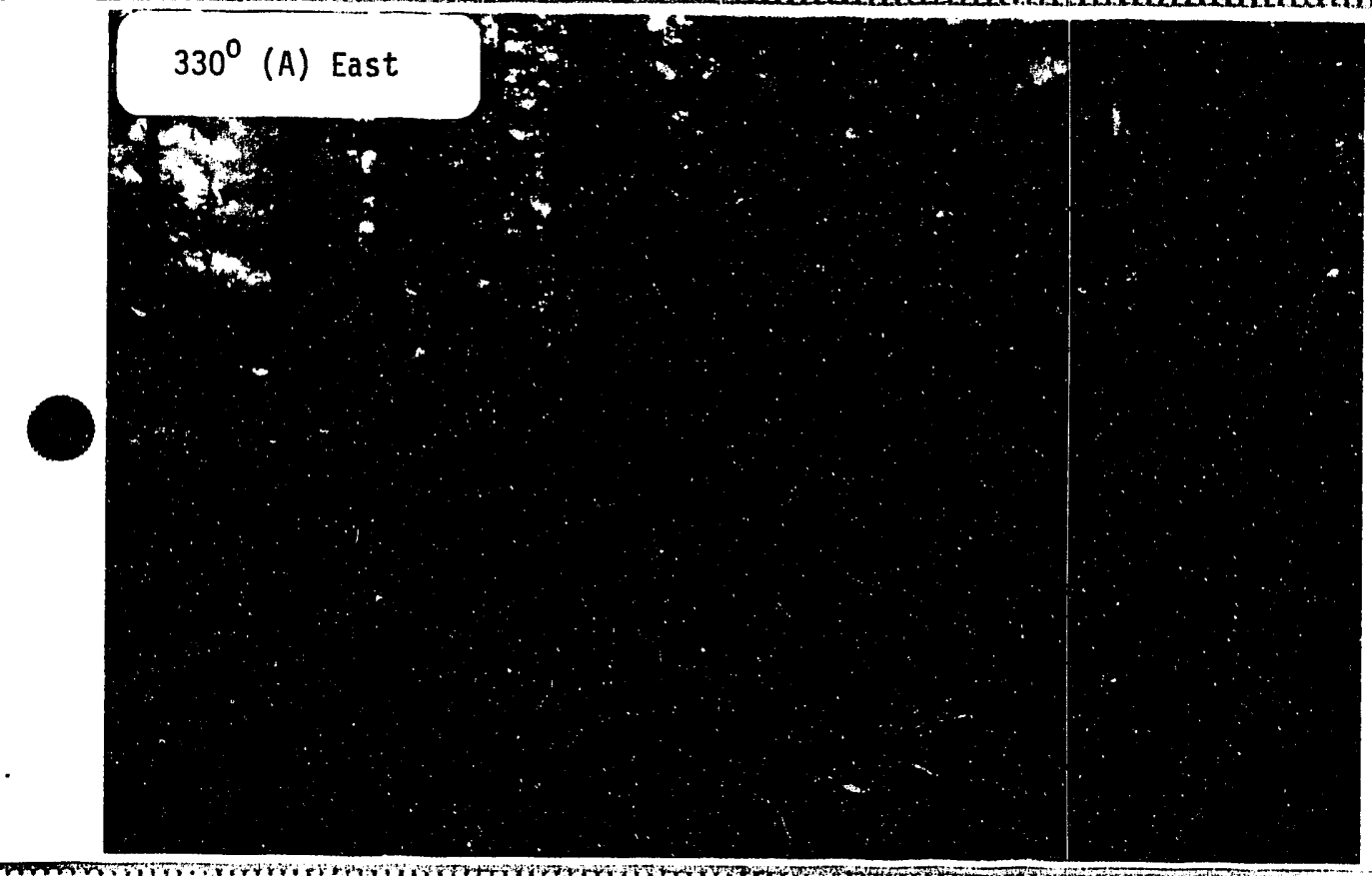

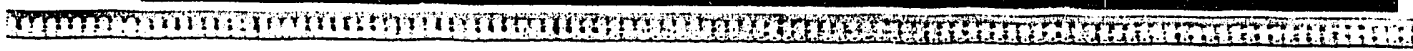

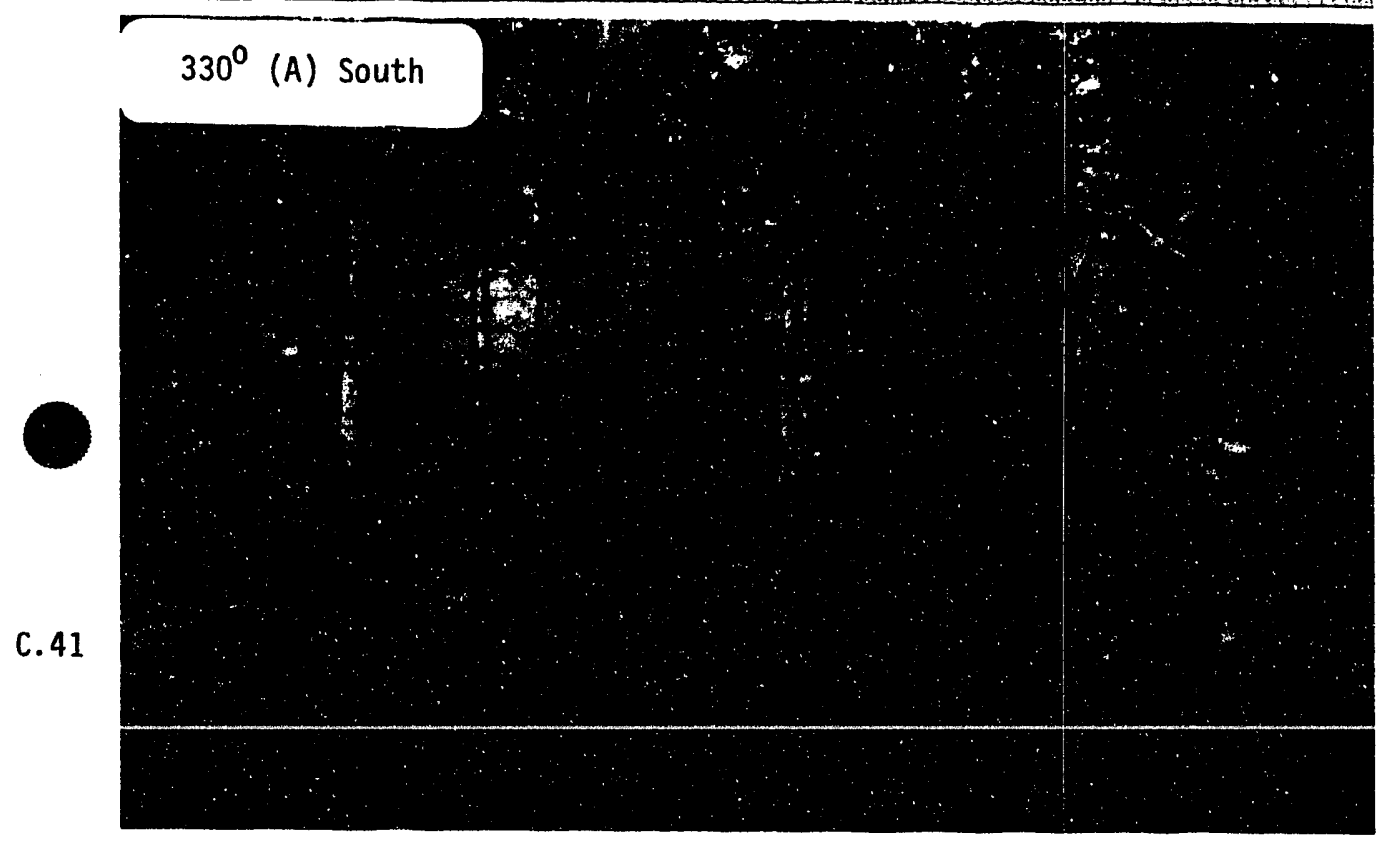




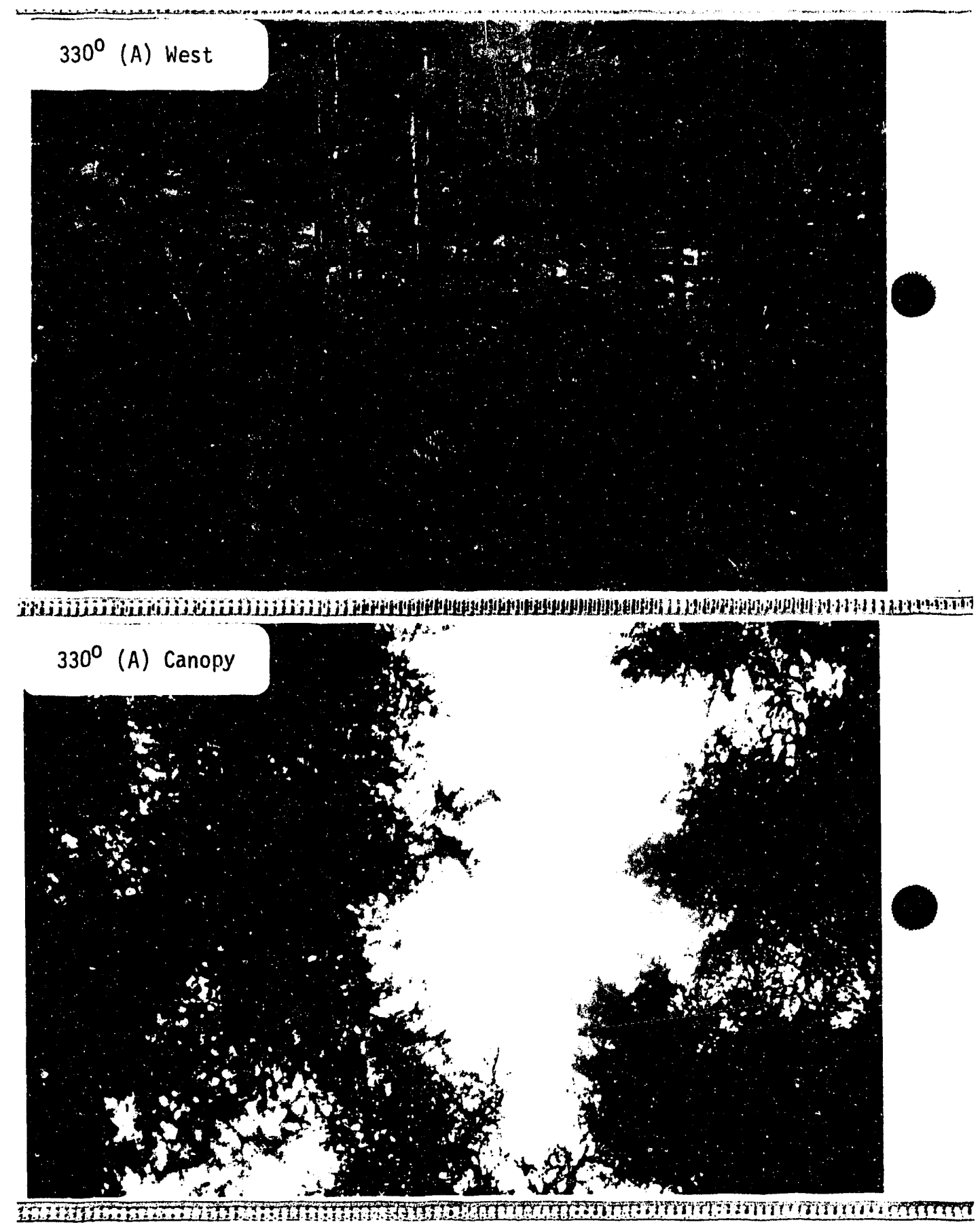

C. 42 


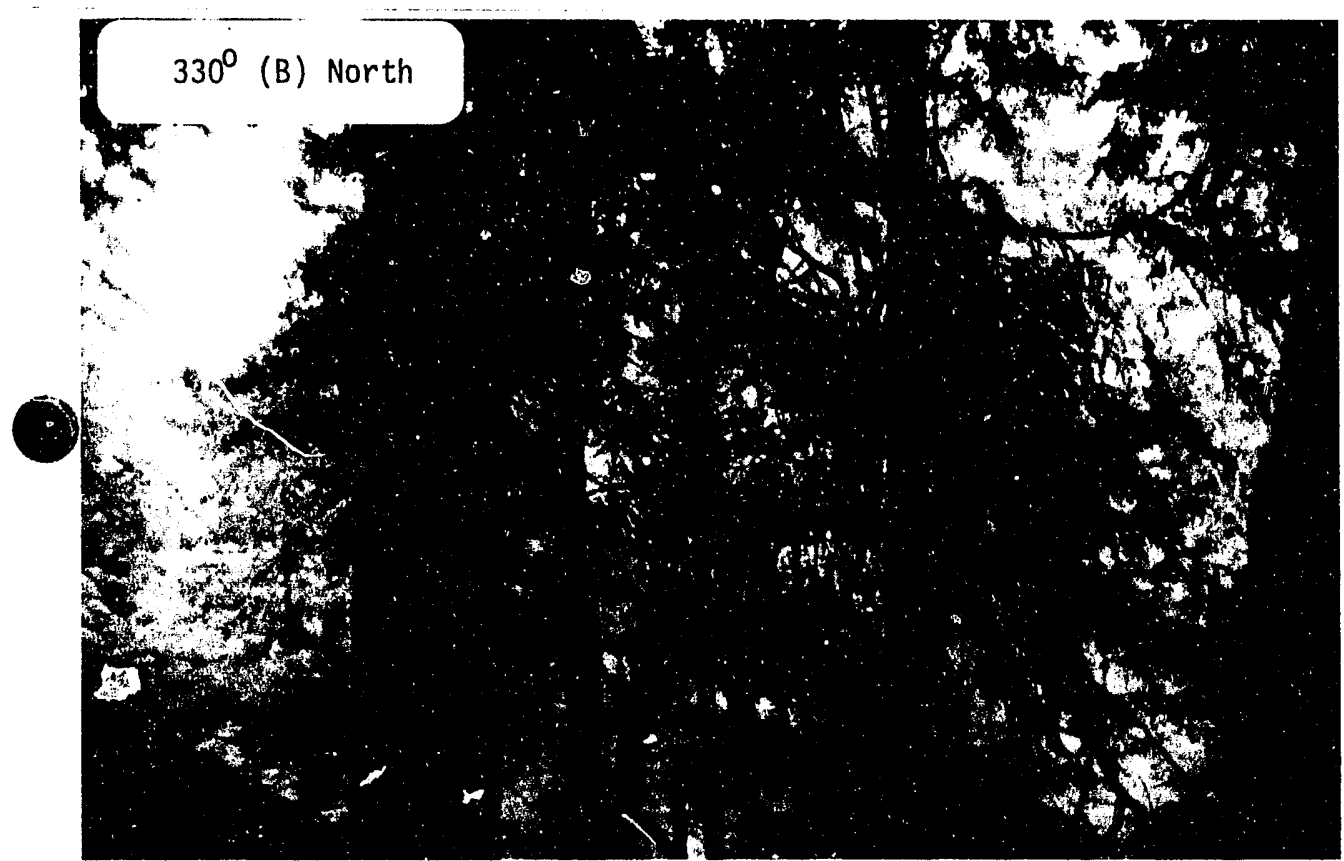

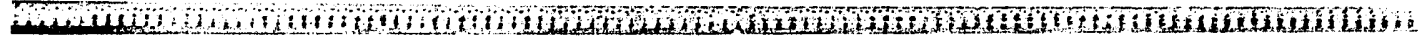

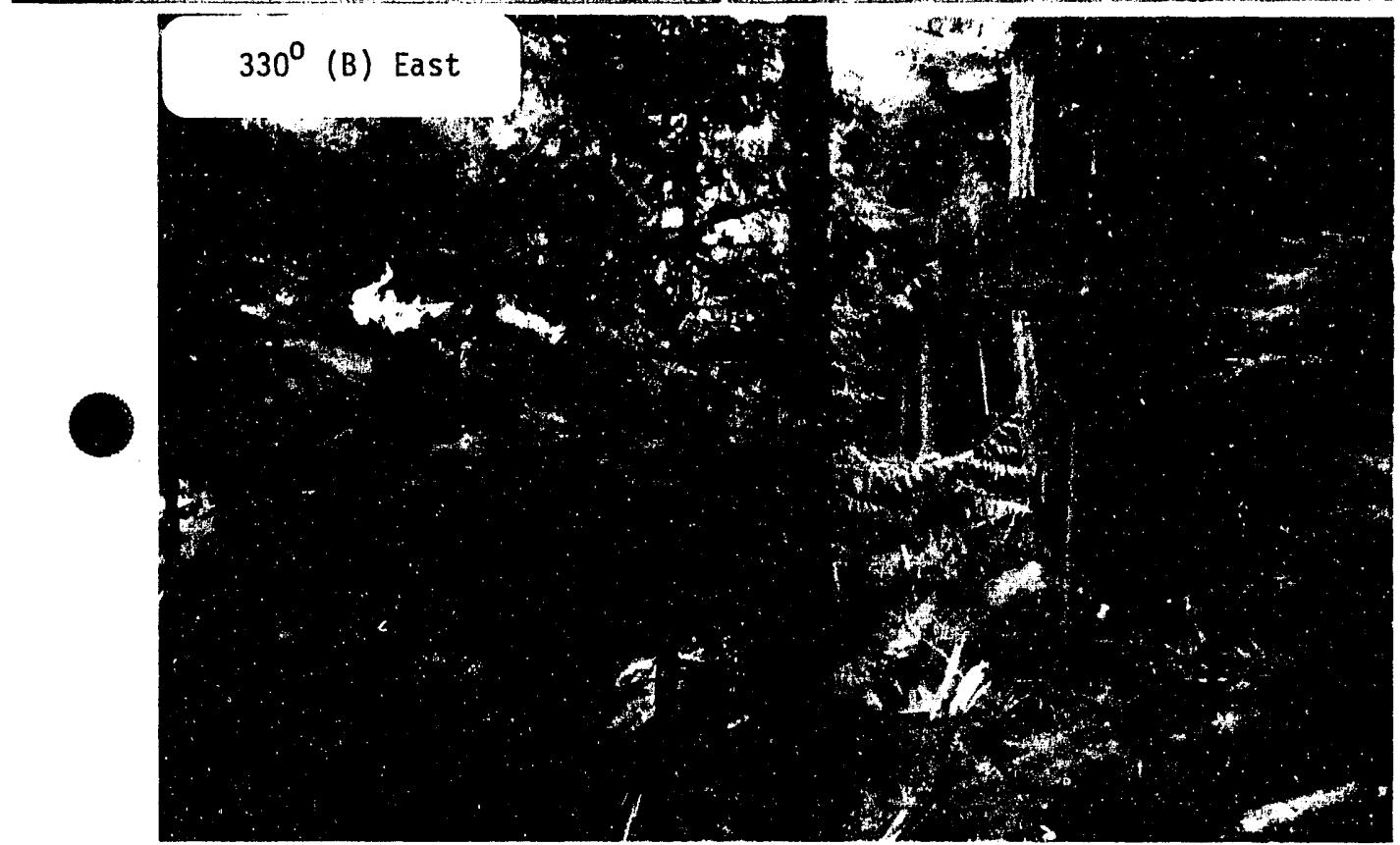

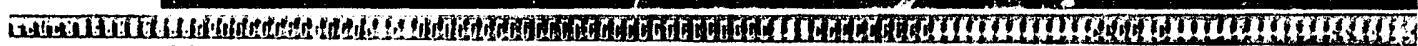

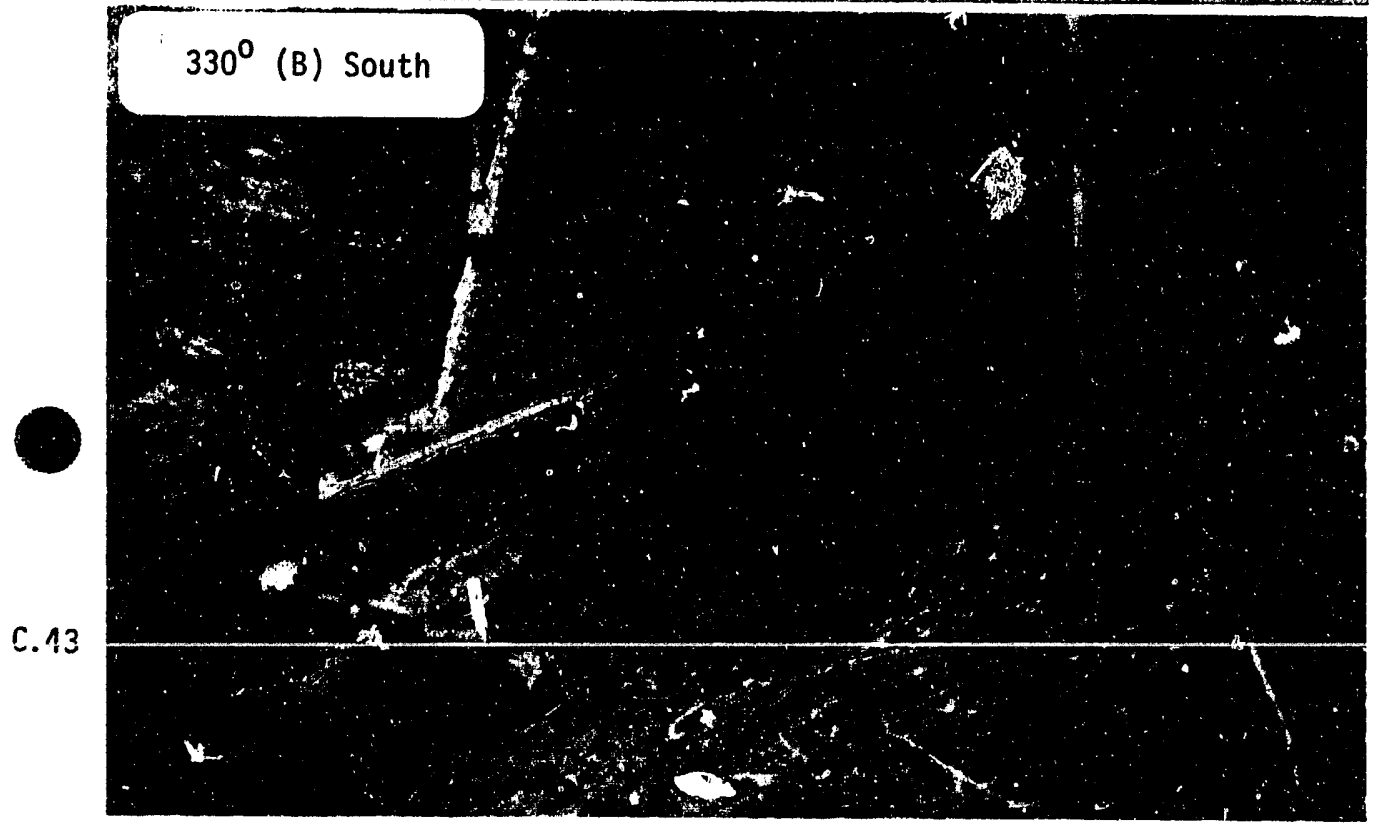




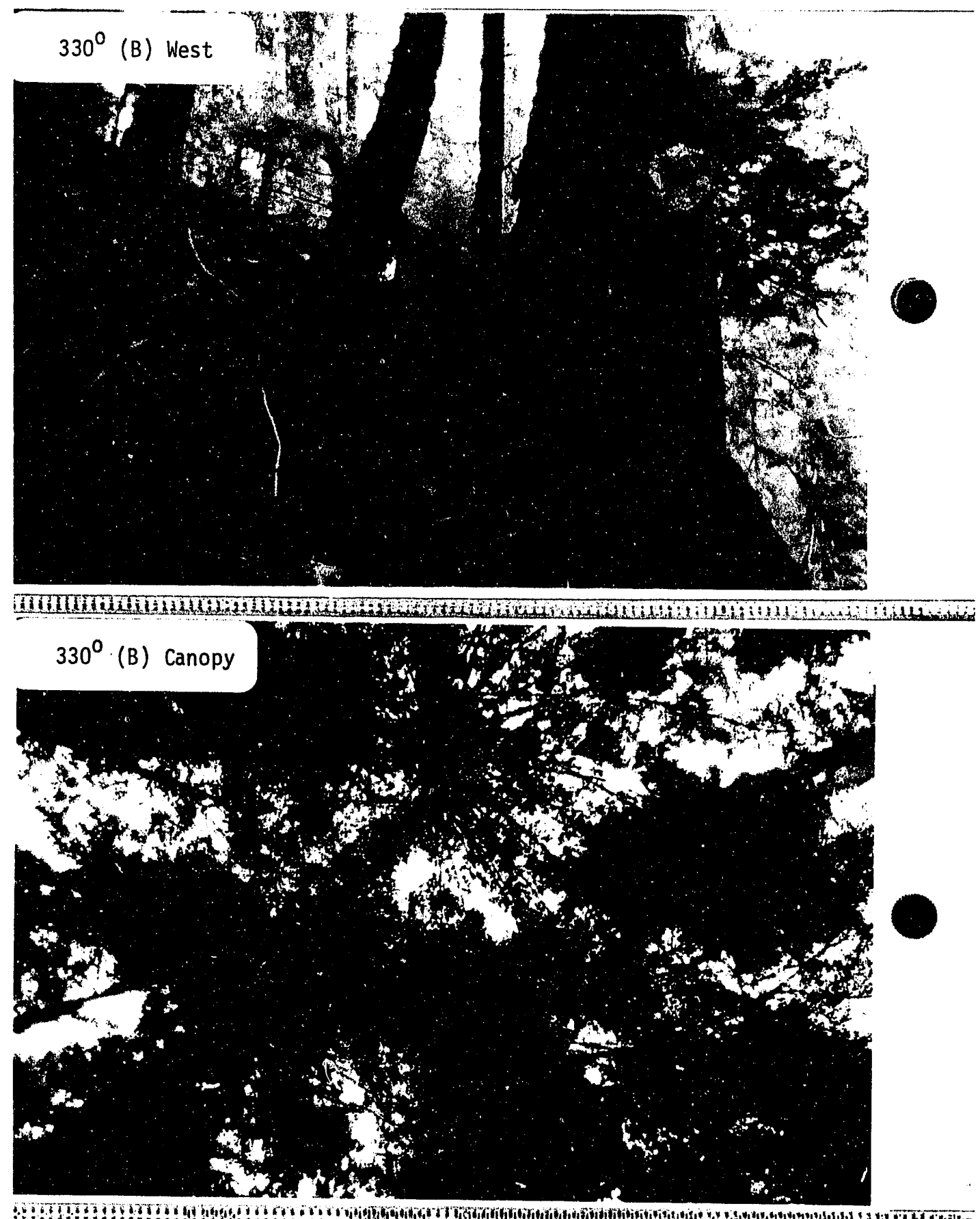

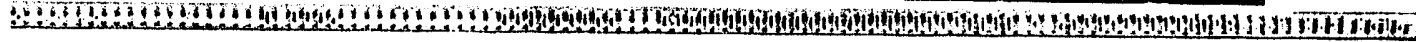




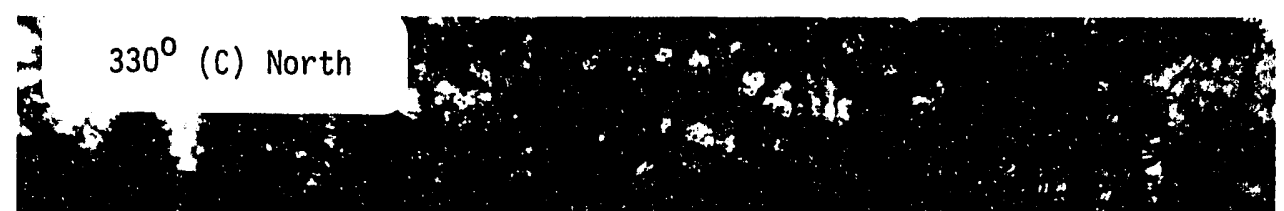

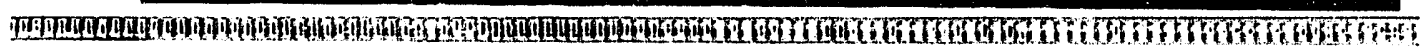
$330^{\circ}$ (C) East

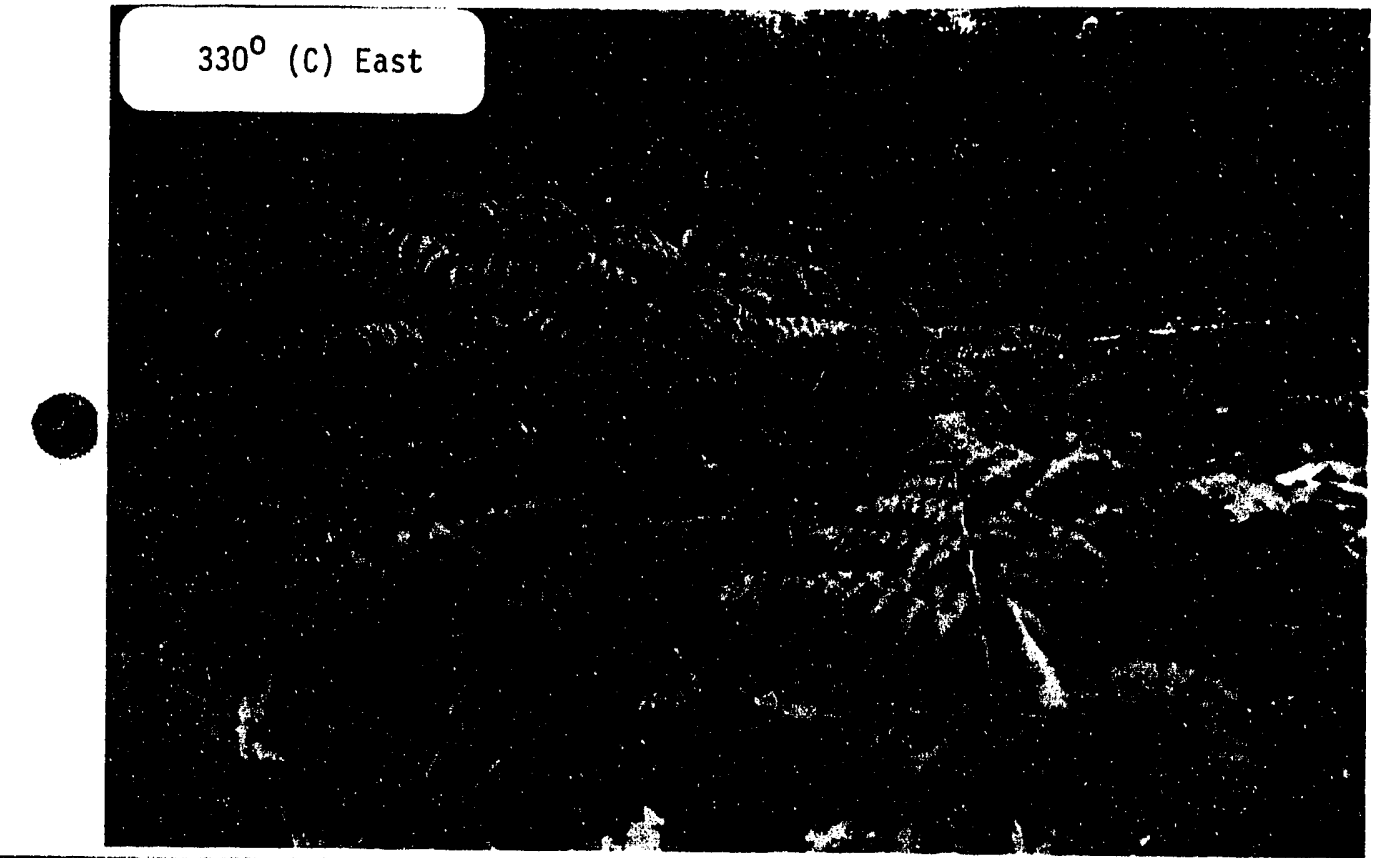

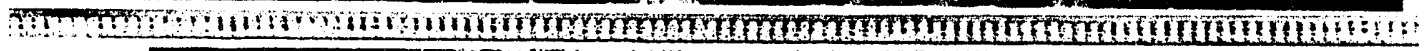
$330^{\circ}$ (C) South

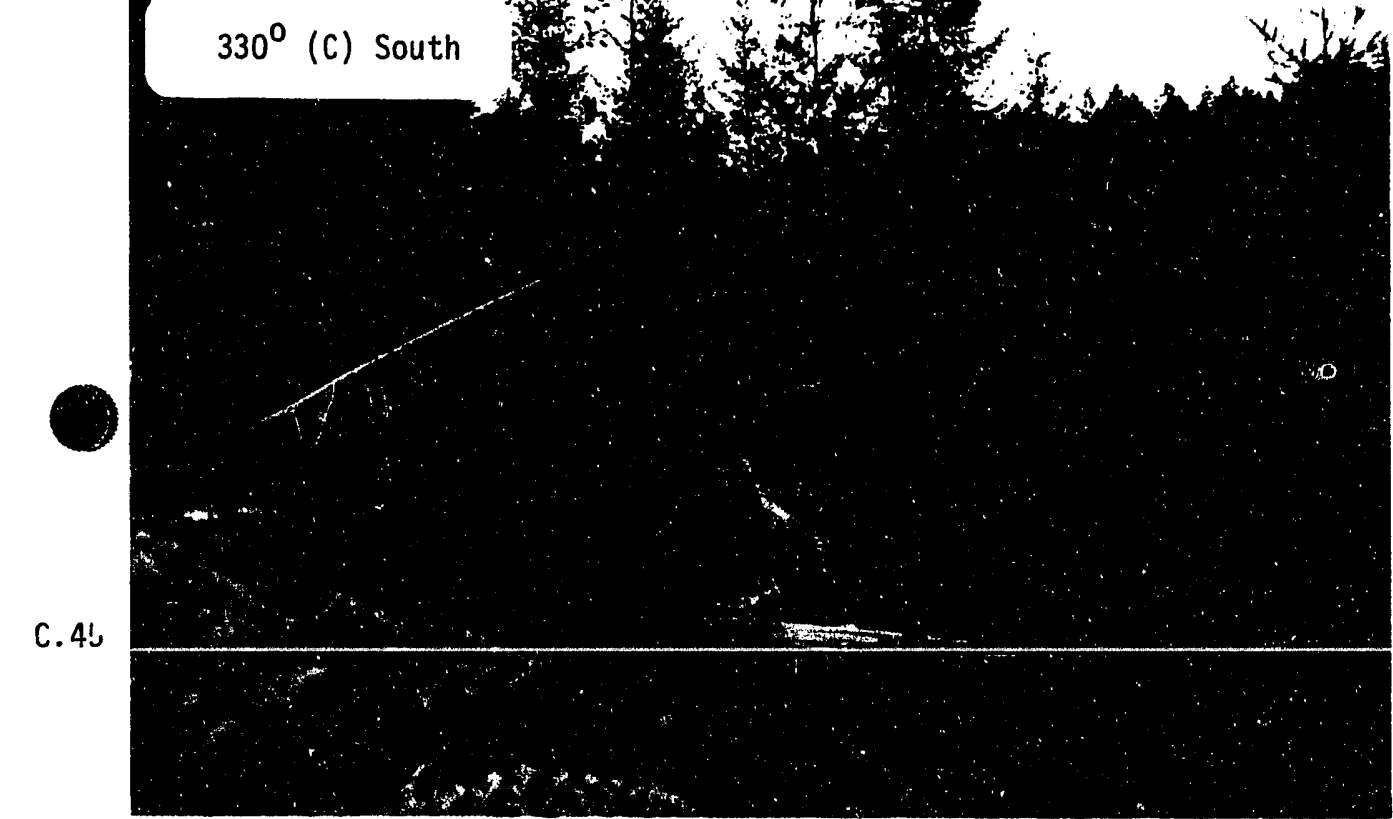




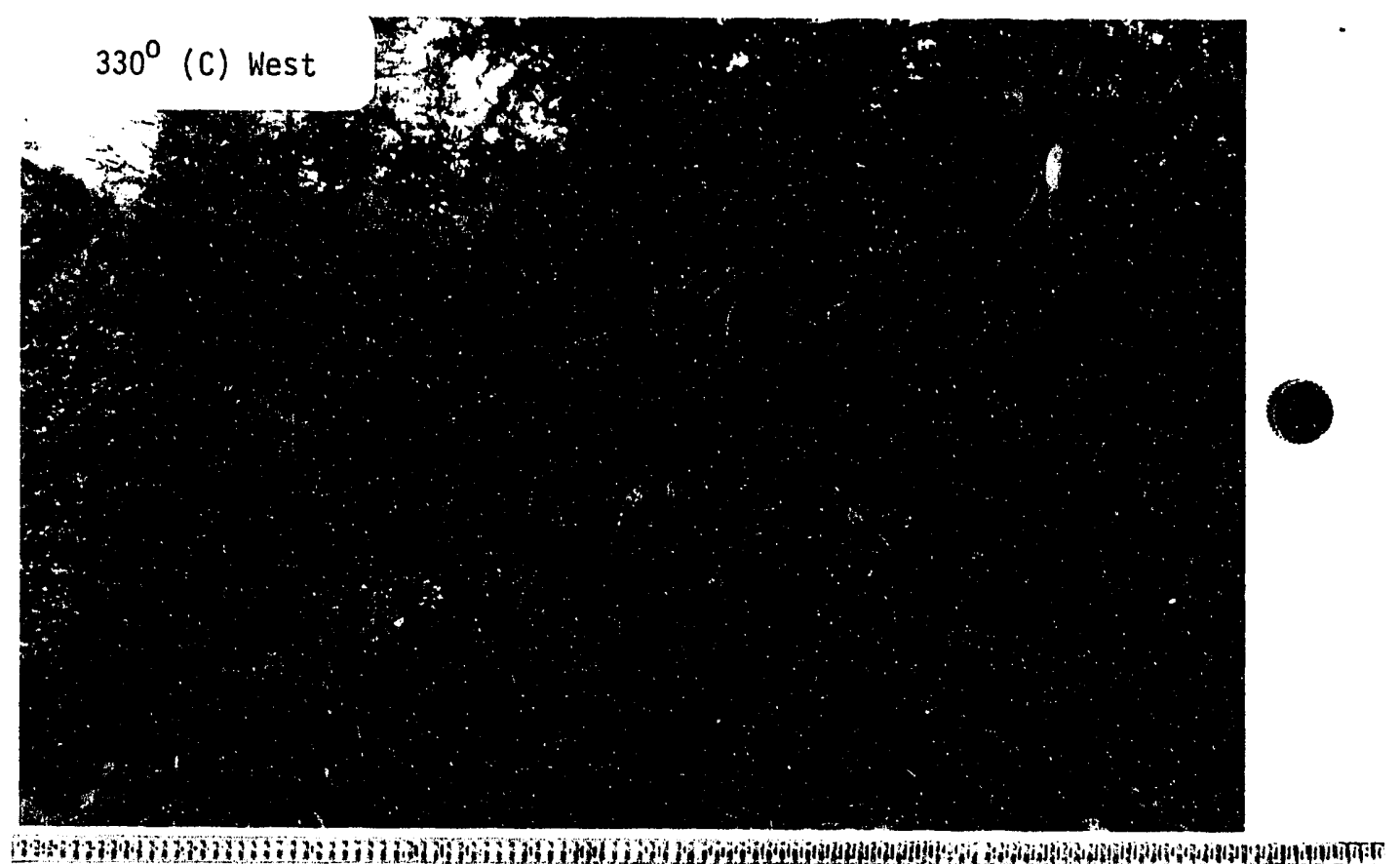
$330^{\circ}$ (C) Canopy

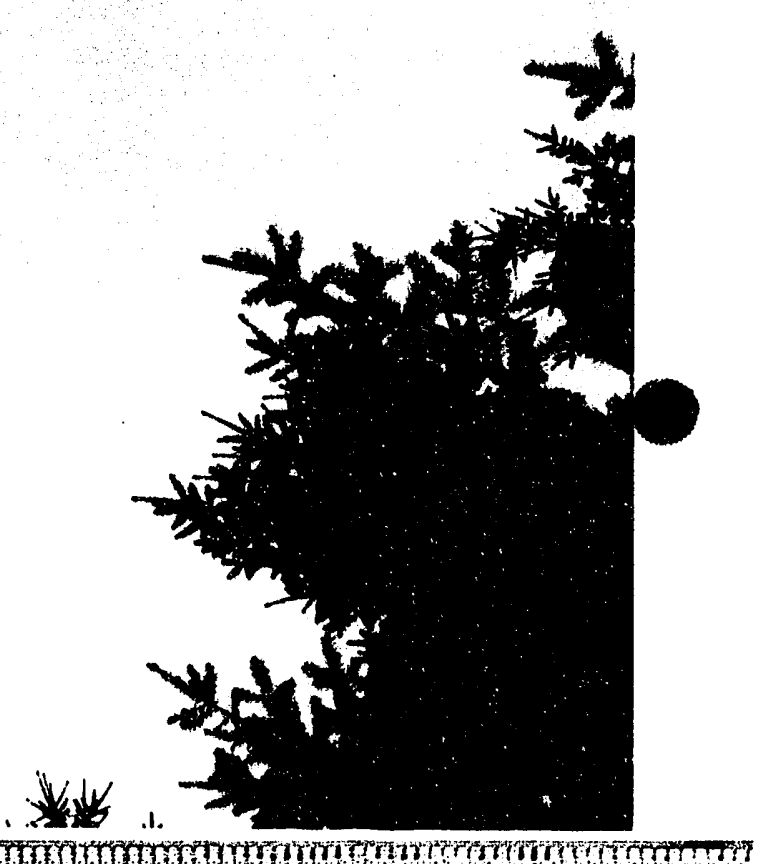

C. 46 


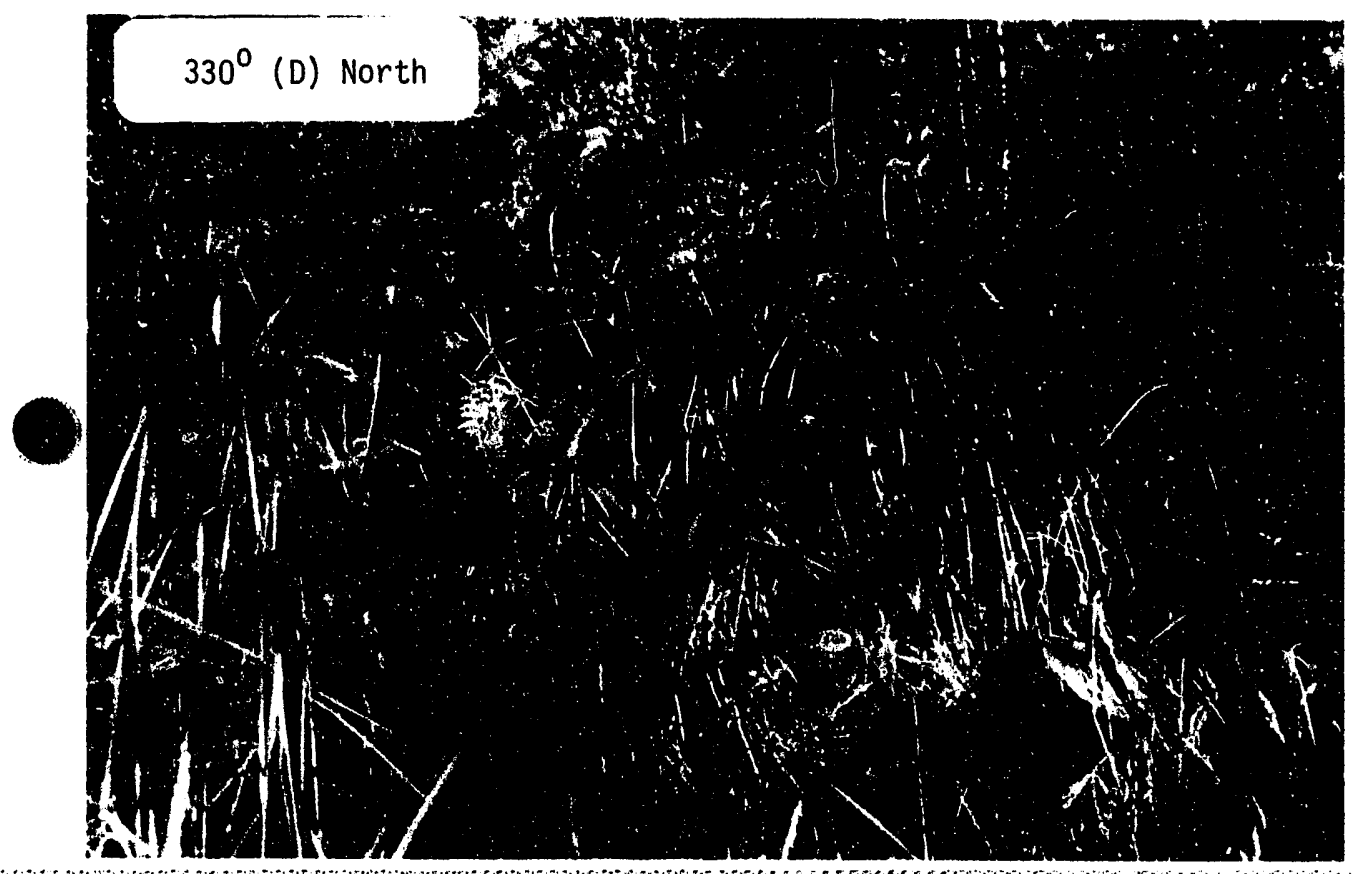

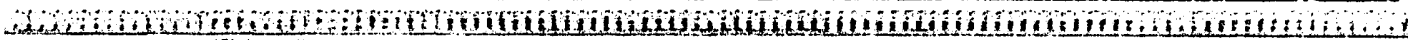
$330^{\circ}$ (D) East
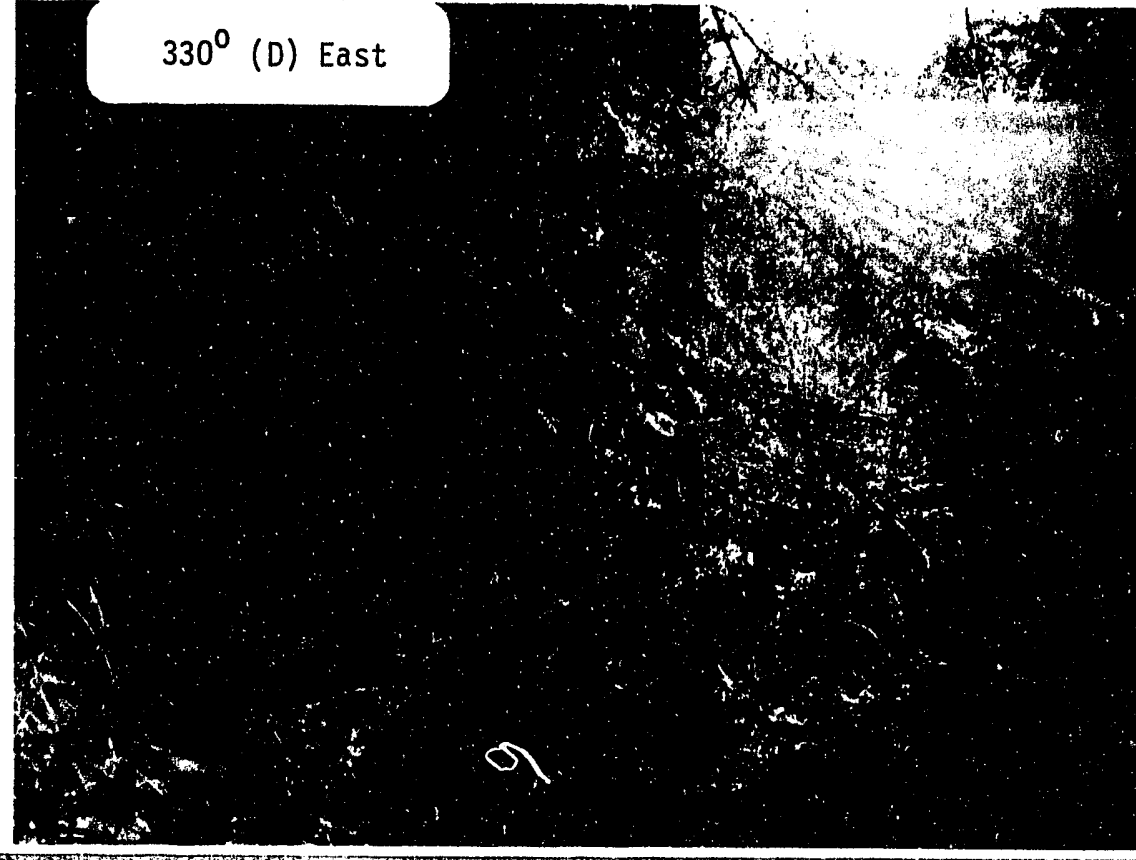

7nimi

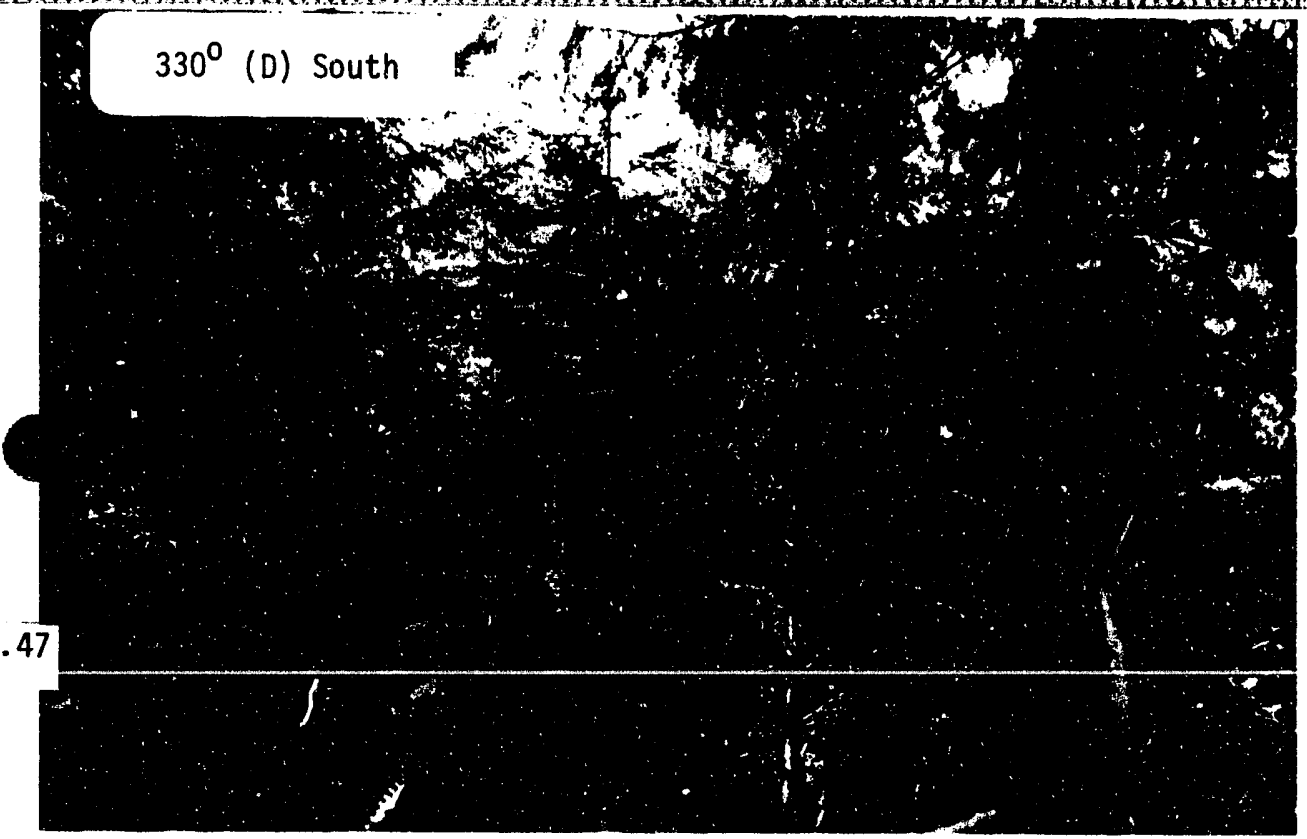




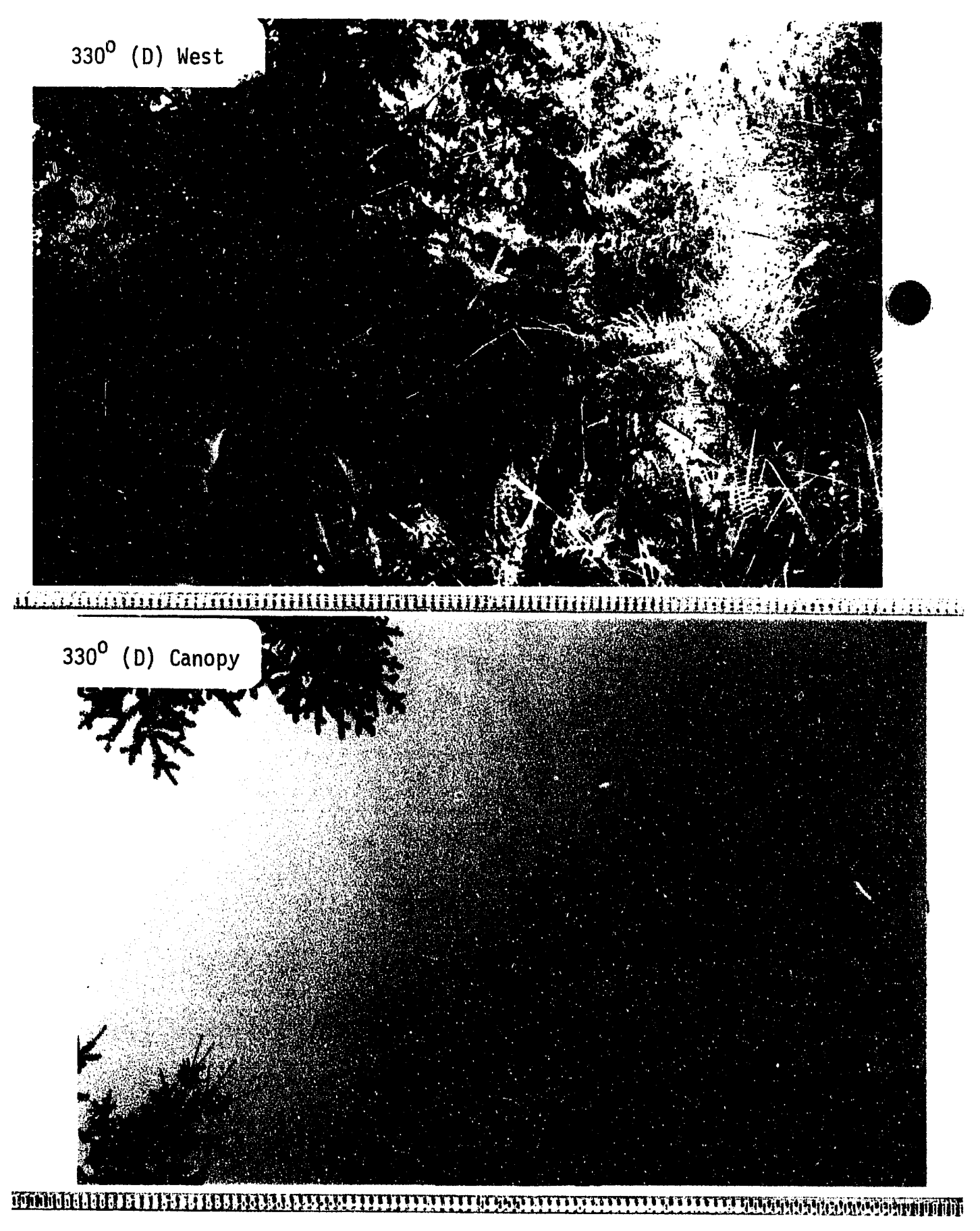

C. 48 


\section{Distribution}

No. of

Copies

\section{QFFSITE}

2 DOE/Office of Scientific and Technical Information

4 D. Giglio Department of Defense, DARPA 3701 North Fairfax Drive Arlington, VA 22203-1714

J. M. Ralson Inst. for Defense Technologies 1801 N. Beauregard Street Alexandria, VA 22331

G. T. Ruck

Battelle Columbus Office 505 King Avenue Columbus, OH 43201-2693

M. T. Tuley GTRI/MAL CRB 564

Georgia Technology Atlanta, GA 30332-0800
No. of

Copies

ONSITE

DOE Richland Operations Office

J. J. Sutey, A5-90

22 Pacific Northwest Laboratory

J. C. Becker, K7-02

H. D. Collins, K2-31

K. C. Davis, K5-25

R. H. Severtsen, K2-31

D. M. Sheen, K2-31 (12)

Publishing Coordination

Technical Report Files (5) 

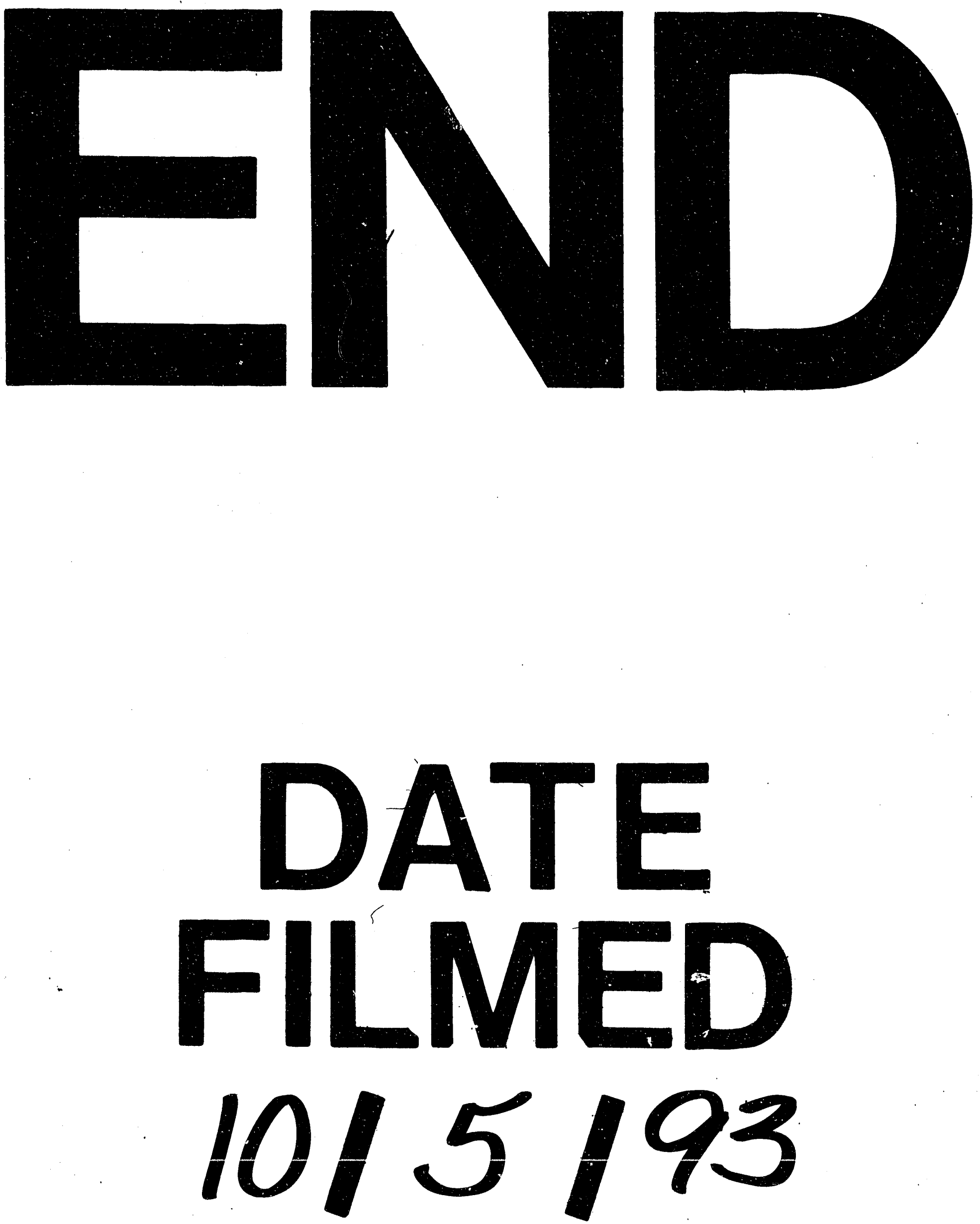
